International Labour Conference, 98th Session, 2009

Report VI

\title{
Gender equality at the heart of decent work
}

Sixth item on the agenda

International Labour Office Geneva 
ISBN 978-92-2-120654-5

ISSN 0074-6681

First edition 2009

The designations employed in ILO publications, which are in conformity with United Nations practice, and the presentation of material therein do not imply the expression of any opinion whatsoever on the part of the International Labour Office concerning the legal status of any country, area or territory or of its authorities, or concerning the delimitation of its frontiers.

Reference to names of firms and commercial products and processes does not imply their endorsement by the International Labour Office, and any failure to mention a particular firm, commercial product or process is not a sign of disapproval.

ILO publications can be obtained through major booksellers or ILO local offices in many countries, or direct from ILO Publications, International Labour Office, CH-1211 Geneva 22, Switzerland. Catalogues or lists of new publications are available free of charge from the above address, or by email: pubvente@ilo.org.

Visit our web site: www.ilo.org/publns.

Formatted by TTE: reference: ILC98-VI[2008-12-0081-1(Rev.1)]-En.doc

Printed in Switzerland. 


\section{Contents}

Page

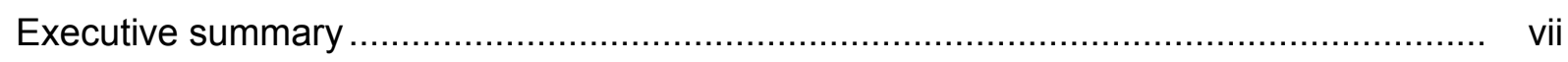

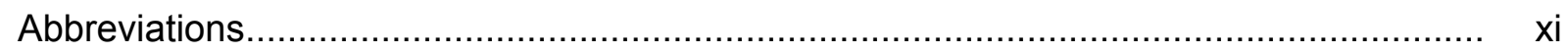

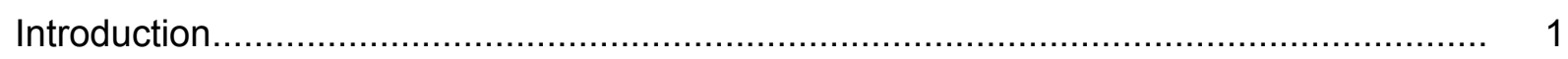

Chapter 1. Gender equality and the Decent Work Agenda ..................................... 7

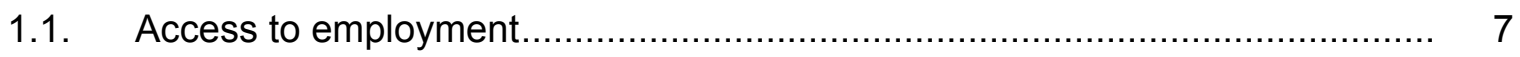

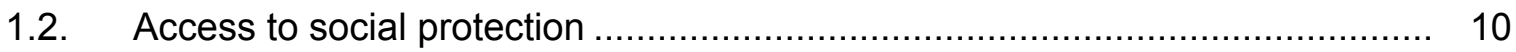

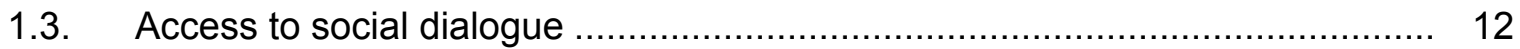

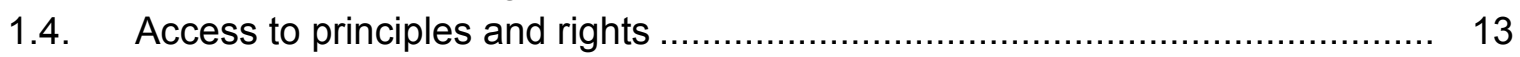

1.5. Gender, the ILO and the United Nations ............................................. 17

1.5.1. ILO tools in UN collaboration ..................................................... 18

1.5.2. ILO and the inter-agency system.......................................... 19

1.5.3. The ILO and One UN country programmes .................................. 21

1.5.4. Functional commissions and treaty bodies .................................. 22

Chapter 2. Gender equality and tensions in a globalized world ................................ 23

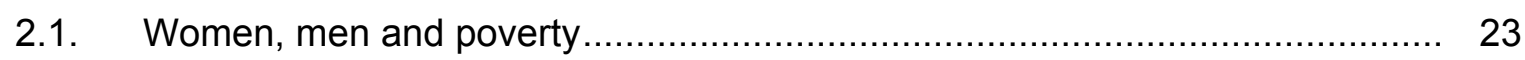

2.2. Gender and the current financial and economic crisis ................................ 25

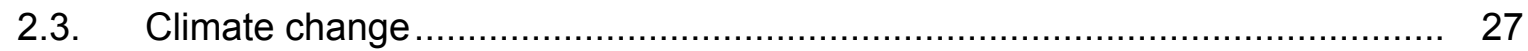

2.4. Gender and the demographic situation.............................................. 28

2.5. Decent work in the life cycle ........................................................... 31

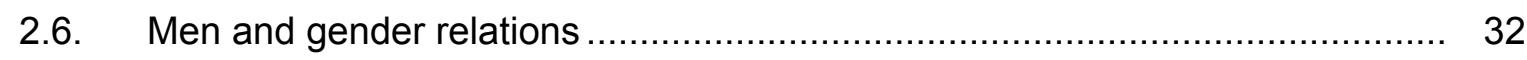

2.7. Selected themes common across the life cycle .......................................... 33

2.7.1. Violence against women and girls ........................................... 33

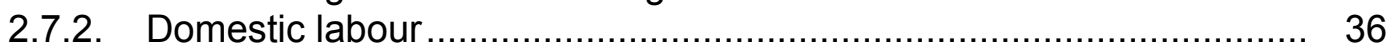

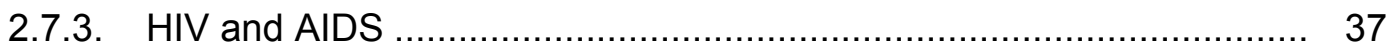

Chapter 3. Maternity, healthy infancy and working parents.................................... 41

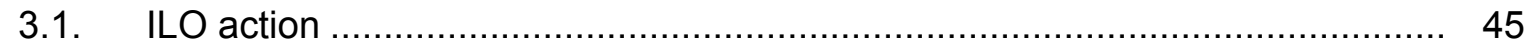

3.1.1. Employment................................................................. 45

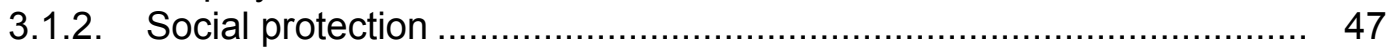

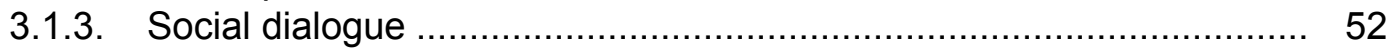

3.1.4. Principles and rights .......................................................... 54 
3.2. Links to the United Nations and international agencies .............................. 56

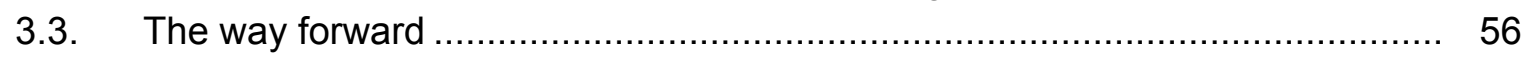

Chapter 4. A decent childhood for both girls and boys ......................................... 59

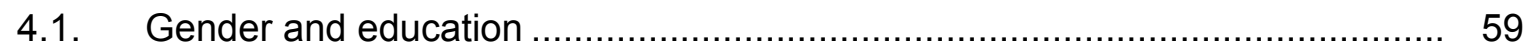

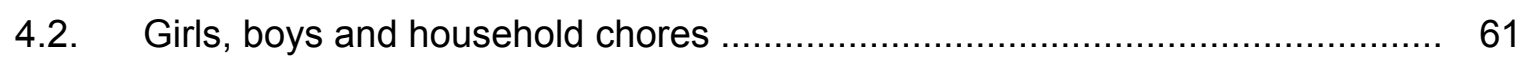

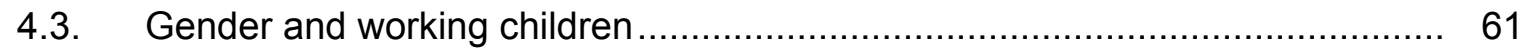

4.3.1. Worst forms of child labour ........................................................... 65

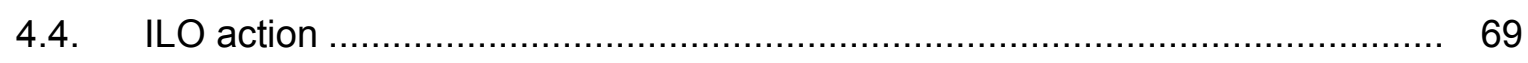

4.4.1. Adult employment instead of child labour .................................. 69

4.4.2. Social protection .................................................................... 70

4.4.3. Social dialogue in defence of children ...................................... 71

4.4.4. Principles and rights ....................................................... 73

4.5. Links to the United Nations and international agencies .............................. 75

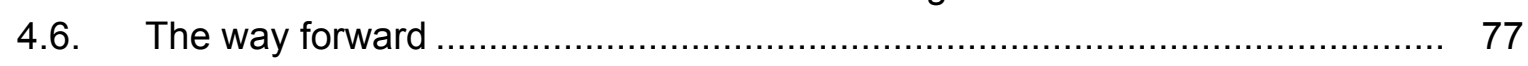

Chapter 5. Gender, youth and employment ….................................................... 79

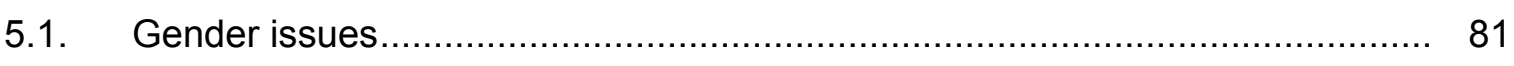

5.1.1. Gender, youth and social stability ........................................ 83

5.1.2. Gender roles and women's labour force participation .................... 84

5.1.3. Occupational segregation and stereotyping …........................... 86

5.1.4. Export processing zones .................................................. 87

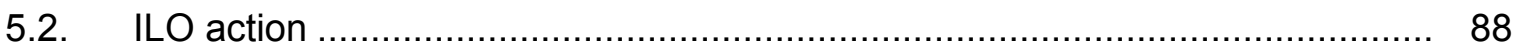

5.2.1. Employment.................................................................. 88

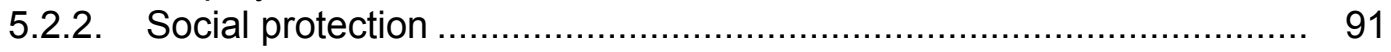

5.2.4. Social dialogue ................................................................. 96

5.2.5. Principles and rights ...................................................... 98

5.3. Links to the United Nations and international agencies ............................ 101

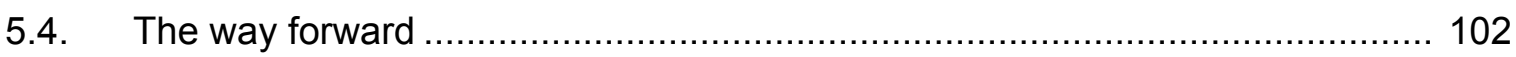

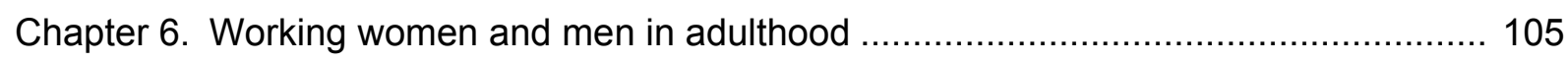

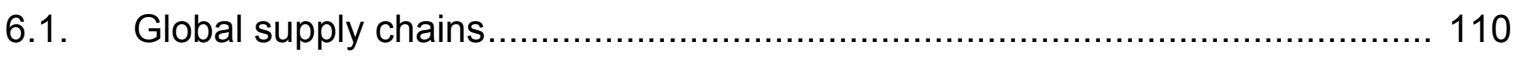

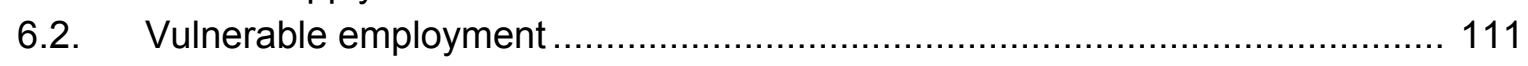

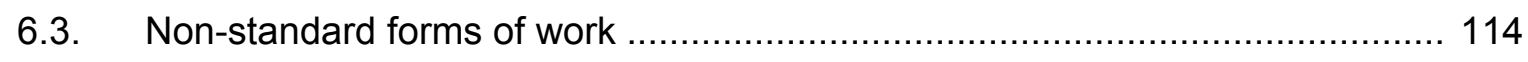

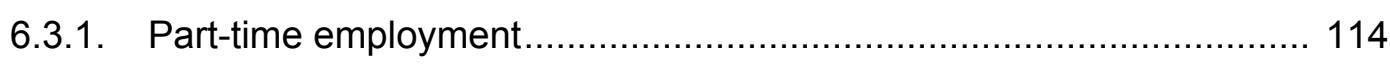

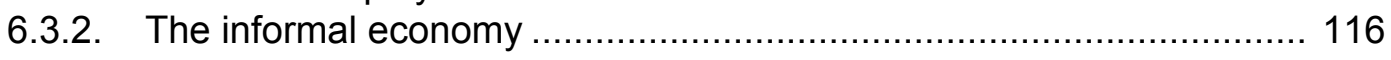

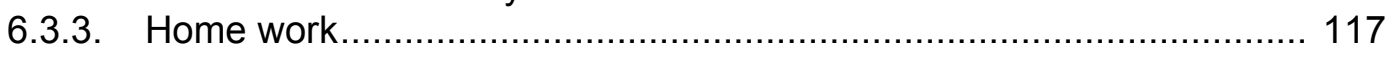

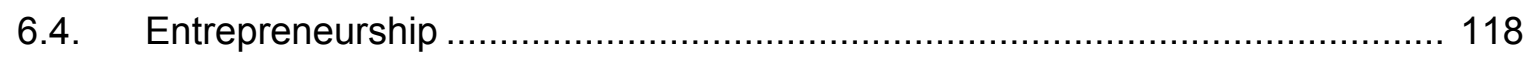

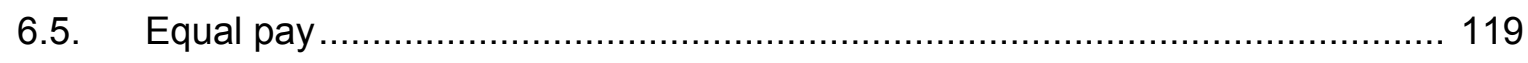

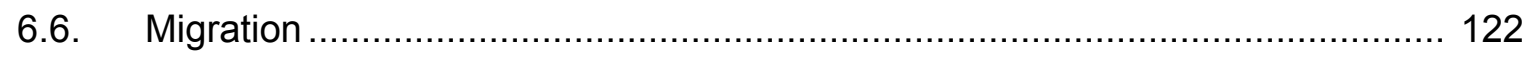

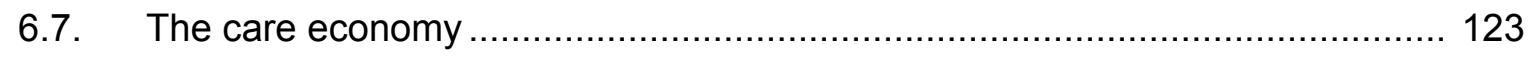




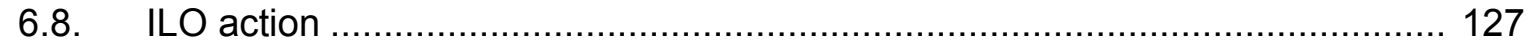

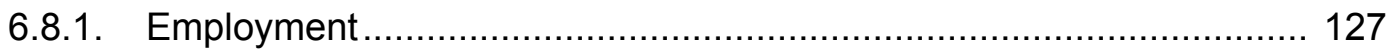

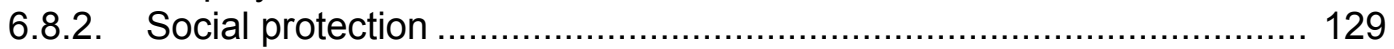

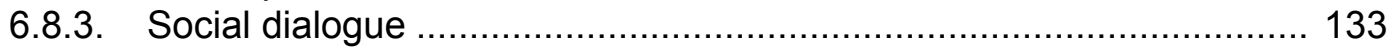

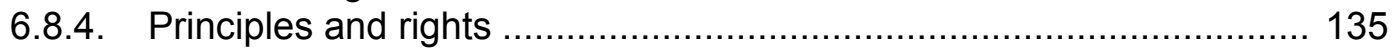

6.9. Working with the United Nations and international agencies........................ 141

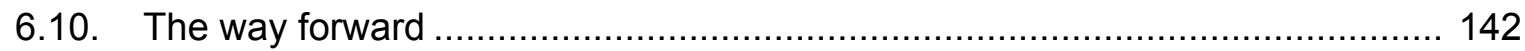

Chapter 7. Older workers and the senior years: Rights, jobs and social security ............. 145

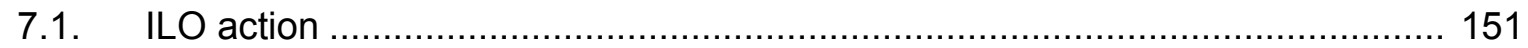

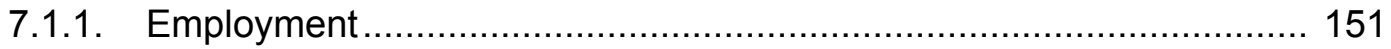

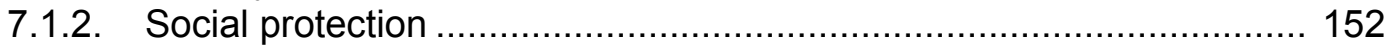

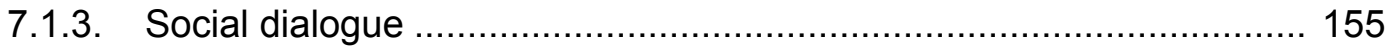

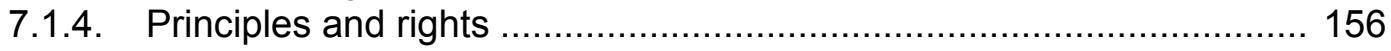

7.2. Links to the United Nations and international agencies .............................. 158

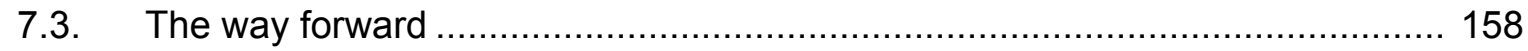

Chapter 8. Main policy orientations for international and national action ....................... 161

8.1. Leveraging social dialogue for gender equality ....................................... 161

8.2. Men and women in leadership positions...................................................... 162

8.3. Enhancing governance through gender equality ...................................... 163

8.4. What has worked and what needs more attention...................................... 166

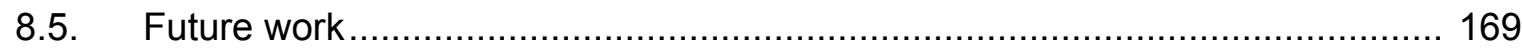

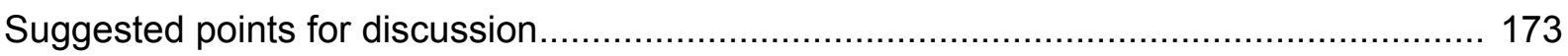

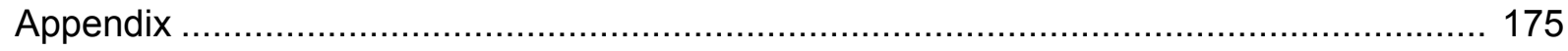





\section{Executive summary}

This report has three aims: reviewing the ILO's progress in assisting constituents to achieve gender equality in the world of work; highlighting its current efforts to implement International Labour Conference (ILC) resolutions and Governing Body decisions on promoting gender equality and mainstreaming it in the Decent Work Agenda; and providing background for constituents to chart a strategic course for future work. The context of the current financial and economic crisis has made the analysis of successful initiatives especially relevant. The crisis will impact heavily on both women's and men's efforts to find and keep decent work, and the progress made by ILO constituents around the world is threatened. Recovery packages that are designed too hurriedly and without sufficient social dialogue may inadvertently exacerbate existing sex discrimination in the labour market.

The report makes the case for scaling up measures to eliminate sex discrimination in the world of work and highlights ILO interventions in all regions. The ILO approach is grounded in the rights-based argument and the economic efficiency rationale: not only is gender equality in the world of work a matter of human rights and justice for workers, it also makes good business sense for employers and is instrumental in achieving economic growth and poverty reduction at national levels. The attainment of equality of opportunity and treatment for women and men despite the context of the current crisis may well be the litmus test for gauging whether member States are committed to greater coherence in economic and social policy.

Equality of rights applies throughout life. Women and men, from their early years through to old age, may face different manifestations of sex discrimination. This has clear life-cycle dimensions. More and more governments - as well as the social partners - are recognizing that if no remedial action is taken, disadvantages tend to accumulate and intensify over time and through generations, with negative repercussions for women, families and societies.

Safe maternity and health care for mother and infant survival is at the core of life itself, for mothers, infants, communities and nations. It is also central to decent work and productivity for women. The integration of maternity protection as part of social and economic policy is recognized in all regions. Maternity protection has two aims. First, it preserves the special relationship and the health of the mother and her newborn. Second, it provides a measure of job security, crucial for protecting pregnant workers and mothers. Pregnancy or motherhood should not constitute a source of discrimination in access to training, skills development and employment.

Having to work is one of the biggest obstacles to a decent childhood. Where poverty and discrimination prevail, so can child labour. Children may be freed from poverty and economic and social marginalization through education. Evidence from a range of countries shows that educating girls is one of the most effective ways of fighting poverty. Educated girls are more likely to have higher incomes and increased control over resources as adults, marry later, have fewer and healthier children and 
exercise greater decision-making power within the household. Importantly, they are also more likely to ensure that their own children are educated, thus increasing their earnings, avoiding future child labour and breaking the cycle of poverty.

Much action has to be taken to avoid exacerbating growing youth unemployment and working poverty, which are likely to worsen in the current global financial and economic crisis. Sex is not an indicator of competence, and the decision to recruit, train or promote young women and men should always be based on reasons such as skills and the inherent requirements of the job. It is now widely accepted that long-term investments in human capital play a key role in enhancing productivity and growth. Ensuring that adolescent and young girls are provided with quality formal and non-formal education programmes is essential. Young women and men need to be made aware of their rights, including freedom of association and collective bargaining as means for attaining decent work.

For both adult men and women, pursuing decent work, providing and caring for family members, as well as fulfilling obligations to enterprises, communities and societies, is a tall order indeed. Women experience systemic barriers in almost every aspect of work - this ranges from whether they have paid work at all (full time or part time); the type of work they obtain or are excluded from; the availability of supports such as childcare; their pay, benefits and conditions of work; their access to higherpaying "male" occupations; the insecurity of their jobs or enterprises; the absence of pension entitlements or benefits; and the lack of the time, resources or information necessary to enforce their rights. Changing the gender division of labour in the household to a more equitable distribution of tasks, as well as investing in labour-saving technology, can have a significant impact on productivity. Men stand to gain in dual-income partnerships through better work/family balance, improved contact with children and inclusion in family life, as well as less vulnerability to economic shocks.

Longevity is one of the most positive and relevant demographic phenomena to emerge in recent decades, and a fundamental policy objective is to build societies fit for people of all ages. The ageing of populations and the new inter-generational relationships radically affect the human landscape and decent work. The ILO emphasizes that adequate employment policies, human resource development and lifelong learning are crucial in maximizing the potential of older women and men. The gender dimension of older workers' labour force participation has been an important feature in employment policies targeting this age group. The shortfall in women's economic participation and earnings means that they are inevitably at an economic disadvantage in old age. If and when better-educated women enter the labour force in greater numbers, and earn equal pay for work of equal value, they will be able to provide for themselves.

Looking at achievements since the last ILC discussion on the subject in 1985, it is generally recognized that there have been improvements in the policy and legislative framework for gender equality in the world of work and the enforcement of laws. Whether in the form of revised labour codes, equality or human rights acts or stand-alone equal pay statutes, legislators have included not only clear prohibitions of sex discrimination, but also proactive provisions aimed at equality of opportunity and treatment in the world of work. Both state bodies (such as labour administration systems, including inspectorates, labour tribunals and courts) and private-sector initiatives (such as corporate social responsibility and framework agreements) are better monitoring the application of laws and agreed principles.

Awareness of workers' rights concerning equality of opportunity and treatment has increased across all regions. Information campaigns and constituents' training courses 
have empowered men and women workers - and their organizations - to protect their rights.

In addition, many governments have adopted active labour market policies that address gender inequalities within their overall objectives of job-rich growth and sustainable enterprises. ILO expertise has contributed to progress in women's economic empowerment through its research, services and advocacy efforts in lifelong learning and skills development, entrepreneurial skills enhancement, and microfinance and credit access.

This report gives an overview of ILO efforts to improve labour protection and promote the adoption of a basic social security package that assists both women and men. Establishing technically feasible and financially viable ways of extending coverage of basic health care, family/child benefits, targeted income support for the poor and unemployed, and old-age and disability pensions would provide a minimum safety net. Since poverty has a gender dimension that cannot be ignored, and the effects of economic growth have not trickled down to the poorest, public policies that encourage a fair distribution of national resources by implementing social security systems would make a substantial contribution to lifting the poorest out of extreme poverty.

ILO action over the last decades has also focused on the voice and visibility of women of all ages in the world of work. Tripartism and social dialogue are essential if real progress is to be made in attaining gender equality. Increasing the institutional capacity of member States, as well as of representative organizations of employers and workers, to facilitate meaningful and coherent social dialogue on gender equality will be necessary to mark an improvement in current practices. It is not only a matter of national gender machineries being more sensitive to world of work issues. It is also essential that national social dialogue institutions increase women's membership, and address gender concerns more seriously their policies and programmes.

Obstacles remain for the achievement of gender equality, such as poor implementation and enforcement of national policies. These occur at various levels; while it is increasingly accepted that obtaining and using sex-disaggregated data is the only firm basis for an accurate situation analysis and for gender-responsive planning, and for monitoring and evaluation, national capacity remains weak. Development policies and programmes must challenge stereotyped assumptions about gender roles that have become systemic. Proactive measures should be used, such as affirmative action, awareness raising on workers' rights, lifelong skills development and women's economic empowerment. Outdated systems that affect gender-neutral job evaluation for equal pay should be reformed.

Once again, by leveraging social dialogue for gender equality, political leadership can be influenced. First, an increase in the participation and status of women in the dialogue processes is necessary. Second, there is the challenge of introducing a gender perspective into the content of the issues on the social dialogue agenda, so as to reflect the changing nature of labour markets and patterns in the world of work. Within a broader development context, the ILO collaborates extensively on gender equality with the United Nations and its specialized agencies as part of the "Delivering as One" and UN reform process.

The report lists priorities in the concluding sections of the life cycle chapters, and in the last chapter on the main policy orientations for international and national action. These may guide the tripartite constituents in implementing measures to advance gender equality in the workplace, while charting a strategic course for the ILO's future work as it approaches its centennial. 



\section{Abbreviations}

ACT/EMP

ACTRAV

AIDS

CCT

CEACR

CEDAW

CEDAW Committee
Bureau for Employers' Activities (ILO)

Bureau for Workers' Activities (ILO)

acquired immunodeficiency syndrome

conditional cash transfer

Committee of Experts on the Application of Conventions and Recommendations (ILO)

Convention on the Elimination of All Forms of Discrimination against Women (United Nations)

Committee on the Elimination of Discrimination against Women (United Nations)

CIS

Commonwealth of Independent States

CSW

DAW

DESA

DIALOGUE

ECLAC

ECOSOC

EFA

EI

EPZ

ERM

ETUC

EU

FAO

GDP

GEA

GENDER

GPE
Commission on the Status of Women (United Nations)

Division for the Advancement of Women (United Nations)

Department of Economic and Social Affairs (United Nations)

Social Dialogue, Labour Law and Labour Administration Branch (ILO)

Economic Commission for Latin America and the Caribbean (United Nations)

Economic and Social Council (United Nations)

Education for All

Education International

export processing zone

European Regional Meeting (ILO)

European Trade Union Confederation

European Union

Food and Agriculture Organization of the United Nations

gross domestic product

Global Employment Agenda

Bureau for Gender Equality (ILO)

Gender, Poverty and Employment Programme (ILO) 
GRB

HIV

IBRD

ICFTU

ICT

IFAD

IILS

ILC

IOE

IPEC

IPU

ITC-ILO

ITUC

IUF

MDG

NGO

OECD

$\mathrm{OSH}$

PGA

PRS

PRSP

PSI

PTE

SIYB

SME

TRAVAIL

UN

UNAIDS

UNCT

UNDAF

UNDP

UNEP

UNESCO

UNFPA

UNGEI gender-responsive budgeting

human immunodeficiency virus

International Bank for Reconstruction and Development

International Confederation of Free Trade Unions (now ITUC)

information and communication technology

International Fund for Agricultural Development

International Institute for Labour Studies

International Labour Conference

International Organisation of Employers

International Programme on the Elimination of Child Labour (ILO)

Inter-Parliamentary Union

International Training Centre of the ILO

International Trade Union Confederation

International Union of Food, Agricultural, Hotel, Restaurant, Catering, Tobacco and Allied Workers' Associations

Millennium Development Goal

non-governmental organization

Organisation for Economic Co-operation and Development

occupational safety and health

Participatory Gender Audit (ILO)

Poverty Reduction Strategy

Poverty Reduction Strategy Paper

Public Services International

part-time employment

Start and Improve Your Business

small and medium-sized enterprise

Conditions of Work and Employment Programme (ILO)

United Nations

Joint United Nations Programme on HIV/AIDS

United Nations country team

United Nations Development Assistance Framework

United Nations Development Programme

United Nations Environment Programme

United Nations Educational, Scientific and Cultural Organization

United Nations Population Fund

United Nations Girls' Education Initiative 
UNICEF

UNIFEM

UNRISD

WEDGE

WHO
United Nations Children's Fund

United Nations Development Fund for Women

United Nations Research Institute for Social Development

Women's Entrepreneurship Development and Gender Equality

World Health Organization 



\section{Introduction}

1. Securing decent work is crucial for women and men, making it possible for them to build more promising futures for themselves, their families and their communities. Sustainable development is achieved through the contributions of both women and men. Socially constructed gender roles, the biological differences between men and women, and how these interact in the world of work are therefore at the core of decent work. ${ }^{1}$ The ILO Constitution foresaw the need for workplace equality, and today, in the twentyfirst century, the ILO continues to pursue this goal. This was strongly reaffirmed in the landmark ILO Declaration on Social Justice for a Fair Globalization (the 2008 Declaration), adopted at the International Labour Conference (ILC) at its 97th Session in 2008. In an opportune coincidence, the item "Gender equality at the heart of decent work" ${ }^{2}$ was chosen for a general discussion by the ILC in 2009 , the year in which the ILO celebrates its 90th anniversary. This report therefore aims to provide a basis for constituents to engage in dialogue on this cross-cutting issue at the heart of the ILO's four strategic objectives (employment, social protection, social dialogue and tripartism, and principles and rights). The main premise of the report is that there is a gender dimension to all aspects of the world of work and the life cycle of human beings. That premise is grounded in research, analysis and the legal underpinning of the four international labour Conventions recognized as the key equality Conventions: the Discrimination (Employment and Occupation) Convention, 1958 (No. 111); the Equal Remuneration Convention, 1951 (No. 100); the Workers with Family Responsibilities Convention, 1981 (No. 156); and the Maternity Protection Convention, 2000 (No. 183).

2. It has been over 20 years since gender equality was the topic of a general discussion by the ILC; the last time was in 1985, when the subject "Equal opportunities and equal treatment for men and women in employment" was debated. ${ }^{3}$ As table 1 shows, there have been many positive developments in gender equality throughout the world over the past two decades. Yet many gender equality issues have not been adequately addressed over the years, and important gaps observed in the 1985 report still

\footnotetext{
1 Gender roles are defined by social groups and cultural traditions. They greatly affect the world of work and condition which activities, tasks and responsibilities are perceived as appropriate to men and women. These divisions of labour are formed by age, race and ethnicity, religion and culture and are also influenced by socio-economic class and the political environment. They change over time. The biological differences in the sexes are governed by their singular physiological attributes, such as female and male musculoskeletal builds or their reproductive functions. These differences clearly have a bearing on the world of work. ILO: $A B C$ of women workers' rights and gender equality, second edition (Geneva, 2007), p. 89 ff.

2 The agenda item was proposed to the ILO Governing Body at its 298th Session (March 2007) in document "Agenda of the 98th Session (2009) of the International Labour Conference" (GB.298/2, point 6, para. 75). The ILO Governing Body took the decision to select this agenda item, as reflected in the minutes of the 298th Session (GB.298/PV, para. 57(ii)).

${ }^{3}$ ILO: Equal opportunities and equal treatment for men and women in employment, Report VII, ILC, 71st Session, Geneva, 1985 (referred to hereinafter as the 1985 report).
} 
exist today across the regions. And in times of crisis, such as the current financial and economic downturn, fragile gains could be jeopardized. After decades of national and international commitment to gender equality, the unfortunate reality is that much discrimination still persists.

Table 1. Historical timeline of gender equality in the world of work: Selected dates

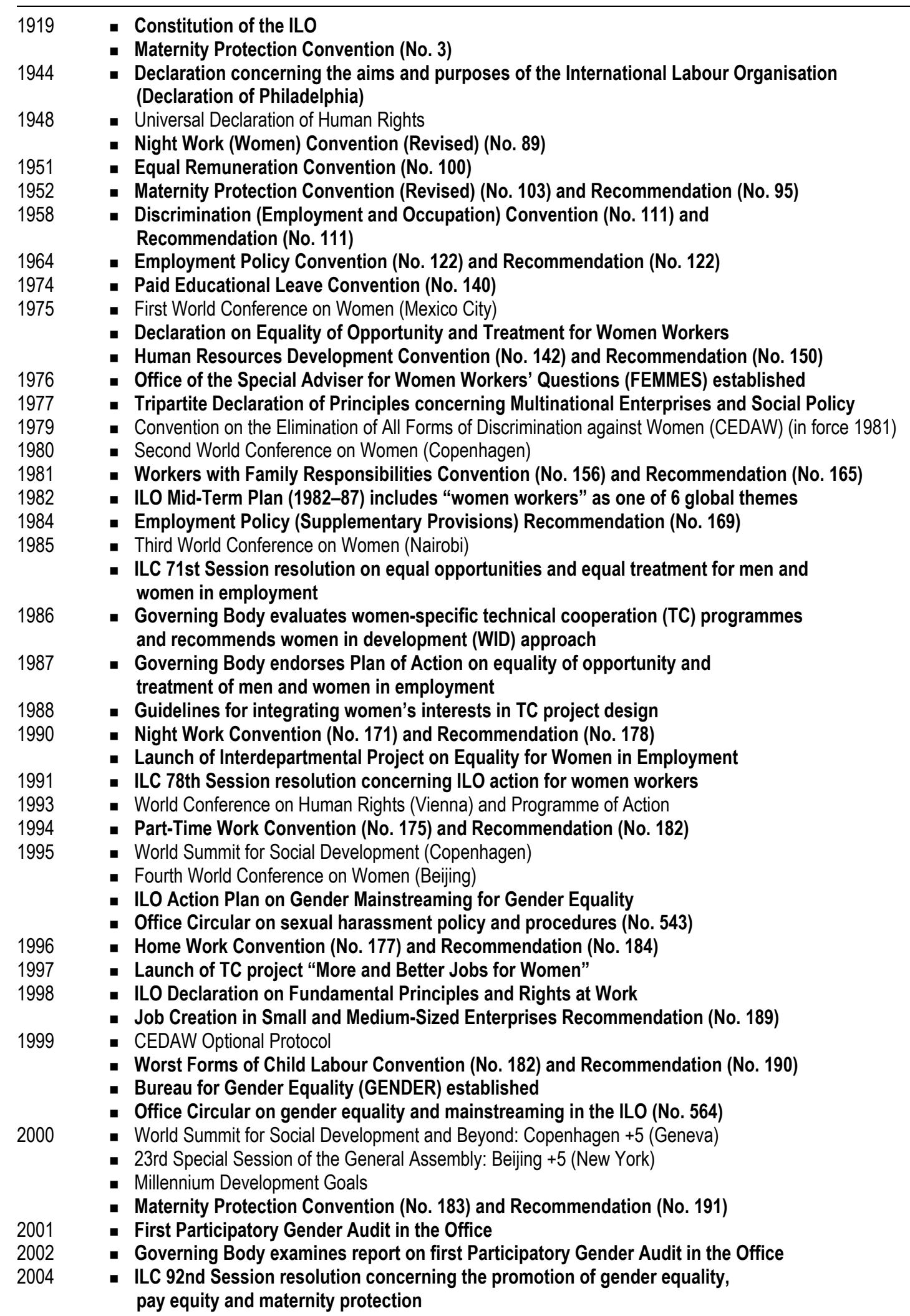


3. One area in which progress has certainly been made is the level and intensity of the debate on gender equality within the ILO itself. Positioning it as a cross-cutting issue has given a solid boost to the incorporation of the gender dimension into all of the ILO's work. This is due to a better understanding of gender issues within the Office, resulting from a surge of support from the highest levels of management. The ILO's commitment to developing an evidence base despite the paucity of data, its promotion of the key equality Conventions, and its advice to constituents on policy and legal frameworks for equality have led to considerable advances over the last decades. Efforts to view the employment and social protection issues facing women and men through a gender lens have resulted in both internal capacity building and outreach to constituents. The International Training Centre of the ILO (ITC-ILO) in Turin has been working for more than two decades in developing and implementing gender training programmes for ILO constituents, development agencies and other stakeholders. ILO researchers have tracked academic studies and conducted primary research on a wide variety of gender equality issues in the world of work. ${ }^{4}$ A commitment to gender equality by key ILO donors has led to technical cooperation projects and programmes being expanded beyond women-specific goals towards an approach that incorporates the implications for both sexes. This was reflected in the Governing Body's decision on gender mainstreaming in technical cooperation of 2005. ${ }^{5}$ The importance of social dialogue in making inroads for gender equality is both recognized and integrated in the means and the end results of ILO action. The 2009 general discussion offers a timely opportunity to move the discourse to action and guide the Organization's future aspirations for promoting gender equality. ${ }^{6}$

4. The three objectives of this general discussion are: (1) to conduct a comprehensive review of the ILO's progress in assisting constituents to achieve gender equality in the world of work; (2) to highlight its current efforts to implement ILC resolutions and Governing Body decisions on promoting and mainstreaming gender equality into the Decent Work Agenda; and (3) to provide a forum to help constituents chart a strategic course for future work. This third objective is crucial as the Organization gears up for the Strategic Policy Framework 2010-15. Its conclusions will guide the ILO and its constituents over the coming decade in ensuring that gender equality remains a top priority on decent work agendas at international, regional and national levels.

5. This report offers the basis for a review in the light of ILC resolutions and Governing Body decisions on gender equality and the relevant international labour

\footnotetext{
${ }^{4}$ For example, M. Fetherolf Loutfi (ed.): Women, gender and work: What is equality and how do we get there? (Geneva, ILO, 2001).

5 See ILO: Thematic evaluation report: Gender issues in technical cooperation, Governing Body, 292nd Session, Geneva, Mar. 2005, GB.292/TC/1, para. 46; and GB.292/PV, para. 223.

6 The ILO's goal is gender equality. This is supported by gender mainstreaming, which is the primary tool used to accelerate progress toward equality between women and men. In the ILO, a two-pronged approach to mainstreaming is applied: first, through explicitly and systematically addressing the specific and often different needs and concerns of both women and men in all policies, strategies and programmes; and second, through targeted interventions when analysis shows that one sex - usually women - is socially, politically and/or economically disadvantaged. Such initiatives aimed at women's empowerment are an essential part of gender mainstreaming and might include, for example, affirmative action measures.
} 
standards mentioned above. In addition to the selected milestones listed in table 1, the major policy documents in question are indicated in table 2 .

\section{Table 2. ILO policy on gender equality}

\begin{tabular}{ll}
\hline ILC resolutions & Governing Body decisions \\
\hline $\begin{array}{l}\text { 1991 resolution concerning ILO action for women } \\
\text { workers (ILC, 78th Session) }\end{array}$ & $\begin{array}{l}\text { 2002 endorsement of the first ILO Participatory } \\
\text { Gender Audit, based on Committee on Employment } \\
\text { and Social Policy document GB.285/ESP/7/1, }\end{array}$ \\
$\begin{array}{ll}285 \text { th Session, Nov. } 2002 \\
\text { - } 2004 \text { resolution concerning the promotion of gender } \\
\text { equality, pay equity and maternity protection } \\
\text { (ILC, 92nd Session) }\end{array}$ & $\begin{array}{l}2005 \text { instruction to include gender equality in the } \\
\text { Office's technical cooperation, based on Committee } \\
\text { on Technical Cooperation document GB.292/TC/1, } \\
\text { 292nd Session, Mar. 2005 }\end{array}$ \\
\end{tabular}

6. This general discussion takes place at a time when globalization and the current global financial crisis, as well highly volatile food prices and oil price fluctuations, are profoundly affecting societies worldwide. These crises highlight the importance of the ILO's Decent Work Agenda, and vindicate the Organization's adherence to its rightsbased mandate and the principles of tripartism and social dialogue. In 2004, the World Commission on the Social Dimension of Globalization was prescient in pointing to persistent concern over the uneven impact of globalization on many people, and the exclusion of many others from its benefits. ${ }^{7} \mathrm{~A}$ piecemeal approach to addressing the challenges of globalization would not work; there was a need for greater coherence in economic and social policy and greater accountability to all.

7. The 2008 Declaration has proven to be prophetic in its timing. Reaffirming the four ILO strategic objectives as sound bases for economic and social policies and with gender equality cutting across all four, it provides a global compass to help prevent vulnerable countries from drifting further into inequality. It aims for "an improved and fair outcome for all".

8. The World of Work Report $2008^{8}$ draws attention to the disproportionate effects of the current global economic slowdown on low-income groups. Income inequality was already on the rise in most countries, despite the recent period of economic expansion and a 30 per cent increase in world employment. However, employment growth was accompanied by a redistribution of income away from labour. Not everyone enjoyed the same opportunity for employment gains. Two-thirds of the countries surveyed in the above Report experienced an increase in income inequality between their richer and poorer households. It comes as no surprise that current forecasts point to a continued rise in global income inequality, which in the worst cases can lead to social instability, violence, higher crime rates and lower life expectancy. The ILO Global Employment Trends for January 2009 project sharp increases in unemployment. In addition, both working poverty and vulnerable employment will be affected, and encouraging trends that were seen up to 2007 might reverse, or at least stagnate. ${ }^{9}$

\footnotetext{
${ }^{7}$ See ILO: Decent work for a fair globalization: Broadening and strengthening dialogue, Overview paper for the ILO Forum on Decent Work for a Fair Globalization, Lisbon, 31 October-2 November 2007, p. 2.

${ }^{8}$ International Institute for Labour Studies (IILS): World of Work Report 2008: Income inequalities in the age of financial globalization (Geneva, ILO, 2008), pp. 1-2.

9 ILO: Global Employment Trends: January 2009 (Geneva, 2009), p. 24.
} 
9. Against this background, the pursuit of gender equality is justified on two grounds:

a First, there is the rights-based equity rationale. It argues the need to address the discrimination ${ }^{10}$ women face in the world of work, as a matter of fundamental human rights and justice. Despite the noble goal of outlawing discrimination based on sex, women continue to face disadvantages compared with men, who enjoy greater opportunities and better treatment in all areas of economic life. Although in recent decades more women have been participating in the labour force, job quantity has not been matched by job quality. In 2007, some 1.2 billion women were either employed or looking for work, yet many millions of them faced discrimination in access to training and jobs, were confined to mostly "female" occupations, had little chance of mobility, received lower pay for work of equal value or were unable to earn an adequate income. In a number of regions, women continue to feature disproportionately among the non-employed - reaching nearly 80 per cent in the Middle East, North Africa, and Asia and the Pacific. ${ }^{11}$ Marginalized populations, especially indigenous and tribal women, are exposed to multiple forms of discrimination and consistently fare poorly in terms of socioeconomic opportunities and treatment. ${ }^{12}$ These types of inequality deprive women of choice and opportunities in employment and are contrary to normative considerations of fairness and justice.

- Second, there is the economic efficiency rationale, which argues that women can play a critical role as economic agents capable of transforming societies and economies. Equality is not just an intrinsic value and a right in itself, but is instrumental in achieving economic growth and poverty reduction. Relevant in all cultural settings, economic empowerment of women unleashes their socioeconomic potential as a force for development. ${ }^{13}$ Women's increased bargaining power and decision-making ability in the household, as well as their improved status and income, have led to a number of positive secondary effects, such as enhanced child nutrition, health and education, better childcaring practices, ${ }^{14}$ lower infant mortality rates and less child labour.

10. Equality of rights applies throughout life. This is recognized in the Preamble to the Constitution of the ILO, adopted in 1919, which refers to the need to eliminate workplace injustice and improve conditions of labour across all age groups. The life-

\footnotetext{
10 Article 1(1)(a) of Convention No. 111 defines discrimination as any distinction, exclusion or preference based on the grounds of race, colour, sex, religion, political opinion, national extraction or social origin which has a negative effect on equality of opportunity or treatment in employment or occupation.

11 IILS: World of Work Report 2008: Income inequalities in the age of financial globalization (Geneva, ILO, 2008), p. 1.

12 Recent ILO studies reveal that indigenous and tribal women and girls have been amongst the most vulnerable in the context of globalization. See ILO: Eliminating discrimination against indigenous and tribal peoples in employment and occupation: A guide to ILO Convention No. 111 (Geneva, 2007). See also ILO: Indigenous women in the world of work: Based on case studies from Bangladesh, Nepal and Latin America (Geneva, forthcoming).

13 This includes programmes, policies and special measures for the improvement of indigenous women's economic and social conditions through support of their traditional occupations and expansion of alternative employment opportunities if they so choose. See ILO: Indigenous women in the world of work, op. cit.

${ }^{14}$ N. Jones, M. Mukherjee and S. Galab: Ripple effects or deliberate intentions? Assessing linkages between women's empowerment and childhood poverty (UNICEF, May 2007), p. 31.
} 
cycle approach has been used by the United Nations to tackle gender issues, and was advocated at both the Beijing and the Copenhagen Conferences (see table 1). This report has adopted a gender and life-cycle framework for the following reasons:

(a) Inequalities are accumulated throughout life and through generations. Female infants and girls, and young and mature women have often been targets of sex discrimination, leading to a cumulative burden of discrimination throughout their lifetimes and into their later years. Equality of opportunity and treatment in work needs to be ensured not just when a person enters the labour market, but from the earliest years - in health and nutrition, and through education and training. Throughout their lifetimes, women may be subject to direct or indirect sex discrimination. At work, direct sex discrimination might take the form of legislation that specifically excludes women from performing certain jobs or sets different retirement ages for men and women. Although direct sex discrimination has declined over the years, indirect discrimination persists in many forms. It occurs when apparently neutral measures have a disproportionately adverse impact on one particular group of the population. At the same time, the disadvantages of discrimination can be addressed and mitigated during different phases of an individual's life.

(b) The universality of the decent work concept encompasses all forms of work and thus all who perform work - young and old, women and men. The ILO understanding of the term "work" includes unpaid work in the family and in the community, which is often ignored in current thinking about the economy and society. Economic productivity is in fact indirectly subsidized by the social productivity of unpaid female work, which is also often carried out alongside paid female work. Information sources to quantify and value such work are extremely scarce. Much research is needed to better analyse and value the contribution of unpaid work, whether it involves raising a family, helping the elderly or undertaking community responsibilities. ${ }^{15}$

11. This report reviews ILO action throughout the life cycle and within the four strategic objectives. Chapter 1 places gender equality at the heart of the Decent Work Agenda. Chapter 2 addresses gender equality and tensions in a globalized world. Chapter 3 deals with maternal health and employment and their positive bearing on nurturing infants. Chapter 4 covers girls and boys and gender challenges facing children. Chapter 5 looks at young women and men, while Chapter 6 addresses the multiple facets of gender equality affecting adult workers. Chapter 7 examines the gender equality issues that concern older women and men workers. The last chapter draws conclusions to guide the ILC discussion on the ILO's future work.

\footnotetext{
${ }^{15}$ ILO: Changing patterns in the world of work, Report I(C), Report of the Director-General, ILC, 95th Session, Geneva, 2006, p. vi.
} 


\section{Chapter 1}

\section{Gender equality and the Decent Work Agenda}

12. The overall goal of decent work is to effect positive change in people's lives at the national and local levels. The Decent Work Agenda is best implemented through integrated and coordinated policy and institutional interventions, covering the ILO's strategic objectives - employment creation, social protection, tripartism and social dialogue, and principles and rights. A holistic approach to gender equality forms an intrinsic part of the Decent Work Agenda.

\subsection{Access to employment}

13. Sustained job-rich growth is needed to create productive and decent employment opportunities for women and men. However, growth must also be inclusive, and needs to be coordinated and coherent at national level. It should be backed by public and private investment, adopt a gender perspective, target specific needs, and be developed with the full engagement of the tripartite constituents. The 2008 Declaration stresses the promotion of employment by creating a sustainable institutional and economic environment in which individuals are enabled to pursue productive work, enterprises generate greater employment and income opportunities for all, and societies achieve their goals of economic development, good living standards and social progress. In the context of Decent Work Country Programmes, increasing labour demand, employability and quality of work according to levels of development would be a winning formula against poverty. ${ }^{1}$ But if there is an employment deficit, then the challenge of working out of poverty is even more daunting for women than for men.

14. The ILO Global Employment Agenda (GEA) was set up in response to United Nations (UN) calls for a coherent and coordinated international strategy for the promotion of freely chosen and productive employment. The ILO has played a critical role in promoting gender-sensitive employment policies in the GEA, which specifically advocates policies targeting men and women at risk of marginalization and exclusion from working life. It also calls for policies that can promote greater equity, ensuring that labour markets are free from discrimination. ${ }^{2}$ The GEA recognizes that addressing gender equality is integral to the areas of employment creation, skills and employability development, enterprise development and labour market policies. Timely, accurate and

\footnotetext{
${ }^{1}$ By the end of 2008, there were 53 gender equality country outcomes in the 38 finalized or draft Decent Work Country Programmes.

2 J. Rubery: Mainstreaming gender into the Global Employment Agenda, GEA Discussion Papers Series (Geneva, 2005), unpublished document, at www.ilo.org/public/english/employment/empframe/ practice/download/rubery.pdf.
} 
accessible sex-disaggregated labour market information and gender-sensitive analysis, as well as comparative analysis of key elements of national labour markets, are all services that constituents can obtain from the ILO. Information on global and regional trends, such as labour force estimates and employment and unemployment rates, is necessary for policy-makers as well. The gender mainstreaming strategy of the GEA is supported by a policy checklist on the gender dimensions of different areas covered under the GEA. ${ }^{3}$

15. Employment policies and active labour market policies are aimed at strengthening the functioning of the labour market to ensure that growth is labour intensive and that quality jobs are created through the development of an appropriate regulatory framework and institutional capacity. Because of the gendered nature of labour markets, specific mechanisms are needed so that gender concerns are mainstreamed in both policy development and policy implementation. Some examples of this are equal opportunity commissions, enterprise codes of practice and gender-responsive budgeting (GRB). More specifically, the ILO's post-conflict reconstruction and employment programmes emphasize systematic assessments of opportunities in a sex-disaggregated way and, in their implementation, support both women's and men's efforts to build new social and economic relationships.

16. A skilled workforce is a necessary condition for inclusive growth and competitive and sustainable enterprises. ${ }^{4}$ Employers have identified the shortage of skills as a primary concern, in particular the need to link the skills required in the labour market to education systems and training for reskilling and upskilling. ${ }^{5}$ Workers have emphasized the importance of social dialogue on training issues and on expanding opportunities for early skills development and lifelong learning in order to sustain employability and improve earnings in the face of technological and market changes. Sex discrimination in skills development is common, and leads to lower pay and occupational segregation for women. The ILO believes that attention to gender equality is particularly important in apprenticeships, community-based training, and the recognition of informally acquired skills. Moreover, the Human Resources Development Recommendation, 2004 (No. 195), specifically provides that Members should promote equal opportunities for women and men in education, training and lifelong learning. Special consideration is being given to employment-intensive infrastructure programmes incorporating gender-sensitive strategies.

17. The enabling environment for sustainable enterprise development comprises a large array of factors that have gender dimensions. Some basic conditions agreed at the 2007 session of the ILC are: (1) peace and political stability; (2) good governance; (3) social dialogue; (4) respect for universal human rights and international labour standards; (5) entrepreneurial culture; (6) sound and stable macroeconomic policy and good management of the economy; (7) trade and sustainable economic integration; (8) an enabling legal and regulatory environment; (9) rule of law and secure property rights; (10) fair competition; (11) access to financial services; (12) physical infrastructure; (13) information and communication technologies (ICTs); (14) education,

\footnotetext{
3 For an update on the results of the GEA, see ILO: Implementation of the Global Employment Agenda: An update, Governing Body, 303rd Session, Geneva, Nov. 2008, GB.303/ESP/2.

4 ILO: Skills for improved productivity, employment growth and development, Report V, ILC, 97th Session, Geneva, 2008.

${ }^{5}$ International Organisation of Employers (IOE): Trends in the workplace survey 2008: Enterprises in a globalizing world (Geneva, 2008), pp. 5-6.
} 
training and lifelong learning; (15) social justice and social inclusion; (16) adequate social protection; and (17) responsible stewardship of the environment. ${ }^{6}$ Much work has been done to harness the creative entrepreneurial spirit of women and foster it with capacity building and training to create sustainable enterprises. National policies and regulatory reforms that support a conducive environment for enterprises, including respect for workers' rights and gender equality, are ILO priorities.

18. Access to formal credit has been a constraint faced by women more than men. One of the responses is microfinance. While it is not a universal panacea, ${ }^{7}$ it helps empower women from poorer households to contribute to the livelihood of their families and communities. Microfinancial services - which by the end of 2006 had reached over 79 million of the poorest women in the world ${ }^{8}$ - have enabled female clients to develop their businesses, registering higher repayment rates. Research shows a positive side effect, in that the income generated by female borrowers was invested in their households for children's education and better health and nutrition practices. Daughters of women microfinance clients also reap the benefits, as there is an increased likelihood of full-time school enrolment and lower drop-out rates for these girls.

19. Cooperatives, as defined by the Promotion of Cooperatives Recommendation, 2002 (No. 193), represent another positive measure for addressing poverty and gaining sustainable livelihoods. The Recommendation calls for the promotion of gender equality in cooperatives and in their work. Recent research in Africa points to a new dynamism in the cooperative sector, while noting that most cooperatives are initiated, composed and run by men. ${ }^{9}$

${ }^{6}$ ILO: Conclusions concerning the promotion of sustainable enterprises, in Report of the Committee on Sustainable Enterprises, Provisional Record No. 15, ILC, 96th Session, Geneva, 2007, para. 11.

7 For microfinance to contribute genuinely to women's economic empowerment, other factors need to be taken into account. Intra-household power and decision-making dynamics, differences in literacy, property rights and societal attitudes about women may limit the impact of the credit.

8 S. Daley-Harris: State of the Microcredit Summit Campaign Report 2007 (Washington, DC, Microcredit Summit Campaign, 2007).

${ }^{9}$ P. Develtere, I. Pollet and F. Wanyama, (eds): Cooperating out of poverty: The renaissance of the African cooperative movement (Geneva, ILO, 2008), pp. 33 and 59. 


\section{Box 1.1 \\ The transition from informal economy to formalization: Astride all ILO objectives}

The lack of social security, inadequate labour protection and poor working conditions characterize informal jobs in both urban and rural settings. These conditions, combined with insufficient knowledge of labour rights and the absence of voice and representation, mean that informal economy workers have a raw deal. Women workers in the informal economy are often at the lower end of precarious and poorly paid work, and are subject to further social exclusion as they struggle to balance their productive and reproductive roles. The decline of the industrial sector, the inability of most economies to create sufficient numbers of quality jobs and the impact of the current financial and economic crisis have yet to make themselves fully felt. Greater efforts will be needed to support employment creation and enterprise development to make the transition from informality to formality.

The ILO aims to upgrade the informal economy through the adoption of a policy mix. Moving out of informality requires large-scale social assistance programmes for the underprivileged. Social transfers combined with measures promoting decent work and the transition to formalization would lift the neediest out of abject poverty. It is essential that solutions targeting gender equality in these objectives be expressed clearly and simply, so as to make them accessible to the non-gender specialists ultimately responsible for their implementation.

Sources: ILO: Conclusions concerning decent work and the informal economy, in Report of the Committee on the Informal Economy, Provisional Record No. 25, ILC, 90th Session, Geneva, 2002; and ILO: Decent work and the transition to formalization: Recent trends, policy debates and good practices, Report of the Tripartite Interregional Symposium on the Informal Economy: Enabling Transition to Formalization (Geneva, 27-29 November 2007).

\subsection{Access to social protection}

20. Social protection ${ }^{10}$ is a powerful tool to alleviate poverty and inequality. Welldesigned social policies can go hand in hand with strong economic performance. According to the ILO, less than 2 per cent of global gross domestic product (GDP) would be necessary to provide a basic set of social security benefits to all the world's poor. ${ }^{11}$ Establishing technically feasible and financially viable ways of extending coverage of basic health care, family/child benefit, targeted income support for the poor and unemployed, and old-age and disability pensions would provide a minimum safety net. The ILO Global Campaign on Social Security and Coverage for All was launched in 2003 , with the aim of achieving concrete improvements in social security coverage in as many countries as possible and placing social security at the top of the international policy agenda. Since poverty has a gender dimension that cannot be ignored and the

\footnotetext{
${ }^{10}$ Social protection is the provision of a generalized basic social support for all citizens, regardless of contribution or employment history, for instance for the purpose of income support on the basis of need rather than acquired rights, and health care for the entire population. Social security can be defined as the protection which society provides for its members against the economic and social distress that would otherwise result from the interruption or substantial reduction of earnings linked to contingencies such as maternity, old age or unemployment. ILO: ABC of women workers' rights and gender equality, second edition (Geneva, 2007), pp. 172-176.

${ }^{11}$ ILO: Social security policies for social cohesion and economic development: Towards a global social floor? Issues paper for the ILO Forum on Decent Work for a Fair Globalization, Geneva, 2007, p. 1. A recent study in the United Republic of Tanzania confirms that a minimum package of universally acceptable benefits would indeed be affordable. Such a package, including targeted social assistance, a universal old-age pension and a child benefit, would cost just over 1.8 per cent of the country's GDP. See ILO: Tanzania mainland: Social protection expenditure and performance review and social budget, executive summary (Geneva, 2008), pp. 16-17.
} 
effects of economic growth have not trickled down to the poorest, public policies that encourage a fair distribution of national resources by implementing social security systems would make a substantial contribution to lifting the poorest out of extreme poverty.

21. Gender equality and women's empowerment are major components of the ILO's work on improved wages and incomes, working time, maternity protection, health and safety, and work-family reconciliation. The Global Wage Report 2008/09 ${ }^{12}$ highlighted the glaring wage differences between the sexes. The working and employment conditions of precarious, part-time and informal workers - most of whom are women receive concerted attention.

22. Aside from maternity protection issues, the biological and reproductive differences between the sexes in occupational safety and health (OSH) had not been given priority attention by the ILO until recently. The Global Strategy on Occupational Safety and Health is aimed at supporting constituents' efforts to place OSH high on national agendas by creating a preventive safety and health culture and a systems approach. This strategy contains a commitment to include specific OSH issues pertaining to women's health and safety. National programmes are linked to Decent Work Country Programmes to reinforce countries' systems, with the aim of expanding coverage to small enterprises and the informal economy, which would lead to a greater focus on women as well. The 2009 World Day for Safety and Health at Work, which reinforces the safety and health culture and dialogue between the social partners, also enhances the visibility of gender equality in $\mathrm{OSH}$, giving a much needed boost to the issue.

23. The HIV/AIDS epidemic disproportionately affects the poor, unemployed, and women and girls. Migrant and mobile workers have a higher risk of exposure, in the absence of HIV- and AIDS-related prevention and health-care services. Among all persons living with HIV aged 15 years and over, the proportion of women has remained stable at about 50 per cent. In contrast, in sub-Saharan Africa, women have accounted for 60 per cent of adults living with HIV since 2000. In the Caribbean, women now make up 43 per cent of adults living with HIV, up five percentage points since 2001 . $^{13}$ The ILO code of practice on HIV/AIDS and the world of work advocates mainstreaming gender in HIV/AIDS awareness raising. ILO legislative research ${ }^{14}$ and capacity building for labour ministry officials, dispute settlement bodies and judges have built-in gender components. The Office's preparatory work for the double discussion with a view to the adoption of an autonomous Recommendation on HIV/AIDS and the world of work in 2010 has mainstreamed women- and gender-specific concerns.

24. International labour migration is on the rise. A force for growth and development, migration is most beneficial when it is a choice rather than a necessity, for the migrants themselves, for the countries of origin and for the countries of destination. It is essential to take a rights-based approach in ensuring decent jobs for migrants in destination countries. Migrants' remittances represent an important and visible contribution to development. According to the World Bank, a 10 per cent increase in the share of remittances will lead to a roughly 2 per cent decline in the depth of poverty in the

\footnotetext{
12 ILO: Global Wage Report 2008/09: Minimum wages and collective bargaining: Towards policy coherence (Geneva, 2008).

13 ILO: HIV/AIDS and the world of work, Report IV(1), ILC, 98th Session, Geneva, 2009, para. 19.

14 J. Hodges: Digest of good legislative practices relating to HIV/AIDS in selected African countries, Social Dialogue, Labour Law and Labour Administration Branch Paper No. 12 (Geneva, ILO, 2007), p. 5 .
} 
developing world. ${ }^{15}$ Over 190 million people - close to 50 per cent of them women had migrated by 2005 . The vast majority were migrant workers and their families (roughly 170 million). ${ }^{16}$ Effective protection of migrant workers remains a challenge, and when families are separated, this represents the ultimate imbalance in the reconciliation of work and family. The 2004 ILC resolution concerning a fair deal for migrant workers in a global economy, the resulting plan of action and the ILO Multilateral Framework on Labour Migration address the specific needs of female migrants within the context of developing regular, protected and beneficial migration that responds to the labour market needs of countries of destination and alleviates pressures in countries of origin.

\subsection{Access to social dialogue}

25. Tripartism and social dialogue are essential if real progress is to be made in attaining gender equality. In today's reality of eroding employment relations and increasingly precarious jobs in both developed and developing countries, the right to freedom of association and collective bargaining in law and practice must not be denied. Yet ministries responsible for employment, labour and social affairs do not always have the capacity, authority and resources needed to formulate appropriate labour policies. Increasing the institutional capacity of member States, as well as of representative organizations of employers and workers, to facilitate meaningful and coherent social dialogue on gender equality will be necessary to improve current practices. Efforts must be made at country level to strengthen the participation, expertise and experience of women constituents so that they may actively contribute to mechanisms for social dialogue. At present, women account for approximately 15 per cent of total members governments, workers and employers - of social dialogue institutions. Governments show the highest rates of female participation in these bodies (19 per cent), followed by workers' representatives with about 13 per cent, and employers' representatives with 10 per cent. ${ }^{17}$

26. Building and strengthening employers' and workers' organizations and their ability to participate effectively in the development and implementation of social, economic and labour policy will remain one of the ILO's top priorities. ${ }^{18}$ Well-functioning employers' organizations are crucial for shaping an environment conducive to competitive and sustainable enterprises. Employers note that in all regions more women are working than ever before, and that this process is facilitated by the availability of work arrangements that differ from the traditional employer/employee relationship. ${ }^{19}$ Workers are

${ }^{15}$ R.H. Adams and J. Page: International migration, remittances and poverty in developing countries, Policy Research Working Paper Series, No. 3179 (Washington, DC, World Bank, 2003), p. 22.

16 ILO: Independent evaluation of ILO's strategy for the protection of migrant workers: 2001-07, Evaluation Unit (Geneva, 2008), para. 18.

17 T. Breneman-Pennas and M. Rueda Catry: Women's participation in social dialogue institutions at the national level, Social Dialogue, Labour Law and Labour Administration Branch Paper No. 16 (Geneva, ILO, 2008).

18 For example, see research on gender and trade union density in J. Ishikawa and S. Lawrence: Trade union membership and collective bargaining coverage: Statistical concepts, methods and findings, Social Dialogue, Labour Law and Labour Administration Branch Paper No. 10 (Geneva, ILO, 2005), pp. 30-32.

19 IOE: Trends in the workplace survey 2008: Enterprises in a globalizing world (Geneva, 2008), p. 5 . 
concerned that these flexible arrangements contribute to inequality and precarious jobs, such as temporary or contract work or disguised employment relationships that perpetuate poor labour practices. ${ }^{20}$ Recognizing these different views, the Employment Relationship Recommendation, 2006 (No. 198), encourages the establishment of mechanisms for monitoring developments in the labour market and the organization of work. The most representative organizations of employers and workers should work together on an equal footing in these mechanisms. Freedom of association and collective bargaining remain the essential tools to empower women and secure their place in information sharing, consultations and negotiations. Fostering sectoral social dialogue in specific economic sectors, both public and private, and promoting ILO sectoral standards in tandem with the key equality Conventions enable gender issues to be treated as a shared concern for which good practices and negotiation strategies could be identified.

27. Labour administrations, including effective and well-resourced labour inspection systems, are instrumental in enforcing gender equality labour legislation and policy. Experience shows that where legislation is clear on its gender implications and is well implemented, gender equality has a better chance of being achieved. An example is the 2006 European Union (EU) Directive on the implementation of the principle of equal opportunities and equal treatment of men and women in matters of employment and occupation (recast), which is being transposed into national legislation. This resulted in gender equality being covered in 64 per cent of the social dialogue bodies of the EU. ${ }^{21}$

28. The ILO has decades of expertise on how to mainstream gender equality into labour law. ${ }^{22}$ A gendered approach is vital for substantive provisions and workable enforcement clauses. Member States must bring their national law and practice into conformity with ratified international labour Conventions and must respect, promote and realize the equality principle of the 1998 ILO Declaration on Fundamental and Rights at Work and its Follow-up. It is also important in the drafting and adoption process (using tripartite consultations, together with women's organizations). The ITC-ILO courses on participatory labour law drafting include dedicated modules on gender-inclusive processes and content.

\subsection{Access to principles and rights}

29. International labour standards are a primary means of ILO action to improve working and living conditions, and to promote equality in the workplace for all workers. Irrespective of the economic and social development of any ILO member State, the relevant Conventions represent a minimum level for protection, although, of course, States are encouraged to grant more favourable conditions according to their national circumstances.

\footnotetext{
${ }^{20}$ M. Malentacchi: Precarious work - what needs to be done?, Global Unions/ACTRAV Forum Towards Social Justice: Applying Labour Standards to Precarious Workers, Geneva, 3 October 2008, p. 2.

21 T. Breneman-Pennas and M. Rueda Catry: Women's participation in social dialogue institutions at the national level, Social Dialogue, Labour Law and Labour Administration Branch Paper No. 16 (Geneva, ILO, 2008), p. 25.

${ }^{22}$ See Labour Legislation Guidelines on the web site of the Social Dialogue, Labour Law and Labour Administration Branch, Chapter VII - Substantive provisions of labour legislation: The elimination of discrimination in respect of employment and occupation, at www.ilo.org/public/english/dialogue/ ifpdial/llg/index.htm.
} 
30. The evolution of standards generally in the ILO is closely linked to global reassessment of discrimination and equality. After the early decades of texts that protected women in formal work, the post-war years witnessed the adoption of the first two key equality Conventions. From the second half of the 1970s to date, standards echoed the UN policy shift from looking at women as vulnerable "objects" to acknowledging them as central players in all aspects of social and economic development. ${ }^{23}$ Soon after the 1995 Copenhagen World Summit for Social Development, the 1998 ILO Declaration on Fundamental Principles and Rights at Work and its Followup was adopted and the Director-General's policy circular of 1999 on gender equality and mainstreaming in the ILO was released (see table 1 in the Introduction). Genderinclusive and non-sexist language is important in both international texts and national policies and laws for achieving gender equality, rendering texts explicitly gendersensitive. This is reflected in the adaptation of language used in standards. ${ }^{24}$

31. The Discrimination (Employment and Occupation) Convention, 1958 (No. 111), is the reference point for the fundamental right of non-discrimination at work. It is the most comprehensive instrument on the subject. Ratifying member States must declare and pursue a national policy to promote equality of opportunity and treatment in respect of employment and occupation, with a view to eliminating discrimination. The prohibited grounds of discrimination cover sex as well as race, colour, religion, political opinion, national extraction and social origin. Sex discrimination includes discrimination on the grounds of maternity and family responsibilities and extends to sexual harassment (of both women and men). According to Article 1(1)(b) of Convention No. 111, other grounds can be added to this list after consultation with representatives of employers' and workers' organizations and other appropriate bodies. Some member States have added new grounds that are highly relevant to gender equality, such as age, HIV and AIDS status and sexual orientation. ${ }^{25}$ The very high rate of ratification of Convention No. $111-168$ as of January 2009 - proves its ongoing relevance (see figure 1.1). Under the Convention, there are only a few cases in which distinctions based on sex are acceptable, when the distinction relates to an inherent requirement of a specific job (for instance, being male or female may be a requirement in the performing arts and for jobs involving close physical contact, such as medical personnel or airport security). Another example would be affirmative action as a temporary labour market measure to redress past inequalities based on sex.

${ }^{23}$ See ILO: ABC of women worker's rights and gender equality, second edition (Geneva, 2007), pp. $8-10$.

${ }^{24}$ See ILO: Manual for drafting ILO instruments, Office of the Legal Adviser (Geneva, 2006), paras 254-266.

${ }^{25}$ See, for example, ILO: HIV/AIDS and the world of work, Report IV(1), ILC, 98th Session, Geneva, 2009 , para. 246. 
Figure 1.1. Number of ratifications of Convention No. 111 (168 as of January 2009)

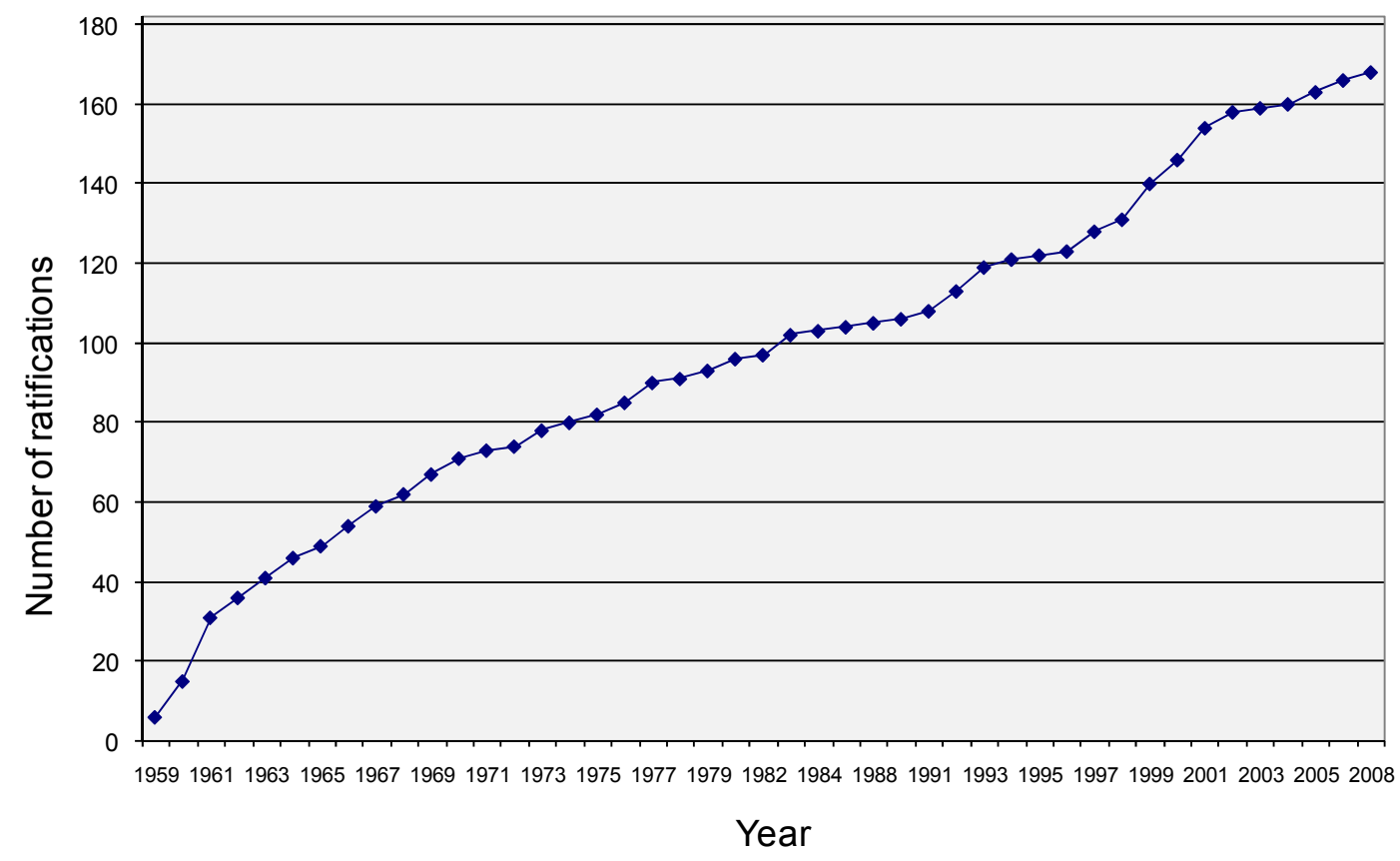

32. No society is free from sex discrimination. Convention No. 111 recognizes that continuous action is required to address it. Implementation gaps include: lack of legislative coverage for certain categories of work where women predominate, such as domestic and casual work; anti-discrimination laws that do not cover all aspects of employment and occupation (from recruitment to termination); discriminatory legal provisions (for example, laws which place limitations on the types of work women can do, such as night work); and outdated laws governing personal and family relations (such as those authorizing a husband's objection to his wife working outside the home). The debate on whether women need to be protected from hazardous or night work is not over yet. In an increasing number of countries it is agreed that work needs to be made safe for both women and men rather than excluding women alone from certain occupations. Rather than barring women from male-dominated jobs, workplaces need to be made safe and free of health and other risks. ${ }^{26}$ Enforcement of the laws in practice needs improvement.

33. The second key equality instrument is the Equal Remuneration Convention, 1951 (No. 100). It specifically addresses equal remuneration between men and women for work of equal value and echoes the wording of the ILO Constitution of 1919, which called for an urgent improvement in labour conditions through, among other things, "recognition of the principle of equal remuneration for work of equal value". Convention No. 100 also has a high ratification rate (figure 1.2).

${ }^{26}$ N. Haspels and E. Majurin: Work, income and gender equality in East Asia (Bangkok, ILO, 2008), p. 58 . 
Figure 1.2. Number of ratifications of Convention No. 100 (166 as of January 2009)

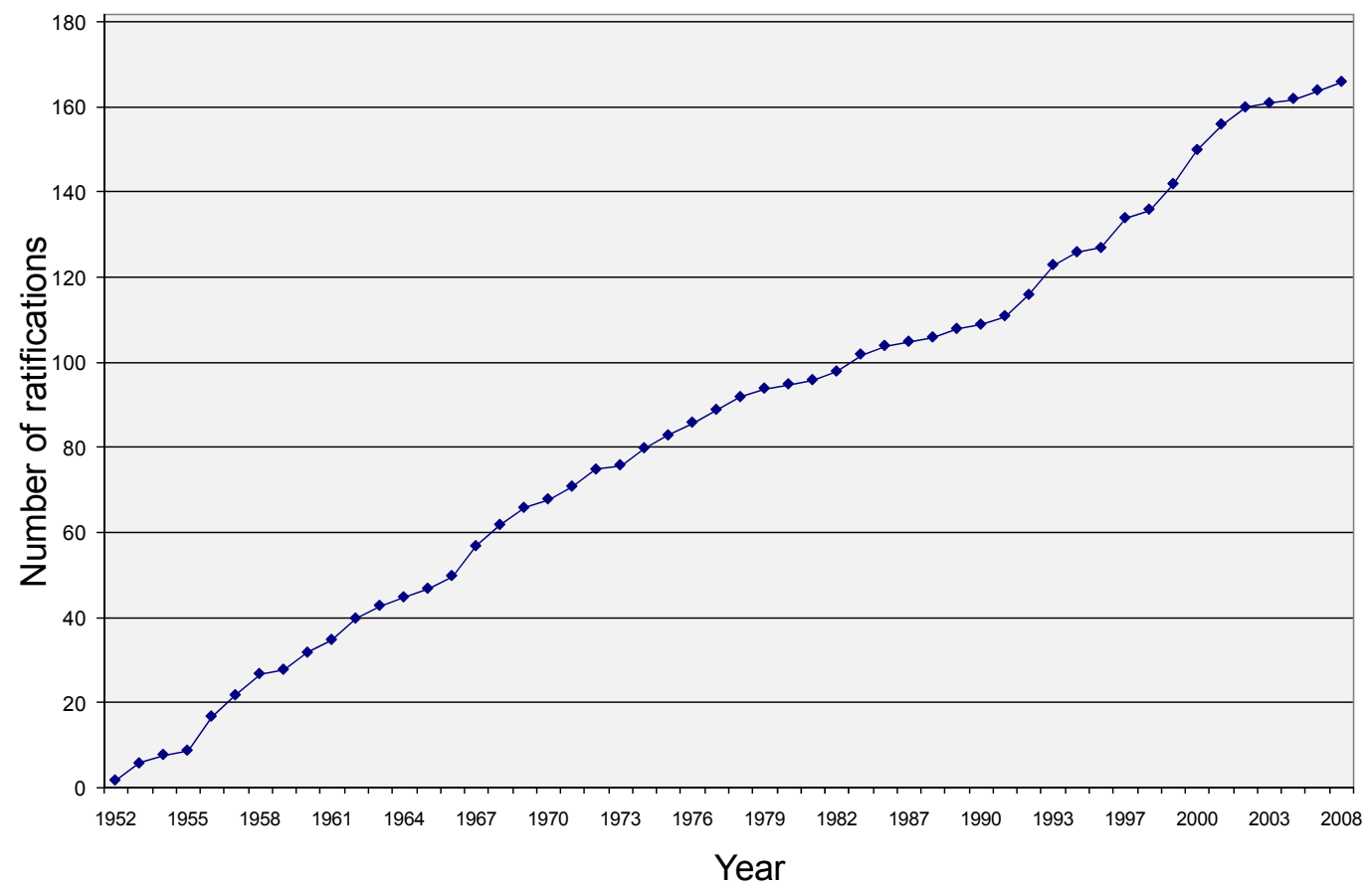

34. Considerable difficulties remain in applying the principle of equal pay for work of equal value in law and practice. Contrary to popular belief, women's lower educational qualifications and intermittent labour market participation are not the main reasons for the gender pay gap. The gap is in fact a visible symptom of deep, structural sex discrimination. Factors such as the existence and persistence of gender stereotypes, occupational segregation, sex-biased job classification systems and pay structures, and weak collective bargaining are important determinants of pay inequalities. ${ }^{27}$ The scope and implications of "work of equal value" are poorly understood. ${ }^{28}$ The notion goes beyond equal remuneration for "equal", the "same" or "similar" work: it also encompasses work of an entirely different nature, but nevertheless of equal value. This concept is essential in order to address occupational segregation where men and women often perform different jobs, in different conditions, and even in different establishments. It is also important, when determining wage rates, to counter the undervaluation of "female jobs" by comparison with those of men, which is often caused by gender-biased job descriptions. Assessing jobs objectively may increase not only women's income, but also the national income. ${ }^{29}$

35. A third key equality Convention is the Workers with Family Responsibilities Convention, 1981 (No. 156). It has been ratified by 40 countries as of January 2009. Recognition of the need to reconcile work and family (both children and adult dependants) responsibilities and its implications for gender equality in the labour market

27 ILO: Time for equality at work, Global Report under the follow-up to the ILO Declaration on Fundamental Principles and Rights at Work, Report I(B), ILC, 91st Session, Geneva, 2003, p. xi.

${ }^{28}$ CEACR: General observation on Convention No. 100, in ILO: Report of the Committee of Experts on the Application of Conventions and Recommendations (hereafter RCE), Report III (Part 1A), ILC, 96th Session, Geneva, 2007, pp. 271-272.

29 A study in Latin America estimated that ending inequalities against women in the labour market could increase women's wages by 50 per cent while raising national output by 5 per cent. United Nations Population Fund (UNFPA): The State of World Population 2000: Lives together, worlds apart: Men and women in a time of change (New York, 2000), p. 38. 
have become increasingly prominent in the twenty-first century. Factors such as long working hours have uneven effects on women, who are most likely to be the main care providers for their families. ${ }^{30}$ The availability of childcare and commuting distances between home and work are also relevant. Differences in the working patterns of women and men have a negative impact on women's job prospects, occupational choices, careers and pay, while increasing their overall workload. In some ways, the availability of part-time work has opened doors to reconciling work and parenthood. ${ }^{31}$ However, in most countries, part-time work remains "women's work", thus reinforcing the traditional sexual divisions of labour. ${ }^{32}$ Women and men in developing countries face additional challenges to balancing work and family, especially in rural areas where time-consuming chores, long distances, poor infrastructure and general poverty prevail.

36. Maternity protection has been a major issue for the ILO since its foundation. The ILO has adopted three Conventions on maternity protection: Convention No. 3, 1919; No. 103, 1952; and No. 183, 2000. Together with their corresponding Recommendations, these Conventions have gradually expanded the scope and entitlements of maternity protection at work and provide detailed guidance orienting national policy and action. The core concerns have been to enable women to combine their reproductive and productive roles successfully, and to prevent unequal treatment in obtaining and keeping jobs because of their reproductive role. Convention No. 183 has been ratified by 16 member States as of January 2009.

37. Many other Conventions, especially the fundamental ILO Conventions, have particular implications for gender equality and will be referred to throughout this report. ${ }^{33}$ The gender implications of all ILO standards should be considered in ensuring their effective application in law and in practice. And beyond ratification of all relevant Conventions, this report will identify challenges to their implementation. Enforcement at the national level is guided by the Labour Inspection Convention, 1947 (No. 81), and the Labour Inspection (Agriculture) Convention, 1969 (No. 129).

\subsection{Gender, the ILO and the United Nations}

38. Throughout this report, areas of inter-agency cooperation will be highlighted regarding the specific issues concerning the different phases of the life cycle of women and men. In addition, the ILO collaborates extensively on gender equality with the United Nations and its agencies within the context of "Delivering as One" and UN reform. Examples of successful ILO mechanisms and collaborative efforts undertaken in recent years are given below.

\footnotetext{
${ }^{30}$ In Japan, for instance, the average time men spent on domestic tasks was just one-seventh of the time spent by women. J.Y. Boulin et al. (eds): Decent working time: New trends, new issues (Geneva, ILO, 2006), p. 352.

${ }^{31}$ ILO: Equality at work: Tackling the challenges, Global Report under the follow-up to the ILO Declaration on Fundamental Principles and Rights at Work, Report I(B), ILC, 96th Session, Geneva, 2007, para. 302.

${ }^{32}$ In Norway, for instance, 43 per cent of women versus 13 per cent of men work part time. Statistics Norway: "Still male and female professions", 24 Jan. 2006, at http://ssb.no/ola_kari_en/arbeid_en/ main.html. This study also showed that women with more than one child under $1 \overline{6}$ years of age most frequently worked part time.

${ }_{33}$ See ILO: Gender equality and decent work: Selected ILO Conventions and Recommendations promoting gender equality, second edition (Geneva, 2006).
} 


\subsubsection{ILO tools in UN collaboration}

39. The ILO has been a forerunner among UN agencies in recognizing that, while social justice is the ultimate justification for paying attention to gender equality, there is also a strong economic argument for equality. Apart from the World Bank, the ILO was one of the first UN agencies to use the business case argument alongside the rights-based argument. This approach is now promoted in forums such as the Committee on the Status of Women (CSW) and in recent gender policies, strategies and action plans of UN agencies such as the United Nations Development Programme (UNDP), the Food and Agriculture Organization of the United Nations (FAO), the United Nations Children's Fund (UNICEF) and the United Nations Educational, Scientific and Cultural Organization (UNESCO).

40. The ILO has been consistent in applying a gender mainstreaming strategy that does not exclude the use of women-specific activities and/or affirmative action whenever women are disadvantaged in the world of work. The Organization's two-pronged approach in gender mainstreaming and women-specific interventions has been subsequently adopted by most UN agencies, as well as bilateral agencies. The ILO has been recognized as a source of good practice on gender mainstreaming and over the years has regularly been called upon for guidance by the UN family.

\section{ILO Action Plan for Gender Equality}

41. The ILO Action Plan for Gender Equality calls for an explicit and systematic assessment of the different needs of both women and men in all policies, strategies and programmes. This entails a comparative analysis of the situation of women and men in the world of work and the labour market. At the same time, the Plan acknowledges the need for targeted interventions where one or the other sex faces social, political or economic disadvantage. The Plan, which reinforces accountability and monitoring mechanisms, was recognized as a good practice in the report of the UN SecretaryGeneral on improvement of the status of women in the UN system, presented to the 63rd Session of the General Assembly. ${ }^{34}$

\section{Participatory Gender Audit}

42. In the past decade, the ILO itself has undergone an institutional transformation with regard to the mainstreaming of gender equality into all aspects of its mandate. The ILO's commitment to assist its own constituents and officials in re-evaluating the gender dimensions of their work is successfully under way. Central to the effort is the ILO Participatory Gender Audit (PGA) - a unique tool for assessing and monitoring the achievement of gender equality both within the Organization and in the world of work. ${ }^{35}$

\footnotetext{
${ }^{34}$ UN document A/63/364, dated 18 Sep. 2008, para. 46.

35 To date, a total of 29 ILO units have been audited. In addition, PGAs have gained momentum among constituents through capacity building on how to use this evaluation methodology within the framework of decent work country programming, and constituent-run PGAs have taken place in Pakistan, Russian Federation, Sri Lanka and Yemen, with others in the pipeline.
} 


\section{Box 1.2 \\ The ILO Participatory Gender Audit}

A participatory gender audit is a process based on an interactive methodology to promote learning at the individual, work unit and organizational levels on how to mainstream gender practically and effectively. It considers whether internal policies, practices and related support systems for gender mainstreaming are effective and reinforce each other by establishing a baseline and identifying gaps and good practices. It helps to build organizational ownership for gender equality initiatives and sharpens learning in the process.

Source: ILO: A manual for gender audit facilitators: The ILO participatory gender audit methodology (Geneva, 2007).

43. In 2001, the ILO introduced the PGA - the first of its kind - to the UN system. UN agencies in Mozambique, Nigeria, United Republic of Tanzania and Zimbabwe have gone through the audit process. By 2007, the intensive Training of Facilitators (TOFs) on audit facilitation skills and methodology had been developed so that a multiplier effect is achieved by creating capacity among national gender experts and UN staff.

44. The PGA can serve as a significant learning experience on where the UN stands today on gender equality, and where institutions need to go to transform policies into practical application by UN Country Teams (UNCTs), for example, in the United Nations Development Assistance Framework (UNDAF) process. The PGA has been presented to many task forces and to the Economic and Social Council (ECOSOC). In the context of developing system-wide standards for gender mainstreaming as an accountability framework, the ILO's PGA has been accepted as a valuable preparatory intervention to be used as a complement to the UNCT Performance Indicators for Gender Equality and Women's Empowerment (known as the "Scorecard"). ${ }^{36}$

\section{Results-based management}

45. The ILO was one of the first UN agencies to incorporate gender mainstreaming into the results-based management (RBM) approach; this experience has, over the years, been tapped by other UN agencies. A 2006 review of gender in ILO programming found that RBM was conducive to making gender equality explicit in the results chain. ${ }^{37}$ It showed that, while there was room for improvement, the extent to which gender was mainstreamed in the ILO programme and budget increased from one biennium to the next, with just over one-third of outcomes in 2006-07 being gender responsive, and an increasing number of gender-sensitive indicators in use.

\subsubsection{ILO and the inter-agency system}

46. Better alignment between national goals and international cooperation is a concern of the UN system. The ILO is aware of the crucial significance of tripartism and social dialogue and the inclusion of its Decent Work Country Programmes within the "Delivering as One" objectives. ${ }^{38}$ The ILO's tripartite structure provides an opportunity for other UN agencies to connect with important economic and social actors. The mandate of the Organization and the nature of tripartism mean that gender equality will be discussed and addressed by governments, workers and employers collectively. This

\footnotetext{
${ }^{36}$ See Report of the Seventh Session of the Inter-Agency Network on Women and Gender Equality (IANWGE), New York, 19-21 February 2008.

37 C. Gaynor: Gender equality in ILO strategic programming, paper commissioned by the Bureau for Gender Equality (Geneva, ILO, 2006), unpublished.

38 See ILO: Decent work and UN reform: What's in it for the workers? (Geneva, 2008), p. 11.
} 
has particular resonance at country level, where the ILO supports social dialogue within its member States. ${ }^{39}$

47. The ILO message on the Millennium Development Goals (MDGs) relates to working out of poverty: "if the international community, working together, can just deliver the convergence of policies that will allow every woman and man to work their way out of poverty, the rest will follow". ${ }^{40}$ Within the UN system, the ILO takes the lead on two specific MDG indicators that refer to the world of work: indicator 11 - share of women in wage employment in the non-agricultural sector; and indicator 45 unemployment rate of 15- to 24-year-olds. Since 2007 there has been an improved target for MDG 1, advocated by the ILO.

\section{Box 1.3 \\ Introduction of the new target relating to full and productive employment and decent work for all}

In discussions on the MDGs, the ILO has always advocated that realizing full and productive employment and decent work for all is the main route for people to escape poverty. This message was picked up at the 2005 Social Summit and by the former Secretary-General of the United Nations, Kofi Annan, who recommended new targets under the MDGs in his last report to the General Assembly in August 2006:

"A new target under Millennium Development Goal 1: to make the goals of full and productive employment and decent work for all, including for women and young people, a central objective of our relevant national and international policies and our national development strategies."

The ILO worked with the UN Department of Economic and Social Affairs (DESA) and the Statistics Division, the World Bank and specialized agencies to develop a set of indicators to measure the new target; these were approved in 2007.

Sources: United Nations: Report of the Secretary-General on the work of the Organization, A/61/1 (New York, 2006), para. 24; D. Schmidt: "Decent employment and the Millennium Development Goals: Description and analysis of a new target" in ILO: Key Indicators of the Labour Market, fifth edition (Geneva, 2007).

48. Decent work offers practical ways of accelerating the implementation of the Beijing Platform for Action and achieving all of the MDGs, especially MDG 3 on gender equality. Other UN agencies welcome the ILO's work in promoting women's employment and its ongoing activities covering several MDGs. ${ }^{41}$ The ILO is assisting the entire UN system to mainstream employment and decent work into their programmes, policies and activities through the Toolkit for mainstreaming employment and decent work, which itself mainstreams gender. ${ }^{42}$

\footnotetext{
39 A review of gender mainstreaming in UNDP, the World Bank and the ILO found the ILO's governance structure the most "permeable" and its mandate the most "hospitable" of the three agencies in promoting gender equality, through the framing of international labour standards. S. Razavi and C. Miller: Gender mainstreaming: A study of efforts by the UNDP, the World Bank and the ILO to institutionalize gender issues (Geneva, United Nations Research Institute for Social Development (UNRISD), 1995).

40 ILO: Working out of poverty: Facts on the ILO and the Millennium Development Goals (Geneva, Sep. 2005).

41 S.R. Osmani: The role of employment in promoting the Millennium Development Goals (Geneva, ILO, 2005).

42 The Toolkit was developed at the request of ECOSOC in 2006 and approved by the United Nations Chief Executives Board for Coordination (CEB) in April 2007.
} 
49. Better cooperation between $\mathrm{UN}$ agencies and their national partners is sought through Common Country Assessments (CCA), the UNDAFs, MDG Reviews and Poverty Reduction Strategy Papers (PRSPs). The gender-inclusive Decent Work Country Programmes define the ILO contribution to such frameworks. In the United Republic of Tanzania, for example, the United Nations Development Fund for Women (UNIFEM) and the ILO have collaborated to mainstream gender and Decent Work Country Programmes issues in the PRSP process. The ILO is the lead agency in the country for the UN Programme on Wealth Creation, Employment and Economic Empowerment, under which the mainstreaming of gender equality and decent work falls. In China, the ILO is a catalyst for collaboration on gender equality between UN agencies; there are $26 \mathrm{UN}$ inter-agency projects with non-governmental organizations (NGOs), workers and employers.

50. The ILO has contributed to a number of regional initiatives aligning inter-agency work with the MDGs. ${ }^{43}$ For example, the Inter-agency and Expert Group Meeting on Gender and the Millennium Development Goals in the Arab Region, organized by the United Nations Economic and Social Commission for Western Asia (ESCWA) and UNDP in 2007, supported research and analysis on gender equality and labour market indicators in the Arab States in the context of the MDGs. ${ }^{44}$ The expert exchanges provided guidance on adjusting the MDG indicators to monitor the labour market realities of Arab States.

\subsubsection{The ILO and One UN country programmes}

51. The eight "Delivering as One" pilot countries (Albania, Cape Verde, Mozambique, Pakistan, Rwanda, United Republic of Tanzania, Uruguay and Viet Nam) offer an important opportunity to generate lessons and knowledge on how the UN system can better deliver on gender equality commitments. ${ }^{45}$ The ILO PGA, already used in three of them, has been recognized by both UNCTs and UNIFEM as a useful analysis tool.

\footnotetext{
43 In December 2006, UNDP and the Government of Spain signed an agreement to establish an MDG Achievement Fund (MDG-F) to accelerate efforts to reach the MDGs in selected countries, and to support UN reform. Gender equality and women's empowerment is one of the Fund's themes and covers three dimensions: capabilities; access to resources and opportunities; and security. The ILO is involved in MDG-F gender equality programmes in Algeria, Bangladesh, Brazil and Morocco. Moreover, six United Nations agencies (UNDP, UNIFEM, UNFPA, UNESCO, United Nations Relief and Works Agency for Palestine Refugees in the Near East (UNRWA) and the ILO) are working together on a three-year joint programme to promote women's social, economic and political empowerment in the occupied Palestinian territories.

44 S. Esim: Gender equality and labour market indicators in the Arab States in the context of MDGs (Beirut, ILO, 2007), unpublished.

45 In November 2008, the first UN retreat on "Delivering as One" on gender equality and women's empowerment was held in Hanoi and its decisions on gender-sensitive terms of reference for the midterm assessment of One UN pilots, improving system-wide capacity building, and accounting for resources under the One UN budget framework were endorsed at the UN Development Group Meeting (New York, January 2009).
} 


\section{Box 1.4 \\ "Delivering as One" in Mozambique}

Although it is a non-resident agency in Mozambique, the ILO has been an active partner in the UNCT and its Gender Theme Group. Early in 2007, during the formulation of the Joint UN Programme on gender equality and empowerment of women, the ILO gave detailed inputs on its materials, manuals and tools developed by the Women's Entrepreneurship Development and Gender Equality (WEDGE) team, and these created demand among the UN partners. As the Joint UN Programme on Gender evolved, the ILO continued its contributions on entrepreneurship, economic empowerment of women, the four key equality Conventions, and issues relating to women workers' rights. Once it was finalized, the ILO was allocated a budget from the One UN Fund in Mozambique to enable it to intensify these approaches and activities.

\subsubsection{Functional commissions and treaty bodies}

\section{Commission on the Status of Women}

52. The ILO is regularly invited to contribute to the Expert Group Meetings called to prepare the Secretary-General's reports to CSW. It also participates in the main CSW panels on thematic discussions. Each year the Organization is part of the formal programme and is also active in related events. PGA information sessions have proven to be very popular. Recent side event themes have included equal sharing of responsibilities between women and men (2009), promoting gender equality at country level (2008), and breaking the cycle of violence against girls: from child labour to education (2007), which included a focus on exploitation of girl domestic workers. In preparation for the 2008 session of CSW on "Financing for gender equality and the empowerment of women", the ILO, together with UNIFEM, the Economic Commission for Africa (ECA) and the African Union, provided capacity-building training for ministers of gender from the continent to help them effectively highlight the African perspective.

\section{UN human rights treaty bodies}

53. The ILO cooperates with the UN human rights treaty bodies that deal with equality issues, including the Committees that monitor the 1966 International Covenants on Civil and Political Rights and on Economic, Social and Cultural Rights. The principal treaty body with which the ILO works is the Committee on the Elimination of Discrimination against Women (CEDAW Committee), which examines the implementation of the Convention on the Elimination of All Forms of Discrimination against Women (CEDAW). A number of provisions of CEDAW are closely related to the ILO's standards on gender equality. CEDAW thus provides the ILO with an entry point for promoting the ratification and application of ILO standards in this area. The ILO reports centrally to the CEDAW Committee for all countries under examination, drawing on the recommendations of the ILO supervisory bodies and on other appropriate information, such as relevant ILO research, constituents' studies and technical cooperation results.

54. Reports are also submitted to the private session of the CEDAW Committee, focusing on country-specific issues. Advice is provided to the Committee on technical issues, such as special temporary measures or equal pay. The ILO has also followed CEDAW-related activities within UNCTs. The CEDAW process illustrates the twofold purpose of ILO cooperation with this treaty body: (1) to ensure coherent and consistent recommendations of the United Nations and ILO supervisory bodies; and (2) to provide a platform for joint action within the UN system to promote gender equality at the country level. ${ }^{46}$

\footnotetext{
46 ILO: General status report on ILO action concerning discrimination in employment and
} occupation, Governing Body, 301st Session, Geneva, Mar. 2008, GB.301/LILS/7, para. 34. 


\section{Chapter 2}

\section{Gender equality and tensions in a globalized world}

55. Changes in the roles of women and men, their relations with each other, and the nature of the households, markets and societies in which they live, continue to accelerate in a globalized world. Gender equality cannot be achieved when biases remain embedded in economic and social institutions and in development processes. It often remains unaddressed or is addressed in an uneven manner. Shifting boundaries and values create tensions that are sometimes magnified by rapid globalization. Men and women may experience the day-to-day manifestations of these strains in their households, in their search for jobs and participation in the labour market, or in accessing credit, technology and assets as they continue to perform their socially ascribed roles. While some may benefit from new opportunities, many may continue with traditional gender roles and suffer from increased burdens and stress.

\subsection{Women, men and poverty}

56. In 2008, the World Bank published new poverty estimates showing that close to 1.4 billion people in less developed regions of the world - about 26 per cent of the world's population - lived on less than US\$1.25 per day in 2005. This represents an increase of some 500 million people over previous estimates of 931 million in poverty. ${ }^{1}$

57. These estimates were not supplied with a gender dimension. To fill this gap, the ILO used the World Bank poverty estimates and data on the estimated earned income of women and men, published by the UNDP in its 2007-08 Human Development Report, to calculate the shares of overall poverty according to sex in 2005 (see table 2.1 and table A in the appendix).

58. The data show that about 829 million people living below the poverty line were female (girls and young, adult and older women), compared with about 522 million in the same situation who were male. These findings confirm that poverty is increasingly feminized. ${ }^{2}$ Poverty not only has a strong female dimension but is also embedded within

\footnotetext{
${ }^{1}$ S. Chen and M. Ravallion: The developing world is poorer than we thought, but no less successful in the fight against poverty, Policy Research Working Paper No. 4703, Development Research Group (Washington, DC, World Bank, Aug. 2008).

${ }^{2}$ Figures do not add up to the total estimate of 1.4 billion people living below the US\$1.25 poverty line because of rounding. The ILO estimate is probably conservative with respect to the gender divide of poverty because it assumes that children under 15 are proportionately distributed between persons who are poor and persons who merely live above the poverty line according to the total population of children and the overall poverty rate. Yet it is likely that poor adult women are accompanied by a larger proportion of children, who are therefore also poor, because of the inverse relationship between fertility and income, and because of the economic burden of large families.
} 
rural communities. ${ }^{3}$ In almost all parts of the world, rural poverty rates are higher than urban ones and the depth of poverty is greater; some 75 per cent of the world's poor live in rural areas in developing countries. ${ }^{4}$ ILO analysis also shows regional differences. According to table 2.1, in Africa, of an estimated total population of about 909 million, some 373 million people were living below the poverty line in 2005; the ILO estimates that over 214 million of them were female and 158 million were male. Some 41 per cent of Africans lived below the poverty line, but the female population is poorer than the male population. Over 57 per cent of all persons living in poverty were women.

Table 2.1. Numbers of females and males and total population living below the poverty line of US\$1.25 (ILO member States with data, regional summaries, 2005)

\begin{tabular}{lrrr}
\hline Region & $\begin{array}{l}\text { Estimated total } \\
\text { female population } \\
\text { living below the } \\
\text { poverty line, 2005 } \\
\text { (absolute numbers) }\end{array}$ & $\begin{array}{l}\text { Estimated total male } \\
\text { population living } \\
\text { below the poverty } \\
\text { line, 2005 (absolute } \\
\text { numbers) }\end{array}$ & $\begin{array}{l}\text { Estimated total } \\
\text { population living } \\
\text { below the poverty } \\
\text { line, 2005 (absolute } \\
\text { numbers) }\end{array}$ \\
\hline World & 829047000 & 522349000 & 1.4 billion \\
Africa & 214365000 & 158343000 & 373 million \\
Americas & 27169000 & 18628000 & 46 million \\
Asia & 575573000 & 337019000 & 913 million \\
Europe & 11940000 & 8359000 & 20 million
\end{tabular}

ILO member States not included for lack of data: in Africa - Liberia, Seychelles and Somalia; in the Americas - Antigua and Barbuda, Dominica, Grenada and Saint Kitts and Nevis; in Asia - Afghanistan, Iraq, Kiribati, Marshall Islands, Myanmar, Timor-Leste and Tuvalu; and in Europe - Montenegro, San Marino and Serbia.

Sources: Adapted from Human Development Report 2007-08: Fighting climate change: Human society in a divided world (UNDP, 2007); and The World Bank Group: PovcalNet.

59. In the Americas, out of a total population of about 884 million, nearly 46 million persons were living below the poverty line in 2005; of these, ILO estimates suggest that over 27 million were women and girls and around 19 million were men and boys. The poverty rate is lower in the Americas than in Africa: about one in 20 people live below the poverty line. Yet in the Americas the female population is relatively poorer than in Africa, as the female population comprises nearly 59 per cent of all people living below the poverty line.

60. In absolute numbers, Asia has the largest population living below the poverty line: out of a total population of 3.7 billion, about 913 million people live in poverty. Yet the overall rate - about 25 per cent - is far lower than in Africa, even if it is five times the poverty rate of the Americas. And female poverty is far greater than in the Americas or Africa, as the female share of poverty represents 63 per cent of all persons in Asia living below the poverty line.

\footnotetext{
${ }^{3}$ UNIFEM: Women, work and poverty, Progress of the World's Women 2005 (New York, 2005).

4 World Bank: World Bank Development Report 2008: Agriculture for development (Washington, DC, 2007), p. 45.
} 
61. Although it displays large intra-regional differences, Europe has a lower poverty rate: 20 million people live below the poverty line in European countries, which yields an overall rate of just over 2 per cent. Yet the female proportion of the population living below the poverty line (59 per cent) is as great as in the Americas.

62. Areas with the highest concentration of indigenous and tribal peoples are also those with the highest incidence of poverty or extreme poverty. A strong correlation between being indigenous and being poor or extremely poor indicates that indigenous female workers (and their children) may have fared worse than their male and non-indigenous counterparts in most socio-economic aspects. ${ }^{5}$

\subsection{Gender and the current financial and economic crisis}

63. Turmoil in the financial markets of the industrialized countries, which originated in the United States in late 2008 and spread worldwide, is creating great uncertainty. The latest ILO data project job losses of up to 50 million men and women across the globe to the end of $2009 .^{6}$

64. A distinction should be drawn between the disadvantaged position of women in global labour markets, and the immediate impact of the current economic crisis. In developed economies, there are signals that the crisis may be at least as detrimental for men as for women, and possibly more so initially, as witnessed by the stronger increase of the unemployment rate in developed economies for men compared to women in 2008 (1.1 percentage points for men versus 0.8 points for women). ${ }^{7}$ This has led to a narrowing of the gender gap in the unemployment rate in 2008, but only because the situation of men in the labour market worsened, not because of any equality gains. In addition, sectoral employment patterns of men and women show initial job losses in the male-dominated construction and automotive industries. At the other end of the spectrum, women make up two-thirds or more of the workforce in the education and health services sectors that have been less affected by the economic crisis in the short run. Forecasts point to other female-dominated areas of the economy, such as tourism and clerical support staff, as being next in line for layoffs, with redundancies in these sectors already starting in many countries.

\footnotetext{
${ }^{5}$ Indigenous women and men represent over 15 per cent of the world's poor but account for only 5 per cent of the world's population. See World Bank: Implementation of Operational Directive 4.20 on indigenous peoples: An independent desk review, Report No. 25332, Operations Evaluation Department, Country Evaluation and Regional Relations (Washington, DC, 2003). See also M. Tomei: Indigenous and tribal peoples: An ethnic audit of selected Poverty Reduction Strategy Papers (Geneva, ILO, 2005).

${ }^{6}$ ILO: Global Employment Trends (Geneva, 2009).

${ }^{7}$ ILO: Global Employment Trends for Women (Geneva, 2009), p. 2.
} 
65. The crisis has drawn attention to the need for a dramatic shift towards an improved globalization that includes sustainable and high-quality jobs, broader social protections and social dialogue. The German Chancellor, the OECD Secretary-General, the World Trade Organization (WTO) Director-General, the ILO Director-General, the International Monetary Fund (IMF) Managing Director and the World Bank President have called for a new charter for sustainable economic governance, noting that the ILO's Decent Work Agenda "provides complementary elements regarding employment and enterprise development, social protection, human working conditions, sound labour relations and rights at work". ${ }^{8}$ Policies need strong gender components on mitigating, and preventing in the future, disparate effects on women and men. The CEDAW Committee underscores the importance of recognizing the unique contribution that women can make in the timely resolution of the global financial and economic crisis and calls for the inclusion of women in the dialogue and decision-making processes. ${ }^{9}$ ILO projections show the impact on and the likely rise in working poverty, implying that the working poor will get even poorer. In designing policy responses, care should be taken to protect the working poor, who are, as noted above, mostly women.

66. The ILO itself places the crisis high on its own agenda. ${ }^{10}$ As already mentioned, Decent Work Country Programmes could be a tool for reducing poverty and inequality, especially during the crisis at the national level. ${ }^{11}$ Policy responses could include the following: (i) wider coverage of unemployment benefits and insurance schemes, reskilling redundant workers and protecting pensions from devastating declines in financial markets; (ii) public investment in infrastructure and housing, community infrastructure and green jobs, including through emergency public works; (iii) support to small and medium-sized enterprises (SMEs) and microcredit; and (iv) social dialogue at enterprise, sectoral and national levels, including consultations with national women's organizations.

\footnotetext{
8 OECD: Joint press release on the global economic crisis, available at www.oecd.org/document/32/0,3343,en_2649_34487_42124384_1_1_1_1,00.html.

9 UN News Centre: "Women must be included in solving global economic meltdown, UN says" (New York, 6 Feb. 2009).

10 The Office response has been coordinated and rapid. Consultations with constituents commenced with a series of regional meetings: with Ministers of Labour of Argentina, Brazil, Chile and Mexico (15 January 2009); the European Regional Meeting (Lisbon, Portugal, 9-13 February 2009); a Regional Forum on Responding to the Economic Crisis in Asia and the Pacific (Manila, Philippines, 18-20 February 2009); a Regional Tripartite Forum on Responding to the Economic Crisis in Africa (late February 2009); and a Global Dialogue Forum on the Impact of the Financial Crisis on Financial Sector Workers (Geneva, 24-25 February 2009).
}

11 ILO: Shaping a fair globalization: Perspectives and prospects for the Decent Work Agenda, Working Party on the Social Dimension of Globalization, Governing Body, 303rd Session, Geneva, Nov. 2008, GB.303/WP/SDG/1. See also idem: Economic forecasts for 2008-09, GB.303/WP/SDG/1(Add.). 


\section{Box 2.1 \\ Gender equality in development: A priority during the 2008 financial crisis}

Concerned by the fallout from the crisis, Heads of State and Government and high representatives gathered in Doha, in December 2008, to reiterate their resolve to take concrete action in order to, among other things, eradicate poverty, achieve sustained economic growth and promote sustainable development while advancing towards a fully inclusive and equitable global economic system. They stated:

4. We recall that gender equality is a basic human right, a fundamental value and an issue of social justice; it is essential for economic growth, poverty reduction, environmental sustainability and development effectiveness. We reiterate the need for gender mainstreaming into the formulation and implementation of development policies, including financing for development policies, and for dedicated resources. We commit ourselves to increasing our efforts to fulfil our commitments regarding gender equality and the empowerment of women.

$[\ldots]$

19. Gender equality and women's empowerment are essential to achieve equitable and effective development and to foster a vibrant economy. We reaffirm our commitment to eliminate gender-based discrimination in all its forms, including in the labour and financial markets, as well as, inter alia, in the ownership of assets and property rights. We will promote women's rights, including their economic empowerment, and effectively mainstream gender in law reforms, business support services and economic programmes, and give women full and equal access to economic resources. We will further promote and reinforce capacity building of state and other stakeholders in gender-responsive public management, including, but not limited to, gender budgeting.

Source: United Nations: Doha Declaration on Financing for Development: Outcome document of the Follow-up International Conference on Financing for Development to Review the Implementation of the Monterrey Consensus, adopted 2 December 2008 (A/CONF.212/L.1/Rev.1).

\subsection{Climate change}

67. The impacts of climate change on children, the elderly, persons with disabilities and the very poor have been a source of concern for experts and decision-makers, especially regarding developing countries. ${ }^{12} \mathrm{In}$ addition, climate change is likely to magnify existing patterns of gender disadvantage, ${ }^{13}$ which is linked to women's and men's exercise of economic and social rights. ${ }^{14}$ Worldwide, women have less access than men to financial, institutional and other resources that would enhance their capacity to adapt to climate change, including access to land, credit, agricultural inputs, decisionmaking bodies, technology and training services. ${ }^{15}$ In many countries, droughts, floods and deforestation increase the burden of unpaid work on girls and women, leaving them

\footnotetext{
12 Intergovernmental Panel on Climate Change (IPCC): Climate change 2001: Impacts, adaptation and vulnerability, Contribution of Working Group II to the Third Assessment Report of the IPCC, 2001.

13 UNDP: Human Development Report 2007/2008: Fighting climate change: Human solidarity in a divided world (New York, 2007), pp. 81-82.

14 Gender Action: Gender Action Link: Climate change (Washington, DC, 2008).

15 L. Aguilar: Is there a connection between gender and climate change?, International Union for Conservation of Nature, Office of the Senior Gender Adviser, Paper for presentation at the 3rd Global Congress of Women in Politics and Governance, Manila, 19-22 October 2008.
} 
less time for education or earning an income. For example in Africa, climate change is now threatening the viability of subsistence farming and the survival of millions of rural dwellers, 75 per cent of whom are women. ${ }^{16}$ The situation is worse for women attempting to recover from environmental disasters. When Hurricane Katrina struck New Orleans in August 2005, the hardest hit were women, mostly African-American. ${ }^{17} \mathrm{In}$ some societies, boys are likely to receive preferential treatment in rescue efforts, and both women and girls suffer more than men and boys from shortages of food and economic resources in the aftermath of disasters. ${ }^{18}$

68. Integrating the goal of gender equality into the design and implementation of policies and laws helps to address the gender-differentiated impacts of environmental degradation. ${ }^{19}$ Women also function as "change agents" in community natural resource management, farming and adaptation to climate change. ${ }^{20}$ Global efforts to tackle climate change could produce millions of green jobs, but will these jobs offer an opportunity for improving gender equality? Some 2.3 million women and men have found renewable energy jobs in recent years, and projected investments of US $\$ 630$ billion by 2030 might, according to a pre-crisis scenario, lead to the creation of at least 20 million additional jobs. ${ }^{21}$ However, there is no indication of how many of these new jobs would be for women. The impact of the current financial and economic crisis on developing green technology and green jobs will need to be analysed as well.

\subsection{Gender and the demographic situation}

69. Other current tensions reflect changes in the global demographic situation and urban/rural population shifts. For a number of years, the ILO has been focusing in a concerted manner on the creation of employment for young women and men. At the other end of the life spectrum, however, the world's population is living longer than at any other time in history. By way of illustration, figures 2.1 and 2.2 demonstrate the demographic change in the life cycles of women and men, comparing average world figures for 1919, the year in which the ILO was founded, and projected to 2019, the ILO's centennial year. In 1919, few people made it to the present-day average age of retirement (65 years). Those who lived longer were generally to be found in the developed countries, and even they did not generally live very long after reaching today's retirement age.

\footnotetext{
${ }^{16}$ G. Gaphihan: "Climate change, subsistence farming, food security and poverty: The consequences of agricultural policies on women and men farmers in Burkina Faso and Cote d'Ivoire", in Africa Policy Journal, John F. Kennedy School of Government, Harvard University (Cambridge, Massachusetts, 2008), Vol. IV.

${ }^{17}$ OECD: Gender and sustainable development, maximizing the economic, social and environmental role of women (Paris, 2008), pp. 73-74.

${ }^{18}$ E. Neumayer and T. Plümper: The gendered nature of natural disasters: The impact of catastrophic events on the gender gap in life expectancy, 1981-2002.
}

${ }^{19}$ Network of Women Ministers and Leaders for the Environment and UNEP: Bridging the gap: Gender transforming environmental management, Concept Note for the First Joint Gender Forum, Nairobi, 15 February 2009. The ILO's work in this area was presented to the meeting.

${ }^{20}$ Women's Environment \& Development Organization (WEDO): Changing the climate: Why women's perspectives matter (New York, 2007), p. 3.

${ }^{21}$ UNEP, ILO, IOE, ITUC: Green jobs: Towards decent work in a sustainable, low-carbon world (Nairobi, United Nations Office, 2008), p. 11. 
Figure 2.1. Extension of life expectancy of women during the ILO's first century
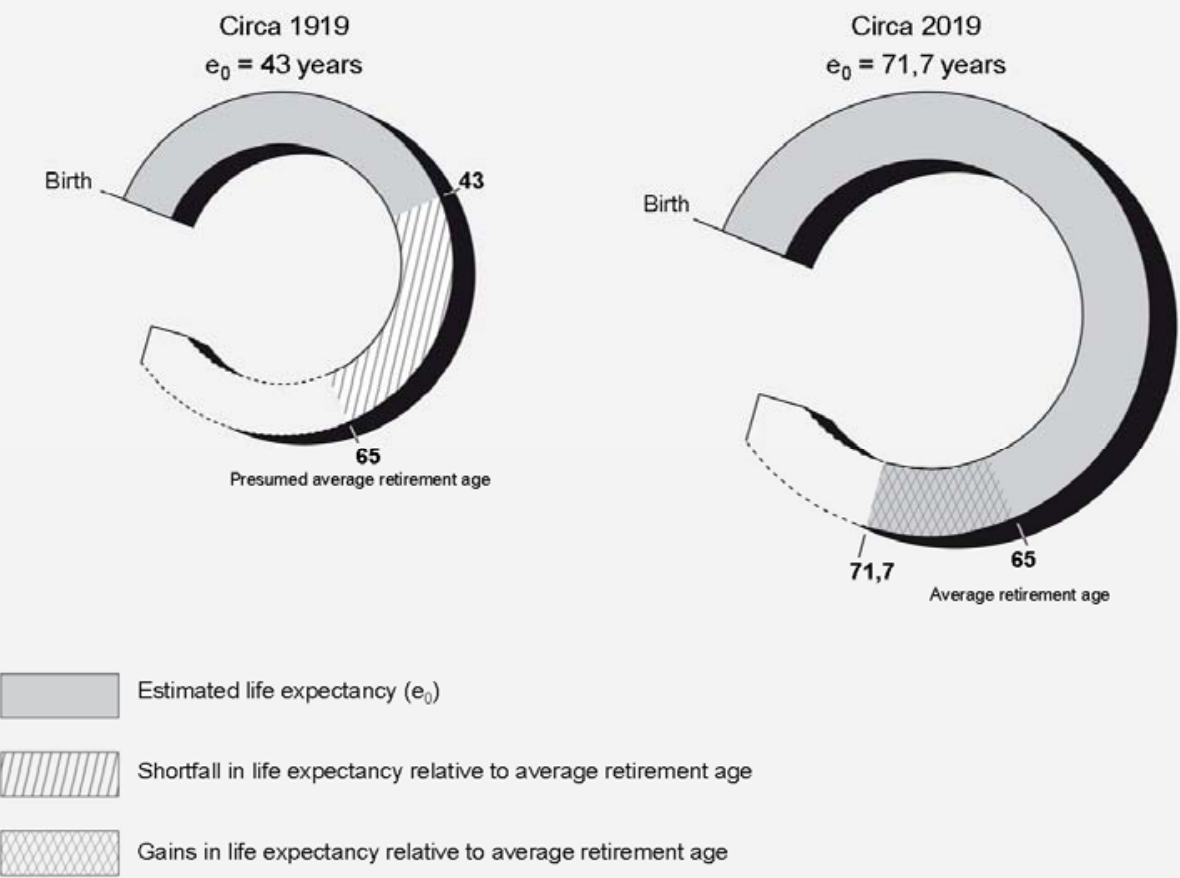

Source: ILO (GENDER), 2009.

Figure 2.2. Extension of life expectancy of men during the ILO's first century
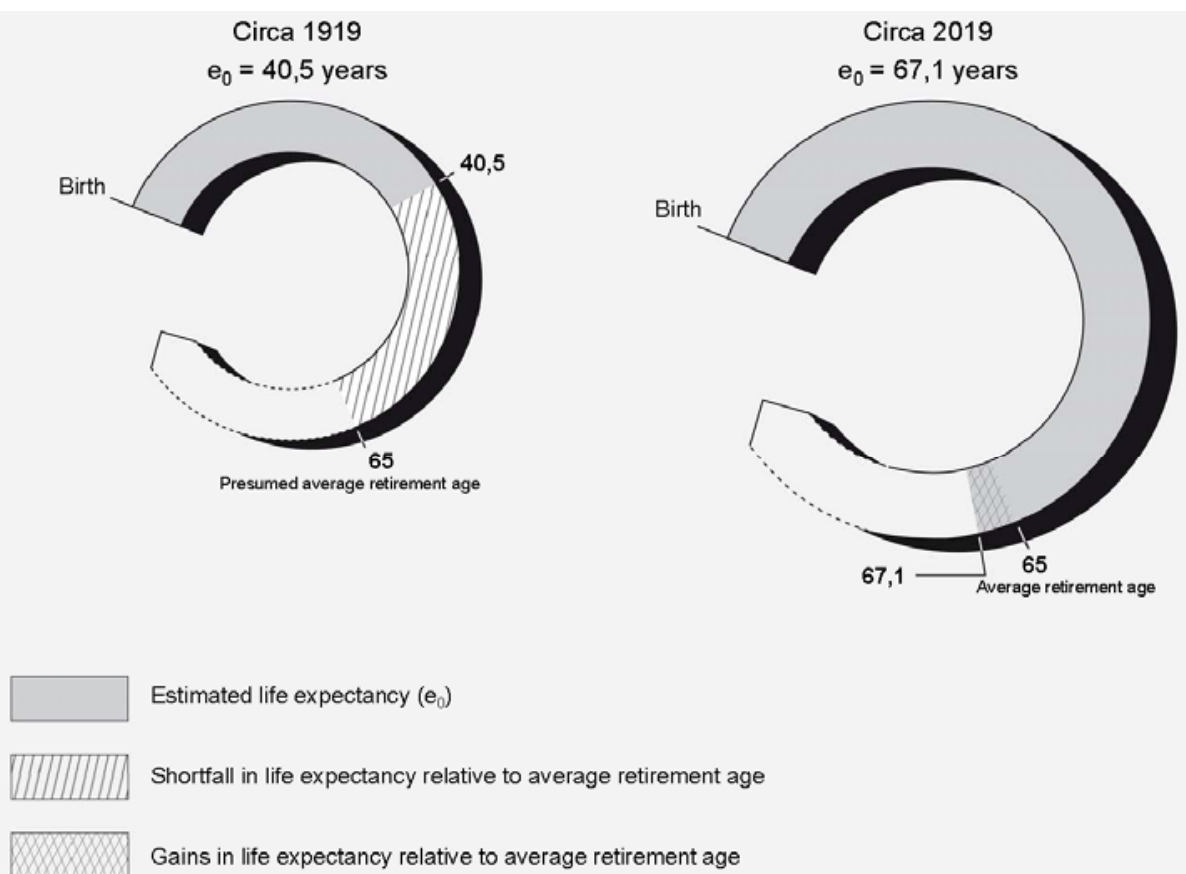

Estimated life expectancy $\left(\mathrm{e}_{0}\right)$

Shortfall in life expectancy relative to average retirement age

Gains in life expectancy relative to average retirement age

Source: ILO (GENDER), 2009.

70. On average, men today live close to 27 years longer and women close to 30 years longer than a hundred years ago. In 2019, the expected differences in female and male life expectancies will mean that older women will far outnumber older men. Another new dimension is the fact that people are not only living longer, but also having fewer children. This is affecting nearly all countries, although certain regions show variations 
in longevity gains and fertility declines. Globally, the number of older people is expected to exceed the number of children for the first time in 2047; this tipping point was already reached in many developed countries in $1998 .{ }^{22}$ By 2010 , fertility will be below replacement levels in affluent industrial countries such as France, Italy and Japan. ${ }^{23}$ Populations are also rapidly ageing in Eastern Europe, creating a unique set of problems for that region. ${ }^{24}$ Populations of all countries are ageing, even in countries that are now relatively "young". These countries have comparatively high fertility rates but low life expectancy at birth ${ }^{25}$ - for example, in Africa and the Middle East. The impact on society, work and gender roles in caregiving will need to be considered when reshaping social protection policies and priorities.

71. In addition, the global urbanization process has significant social and economic implications for the decline of fertility and - to some extent - for mortality rates. ${ }^{26}$ The world reached another milestone in 2008: for the first time in history, half the world's population (3.3 billion) now lives in urban areas. By 2030, that figure is expected to reach almost 5 billion. ${ }^{27}$ Decent work deficits are severe in rural areas; underemployment is widespread, incomes are generally low, and access to social protection is extremely limited. Unless rural employment strategies form an integral part of national employment strategies, certain remote regions will be drained of inhabitants by outward migration. ${ }^{28}$ It is predicted that by 2030 , some regions of the Baltic States and Eastern Europe will have lost up to 18 per cent of their populations to urban centres. ${ }^{29}$

72. In Africa and Asia, the urban population is expected to double over the next 20 years. ${ }^{30}$ This has significant gender implications for work in both rural and urban areas. It should be kept in mind that women are estimated to produce, process and store up to 80 per cent of foodstuffs in Africa, and approximately 60 per cent in South and South-East Asia. The challenge is to ensure that a gender perspective contributes to the elimination of discrimination and to the formulation of effective rural development/poverty reduction policies that give women access to education and health services, security of land tenure in their own right, control over other productive assets, and access to inputs such as credit, fertilizers and extension services. Governments need

\footnotetext{
22 United Nations: World population ageing 2007, DESA, Population Division, p. xxvi.

23 All countries are expected to face dramatic changes in their age structure. See A. Hayutin: How population ageing differs across countries: A briefing on global demographics, Stanford Center on Longevity (Stanford, 2007), pp. 8-9.

24 M. Chawla et al.: From red to gray: The "third transition" of aging populations in Eastern Europe and the former Soviet Union (Washington, DC, World Bank, 2007), p. 1.

25 Even in countries with low life expectancies at birth (due mainly to child mortality), men and women who survive to an older age (60 or more) will have life expectancies not much lower than those living in rich countries with high life expectancies at birth.

${ }^{26}$ United Nations: Report of the United Nations Expert Group Meeting on population distribution, urbanization, internal migration and development, New York, 21-23 January 2008, p. iii.

27 UNFPA: State of World Population 2007: Unleashing the potential of urban growth (New York, 2007), pp. 18-22.

28 ILO: Conclusions on promoting rural employment for poverty reduction, Report of the Committee on Rural Employment, Provisional Record No. 15, ILC, 97th Session, Geneva, 2008, p. 63.

29 P. Runner: "European regions face population drain”, http://euobserver.com, 22 Aug. 2008.

30 UNFPA: State of World Population 2007, op. cit., p. 1.
} 
to collect reliable data on the livelihood characteristics of rural households, including sex-disaggregated data, to assist policy-makers in evidence-based policy-making.

73. The particular needs and capabilities of poor women and girls are assumed to be the same as those of poor men and boys and are often unaccounted for. In addition to poverty, sex discrimination in rural areas in the form of restrictive social customs, unequal access to education, training and employment, and restrictions on property, land rights and credit, often hamper women's development. Without adequate infrastructure investment in rural areas, urban areas may offer women better options, greater flexibility and diversity, and access to services such as water, sanitation, education, health, transportation and employment. ${ }^{31}$ Poverty and inequality are, however, certainly present in most urban settings too, and are visible in slums and reflected in inner city criminality. These also have different gender implications.

\subsection{Decent work in the life cycle}

74. Certain phases of the life cycle are driven by physiology. People are born and experience the physical changes characterizing infancy, childhood, puberty, youth, maturity and old age. These are normal phases, although recent scientific advances and improved health have helped to prolong maturity and productivity, allowing a more active old age. Many populations do not have the means to secure longer, healthier lives, and efforts to provide people with affordable access to high-quality care should be part of overall development goals. The phases are not rigidly defined, and the ages mentioned in figure 2.3 are merely indicative. Physical, mental and emotional growth varies among individuals. The transition from one stage to another occurs naturally, but society often marks these transitions in some way, and many cultures and religions have clear rites of passage. Countries may vary in their definitions and legal provisions regarding, for example, school enrolment age, minimum age for employment or marriage, or a set retirement age. ${ }^{32}$

\section{Figure 2.3. Linking decent work to the life cycle}

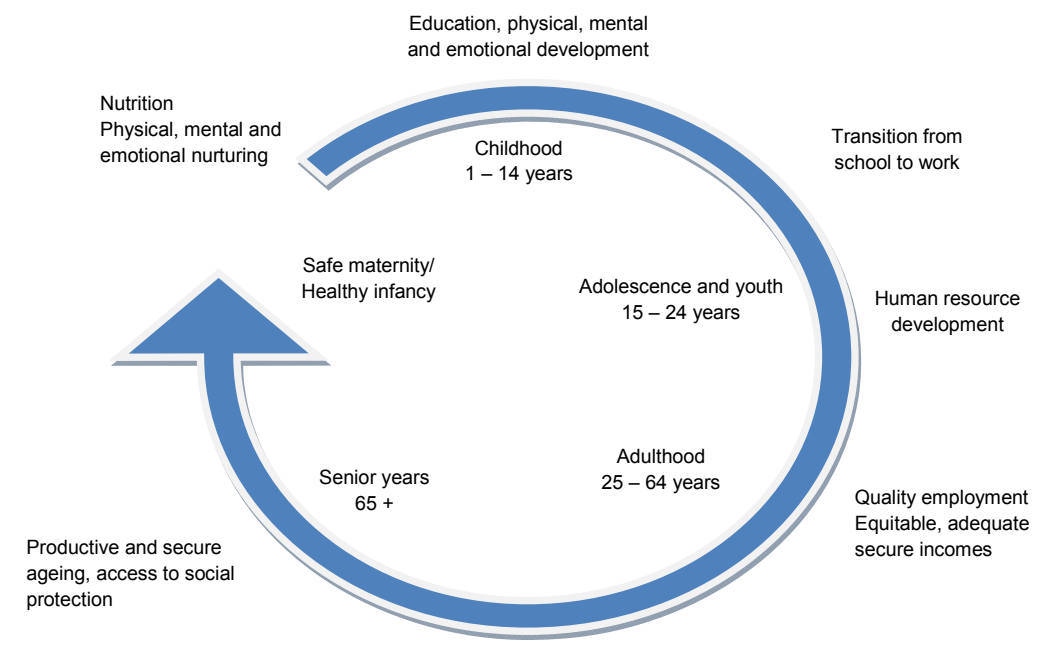

Source: Based on ILO: Gender Promotion Programme, 2003.

31 ibid., pp.18-20.

${ }^{32}$ See tables $C$ and $D$ in the appendix. 
75. Accompanying the physical phases of the life cycle are the social models that apply across societies. Infancy and early childhood are often governed by a protected discovery of the physical, social and emotional world surrounding the child, who is totally dependent on adults, especially mothers, for nutrition and care. Childhood is the period for learning - either through formal education or by observing the work of adults. The period of transition from youth to adulthood is one for developing partnerships, founding families and working to earn a livelihood, provide for a family and realize potentials. Finally, where finances and socio-economic conditions permit, the later years are usually governed by a scaling-back of work and family responsibilities, leaving time for selected leisure or income-related activities.

76. These life-cycle patterns - both the biological and the socially constructed ones are changing. As mentioned above, even in developing countries people are living better and longer. Separation or divorce, remarriage and step-families are fairly commonplace at all levels of society. Even where it existed, the married couple, male breadwinner, "job for life" model is challenged. Single-parent households - usually headed by women - are widespread. Grandparents may be bringing up grandchildren because of the absence of parents (because parents are working, or migrants, or because the children have been abandoned or orphaned).

77. What do these changes mean for gender equality? Young women and men in the more affluent social strata of both developed and developing countries may spend more years in education. Young people may marry later or not at all. Starting a family may be postponed, with an increasing number of women giving birth in later years and some couples choosing not to have children at all. In the formal economy, steady career advancement until retirement is no longer the norm, as many occupational shifts and lifelong learning opportunities and increased mobility allow for career changes and reskilling. These changes may either be the result of necessity, such as enterprise closures and worker layoffs, or arise from individual choices to seek better opportunities. ${ }^{33}$

78. For the less affluent, however, life-cycle patterns are most often governed by necessity rather than by choice. For the poorest women and men, life is dominated by survival needs. Family planning and birth spacing may not have taken root, resulting in higher maternal and infant mortality. Life may be shorter for both women and men. Options for earning incomes are limited, and often confined to low-skilled, low-paid jobs, or those that are dangerous, dirty and difficult. Informality is prevalent, and men and women may have to work until their last breath with no social protection.

\subsection{Men and gender relations}

79. Equal sharing of responsibilities and a harmonious partnership between women and men are critical to their well-being, to that of their families and to the consolidation of democracy. ${ }^{34}$ The achievement of gender equality requires a context in which men and women work together, and work and family responsibilities are shared. As gender mainstreaming became the accepted framework for action to achieve gender equality, an interest arose in the role of men and boys as a counterpoint to women-specific approaches. There is evidence that taking "masculinities" (men's attitudes, aspirations

\footnotetext{
33 A. Bonilla García and J.V. Gruat: A life-cycle continuum investment for social justice, poverty reduction and sustainable development (Geneva, ILO, 2003), p. 3.

34 United Nations: The Beijing Declaration, adopted by the Fourth World Conference on Women, September 1995, para. 15 .
} 
and anxieties) into consideration is important in designing methodological frameworks, holistic strategies and successful tools to end sex discrimination and achieve equality between men and women. Researchers worldwide are analysing how patriarchal systems may be holding male workers back from playing their full role for gender equality. ${ }^{35}$

80. The gender approach therefore allows for clarification of the roles commonly associated with being male or female in public and in private life, starting in childhood, consolidating throughout youth, into the adulthood reality of "men's jobs" and "women's jobs". Typecasting continues to place greater emphasis, as well as greater value, on the role of men in public life and in the workplace, as opposed to women's role in unpaid family labour, caregiving and community work. Analysis of the differences between women and men in responsibilities assigned, activities undertaken, access to and control over resources, as well as in decision-making, provides the basis for appropriate policy decisions when inequalities are identified.

81. A reassessment of existing power relations between women and men with a view to their working together towards gender equality is now called for. Overcoming resistance - by both women and men - in shifting gender relations that are supportive of men's positive role in gender equality is essential, especially in the workplace. Positive elements of equality outcomes for men (such as less pressure to be breadwinners and deeper relationships with their immediate family) should be promoted. Policy and regulatory measures, proactive legislation, incentives and awareness raising, as well as cooperation between employers and workers and other institutional players to eliminate obstacles to workplace gender equality, will be crucial.

\subsection{Selected themes common across the life cycle}

82. There are some specific topics that clearly cut across many different phases of the life cycle and merit attention in this chapter. The following selected areas are relevant to the ILO's work and across the UN system.

\subsubsection{Violence against women and girls}

83. No society seems entirely to escape a culture of violence, including gender-based domestic violence, ${ }^{36}$ and the spillover effect into the workplace is inevitable. As women (especially young women) increasingly enter the global workforce and move beyond the home, more attention must be paid to workplace violence in order to protect their freedom, equity, security and human dignity. From infancy, through childhood, adolescence, adulthood and into old age, all people face this risk of violence. Violence is used against females more than males, except during the vulnerable childhood and adolescent years, when boys are equally at risk of abuse. ${ }^{37}$ Young males in many

35 ILO: Men and masculinities and gender issues: An annotated bibliography, GENDER (Geneva). Men are often victims of stereotypes and norms about masculine behaviour which may lead to unsafe sex and/or non-consensual sex. See ILO: HIV/AIDS and the world of work, Report IV(1), ILC, 98th Session, Geneva, 2009, p. 130.

36 United Nations: Towards an effective implementation of international norms to end violence against women, Report of the Special Rapporteur on violence against women, its causes and consequences, Commission on Human Rights, E/CN.4/2004/66 (Geneva, 26 Dec. 2003).

37 Exact data on the sex of victims are difficult to find. See, for example, United Nations Department of Economic and Social Affairs: The World's Women 2005: Progress in statistics (New York, 2006). This analysis of countries' capacity for collecting and reporting statistics on women and men using gender-sensitive methods showed that many countries do not mainstream gender in the collection and dissemination of official statistics, nor do they collect or report basic statistics on violence. 
societies are reported to be disproportionately affected, especially by physical violence, and are often perpetrators and victims of violence at the same time. Manifestations of this type of gender inequality range from the physical (beatings, sexual abuse) to the psychological (threats, mobbing). Despite an increase in policies and laws to eliminate these human rights violations, ${ }^{38}$ enforcement remains a challenge. Much abuse goes on behind closed doors, victims are fearful of lodging complaints and the criminal law enforcement system in many countries is ill-prepared when it comes to punishing the guilty and compensating victims. Historically, one of the justifications for limiting women's activities to the home sphere was the fear of violence against women outside it. In reality, most cases of violence against women are perpetrated in the home by partners or male relatives. According to the World Health Organization (WHO), one out of six women is exposed to violence inside her home rather than in public or at work. ${ }^{39}$ As more and more people age around the world, the risk of elder abuse increases as well. ${ }^{40}$ And since the proportion of ageing women to men is higher, it follows that women are at higher risk of abuse in their older years. This can be physical, sexual, emotional or psychological violence, or simple neglect or abandonment. In addition to the empowerment of older women and men to act for themselves and exercise their rights, structural solutions are needed that centre around strong protective laws and improved health care. ${ }^{41}$

84. The ILO's commitment to combating violence against women and girls is based, first, on the governance principle of respect for the prevailing juridical and moral norms and, second, on the realization that any successful policy in this area must include the workplace dimension. The ILO's tripartite constituency provides privileged access to one environment where violence occurs: the world of work. Workers in femaledominated sectors such as the health services, social services and domestic work complain of high rates of violence. Violent incidents in health services alone, a sector with an 80 per cent female workforce, account for 25 per cent of workplace violence. ${ }^{42}$ In the retail sector, fatalities due to violence are increasing in some countries and represent a high proportion of female deaths. ${ }^{43}$

85. ILO initiatives on violence include: the code of practice on violence and stress in the services sector; the framework guidelines for addressing workplace violence in the

\footnotetext{
${ }^{38}$ Recent examples include Algeria, Brazil, Colombia, Ecuador, Hungary, Lao People's Democratic Republic, Mexico, Netherlands, Peru and Turkey. See UN General Assembly: Intensification of efforts to eliminate all forms of violence against women, Report of the Secretary-General (New York, 2008), p. 4. In Africa, recent progress comprises the adoption of the Penal Code and establishment of gender-based violence victim support units in police stations in Zambia and the Human Trafficking Bill, Domestic Violence Bill and Children's Act in Ghana.

39 As cited in UNIFEM: Report on violence against women in the Gulf and Saudi Arabia (Amman, 2008), p. 6.

40 "Elder abuse" is an umbrella term referring to any knowing, intentional or negligent act by a caregiver or any other person that causes harm or a serious risk of harm to a vulnerable adult. See S. Perel-Levin: Discussing screening for elder abuse at primary health care level (Geneva, WHO, 2008).

41 WHO: Missing voices: Views of older persons on elder abuse, Study from eight countries: Argentina, Austria, Brazil, Canada, India, Kenya, Lebanon and Sweden (Geneva, 2002), pp. 19-20.

42 ILO/WHO/ICN/PSI: Framework guidelines for addressing workplace violence in the health sector: The training manual (Geneva, ILO, 2005), p. 5.

${ }^{43}$ European Agency for Safety and Health at Work: OSH in figures: Young workers - Facts and figures (Brussels, 2007), p. 13.
} 
health sector; working papers on workplace violence and stress in education, hotels and catering and tourism, financial services, the performing arts and journalism, and in the postal and transport sectors; ${ }^{44}$ research and training packages produced by the International Programme on the Elimination of Child Labour (IPEC) on the vulnerability of girls and boys to violence, in particular its contributions to the World report on violence against children; ${ }^{45}$ publications on violence in the workplace, including the key 2006 publication Violence at work; ${ }^{46}$ training materials on gender-based violence in post-conflict situations; ${ }^{47}$ and education programmes to assist employers and workers in developing policy and action to address psychosocial issues in the workplace. ${ }^{48}$

86. Within the UN, to give impetus to implementation of the relevant political and normative texts, ${ }^{49}$ the Secretary-General's UNiTE Campaign to end violence against women and girls calls for - and will monitor -the adoption and enforcement of national laws to punish all forms of such violence by 2015. ${ }^{50}$ The UN Division for the Advancement of Women (DAW) has issued Guidelines and model framework for legislation on violence against women, with technical inputs from the Office. ${ }^{51}$ The ILO supports these UN initiatives to address gender-based violence through membership of the relevant system-wide Task Force of the Inter-Agency Network on Women and Gender Equality (IANWGE) and its information-sharing activities at sessions of the Commission on the Status of Women. In various regional initiatives focused on violence against women and girls, ILO constituents play a role and have the potential to support national attention to the issue through their involvement in development frameworks, in particular Decent Work Country Programmes. ${ }^{52}$ For example, the African Development Forum (ADF) - with ILO constituents' support - recently took action to end violence against women in Africa. ${ }^{53}$

${ }^{44}$ For information on specific sectors see the Sectoral Activities Programme web site, at
www.ilo.org/sector.
${ }^{45}$ United Nations: World report on violence against children (New York, Nov. 2006).
${ }^{46}$ D. Chappell and V. di Martino: Violence at work, third edition (Geneva, ILO, 2006).
${ }^{47}$ ILO: ILO generic crisis response modules (Geneva, 2002); and ILO crisis response trainers' guide (Geneva, 2003).

48 See SOLVE package (stress, tobacco, alcohol and drugs, HIV/AIDS and violence, including sexual harassment), Programme on Safety and Health at Work and the Environment (SafeWork).

49 UN General Assembly resolution 63/155, adopted on 18 December 2000; Security Council resolution 1325 (S/RES/1325(2000)); the International Covenants on Human Rights; the Convention on the Rights of the Child; and CEDAW, to list but a few.

${ }^{50}$ United Nations: Words to action: An electronic newsletter on violence against women, Issue No. 1, Division for the Advancement of Women (DAW) (DESA) (New York, Oct. 2008).

51 Available at: www.un.org/womenwatch/daw/egm/vaw_legislation_2008/vaw_legislation_2008.htm.

52 For Africa, 19 countries out of 30 having first-generation poverty reduction strategies (PRS) and 17 countries out of 18 which have second-generation PRS refer to prioritization of ending gender violence. See ILO: Violence against women in PRS for African countries, INTEGRATION paper (Geneva, 2008), p. 2.

53 The Forum's Consensus Statement and Plan of Action identified three priority actions, including an Africa-wide Campaign to Eliminate Violence against Women and Girls, and insisted on reliable data collection on gender equality, women's empowerment and violence against women and girls. The Forum was held from 19 to 21 November 2008 in Addis Ababa, Ethiopia. See www.uneca.org/adfvi/index.asp. 


\subsubsection{Domestic labour}

87. Domestic work can be carried out by individuals of all ages. The gender dimension arises from the high percentage of female workers in such jobs. ${ }^{54}$ As more and more women enter the labour force, their family care and household tasks are delegated to household employees on whose care the well-being of entire generations may depend. The demand for domestic workers is a key factor in opening up legal channels of temporary migration to some countries for large numbers of women with few employment options at home. The remittances of these migrant women have created pockets of relative prosperity in otherwise resource-starved communities. If performed under fair working conditions, domestic work has tremendous potential for reducing poverty and empowering women. ${ }^{55}$ However, since domestic work is often regarded as an extension of women's traditional unpaid household and family responsibilities, it is still mostly invisible, undervalued and unprotected. In many countries, domestic work is beyond the reach of labour law, either because it is expressly excluded or because monitoring compliance in the private sphere of the household is too difficult. The ILO recognizes the need to adopt an agreed minimum benchmark to guide policy, programmes and activities worldwide to provide decent work to women engaged in domestic work. The ILC standard-setting agenda for 2010 and 2011 concerning domestic workers has important implications for this group of vulnerable workers and their employers.

88. Domestic work is undertaken predominantly by girls, young women, adult women workers and older workers. It is one of the most invisible of the female-dominated occupations. Nine out of ten children doing such jobs are girls, usually working in other people's homes, sometimes those of relatives. Working away from home, girl domestic labourers are often isolated on the household premises, with little or no protection or social support. In some countries, child domestic labour is considered one of the worst forms of child labour under the terms of ILO Convention No. $182 .{ }^{56}$

89. Domestic work draws large numbers of young women migrants from countries with an oversupply of labour and high unemployment, and where sex discrimination against women operates in national labour markets. As much as 81 per cent of all Sri Lankan women migrant workers and 38 per cent of those from the Philippines are employed in domestic work. ${ }^{57}$ An ILO situation analysis in the Philippines ${ }^{58}$ shows that domestic workers who migrate internationally are drawn from a different labour pool

\footnotetext{
54 European Trade Union Confederation (ETUC): Out of the shadows. Organizing and protecting domestic workers in Europe: The role of trade unions (Brussels, 2005), p. 9. Solid facts and figures on the nature and extent of domestic work in the EU are hard to come by. There are estimates for individual countries such as Italy and France but often these are disputed on the grounds, for example, that they only cover certain categories of work. It is also true that official data gathering will miss many domestic workers precisely because they are "invisible", especially the undocumented migrants among them.

55 For example, the Lebanese Ministry of Labour has recently issued a decree for the regulation of employment agencies that bring women migrant domestic workers to Lebanon (22 January 2009) and the use of a unified contract for migrant domestic workers.

56 Source: ILO-IPEC: Helping hands or shackled lives? Understanding child domestic labour and responses to it (Geneva, 2007) in Child domestic labour information resources: A guide to IPEC child domestic labour publications and other materials.

57 G. Moreno-Fontes Chammartin: "Women migrant workers' protection in Arab League States" in: Gender and Migration in Arab States: The case of domestic workers (Beirut, ILO, 2004).

58 N.J. Sayres: An analysis of the situation of Filipino domestic workers (Manila, ILO, 2005).
} 
than those who migrate within the country. Those working overseas generally come from urban areas, are better qualified and have prior work experience in different fields. Indeed, some have qualifications far superior to those required for domestic work, but at home face a lack of employment opportunities commensurate with their qualifications. The sector mainly attracts young women entering the labour market for the first time. Approximately 11 million women in Latin America - mostly young and of indigenous or African descent - work in domestic service and are thus prevented from improving their education or social mobility. ${ }^{59}$ They are often paid below the minimum wage, and their working hours are longer because the law does not stipulate the length of their working day.

90. An ILO meeting of experts in 1951 highlighted the need for better working conditions for domestic workers. In 1965, the ILC adopted a resolution concerning the conditions of employment of domestic workers, which drew attention to the urgent need to provide domestic workers with the basic elements of protection that would assure them a minimum standard of living, compatible with the self-respect and dignity essential to social justice. ${ }^{60}$ The Committee of Experts on the Application of Conventions and Recommendations (CEACR) has, since 2002, issued 207 observations and direct requests concerning domestic work. More recently, the 2006 ILO Multilateral Framework on Labour Migration made specific reference to domestic workers. ${ }^{61}$ National, regional and international meetings on the status and conditions of domestic work have been organized, in which trade unions have played a leading role. Trade unions are now reaching out to domestic workers despite the difficulty of organizing caused by their dispersal. ${ }^{62}$ Employers' organizations in certain countries have adopted codes of conduct for the employment of domestic workers. ${ }^{63}$ ILO research and technical cooperation on domestic work have intensified, approaching the subject from the angle of gender equality, protection of informal economy workers, migrant workers' rights, freedom of association, the elimination of forced labour and trafficking and the abolition of child labour, particularly its worst forms.

\subsubsection{HIV and AIDS}

91. HIV infection and AIDS ${ }^{64}$ can dramatically affect the life cycles of individuals and impact on the immediate family and community of a person living with the virus. In countries of high HIV prevalence, life expectancy at birth has fallen. In southern Africa, average life expectancy at birth is estimated to have declined to levels last seen in the 1950s; it is now below 50 years for the subregion as a whole. Steady gains in life

59 ILO: Decent work and youth: Latin America (Trinidad and Tobago, 2007), pp. 40-41.

60 ILO: Record of Proceedings, Appendix XII: Resolutions adopted by the Conference, ILC, 49th Session, Geneva, 1965.

61 See A. D'Souza: Decent work for domestic workers: Towards a new international labour standard (Geneva, ILO, forthcoming), pp. 29-31.

62 International Restructuring Education Network Europe (IRENE) and IUF: Respect and rights: Protection for domestic/household workers!, Report of the international conference held in Amsterdam, 8-10 November 2006 (Netherlands, 2008), p. 13.

63 See, for example, Employers' Confederation of the Philippines: Ethical guidelines on the employment of domestic workers, pp. 3-4.

64 The 98th Session (2009) of the ILC has before it the following report: HIV/AIDS and the world of work, Report IV(1), with a view to the adoption of an international labour standard on the subject. All data quoted here come from the Joint United Nations Programme on HIV/AIDS (UNAIDS): Report on the global HIV/AIDS epidemic 2008 (Geneva, 2008). 
expectancy experienced in East Africa since the early 1950s stalled in the late 1980s, although falling HIV prevalence in some East African countries is expected to lead to an increase in life expectancy there. Adult workers - women and men - living with the virus face the stigma and discrimination that accompany the myths surrounding the disease, and often find themselves out of jobs or working in poor conditions in many regions. Child raising, often on extremely meagre means, has fallen disproportionately on grandparents, and especially grandmothers, who have lost their children to AIDS. In Africa and the Caribbean, they are increasingly being called upon to take care of the sick because of the lack of hospital beds or the stigma and discrimination associated with the disease, which again makes this unpaid work invisible. Inadequate social service delivery programmes, the lack of access to social security and the lack of income are major challenges for these older women. ${ }^{65}$

92. The HIV epidemic is becoming one of the most obstinate root causes of child labour in high-prevalence countries and regions. ${ }^{66}$ In sub-Saharan Africa alone, the epidemic has orphaned nearly 12 million children aged under 18 years. Globally, the number of children aged under 15 years and living with HIV increased from 1.6 million in 2001 to 2 million in 2007; almost 90 per cent live in sub-Saharan Africa. Gender differences play a major role in the impact of HIV on child labour. The face of the AIDS epidemic is increasingly young, poor and female. ${ }^{67}$ When a parent falls ill with an AIDS-related illness, it is daughters who are statistically more likely to be called upon to drop out of school to shoulder the burden of care. As the illness progresses, it is usually the girl child who is expected to continue to run the household, often in addition to work outside the house. The boy is likely to follow male patterns of family and social interaction and may be expected to earn money to support the family, thus being propelled into hazardous work such as mining, fishing or agricultural labour.

93. Young people account for an estimated 45 per cent of new HIV infections worldwide. Biologically and also economically, women are particularly vulnerable to contracting the disease. Because of high unemployment and poverty, young women and men may resort to prostitution for survival, often practising unsafe sex. In all regions of the world, unemployment and poverty are reported as the main reasons for young people entering the sex trade. In most transition economies, youth unemployment rates are more than twice the overall unemployment rate, increasing young people's social exclusion, including drug abuse, and fuelling the spread of HIV in the region. Eastern Europe and the Commonwealth of Independent States (CIS) are the regions where the epidemic is growing fastest in the world. Current statistics indicate that the overwhelming majority of people living with HIV/AIDS there are aged under 30.

\footnotetext{
${ }^{65} \mathrm{UN} / \mathrm{ECLAC}:$ The contribution of women to the economy and social protection especially in relation to unpaid work performed by women in the Caribbean, Tenth Session of the Regional Conference on Women in Latin America and the Caribbean, Quito, Ecuador, 6-9 August 2007. See also ILO: Conclusions concerning social security, Report of the Committee on Social Security, ILC, 89th Session, Geneva, 2001.

${ }^{66}$ ILO-IPEC: SCREAM: A special module on HIV, AIDS and child labour (Geneva, 2007), pp. 36-40.

${ }^{67}$ Females are thought to be three times more likely to contract HIV than males in the 10-24 year age group, according to WHO/UNAIDS data.
} 
94. For workers in their prime, the impact of HIV and AIDS can be tracked in the number of dismissals being reported to labour courts and tribunals. ${ }^{68}$ Employers, enterprises and workers' organizations work together in particularly effective ways to adopt prevention strategies and anti-discrimination policies, and generally to manage and mitigate the cost of HIV/AIDS in the world of work. At the enterprise level, results are visible from ILO programmes such as Strategic HIV/AIDS Responses by Enterprises (SHARE) (active in 650 workplaces in 24 countries). Constituents have adopted sectoral policies in the education, transport and health sectors ${ }^{69}$ at regional and global levels. Governments have developed gender-sensitive prevention programmes, undertaken legal reform and disseminated policy advice on care and treatment, with Office support based on the 2001 code of practice on HIV/AIDS and the world of work and the relevant international labour standards. ${ }^{70}$

\footnotetext{
${ }^{68}$ J. Hodges: Digest of good legislative practices relating to HIV/AIDS in selected African countries, DIALOGUE Working Paper No. 12 (Geneva, ILO, 2007).

${ }^{69}$ Examples include the Joint ILO/WHO guidelines on health services and HIV/AIDS (Geneva, ILO, 2005); and An HIV/AIDS workplace policy for the education sector in the Caribbean (2006). Guidelines for other sectors, such as mining and construction, are being prepared.

70 Relevant international instruments include the 1996 Guidelines on HIV/AIDS and Human Rights: Report of the Secretary-General to the Commission on Human Rights, UN doc. E/CN.4/1997/37. Guidance on the role of laws generally is set out in the UNAIDS Handbook for legislators on HIV/AIDS, law and human rights, in WHO: Directory of legal instruments dealing with HIV infection and AIDS, WHO/UNAIDS/HLE/97.1, Geneva, 1997. Policy advice on public health legislation has been provided by WHO and UNAIDS and on labour legislation by the ILO.
} 



\section{Chapter 3}

\section{Maternity, healthy infancy and working parents}

95. Safe maternity and health care for mother and infant survival is at the core of life itself, for mothers, infants, communities and nations. It is also central to decent work and productivity for women. Since its early years, the ILO has recognized that for working women, balancing maternity and family responsibilities with work represents a daunting challenge. More recently, the Director-General suggested that for a woman it is not an unreasonable demand to be able to bear a child safely and to nurture that child for some time after birth without fear of losing her job, her income or her career. The response cannot just be a business or a market decision - it is a societal decision. ${ }^{1}$

96. MDG 5 aims to reduce the maternal mortality ratio by three-quarters and to achieve universal access to reproductive health by 2015. While great improvements have been made in many countries, many others are off course. ${ }^{2}$ In the developing world as a whole, a woman has a one in 76 lifetime risk of maternal death, compared with a probability of just one in 8,000 for women in industrialized countries. ${ }^{3}$ Maternal mortality is higher for indigenous communities, especially in remote areas where maternal mortality rates can be twice or three times as high as national averages. ${ }^{4}$ It is estimated that worldwide, one woman dies every minute of every year from pregnancy complications or childbirth. For every woman who dies, roughly 20 more suffer serious injury or disability. ${ }^{5}$ Babies and young children who have lost their mothers in childbirth are up to ten times more likely to die prematurely than their peers.

97. Figures 3.1 and 3.2 show how maternal and infant care may be influenced by differing attitudes to the sex of the newborn. In certain regions, for example, infant girls may not see the light of day if the sex is known, or they may suffer neglect, poor nutrition and lack health care after birth simply because they were born female. Infant boys often stand a higher probability of survival from infancy to childhood. Many of these gender attitudes are influenced by parental socio-economic and education levels. ILO action in the areas of rights, employment and poverty alleviation, social protection (especially maternity protection), as well as representation through social dialogue, can promote change.

\footnotetext{
${ }^{1}$ Address by Mr Juan Somavia, Secretary-General of the ILC, 88th Session, 5 June 2000.

${ }^{2}$ United Nations: Summary of the General Assembly thematic debate on the MDGs (New York, 1-4 April 2008).

${ }^{3}$ Lifetime risk of maternal death reflects the probability of becoming pregnant and the probability of dying from a maternal cause during a woman's reproductive lifespan. See UNICEF: The state of the world's children 2009: Maternal and newborn health (New York, 2009), pp. 7-8.
}

${ }^{4}$ R.A. Montenegro and C. Stephens: "Indigenous health in Latin America and the Caribbean", in The Lancet, Vol. 367, Issue 9525, pp. 1859-1869.

${ }^{5}$ UNFPA: Maternal mortality, Reproductive health fact sheet (New York, 2005). 
Figure 3.1. Access to maternal and infant care: Girls

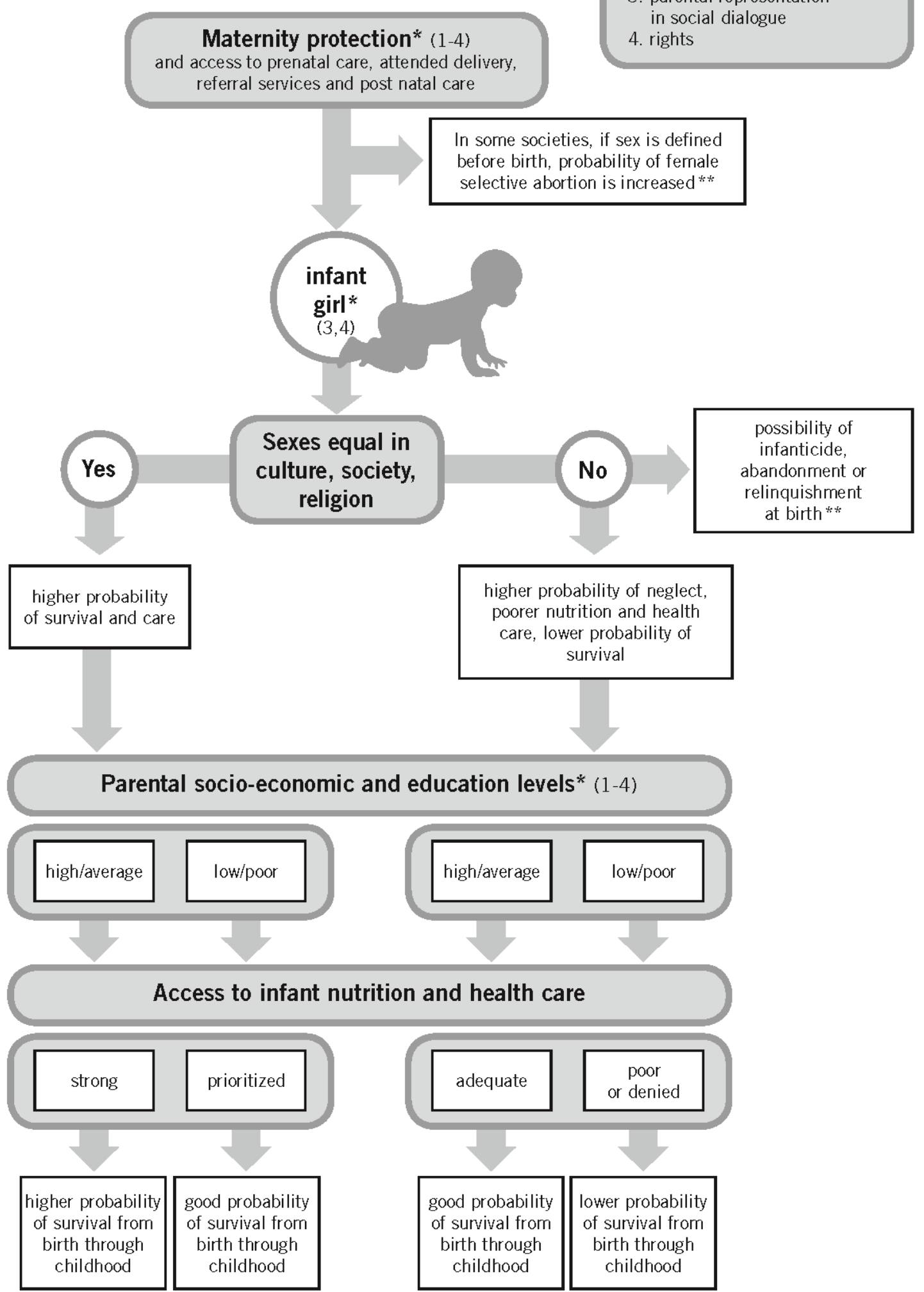

*Access to ILO action:

1. parental employment

2. social protection

3. parental representation

in social dialogue

access to prenatal care, attended delivery,

In some societies, if sex is defined

before birth, probability of female

selective abortion is increased ${ }^{* *}$

poorer nutrition and health survival

${ }^{* *}$ In the early 1990s, Amartya Sen, Master at Trinity College and Nobel laureate, raised international interest concerning the number of "missing" girls and women in certain regions of the world.

Source: ILO (GENDER), 2009. 
Figure 3.2. Access to maternal and infant care: Boys

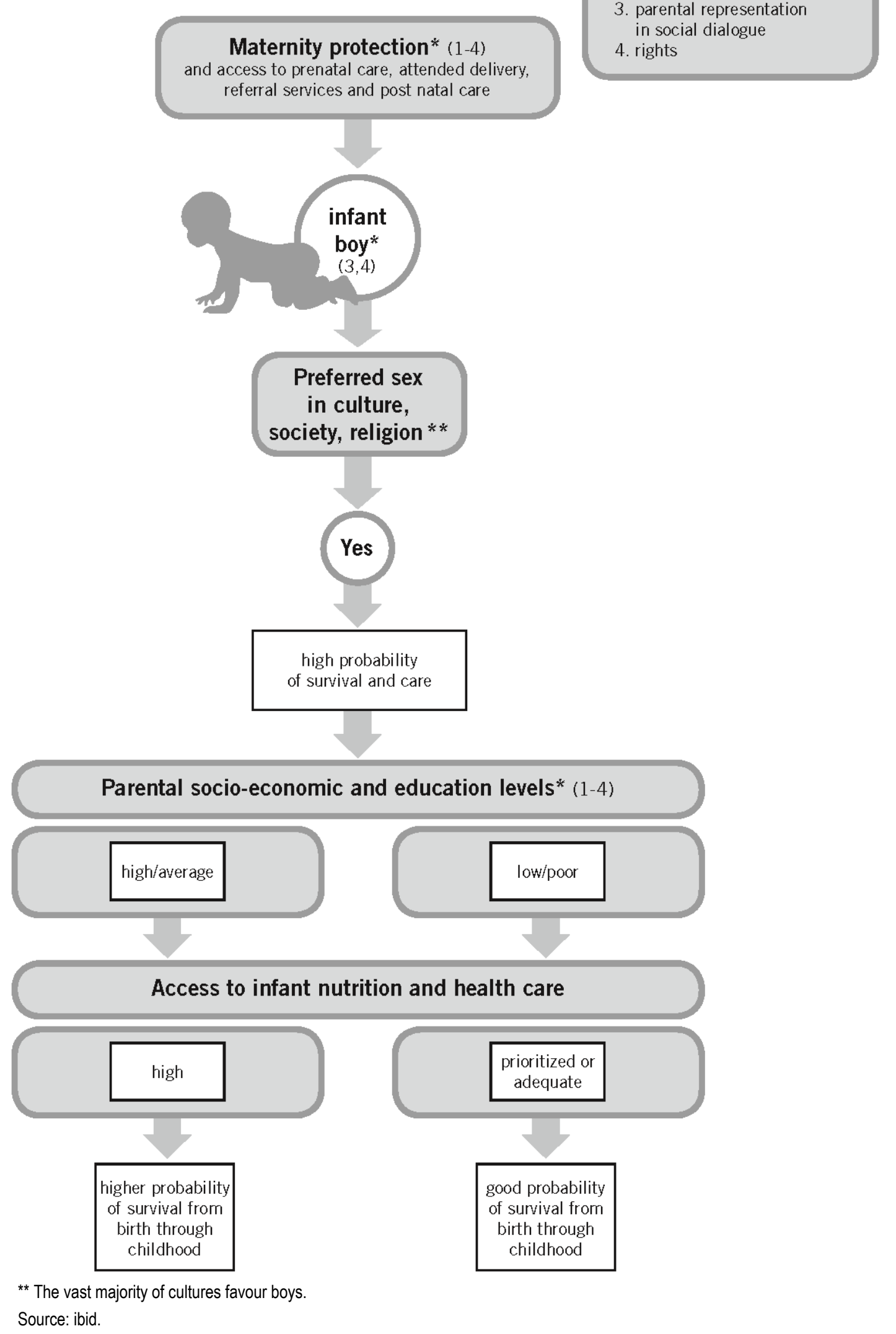

*Access to ILO action:

1. parental employment

2. social protection

3. parental representation

in social dialogue

rights

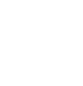


98. Table B in the appendix is based on fertility projections to 2050 published by the UN and on labour force projections to 2020 published by the ILO. The numbers of both women of working age (15-49 years) expected to be pregnant in 2010, 2020 and 2050 and of women in the labour force who are expected to be pregnant in 2010 and 2020 are presented. ${ }^{6}$ Importantly, the table makes a fundamental assumption that there is no incompatibility between work and motherhood: the fertility of women who work is assumed to be the same as that of women who are not in the labour force. In fact, many women juggle work and motherhood in such a way as to stay out of the labour market during pregnancy and motherhood, often forfeiting re-entry, risking re-entry difficulties or having to accept a diminished quality of both working and retirement life after reentry.

99. The table demonstrates three phenomena:

- The number of women aged between 15 and 49 years is expected to increase from about 1.7 billion in 2010 to 1.9 billion 2020 and 2.1 billion in 2050, despite a widespread decline in fertility that has already taken place and is expected to continue. This is because of the persistent effects of high fertility in the recent past in most regions: many girls were born and are now growing to adulthood.

- The number of pregnant working women aged 15-49 years is expected to decline, from about 136 million in 2010 to 135 million in 2020 and 123 million in 2050. This is because of the recent and ongoing global decline in fertility. The decline in the number of pregnancies can be seen in all regions except Africa, where the number of pregnant women is still expected to increase. This is because fertility decline is more recent in Africa, and a large part of it will occur in the future.

- Despite declining fertility in most regions, the number of pregnant women aged 15-49 years in the labour force is expected to increase, from about 78 million in 2010 to 80 million in 2020, the term of the ILO labour force projections. This projection is based on the expected global increase in the number of women economically active in the labour force.

100. According to UNFPA, women and couples globally are waiting longer than ever before getting married and having children. Regional average ages of women at marriage are 22 years in Africa, 23 years in Asia and Oceania, 25 years in Latin America, and 26 years in Europe and North America. Men's mean age at marriage is considerably higher than women's in all regions. The trend towards postponement of marriage is due in part to the growing emphasis on access to education. Worldwide, the mean age for first marriage has increased 1.6 years among women and 1.2 years among men over the past decade alone.

101. In cultures where there are pressures to conform to societal expectations by entering into early marriage, parenthood is one of the factors that perpetuate the intergenerational cycle of poverty for both young women and men. The social and economic costs are high for both individuals and communities. Many young women from poor family backgrounds have little option but to get married, which is most likely just a move from one poor household to another. For millions of teenage brides, early marriage means lost opportunities for education, as well as limited chances of social and

\footnotetext{
${ }^{6}$ It should be noted that the numbers of women pregnant in a given year probably falls short of actual births, as a tiny but consistent proportion of women will give birth twice in a year, especially in countries with higher fertility rates. The numbers of women pregnant are also conservatively estimated, as fertility refers only to live births, so pregnancy loss at any stage, including third trimester miscarriages and stillbirths, is not included.
} 
political participation. ${ }^{7}$ In some parts of the world this reinforces the lack of parental investment in the education of girls on the assumption that they will leave the family upon marriage. In addition, early pregnancy may cause complications. ${ }^{8}$ Even in regions with falling fertility rates, early pregnancy is one the pitfalls restricting access to productive jobs, particularly among poor women with little education. Whether married or unmarried, young women facing maternity will have the tasks of caring for infants, in addition to extra household chores, increased financial burdens and curtailed chances of earning a decent income. The range of unplanned pregnancies among adolescent girls is highest in Latin America and the Caribbean, as well as in some sub-Saharan African countries, where up to 50 per cent of adolescent mothers reported that their pregnancies were unplanned. ${ }^{9}$ In Latin America, teenage pregnancy is one of the main reasons for school dropout. ${ }^{10}$

102. When young women have the opportunity to earn wages, even in low-skilled jobs, different choices can emerge. For example, in Bangladesh and Malaysia, young working women have improved their status and influence in their families as earners. As a result, they can better control the timing of marriage and the choice of partner. Once married, however, these young women have tended to leave wage employment, thus only working for a few years. ${ }^{11}$

\subsection{ILO action}

\subsubsection{Employment}

103. Pregnancy and maternity protection has two aims: to preserve the special relationship and the health of the mother and her newborn; and to provide a measure of job security (access to jobs for women of childbearing age, maintenance of wages and benefits during maternity and prevention of dismissal). Security of employment is crucial for protecting pregnant workers. Pregnancy or motherhood should not constitute a source of discrimination in access to training, skills development and employment, as the ILC 2004 resolution on gender equality, pay equity and maternity protection emphasized. Yet discrimination in the hiring and firing of women workers in their childbearing years is often cited in research. For example, a UK survey showed that 52 per cent of managers consider a job applicant's pregnancy potential, by looking at the candidate's age and marital status. Seventy-six per cent of the managers surveyed would not hire a new recruit if they knew she would become pregnant within six months of starting the job. ${ }^{12}$ Although the Termination of Employment Convention, 1982

\footnotetext{
7 ILO: Decent work and youth: Latin America (Trinidad and Tobago, 2007).

8 Pregnancy is the main cause of death for young women aged 15-19 years. See World Bank: Public health at a glance - Maternal mortality, May 2006.

9 United Nations: Implementation of the World Programme of Action for Youth: Progress and constraints with respect to the well-being of youth and their role in civil society, Report of the Secretary-General to the General Assembly, 64th Session, A/64/61-E/2009/3 (New York, Oct. 2008), p. 8 .

10 In Brazil, Colombia, Nicaragua, Panama and the Bolivarian Republic of Venezuela, adolescent fertility rates exceed 17 per cent. UN DESA: Young people's transition to adulthood: Progress and challenges (New York, 2007), p. 58.

11 IBRD/World Bank: World Bank Development Report 2007: Development and the next generation, (Washington, DC, 2006), p. 51.

12 BBC: "Bosses weigh up pregnancy risk", 21 April 2008, at http://news.bbc.co.uk/2/hi/business/7357509.stm.
} 
(No. 158), explicitly prohibits dismissals based on, among other grounds, pregnancy and absence from work during maternity leave, ${ }^{13}$ complaints of maternity-related dismissals are common in the courts. ${ }^{14}$ The Workers with Family Responsibilities Recommendation, 1981 (No. 165), offers practical guidance on workplace policies for managers to ensure that workers can cope with work and family and remain productive. It offers guidance on reducing daily hours of work and overtime, flexible working schedules, shift work and rearrangement where the job requires night work, and spouse mobility options in case of transfers.

104. A number of countries have adopted active labour market policies with a maternity and family component. For example, in Mexico, the 2003 Federal Act for the prevention and elimination of discrimination on grounds of sex, pregnancy and marital status promotes affirmative action in enterprises. ${ }^{15}$ In other developing countries, women informal economy workers might be hindered in their access to livelihoods during maternity. For example, the requirements for the application of maternity protection provisions may be very demanding in law and practice and exclude women agricultural workers. ${ }^{16}$ The ILO considers it important to take account of the availability of such measures in the informal economy, where many women are concentrated in seasonal and temporary labour forces.

\section{Box 3.1 \\ Maternity and gender equality in Spain}

Spain has the lowest birth rate in the EU (1.07 children per woman of childbearing age). Amortizing women's higher levels of education through labour force participation, later marriage, inadequate childcare, economic pressures and fear of dismissal because of pregnancy have led many Spaniards to postpone or forgo having children. This has demographic implications for the country. Aware of the pressures on women in the workforce, the Government has been addressing inequality issues, notably nonrecruitment and dismissals due to maternity considerations (in a 2001 decision the European Court of Justice upheld the complaint lodged by a woman municipality worker whose contract non-renewal was linked to her recent delivery). In a recent labour court decision, the judge ruled that the Equality Law of 2007, which incorporated maternity protection, was also applicable to the case of a pregnant domestic worker, and decided that her dismissal was void. This is an important ruling for a group of workers who had previously been unprotected. In April 2008, in a visible show of support for gender equality and maternity protection, Spain's first cabinet with a majority of women members was appointed. The Minister for Defence, Carme Chacón, was seven months pregnant at the time, has since given birth, taken maternity leave and returned to work.

Source: European Court of Justice: Jiménez Melgar v. Ayuntamiento de Los Barrios, Case C-438/99 reported in [2001] IRLR 848. European Industrial Relations Observatory on-line, European Foundation for the Improvement of Living and Working Conditions, see www.eurofound.europa.eu/areas/gender/; M. GutiérrezDoménech, "The impact of the labour market on the timing of marriage and births in Spain", in Journal of Population Economics, Vol. 21, No. 1, Jan. 2008; J. Lazaro, "Una sentencia aplica por primera vez la Ley de Igualdad al servicio doméstico", in El País, 22 Apr. 2008, printed edition.

\footnotetext{
${ }^{13}$ For a collection of national summaries and comparative tables covering 77 countries, see Termination of Employment Legislation Digest, at www.ilo.org/public/english/dialogue/ifpdial/info/termination/tables.htm.

14 EU cases and their successful outcomes for this aspect of gender equality are analysed in E. Landau and Y. Beigbeder: From ILO standards to EU law: The case of equality between men and women at work (Martinus Nijhoff, Leiden and Boston, 2008), pp. 143-165.

15 ILO: Equality at work: Tackling the challenges, Report of the Director-General, ILC, 96th Session, Geneva, 2007, p. 58.

16 World Bank/FAO/International Fund for Agricultural Development (IFAD): Gender in agriculture sourcebook (Washington, DC, 2009), p. 337.
} 


\subsubsection{Social protection}

105. Workplace hazards for workers in both the formal and informal economies that may affect reproductive health are important considerations. Most women work through their pregnancies and subsequently return to work after childbirth. Certain working demands may be harmful, such as long or excessive working hours, night work, inadequate maternity leave, or lack of nursing breaks after childbirth. ${ }^{17}$ Exposure to biological or chemical agents or exposure to physical demands of excessive vibration, jolts, noise or extreme heat or cold can also be hazardous. These have to be recognized and mitigated or eliminated.

106. An adequate level of social protection encompasses protection for the life and health of workers in all occupations, including the protection of child welfare and of maternity. In practice, however, only 20 per cent of the world's population today has access to adequate social protection, while more than half have none at all. Informaleconomy workers are among the most numerous of workers with little or no social protection, and women predominate in this sector. Women workers in the informal economy are especially vulnerable to multiple risks because of their dual roles in the workplace and the home, their greater social exclusion, and the difficulty of extending social protection to them.

107. Several ILO programmes work on aspects of maternity, paternity, childcare, healthy working conditions and social security. The programmes develop comparative analyses, tools, good practices, and technical cooperation to help and encourage ILO constituents to improve the conditions of employment of women and men workers by taking an integrated approach to working time and work organization, wages and incomes, work and family, maternity protection and conditions of work. The Office runs a series of dialogues with the social partners on work and family, including maternity. Some successful Office interventions are described below.

\section{Social security: Income replacement, income support and affordable medical care}

108. The Maternity Protection Convention, 2000 (No. 183), calls for cash benefits during maternity leave so that women can maintain themselves and their children. Increased recognition of gender equality in the world of work and its role as a driver of sustainable development should support women in both their reproductive and their productive roles. Most countries - 97 per cent in an ILO survey - have embraced this principle, and only five ${ }^{18}$ had maternity leave but no national legal provision for payment. ${ }^{19}$ In many countries, cash benefits do not yet reach the level prescribed by the Convention: just 36 per cent of countries studied reach the standard of at least two-thirds of a worker's previous earnings for 14 weeks.

\footnotetext{
17 J. Paul: Healthy beginnings: Guidance on safe maternity at work (Geneva, ILO, 2004); and ILO: Information sheet on maternity protection (No. 4), Conditions of Work and Employment Programme (Geneva, 2004).

18 Australia, Lesotho, Papua New Guinea, Swaziland and the United States.

19 I. Öun and G. Pardo Trujillo: Maternity at work: A review of national legislation (Geneva, ILO, 2005), p. 14. Figures based on review of legislation for 166 countries.
} 
109. Over time, and in line with international policy prescriptions, countries have shifted from financing mechanisms that placed the direct costs of maternity on employers - a potential burden for employers and a possible source of discrimination against women - towards greater reliance on compulsory social insurance or public funding, or a mixed system dividing responsibility between employers and social security systems. ${ }^{20}$ Today, in about a quarter of all the countries surveyed, employers are directly responsible for providing cash benefits, half of them rely on social insurance or public funds, and 20 per cent have mixed funding systems. ${ }^{21}$

\section{Box 3.2 \\ Maternity benefits in Jordan}

In 2007, the ILO conducted a feasibility study on the implementation of a maternity cash benefits scheme for the Hashemite Kingdom of Jordan. The full cost of maternity leave, which was being borne by employers, had given rise to discrimination against women workers, because of the perception that they cost more than men. The study pointed to a fair and affordable maternity protection scheme for Jordan that would benefit women workers, labour markets and society as a whole. The findings showed that the introduction of a maternity cash benefits scheme in Jordan appeared to be feasible and financially sustainable. A proposal for its adoption has been presented to the Jordanian Parliament in 2008.

Source: ILO: Feasibility study on the implementation of a maternity cash benefits scheme, Report to the Government of the Hashemite Kingdom of Jordan, Social Security Department and Regional Office for Arab States (Geneva, 2007).

110. Another innovative approach is the linking of microfinance and maternity protection. The ILO is exploring ways of extending maternity protection to women in the informal economy through micro-insurance and other community-based health-financing schemes. ${ }^{22}$ Initial research has been carried out into how these community-based initiatives have integrated maternity protection within the services they offer to their members and their families. Information has been gathered in nine countries from Africa, Asia and Latin America: Argentina, Chile, Colombia, India, Nepal, Philippines, Senegal, United Republic of Tanzania and Uganda. The information collected and its subsequent analysis provided the evidence base for the development of practical guidelines to help promote health-financing schemes that embody maternity protection services. ${ }^{23}$

\footnotetext{
20 ibid., p. 26.

21 A 2001 study of who pays for income replacement during maternity leave reported that national social security covered this contingency (wholly or in part) in 12 Asia/Pacific and Arab States combined, in 27 African countries, 30 Latin American and Caribbean countries, and in 40 European countries. ILO: Maternity leave around the world, Information booklet on Convention No. 183 (Geneva, 2001).

22 ILO: Extending maternity protection to women in the informal economy: An overview of community-based health financing schemes, Social Security Department - Strategies and Tools against Social Exclusion and Poverty Programme (STEP), and Conditions of Work and Employment Programme, TRAVAIL (Geneva, 2003).

23 ILO: Extending maternity protection to women in the informal economy: The case of Nepal, STEP Working Paper (Geneva, 2002).
} 


\section{Box 3.3 \\ Financing maternity benefits in Latin America}

In Argentina, Brazil and Uruguay, the means to fund maternity benefits are based on employers' contributions to social security. In Mexico, the contributions are tripartite, coming from a state subsidy, enterprise quotas and employees' contributions. In all four countries, employers' contributions are based on the number of workers registered for social security, regardless of their age or sex, so that even those who do not employ any women make contributions. This reflects the worldwide social security principle regarding the basis for contributions.

Sources: L. Abramo and R. Todaro: Costos Laborales y Reproduciòn social: Analysis Comparativo de Cinco Paises Latinamericanos; in Abramo and Todaro (eds): Cuestionando un Mito: Costos Laborales de Hombres y Mujeres en America Latina (ILO Regional Office for Latin America and the Caribbean); C. Hein: Reconciling work and family responsibilities: Practical ideas from global experience (Geneva, ILO, 2005).

\section{Childcare}

111. The development of affordable, reliable and high-quality social care services, in an effort to ease the conflict between work and caring for young, elderly or sick relatives, is recognized as one of the most cost-effective and gender-sensitive ways of meeting workers' needs. In particular, ILO research on childcare for working parents has found that the external benefits related to these measures accruing to society, employers, workers and their families, are numerous. In particular, high-quality childcare:

- promotes gender equality, improving women's opportunities for employment, self-development and empowerment;

- helps prevent the perpetuation of social inequalities and intergenerational poverty, strengthening families' social and economic security and reducing their vulnerability to risk;

- facilitates the smooth and efficient functioning of labour markets, through the full utilization of society's growing investment in women's education and a diversified labour force;

a provides a stronger start for disadvantaged children, enhancing their physical wellbeing, cognitive and language skills, and social and emotional development;

a contributes to job creation in the service sector to replace some of the unpaid household work;

- increases tax revenues, since higher participation rates and earnings of parents increase national production. ${ }^{24}$

\section{Flexible working time}

112. Another important measure is linked to decent working time, providing workers with the time and flexibility they need to handle their family responsibilities. Familyfriendly measures need to be designed to allow parents - both women and men sufficient time to care for their families on a daily basis. By allowing individuals to adjust their work schedules flexibly to meet essential domestic obligations, familyfriendly working-time benefits workers and their workplaces, as well as society as a whole. ${ }^{25}$

${ }^{24}$ C. Hein and N. Cassirer: Workplace partnerships for childcare solutions (Geneva, ILO, forthcoming).

${ }^{25}$ ILO: Decent working time: Balancing workers' needs with business requirements, Conditions of Work and Employment Programme, TRAVAIL (Geneva, 2007), pp. 8-9. 
Leave

113. Labour protection is also crucial to enable working mothers and fathers to do their work without neglecting their families. In addition to maternity leave, there are other kinds of leave that can enable workers to achieve a work-life balance, including paternity and parental leave, and adoption leave.

114. The mother's right to a period of rest in relation to childbirth is crucial to protecting the health of the mother and her child. Convention No. 183 requires ratifying States to provide a minimum of 14 weeks, six of which must be taken immediately after giving birth. The Maternity Protection Recommendation, 2000 (No. 191), proposes that this period should be at least 18 weeks. This is intended to protect the woman from being pressured into returning to work when it could be detrimental to her health and that of her child. The Convention establishes a right to additional leave in the event of illness or complications. In practice, the length of maternity leave varies widely across the world. Figure 3.3 shows that the length of maternity leave is increasing even if the improvements are unevenly spread among regions.

Figure 3.3. Length of maternity leave by region, 2004 (166 countries)

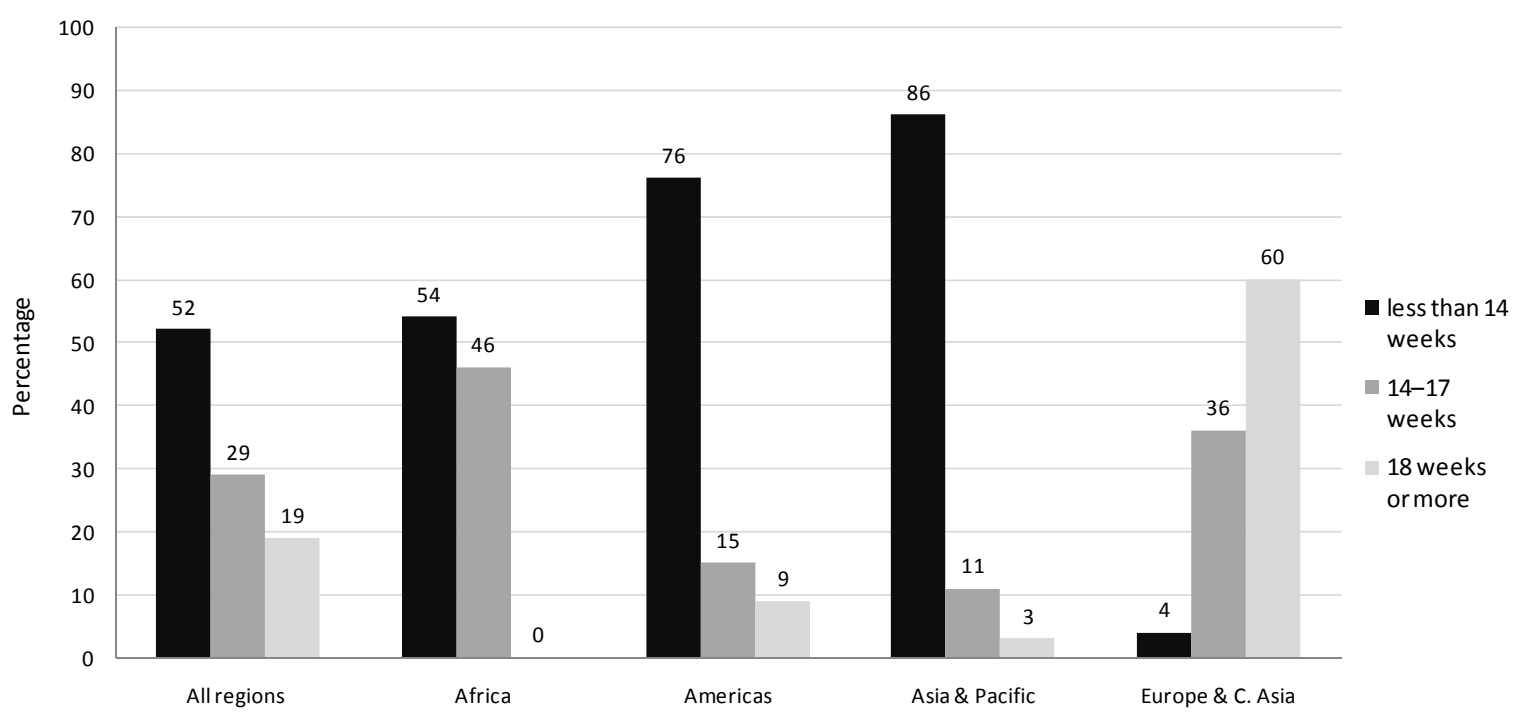

Source: ILO Conditions of Work and Employment Database on maternity protection (2005). 
115. One important development in ILO policy has been the recognition of the importance of fathers' involvement in family responsibilities in general and the link between equality at home and equality in the workplace. Parental leave has been an important step in the sharing of family responsibilities, and in acknowledging that both mothers and fathers are responsible for raising their children. ${ }^{26}$ The provision of parental leave is not included in any ILO Convention, ${ }^{27}$ but is referred to in Recommendations Nos 191 and 165.

\section{Box 3.4 \\ Female public servants take leave - to their cost}

A workplace survey in Australia has shown that women who have taken maternity leave are less likely to receive promotion after their return to work. Of female public servants who took maternity leave in 2000-01, 65 per cent had not been promoted as of June 2007. By contrast, in the same period, 42 per cent of women without children had not received a promotion. According to the PSI-affiliated Community and Public Sector Union, a range of factors accounted for the figures, including a lack of flexible working arrangements, a bias against providing part-time work opportunities in higher grades, and a lack of well-funded and high-quality childcare arrangements. The public service has some of the most competitive family-friendly work provisions in Australia, including 12 weeks' paid maternity leave and flexible working hours.

Source: Public Services International (PSI), www.world-psi.org.

116. Leave provisions are not found exclusively in statutes. Family-care provision exists in collective agreements across regions where workers' organizations and employers are willing, and technically prepared, to negotiate them. For example, in Finland some sectoral agreements increase workers' entitlement to short temporary absences from work in the event of illness of children aged under ten years. In Greece, Cosmote, a mobile telephone provider, allows 32 hours of annual leave for employees to monitor children's progress in school. In Italy, company-level collective agreements provide employees with time off to care for sick family members and disabled or drug-addicted children. In Canada, leave provisions for employees to accompany family members to medical appointments, graduation or court hearings have appeared in collective agreements in both the public and the private sector. ${ }^{28}$

\footnotetext{
${ }^{26}$ I. Öun and G. Pardo Trujillo: Maternity at work: A review of national legislation (Geneva, ILO, 2005), p. 42.

${ }^{27}$ Parental leave, a relatively long period following the expiry of maternity leave, is available in some countries for both women and men. It can be a shared entitlement that either parent can take (for example, in Cuba, Estonia, Hungary and Viet Nam); an individual, non-transferable entitlement (for example, in Belgium, Iceland and Ireland); or a mixed entitlement, combining individual and family entitlements (for example, in Norway and Sweden). In the EU, the Council Directive on the framework agreement on parental leave has been instrumental in increasing the number of countries providing for individual parental leave, thus encouraging fathers to take up parental leave, and resulting in gender equality. ILO: Equality at work: Tackling the challenges, Report of the DirectorGeneral, ILC, 96th Session, Geneva, 2007, pp. 80-81.

${ }^{28}$ For Finland, Greece and Italy see European Foundation for the Improvement of Living and Working Conditions: Reconciliation of work and family life and collective bargaining in the European Union, (Dublin, 2006); for Canada, see K. Bentham: "Labour's collective bargaining record on women and family issues", in G. Hunt and D. Rayside (eds): Equalizing labour: Union response to equity in Canada (University of Toronto Press, forthcoming); and ILO: Equality at work: Tackling the challenges, Report of the Director-General, ILC, 96th Session, Geneva, 2007, p. 88.
} 
117. Paternity leave provides an important opportunity for fathers around the time of birth to nurture their infants and to support the mothers through the many physical and emotional demands related to childbirth and caring for newborns. Recognition of the usefulness of paternity leave is spreading around the world, reflecting evolving views of fatherhood and the needs of men as well as women to reconcile work and family life. This recognition may herald more gender-balanced approaches to caregiving and unpaid work. While no ILO standard explicitly requires ratifying States to provide for paternity leave, provision is made in national laws and collective bargaining agreements in a number of countries, including more general provisions for family leave which can be used by new fathers. ${ }^{29}$ The duration and compensation of paternity leave vary considerably. ${ }^{30}$ Encouraging examples of paternity leave provisions and take-up come from Italy and France. In Italy, Act No. 53 of 8 March 2000 provides for maternity and paternity leaves, the right to care and training and coordination of leisure time. It has resulted in promoting a gender balance between working time and family responsibilities. In France, the law of 2002 introduced paternity leave of 14 days, the first three fully paid by the employer and the rest paid by social security, up to 80 per cent of gross salary. The provision has had a remarkable success: as of 2004, almost two-thirds of eligible fathers (including wage earners, the self-employed and farmers) had made use of this leave. ${ }^{31}$

\subsubsection{Social dialogue}

118. Social dialogue is a key way of achieving recognition of the importance of protection for working mothers and fathers. At tripartite level, it can ensure that the State plays its required role in adopting sustainable social protection systems. At bipartite level, collective bargaining enables segments of society that may be struggling to balance often conflicting roles to make their voices heard. The relatively small number of women in key positions in representative bodies acts as a brake on the advancement of gender equality in general and on improving the situation of both female and male workers with family responsibilities. Specific issues such as childcare, elder care and working-time arrangements will be addressed regularly in social dialogue once a critical mass of women is participating actively and meaningfully in the social dialogue and has access to decision-making roles in the process. There is a pressing need to increase women's participation in existing social dialogue structures, to encourage men to take up

${ }^{29}$ I. Öun and G. Pardo Trujillo: Maternity at work: A review of national legislation (Geneva, ILO, 2005), p. 39.

${ }^{30}$ Leave provisions which can be used by new fathers exist in Africa (Cameroon, Chad, Côte d'Ivoire, Gabon - national laws provide up to ten days' paid leave for family events concerning the worker's home); in Asia (Indonesia - two paid days at time of birth, Philippines - seven days' paid paternity leave for married workers, Cambodia - ten days' special leave for family events); in the Americas (Brazil - seven days' paid paternity leave, Paraguay and Argentina - two days' paid paternity leave); and in the EU (Slovenia - 90 days' paid paternity leave, Finland - 18 days' paid paternity leave, Denmark - 14 days' paid paternity leave and two weeks' paid parental leave, Estonia - 14 calendar days, Sweden - ten days' paid paternity leave and two months' paid parental leave, Latvia - ten calendar days). Other European and CIS States allow three months' paid paternity leave. In other regions, Algeria permits three days' paternity leave, and Saudi Arabia and Tunisia both provide one day's paid paternity leave. Leave provisions noted here are those reserved for fathers and do not include leave provisions which may be shared; see C. Hein: Reconciling work and family responsibilities: Practical ideas from global experience (Geneva, 2005), pp. 120-121.

31 D. Bauer and S. Penet: Le congé paternité, Etudes et Résultats No. 442 (Paris, DREES, 2005). 
issues of gender equality, and to have the gender dimension mainstreamed into consultations on maternal health and infant protection. ${ }^{32}$

Box 3.5
Rights and responsibilities
If workers and employers are not aware of their rights and responsibilities under
national law, they cannot exert them. The ILO's Better Factories Cambodia project works
with managers and workers in Cambodia's garment sector to raise their low level of
awareness of national labour laws - including maternity protection. It has developed
awareness-raising materials and training with employers and workers on leave
provisions, benefits and breastfeeding breaks, among other working conditions. It has
also produced an episode on maternity protection at work for a popular national televised
series seeking to communicate workers' rights and responsibilities through dramatization
in a Cambodian factory setting.
Source: www.betterfactories.org.

119. Employers' organizations have long called for the recognition of the challenges that enterprises, in particular SMEs, face when obliged to assume responsibility for maternity protection on their own. Employers rightly expect not to carry undue financial and compliance costs arising from maternity leave, and have insisted that governments should set national policy in line with the economic and social expectations of the wider community. Employers' organizations recognize that one of the major obstacles to achieving workplace equality continues to be the difficulty of combining family responsibilities with a paid job, and that women therefore require special protection to ensure that their reproductive role is not held against them in their work and careers. ${ }^{33} \mathrm{~A}$ recent survey by the International Organisation of Employers (IOE) noted that greater research was necessary on the ways in which available and accessible childcare encouraged maternal participation in work. ${ }^{34}$ The ILO has developed a training package on work and family, ${ }^{35}$ notably on maternity protection and myths and misconceptions about workers with family responsibilities, especially those that arise during the recruitment of women of childbearing age.

120. Workers' organizations have long supported maternity protection as a basic right in striving towards equality in employment and crucial to the renewal of populations and the labour force. The ITUC, PSI and Education International (EI) have been active in giving the issue visibility. ${ }^{36}$ The ILO publication Gender equality: A guide to collective bargaining ${ }^{37}$ provides practical advice to workers' organizations and others on collective bargaining on a range of issues, including maternity.

32 ILO: Safe maternity and the world of work (Geneva, 2007), pp. 3-4.

33 ILO: Employers' organizations taking the lead on gender equality: Case studies from ten countries, Bureau for Employers' Activities (ACT/EMP) (Geneva, 2005).

34 IOE: Trends in the workplace survey 2008: Enterprises in a globalizing world (Geneva, 2008).

35 ILO: A training package on work and family, ACT/EMP and TRAVAIL (Geneva, 2008), p. 35.

36 International Confederation of Free Trade Unions (ICFTU)-PSI-EI Maternity protection campaign kit for the ratification of ILO Convention No. 183 (Brussels and Ferney-Voltaire, 2001).

37 S. Olney et al.: Gender equality: A guide to collective bargaining, Bureau for Workers' Activities and InFocus Programme on Strengthening Social Dialogue (Geneva, ILO, 2002). 


\section{Box 3.6 \\ Maternity protection: A trade union priority}

The ITUC renewed its commitments and efforts in 2007 to make maternity protection a reality in more countries, noting that a large proportion of women still face unequal treatment in employment owing to their reproductive function, and that women in the informal economy and non-standard jobs are among the most vulnerable. In its campaign for maternity protection, the ITUC calls for a strong standard of maternity protection for all women workers; new efforts to ratify and implement Convention No. 183 and Recommendation No. 191; and new commitments by trade unions to prioritize maternity protection through the application of these two instruments in collective agreements and labour legislation. It appeals to trade unions to "organize collective activities in their countries to raise awareness among political leaders, employers and society as a whole about the vital importance of maternity protection and paid maternity leave".

Source: ITUC: Statement for maternity protection, 8 Mar. 2007, at

www.ituc-cis.org/IMG/pdf/Statement_8_march_EN.pdf.

\subsubsection{Principles and rights}

121. The ILO gives a high priority to the adoption by member States of regulatory frameworks that are sensitive to this aspect of gender equality, and supports institutional improvements for all matters relating to pregnant and nursing women's status and lives, in particular their maternal health at the workplace - whether public or private, formal or informal. Protecting maternity has therefore received much attention from ILO member States: no fewer than three Conventions have been adopted which gradually expanded the scope and entitlements. ${ }^{38}$ And yet, historically, the maternity protection Conventions have not been widely ratified. Constituents have endeavoured to adopt instruments that are not overly prescriptive but provide minimum standards allowing countries to offer higher protection. Why then do ratifications remain low? Some governments feared that the most recent text, for lack of flexibility, would have still fewer ratifications. Employers' organizations argue that ratification is not an end in itself. Rather, ratification is important because it requires countries to commit themselves to bringing their domestic law into line with the Convention and to implementing its provisions in full. ${ }^{39}$

122. The four key equality Conventions are relevant in one way or another to maternity. However, it is Convention No. 183 that broke new ground in pre- and post-partum mother and infant health, breastfeeding, maternity leave of 14 weeks, and cash and medical benefits. It strengthens the link between maternal health, discrimination against women of childbearing age and the socio-economic security that women must be given

\footnotetext{
${ }^{38}$ The Maternity Protection Convention, 1919 (No. 3), was limited to women employed in public or private industrial or commercial undertakings. It provided basic protection by entitling women to 12 weeks' maternity leave with cash benefits to ensure continuity of income, daily breaks for nursing and protection against dismissal during leave. The Maternity Protection Convention (Revised), 1952 (No. 103), extended the scope of protection to more categories of women workers to include women employed in industrial undertakings and in non-industrial and agricultural occupations, including female wage earners working at home. It provided further protection with leave entitlement to cover illness resulting from pregnancy or confinement, and expanded the types of medical benefits provided. The Maternity Protection Convention, 2000 (No. 183), and its accompanying Recommendation No. 191 are the most recent standards, which constitute a step forward with regard to both persons covered and protection provided.

39 ILO: Report of the Committee on Maternity Protection, Provisional Record No. 20, ILC, 88th Session, Geneva, 2000, para. 15.
} 
in order to nurture and sustain future generations. The Convention also ensures the right to return to work which, when not adequately protected, remains one of the main sources of women's disadvantage and gender inequality in the labour market, as well as a worrying source of economic insecurity for mothers. Convention No. 183 broadens the scope of protection to include all employed women, no matter what occupation or type of undertaking, including women employed in non-standard forms of dependent work who often enjoyed no protection.

\section{Box 3.7 \\ Going beyond the ILO technical standard?}

EU Member States are subject to the Pregnant Workers Directive, which encourages measures to improve the health and safety at work of pregnant workers and workers who have recently given birth or are breastfeeding. Significantly, in 2008 the European Parliament proposed action for a new EU standard to help women to combine work and family life. Under the proposal, there would be an extension of maternity leave from 14 to 18 weeks, with the possibility of extending it to 52 weeks in some circumstances. This is controversial in some circles.

Source: I. Öun, and G. Pardo Trujillo: Maternity at work: A review of national legislation, TRAVAIL, (Geneva, ILO, 2005); ILO Conditions of Work and Employment: Database on maternity protection; and EU: Council Directive 92/85/EEC of 19 Oct. 1992. See also European Commission: Renewed social agenda: Opportunities, access and solidarity in 21st century-Europe, 2 July 2008, COM (2008) 412 final.

123. Although Convention No. 183 extends coverage to all employed women, large numbers of women continue to receive no protection where they are excluded from labour legislation or social security systems. Countries have increasingly moved to fill that gap. For example, Uruguay's maternity protection provisions explicitly apply to women domestic workers; in Mauritius, casual workers, apprentices and part-time workers are included; and in Viet Nam, apprentices and domestic servants are listed in the legislation. ${ }^{40}$ Even when vulnerable groups of women are covered by law, practical challenges remain in reaching them and ensuring effective access to maternity protection. The social partners are building a body of good practices to extend maternity protection through new forms of paid maternity leave, and some governments (Ghana, Thailand, Philippines) are working to enable informal economy workers to contribute to formal social security schemes.

124. The Social Security (Minimum Standards) Convention, 1952 (No. 102), is also highly relevant. It sets minimum requirements for health care during pregnancy and confinement, cash maternity benefits replacing lost income and access to preventive and curative health services in general. Other relevant Conventions include the Medical Care and Sickness Benefits Convention, 1969 (No. 130), which sets standards for access to preventive and curative medical care. Hazardous work is a threat to the reproductive health of workers, male and female, and a number of occupational safety and health labour standards help establish the context for safe work, providing guidance on protection in specific branches of economic activity, and protection against specific risks. ${ }^{41}$

${ }^{40}$ I. Öun and G. Pardo Trujillo: Maternity at work: A review of national legislation (Geneva, ILO, 2005), in particular p. 30.

${ }^{41}$ ILO: Safe maternity and the world of work, Conditions of Work and Employment Programme, TRAVAIL (Geneva, 2007), pp. 2-3. 


\subsection{Links to the United Nations and international agencies}

125. Several UN agencies work on maternal health and infancy protection in fields closely related to the world of work. This is clear from the various contributions to the achievement of the Millennium Development Goals (MDGs). ${ }^{42}$ The ILO cooperates with the UN human rights treaty bodies that deal with non-discrimination and gender equality, for example by providing reports with detailed data on maternity protection laws, employment policies and social protection measures. ${ }^{43}$ The ILO has engaged with $\mathrm{UN}$ and other actors to promote maternity protection as part of a broader set of policies to improve maternal and newborn health, as well as to improve women workers' rights. The ILO is a member of the Countdown 2015 monitoring group for MDGs 4 and 5, for which Convention No. 183 is among the indicators of progress. The ILO is also a member of the Partnership on Maternal, Newborn and Child Health which mobilizes support for policy and action to improve health outcomes; its membership brings awareness of the social partners' recognition of workforce maternity protection to international and national policy agendas regarding health.

126. WHO supports countries in their efforts to improve maternal health, and focuses on 75 priority countries that account for 97 per cent of all maternal deaths worldwide. It aims to reduce maternal mortality by providing and promoting evidence-based clinical and programmatic guidance. The ILO's Sectoral Activities Programme has worked intensely with international partners, particularly WHO, to strengthen the world's healthcare workforce. The ILO is a member of the Global Health Workforce Alliance.

127. The UNFPA's approach to reducing maternal mortality is grounded in human rights and gender equality. Recognizing the role of gender in influencing access to and quality of health care, a rights-based approach promotes the empowerment of women and supports conditions in which they can choose safe delivery. There are several areas of joint ILO-UNFPA field work. The ILO participates in the UN "Delivering as One" joint programme on maternal health in the United Republic of Tanzania, bringing trade unions, employers and the Ministry of Labour together with actors in the health field to discuss policies and programmes on maternity protection. From 2000 to 2005, the ILO's relevant field office and UNFPA collaborated in West and Central Africa on gender mainstreaming and stocktaking of women workers in the informal sector and women's reproductive rights. In six Pacific Island States, the ILO has been working together with UNFPA to address issues of masculinities and gender equality among male workers in the formal economy.

\subsection{The way forward}

128. Maternity protection of women workers is the first key step towards greater equality in the life cycle, for the women themselves and for their offspring. Not only maternal health, but also healthy working conditions when workers with families resume their jobs, reduce sex-based imbalances in doing unpaid care work. While constraints face all workers called on to care for children, the elderly or sick relatives, it is traditionally women who shoulder the main responsibility, which means that working

\footnotetext{
${ }^{42}$ The MDGs relevant to this chapter are MDG 3 (gender equality and women's empowerment); MDG 4 (reduction of child mortality); and MDG 5 (improvement of maternal health).

43 See ILO: General status report on ILO action concerning discrimination in employment and occupation, Governing Body, 301st Session, Geneva, Mar. 2008, GB.301/LILS/7, para. 34.
} 
women are perceived to have less time to devote to their jobs. But balancing work and family life is increasingly an issue for men workers too. The following indicative list highlights areas where the ILO's policies, programmes and activities can have an impact:

- Recognizing the integration of maternity protection as part of governments' responsibility for social and economic policy as a whole. Maternity protection is not just about equality for women. It is about social policy that enables working men and women to have families and to regenerate the labour force.

- Eliminating maternity-related discrimination and ensuring employment security through better legal frameworks and their effective application in practice, including dissemination of court decisions on maternity-based discrimination.

- Developing systems and means to give effect to the principle of paid maternity leave, which could form part of a basic social security package.

- Intensifying public policy and practical interventions for flexible work schedules, working time, parental leaves, state-run childcare and other family services.

- Adopting new or strengthening existing policies on paternity, including jobsharing, leave, re-balancing work schedules and employment-related benefits for men.

a Promoting greater action and awareness on OSH and safe working conditions, throughout maternity but also for the reproductive health of all men and women alike.

- Conducting wider public information campaigns about equal opportunities and treatment for women and men workers who have family responsibilities and their monitoring to evaluate their success in eliminating maternity and family-based discrimination, including awareness-raising activities to promote Conventions Nos 156 and 183.

- Increasing training and technical assistance on these international labour standards and on specific matters relating to maternity protection for governments, employers and trade unions in order to highlight its workplace importance and the national benefits of providing for maternal and infant health.

- Expanding research into paid/unpaid care work as it affects women and men workers and intensifying dissemination of good practices that holistically address working conditions, rights and responsibilities.

a Mobilizing sectoral and regional networks that include governments, employers and workers and specialized gender machineries to undertake dialogue on innovative maternity and family interventions. 



\section{Chapter 4}

\section{A decent childhood for both girls and boys}

129. In the twenty-first century, MDG 2 - Achieve universal primary education - attests to the fact that childhood is still a vulnerable phase in the life cycles of women and men. It is internationally recognized that achieving Education for All (EFA) is a crucial step towards development and decent work. As an empowerment right, education is a key vehicle through which economically and socially marginalized children can lift themselves out of poverty and obtain the means to participate fully in their communities. ${ }^{1}$ There has been impressive progress in all regions over the last few years towards attaining the EFA goals. Primary-school enrolment rose from 647 million to 688 million worldwide between 1999 and 2005, increasing by 36 per cent in sub-Saharan Africa and 22 per cent in South and West Asia. ${ }^{2}$ As a result, the number of out-of-school children declined from 96 million in 1999 to 72 million in 2005, gathering pace after 2002. ${ }^{3}$

\subsection{Gender and education}

130. The ILO's twofold rights-based and efficiency-based gender equality argument applies here, too. Education and gender equality have long been recognized as fundamental human rights. The economic efficiency rationale for empowering girls through education is similarly compelling, for women's potential as key contributors to development depends on their access to education. ${ }^{4}$ The goal of gender parity in primary education has been achieved in 118 countries. However, many of these already had the right to free compulsory education. In 2005, about one-third of countries reported parity in both primary and secondary education; in 2008, 54 countries still fell short of the mark and are at risk of not reaching it. ${ }^{5}$

\footnotetext{
1 IPEC: IPEC action against child labour 2006-07: Progress and future priorities (Geneva, ILO, 2008), p. 73.

${ }^{2}$ UNESCO: Education for All Global Monitoring Report 2008: Education for all by 2015 - Will we make it? (Paris, 2008), pp. 1 and 49.

3 ibid., p. 49.

4 See MDG 3: Promote gender equality and empower women, Target 3a: Eliminate gender disparity in primary and secondary education preferably by 2005, and at all levels by 2015 .

${ }^{5}$ UNESCO: Education for All Global Monitoring Report 2008, op. cit.
} 
131. MDG 2 has had a positive impact on girls moving out of work - whether paid or unpaid - and into school. The abolition of school fees in a number of countries has contributed to closing the academic gender gap. In Kenya and the United Republic of Tanzania, enrolment increased by 18 and 23 per cent, respectively, including newly enrolled girls. Nevertheless, UNESCO has indicated that of the 72 million primaryschool-age children out of school, 44 million are girls. In South and West Asia, 66 per cent of out-of-school children were girls, and in the Arab States 60 per cent were girls. ${ }^{6}$ Despite increasing international recognition that the education of girls is one of the most powerful tools for progress, girls suffer from discrimination in relation to education. ${ }^{7}$

132. Figures 4.1 and 4.2 show the impact of cultural and societal norms on education for girls and boys, as well as the strong influence of parental socio-economic and education levels. Yet empirical evidence from a range of countries shows that educating girls is one of the most effective ways of fighting poverty. Educated girls are more likely to have higher incomes and increased control over resources as adults, marry later, have fewer and healthier children and exercise greater decision-making power within the household. Importantly, they are also more likely to ensure that their own children are educated, thus increasing their earnings, avoiding future child labour and breaking the cycle of poverty. ${ }^{8}$ Research demonstrates the link between enhanced educational access for girls and GDP growth. ${ }^{9}$

133. What, then, are the underlying reasons why boys are favoured over girls in education in several regions of the world? Social and cultural constructs determine the attention paid to the development of boys and girls. When families have limited resources, they may have to choose between educating their sons or daughters, regardless of natural aptitudes, skills or motivation levels. Age-old patriarchal traditions, religious interpretations, existing gender role models based on supposed male superiority, inheritance laws and the invisibility of women's work may compound justifications for choosing to educate boys. Unequal relations of power propel a vicious cycle of underinvestment in girls throughout their life cycles. Today, over two-thirds of the world's 860 million illiterate persons are women, and the link to poverty arises here (see table $\mathrm{A}$ in the appendix).

134. Predetermined gender roles may not necessarily benefit young boys either, and may even be harmful. From a young age they may feel a heavy burden to perform academically - perhaps beyond their capacities - in order to live up to their families' expectations to succeed. Boys are more likely to repeat grades and leave school to take up work at a younger age than girls. According to UNICEF, poor boys in Chile are four

6 ibid., p. 49.
7 ILO: Formula for progress: Educate both girls and boys! (Geneva, 2008), p. 2.

8 ibid. See also M. Buvinić et al. (eds): Equality for women: Where do we stand on Millennium Development Goal 3? (Washington, DC, World Bank, 2008), p. 5.

9 One study estimates that if the countries in South Asia, sub-Saharan Africa and the Middle East and North Africa had started with the gender gap in average years of schooling that East Asia had in 1960 and had closed that gender gap at the rate achieved by East Asia from 1960 to 1992, their per capita income could have grown by $0.5-0.9$ percentage points per year - substantially higher than actual growth figures. Estimates show that even for middle- and high-income countries with higher initial education levels, an increase of one percentage point in the share of women with secondary education is associated with an increase in per capita income of 0.3 percentage point. Both studies control for other variables commonly found in growth literature. World Bank: Engendering development through gender equality in rights, resources and voice (2001), pp. 11-12. 
times more likely to drop out of school and enter the workforce than poor girls. ${ }^{10}$ Boys often end up in physically demanding, dirty and dangerous jobs after leaving school.

135. But even if both boys and girls attend school, are they receiving an education free of gender bias? Preconceived notions of competency based on sex are present in most parts of the world. According to the EFA report, textbooks often show stereotyped occupational roles, and teachers too may perpetuate gender biases.

\subsection{Girls, boys and household chores}

136. A particular area of inequality is to be found in the private sphere of the home. The invisibility and undervaluation of women's work at home start when girls are very young, with a heavy burden placed on girls to help the adults - mainly the women. In many regions, it is common for girls to take on a great deal of household work for their families, including caregiving, cooking, cleaning, laundry, and gathering water and fuel. Boys also participate in household chores, but spend fewer hours on them than do girls. Although much focus has been placed on the negative effect of child labour on education, the impact of household chores has not received much international attention. ${ }^{11}$ Table $\mathrm{C}$ of the appendix compares the legal age for entry into employment in selected countries to the age at which compulsory schooling ends. The following analysis of ILO data, which plots the real end of schooling age against the increasing intensity of household chores, tells a story of missed opportunities for both boys and girls, but especially girls. Figure 4.3 shows that school attendance declines for both girls and boys as the time spent on household chores increases from under 14 hours to over 28 hours per week. However, girls' school attendance decreases more rapidly than that of boys. Between 14 and 28 hours of chores, girls' school attendance drops from 90 to 70 per cent, whereas boys' attendance falls by half as much for the same increase in hours.

\subsection{Gender and working children}

137. Children may have to balance school and work. ${ }^{12}$ Table $\mathrm{C}$ of the appendix shows that many girls and boys both work and go to school. School enrolment does not necessarily equate with school attendance. In rural areas, for example, crop and harvest cycles may dictate when children have to work. In urban areas, where nearly half the world's population already lives - especially in Africa and Asia - when not in school, children are particularly vulnerable to engaging in dangerous illegal activities such as drug trafficking, or they may be susceptible to sexual exploitation.

\footnotetext{
${ }^{10}$ UNESCO: Education for All Global Monitoring Report 2008, op. cit., box 2.9.

11 A comprehensive study that included gender and household chores is L. Guarcello et al.: Child labour in the Latin America and Caribbean region: A gender-based analysis (Geneva, ILO, 2006).

12 In this section the terms "working children" and "children who work" denote a broader concept than child labour, and cover all those who supply labour for the production of goods and services. They do not cover household chores. Statisticians include child labourers within the broader definition of working children, thus making it difficult to distinguish between what is age-appropriate, legitimate work and what is child labour. The further distinction of "children in hazardous work" reflects the urgent need to withdraw the children from such conditions, as they may lead to the worst forms of child labour.
} 
Figure 4.1. Access to education: Girls

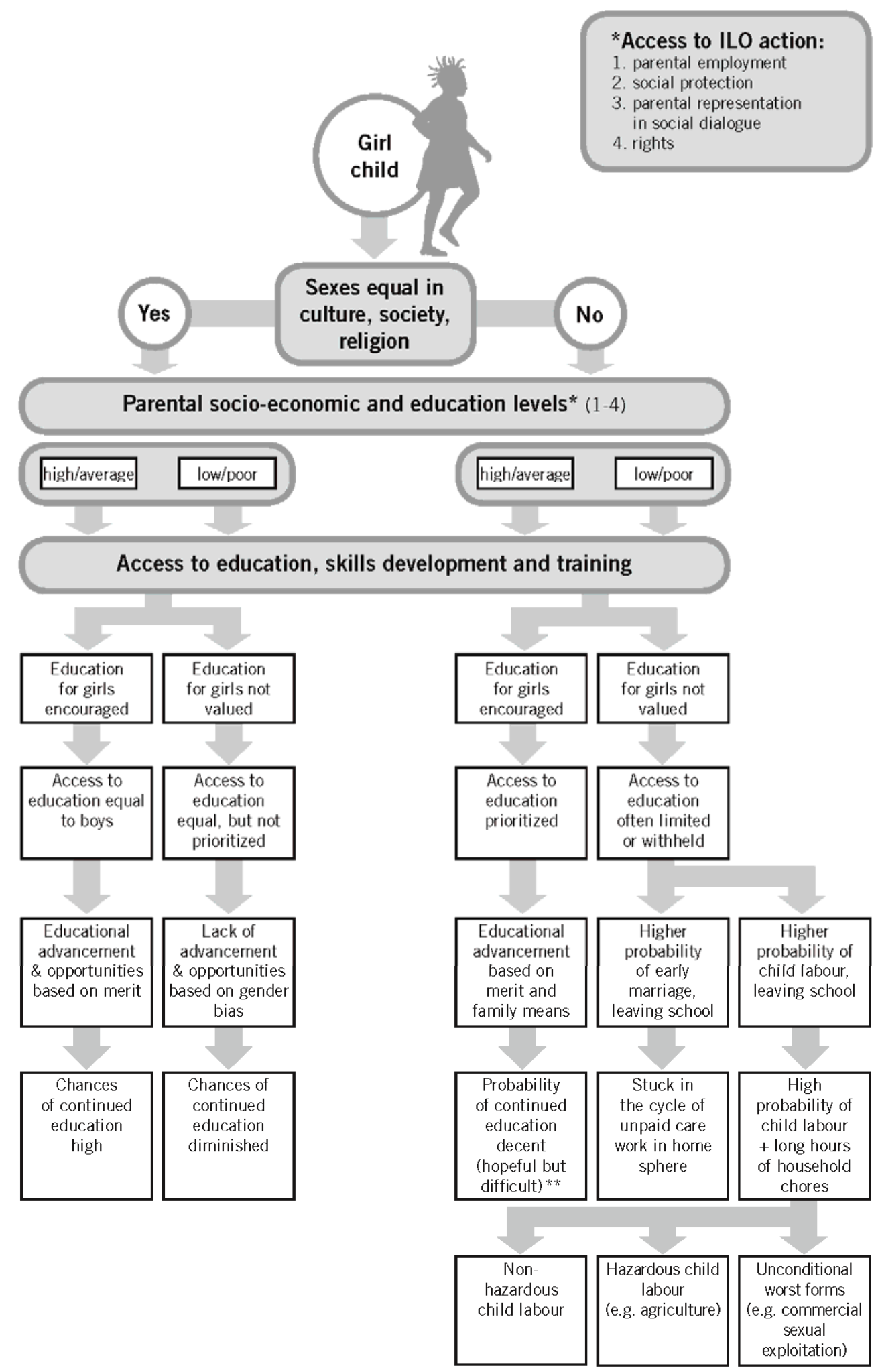

** Educated girls are more likely to ensure that their own children are educated, thus often breaking the cycle of poverty and avoiding child labour.

Source: ILO (GENDER), 2009. 
Figure 4.2. Access to education: Boys

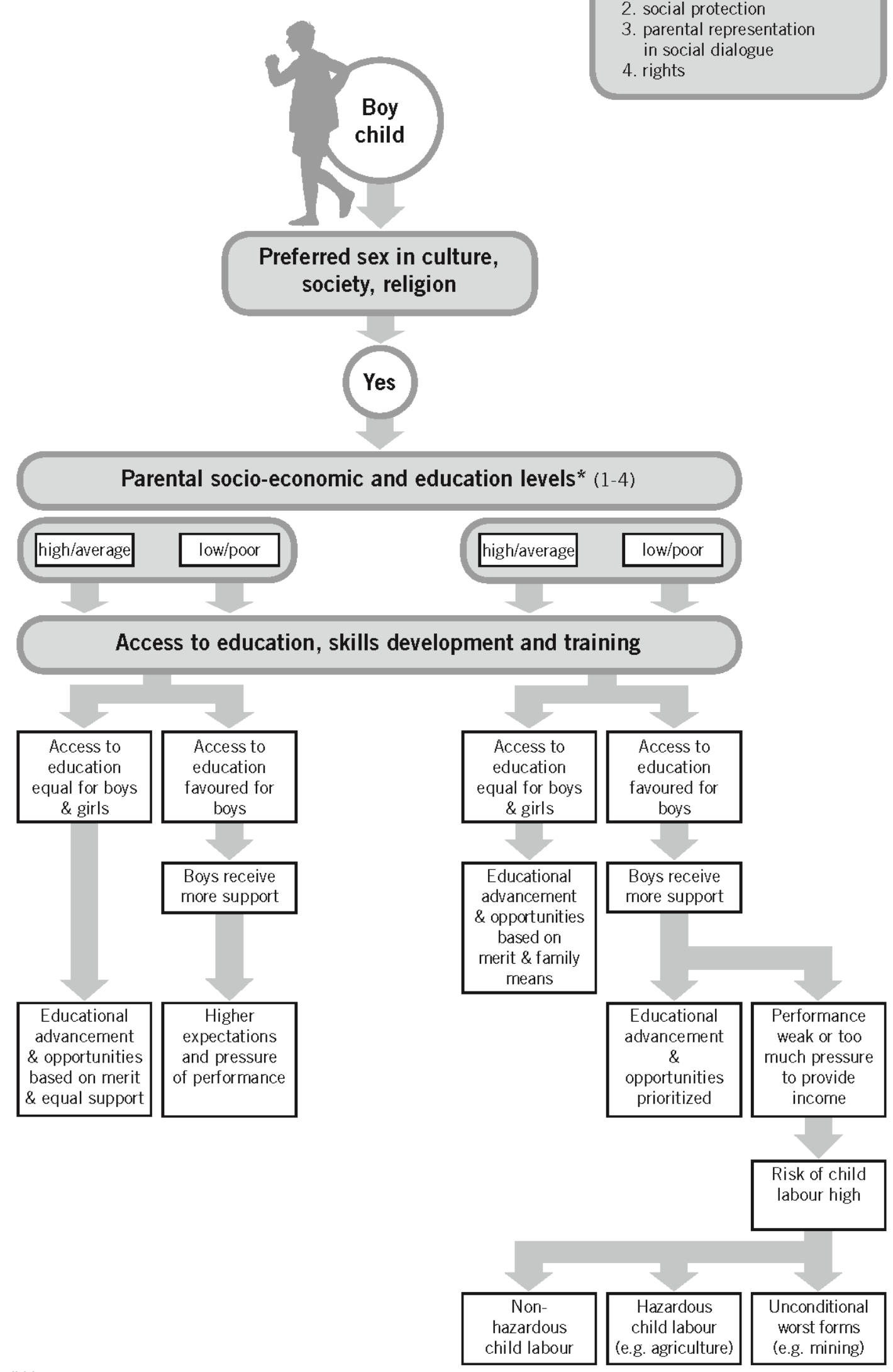

Source: ibid. 


\section{Figure 4.3. School attendance rate according to hours of household chores for girls and boys, 23 ILO member States, most recent year between 1999 and 2006}

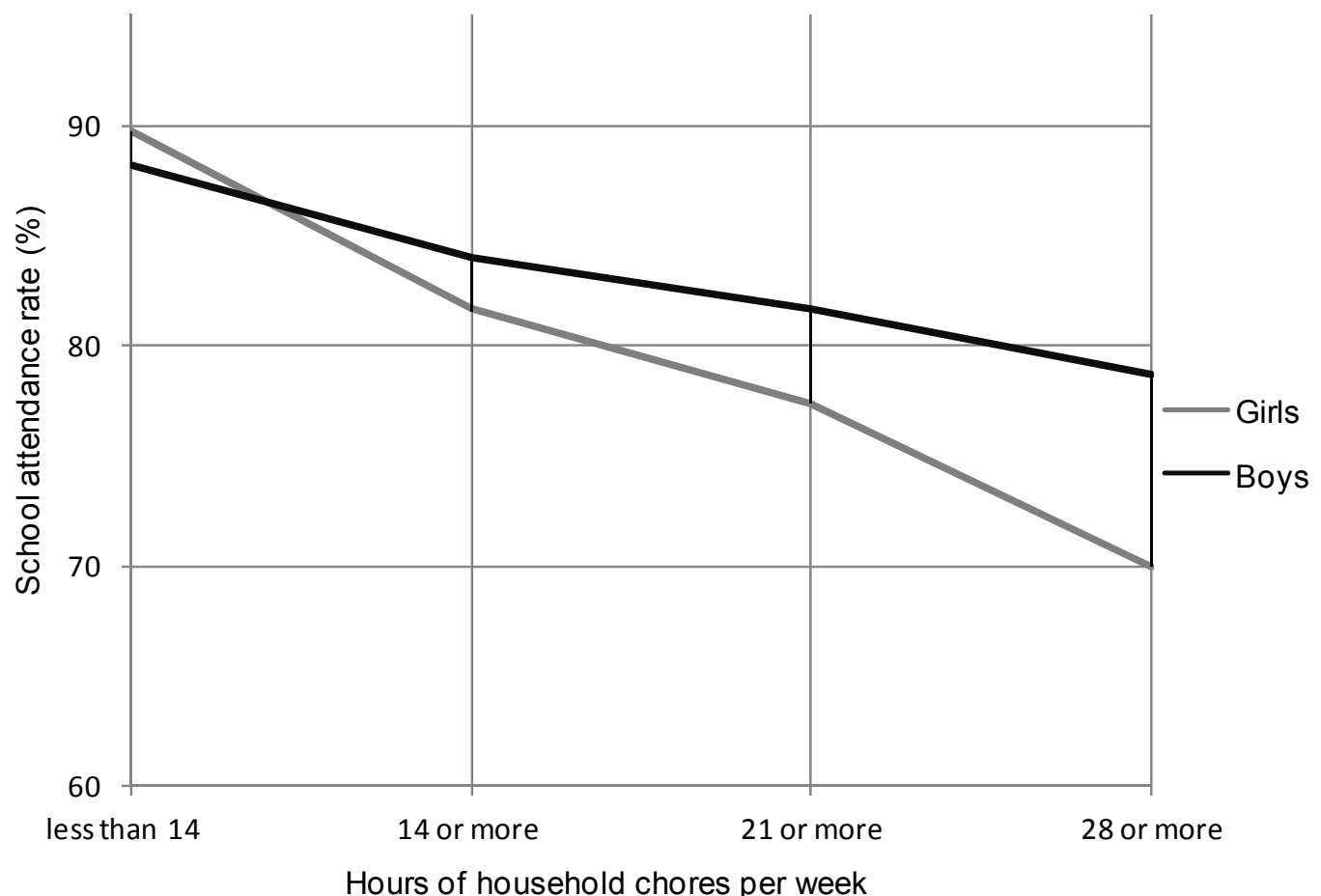

Source: ILO Statistical Information and Monitoring Programme on Child Labour (SIMPOC) calculations based on the following household survey datasets: Argentina, 2004; Azerbaijan, 2005; Belize, 2001; Brazil, 2004; Cambodia, 2000; Colombia, 2001; Costa Rica, 2002; Dominican Republic, 2000; Ecuador, 2006; El Salvador, 2001; Ghana, 2000; Guatemala, 2000; Honduras, 2002; Malawi, 2002; Mali, 2004; Mongolia, 2002; Nicaragua, 2000; Philippines, 2001; Romania, 2001; Senegal, 2005; Turkey, 2006; Uganda, 2001; Ukraine, 1999.

138. The incidence of children's work has declined in recent years. While about onesixth of the total child population aged 5 to 14 - i.e. 191 million children - were still involved in some kind of economic activity in 2004, there were some 20 million fewer working children in this age group than there had been four years earlier. ${ }^{13}$

139. Table $\mathrm{C}$ of the appendix ${ }^{14}$ displays information about girls and boys aged under 15 years, including their mortality and school enrolment rates and their experience of work, and estimated proportions of children who only work, and those who both work and attend school. The table shows large proportions of children aged under 15 working in selected countries. ${ }^{15}$ It also indicates that the proportion of children who only work

13 ILO: The end of child labour: Within reach, Global Report under the follow-up to the ILO Declaration on Fundamental Principles and Rights at Work, Report I(B), ILC, 95th Session, Geneva, 2006, table 1.1. See also F. Hagemann et al.: Global child labour trends 2000 to 2004 (Geneva, ILO, 2006).

14 Children: projected infant and child mortality, children at school and children at work, selected ILO member States, 2003, 2004, 2005-10 and latest available year.

${ }^{15}$ For both sexes, there are potential mismatches between the legislated age for the end of compulsory schooling and the legal age for work, which may have a different impact according to gender. In as many as seven countries, the legal age for work is below the school-leaving age, and in one of those cases the difference is two years. This means that in some societies, children faced with economic and social pressures who can legally work before they can legally leave school are likely to flout the legal school-leaving age, or to be encouraged to flout it. At the same time, in six countries the legal age for work is one or more years beyond the end of compulsory schooling; in three cases, the gap is two or four years. In such cases, the absence of access to genuine post-obligatory educational opportunities means that children may ignore the minimum legal age for work. In only seven countries, the legal 
and do not attend school is generally high (in seven of the sample countries, more than half of the working children are not in school). A large proportion of children combine school and work: in nine of the 24 countries presented, more than 80 per cent of girls and boys who work also attend school, and in a further eight countries, over half of working children attend school.

140. The table also shows that primary-school enrolment of boys is greater than (or equal to) enrolment of girls in most of the countries selected; yet girls manage to continue to grade 5 more often than boys do. Enrolment at lower secondary level favours boys even more than enrolment at primary level.

141. The data also demonstrate gender differences between working children: generally, the higher the proportion of young working children -14 years or under - the more likely that the proportion of girls will be greater than the proportion of boys. Furthermore, among children who only work, the proportion of girls is greater than that of boys in the vast majority of countries examined. Girls suffer discrimination because they start working younger and are often paid less. Boys are also discriminated against in certain situations: they may be employed in hazardous "men's work", or expected to emulate masculine behaviour, often in dangerous situations. Boys are also found in femaledominated work, such as domestic work or commercial sexual exploitation. Boys may find themselves in conditions of servitude, in which they are obliged to beg daily, for example. ${ }^{16}$

\subsubsection{Worst forms of child labour}

142. The international framework defines the worst forms of child labour as the use of children in: (a) all forms of slavery-like practices (for example, debt bondage or forced or compulsory labour); (b) armed conflict; (c) commercial sexual exploitation (prostitution, pornography); (d) illicit activities (in particular the drug trade); and (e) hazardous work (likely to harm their health, safety or morals). The incidence of child labour in certain situations and sectors has long been recognized. Armed conflict and commercial sexual exploitation have received much attention. There are many sectors in which the conditions of work may relegate them to the category of worst forms of child labour; the examples of agriculture, mining and tourism are highlighted below.

143. The ILO estimates that about 218 million children are involved in child labour, 127 million of them engaged in hazardous work, while over 8 million have been forced into work as victims of child trafficking, as child soldiers or bonded labourers or in sexual exploitation. Indigenous children are disproportionately affected by the worst forms of child labour. Additional factors leading to child labour are losing one or both parents to AIDS, and conflict or post-conflict situations, in which education may simply be unavailable.

\section{Agriculture}

144. Seventy per cent of all child labourers work in agriculture - an industry with a very poor safety and health record. Over 150 million girls and boys work as paid or unpaid labourers in crop and livestock production, planting, weeding and harvesting crops, tending cattle, and handling machinery. Whether child labourers work on their parents'

school-leaving age and the minimum legal age for work are the same, which is the ideal envisaged under the Minimum Age Convention, 1973 (No. 138).

${ }^{16}$ See, for example, CEACR observations on the application of the Worst Forms of Child Labour Convention, 1999 (No. 182), in Burkina Faso, Mali, Mauritania and Niger, 2008, in RCE, 2008. 
farms, are employed on the farms or plantations of others, or accompany their migrant farm-worker parents, they carry out virtually the same work as adults and face many of the same hazards and risks, ranging from the carrying of heavy loads to exposure to extreme temperatures or to dangerous substances. Much of their work is unacknowledged, and the accidents and ill health they suffer go unrecorded and unreported. In addition to their work in agriculture, rural girls invariably carry out numerous household duties: looking after younger siblings, cooking, cleaning, and carrying water and firewood over long distances. In contrast, boys are typically allowed to engage in more leisure-type activities when not working in the fields or attending school.

\section{Armed conflict}

145. It is estimated that women and children account for 80 per cent of civilian casualties during armed conflict. ${ }^{17}$ Some of these casualties may be caused by children themselves who have been forced into fighting. In addition, "children who live in conflict or post-conflict situations, many of them orphans, internally displaced children and other vulnerable children, particularly girls, are at high risk of being trapped in other worst forms of child labour in order to survive, such as commercial sexual exploitation, involvement in illicit activities or hazardous work". ${ }^{18}$ Boys are particularly vulnerable to being recruited to serve as child soldiers, but also for auxiliary activities such as cooking, porterage or sex. Young boys who have fought in wars become used to a culture of violence, often not knowing any other way of life.

146. Although girls are also recruited to provide domestic labour for armed groups, they run a greater risk of becoming victims of sexual exploitation. ${ }^{19}$ Some girls become combatants themselves; in certain countries of Central Africa as many as 30 per cent of the children involved in armed conflict were girls. ${ }^{20}$ It is estimated that 100,000 girls have been combatants in recent violence. ${ }^{21}$ It is significantly more difficult to trace what happens to girls after they leave armed units than is the case for boys. Many girls are reported to leave when they become pregnant; thus, because of their pregnancy or early motherhood, programmes designed to benefit former child soldiers do not reach them. Such girls often suffer the double stigma of having participated in battle and of being unmarried mothers. ${ }^{22}$ Of all the disadvantaged groups of children and young people, this one needs special attention because of the girls' state of trauma and pressing need for social integration.

\footnotetext{
${ }^{17}$ UNICEF: The State of the World's Children 2007: Women and children: The double dividend of gender equality (New York, 2006), p. 10.

${ }^{18}$ ILO: Prevention of child recruitment and reintegration of children associated with armed forces and groups: Strategic framework for addressing the economic gap (Geneva, 2007), p. iii.

19 The ILO supervisory bodies have examined the sexual exploitation of girls and women during the Second World War in the context of Japan's application of the Forced Labour Convention, 1930 (No. 29). See observations of the CEACR, 2002-08, RCE, various years. They have also examined the issue under Convention No. 111 in Sudan (Darfur), and under Convention No. 182 in the Democratic Republic of the Congo and Uganda (RCE, 2008, op. cit.).

${ }^{20}$ I. Specht: Red shoes: Experiences of girl combatants in Liberia (Geneva, ILO, 2006).

${ }^{21}$ Plan: Because I am a girl: The State of the World's Girls 2008, Special focus: In the shadow of war, p. 14.

${ }^{22}$ ILO: Breaking the cycle of violence against girls: From child labour to education, panel discussion (Geneva, 2007), unpublished.
} 


\section{Commercial sexual exploitation}

147. Commercial sexual exploitation of children is a heinous violation of their rights. ${ }^{23}$ In the early stages of their development, they are vulnerable to physical and psychological abuse, as well as sexually transmitted diseases and HIV infection. Both girls and boys are victims of commercial sexual exploitation, but girls are disproportionately affected. They may be abducted and trafficked within their country or to other countries by organized criminal networks. An IPEC rapid assessment in Zambia in 2002 found that nearly three-quarters of the children in prostitution were orphans, half having lost both parents and one-quarter one parent. ${ }^{24}$ Large segments of the population in South-East Asia - notably poor rural families sending their daughters to work as prostitutes - rely upon remittances from prostitution for their well-being, if not for outright survival. A large number of countries have adopted or amended legislation to prohibit the use, procuring or offering of children aged under 18 years for prostitution. In certain cases, the CEACR has asked countries to extend the prohibition on the commercial sexual exploitation of children to boys where the legislation only applies to girls.

\section{Mining}

148. It has been estimated that roughly 1 million children are engaged in mining. This type of work is dangerous to children in every way. Artisanal mining is predominantly a male occupation, and therefore it is typically boys who are found in this type of hazardous work. It is physically dangerous (heavy and awkward loads, strenuous work, unstable structures, unwieldy tools and equipment, toxic and explosive chemicals, and extremes of heat and cold). Children working in mines in remote areas are often exposed to economic and social disruption, conflicts and civil wars, which can foster violence, substance abuse and prostitution. The dangers are so obvious that there are no conditions - poverty included - in which child work in mining can be tolerated.

149. Girls and women also work in mining, although in lesser numbers. They often transport, process and sort minerals outside underground mines, hauling loads and working with dangerous substances such as mercury. The latter represents a special risk of contamination for them. ${ }^{25}$ They also work in market activities in the mining community, often for longer hours than boys because they are required to perform other household tasks and services for the male miners.

\section{Tourism}

150. Around the world, between 13 and 19 million people aged under 18 work in an occupation linked to tourism. ${ }^{26}$ They represent some $10-15$ per cent of the tourism

\footnotetext{
23 See the Convention on the Rights of the Child, 1989 (CRC), the Convention on the Elimination of All Forms of Discrimination against Women, 1979 (CEDAW) and ILO Convention No. 182.

24 ILO: HIV/AIDS and work: Global estimates, impact on children and youth, and response 2006 (Geneva), p. 37.

25 Research shows that even minute amounts have a deleterious effect on the neurological system of a foetus. See GENDER/IPEC: Girls in mining: Research findings from Ghana, Niger, Peru and the United Republic of Tanzania (Geneva, ILO, 2007).

${ }^{26}$ M. Black: In the twilight zone: Child workers in the hotel, tourism and catering industry, ILO Child Labour Collection (Geneva, ILO, 1995). The figures are based on World Tourism Organization estimates. In Turkey, the number of workers in the 12-19 year-old age group has been estimated at 90,000 , that is 16.4 per cent of employees in this sector. In the Philippines, a projection based on a national survey of working children and young people between 5 and 17 years of age estimated that approximately 66,000 young people were working in the tourism industry. C. Plüss: Quick money -
} 
workforce. Both girls and boys work behind the scenes in cheaper tourist accommodation, providing food and beverages (especially in informal street settings), supporting recreational activities (caddying, carrying purchases), or producing and selling trinkets and souvenirs. Many work long hours in poor or dangerous working conditions. It is estimated that 2 million children in the world are victims of commercial sexual exploitation, much of it linked to entertainment and tourism. Much has been done to highlight the shameful practices of sex tourism, particularly in regard to violation of the rights of girls. In India, for instance, the Schedule of the Child Labour (Prohibition and Regulation) Act, 1986, prohibits the employment of children in roadside restaurants, hotels and tea-shops.

\section{Hazardous work}

151. Hazardous work is prevalent in all the worst forms of child labour, and involved over 125 million children in 2004 (down from 170 million in 2000). The gender gap widens with age (figure 4.4). In the 5-11 age group, there is little difference between the proportion of boys and of girls in hazardous work. By the ages of 12-14 years, there are three boys in hazardous work for every two girls. In the 15-17 age group, the proportion of boys to girls has increased again.

Figure 4.4. Children in hazardous work by sex and age group

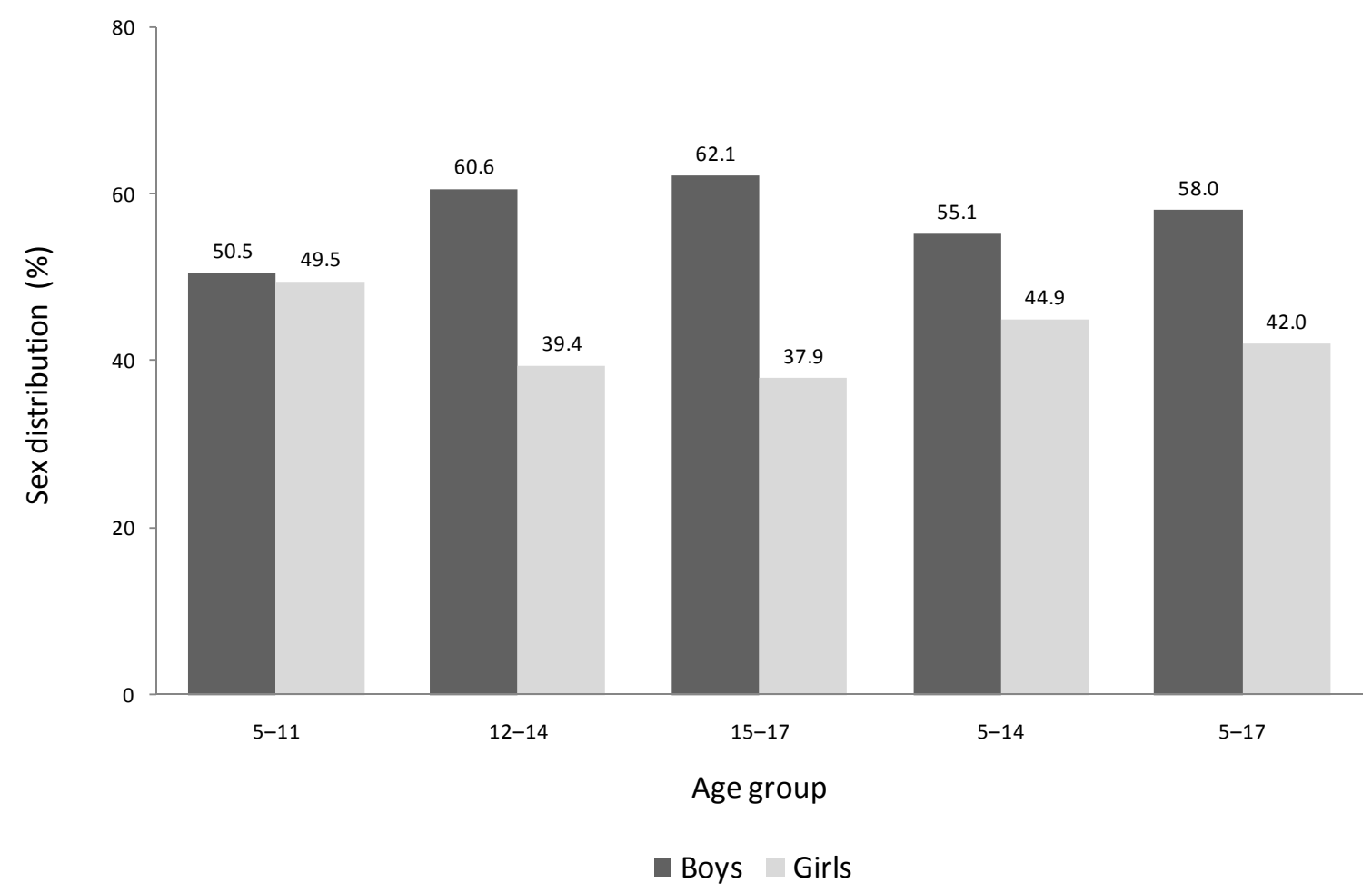

Source: F. Hagemann et al.: Global child labour trends 2000 to 2004 (Geneva, ILO, 2006), chart 7.

Easy money? A report on child labour in tourism, Swiss Agency for Development and Cooperation (SDC) Working Paper 1/99 (Berne, 1999). 


\subsection{ILO action}

\subsubsection{Adult employment instead of child labour}

152. Providing decent work for adults is crucial to eliminating the numerous forms of child labour. Child labour represents a double problem of labour market efficiency: first, it deprives adult women and men of jobs they would perform more satisfactorily than children; and second, it prevents the development of sound employment policies and programmes, since children are often hired instead of young people or adults simply because they work for lower wages. In agriculture, for example, children may accompany their parents and help them meet daily quotas for no additional remuneration. Unfortunately, the short-term gains are offset by the long-term losses to future adult women and men in terms of their lack of education and personal development. Child labour is very much linked to the persistence and growth of the informal economy.

153. There is evidence that the economic empowerment of women brings considerable benefits for their children and families. Increased bargaining power and decision-making ability in the household, as well as the higher status and income of women, have led to positive results, such as enhanced nutritional status of families, lower infant mortality rates, decreased child labour and better access to education for children. Studies of household consumption and expenditures reveal significant differences according to whether family income is controlled by a male or a female member. ${ }^{27}$ Where a man controls income, underinvestment in children, and in girls in particular, is more likely. Conversely, where women have had greater access to education and income, it is primarily the children who benefit.

154. Strategies to combat child labour need to take into consideration the decent work prospects of parents and access to quality education for the children. "Work-to-school" policies and programmes are being met with success. For example, the European Union has funded an ILO project (TACKLE) in 11 countries in Africa, the Caribbean and the Pacific to eliminate child labour through access to education. ${ }^{28}$ The project works with both ministries of labour and education and employers' and workers' organizations to follow policy dialogue with action; special attention has been paid to sensitizing all parties to the earning potential of educated young women.

155. Many economic sectors where child labour is found are part of global supply chains - in informal and formal settings - that connect firms and production sites to global markets. The removal of child labour from global supply chains is being addressed through social dialogue. ${ }^{29}$ Examples include the sporting goods industry in Pakistan, the garment industry in Bangladesh, and the global cocoa industry in Western Africa. IPEC has implemented the child labour monitoring (CLM) concept, with the overall objective of ensuring that children are safe from exploitation and hazardous work. Special consideration is being given to the gender dimensions of monitoring. ${ }^{30}$

\footnotetext{
27 See ILO: Small change, big changes: Women and microfinance, GENDER/Social Finance Programme (SFP) (Geneva, 2007), p. 2.

28 IPEC: Tackle child labour through education: Moving children from work to school in 11 countries (Geneva, ILO, undated).

${ }^{29}$ The ILO's technical cooperation programme "Better Work" offers modular training packages for suppliers which instil an understanding of the rights and efficiency arguments against child labour and for gender equality. See www.betterwork.org.

30 ITC-ILO and IPEC: How to address child labour in the supply chain in a responsible way? Experiences and practices of child labour monitoring, Workshop, Turin, 4-8 September 2006.
} 


\subsubsection{Social protection}

156. The safety and health of child labourers is a matter of the utmost concern, and is the key driver to getting them out of child labour. Numerous OSH hazards are associated with various types of child labour. The damage done to young children is often irreparable and can have lifelong health consequences. ILO programmes to upgrade labour inspection services target issues such as recording of accidents and diseases among child labourers. Given the geographically dispersed nature of agriculture and the limited resources of labour inspection services, in many countries labour inspectors can only enforce child labour legislation in large agricultural enterprises and commercial plantations. However, the role of labour inspectors in combating child labour in all economic sectors has increased in recent years, in cooperation with agencies responsible for children's welfare. As a result of specific training provided by IPEC, labour inspectors' capacity to identify under-age workers and the hazards that put them at special risk has been substantially improved over the past decade.

157. If parents have adequate social protection, then it is more likely that their children will not work. Evidence from studies shows that social pensions have a remarkable impact not only on older persons but also on the living standards of their families and children. ${ }^{31}$ ILO studies have found that the projected costs for a basic universal child benefit for the year 2010 would vary in selected developing countries in Africa and Asia between 1.2 per cent of GDP in India and 3.6 per cent of GDP in the United Republic of Tanzania. ${ }^{32}$ Yet most of the world's population -80 per cent - still has no access to comprehensive social security protection.

158. The Social Security (Minimum Standards) Convention, 1952 (No. 102), requires ratifying States to provide a family benefit in cash or in kind or a combination of both for children up to the age of completion of compulsory schooling or age 15. Conditional cash transfer (CCT) programmes typically give a certain amount of cash to poor households on a regular basis, on condition that the beneficiaries fulfil some obligation(s) aimed at human development, such as sending their children to school or participating in health and nutrition programmes. Pioneered by Brazil and Mexico in the mid-1990s, CCT programmes have been most prevalent in Latin America, where virtually every country now boasts some such scheme. Many of these programmes have had a marked impact on poverty reduction as well as on school attendance. Although evidence of their effects on the reduction of the worst forms of child labour is not conclusive, evaluation suggests a positive impact in some countries, particularly when cash benefits are combined with after-school activities. ${ }^{33}$ However, a recent impact evaluation of Paraguay's CCT pilot programme, Tekoporã, has reached the counter-intuitive conclusion that child labour may increase when mothers go to work. The assumption had been that children were not pressured to work if mothers were earning income. This study revealed that mothers' examples of earning encouraged children to work as a way of improving their own well-being. ${ }^{34}$

\footnotetext{
${ }^{31}$ A. Barrientos and P. Lloyd-Sherlock: Non-contributory pensions and social protection, Issues in Social Protection Discussion Paper No. 12 (Geneva, ILO, 2003).

${ }^{32}$ ILO: Can low-income countries afford basic social security? Social Security Policy Briefings (Geneva, 2008).

${ }^{33}$ H. Tabatabai: Eliminating child labour: The promise of conditional cash transfers (Geneva, ILO, 2006)

${ }^{34}$ G. Issamu Hirata: Cash transfers and child labour: An intriguing relationship (Brasilia, International Poverty Centre (IPC)-UNDP, 2008).
} 
159. Other impact evaluations have indicated that CCTs are effective in substantially increasing households' use of schools and health services, and evidence shows how gender gaps can be closed by giving families financial incentives to invest in their girls. For example, Mexico's Oportunidades programme pays higher cash transfers to mothers for daughters' school enrolment. In Bangladesh, the Female Secondary School Stipend Programme gives money directly to girls on condition that they enrol in secondary school and remain unmarried until the age of 18. In Cambodia and Pakistan, scholarship programmes give families cash transfers, provided their daughters enrol in secondary school. ${ }^{35}$ Brazil's PETI remains the sole example of a major CCT programme whose foremost objective is to reduce child labour. It directly requires a child to stop working in order for the household to receive benefits, ${ }^{36}$ and is now being gradually incorporated into the national CCT programme, Bolsa Familia.

160. CCTs are proving to be effective in addressing gender concerns. However, they may have adverse effects on the woman of the household. For example, Oportunidades pays a higher stipend for girls attending school in order to redress gender imbalances, which is commendable. However, the programme pays its transfers to mothers rather than fathers, thus reinforcing the traditional role of the mother's responsibility for children and the domestic sphere. Granted, paying transfers to women may be valuable for their self-esteem as responsible mothers and it increases the chances of the money reaching their children. But these payments do not empower them personally, nor do they attempt to change the behaviour of men by encouraging them to assume a stronger domestic role. Other conditions for receiving CCTs, such as requiring women to do unpaid community work, again strengthen stereotypes and add to women's unpaid burdens. ${ }^{37}$

\subsubsection{Social dialogue in defence of children}

161. As the voice of children is rarely heard, it is up to those who can speak for them to defend their right to a decent childhood. The Freedom of Association and Protection of the Right to Organise Convention, 1948 (No. 87), and the Right to Organise and Collective Bargaining Convention, 1949 (No. 98), are key instruments that underpin efforts to fight child labour. By strengthening the representation of women and men workers, the health, well-being and development of children can be preserved. It is also important that young workers under 18 but over the national minimum working age (often 15 or 16 years) should be able to unionize.

162. Where women have less power to speak out, control household resources, or seek decent employment, the impact on children is significant. ${ }^{38}$ Because of the lower social status of girls and women in most societies and the direct and indirect discrimination that they experience, specific measures to facilitate access to education for girls in national plans, policies and programmes need to be promoted. For that to happen, governments and social partners can put tripartism to work in national social dialogue, negotiations,

\footnotetext{
35 N. Sinha: "World Bank to review the potential of conditional cash transfers to bridge gender gaps", in Gender Equality as Smart Economics, Gender Action Plan Newsletter, Mar. 2008 (World Bank).

36 Programme for the Eradication of Child Labour (PETI), discussed in G. Issamu Hirata: Cash transfers and child labour, op. cit.

${ }^{37}$ M. Molyneux: Change and continuity in social protection in Latin America: Mothers at the service of the State? UNRISD Gender and Development Programme Paper No. 1 (Geneva, UNRISD, 2007).

38 Save the Children UK: The Child Development Index: Holding governments to account for children's well-being (London, 2008), p. 16.
} 
consultations and information sharing. For example, Office research shows that social and economic councils can lead the debate on stopping child labour. ${ }^{39}$ The tripartite partners can use their leverage to ensure that national action to combat child labour and its worst forms highlights the gender dimensions.

163. Employers have been playing a fundamental role at different levels in fighting child labour. Local enterprises and industries can refuse to hire children or, if child labour already exists, they can remove the children from work. At the political level, employers and their organizations can lobby for effective training and education systems for both girls and boys. The ILO has been running a gender-sensitive technical cooperation programme, funded by the Norwegian Government, aimed at building the capacity of employers and their organizations in combating child labour. ACT/EMP and the IOE have worked closely together to develop a set of practical guides that consider child labour from the perspective of employers and their organizations, while keeping the welfare of children and their families at the centre of the analysis. ${ }^{40}$

164. Workers' organizations are also leaders in combating child labour at the local, national and international levels. With appropriate interventions, unions can become credible advocates for the protection of girls and boys against exploitation and abuse. They promote the right of workers to adequate remuneration, thereby reducing the dependence of poor families on their children's labour. The Bureau for Workers' Activities (ACTRAV) has been conducting technical cooperation programmes to intensify the contribution of workers' organizations to the fight against child labour across the world, and has been making considerable efforts to incorporate gender dimensions as well. ${ }^{41}$

165. The international trade union confederations have an important role to play, since action at international level can complement action at regional, national or enterprise level. Some global union federations have been active in combating child labour. The International Union of Food, Agricultural, Hotel, Restaurant, Catering, Tobacco and Allied Workers' Associations (IUF) has provided expertise and information and enlarged the discussion on gender equality to be integrated into protection of the environment, use of chemicals, health and safety, HIV/AIDS, employment policies and child labour. Technical cooperation activities sponsored by ACTRAV in the field of child labour highlight the roles of girls and boys and ways of developing national and international trade union strategies to combat it. One successful advocacy tool, Bitter harvest, ${ }^{42}$ is used widely by the IUF and other organizations.

166. Education International (EI) provides a network of key actors who can be mobilized against child labour, as it represents 30 million teachers worldwide in more than 170 countries. It is working to raise awareness of the need to link efforts to tackle child labour within the Education for All framework. EI has consistently tackled the

\footnotetext{
39 A. Sivananthiran and C.S. Venkata Ratnam (eds): Best practices in social dialogue (New Delhi, ILO, 2003), p. 12.

40 ILO: Eliminating child labour: Guides for employers, at www.ilo.org/public/english/dialogue/actemp/whatwedo/projects/cl/guides.htm.

${ }^{41}$ www.ilo.org/public/english/dialogue/actrav/genact/child/index.htm\#. See also ILO: ILO-IPEC Interregional Workshop on Child Domestic Labour and Trade Unions: Report, Geneva, 1-3 February 2006.

42 ILO: Bitter harvest: Child labour in agriculture (Geneva, 2002).
} 
gender dimension of child labour. ${ }^{43}$ As teaching is a predominantly female occupation worldwide, EI is well placed to encourage girls to value education as a vehicle for advancement out of poverty.

\subsubsection{Principles and rights}

167. The ILO has a strong normative base for its work on the elimination of child labour. The Minimum Age Convention, 1973 (No. 138), stipulates that no child below the minimum working age, which should correspond to the age of completion of compulsory education (usually 15 years), may be employed or work in any occupation. The Worst Forms of Child Labour Convention, 1999 (No. 182), urges immediate action against the worst forms of child labour, such as the use of any girl or boy aged under 18 in forced labour, armed conflict, prostitution, pornography or hazardous work, the latter to be determined at the national level. ${ }^{44}$ Some provisions of Convention No. 138 are applicable with a gender perspective in mind. The provision stating that the minimum working age should not be less than the age of completion of compulsory schooling is relevant for girls: it can be used to counter practices in certain countries where girls may be taken out of school before completing their compulsory education. The ILO supervisory machinery has been focusing on the situation of girls, highlighting the need to take their special needs into account as a way of preventing child labour.

168. Convention No. 182 specifically provides that member States shall "take account of the special situation of girls". Monitoring of the application of other Conventions has since been influenced by this drafting.

169. Despite the wide ratification of Conventions Nos 138 and 182 and the fact that, as a result, many countries have legislated to define the minimum age for admission to employment and to eliminate the worst forms of child labour, there are still important gaps in their implementation. For example, regulations often do not extend to work carried out on private premises and in households. Convention No. 182 does not explicitly define domestic work as a worst form of child labour, but its provisions could apply if that occupation is listed as hazardous work from which children should be protected, a possibility that exists under both Conventions. Furthermore, many child domestic workers may be trafficked or in forced labour situations, in which case this becomes a worst form of child labour.

170. Convention No. 182, together with the Forced Labour Convention, 1930 (No. 29), offer a set of international labour standards to address the trafficking of girls and boys. The worst forms of child labour as characterized in Convention No. 182 include all forms of slavery or practices similar to slavery, such as the sale and trafficking of children, debt bondage and serfdom, and forced or compulsory labour. ${ }^{45}$ This protects against both labour exploitation of children and commercial sexual exploitation, to

${ }^{43}$ ILO-EI: World Day Against Child Labour 2008: Quality education is the right response to child labour: A resource for teachers and educators (Geneva, 2008).

${ }^{44}$ Both Conventions are widely ratified: Convention No. 138 has been ratified by 151 countries and Convention No. 182 has been ratified by 169 countries as of January 2009 .

${ }^{45}$ IPEC has been working at the global level on raising awareness of the labour exploitation aspect of child trafficking. Together with a broad network of local partner organizations, IPEC has operated a number of regional and national programmes over the past 12 years in West, Central, East and southern Africa, Europe, particularly the Balkan countries and Ukraine, Central and South America, South Asia, the Mekong subregion and China. ILO: Child trafficking. The ILO's response through IPEC (Geneva, 2007). 
which girls are more vulnerable. ${ }^{46}$ In addition, the ILO works through its constituents to abolish the recruitment of children for use in armed conflict as part of its programme to eliminate the worst forms of child labour. ${ }^{47}$

171. The elimination of child labour captured the hearts and minds of ILO constituents and the donor community from the early 1990s. ${ }^{48}$ IPEC is the flagship programme seeking to end child labour and support efforts to fulfil international obligations under ILO Conventions and other relevant instruments. ${ }^{49}$ IPEC has made great strides towards more systematic implementation of a gender-sensitive approach to all aspects of its interventions. One of its aims is to fully and concretely take into account the policy and programming links between "the elimination of child labour", "education for all" and "gender equality". Despite a strong general commitment to equality of opportunities for boys and girls, research has found that a comprehensive gender perspective when fighting child labour is still lacking in many areas and a thorough gender analysis needs to be built into all initiatives combating child labour.

172. The regional spread of IPEC interventions is impressive. Between 2000 and 2008, the Yemen project contributed to the establishment of three rehabilitation centres for working children, reaching nearly 2,000 girls and boys. The project coordinated the development of a rapid assessment on girl child labour which led to a specific action plan. ${ }^{50}$ The Subregional Project on Prevention and Elimination of the Worst Forms of Child Domestic Labour in Central America and the Dominican Republic, during its three years of implementation, worked to promote greater reflection on gender-related aspects of the problem. ${ }^{51}$ The project "Preventing and eliminating exploitative child domestic work through education and training in South-East and East Asia", developed within the framework of the ILO's Gender Equality Mainstreaming Strategy for Asia and the Pacific (GEMS), aims to eliminate child labour through gender-sensitive action. The project "Prevention and elimination of bonded labour in South Asia" uses women's

\footnotetext{
46 The ILO's work on child labour is influenced by the Protocol to Prevent, Suppress and Punish Trafficking in Persons, especially Women and Children, Supplementing the United Nations Convention against Transnational Organized Crime (2000), commonly known as the "Palermo Protocol". This Protocol stipulates that in the case of children (under 18 years of age), "the recruitment, transportation, transfer, harbouring or receipt of a child for the purpose of exploitation shall be considered "trafficking in persons"".

47 The Principles and Guidelines on Children Associated with Armed Forces or Armed Groups (Paris Principles), adopted by governments, UN agencies, including the ILO, and NGOs in 2007, cover children below 18 years of age who are recruited by armed forces and groups in any capacity, including but not limited to boys and girls used as fighters, cooks, porters, messengers, spies or for sexual purposes. See ILO: Prevention of child recruitment and reintegration of children associated with armed forces and groups: Strategic framework for addressing the economic gap (Geneva, 2007).

48 The 1985 report made few references to child labour, as the Office was not systematically working on the issue at the time. ILO: Equal opportunities and equal treatment for men and women in employment, Report VII, ILC, 71st Session, Geneva, 1985.

49 In over 80 countries IPEC projects help governments and social partners to put in place policies to eliminate child labour and assist children. Education is central to the work of IPEC, as it is instrumental in developing measures to prevent child labour, removing children from hazardous work, providing for their rehabilitation and offering alternatives for them, their families and communities as a whole. See, for example, ILO: Child domestic labour information resources: A guide to IPEC child domestic labour publications and other materials (Geneva, 2007).

50 ILO: Country Brief 3: Promoting decent work and gender equality in Yemen (Beirut, 2008).

51 ILO-IPEC: Good practices and lessons learned on child and adolescent domestic labour in Central America and the Dominican Republic: A gender perspective (San José, 2005).
} 
entrepreneurial activities as a means of combating bonded labour in Pakistan. The project "Promoting the linkages between women's employment and the reduction of child labour" piloted the innovative approach of promoting women's entrepreneurship as part of overall strategies to eliminate child labour in the United Republic of Tanzania. In the same country, the project "Promoting gender equality and decent work throughout all stages of life" led to a reduction in child labour and increases in school attendance through microfinance loans.

173. Under the gender equality theme of the ILO-Netherlands Partnership Programme (2004-06), several gender-specific projects were funded and allocations for gender mainstreaming and child labour were provided. Similarly, the ILO-Norway Partnership Agreement included a technical cooperation component enabling gender-specific action by IPEC, workers and employers in collaboration with the Bureau for Gender Equality. Funds were provided by the United Kingdom Department for International Development (DfID) to supplement available ILO regular budget and extra-budgetary resources in Africa and directed at results-based and quality-controlled Decent Work Country Programme objectives to reduce child labour. ${ }^{52}$

174. In 2007, the ITC-ILO organized several sessions on gender and child labour linked to major training activities:

(1) specific gender training for staff and partners of the project "Combating the trafficking of children for labour exploitation in West and Central Africa" (LUTRENA);

(2) specific gender and child labour training for officials of the Turkish Labour Ministry;

(3) sessions on gender issues related to child labour in agriculture; and

(4) sessions relating to good practices in combining gender, education and child labour in programming. ${ }^{53}$

\subsection{Links to the United Nations and international agencies}

175. The UN Convention on the Rights of the Child (CRC) incorporates the full range of children's human rights, including civil, political, economic, social and cultural rights. ${ }^{54}$ Together with ILO Conventions Nos 138 and 182, the three form a legally binding floor of rights and responsibilities. The ILO, through its regular participation in CSW, has not only influenced policy but also provided concrete assistance and technical support for African ministers to coordinate the African Common Position paper. The agreed conclusions of CSW (2007) referred to the work of the ILO, including implementation of Conventions Nos 138 and 182 and developing educational and livelihood skills programmes to reach girls. CSW benefited from ILO expertise when it

\footnotetext{
${ }^{52}$ Under the Second DfID-ILO Partnership Framework Agreement 2008-09.

${ }^{53}$ IPEC: IPEC action against child labour 2006-2007: Progress and future priorities (Geneva, ILO, 2008), p. 50.

${ }^{54}$ While this instrument does use masculine/feminine pronouns and adjectives, it does not make any gender distinctions in its text. The Committee that oversees compliance with this treaty has, however, examined States parties' reports from a gender equality angle. See, for example, CRC: General Comment No. 1 on the Aims of Education, 2001, CRC/GC/2001/1, para. 10.
} 
adopted the 2006 resolution on women, the girl child and HIV/AIDS, which had implications for child labour as well. ${ }^{55}$

176. ILO partnerships within the broader framework of the UN system and other intergovernmental organizations are actively pursued. A number of existing international platforms lend themselves to promoting gender equality and eliminating child labour. The MDGs, the PRSPs and Education for All are prime examples. Global action was initiated at the first World Congress against Commercial Sexual Exploitation of Children, held in Sweden in 1996. Subsequently, efforts to engage the tourism industry have led to the formation of the Task Force for the Protection of Children in Tourism. ${ }^{56}$ The 2007 Principles and Guidelines on Children Associated with Armed Forces or Armed Groups (the Paris Principles), endorsed by a wide range of actors, including governments, the ILO and UN agencies and NGOs, pay special attention to the situation of the girl child. Strong emphasis is put on the need to ensure that programmes include gender-sensitive measures.

177. The International Partnership for Cooperation on Child Labour in Agriculture (IPCLA) ${ }^{57}$ was established in 2007. Key objectives include the effective application of the minimum legal working age to jobs in agriculture, the prohibition of hazardous work in agriculture for girls and boys aged under 18, and the exclusion of children from such work. Another aim is to protect children who have reached the minimum legal age to work, by improving health and safety standards in the agricultural sector. The ILO has recently engaged in substantial work on girls in agriculture, notably with FAO.

178. The ILO is a core member of the Global Task Force on Child Labour and Education for All, ${ }^{58}$ which has gender equality high on its agenda. The ILO provides the Task Force's secretariat. It is also a key partner of the United Nations Girls' Education Initiative (UNGEI). Its goal is to narrow the gender gap in primary and secondary education and to ensure that by 2015 , all children complete primary schooling.

179. Non-formal education may also be an important contribution to preparing children to catch up on schooling or to absorb important life skills. These may take the form of "equivalency" programmes and transitional assistance, such as those promoted and documented by UNGEI. In other cases, programmes have been developed to improve children's life skills for livelihood support and food security.

180. IPEC has also taken a new approach to combating and preventing commercial sexual exploitation by addressing men and masculinities. Recognizing the need to deal with the problem of the demand side for sexual exploitation of girls and boys, IPEC programmes in Central America in 2007 incorporated training, awareness raising and

\footnotetext{
${ }^{55}$ United Nations: Resolution on women, the girl child and HIV/AIDS. Resolution 50/2, Final Report on the 50th Session of the Commission on the Status of Women, Doc. E/2006/27/Corr.1-E/CN.6/ 2006/15/Corr.1, Economic and Social Council, Official Records, Supplement No. 7.

56 World Tourism Organization (UNWTO) Protect Children web site. During the first phase (19972007), the focus of the task force was the prevention of sexual exploitation of children in tourism. In 2007, the mandate was extended to cover all forms of exploitation of children and young people in tourism. See www.unwto.org/protect_children.

57 The members of this partnership are the ILO, FAO, IFAD, the International Food Policy Research Institute (IFPRI) of the Consultative Group on International Agricultural Research (CGIAR), the International Federation of Agricultural Producers (IFAP) and the IUF.

58 The other members are UNESCO, UNICEF, UNDP, World Bank, EI and the Global March against Child Labour, together with a number of donor countries.
} 
capacity building targeted at potential "clients". This has generated interest among other UN agencies, such as UNICEF and the UNFPA, and is welcomed as a good practice. ${ }^{59}$

\subsection{The way forward}

181. Having to work is one of the biggest obstacles to a decent childhood. Parents living in poverty must often choose between educating their children or sending them to work in order to help feed the whole family. Where poverty and discrimination prevail, so can child labour. Child labour concerns the human rights of the child, and is detrimental to a child's health, education, welfare and development. The following indicative list highlights areas where ILO policies, programmes and activities can have an impact:

a Developing employment-creation and income-generation strategies for parents, as this is a crucial element for the elimination of child labour. Increasing a mother's income has been shown to have greater impact on getting children into school than increasing a father's income.

a Recognizing the barriers to girls' education through properly considered and adequately resourced education policies and plans, and possible incentives to enrol girls in school.

- Evaluating and correcting gender stereotyping in the education of boys and encouraging the development of new images of male roles so as to promote future equal sharing of work and family responsibilities.

- Improving the availability of affordable, quality childcare for young children, to ease pressure on parents to take their children to work or leave them with older girl siblings. Childcare will also reduce the demand for child domestic workers.

- Providing adolescent girls with quality formal and non-formal educational programmes, including vocational training, which would lead to their empowerment and to more opportunities for decent work in their adulthood.

- Addressing gender stereotyping in education by reforming curricula and ensuring adequate numbers of male and female teachers at all levels of education and academic management.

- Ensuring that attention is paid to gender issues in the design of projects aimed at eliminating child labour.

a Sharing internationally the good practices on strategies to enrol and retain girls in school.

${ }^{59}$ IPEC: IPEC action against child labour, 2006-2007: Progress and future priorities (Geneva, ILO, 2008), p. 51. 



\section{Chapter 5}

\section{Gender, youth and employment}

182. In the two decades since the 1985 report, worldwide attention has been drawn to young people's potential contribution to sustainable development. Youth is that time between childhood and adulthood when men and women are most eager to strike out to secure their futures and to contribute to their families, communities and societies. This stage of life is crucial in determining young people's paths to achieving productive employment and decent work. ${ }^{1}$ Over the next decade, 500 million young people are expected to reach working age. ${ }^{2}$ Providing them with the opportunity to secure full, freely chosen and productive employment is a national and global challenge. It is no wonder that youth employment is listed high on the international community's agenda. ${ }^{3}$

183. While young people do not constitute a homogeneous group, this is the best educated and best trained generation of young men, and especially young women, ever. They possess skills that can make communities flourish and nations strong through personal endeavour and active citizenship. However, although more children have access to education, this does not always translate into productive youth employment and decent work. While rapid globalization and technological change may offer new opportunities for productive work and incomes for some, for many young people entering the labour market the lack of decent job prospects increases their vulnerability. The investment of governments in education and training will be lost if young women and men do not move into decent jobs. On average, young men and women are two to three times more likely to be unemployed than adults, ${ }^{4}$ and the gap is particularly pronounced for young women. All too often, they work unacceptably long hours in informal, intermittent and insecure work arrangements, characterized by low productivity, meagre earnings and reduced labour protection. High and sustained economic growth is a necessary condition for the creation of employment, including quality employment for young people. This requires macroeconomic policy supportive of increased and sustainable employment growth through expanded investment, productive capacity and aggregate demand in conditions of economic and political

\footnotetext{
1 The ILO uses an international working definition of youth as persons aged between 15 and 24, and adults as those aged 25 and above. Often the lower age limit for young people is determined by the minimum age for leaving school, where this is legislated. Countries vary in their operational definitions of youth.

2 ILO: Facts on youth employment (Geneva, 2006).

3 "Achieving full and productive employment and decent work for all, including women and young people" is one of the targets of Millennium Development Goal (MDG) 1, Eradicate extreme poverty and hunger. MDG 8, Develop a global partnership for development, also targets decent and productive work for youth in cooperation with developing countries.

4 ILO: Youth Employment web site, at http://ilo.org/public/english/employment/yett/index.htm.
} 
stability. ${ }^{5}$ Yet given the current economic downturn, the youth labour market situation is all the more worrisome in view of the lack of progress in addressing youth labour market issues during more prosperous years. ${ }^{6}$ Will the downturn lead to even less investment by governments and training for youth?

184. Youth employment is closely linked to the overall employment situation. It has its own characteristics, however, which require specific responses. In developed economies, youth unemployment may be related to the school-to-work transition, age discrimination, disadvantages due to lack of job experience, cyclical labour market trends, and a number of structural factors. In developing economies, it is a characteristic of insufficient growth and may disproportionately affect those who already do not share in the benefits of globalization. In many poor communities, underemployment and working poverty are acute problems for many young women and men as they struggle to earn an income. A large number of poorly educated young people in rural areas cannot thrive because of a lack of policy and infrastructure support.

185. Apprenticeship training is an important mechanism of skills transmission for young people, particularly in developing countries. Within the informal economy, it is one of the largest sources of skills formation, especially in parts of East and West Africa, where it is closely linked to socio-cultural traditions. It is often a practical and less expensive alternative to centre-based training and helps young people build up their social and economic networks. However, an important weakness of apprenticeship training is that it tends to benefit young men more than young women because of the traditionally maleoriented sectors in which it is embedded, such as carpentry and mechanics. Apprenticeships do exist for female-dominated sectors such as hairdressing and embroidery, but tend to be on a lesser scale. An important component of current ILO research on upgrading informal apprenticeship systems is to look at how apprenticeships can be used within local cultures to end occupational segregation.

186. Youth employment opportunities may vary according to sex, age, ethnicity, educational level and training, family background, health status and disability, and urban/rural locations, among others. ${ }^{8}$ Some groups are more vulnerable and face particular disadvantages in entering and remaining in the labour market: for example, for young women from ethnic minorities or with a disability, discrimination and disadvantage are compounded.

187. The danger of not addressing these issues is a build-up of grievances. Vulnerable youth may become "discouraged youth" - the term used to describe those who have given up seeking work, perceiving the job search as futile. They lose faith in the system of governance, which they feel has failed to live up to their expectations, and in severe cases this can lead to political instability.

188. Eighty-five per cent of young people live in developing countries, where many are especially vulnerable to extreme poverty. The ILO estimates that around 71 million young women and men are unemployed throughout the world, accounting for 40 per cent

5 ILO: Conclusions on promoting pathways to decent work for youth, Report of the Committee on Youth Employment, Provisional Record No. 20, ILC, 93rd Session, Geneva, 2005, para. 20.

${ }^{6}$ ILO: Global Employment Trends: January 2009 (Geneva, 2009), p. 12.

${ }^{7}$ See ILO: Promotion of rural employment for poverty reduction, Report IV, ILC, 97th Session, Geneva, 2008.

8 See ILO: Youth: Pathways to decent work. Promoting youth employment - Tackling the challenge, Report VI, ILC, 93rd Session, Geneva, 2005, section 1.6. 
of the world's unemployed persons. ${ }^{9}$ Many young people are struggling in the informal economy. Child labourers grow into unemployed, unskilled young people. Younger children are hired to replace them for lower pay, and the chances of securing an education for either group are significantly reduced.

189. These last decades have seen broad demographic changes that affect young people and their chances to obtain decent work. Growth in the working-age population will slow in almost all corners of the world, owing to declines in fertility. The retirement burden on the workforce will become increasingly heavy in countries where the labour force is shrinking. Yet, in regions with an ageing population and a rising dependency rate, such as Eastern Europe and Central Asia, youth unemployment has remained at very high levels over the past decade. ILO figures for 2007 record a youth labour force participation rate of 39 per cent for these regions, compared with 51 per cent for the EU and most developed countries. ${ }^{10}$ In Europe and Central Asia, young people are more than twice as likely as adults to be unemployed, or employed in precarious, lowproductivity and low-wage jobs. ${ }^{11}$

\subsection{Gender issues}

190. Globally, while a young person's likelihood of being unemployed continues to be three times higher than an adult's, the unemployment rate of young women (aged 15-24 years), at 12.5 per cent, is only slightly higher than that of young men (12.2 per cent). ${ }^{12}$ The global youth labour force participation rate fell from 55.2 to 50.5 per cent between 1997 and 2007 (table 5.1). This decline is not necessarily a bad thing, and may be driven by young people staying longer in education. Many now remain in education throughout the entire 15-24 age span.

Table 5.1. Global labour market indicators for youth, 1997 and 2007

\begin{tabular}{|c|c|c|c|c|c|c|}
\hline & \multicolumn{2}{|l|}{ Total } & \multicolumn{2}{|l|}{ Male } & \multicolumn{2}{|c|}{ Female } \\
\hline & 1997 & 2007 & 1997 & 2007 & 1997 & 2007 \\
\hline Labour force (millions) & 576.9 & 602.2 & 339.0 & 354.7 & 237.8 & 247.5 \\
\hline Employment (millions) & 514.0 & 530.8 & 302.9 & 313.5 & 211.1 & 217.3 \\
\hline Unemployment (millions) & 62.8 & 71.4 & 36.1 & 41.2 & 26.7 & 30.1 \\
\hline Labour force participation rate (\%) & 55.2 & 50.5 & 63.5 & 58.0 & 46.5 & 42.6 \\
\hline Employment-to-population ratio & 49.2 & 44.5 & 56.7 & 51.3 & 41.3 & 37.4 \\
\hline Unemployment rate (\%) & 10.9 & 11.9 & 10.7 & 11.6 & 11.2 & 12.2 \\
\hline
\end{tabular}

\footnotetext{
${ }^{9}$ Changing demographics also play a role. The number of employed youth was 531 million in $2007-$ an increase of 17 million from 1997. However, the youth population grew at a quicker pace than youth employment; the share of youth who are employed in the youth population saw a decrease from 49.2 to 44.5 between 1997 and 2007. ILO: Global Employment Trends for Youth (Geneva, 2008), p. 3.

${ }^{10}$ ibid., table A3, p. 53.

11 ILO: Facts on youth employment, Seventh European Regional Meeting (Budapest, 2005), at www.ilo.org/public/english/bureau/inf/download/factsheets/pdf/budapest/youth.pdf.

${ }^{12}$ ILO: Global Employment Trends for Women (Geneva, 2008), p. 3.
} 
191. In most regions, young women often face barriers to labour market entry. However, the difference between the experience of young men and women in this respect has been decreasing over the years. All regions register shrinking gender gaps in both male-tofemale labour force participation rates and employment-to-population ratios. In fact, employment growth for young women outpaced that of young men in six of the nine regions. ${ }^{13}$ Table D in the appendix covers a range of information on young people, including ages at legal status changes, economic activity rates, and education and training. Gender differences emerge among young people, as they do among children. In most countries with data, the age at the end of compulsory schooling is the same for girls and boys, but the legal minimum age at marriage is lower for girls than for boys.

192. The greatest gender inequalities in education are found in North Africa and Western Asia. Countries in East Asia and the Pacific have come close to gender parity in access to education. Disconcerting trends in Latin America and the Caribbean indicate low participation of boys in secondary education. In 11 countries, for every 100 girls, 90 boys or fewer are enrolled. ${ }^{14}$ Yet despite having increased their levels of education relative to men, young women show low rates of labour market participation. In addition, their share in the group of young people who are neither studying nor working is high.

193. Most young women continue to choose economic activities traditionally perceived as female occupations, which require general and professional skills different from those of men, and which are not highly valued in the labour market. It is not just the level of education achieved, but also the quality and relevance of education and training that are important in subsequently securing jobs. Stereotypes of girls represent them as less interested or capable in certain subjects - such as mathematics and science. This inevitably reduces their access to jobs with better pay or labour markets that may offer better opportunities.

194. This was not the case in the former socialist States of Eastern Europe. Before their transition to a market economy, school enrolment there was very high for both girls and boys, and their equal participation in scientific studies was encouraged. During the transition, both primary and secondary schooling decreased in some countries of the region. By contrast, enrolment in higher education has continuously increased in most transition economies, and more rapidly in recent years. The share of young women in tertiary education has grown in many countries of the region, and now exceeds that of young men.

195. With few exceptions, the activity rates of young men are greater than those of young women in the 15-19 years age group. The same applies in the 20-24 years age range. Many factors contribute to this difference, but greater illiteracy is likely to grievously hamper women in their attempts to enter the labour force. Altogether, the literacy rate of young men exceeds that of young women in 26 of the 39 countries with data. This literacy imbalance rests on the gender differences in primary-school enrolment and in the school attendance of working and non-working children revealed in table $\mathrm{C}$ of the appendix. Again, in the case of technical and vocational training, the enrolment rate of young men is higher in 26 of the 48 countries with data.

${ }^{13}$ The growth of female employment was as much as twice that of males between 1997 and 2007 in the Middle East, North Africa, Latin America and the Caribbean. Despite this encouraging trend in the Middle East, the region still had the lowest labour force participation rate for young women of all regions at 21.5 per cent in 2007 (compared to 50.7 per cent for young males). ILO: Global Employment Trends for Youth, op. cit., pp. 4-5, 20.

${ }^{14}$ UNESCO: Education for All Global Monitoring Report 2008: Education for All by 2015 - Will we make it? (Paris, 2008), p. 83. 
196. Data show that indigenous young people or those belonging to certain castes or ethnic minorities are more disadvantaged in most countries. Australia reported for 2001 that 70 per cent of indigenous young people aged 20-24 years were neither in full-time education nor working. In Hungary, the Roma population has a much lower average educational level than the rest of the population. In India, 37 per cent of girls belonging to the lowest castes or tribes do not attend school, versus 26 per cent of non-indigenous girls of the same age. In Guatemala, only 26 per cent of indigenous non-Spanishspeaking girls complete primary school, compared with 62 per cent of Spanish-speaking girls. ${ }^{15}$

197. Investments made at certain points in young people's lives are underlined as particularly critical. Gender differences emerge sharply at the onset of puberty, leading to concerns about protecting adolescent girls in some societies, sometimes to the point of overly restricting or even secluding them. ${ }^{16}$ This can also lead to teenage marriage for girls, which can affect their further education and employment prospects. And young men face societal pressure in some communities to conform to gender stereotypes as "breadwinners", incurring shame if they cannot live up to such expectations. If they have difficulty finding employment, young women and men may opt to prolong their education, if this option is economically viable. Or they may consider migrating in order to earn a livelihood elsewhere.

\subsubsection{Gender, youth and social stability}

198. In certain circumstances, rapid population growth and expanding youth cohorts may be considered as risk factors for instability, ${ }^{17}$ together with rapid urban population growth, diminishing per capita supplies of cropland and fresh water, and high mortality rates among working-age adults. Since the employment of young men is an important factor contributing to social order and peace, most youth employment programmes in the past decades have focused on job creation for young men. If young men cannot find work and become marginalized, the consequences for them and society are very real: delinquency and social unrest.

199. Many governments "disarm" this potential for social unrest through the active recruitment of young men into their armed forces. Table E of the appendix shows the percentage of the male population engaged in the armed forces for all countries where data are available. ${ }^{18}$ Induction provides societies with a means of equalizing opportunities for young men from all backgrounds. In addition to serving, they may obtain a livelihood, an occupation or a career. Service in the armed forces provides young people with training skills that can subsequently prove useful in employment in civilian life. In certain countries, service is rewarded with education grants as well.

15 D. Freedman: Improving skills and productivity of disadvantaged youth, Employment Sector Working Paper No. 7 (Geneva, ILO, 2008), p. 13.

16 World Bank: “A gender filter on the youth lens”, in World Development Report: Development and the next generation (Washington, DC, 2007).

17 The vast majority of new civil conflicts in recent decades have occurred in countries in which young people account for at least 60 per cent of the entire population. E. Leahy et al.: The shape of things to come: Why age structure matters to a safer, more equitable world (Washington, DC, Population Action International, 2007), p. 24.

18 See table E: Numbers in the armed forces as a proportion of the estimated male population aged 17.5 to 29 years, ILO member States with data and regional summaries, 2005-07. All armies have hierarchies with older professional members, but the relation drawn here is limited to the bulk of youth. 
However, budgets are often skewed towards the military and not towards investment in youth employment, preventing public expenditure on other needed areas, such as civilian job creation.

200. In post-conflict countries with high numbers of ex-combatants, the process of rehabilitation for civilian life is directed at young men. Yet both during and after the conflict, young girls and women who have been victims of conflict and violence need special support to overcome trauma and stigma and to build confidence. For example, the "bush wives" in Sierra Leone were girls and young women abducted and exploited by combatants during the protracted conflict there. However, once it was over they received neither protection nor special attention in rehabilitation, guidance or training, and many had no option but to remain under the control of their exploiters. ${ }^{19}$ Many women break gender stereotypes during conflicts; in fact, women often constitute the labour force while the men are away at war. They deserve support to maintain equal access to the resources that are available after conflict.

\section{Box 5.1 \\ Peace, jobs and gender}

"For us, employment is synonymous with peace", stated Ellen Johnson Sirleaf, President of Liberia, addressing the International Labour Conference in 2006. She recognized the importance of keeping future conflict at bay and restoring social progress through job creation, and pointed out that women's employment had significant implications for her country as well. Referring to the ILO's Decent Work Agenda, President Sirleaf said that "it is rooted in the central role of work in the lives and wellbeing of women and men, their families, their communities and their societies". By placing the emphasis on women, she also alluded to the primordial role that she expects them to play in the development of peace and prosperity. Generating decent work for young women and men is instrumental in preserving peace through social justice, as well as helping restoring it in post-conflict situations.

Source: Address by Her Excellency Ms Ellen Johnson Sirleaf, President of the Republic of Liberia, Provisional Record No. 12, ILC, 95th Session, Geneva, 2006.

\subsubsection{Gender roles and women's labour force participation}

201. Despite some encouraging progress, it must be recognized that young women have even more difficulties finding work than young men. In 2007, global youth labour force participation rates were 58 per cent for men and 42.6 per cent for women (table 5.2). Even where young women's level of education is higher than men's, they still experience sex discrimination when they try to find work. The ILO's School-to-Work Transition Surveys provide evidence of this in a number of countries. Women have even more limited access to information channels and job search mechanisms than young men and, importantly, employers in a range of countries have revealed a striking preference for hiring young men. ${ }^{20}$

\footnotetext{
${ }^{19}$ United Nations: Security Council Resolution 1325: Implementation in West Africa, Meeting Report, Experts' Meeting, United Nations Office for West Africa (UNOWA) (Dakar, 27 April 2007), p. 5 .

${ }^{20}$ Some reports refer to employers' perceptions that as soon as young women marry and have children they will be less productive or will leave their jobs. See C. Hein: Reconciling work and family responsibilities: Practical ideas from global experience (Geneva, ILO, 2005), p. 113. Moreover, the CEACR has noted with concern that some employers use pregnancy tests as part of their hiring practices so as to avoid offering work to young women. See $R C E, 2008$, Observations under Convention No. 111 addressed to the Dominican Republic and Mexico.
} 
Table 5.2. Youth labour force participation rates by region: 1997, 2006 and 2007

\begin{tabular}{|c|c|c|c|c|c|c|c|c|c|}
\hline & \multicolumn{3}{|c|}{ Total (\%) } & \multicolumn{3}{|c|}{ Male (\%) } & \multicolumn{3}{|c|}{ Female (\%) } \\
\hline & 1997 & 2006 & 2007 & 1997 & 2006 & 2007 & 1997 & 2006 & 2007 \\
\hline World & 55.2 & 50.9 & 50.5 & 63.5 & 58.6 & 58.0 & 46.5 & 42.8 & 42.6 \\
\hline $\begin{array}{l}\text { Developed economies } \\
\text { and EU }\end{array}$ & 52.9 & 50.9 & 50.9 & 56.2 & 53.4 & 53.3 & 49.6 & 48.3 & 48.4 \\
\hline $\begin{array}{l}\text { Central and South- } \\
\text { Eastern Europe (non- } \\
\text { EU) and CIS }\end{array}$ & 45.0 & 40.0 & 39.3 & 50.7 & 46.0 & 45.1 & 39.1 & 33.9 & 33.4 \\
\hline South Asia & 49.0 & 46.9 & 46.6 & 66.8 & 64.8 & 64.3 & 29.8 & 27.5 & 27.5 \\
\hline $\begin{array}{l}\text { South-East Asia and } \\
\text { the Pacific }\end{array}$ & 56.6 & 53.4 & 52.7 & 64.2 & 60.8 & 60.0 & 48.9 & 45.8 & 45.1 \\
\hline East Asia & 69.7 & 58.2 & 57.5 & 67.4 & 54.5 & 53.5 & 72.1 & 62.2 & 61.8 \\
\hline $\begin{array}{l}\text { Latin America and the } \\
\text { Caribbean }\end{array}$ & 55.0 & 54.0 & 53.7 & 68.4 & 64.3 & 63.7 & 41.6 & 43.8 & 43.8 \\
\hline Middle East & 35.8 & 36.7 & 36.4 & 52.2 & 51.1 & 50.7 & 18.4 & 21.4 & 21.5 \\
\hline North Africa & 38.2 & 35.6 & 35.3 & 52.8 & 46.9 & 46.1 & 23.2 & 24.1 & 24.3 \\
\hline Sub-Saharan Africa & 58.3 & 56.6 & 56.3 & 65.1 & 62.1 & 61.5 & 51.5. & 51.1 & 51.0 \\
\hline
\end{tabular}

202. There are countries and regions where unemployment is lower for young women than for young men, but this often means that women do not even try to find a job and leave the labour market, completely discouraged. They stay at home, where household chores have long been viewed as a female occupation. ${ }^{21}$ When they do find a job, it is often lower paid and in unprotected low-skilled jobs in the informal economy (see figure 5.1), which implies greater job insecurity, as well as denying them access to formal training, social protection or other resources; this makes them comparatively more vulnerable to poverty and marginalization.

21 See ILO: Regional labour market trends for youth: Africa, Youth Employment Programme (YEP) (Geneva, Sep. 2006). 


\section{Figure 5.1. Example of cause-effect relationship (problem tree) of high numbers of young women in the informal economy}

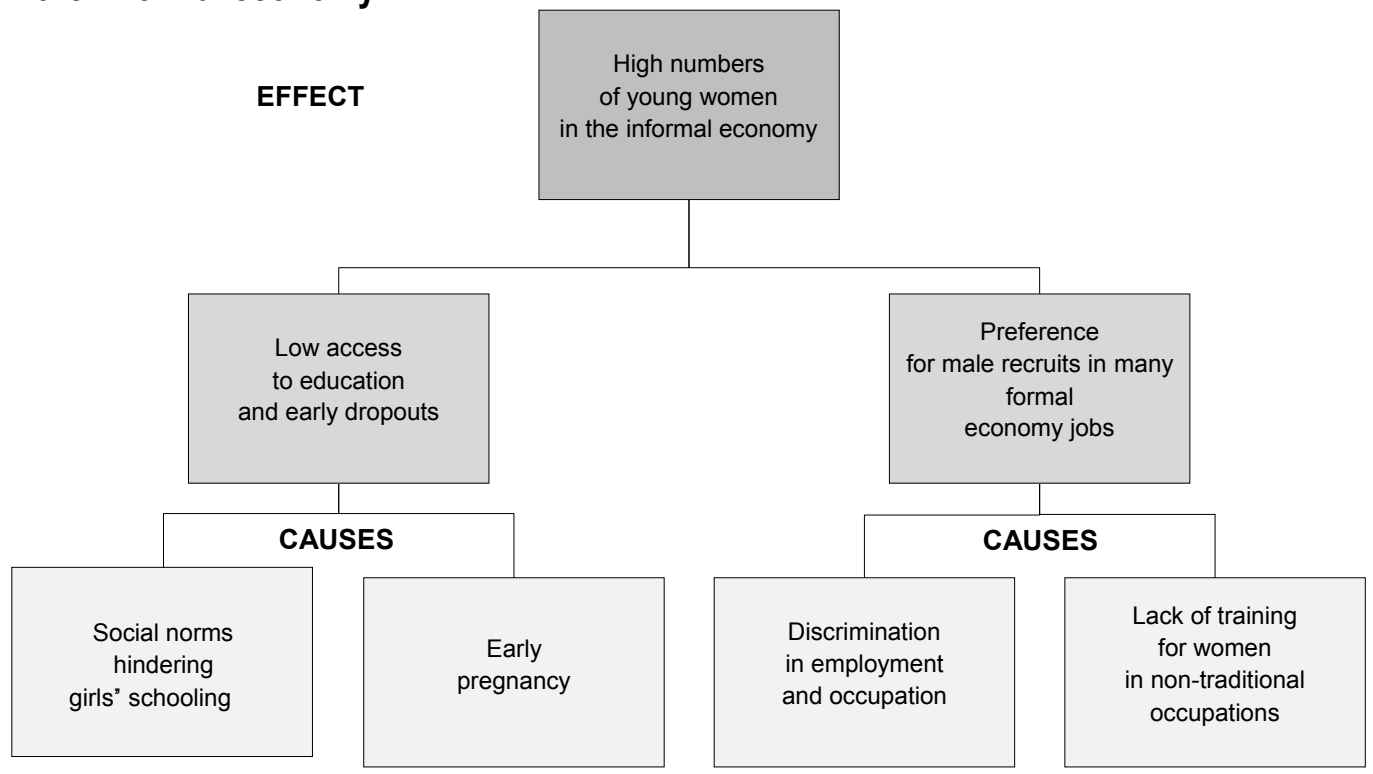

Source: G. Rosas and G. Rossignotti: Guide for the preparation of national action plans on youth employment, YEP (Geneva, ILO, 2008).

\subsubsection{Occupational segregation and stereotyping}

203. One important challenge is tackling the occupational segregation of traditionally accepted "male" and "female" jobs by opening them up to both sexes. Often unaware of their legal rights and lacking role models, women are only slowly entering the professions traditionally dominated by men. Young women, particularly in developing countries, face barriers in taking advantage of training opportunities owing to discrimination and gender stereotyping. In the informal economy, apprenticeship systems for young women and men show similar patterns.

204. Persons providing vocational guidance and counselling frequently display stereotyped attitudes, which discourage young women from undertaking training programmes that would lead them to higher long-term earnings and improved employability. In many countries, young women are encouraged to train in relatively low-skilled and poorly paid "feminine" occupations that are extensions of household work, such as food preparation and garment manufacturing. ${ }^{22}$ Young men are encouraged to seek modern, technology-based training and employment. Segregation also exists at higher levels of education, where young women may be discouraged from choosing certain fields. Women are often steered towards the traditional caring occupations of teaching and nursing. These are important professions for the economy and social welfare of countries, in which women make crucial contributions, especially as labour shortages have already developed and will continue in these key sectors. But men should be equally encouraged to embrace these professions, thereby also breaking gender barriers. However, what is considered a mostly feminine profession in one culture - for example, construction labour in certain parts of India - is seen as masculine in other parts of the world. The information and communication technology (ICT) sector

\footnotetext{
${ }^{22}$ The CEACR regularly comments on legal or cultural restrictions that keep young women out of technical education and vocational training when it examines government reports on the application of Convention No. 111. See, for example, the observations addressed to Algeria, Guyana, Islamic Republic of Iran, Jordan, Kuwait, Libyan Arab Jamahiriya and the Russian Federation in RCE, 2008.
} 
in Asia employs many women, but in Europe it is seen as a predominantly male sector. Efforts should be supplemented by vocational guidance better suited to the capabilities and needs of young men and women, as well as by gender-sensitive counselling and placement services to enable young women to fulfil their potential.

\subsubsection{Export processing zones}

205. Today there is a range of different export processing zones (EPZs), ${ }^{23}$ from initial assembly and simple processing activities to high-tech and science parks, and even tourist resorts. From 2002 to 2006, rough estimates indicate that the numbers employed in EPZs grew from 43 million to 66 million. EPZs employ mostly young people, particularly young women. Such employment offers them the chance of entry-level jobs, sometimes with better wages than in agriculture or domestic service. In Madagascar, for example, more than 50 per cent of EPZ workers were young adults aged between 19 and 24. Of these young persons, 71 per cent were women. Women workers also represented 70 per cent of the EPZ workers in Sri Lanka, with the garment sector alone providing direct employment to close to 300,000 women. In India, women accounted for nearly 72 per cent of EPZ workers in the 20-29 age group, only 13 per cent in the 30-39 age bracket and none in the 40-49 age bracket. ${ }^{24}$ Women made up more than 90 per cent of EPZ workers in Jamaica and Nicaragua. ${ }^{25}$

206. It has been noted that EPZs often recruit young persons as employees precisely because they are young, inexperienced and unaware of their rights. EPZs are subject to lower taxes and lower levels of regulation, both of which translate into lower short-term costs for enterprises facing competition in globalized markets. However, deregulation often leads to substandard labour conditions. Even in countries where labour legislation covers EPZs, enforcement and inspection mechanisms are weak. Young women in particular are willing to work for lower wages in typically labour-intensive manufacturing centres and often in poor work environments. In many EPZs, freedom of association and collective bargaining are non-existent, ${ }^{26}$ with the threat of dismissal strong for those who attempt to organize. As EPZs gradually shift from traditional manufacturing activities to information technology and services that require skilled

${ }^{23}$ The ILO has defined EPZs as "industrial zones with special incentives set up to attract foreign investors, in which imported materials undergo some degree of processing before being re-exported". They may also be referred to as free trade zones, special economic zones, bonded warehouses, free ports, customs zones and maquiladoras. ILO: What are EPZs? Sectoral Activities web site, at www.ilo.org/public/english/dialogue/sector/themes/epz/epzs.htm.

${ }^{24}$ A. Aggarwal: Impact of special economic zones on employment, poverty and human development, Indian Council for Research on International Economic Relations, Working Paper No. 194 (New Delhi, 2007), p. 21.

${ }^{25}$ For a complete list see J.-P. Singa Boyenge: ILO database on export processing zones, Sectoral Activities Programme Working Paper No. 251 (Geneva, ILO, 2007), available at www.ilo.org/public/english/dialogue/sector/themes/epz/epz-db.pdf.

${ }^{26}$ ILO: Freedom of association in practice: Lessons learned, Global Report under the follow-up to the ILO Declaration on Fundamental Principles and Rights at Work, Report I(B), ILC, 97th Session, Geneva, 2008, para. 195 ff. Paragraph 46 of the ILO Tripartite Declaration of Principles concerning Multinational Enterprises and Social Policy provides that special incentives to attract foreign investment should not include any limitation of the workers' freedom of association or the right to organize and bargain collectively, at www.ilo.org/public/english/employment/multi/download/ english.pdf. 
workers, the number of jobs for women workers could decline. ${ }^{27}$ Skills development for young women is necessary in order to help them bridge the technology gap and aspire to better-paying jobs, and women will need to bargain, along with men, to defend and preserve their rights.

207. Long working hours take their toll on women's health. The lack of safe accommodation or safe transportation for women workers has led to increased risk of sexual harassment and violence, with little possibility of redress.

208. Supporters of EPZs argue that the zones create new jobs and generate expansion. Sometimes, EPZ wages are higher than average national wages; EPZ factories may also offer more modern physical plant than domestic industry. ${ }^{28}$ International framework agreements with multinational enterprises can have an impact at the national level, including in EPZs. The Governing Body of the International Labour Office, cognizant of differing views regarding the benefits of EPZs, has requested more research on industrial relations, labour administration and labour inspection in these zones.

\subsection{ILO action}

\subsubsection{Employment}

\section{Supporting education, skills and employment services}

209. Access to universal, free, quality public primary and secondary education and investment in vocational training, skills development and lifelong learning are essential for individual and social enhancement and for the preparation of young persons' future employability. ${ }^{29}$ This assistance is crucial to improving and sustaining workers' productivity and income-earning opportunities. It serves to enhance their mobility in the labour market and offers the potential for increased career choices. ${ }^{30}$ The ILO Conventions on public and private employment services can be used for policy development that is gender sensitive as well as adequately designed and targeted in providing tailored help to young women and men. ${ }^{31}$ Legislation in this area can address sex discrimination in the functioning of such services. For example, South Africa's regulations with regard to private employment agencies (No. R.608 of 2000), require the owner or manager of an employment service to submit to the competent labour authorities a yearly report stating the number of persons, classified according to race, gender and occupation, who were placed in or recruited for employment. In practice, some employment services are offered through women-specific centres or by counsellors who have specialized in employment advice to youth. Besides assisting constituents in the reform of their vocational education and training systems, the ILO supports the

\footnotetext{
27 ILO: Report of the InFocus Initiative on export processing zones (EPZs): Trends and policy developments in EPZs, Governing Body, 301st Session, Geneva, Mar. 2008, GB.301/ESP/5, para. 22.

${ }^{28}$ For example, Nike encouraged important improvements in the working environment and conditions in its factories in EPZs. I. Kawachi and S. Wamala (eds): Globalization and health (Oxford University Press, 2006), pp. 142-143.

${ }^{29}$ ILO: Conclusions on promoting pathways to decent work for youth, Report of the Committee on Youth Employment, Provisional Record No. 20, ILC, 93rd Session, Geneva, 2005, para. 32.

30 During its 97th Session in June 2008, the ILC considered the report Skills for improved productivity, employment growth and development and adopted gender-inclusive conclusions to guide both the constituents and the Office on the way forward.

31 The Employment Service Convention, 1948 (No. 88), and the Private Employment Agencies Convention, 1997 (No. 181).
} 
upgrading of informal apprenticeship. Many young women and men, in particular in African countries, do not have access to formal training. For them, informal apprenticeship provides the main training route to acquiring skills. Upgrading apprenticeship in the informal economy means smoothing the transition between education, training and work, and building links between the informal and the formal training system. These links should be aimed at improving the training process, training quality, use of new technologies and enhancing recognition of skills acquired through informal apprenticeship.

\section{Box 5.2 \\ Gender mainstreaming and employability}

The project "Increasing employability of disadvantaged young women and men and other marginalized groups in the Caucasus and Central Asia through skills development and entrepreneurial education" was implemented in Armenia, Azerbaijan, Georgia, Kazakhstan, Kyrgyzstan and the Russian Federation. A series of gender-specific interventions were made possible through support for the gender mainstreaming strategy; several elements of good practice have been noted. The Government of the Netherlands, which financed these earlier efforts, has continued support to the Boosting Youth Employment (BYE) project in Azerbaijan and Kyrgyzstan. The project has developed an explicit strategy on gender mainstreaming in employment and labour market interventions, and is actively promoting the ILO's key equality Conventions.

Source: ILO: Evaluation: "Increasing employability of disadvantaged young women and men and other marginalized groups in Caucasus and Central Asia through skills development and entrepreneurial education" (Geneva, 2006).

210. In Sri Lanka, in collaboration with the national Tertiary Vocational Education Commission and World University Service of Canada, the ILO is in the process of finalizing a Handbook on gender for training in technical professions for use in courses on gender awareness for training designers and practitioners in governmental and nongovernmental training organizations.

\section{Creating employment opportunities}

211. The ILO's Youth Employment Programme (YEP) operates through a global network of technical specialists in headquarters and in more than 60 field offices. It helps countries develop coherent and coordinated measures for youth employment. The YEP is based on three pillars: building knowledge; advocacy; and technical assistance. Equality of opportunity and treatment between young women and men is central to its work. The Bureau for Gender Equality actively supports the YEP in incorporating the gender dimensions of youth employment. Active labour market policies and programmes are key instruments for the promotion of employment and decent work among young women and men. Research shows that they enhance the security of workers and contribute to fair globalization. ${ }^{32}$ Such policy advice needs solid, empirical research as well as quantitative assessments of the realities of youth labour markets. The Office provides this analytical starting-block from which countries can identify the main challenges facing young people in the Global Employment Trends for Youth, disaggregated by sex and age.

212. The ILO's School-to-Work Transition Survey is a statistical tool designed to help countries improve their youth employment policies and programmes. It enables analysis of both quantitative and qualitative variables that define the relative ease or difficulty of

\footnotetext{
32 See P. Auer, Ü. Efendioğlu and J. Leschke: Active labour market policies around the world: Coping with the consequences of globalization (Geneva, ILO, 2005).
} 
young women's and men's differential transition from school to working life, such as education and training experience; perceptions and aspirations in terms of employment; the job-search process, barriers to and supports for entry into the labour market; preference for wage employment or self-employment; and attitudes of employers towards hiring young workers. ${ }^{33}$

213. To assist constituents in improving national career guidance programmes, the ILO published Career guidance: A resource handbook for low- and middle-income countries in 2006. Core issues in the reform of career guidance services are addressed, offering a wide variety of country examples and gender-sensitive tools. Specific national handbooks were developed in Indonesia, the Philippines and Mongolia.

214. Primary responsibility for promoting youth employment lies with governments, but coherence and coordination are needed between different government institutions and with the social partners. The Office's Guide for the preparation of National Action Plans on Youth Employment assists constituents in this important task. The Guide recommends that technical experts knowledgeable on gender issues be involved in policy formulation and in identifying and analysing the gender differences in the labour market, so as to map the diverse situations that young women and men face in the labour market. ${ }^{34}$

215. Funded by the Netherlands, the "Working Out of Poverty" (WOOP) project in Mozambique is designed to contribute to work/family balance goals. The Decent Work Country Programme agreed with the ILO constituents specifies its main goal as the reduction of poverty through employment creation with a specific focus on young people.

\section{Box 5.3 \\ "Flexicurity" in Eastern Europe}

In Eastern Europe, governments and employers have often stressed that flexibility in labour markets is crucial for improving economic productivity, and that productivity is in turn a prerequisite for decent work. Rigid employment legislation could be considered a barrier to labour market entry, yet flexible forms of work and insecurity often go hand in hand with insufficient coverage and effectiveness of social protection. This especially affects young women and men in fluctuating labour markets. Workers' security is considered essential to fair globalization underpinned by international labour standards, and employers have emphasized that secure workers are partners in efforts to raise productivity. A "flexicurity" approach to maintain and improve competitiveness while making use of social policy as a productive factor could have a positive impact on the employment of young women and men. Several countries were included in the project "Labour market flexibility and employment security in Central and Eastern Europe and the Baltic States", which emphasized the gender dimensions of flexicurity. Research from Western Europe shows that women are disproportionately represented in flexible employment relationships, and the project (implemented in Croatia, Hungary, Lithuania and Poland in 2004-05) collected sex-disaggregated data and stimulated policy debates on the gender dimensions of flexicurity at national tripartite workshops.

Sources: ILO: Report, Seventh European Regional Meeting, Budapest, 14-18 February 2005, ERM/VII/D.7, p. 5. S. Cazes and A. Nesporova (eds): Flexicurity: A relevant approach in Central and Eastern Europe (Geneva, ILO, 2007).

\footnotetext{
33 For example, the project on "Promoting more and better jobs for young women in Viet Nam" facilitates school-to-work transition and improves opportunities for decent employment for young women through knowledge and training.

${ }^{34}$ G. Rosas and G. Rossignotti: Guide for the preparation of National Action Plans on Youth Employment, YEP (Geneva, ILO, 2008).
} 


\section{Fostering enterprise development and entrepreneurship}

216. Women of all ages often face greater obstacles when starting a business, because of limited access to entrepreneurship training and capital, as well as lack of information. Not enough young women graduates see enterprise development as a viable or appropriate employment option, with many preferring to seek employment either in the diminishing public sector or in the private sector, where there may be significant discrimination against women in recruitment. Entrepreneurship development is therefore an underutilized employment alternative for many young women, and one in which their talents, creativity and innovation could flourish, given an enabling policy environment.

217. At enterprise level, poor women have often successfully organized in cooperatives and other associations that enable economies of scale in production. Group-based savings and loans schemes have enabled many women to enjoy multiplier effects not available through individual loans, and they can facilitate access to technology and skills training, and enhance design and quality.

218. Most enterprise and entrepreneurship programmes are open to all young people, whether currently self-employed or wishing to set up their own business. The ILO Start and Improve Your Business (SIYB) programme does not specially target young people; nevertheless, 40 to 50 per cent of participants are aged under 25, and approximately half are women.

219. The ILO's Small Enterprise Development Programme is active in youth entrepreneurship. The Women's Entrepreneurship Development and Gender Equality (WEDGE) programme, funded by the Government of Ireland, works on enhancing economic opportunities for women by taking positive action to support women, including those with disabilities and living with HIV and AIDS. Its success lies in practical guidance for women starting, formalizing and developing their enterprises, establishing a knowledge base on women entrepreneurs, and innovative support services. The Know About Business (KAB) package is directed at educators in vocational and technical training institutions, general secondary education, and higher technical education, where the learning curriculum encompasses entrepreneurship education. The package is being modified to further integrate gender issues.

\subsubsection{Social protection}

\section{Social security}

220. As mentioned, most working youth are often found in low-paying jobs or unpaid family work. Estimates show that only 25 per cent of working youth in low-income countries are in paid work, compared to 57 per cent in the middle-income group and 74 per cent in the high-income countries. Even those who are paid are less likely to have access to social security compared with older workers. ${ }^{35}$ The integration of first-time jobseekers, many of whom are young women, into the labour market is a major concern in many countries. Unemployment benefit linked to training activities can constitute an important tool for supporting young people's and, in particular, young women's entry into the labour market.

\footnotetext{
${ }^{35}$ World Bank: World Development Report 2007: Development and the next generation (Washington, DC, 2006), pp. 101-102.
} 


\section{Box 5.4 \\ Bahrain: Introduction of unemployment benefits}

The Government of the Kingdom of Bahrain adopted its first unemployment insurance law in 2006, and the payment of unemployment benefits started in December 2008 after one year of contribution collection. Statistics show that in 2008, most of the beneficiaries were young women, mainly first-time jobseekers (78 per cent women and 22 per cent men).

Bahrain: Unemployment benefit recipients by sex and educational status, November 2008

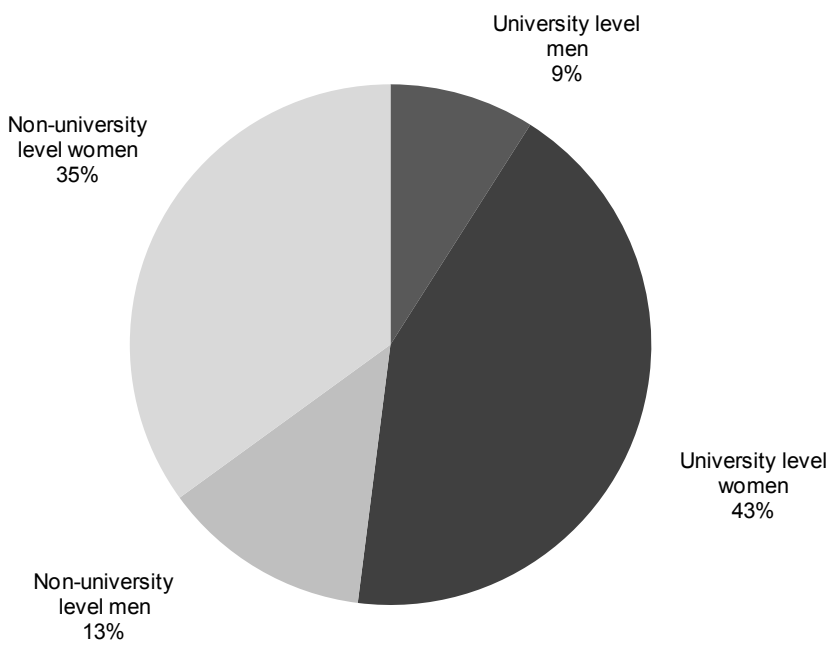

Source: ILO, Social Security Department, 2008

\section{Occupational safety and health and working conditions}

221. Considered as possessing the attributes of good health and energy, young persons are expected to work long hours. Young workers are often assigned night shifts and asocial working hours, or they choose to work long hours out of eagerness to prove themselves, either to hold on to their jobs or to seek promotion. But in many cases, long working hours are imposed on them, leading to situations of pressure and exploitation.

222. The protection of reproductive health and the conditions of work in which young people operate are pressing OSH considerations. Young men are often given the most dangerous and physically taxing jobs without adequate training or security measures. They are more exposed to accidents or hazards caused by substances that are carcinogenic or may cause circulatory and respiratory diseases. They may also take fewer precautions - women tend to adopt more preventive and protective ways of carrying out work. ${ }^{36}$

\footnotetext{
${ }^{36}$ ILO: World Day for Safety and Health at Work 2005: A background paper, ILO InFocus Programme on SafeWork (Geneva), p. 7.
} 
223. Young workers are much more likely to suffer serious (but non-fatal) accidents at work, compared with their older colleagues. In the European Union, for example, the incidence of non-fatal accidents is at least 50 per cent higher among workers aged 18 to 24 than in any other age category. ${ }^{37}$ Nevertheless, fatal accident rates of young workers can be considerable in some sectors. In Europe, agriculture has the highest incidence of fatal accidents among young workers, followed by construction and transport.

224. Different hazard exposures contribute to different health outcomes for women. Hairdressing is a predominantly young, female profession: in the EU, women account for 87 per cent of workers in this sector, which employs more than a million persons. ${ }^{38}$ Skin problems, asthma and musculoskeletal disorders are the main risk factors. Similarly, the proportion of young women among call-centre operators is generally high. In addition to great time pressure and poor work organization, the various risk factors to which they are exposed include prolonged sitting, background noise, insufficient ventilation, unergonomic design of the work equipment and burnout. ${ }^{39}$ In one call centre in Morocco servicing France, women's right to three months of maternity leave was respected, but the women coming back from maternity leave had to work additional hours to make up for lost time. ${ }^{40}$

225. Women's safety and health problems are frequently ignored or not accurately reflected in research and data collection. OSH inquiries seem to pay more attention to problems relating to male-dominated work, and the data collected by OSH institutions and research often fail to reflect adequately the illnesses and injuries that women experience. In addition, precarious work is often excluded from data collection. Since much of women's work is unpaid, or in self-employment or in the informal economy, many accidents are simply not recorded. Research provides compelling arguments for the consideration of women's and men's biological differences, in order to ensure that the workplace is adapted to the physical aspects and capacities of both sexes; the findings seem to have been ignored. ${ }^{41}$

\section{Migration}

226. With globalization and current demographic patterns, migration for employment has increasingly become a key economic, social and political issue, raising expectations with regard to the collection of detailed sex-disaggregated data that could help policymakers correctly judge the impact of migration patterns and their influence on the global labour market. ${ }^{42}$ In 2005, it was estimated that 191 million women and men crossed borders to reside and/or work outside their countries of birth or citizenship. That year,

\footnotetext{
37 ibid., pp. 9-10.

${ }^{38}$ EU: OSH in figures: Young workers - Facts and figures, Institute for Occupational Safety and Health, European Agency for Safety and Health at Work (Brussels, 2007), p. 11.

${ }^{39}$ In the United Kingdom, for example, it is estimated that 1.6-2 per cent of the total workforce is employed in call centres (figures provided by Call Centre Association (CCA) and Communication Workers Union (CWU)). This is more than the combined workforce in coalmining, steel and vehicle production. ibid., p. 56.

40 ITUC: "Spotlight interview with Laïla Nassimi, Morocco - CDT" (Brussels, 30 July 2008), at www.ituc-csi.org/spip.php?article2332.

${ }^{41}$ M. Cornish: Realizing the right of women to safe work - Building gender equality into occupational safety and health governance, ILO concept note for the XVIII World Congress on Safety and Health at Work, Seoul, 29 June-2 July 2008.

42 See ILO: Global Employment Trends for Youth (Geneva, 2006), p. 15.
} 
female migrants made up 49.6 per cent of all migrants worldwide and more than 50 per cent in Europe, Latin America, North America and Oceania. ${ }^{43}$ The ILO estimates that of the 191 million, 94 million were economically active migrant workers. ${ }^{44}$ The probability of migrating peaks in the late teens and early twenties (about half the migrants from all developing countries could be below 29 years old), and hence young women and men represent a disproportionate share of the world's migrants. ${ }^{45}$ As a consequence of higher birth rates in developing countries and ageing of the population in developed countries, migration could further increase over the coming years.

227. Skilled young women usually migrate to jobs in health-care services, education and ICT and clerical positions. Skilled young men enjoy a broader choice when migrating internationally. Increasing numbers of unskilled young women are searching for work beyond their borders, faced with employment discrimination and few opportunities in their home labour markets. The types of jobs available to them in low-skilled occupations add new layers of vulnerability to migrant women, especially when linked to problems of migration status, ethnicity and class. Countries of origin are trying to improve employment conditions for their migrants. For example, under the Memoranda of Understanding signed by the Sri Lanka Bureau of Foreign Employment with recruitment agents in the Middle East, Singapore and Hong Kong, China, employers must sign an employment contract endorsed by the Sri Lankan Embassy before any domestic worker can leave Sri Lanka. ${ }^{46}$

228. The financial benefits that migrant workers transfer in the form of remittances to their families are substantial, ${ }^{47}$ not to mention the benefits for sending countries in terms of foreign exchange earnings and alleviation of pressure on local job markets. During economic downturns, however, migrant workers are often the first to lose their jobs, and while some may opt to return home, policies aimed at repatriating migrant workers are not the solution. Experience has shown that such policies could have disastrous consequences for development, given the scale of remittances (approximately US $\$ 283$ billion to developing countries in 2008) and the already high levels of unemployment in developing countries. ${ }^{48}$

\footnotetext{
${ }^{43}$ UN DESA, Population Division: Trends in Total Migrant Stock: The 2005 revision (New York, United Nations, 2005).

${ }^{44}$ Estimates by the ILO International Migration Programme (MIGRANT).

${ }^{45}$ World Bank: World Development Report 2007: Development and the next generation (Washington, DC, 2006), p. 14.

${ }^{46}$ G. Moreno-Fontes Chammartin: Migration, gender equality and development, Overview paper, International Conference on Gender, Migration and Development: Seizing Opportunities, Upholding Rights, Manila, 25-26 September 2008, p. 41.

${ }^{47}$ The economic impact of remittances in the areas that receive them means that US $\$ 1$ in remittances generates US\$2 in local economic activity, as recipients buy goods or invest in housing, education or health care. P. Martin: Sustainable migration policies in a globalizing world (Geneva, ILO-IILS, 2003).

${ }^{48}$ International Organization for Migration (IOM): The impact of the global financial crisis on migration, IOM Policy Brief, 12 Jan. 2009.
} 


\section{Sexual harassment}

229. Like gender-based violence (examined earlier in this report), sexual harassment ${ }^{49}$ at work is a human rights and sex discrimination issue, and has accordingly been examined in the light of the requirements of Convention No. 111. It also involves OSH issues. It is especially encountered by inexperienced younger women and men whose age and work position make them vulnerable to older persons who wield considerably more power.

230. Sexual harassment is a hazard encountered in workplaces across the world that lowers the quality of working life, jeopardizes the well-being of women and men, undermines gender equality and can have serious cost implications for firms and organizations. ${ }^{50} \mathrm{~A}$ prevailing view has been that sexual harassment was an unspoken occupational hazard that working women were expected to endure. National research establishes beyond doubt that women are far more likely than men to suffer sexual harassment at work. Nevertheless, some surveys show that men also experience sexual harassment, although the scale of the problem for men is substantially less. ${ }^{51}$ In the United States, for example, the percentage of sexual harassment cases filed by men rose from 10 per cent in 1996 to 15.4 per cent in $2006 .{ }^{52}$ It stands to reason that policies and guidelines increasingly confer the same rights on men who have been sexually harassed as they do on women.

231. Recent years have seen a significant number of countries - in all regions of the world - adopt legislation (for example, in equal opportunity statutes, labour codes, OSH regulations, tort law and criminal law) that recognizes sexual harassment at work as a violation of basic principles and rights, prohibited behaviour or an unfair labour practice. These laws not only punish violations, but require preventive action to stop future occurrences. The workplace is a suitable location for prevention messages through educating women and men about both the discriminatory nature and the economic wastefulness of sexual harassment. In parallel, there is a growing body of codes of conduct, enterprise regulations and other forms of guidelines on the subject, because employers now view sexual harassment as a genuine concern of management. In the Republic of Korea, for example, the Equal Employment Act prohibits employers, senior workers and co-workers from engaging in sexual harassment at work, and requires

\footnotetext{
${ }^{49}$ Described as any unwelcome physical or verbal behaviour of a sexual nature, acceptance of which is explicitly or implicitly made a condition for favourable decisions affecting one's employment, or which has the purpose or effect of unreasonably interfering with the individual's work performance or creating an intimidating, hostile, abusive or offensive working environment. See ILO: ABC of women workers' rights and gender equality (Geneva, 2007), pp. 165-166. While sexual harassment is not yet covered by a specific international instrument, the CEDAW Committee has qualified it as a form of discrimination on the basis of sex, and as a form of violence against women, in its General Recommendation No. 19 on violence against women. See United Nations: Report of the Committee on the Elimination of Discrimination against Women, 11th Session, General Assembly, Official Records, 47th Session, Supplement No. 38, A/47/38 (New York, 1992), para. 18.

${ }^{50}$ D. McCann: Sexual harassment at work: National and international responses, Conditions of Work and Employment Series No. 2 (Geneva, ILO, 2005), p. vii. See also ILO: Cambodia: Women and work in the garment industry, Better Factories Cambodia project, pp. 16-20.

${ }^{51}$ ILO: Date, place and agenda of the 88th Session (2000) of the Conference, Governing Body, 271st Session, Geneva, Mar. 1998, GB.271/4/1, para. 159. See also J. Hodges-Aeberhard: "Sexual harassment in employment: Recent judicial and arbitral trends", in International Labour Review, Vol. 135, No. 5 (Geneva, ILO, 1996).

${ }^{52}$ United States Equal Employment Opportunity Commission (EEOC): Sexual harassment charges: EEOC and FEPAs combined: FY 1997-FY 2006.
} 
employers to conduct relevant educational programmes and to take disciplinary measures against harassers. Similarly, the Gender Discrimination Prevention and Relief Act stipulates that neither employers nor employees of public institutions shall engage in sexual harassment. Victims can apply for mediation to the Equal Employment Commission or file petitions with regional labour offices.

232. The only international labour Convention which directly prohibits this type of workplace abuse is the Indigenous and Tribal Peoples Convention, 1989 (No. 169). The 1991 ILC resolution concerning ILO action for women workers requested the Office to hold tripartite meetings with a view to developing guidelines, training and information materials on issues that are of specific and major importance to women, such as sexual harassment at the workplace. Outcomes of the follow-up work include: training programmes on sexual harassment organized by government agencies, employers' organizations and national gender machineries; trade union brochures explaining what sexual harassment is and what can be done about it, and union awareness-raising campaigns urging members to denounce acts of harassment to the works council or trade union representatives; and better use of collective bargaining as a means of tackling sexual harassment in some countries. In 2003, the CEACR addressed a general observation to all States having ratified Convention No. 111, requesting them to take measures to eliminate sexual harassment and to provide information on such measures in their next report.

\subsubsection{Social dialogue}

233. Labour market policies and employment legislation and regulations, adopted through a process of social dialogue and recognizing the right to collective bargaining, should ensure adequate protection of young workers and the improvement of their employment prospects. ${ }^{53}$ The ILO's tripartite constituency and international alliances give it the global reach needed to catalyse support and action on youth employment. At the national level, governments and employers' and workers' organizations are major players in the development of youth employment policies and programmes. Dialogue and alliances with civil society, the public and private sectors and young people themselves are also important for developing solutions and building support for them.

234. Employers recognize that the transition to work is problematic for young people and that despite their being educated, mismatches still exist between employers' needs and young people's skills. This can be frustrating for jobseekers seeking employment, and for employers requiring specific skill sets. In an employers' survey, lack of skills and a national legal and institutional framework that is not conducive to the development of formal enterprises were cited as the key drivers of informality. ${ }^{54} \mathrm{New}$ entrants to the labour market were perceived positively in terms of basic literacy and numeracy skills and positive attitude, but their business awareness, self-management and knowledge of the job were seen as needing improvement.

235. Local and national initiatives by individual companies or employers' associations are growing in many countries. These initiatives are necessarily diverse, depending on the socio-economic, political and institutional context, youth employment needs, and the constraints of the business community in a given country. In general, however, more

${ }_{53}^{5}$ ILO: Conclusions on promoting pathways to decent work for youth, Report of the Committee on Youth Employment, Provisional Record No. 20, ILC, 93rd Session, Geneva, 2005, para. 28.

${ }^{54}$ IOE: Trends in the workplace survey 2008: Enterprises in a globalizing world (Geneva, 2008), p. 18. 
attention needs to be paid to the employment of young women. When the impact of labour and social legislation on hiring and firing was surveyed by the IOE, the results indicated either an unfavourable or a neutral impact on young people and women. Female workers were often targeted for protective legislation that can in practice have the opposite effect. A number of examples were given of legislation that prohibited women from working at night - acting as a direct disincentive to employ that group of workers. ${ }^{55}$

236. Employers remain engaged with youth employment on a number of fronts. ${ }^{56}$ One example is an Asian subregional youth employment workshop that took place in Kathmandu, Nepal, in February 2008 which delivered gender-specific modules through training of employers from Cambodia, India, Indonesia, Nepal and Viet Nam. Another project, funded by the Government of Sweden, focuses on good governance in the labour market and youth employment. The Jamaica Employers Federation (JEF) supported the Youth Employment Network in Jamaica through the design and implementation of youth employment policies. In addition, JEF has a strong policy on workplace sexual harassment. The participation of young entrepreneurs in business organizations is also encouraged, one example being the National Commission for Young Entrepreneurs set up by the Mexican Employers' Confederation (COPARMEX).

237. Attracting new members from among young workers - women and men alike - is key to strengthening unions. Workers' organizations have consistently advocated a rights-based approach to youth employment with the aim of creating decent work for young people. Recognizing that young persons often get short shrift in obtaining quality jobs, they emphasize that young people need to be involved in all social dialogue processes through their union representatives so that good working conditions can be maintained. Workers' groups also point specifically to the need for social security and protection for young people. ${ }^{57}$

238. Unions have been paying increasing attention to young people working in the informal sector and their inability to defend their rights. In Eastern Europe, efforts were made to attract young members through education on the role of unions and workers' rights. Particular attention needs to be given to poor young women, who are vulnerable to sexual exploitation and trafficking for prostitution, to harassment at work or to disguised forms of poor employment. In Latin America, trade unions have made efforts to engage young people through action on vocational training, debate and discussion, as well as studies regarding the relationship between young people and trade unions. An interesting experiment on this subject is the UNI young persons' network in Argentina. ${ }^{58}$

239. Workers' organizations are campaigning to influence the policies of the World Bank, the IMF and the WTO and promote the ILO core standards. ${ }^{59}$ The ITUC is committed to promoting policies and action for the organization and representation of

\footnotetext{
55 ibid., p. 20.

56 See IOE web site: http://ioe-emp.org/en/policy-areas/employment/youth-employment/index.html; and IOE-ILO: Youth: Making it happen. An electronic resource tool for employers, at www.ilo.org/youthmakingithappen.

57 ICFTU (ITUC): Fulfilling the promise: Towards decent work for all young people, Youth Committee, 30-31 May 2006 (Brussels), p. 5.

58 See UNI Youth web site, at www.union-network.org/uniyouth.nsf.

59 See http://ituc-csi.org/spip.php?rubrique94.
} 
young men and women so that rights are protected at work. For example, the ITUC and its Indian affiliate, the Indian National Trade Union Congress (INTUC), support a project in India in the aftermath of the 2004 tsunami. The project's work on youth employment has benefited a substantial number of young women by helping them identify the types of work that are free of gender stereotyping. The Labour Education Programme at the ITC-ILO also offers youth leadership training on freedom of association, with successful participation rates by young women.

\subsubsection{Principles and rights}

240. The four key equality Conventions provide the backbone for addressing young women's and men's employment within a rights-based approach. Convention No. 111, for example, not only covers discrimination based on sex, but can also be used to tackle age discrimination through its Article 1(1)(b). Article 5 envisages the possibility of special measures to meet the particular needs of workers based on age. These can apply to young jobseekers, especially young women, in relation to vocational guidance, vocational training and placement services, access to employment and decent conditions of work once in employment. ${ }^{60}$

241. The Employment Policy Convention, 1964 (No. 122), is an important policy tool for gender equality in youth employment. The Employment Service Convention, 1948 (No. 88), refers to youth: "Special arrangements for juveniles shall be initiated and developed within the framework of the employment and vocational guidance services". The Employment Relationship Recommendation, 2006 (No. 198), specifically recognizes the vulnerability of young women and men. The Employment Promotion and Protection against Unemployment Convention, 1988 (No. 168), contains special provisions for new applicants for employment, which includes young persons. The Private Employment Agencies Convention, 1997 (No. 181), provides for specific measures regarding age discrimination and disadvantaged workers, and the Human Resources Development Convention, 1975 (No. 142), and its accompanying Recommendation (No. 195) are also relevant for young workers, advising the adoption and development of policies and programmes of vocational guidance and vocational training. The important role of the Labour Inspection Convention, 1947 (No. 81), has been highlighted as follows: "Labour inspection is the most important tool governments have at their disposal to ensure compliance with labour laws and to identify gaps in national legislation. The CEACR has emphasized the need to develop labour inspection activities in agriculture, especially to protect young workers and tackle child labour". ${ }^{61}$

242. The CEACR addresses the rights of young women and their situation in relation to the world of work, and welcomes statistics disaggregated by sex, as well as data on balanced representation of men and women in vocational training programmes and on retention of young women in employment. It also highlights efforts to counter occupational segregation; for example, in 1999 the Government of Finland launched a campaign to encourage young women and girls in secondary schools to seek training in information technology (IT). Feedback after a few years marked a clear increase in the proportion of young women entering the IT sector. ${ }^{62}$ The CEACR has also focused on young women's unemployment rates, which are systematically higher than those of

\footnotetext{
${ }^{60}$ ILO: Youth: Pathways to decent work. Promoting youth employment - Tackling the challenge, Report VI, ILC, 93rd Session, Geneva, 2005, para. 70.

${ }^{61}$ ILO: Promotion of rural employment for poverty reduction, Report IV, ILC, 97th Session, Geneva, 2008, para. 244.

${ }^{62}$ ILO: CEACR: Direct request 2003 on the application of Convention No. 111 by Finland.
} 
young men, as well as issues concerning equal pay and precarious employment arrangements of young women.

\section{Box 5.5 \\ Central America: Creating employment opportunities for young men}

Various regions have developed legal frameworks on non-discrimination that combine the provisions of different Conventions to promote equality. In Latin America, the aim was to protect the most vulnerable populations from discrimination, particularly young women and indigenous youth and young persons of African descent of both sexes. Social problems can have a dramatic effect on young men. In Central America, they are joining increasing numbers of violent street gangs. Many of them end up in these gangs out of hopelessness and after dropping out of school or the workforce. Today, local officials estimate their size at between 70,000 and 100,000 members. The gangs, known as maras, "now pose the most serious challenge to peace in the region since the end of Central America's civil wars". Cognizant of these challenges and the failure of law enforcement, the CEACR has welcomed concrete efforts to tackle the problem by introducing youth employment initiatives, including "first jobs for youth at risk" schemes, through improved access to vocational training and employment services.

Sources: ILO: Decent work and youth. Latin America (Lima, 2008), pp. 39-40. A. Arana: "How the street gangs took Central America", in Foreign Affairs (New York), May/June 2005. ILO: CEACR: Direct request on the application of Convention No. 122 by Honduras.

\section{Trafficking and forced labour}

243. The second Global Report on forced labour under the follow-up to the 1998 Declaration observed that that there were an estimated 12.3 million victims of forced labour around the world, of whom more than 2.4 million were victims of trafficking and another 2.5 million were forced to work by the State or by rebel groups. ${ }^{63}$ Despite incomprehension and outrage at the fact that forced labour still persists in the twenty-first century, its presence is irrefutable - on all continents, in some form. ${ }^{64}$ In the case of international trafficking, authorities in countries of destination often investigate the victim of trafficking rather than investigating and prosecuting the rings of traffickers.

244. The elimination of all forms of forced or compulsory labour is one of the requirements of the ILO's 1998 Declaration. The leading standard in this area, the Forced Labour Convention, 1930 (No. 29), is the most highly ratified ILO Convention. The estimated minimum number of persons in forced labour as a result of trafficking is 2.4 million, 56 per cent of whom are women and girls, and 44 per cent men and boys. In the case of forced commercial sexual exploitation, however, the overwhelming majority ( 98 per cent) of victims are women and girls. The exact age of victims is seldom reported, but it is reasonable to assume that the vast majority of those trafficked are young women and men.

63 ILO: A global alliance against forced labour, Global Report under the follow-up to the ILO Declaration on Fundamental Principles and Rights at Work, Report I(B), ILC, 93rd Session, Geneva, 2005, para. 37. The 2009 session of the ILC is examining the third Global Report on forced labour with fresh data. ILO: The cost of coercion, Global Report under the follow-up to the ILO Declaration on Fundamental Principles and Rights at Work, Report I(B), ILC, 98th Session, Geneva, 2009.

64 Traditional forms of forced labour include entrenched bonded labour systems in parts of South Asia, debt bondage affecting mainly indigenous peoples in parts of Latin America, and the residual slavery-related practices most evident today in certain parts of Africa. ILO: Eradication of forced labour, General Survey, Report III (Part 1B), ILC, 96th Session, Geneva, 2007, para. 69. 
245. In South Asia, young women and girls in bonded labour are triply disadvantaged: by their sex, their youth and their caste. Bonded as a commodity, they are not recognized as workers in their own right. They may be coerced to work in prostitution, domestic labour, agriculture or brick-making. These women and girls may be "bought and sold" when landlords agree among themselves to transfer a debt, without prior consultation of those involved. ${ }^{65}$

246. The Office's Special Action Programme to Combat Forced Labour (SAP-FL) was created in 2001, following the publication of the first Global Report on forced labour. It has worked on gender dimensions of the problem since its inception. It raises global awareness and understanding of modern forced labour, assists governments in developing and implementing new laws, policies and action plans and disseminates guidance and training materials on key aspects of forced labour and trafficking. The programme also runs field-based projects directly supporting both the prevention of forced labour and the identification and rehabilitation of its victims.

\section{Occupational safety and health}

247. Better data collection and analysis for the protection of employees' health is a major goal in nearly all of the OSH Conventions. The Occupational Safety and Health Convention, 1981 (No. 155), and Promotional Framework for Occupational Safety and Health Convention, 2006 (No. 187), call on ratifying States to establish policies and programmes to guarantee safety and health at the workplace, including inspection systems. As the wording of the Conventions does not reinforce the development of either sex- or gender-based policies, training and programme development for inspectorates would need to incorporate these dimensions.

\section{Young people with disabilities}

248. Of the estimated 650 million people with disabilities in the world, 80 per cent live in developing countries, most of them below the poverty line. ${ }^{66}$ Over 100 million women and men with disabilities were aged 15-24 in 2003. ${ }^{67}$ They are disproportionately disadvantaged when it comes to employment, especially young women, who may be triply discriminated against for being young and female and having a disability. The labour force participation rate of disabled women is significantly lower than that of disabled men - for example, in India, it is 16.6 per cent, compared to 52.6 per cent; ${ }^{68}$ it is also lower than that of non-disabled women (for example, in EU countries, 49 per cent, compared to 64 per cent). ${ }^{69}$ Discriminatory practices may be compounded by problems such as physical access or transportation, which may be overcome with appropriate enabling policies and practical measures to accommodate the work environment to the workers' needs.

${ }^{65}$ ILO: A global alliance against forced labour, op. cit., p. 32.

${ }^{66}$ World Bank: Development Outreach: Disability and inclusive development (Washington, DC, July 2005).

67 ILO: Youth: Pathways to decent work. Promoting youth employment - Tackling the challenge, Report VI, ILC, 93rd Session, Geneva, 2005, para. 83.

${ }^{68}$ T. Powers: Recognizing ability: The skills and productivity of persons with disabilities, Employment Working Paper No. 3 (Geneva, ILO, 2008), p. 4.

${ }^{69}$ Statistical Office of the European Communities (Eurostat): Employment of disabled people (ad hoc module of the Labour Force Survey 2002). 
249. The Vocational Rehabilitation and Employment (Disabled Persons) Convention, 1983 (No. 159), provides that "Equality of opportunity and treatment for disabled men and women workers shall be respected." Increasing attention is being given to empowering disabled women ${ }^{70}$ and to the inclusion of young women and men with disabilities in education, training and employment. Sheltered workshops are increasingly viewed as impeding disabled persons from access to labour markets, from earning a decent income and from integrating socially into their communities. Instead, the ILO recommends strategies to support their participation in open labour markets. ${ }^{71}$

\subsection{Links to the United Nations and international agencies}

250. Youth employment is of the greatest importance for the development of societies. Today, there is heightened recognition that the magnitude of the youth employment challenge requires a partnership-based response, as evidenced by the inclusion of the issue in the UN MDGs. ${ }^{72}$

251. The United Nations examines issues that affect young women and girls in the context of the areas addressed in the Beijing Platform for Action, as well as emerging issues. ${ }^{73}$ For example, UNIFEM has developed a programme to help bridge the digital divide in Africa by providing women with access to ICTs so as to improve their livelihoods. ${ }^{74}$ Cooperation with the ILO takes place in areas of common concern, such as education, employment, poverty and hunger, health, caregiving, environment, participation in decision-making, HIV/AIDS, and armed conflict. The ILO Toolkit for mainstreaming employment and decent work into the programmes of the UN family affirms that it is crucial that policies and programmes to promote youth employment give attention to gender-based discrimination so that young women enter and remain in the labour market. ${ }^{75}$

252. The United Nations adopted the Convention on the Rights of Persons with Disabilities in 2006. The Convention recognizes multiple forms of discrimination, including that based on sex and age; Articles 6 and 7 specifically address women and children. Furthermore, the Convention reinforces national and international efforts and provides a renewed impetus in eliminating discrimination on the basis of disability and in proactively promoting inclusion.

\footnotetext{
${ }^{70}$ ILO: Count us in! How to make sure that women with disabilities can participate effectively in mainstream women's entrepreneurship development activities (Geneva, 2008).

71 T. Powers: Recognizing ability, op cit., p. 16.

72 The ILO is committed to the achievement of the UN MDGs, particularly Goal 8, which addresses ways in which a global partnership can be established between developed and developing countries to achieve the MDGs, including the halving of world poverty by 2015. ILO: Youth: Pathways to decent work. Promoting youth employment - Tackling the challenge, Report VI, ILC, 93rd Session, Geneva, 2005, para. 189.

73 The Division for the Advancement of Women (DAW) of the UN Department of Economic and Social Affairs has specifically addressed gender and youth topics. See also Youth and the United Nations web site, at http://un.org/esa/socdev/unyin/index.html.

74 See http://unifem.org/campaigns/wsis/unifems_work.html.

75 ILO: Toolkit for mainstreaming employment and decent work, United Nations System Chief Executives Board for Coordination (Geneva, 2007), p. 31.
} 
253. The Youth Employment Network (YEN) - an alliance between the United Nations, the World Bank and the ILO - is an example of a global partnership that strives for better coherence, coordination and knowledge sharing on youth employment. YEN offers an opportunity to build international consensus and influence the international agenda with a comprehensive strategy for the employment and social inclusion of young people. The ILO provides the YEN secretariat. Recent efforts to mainstream the economic empowerment of women into projects include a competitive grant scheme for youth organizations in the Mano River Union, ${ }^{76}$ with additional involvement of the United Nations Industrial Development Organization (UNIDO), UNDP and the Government of Japan.

\subsection{The way forward}

254. Much action has to be taken to avoid exacerbating growing youth unemployment and working poverty, which is likely to worsen in the current global financial and economic crisis. Rather than being viewed as a problem, the expected arrival of young people on the labour market should be recognized as presenting enormous opportunities and a resource for economic and social development. Governments, employers' and workers' organizations, international development partners and civil society need to tap into the vast productive potential of young women and men. The following indicative list highlights areas in which the ILO's policies, programmes and activities can have an impact:

- Adapting an integrated and coherent approach to youth employment that combines macro- and microeconomic interventions and addresses both labour demand and supply. Youth employment should be considered in all relevant social, employment and economic policies through a well-balanced, gender-responsive policy mix.

- Labour market regulations, policies and institutions play a crucial role in matching the supply and demand sides of the labour market. The growing numbers of young people (particularly young women) in intermittent, insecure and low-paid jobs in some countries and their over-representation in the informal economy in others require urgent action.

- There is a close relationship between a young person's employment prospects and education. Basic education constitutes the foundation of young people's employability and is also an effective means of combating child labour and eradicating poverty. It is now widely accepted that long-term investments in human capital play a key role in enhancing productivity and growth. It is essential that adolescent and young girls be provided with quality formal and non-formal education programmes, including vocational training, that would lead to their empowerment and to more opportunities for decent work in their adulthood.

- Integrating core and technical skills training is imperative to improve employability. Literacy, numeracy and core qualifications are necessary tools for most entry-level jobs. ICT proficiency, in which many jobseekers are perceived to be deficient, must be emphasized for young women. Competency-based training free of gender bias shifts the emphasis from time spent in training courses to what trainees can actually do as a result of the training. Certification of skills and recognition of competencies acquired on the job comprise another area for improvement.

\footnotetext{
${ }^{76}$ Covering Côte d'Ivoire, Guinea, Liberia and Sierra Leone.
} 
- Apprenticeships open to young women and men alike are a training pathway integrated into the production process of enterprises that provide readily applicable, relevant skills. Formal apprenticeship and upgraded informal apprenticeship systems should involve employers and trade unions in defining occupational standards and curricula. "Soft" skills, such as communication, customer relations, teamwork and problem solving, should form part of training packages.

- Sex is not an indicator of competence. The decision to recruit, train or promote young women and men should always be based on reasons such as skills and the inherent requirements of the job, and not on the sex of the individual.

- Active labour market policies (ALMPs) and programmes can greatly facilitate young people's entry and re-entry into the labour market. Ensuring young women's access to work through ALMPs is crucial. This may need to be accompanied by complementary measures such as the provision of childcare in order to facilitate their participation.

- High unemployment and long job searches may be manifestations of poor relevance of job-entry training. Reassessing gender and youth employment policies, for example addressing the mismatch between education and market demands, occupational segregation, strengthening vocational training, and forecasting labour and skills needs would be effective in creating a "virtuous circle" of employment and productivity.

- Private-sector growth is a key engine of job creation, and youth entrepreneurship is an important component of employment policies. In most countries with proportionately large populations of young people, the barriers to doing business are high, and even higher for young women. This thwarts enterprise creation, encourages informality and jeopardizes good governance. Supporting young women as entrepreneurs will provide an impetus to social and economic development.

- Young women and men need to be made aware of their rights, including freedom of association and collective bargaining as means of attaining decent work. 



\section{Chapter 6}

\section{Working women and men in adulthood}

255. Adulthood is the prime of working life. Defined by experience and understanding, adult maturity brings to women and men a sense of realism and compromise, and the burden of responsibility. In this "rush hour of life", ${ }^{1}$ it is a tall order to pursue decent work, provide and care for family members, and fulfil obligations to enterprises, communities and societies.

256. Tables F1 to F3 in the appendix present the estimated numbers of women and men in the labour force and of working age in 2000 and 2020, and the activity rates for those estimates that are published by the ILO. The estimates for 2000 show that women were less economically active than men at all ages and in all regions of the world. Projections for 2020 show increases in both women and men in the labour force, with the number of men expected to continue to exceed that of women in the workplace.

257. Women will nevertheless have increased their participation in the economy, according to the ILO projections. There are differences according to region, but activity rates of women are expected to hold or increase in Africa, to increase in the Americas, to remain flat in Asia, and to increase in Europe. Some apparent decreases in the activity rates of younger workers - between 15 and 24 years - are probably due to the expected expansion in the availability of and access to tertiary education in many regions of the world in the coming decades.

258. The ILO assessment of progress towards gender equality is corroborated by the World Economic Forum's (WEF) index to benchmark global gender inequalities based on economic, political, education and health criteria. ${ }^{2}$ The economic component of the Global Gender Gap Index measures the difference in labour force participation rates, remuneration and advancement of women and men (the latter based on the ratio of women to men among legislators, senior officials and managers, and among technical and professional workers). Although the Index shows that much progress has been made on closing gender-based gaps in access to health and education, the difference in men's and women's economic participation is still wide, with only 58 per cent of the economic outcomes gap having been closed.

259. Women experience systemic barriers in almost every aspect of work - this ranges from whether they have paid work at all (full-time or part-time); the type of work they obtain or are excluded from; the availability of supports such as childcare; their pay, benefits and conditions of work; their access to higher-paying "male" occupations; the

\footnotetext{
1 U. Klammer: "Flexicurity in a life course perspective", in Transfer, Feb. 2004, p. 295.

2 The Global Gender Gap Index measures the size of the gender gap in 128 countries, covering 90 per cent of the world's population. R. Hausmann, L. Tyson and S. Zahidi: The Global Gender Gap Report 2007 (Geneva, World Economic Forum, 2007), p. 7.
} 
insecurity of their jobs or enterprises; the absence of equitable pension entitlements - or indeed of any entitlements; and the lack of time, resources or information necessary to enforce their rights. Discrimination is more acute in the case of women who are multiply disadvantaged by factors such as race, ethnicity or indigenous or disability status. ${ }^{3}$

260. Such gender inequality needs to be fought using all the labour market measures available in the twenty-first century. The workplace is a major site of inequality between women and men, and therefore a critical area in which to promote gender equality. For example, the French multinational Michelin has introduced a programme called Michelin Mentoring, as part of a strategy to ensure equal opportunities for professional growth and development of its employees. It encourages women and minorities to perform at high levels of excellence within an enabling environment. ${ }^{4}$

261. The ILO takes the approach - as does the World Bank (figure 6.1) - that labour markets are among the key transmission mechanisms through which the benefits of growth can be distributed to disadvantaged groups. ${ }^{5}$ The economic efficiency rationale for gender equality argues that it serves families: the evidence shows that when women have access to and increased control over resources, children's nutrition, health and education are improved. ${ }^{6}$ In addition, economies and societies benefit from women's participation by harnessing their untapped human capital. It has often been pointed out that the driving force for the industrialization of the Asian "tigers" was women's employment in export industries. ${ }^{7}$ Investing in decent work for women is not just right, but smart.

262. One region's approach to promoting gender equality has been the development of a comprehensive legislative framework, backed by budgetary allocations. In addition to a solid foundation of Council Directives and agreements, the EU has invested in increasing women's participation in the labour market through the European Social Fund. The employment rate of women in the EU rose from 54 to 57.2 per cent between 2001 and 2006, and the objective of 60 per cent by 2010 is within reach. The current Treaty on the functioning of the European Union requires the EU, in all its activities, to aim to eliminate inequalities and promote equality between men and women. The texts shown in box 6.1 shape national implementation, in partnership with the social partners, civil society and other stakeholders.

\footnotetext{
${ }^{3}$ M. Cornish: Securing pay equity for women's work - Everyone benefits: The international experience, Paper for ILO International Seminar on Equal Pay for Work of Equal Value, Santiago, Chile, 25 August 2008, pp. 3-4.

${ }^{4}$ Michelin: Michelin Mentoring, A better way to growth (2006).

5 ILO: Global Employment Trends for Women, March 2008 (Geneva, 2008), p. 1.

${ }^{6} \mathrm{M}$. Buvinić et al. (eds): Equality for women: Where do we stand on Millennium Development Goal 3? (Washington, DC, World Bank, 2008), pp. 5-6.

${ }^{7}$ In this context it is interesting to note that the most successful region in terms of economic growth over the last decade, namely East Asia, also has the highest regional labour force participation rate for women, low unemployment rates for both women and men, and relatively small gender gaps in sectoral as well as status distribution. ILO: Global Employment Trends for Women, March 2008, op. cit., p. 1.
} 


\section{Figure 6.1. Women's earnings, children's well-being, and aggregate poverty reduction and economic growth: The pathways}

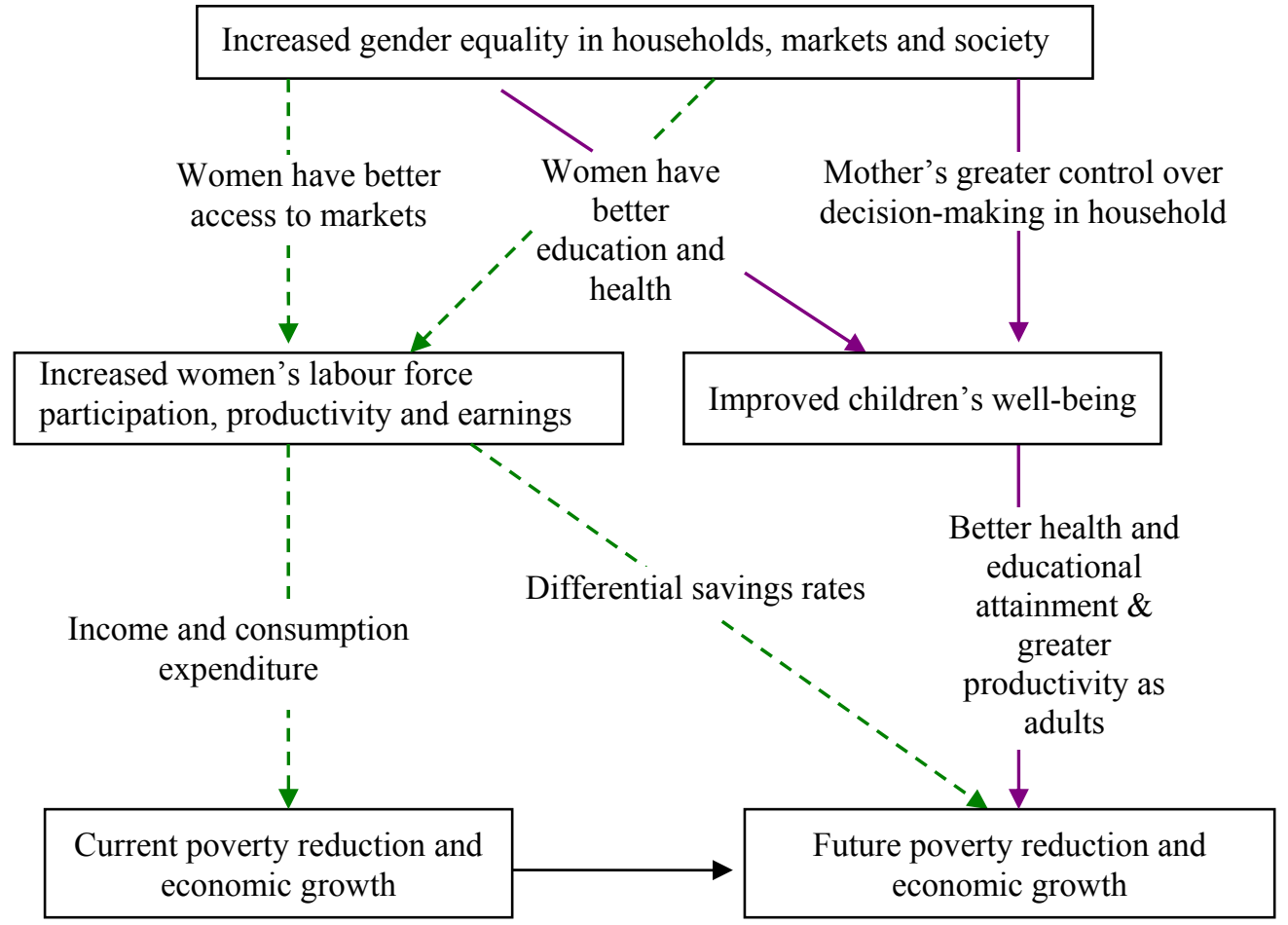

Source: M. Buvinić et al. (eds): Equality for women: Where do we stand on Millennium Development Goal 3 ? (Washington, DC, World Bank, 2008), p. 5.

263. Despite the impressive arsenal shown in box 6.1, EU monitoring of implementation shows that there are still areas of inequality between women and men that need attention, for example:

- the employment rate of women has increased but remains lower than men's, although women represent a majority of students and university graduates;

a women continue to earn on average 15 per cent less than men for every hour worked, and this figure remains stable;

- women are still very under-represented in economic and political decision-making positions, although their share has increased over the last decade;

a the division of family responsibilities between women and men is still very unequal;

a the risk of poverty is higher for women than for men;

a women are the main victims of gender-based violence, and women and girls are more vulnerable to trafficking. ${ }^{8}$

264. A number of factors influence labour force participation and activity rates, including age, sex, disability status and cultural, social and economic differences

${ }^{8}$ Commission of the European Communities: Renewed social agenda: Opportunities, access and solidarity in 21st century Europe, Communication from the Commission to the European Parliament, the Council, the European Economic and Social Committee and the Committee of the Regions, $\operatorname{COM}(2008) 412$ final; and idem: Report on equality between women and men, various years. 
between countries and regions of the world. Table 6.1 shows that the labour force participation rate of men has remained substantially higher than that of women. ${ }^{9}$

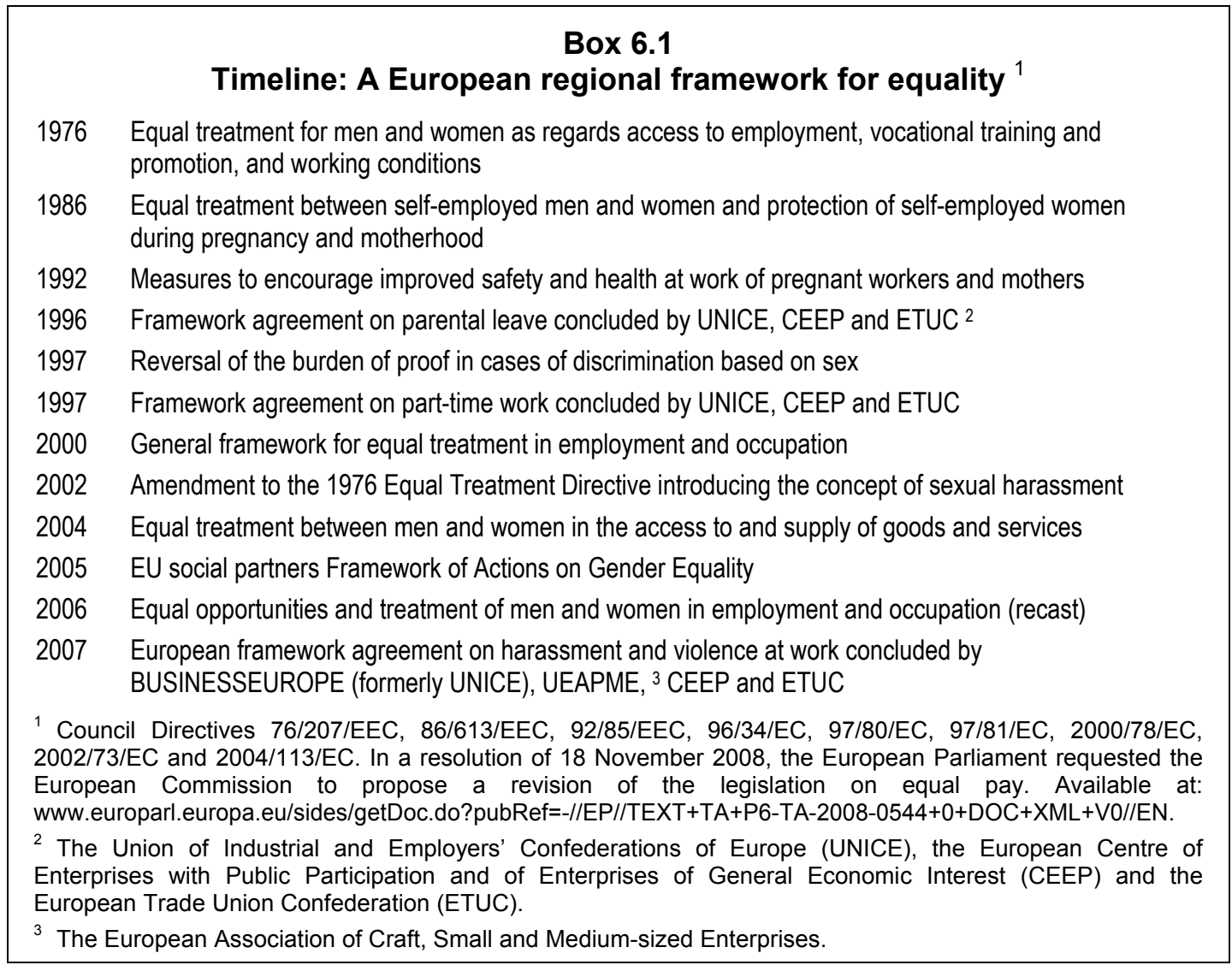

265. ILO data reveal the following significant trends. ${ }^{10}$ The global number of unemployed in 2008 is estimated at nearly 193 million. ${ }^{11}$ The unemployment rate for women was 6.3 per cent in 2008, compared to 5.9 per cent for men. Between 2007 and 2008 , the unemployment rate increased for both men ( 0.4 percentage points) and women ( 0.3 percentage points), thus slightly reducing the gender gap in unemployment rates that has been seen in the past decade. The effects of the current financial downturn may explain why male unemployment has risen, as men work in sectors affected by the first wave of retrenchments. In terms of numbers of unemployed, 112 million out of the total of 193 million are men, and 81 million are women (table 6.2).

\footnotetext{
9 See also tables F1 to F3 in the appendix.

10 The data in this section are largely taken from ILO: Global Employment Trends for Women: March 2009 (Geneva, 2009).

11 For the definition of unemployment, and concepts and definitions of all labour market indicators discussed in this report, please refer to ILO: Key Indicators of the Labour Market, fifth edition (Geneva, 2007).
} 
Table 6.1. Labour force participation rate worldwide (percentage)

\begin{tabular}{lccccccccccc}
\hline & $\mathbf{1 9 9 8}$ & $\mathbf{1 9 9 9}$ & $\mathbf{2 0 0 0}$ & $\mathbf{2 0 0 1}$ & $\mathbf{2 0 0 2}$ & $\mathbf{2 0 0 3}$ & $\mathbf{2 0 0 4}$ & $\mathbf{2 0 0 5}$ & $\mathbf{2 0 0 6}$ & $\mathbf{2 0 0 7}$ & $\mathbf{2 0 0 8}$ \\
\hline Total & 65.8 & 65.7 & 65.6 & 65.5 & 65.4 & 65.2 & 65.2 & 65.2 & 65.1 & 65.1 & 65.1 \\
Male & 79.2 & 79.1 & 78.9 & 78.7 & 78.4 & 78.2 & 78.0 & 77.9 & 77.7 & 77.6 & 77.5 \\
Female & 52.4 & 52.3 & 52.3 & 52.3 & 52.3 & 52.3 & 52.3 & 52.5 & 52.6 & 52.6 & 52.6 \\
Youth & 54.4 & 54.2 & 53.5 & 52.9 & 52.5 & 51.9 & 51.6 & 51.3 & 50.9 & 51.0 & 50.9 \\
Adult & 69.7 & 69.6 & 69.7 & 69.7 & 69.7 & 69.7 & 69.7 & 69.8 & 69.8 & 69.7 & 69.7 \\
1 Preliminary estimates. \\
\multicolumn{7}{l}{ Source: ILO: Global Employment Trends for Women: March 2009 (Geneva, 2009), tables A3 and A4, p. 37. } \\
\multicolumn{7}{l}{}
\end{tabular}

Table 6.2. Unemployment worldwide (millions)

\begin{tabular}{|c|c|c|c|c|c|c|c|c|c|c|c|}
\hline & 1998 & 1999 & 2000 & 2001 & 2002 & 2003 & 2004 & 2005 & 2006 & 2007 & $2008^{1}$ \\
\hline Total & 165.1 & 172.1 & 170.7 & 173.4 & 175.5 & 183.9 & 189.1 & 188.3 & 184.4 & 178.9 & 192.7 \\
\hline Male & 95.7 & 99.5 & 100.0 & 100.7 & 101.7 & 107.2 & 108.7 & 108.0 & 105.9 & 103.4 & 111.7 \\
\hline Female & 69.3 & 72.5 & 70.7 & 72.7 & 73.8 & 76.7 & 80.3 & 80.3 & 78.5 & 75.5 & 81.0 \\
\hline Youth & 67.6 & 70.7 & 71.1 & 70.5 & 71.0 & 74.0 & 76.3 & 76.4 & 74.9 & 73.1 & 77.2 \\
\hline Adult & 97.4 & 101.4 & 99.6 & 102.8 & 104.5 & 110.0 & 112.7 & 111.9 & 109.5 & 105.7 & 115.5 \\
\hline
\end{tabular}

266. The male/female unemployment rate is one indication of gender inequalities in global labour markets. Another is the difference in access to labour markets, which is linked to economic empowerment for women. The gap between male and female labour force participation rates is narrowing at a very slow pace, and amounted to almost 25 percentage points in 2008 (table 6.2). Women made up 40.5 per cent of the global labour force in 2008, up from 39.9 per cent in 1998.

267. Out of the 3 billion people employed around the world in 2008, 1.2 billion are women. Only a small proportion of employed women are working in industry (18.3 per cent, compared to 26.6 per cent of men); the large majority are in agriculture and, increasingly, in the services sector (figure 6.2). The latter accounted for 46.3 per cent of all female employment in 2008, compared to 41.2 per cent of male employment. Women are still over-represented in the agricultural sector. Globally, the share of women employed in agriculture stands at 35.4 per cent, compared to 32.2 per cent for men, but this proportion rises to almost half of all female employment (48.4 per cent) if one excludes the more industrialized regions such as the developed economies and EU, Central and South-Eastern Europe (non-EU) and CIS, and Latin America and the Caribbean. The corresponding percentage for males is 40 , resulting in a difference of almost 8 percentage points in the remaining regions of the world. In sub-Saharan Africa and South Asia the agricultural sector makes up more than 60 per cent of all female employment. 
Figure 6.2. Distribution of employment by sector (percentage of total employment), by sex and region, $2008^{1}$

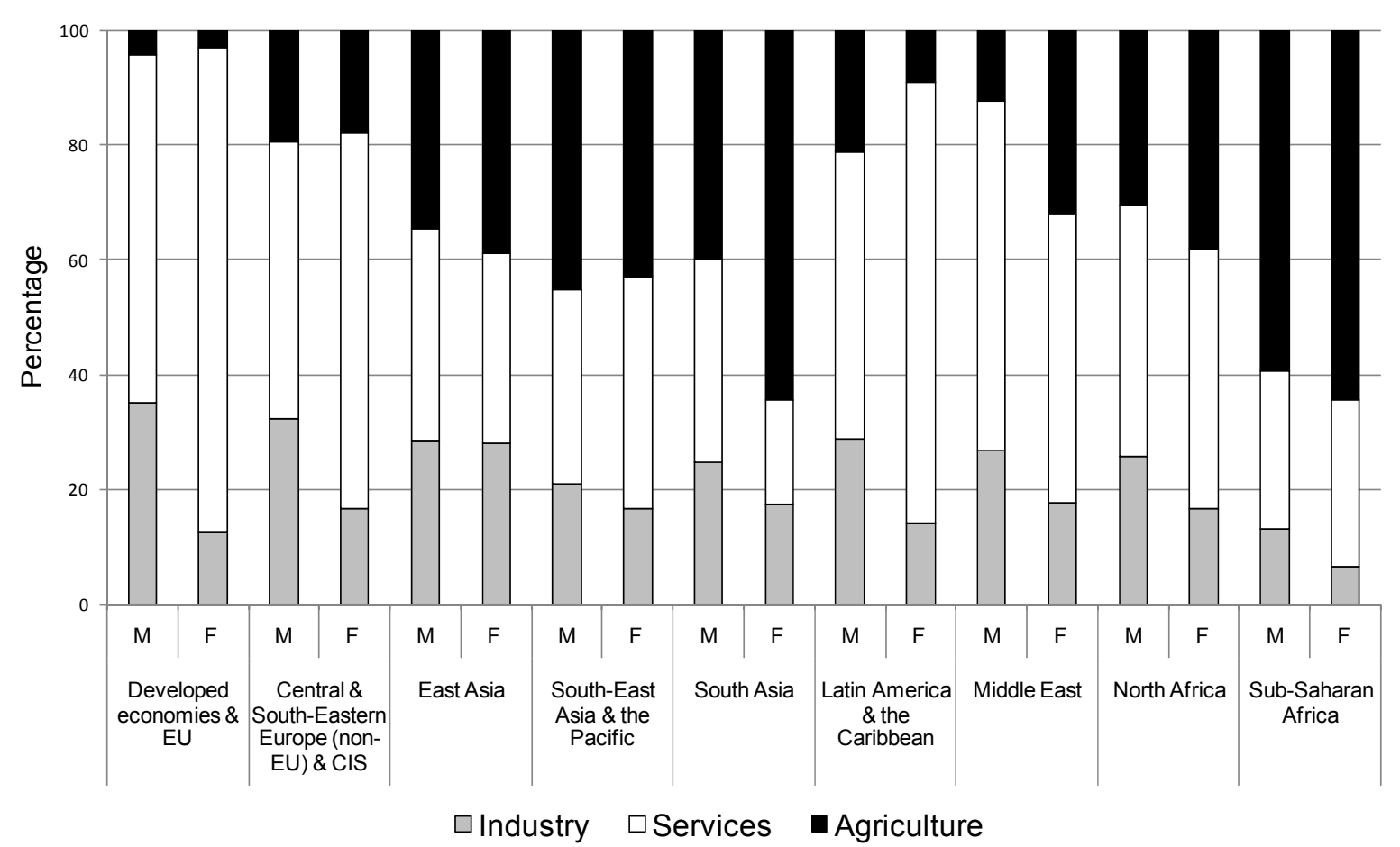

1 Preliminary estimates.

Source: ILO: Global Employment Trends for Women, March 2009 (Geneva, 2009), figure 3, p. 11.

268. The financial crisis will have an impact on these figures, as global exports of manufactured goods slow down and factories close down in industrial areas, workers are laid off and many women and men return to rural areas.

\subsection{Global supply chains}

269. The export performance of developing countries in manufactured goods has relied heavily on female labour. The increased demand for women workers in export industries has been credited, mainly or at least partially, for the expansion of women's paid employment in developing countries, even where women's participation in paid work was traditionally low and socially unacceptable. New job opportunities in outsourced, offshored services (for example in call centres, data entry, payroll and accounting, and financial and legal research) have also expanded as a result of improvements in global telecommunications networks and technology. In recent decades, exports from some developing countries of fruit, flowers and vegetables - again heavily reliant on women's labour - have emerged as new areas for international trade and employment. ${ }^{12}$

270. The optimistic view is that women have benefited significantly from the expansion of export manufacturing, agriculture and business services in terms of increased access to paid jobs and economic opportunities, with all the equality benefits associated with

\footnotetext{
12 This section draws largely on A. King Dejardin: Gender dimensions of globalization, Discussion paper, Policy Integration and Statistics Department (Geneva, ILO, 2008).
} 
paid work (increased autonomy, bargaining power and resources). ${ }^{13}$ The less optimistic view highlights three issues: (i) although jobs have been created, most jobs are not secure, with production relying on casual, temporary, contract or precarious workers, seasonal migrants and homeworkers; (ii) while women's paid employment has vastly expanded, they are concentrated in lower segments of global supply chains; and (iii) work in global production systems has been made more unstable by greater financial and trade integration. This has replicated and reinforced existing gender inequalities, ${ }^{14}$ which are being examined in the light of the current financial downturn. Research tools such as value chain analysis, which examines the different value ascribed to each player in the process of producing a commodity, will help understand the links between trade and gender inequality. ${ }^{15}$

271. However, it is not only goods that are part of supply chains. Men and women also form part of a set of interlinked services, in particular, the "global care chain", in which migrants leave their own dependants in the care of other family members to work as caregivers in wealthier cities or countries. The majority of these care providers are women, ranging from unskilled domestic workers to skilled health services personnel. Rather than creating conditions that might enable existing ways of organizing and valuing care to shift, importing care workers displaces the problem, leaving inequitable gender divisions of labour intact. At the same time, it does little to encourage better state provision of care services, or improved social protection measures for care providers. ${ }^{16}$

\subsection{Vulnerable employment}

272. The less developed the region, the greater the likelihood that women are among the ranks of the contributing family workers or own-account workers who together make up the newly defined "vulnerable employment" group. Female contributing family workers, in particular, are not likely to be economically independent. ${ }^{17}$

\footnotetext{
13 The exact magnitude of employment created is not easy to estimate; many workers are employed by suppliers and subcontractors, both in formal and informal employment.

14 The lessons from developing countries in previous crises are that informal employment tends to rise and earnings to decline. Recovery is long and slow for the most vulnerable workers (for example Thailand in the 1997 Asian crisis or the 1995 crisis in Mexico), with a differential impact on men's and women's employment. A. King Dejardin: Gender dimensions of globalization, op. cit.

15 Z. Randriamaro: Gender and trade: Overview report, Institute of Development Studies, University of Sussex (Brighton), p. 2.

16 E. Esplen: Gender and care: Overview report, Institute of Development Studies, University of Sussex (Brighton, 2009), p. 30.

17 The international classification of status in employment defines four statuses: (1) wage and salaried workers; (2) employers; (3) own-account workers; and (4) contributing family workers. Vulnerable employment refers to persons who are employed under relatively precarious circumstances as indicated by their status in employment. Because contributing family workers and own-account workers are less likely to have formal work arrangements, access to benefits or social protection programmes and are more "at risk" with regard to economic cycles, these are the statuses categorized as "vulnerable". The vulnerable employment rate is thus calculated as the sum of own-account workers and contributing family workers as a percentage of total employment. The indicator is highly gender sensitive since, historically, contributing family work is a status that is dominated by women. See also ILO: Key Indicators of the Labour Market, fifth edition (Geneva, 2007), Chapter 1.
} 
273. At the global level, the share of vulnerable employment in total female employment was 52.7 per cent in 2007 , compared to 49.1 per cent for men, which represents a decline of 0.6 percentage points over the previous year for both men and women. The move away from vulnerable employment into wage and salaried work can be a major step toward women's empowerment. Economic independence or at least codetermination in resource distribution within the family is highest when women are in wage and salaried work or are employers, lower when they are own-account workers and lowest when they are contributing family workers. The share of women in wage and salaried work grew from 41.8 per cent in 1997 to 45.5 per cent in 2007, but female ownaccount workers registered a stronger increase (figure 6.3).

Figure 6.3. Distribution of female status in employment, 2007

(percentage point change from 1997 in parentheses)

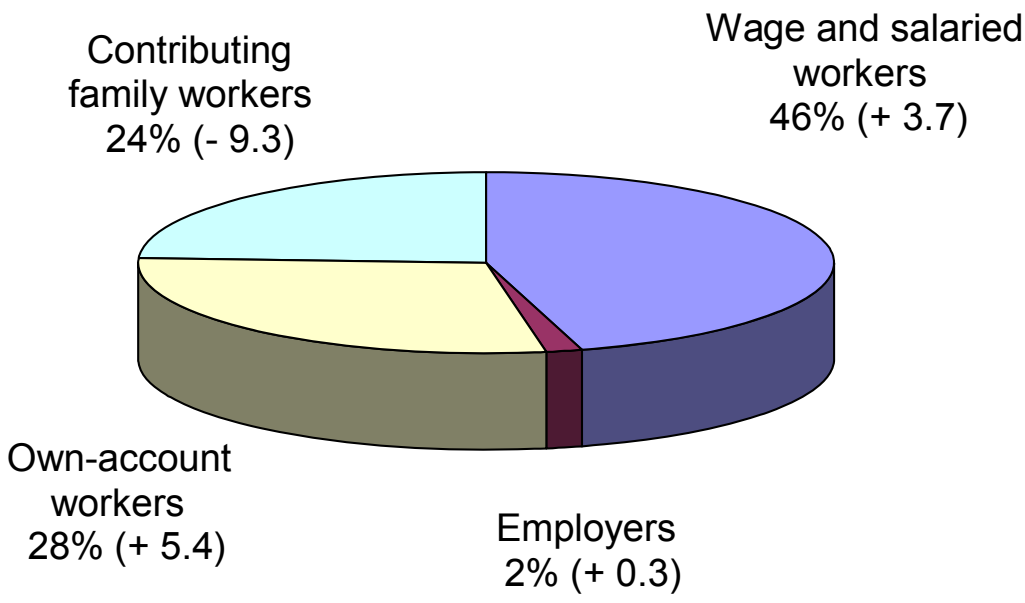

Source: ILO: Global Employment Trends for Women, March 2009 (Geneva, 2009), figure 4, p. 12.

274. The gender gap in the share of vulnerable employment in total employment shows a diverse picture by region. In the developed economies and the EU, Central and SouthEastern Europe (non-EU) and CIS, and Latin America and the Caribbean, this gap was negative in 2007, meaning that women are often in less vulnerable jobs then men (see table 6.3). The largest gaps can be found in North Africa and the Middle East. SubSaharan Africa and South Asia, two of the poorest regions, have not only a relatively high share of vulnerable employment in total employment, but also a large gender gap in vulnerable employment shares (exceeding ten percentage points). The sectoral distribution of male and female employment, as well as the differences in vulnerable employment shares, underline the fact that more access to labour markets is not the same as access to decent jobs. 
Table 6.3. Vulnerable employment shares, world and regions (percentage)

\begin{tabular}{|c|c|c|c|c|c|c|c|}
\hline Total & 1997 & 2002 & 2003 & 2004 & 2005 & 2006 & 2007 \\
\hline World & 53.5 & 52.1 & 52.1 & 51.8 & 51.4 & 51.2 & 50.6 \\
\hline Developed economies and EU & 11.8 & 10.5 & 10.5 & 10.8 & 10.7 & 10.4 & 10.1 \\
\hline $\begin{array}{l}\text { Central and South-Eastern Europe } \\
\text { (non-EU) and CIS }\end{array}$ & 17.8 & 19.2 & 19.5 & 20.6 & 19.1 & 19.2 & 18.2 \\
\hline East Asia & 63.7 & 58.1 & 57.7 & 57.6 & 57.2 & 56.9 & 55. \\
\hline South-East Asia and the Pacific & 65.6 & 64.8 & 64.8 & 63.4 & 62.8 & 62.6 & 61.9 \\
\hline South Asia & 79.8 & 79.1 & 79.3 & 79.0 & 78.8 & 78.4 & 77.5 \\
\hline Latin America and the Caribbean & 32.4 & 35.2 & 35.1 & 34.4 & 33.0 & 32.1 & 31.9 \\
\hline Middle East & 39.3 & 35.8 & 35.3 & 36.1 & 33.5 & 33.6 & 32.3 \\
\hline North Africa & 43.1 & 40.2 & 40.0 & 41.1 & 41.0 & 38.7 & 37.3 \\
\hline Sub-Saharan Africa & 80.2 & 78.7 & 78.5 & 76.8 & 77.1 & 77.8 & 76.8 \\
\hline Males & 1997 & 2002 & 2003 & 2004 & 2005 & 2006 & 2007 \\
\hline World & 51.4 & 50.7 & 50.7 & 50.3 & 50.0 & 49.8 & 49.1 \\
\hline Developed economies and EU & 12.2 & 11.4 & 11.5 & 12.0 & 11.9 & 11.6 & 11.4 \\
\hline $\begin{array}{l}\text { Central and South-Eastern Europe } \\
\text { (non-EU) and CIS }\end{array}$ & 18.4 & 19.2 & 19.8 & 21.2 & 19.6 & 19.5 & 18.6 \\
\hline East Asia & 58.4 & 53.5 & 53.2 & 53.0 & 52.5 & 52.3 & 51.1 \\
\hline South-East Asia and the Pacific & 61.5 & 61.3 & 61.4 & 59.9 & 59.7 & 59.6 & 58.9 \\
\hline South Asia & 76.1 & 76.2 & 76.5 & 76.0 & 75.8 & 75.4 & 74.3 \\
\hline Latin America and the Caribbean & 32.6 & 35.0 & 35.0 & 34.2 & 33.4 & 32.2 & 32.1 \\
\hline Middle East & 35.8 & 32.4 & 32.0 & 33.1 & 30.2 & 30.3 & 29.1 \\
\hline North Africa & 39.5 & 38.4 & 37.0 & 36.8 & 37.3 & 34.7 & 33.4 \\
\hline Sub-Saharan Africa & 75.6 & 73.4 & 72.8 & 70.1 & 71.1 & 72.4 & 71.3 \\
\hline Females & 1997 & 2002 & 2003 & 2004 & 2005 & 2006 & 2007 \\
\hline World & 56.7 & 54.3 & 54.2 & 54.1 & 53.6 & 53.3 & 52.7 \\
\hline Developed economies and EU & 11.2 & 9.4 & 9.4 & 9.3 & 9.2 & 8.9 & 8.6 \\
\hline $\begin{array}{l}\text { Central and South-Eastern Europe } \\
\text { (non-EU) and CIS }\end{array}$ & 17.1 & 19.3 & 19.2 & 19.8 & 18.4 & 18.8 & 17.6 \\
\hline East Asia & 70.1 & 63.6 & 63.1 & 63.1 & 62.6 & 62.3 & 61.4 \\
\hline South-East Asia and the Pacific & 71.3 & 69.9 & 69.7 & 68.4 & 67.3 & 66.9 & 66.2 \\
\hline South Asia & 89.1 & 86.4 & 86.5 & 86.4 & 86.1 & 86.0 & 85.1 \\
\hline Latin America and the Caribbean & 32.0 & 35.5 & 35.3 & 34.6 & 32.5 & 31.9 & 31.5 \\
\hline Middle East & 54.1 & 48.6 & 47.9 & 46.9 & 45.7 & 45.3 & 43.6 \\
\hline North Africa & 54.9 & 45.8 & 49.0 & 54.2 & 52.0 & 50.0 & 48.4 \\
\hline Sub-Saharan Africa & 86.3 & 85.7 & 85.8 & 85.4 & 84.9 & 84.6 & 83.9 \\
\hline
\end{tabular}




\subsection{Non-standard forms of work}

275. The last decades have seen a trend towards non-standard forms of work, ${ }^{18}$ resulting in more part-time and temporary employment in advanced economies and more informal employment in developing countries. There is a clear link between this type of work and income inequality. ${ }^{19}$ There is also an indication that most of these jobs are held by women, sometimes as a means of reconciling work and family responsibilities in the absence of any institutional support. Even formal work is increasingly precarious, with many enterprises relying on a labour force dominated by workers engaged in other forms of employment relationship (atypical, temporary, contract or home-based work). ${ }^{20}$ According to employers' organizations, balancing efficiency with family needs and responsibilities of both men and women employees is becoming increasingly important for businesses, particularly as they operate in tight labour markets. Flexible working arrangements allow employers to retain skills critical for their operation while at the same time providing employees who would otherwise have to leave for family reasons with the opportunity to remain economically active.

276. Precarious work - characterized by job insecurity - offers workers little or no opportunity to control their working conditions, claim benefits or social security or exercise their right to freedom of association. Remuneration is usually low. A common manifestation is successive short-term or fixed-term contracts with short breaks between them. Home work has become more frequent with the growing use of subcontracting, industrial outsourcing and ICT. ${ }^{21}$ Women with disabilities are disproportionately represented in this group.

\subsubsection{Part-time employment}

277. In industrialized countries, the share of part-time employment (PTE) as a proportion of total employment has increased over the last 20 years. ${ }^{22}$ The highest rate of PTE is to be found in the Netherlands, where nearly one-third of all workers are on part-time contracts, followed by Japan, Australia, New Zealand and the United Kingdom. ${ }^{23}$ Table 6.4 shows that the incidence of PTE is much higher for women than for men. The issue raises questions as to how to achieve gender equality without reinforcing gender inequality. Some of those currently in PTE might not have entered the

\footnotetext{
${ }^{18}$ Nomenclature in this area varies. The following are commonly used: casual and seasonal work, job sharing, fixed-term contracts, temporary agency work, home-based work, remote working, selfemployment, and work of unpaid spouses or family members in small enterprises. "Casual work" refers to work for a fixed period, in which workers often have fewer rights and legal and contractual entitlements than permanent staff. It should be noted that self-employment is not necessarily precarious.

${ }^{19}$ U. Rani: Impact of changing work patterns on income inequality (Geneva, ILO-IILS, 2008), pp. 20-21.

${ }^{20}$ ILO: The employment relationship, Report V(I), ILC, 95th Session, Geneva, 2006, paras 31-33. M. Cornish: Securing pay equity for women's work - Everyone benefits: The international experience, Paper for ILO International Seminar on Equal Pay for Work of Equal Value, Santiago, Chile, 25 August 2008, pp. 2-3.

${ }^{21}$ The ILO's Employment Relationship Recommendation, 2006 (No. 198), offers guidance on how to cover workers who may lose protection and benefits in such regimes; several national labour laws explicitly include home work in their scope (Belgium, Chile, Morocco, New Zealand).

22 The Part-time Work Convention, 1994 (No. 175), defines the term "part-time worker" as an employed person whose normal hours of work are less than those of comparable full-time workers.

${ }^{23}$ A. Ghose, N. Majid and C. Ernst: The global employment challenge (Geneva, ILO, 2008), p. 164.
} 
labour force at all if part-time work had not been available, and they might have remained economically inactive. ${ }^{24} \mathrm{PTE}$ in most countries comes at considerable cost to the worker, with lower wages compared to equivalent full-time work, as well as lack of rights, social security benefits and representation and voice.

Table 6.4. Key employment indicators by sex, 2003 (percentages)

\begin{tabular}{|c|c|c|c|c|c|c|c|c|c|c|c|c|}
\hline \multirow[t]{2}{*}{ Country } & \multicolumn{6}{|l|}{ Male } & \multicolumn{6}{|c|}{ Female } \\
\hline & PR & UR & URS & URL & PTE & TEMP & PR & UR & URS & URL & PTE & TEMP \\
\hline (a) & 00 & 5.61 & 1.00 & $1.0<-$ & 15.67 & 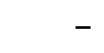 & 66.73 & 5.84 & 4.84 & 1.00 & 39.89 & $\ldots$ \\
\hline ustria & 80.09 & 4.28 & 3.05 & 1.23 & 3.04 & 6.14 & 64.66 & 4.12 & 3.11 & 1.01 & 25.74 & 6.00 \\
\hline Igiun & 73.07 & 7.44 & 4.12 & 3.32 & 5.86 & 5.20 & 56.16 & 8.00 & 4.14 & 3.85 & 33.28 & 9.72 \\
\hline anada & 84.87 & 7.97 & 7.10 & 0.88 & 11.07 & - & 74.05 & 7.18 & 6.62 & 0.56 & 27.86 & \\
\hline enmark & 85.36 & 5.09 & 4.00 & 1.10 & 10.52 & 7.17 & 75.67 & 5.75 & 4.73 & 1.02 & 1.91 & 9.79 \\
\hline nland & 76.70 & 9.19 & 6.77 & 2.41 & 7.89 & 10.60 & 72.37 & 8.90 & 7.11 & 1.80 & 14.86 & 18.24 \\
\hline anice & 75.50 & 8.70 & 5.29 & 3.41 & 4.52 & 9.81 & 63.73 & 10.94 & 6.68 & 4.26 & 22.02 & 13.10 \\
\hline 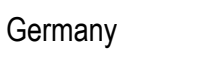 & 78.96 & 9.63 & 4.73 & 4.90 & 5.96 & 10.48 & 65.06 & 8.82 & 4.00 & 4.82 & 36.28 & 11.30 \\
\hline reece & 80.24 & 6.02 & 3.07 & 2.94 & 2.87 & 5.84 & 52.79 & 14.33 & 5.60 & 8.72 & 10.17 & 8.64 \\
\hline 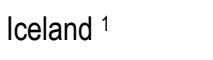 & 04.10 & 3.60 & - & - & 10.24 & 4.15 & 86.70 & 3.08 & - & - & 31.18 & 5.28 \\
\hline eland & 80.31 & 4.76 & 2.78 & 1.98 & 7.58 & 3.37 & 58.23 & 3.85 & 2.83 & 1.03 & 34.37 & 5.55 \\
\hline aly & 10.10 & 6.74 & 2.85 & 3.89 & 4.86 & 5.74 & 48.83 & 11.62 & 4.60 & 7.02 & 23.63 & 9.72 \\
\hline apan & 91.74 & 5.47 & 3.33 & 2.14 & 14.37 & - & 64.31 & 4.86 & 3.69 & 1.17 & 41.26 & \\
\hline uxembourg & 75.88 & 3.00 & 2.03 & 0.96 & 1.63 & 2.73 & 54.70 & 4.63 & 3.77 & 0.87 & 30.06 & 3.90 \\
\hline ther & 84.74 & 4.10 & 3.06 & 1.04 & 14.99 & 10.98 & 68.38 & 4.34 & 3.29 & 1.05 & 60.50 & 14.79 \\
\hline Vew Zealand & 85.40 & 4.34 & 3.76 & 0.58 & 10.70 & - & 70.33 & 4.99 & 4.53 & 0.47 & 35.40 & \\
\hline wo & 84.54 & 4.85 & 4.5 & 0.34 & 7 & 6.85 & 6 & 3.95 & 3 & 0.22 & 33.15 & 10.76 \\
\hline Portugal & 83.88 & 5.55 & 3.93 & 1.62 & 5.85 & 14.42 & 69.40 & 7.33 & 4.84 & 2.49 & 14.98 & 17.64 \\
\hline s & 81.63 & 8.17 & 5.58 & 2.58 & 2.46 & 6 & 0 & 15.91 & 9 & 6.55 & 16.44 & 29.63 \\
\hline Sweden & 82.63 & 6.31 & 5.12 & 1.19 & 7.72 & 10.73 & 77.69 & 5.18 & 4.40 & 0.78 & 20.35 & 16.29 \\
\hline 4 & ( & 3.94 & 3. & 0.84 & 8.14 & 9.53 & 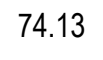 & 4.59 & 3.20 & 1.39 & 45.81 & 10.70 \\
\hline United Kingdom & 85.44 & 5.46 & 3.96 & 1.50 & 10.03 & 4.33 & 70.22 & 4.10 & 3.41 & 0.69 & 39.85 & 6.17 \\
\hline nitod Ctatos & 85.09 & 6.27 & 5.49 & 0.78 & 6.87 & - & 71.88 & 5.66 & 5.04 & 0.62 & 17.28 & - \\
\hline \multicolumn{13}{|c|}{$\begin{array}{l}1 \text { Data on PTE refer to } 2002 . \\
P R=\text { Labour force participation rate. UR = Unemployment rate. URS = Short-term unemployment rate. URL = Long-term unemployment rate. } \\
P T E=\text { Share of part-time employment in total employment. TEMP }=\text { Share of temporary employment in total employment. } \\
\text { - = Data not available. }\end{array}$} \\
\hline \multicolumn{13}{|c|}{ urce: A. Ghose, N. Majid a } \\
\hline
\end{tabular}

24 ibid. 
278. In developed countries, much PTE is reported to be voluntary, particularly among women. This may result from a choice to maintain a balance between work and family, or from the absence of any viable alternatives such as institutional support, affordable, quality childcare and limits on regular working hours. ${ }^{25}$

279. PTE may contribute to greater flexibility (for example, to pursue studies) and higher labour force participation rates, but it is not always voluntary. In some cases it is a refuge from unemployment, as reflected in the increase in the share of involuntary parttime work for men, for example, in Germany, Italy, Japan and Spain. ${ }^{26}$ In Central and Eastern Europe, PTE is systematically higher for women, although the overall figures for both men and women are generally low, ranging from 2.4 per cent in Bulgaria to 10.8 per cent in Poland. ${ }^{27}$ The incidence of part-time work remains low in most developing countries.

\subsubsection{The informal economy}

280. Informal and formal work should not be understood as dichotomous, but rather as intimately linked and frequently overlapping. When it adopted the conclusions concerning decent work and the informal economy in 2002, the ILC noted that informal and formal work exist along a continuum, with informal work lying outside the regulatory framework. The informal economy is expanding with the proliferation of outsourcing, subcontracting and casual work. In the 2008 financial crisis, layoffs in the formal sector led to major increases in informal economy jobs. In developing countries, where the informal economies are already large, the loss of jobs in the formal sector will only make matters worse. In times of crisis, there is a strong positive correlation between the increase in informal jobs and formal job losses. ${ }^{28}$ The informal economy includes both own-account workers and wage workers, who cut across a range of sectors and areas of work. Given that formal wage labour has never been the norm for more than half the population in many parts of the world, classification into "formal" and "informal" may not always be the most relevant or useful basis for analysis. When deciding on measures to transform informal into formal jobs, an appropriate mix of policies must be chosen and implemented, and informal economy workers need a representative voice in these policy decisions. ${ }^{29}$

281. Within the informal economy, women make a sizeable contribution to GDP, either as independent entrepreneurs or in employment relationships in global production chains or small businesses. Yet this is not often captured by national accounts. In West Africa, the Caribbean and Asia, between 70 and 90 per cent of all farm and marine produce is traded by women. Street and market stands are estimated to generate around 30 per cent

${ }^{25}$ See U. Rani: Impact of changing work patterns on income inequality (Geneva, ILO-IILS, 2008), p. 3.

${ }^{26}$ ibid.

27 A. Ghose, N. Majid and C. Ernst: The global employment challenge, op. cit., pp. 216-217.

${ }^{28}$ Examples from the 1997 Asian financial crisis include Indonesia, Malaysia, the Philippines and Thailand. See A. King Dejardin and J. Owens: Asia in the global economic crisis: Impacts and responses from a gender perspective, Technical note for the Asia/Pacific Regional Forum, Responding to the Economic Crisis - Coherent Policies for Growth, Employment and Decent Work in Asia and the Pacific, Manila, 18-20 February 2009, p. 7.

${ }^{29}$ M. Chen: "Addressing informality, reducing poverty", in Jobs, jobs, jobs - The policy challenge, Poverty in Focus No. 16 (Brasilia, International Poverty Centre, Dec. 2008), p. 7. 
of all urban wealth. ${ }^{30}$ Some estimates suggest that the informal economy contributes around 41 per cent of non-agricultural GDP in sub-Saharan Africa. ${ }^{31}$ Nevertheless, the ILC conclusions concerning decent work and the informal economy are clear on the need for transition from informality to formality.

282. Average earnings are lower in the informal economy than in the formal economy. However, it is difficult to generalize: some formal wage workers may be poorer than informal employers, for example. Men tend to be over-represented in the top segment of earnings and women in the lower segment, as illustrated in figure 6.4.

\section{Figure 6.4. Segmentation of informal employment by average earnings and sex}

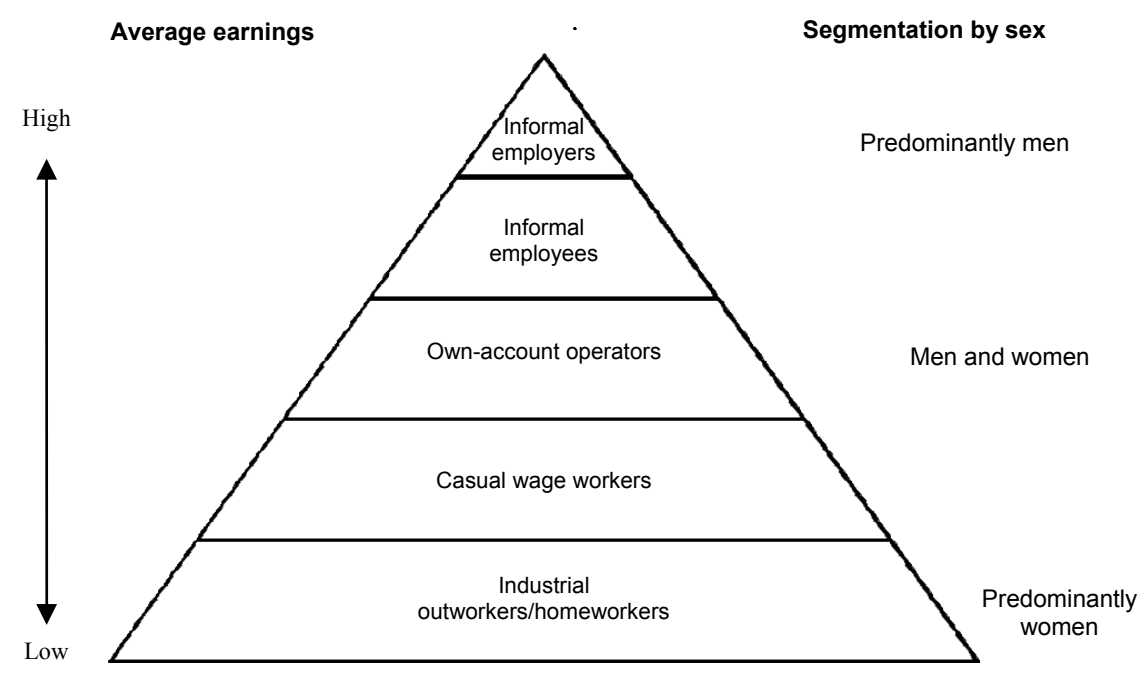

Source: M. Chen: "Addressing informality, reducing poverty", in Jobs, jobs, jobs - The policy challenge, Poverty in Focus No. 16 (Brasilia, International Poverty Centre, Dec. 2008), p. 6.

\subsubsection{Home work}

283. In some developed countries, home-based work ${ }^{32}$ can be a voluntary choice and can be relatively well paid, even if poorly protected. Home-based work can provide a way for women and men to reconcile work and family responsibilities. ${ }^{33}$ In rural communities where commuting is time-consuming, it offers a means of earning a livelihood. However, home work is often a survival strategy, and challenges decent work because of the disadvantages associated with it - long hours, poor pay, limited access to

\footnotetext{
${ }^{30}$ UNFPA: The State of World Population 2000: Living together, worlds apart: Men and women in a time of change.

${ }^{31}$ Country data suggest that in Burkina Faso, out of a total GDP contribution of the informal economy of 36 per cent, 29 per cent comes from women and 7 per cent from men, while in Mali 26 per cent comes from women and 14 per cent from men. M. Blackden et al.: Gender and growth in sub-Saharan Africa, United Nations University, World Institute for Development Economics Research (UNU-WIDER), Research Paper No. 2006/37.

32 Article 1 of the Home Work Convention, 1996 (No. 177), defines home work as "work carried out by a person, to be referred to as a homeworker: (i) in his or her home or in other premises of his or her choice, other than the workplace of the employer; (ii) for remuneration; (iii) which results in a product or service as specified by the employer, irrespective of who provides the equipment, materials or other inputs used, unless this person has the degree of autonomy and of economic independence necessary to be considered an independent worker under national laws, regulations or court decisions".

33 See C. Hein: Reconciling work and family: Practical ideas from global experience (Geneva, ILO, 2005), pp. 151-155.
} 
social protection, safety and health problems, and isolation, making it difficult to organize and bargain effectively. Compliance with regulations - where they exist cannot be easily monitored and enforced through labour inspection, ${ }^{34}$ because of the confusion about whether the person is actually at work or simply at home. Often the work is undeclared by both employers and workers. With globalization and the growth of supply chains, home work is increasingly common, especially among women. A modern offshoot of home work is teleworking, a flexible way of organizing work using ICT so that the worker need not be physically present at the central place of production.

284. Guidance on determining whether a person is a dependent homeworker or an independent own-account worker operating from her or his own home (with subcontractor or industrial outsourcing status) is given in the Employment Relationship Recommendation, 2006 (No. 198). The Home Work Convention, 1996 (No. 177), and Recommendation, 1996 (No. 184), address the specific characteristics of home work. The Convention requires member States to adopt a national policy on the subject, with special attention to equality of treatment between homeworkers and other wage earners. In a growing number of countries, this type of work is being covered by policy and laws. ${ }^{35}$ Attention is also given to enforcement to curb abuses. In practical terms, efforts to improve the situation of homeworkers have involved organizing in order to lobby for rights and protections, as is the case of the Bangladesh Homeworkers Women Association and the National Network of Homeworkers (PATAMABA) in the Philippines.

\subsection{Entrepreneurship}

285. Women's businesses are often smaller than men's, partly because of their limited access to productive resources. Poverty alleviation and growth strategies often recognize the importance of promoting enterprise development for women, as well as for young persons. With the right support, they can offer women the opportunity for social and economic empowerment and enable them to earn a livelihood for themselves and their families. Women have been making substantial inroads in small-scale enterprises in both the formal and informal economies.

286. The growth potential of enterprises is linked to access to and control over resources such as land, credit, technology, networks, information and markets. Women's limited access to each of these factors severely impairs the viability of their income-generating activities, with the result that women entrepreneurs are concentrated in the smallest and most precarious enterprises.

287. The creation of an enabling environment, the pursuit of good governance and the sustainable availability of physical and social infrastructure are necessary for the competitiveness of existing businesses and the start-up of new enterprises. ${ }^{36}$ Lack of infrastructure support and a poor business environment, including complicated

\footnotetext{
34 See W. von Richthofen: Labour inspection: A guide to the profession (Geneva, ILO, 2002), pp. 59-60.

${ }^{35}$ For example, the Moroccan Labour Code applies to homeworkers and provides guidance as to what constitutes essential elements of such employment. The New Zealand Employment Relations Act 2000 defines "homeworker" in a manner that clarifies the existence of an employment relationship even though work is done at home. ILO: The employment relationship: An annotated guide to ILO Recommendation No. 198, DIALOGUE Paper No. 18 (Geneva, 2008).

36 ILO: Conclusions on promoting pathways to decent work for youth, Report of the Committee on Youth Employment, Provisional Record No. 20, ILC, 93rd Session, Geneva, 2005, para. 9.
} 
registration and high transaction costs, affect all enterprises negatively, but the adverse impacts are compounded for women, with their additional work burdens and limited sources of public information. The promotion of women's entrepreneurship thus requires measures such as a conducive regulatory environment, labour laws and collective agreements, as well as simple registration procedures and less red tape. Providing fiscal, training and market access incentives can help generate new enterprise growth and contribute towards formalization of businesses, especially those of women. Fiscal policies can be an important source of support for women entrepreneurs by offering them individual tax structures and insurance and pension schemes which take women's work patterns into account.

288. Policy needs to ensure gender mainstreaming within institutions that support business development through overall analysis of impacts on both sexes, as well as interventions targeting women specifically. Business advisory centres are critical in identifying market niches and enabling enterprise development. Given the gaps in financial service provision for poor women, microfinance institutions can provide collective and individual loans and support savings mobilization and insurance products. ${ }^{37}$ Although access to microfinance is important for many poor women in developing countries, it should be offered within a framework promoting access to formal financial services in the longer term. In addition, measures should be designed so that loans do not pull women further into poverty. Assisting the organization and mobilization of women producers and linking them to existing business networks can ensure that they mutually support each other, as well as developing greater voice and bargaining power. The Office has been working with the Bill \& Melinda Gates Foundation on experimental programmes on microinsurance.

\subsection{Equal pay}

289. If "money talks", women do not have a loud voice. Pay differentials remain one of the most persistent forms of inequality between women and men. They vary from country to country and within countries, between the public and private sectors and between different sectors of the economy. Various factors contribute to the gap, and it is difficult to distinguish between pay differences resulting from different labour market characteristics and those due to indirect or direct discrimination, including societal differences in the evaluation of work in male- and female-dominated sectors and occupations. ${ }^{38}$ The market is itself gender-biased: women's skills and jobs have historically been undervalued and there are differences in collective bargaining power. Policies to eliminate sex-based discrimination in remuneration need to deal not only with labour market inequalities, but also with perceptions of the role of women, their participation in social dialogue and the difficulty of balancing work and family responsibilities. ${ }^{39}$ Research shows that an enterprise will offer different remuneration to

\footnotetext{
37 See ILO: Small change, big changes: Women and microfinance, GENDER/Social Finance Programme (SFP) (Geneva, 2008).

${ }^{38}$ Commission of the European Communities: Tackling the pay gap between women and men, Communication from the Commission to the European Parliament, the Council, the European Economic and Social Committee and the Committee of the Regions, COM(2007) 424 final (Brussels, 2007), p. 16.

39 See I. Bleijenbergh, J. de Bruijn and L. Dickens: Strengthening and mainstreaming equal opportunities through collective bargaining, European Foundation for the Improvement of Living and Working Conditions.
} 
men and women if it expects their share of work in the household to differ systematically. ${ }^{40}$

290. In general, wage inequality is driven by changes at the higher end of the wage scale or by changes at the lower end, or by both. The policy implications are profoundly different. To illustrate this, figure 6.5 shows a typology with three different types of increase in wage inequality. The first - the "collapsing bottom" - refers to the situation where wage inequality is growing as a result of deterioration in the lowest wages. The second - the "flying top" - presents the opposite case, where top wage earnings are increasing faster than in other wage groups. The third type is where both changes are taking place simultaneously, resulting in a "polarization" of wage earnings.

\section{Figure 6.5. Growing wage inequality: A typology}

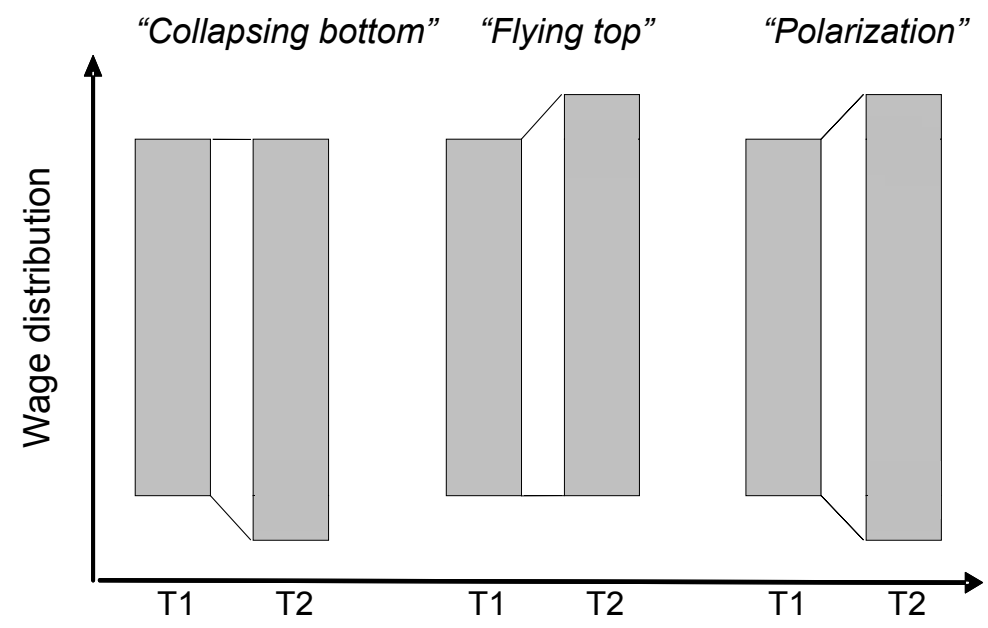

Note: T1 refers to the initial condition; T2 refers to the new condition.

Source: ILO: Global Wage Report 2008/09: Minimum wages and collective bargaining: Towards policy coherence (Geneva, 2008), p. 25.

291. From a gender perspective, women are penalized at both ends in all these models. Because of horizontal occupational segregation, they are concentrated in the lower-paid jobs and are the first to feel the impact of the collapsing bottom. Because of vertical segregation, women rarely benefit from high wages or compensation either, since few women rise to higher career positions either in the public or in the private sector. ${ }^{41}$

292. Direct wage discrimination between a man and a woman performing the same job is generally easy to identify. However, international standards require that there be equal remuneration for work of equal value, ${ }^{42}$ irrespective of the sex of the worker. In order to establish whether different jobs are of equal value, there has to be an examination of the

${ }^{40}$ G. Chichilnisky and E. Hermann Frederiksen: "An equilibrium analysis of the gender wage gap", in International Labour Review, Vol. 147, No. 4 (Geneva, ILO, 2008), p. 300.

${ }^{41} \mathrm{~N}$. Haspels and E. Majurin: Work, income and gender equality in East Asia: Action guide (Bangkok, ILO, 2008), p. 2.

42 The concept of equal value includes, but goes beyond, equal remuneration for "equal", the "same" or "similar" work; it encompasses work that is of an entirely different nature, but is nevertheless of equal value. ILO: $R C E$, 2007, General observation on Convention No. 100. 
respective tasks involved. This examination - often called a job evaluation - must be undertaken on the basis of objective and non-discriminatory criteria, to prevent the findings from being tainted by gender bias. ${ }^{43}$ Without a methodology to compare different work that might be of equal value, key aspects of women's jobs are disregarded or scored lower than those performed by men, thus reinforcing discrimination in pay. In assessing equal pay, it is also important to look at all components of pay packages, including the basic wage, all benefits, and all additional allowances. Two sets of factors have been identified in determining the causes of wage discrimination. The first set covers the educational level and field of study of the individuals; their work experience in the labour market and seniority in the organization or in the job held; the number of working hours; and the size of the organization and sector of activity. The second set of factors includes stereotypes and prejudices with regard to women's and men's work; traditional job evaluation methods designed on the basis of the requirements of maledominated jobs; and the weaker bargaining power of female workers. ${ }^{44}$

293. Accurate and reliable data on a global scale on the gender pay gap, broken down by occupation, are not readily available. The ITUC collection of global data on the average gender pay gap by occupation - highlighted in figure 6.6 - is therefore a welcome step, and confirms that, globally, women continue to earn, on average, lower wages than men.

\section{Figure 6.6 Global gender pay gap, 2006}

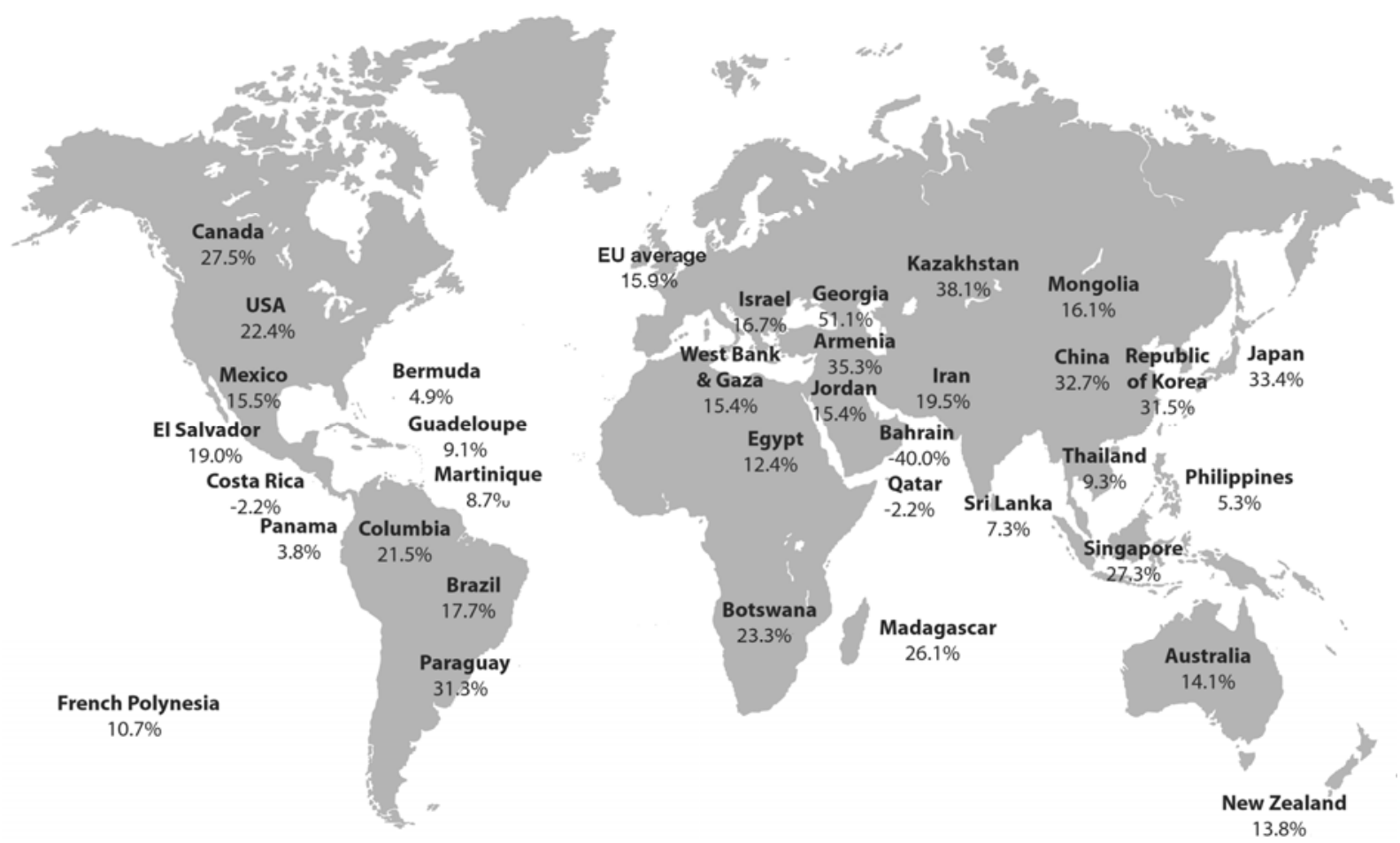

Note: Because of the lack in consistency concerning data collection and methodology and the data deficiencies in a number of countries, caution should be exercised when interpreting and comparing pay gap information from different sources across countries. Decreases in gaps may be caused by falling wages for male workers, rather than an increase in the wages of female employees. This seems to have been the case of Brazil, where drops in wages have affected employed males. The migration of low-skilled male workers will also have a statistical effect on gender pay gaps, as has been the case of migration from Central and Eastern Europe to Western Europe.

Sources: ITUC: The global gender pay gap, ITUC report, Feb. 2008; EU average from 2007 Pay Developments, European Foundation for the Improvement of Living and Working Conditions, 2008, www.eurofound.europa.eu.

43 ibid.

44 M.-T. Chicha: Promoting pay equity: Gender-neutral job evaluation for equal pay: A step-by-step guide (Geneva, ILO, 2008). 
294. According to ILO figures, in about 80 per cent of the countries for which data are available, the pay gap has narrowed, but the change is small, and in some cases negligible. In most countries, women's wages for work of equal value represent on average between 70 and 90 per cent of men's, but it is not uncommon to find much wider differences. This is disappointing in the light of women's recent educational achievements and the gradual closing of the gender gap in work experience. ${ }^{45}$

\subsection{Migration}

295. The global segregation of labour markets largely affects the types of work available to both men and women migrant workers. Faced with employment discrimination and few opportunities in their home labour markets, women account for a rapidly increasing share of migrant workers. Because women and men migrants' experiences often differ, increased attention is given today to the gender dimensions of migration, including issues relating to special protection for women. Overall migration policy therefore requires specific gender-sensitive analysis and solutions. The types of jobs available to them - mostly in low-skilled occupations - add new layers of vulnerability to migrant women, especially when linked to problems of migration status, ethnicity and class. At the same time, migration can also be empowering for women who gain additional portable skills, higher self-esteem and increased economic independence. While many economic sectors are open to men, women migrant workers are heavily concentrated in female-dominated occupations, often in the services sector. These occupations are most commonly associated with traditional gender roles. There is an increasing demand for women migrant workers, at all skill levels, in caregiving jobs. For instance, by the year 2000,11 per cent of nurses and 18 per cent of doctors in OECD countries were foreignborn. ${ }^{46}$

296. Today's migrants, men and women alike, face profound challenges, including poor conditions of work, sexism, racism and labour market discrimination. Despite international standards to protect migrants, their rights as workers are all too often undermined, especially if they go abroad in search of a job without obtaining the necessary travel documents. While no reliable data on undocumented migrants by sex can be found, it has been argued that the undervaluing of women's labour and restrictions on their right to work mean that a higher proportion of women migrants than men are statistically invisible and are, or become, undocumented. ${ }^{47}$ Large numbers of women arriving as spouses of temporary workers may also find themselves excluded from legal employment. A very important reason for women migrant workers' vulnerability is that the jobs they find are concentrated in the informal economy and are thus not covered or only partially covered by the labour legislation and social security and welfare provisions of the country of destination. ${ }^{48}$ In general, abuse and exploitation of women migrant workers are less identifiable than those suffered by men migrant workers, since they occur either at an earlier stage of the migration process or in more

\footnotetext{
${ }^{45}$ ILO: Global Wage Report 2008/09: Minimum wages and collective bargaining: Towards policy coherence (Geneva, 2008).

46 OECD: "International migration to OECD countries continues to grow in response to labour needs" (25 June 2007), www.oecd.org/document/39/0,3343,en_2649_33931_38835943_1_1_1_1,00.html [accessed 5 December 2008].

${ }^{47}$ N. Piper: Gender and migration (2005), Paper prepared for the Global Commission on International Migration, p. 4.

${ }^{48}$ ILO: Preventing discrimination, exploitation and abuse of women migrant workers: An information guide, Booklet 4 "Working and living abroad" (Geneva, ILO, 2004), p. 11.
} 
"invisible" labour market situations with weak labour inspection services, such as domestic work and caregiving. Such abuses may include non-payment or withholding of wages, control or lack of freedom of movement, withdrawal of passports and other identity documents, long working days, seven-day working weeks, and physical and psychological intimidation and punishment. Skilled and highly skilled women migrate to find better-paid jobs, depriving home countries of their often much-needed skills and services.

\subsection{The care economy}

297. The care economy is a complex concept, further complicated by changing demographics and gender roles. Care work is broadly defined as looking after the physical, psychological, emotional and developmental needs of one or more other people. ${ }^{49}$ It spans the public and private spheres and is to be found in a variety of settings and across formal and informal economies. As figure 6.7 shows, care work involves a range of actors. Much of this care is provided by the health services sector, most of which is public. The sector is a large employer of women - over 80 percent predominantly in nursing. However, women are poorly represented in the higher echelons of health services, where men comprise the majority of physicians and management. ${ }^{50}$ Health and medical services overlap with other forms of paid and unpaid care that is given, often because there is a lack of access to quality health services.

298. The terms "unpaid work", "care work" and "unpaid care work" are often used interchangeably, which can lead to confusion when analysing gender inequalities at work. Although they are linked, the differences and overlaps can be distinguished, as illustrated in figure 6.8. Unpaid work is underestimated and inaccurately measured; it is also excluded from gross national product (GNP) and usually ignored when policy decisions are made. Estimates show that the value of unpaid work can be equivalent to at least half of a country's GDP. ${ }^{51}$ The System of National Accounts (SNA) that sets international standards for the measurement of the market economy conventionally measures only some types of unpaid work in calculations of GDP, for example work in family businesses and activities such as the collection of firewood and water. It does not count activities such as cooking, laundry, cleaning, the care of children, the elderly, the sick and people with disabilities and volunteer activities. As a consequence, women's unpaid contribution to the economy has remained unrecognized in data collection and is insufficiently reflected in policy development. ${ }^{52}$ An important breakthrough for gender and labour statistics was reached in 2008 at the 18th International Conference of Labour Statisticians. It is now recommended that the SNA recognize that in order to portray the

\footnotetext{
${ }^{49}$ ILO: ABC of women workers' rights and gender equality (Geneva, 2007), p. 27.

${ }^{50}$ ILO: Social dialogue in the health services: A tool for practical guidance (Geneva, 2004).

${ }^{51}$ See ILO: Overview of gender-responsive budget initiatives (Geneva, 2007); and D. Elson: Genderneutral, gender-blind, or gender-sensitive budgets? Changing the conceptual framework to include women's empowerment and the economy of care, Gender Budget Initiative - Background papers (London, Commonwealth Secretariat, 1999).

${ }^{52}$ UN DAW: The equal sharing of responsibilities between women and men, including caregiving in the context of HIV/AIDS, Report of the Expert Group Meeting, Geneva, 6-9 October 2008, EGM/ESOR/2008/REPORT, para. 47.
} 
world of work adequately, all paid and unpaid work activities, and the relationships between them, need to be acknowledged, quantified and understood. ${ }^{53}$

\section{Figure 6.7. Actors in the care economy}
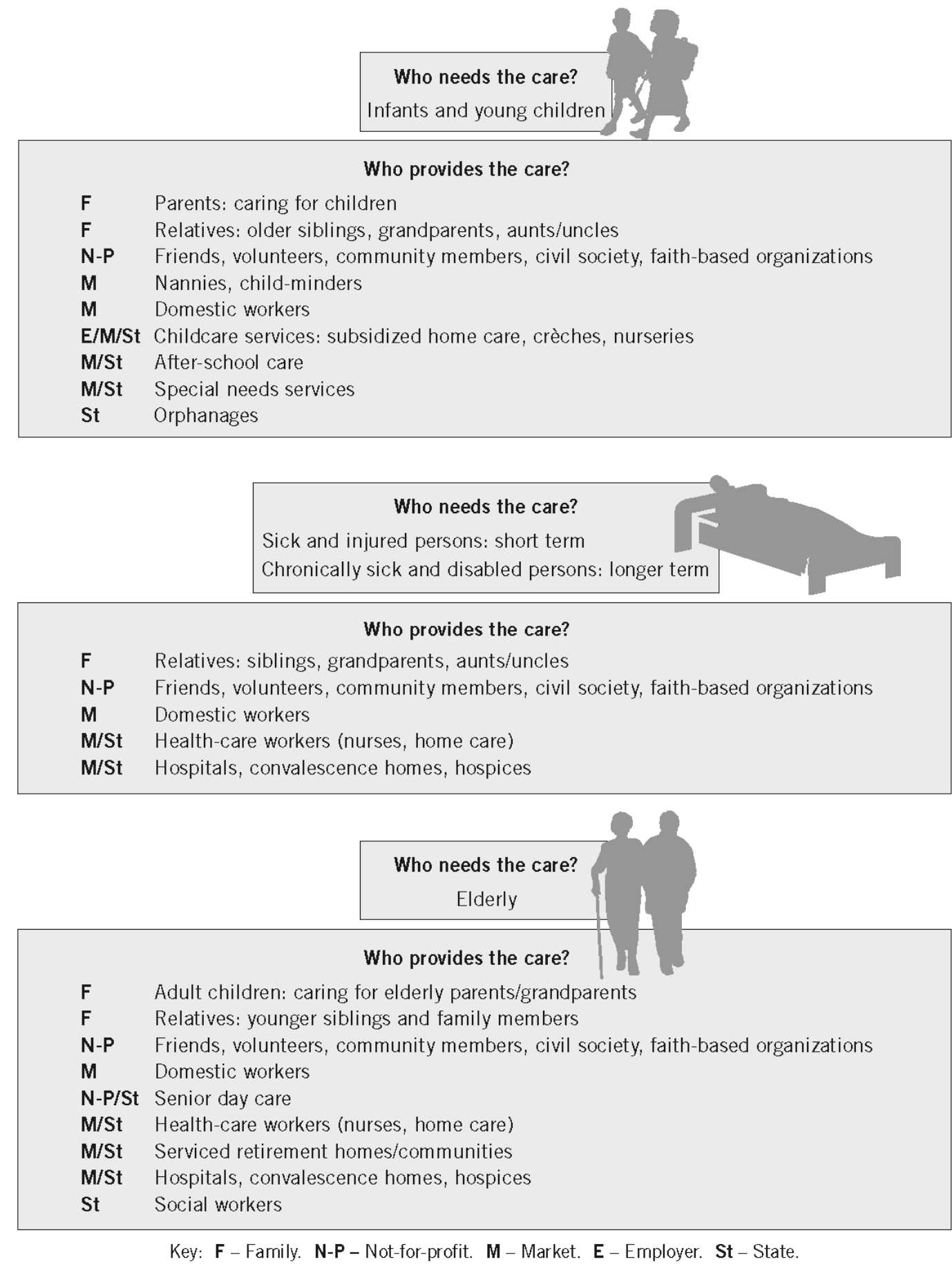

Source: ILO (GENDER), 2009

53 ILO: Report of the Conference, 18th International Conference of Labour Statisticians (ICLS), Geneva, 24 November-5 December 2008, paras 90 and 101; resolution concerning statistics of child labour, para. 14; and resolution concerning the measurement of working time, para. 5. See also: Checklist of good practices for mainstreaming gender in labour statistics, adopted by the 17th ICLS in 2003. 


\section{Figure 6.8. Unpaid work, care work and unpaid care work}

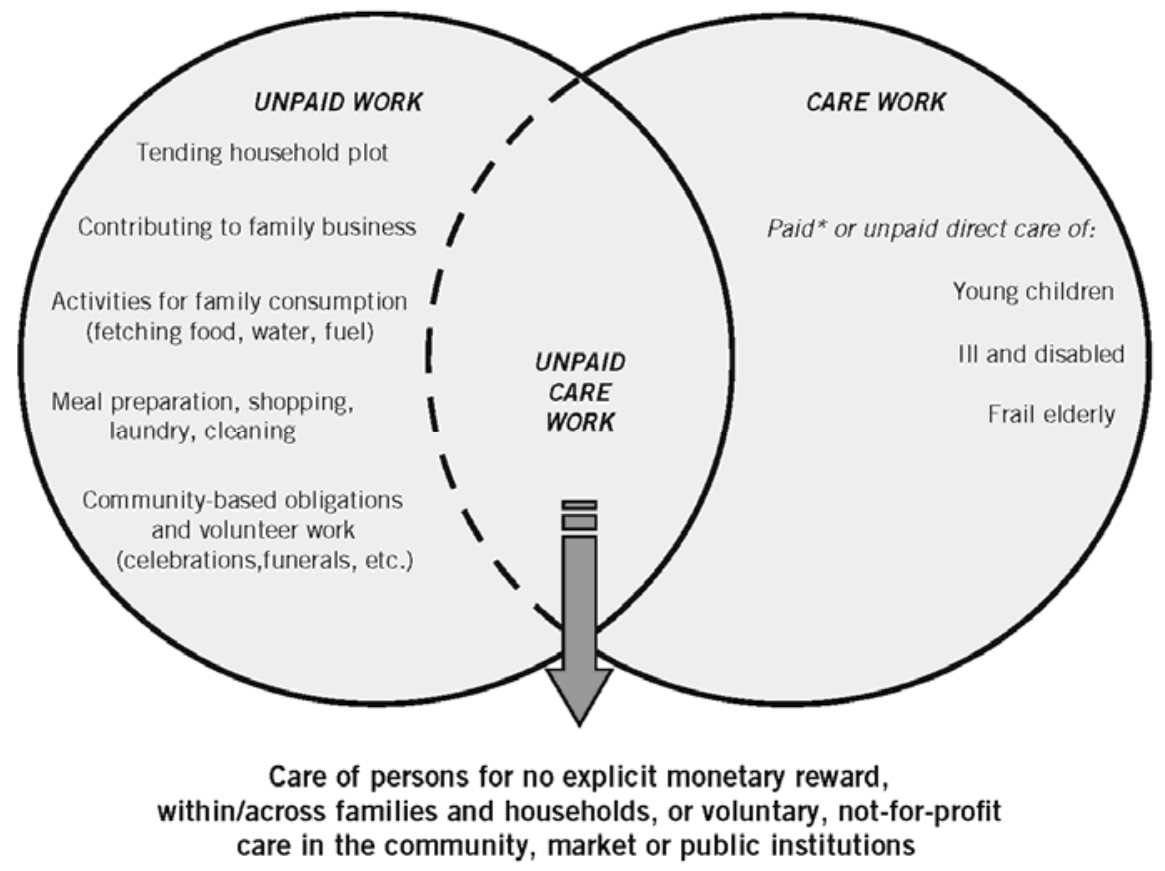

* Boundaries with unpaid work are arbitrary. Direct care usually includes attending, bathing, feeding, accompanying for medical visits, administering medicine.

Source: ILO (GENDER), 2009, based on S. Razavi: The political and social economy of care in a development context: Conceptual issues, research questions and policy options, Gender and Development Programme Paper No. 3 (Geneva, UNRISD, 2007), p. 6.

299. Across the regions, it is most often women rather than men who do this work. ${ }^{54}$ For example, surveys carried out in six countries (Argentina, India, Republic of Korea, Nicaragua, South Africa and United Republic of Tanzania) found that in all of those countries, the mean time spent on unpaid care work by women was more than twice that for men. The gender gap was most marked in India, where women spent nearly ten times as much time on unpaid care work as men. ${ }^{55}$ The breakdown of the multi-generational family model and the emergence of the nuclear family in South Asia have contributed to the challenges facing women and men who try to balance work and family responsibilities. Governments may depend on women's underpaid or unpaid work to deliver or even replace public services ${ }^{56}$ as they seek to reduce care's financial burden on the State. Yet unpaid care work is one of the biggest barriers to equality for women and affects their ability to upgrade skills, find highly paid jobs, join in social dialogue and benefit from social protection. Historically and across a diverse range of countries, women from disadvantaged racial and ethnic groups have tended to provide care services

${ }^{54}$ M. Daly: The equal sharing of responsibilities between women and men, including caregiving in the context of HIVIAIDS, Background paper for the Expert Group Meeting, Geneva, 6-9 October 2008, EGM/ESOR/2008/BP.1.

55 D. Budlender: The statistical evidence on care and non-care work across six countries, Gender and Development Programme Paper No. 4 (Geneva, UNRISD, 2008), p. v.

56 M. Cornish: Securing pay equity for women's work - Everyone benefits: The international experience, Paper for ILO International Seminar on Equal Pay for Work of Equal Value, Santiago, Chile, 25 August 2008, p. 3. 
to meet the needs of the more powerful social groups, while their own needs for care have been neglected or downplayed. ${ }^{57}$

300. Most legal, policy and programmatic frameworks are constructed on the assumption of a specific household structure, usually with the male as the breadwinner. Yet in certain developing countries and in certain conflict settings, for instance in Africa, the household structure with a male breadwinner is not applicable, as many households are maintained by women. In developed countries, the male-breadwinner family model, which does not take account of family-related care responsibilities, is on the wane. The model is shifting to a dual-earner family arrangement, which challenges definitions of femininity and masculinity. Changing the gender division of labour in the household to a more equitable distribution of tasks, and investing in labour-saving technology, have significant benefits for productivity. Men specifically stand to gain in dual-income partnerships through better work/family balance, ${ }^{58}$ from better contact with children and inclusion in family life, as well as less vulnerability to economic shocks. Recognizing these realities will be necessary in order to influence effective policies. ${ }^{59}$

\section{Box 6.2
Calculating women's contribution to GDP through unpaid work:
An example from the Republic of Korea
Three valuation methods were used to measure housework performed by full-time
housewives in the Republic of Korea. Calculations based on the results estimated that
women's unpaid work amounted to between 13 and 23 per cent of GDP in 1999. Policy
recommendations were developed on the basis of these results, including insurance for
full-time housewives, family-friendly policies in the areas of family support, childcare,
after-school care and equality of opportunity at work, and sharing of conjugal assets in
cases of divorce.
Source: United Nations Economic and Social Commission for Asia and the Pacific (ESCAP) and UNDP:
Integrating unpaid work into national policies, Module 6: Some country experiences (2003), pp. 174-184.}

301. Policies that actively encourage men to participate in family responsibilities through the provision of behaviour-changing measures are needed (for example, paid paternity and parental leave). Quantifying the value of unpaid care in terms of market price and explicitly measuring the division of labour would support policy decisions. Education systems that address gender biases to challenge stereotypical, traditional male and female roles provide the foundations for these changes. States have a key role to play in establishing appropriate regulatory frameworks for providers and recipients of care and in providing free, quality public services. Such frameworks could include gender-neutral cash payments, tax breaks, different types of paid and unpaid leave and social security credits.

\footnotetext{
57 S. Razavi: The political and social economy of care in a development context: Conceptual issues, research questions and policy options, Gender and Development Programme Paper No. 3 (Geneva, UNRISD, 2007), p. 2.

58 See J. Marinova: Gender stereotypes and the socialization process, DAW/ILO/UNAIDS/UNDP, Expert Group Meeting on the role of men and boys in achieving gender equality, Brasilia, 21-24 October 2003.

59 See R.W. Connell: The role of men and boys in achieving gender equality, DAW/ILO/UNAIDS/UNDP, Expert Group Meeting, Brasilia, 21-24 October 2003.
} 


\section{Box 6.3 \\ Men and elderly care}

Increasingly, men in the United States worry about the conflict between caring for their parents and their role as breadwinner. It is estimated that men make up nearly 40 per cent of family care providers, up from 19 per cent in 1996 . About 17 million men are primary caregivers for an adult. Just as active fatherhood became more acceptable in the baby-boom generation, so has the caregiving role for many sons as their parents age today. Smaller families and more women working full time have contributed to this shift. Some men are concerned that their caregiving might be held against them in the workplace, feeding into the perception that men are more commonly preferred in recruitment because they will focus 100 per cent on their work.

Source: Alzheimer's Association and National Alliance for Caregiving (United States); J. Leland: "More men take the lead role in caring for elderly parents", in New York Times (New York), 28 Nov. 2008.

302. Yet another new dimension in the twenty-first century is the predominance of migrant workers in the care economy. From skilled health professionals to domestic workers, migrants are moving for work in the globalized care economy. In developed countries, a combination of factors has led to massive demand for skilled health professionals and personal care workers: women's high labour-force participation, the necessity of dual-earner families, fast-ageing populations and the reduction in state provision of social services. ${ }^{60}$ One "quick fix" solution has been to import care. Some countries in the Gulf States, Europe and North America depend significantly on foreign (born or trained) health workers to ensure their health service delivery. Yet this migration is contributing to health-care crises in their countries of origin. ${ }^{61}$ Many nurses accept positions as personal care providers and domestic workers abroad, thereby compromising their technical skills. This happens when health-care workers have poor working conditions, lack career opportunities and are offered higher salaries abroad. The ILO's Nursing Personnel Convention, 1977 (No. 149), requires ratifying States to adopt a national policy for nursing services and personnel to provide the quantity and quality of nursing care necessary for attaining the highest possible level of health for the population. ${ }^{62}$

\subsection{ILO action}

\subsubsection{Employment}

303. Based on the main premise that equality increases productivity and growth, the ILO's GEA has been mainstreaming gender issues into the work of the Employment Sector. An information base on equal employment opportunities for women and men, "e.quality@work", has been created, together with gender-specific tools on cooperatives, crisis and reconstruction. The ILO aims to work in most countries where there is a

60 A. King Dejardin: Gender dimensions of globalization, Policy Integration and Statistics Department (Geneva, ILO, 2008), p. 15.

${ }^{61}$ Overseas nurses made up more than half of new entrants on the UK Nursing and Midwifery Council register in 2003; in Queensland, Australia, 40 per cent of the medical workforce were trained abroad; Ghana had 57 per cent of posts for registered nurses unfilled in 2002; Malawi had a 52 per cent vacancy rate for nurses. S. Maybud and C. Wiskow: "Care Trade': The international brokering of health care professionals", in C. Kuptsch: Merchants of labour (Geneva, ILO-IILS, 2006), pp. 223-238. See also K. van Eyck: Who cares? Women health workers in the global labour market (PSI, 2005). PSI has launched a kit on women health workers' migration.

${ }^{62}$ Convention No. 149 has been ratified by 40 countries (January 2009). 
demand for Women's Entrepreneurship Development (WED) inputs as part of the Decent Work Country Programmes. The WED strategy seeks to unleash the economic potential of women's enterprises to contribute to the creation of quality jobs, gender equality, economic growth and poverty reduction within the framework of the Decent Work Agenda and the GEA and in line with the guidance provided by the recent ILC conclusions concerning the promotion of sustainable enterprises. Local economic development (LED) activities and wage employment for women under ASIST ${ }^{63}$ programmes have had a major impact.

304. Several ILO technical cooperation projects are aimed at overcoming the genderbased inequalities of informality. For example, the ILO/Japan Asian Regional Programme for Expansion of Employment Opportunities for Women (EEOW) has been operating since 1997 to contribute to national efforts in poverty alleviation and promote gender equality through the socio-economic empowerment of women. EEOW was first implemented in in rural areas in Indonesia and Nepal in 1997, followed by Thailand in 2000, Cambodia in 2001 and Viet Nam in 2002; Cambodia is continuing with new approaches to training and gender mainstreaming. ${ }^{64}$

305. The Gender, Poverty and Employment (GPE) programme was implemented in Latin America and other regions between 2000 and 2004 with funding from the Danish International Development Agency (DANIDA). Using tools developed by the ITCILO ${ }^{65}$ institutional partners such as national commissions for equal opportunities and ministries of labour and social welfare have integrated the GPE approach in their own activities. The achievements are unique in that the GPE framework is still used for employment policies and is completely mainstreamed in almost all of the nine countries concerned. The tripartite commissions established as an institutional framework continue to function as active and energetic networks, including in regard to research on gender.

306. Another example is the regional initiative on Gender Equality and Workers' Rights in the Informal Economies of Arab States. ${ }^{66}$ Official statistics, legislation, policies and programmes in Arab States have not sufficiently captured the informalization of jobs. To fill the gap, the ILO Regional Office for Arab States and the Centre of Arab Women for Training and Research (CAWTAR) launched this regional initiative in 2007 from a gender equality and workers' rights perspective. This perspective highlights the need to use labour rights and other relevant human rights standards to identify the problems facing informal workers, the political, economic, social, and cultural causes and consequences of informalization, and the claims, responsibilities, capabilities, and actions required. The strategy underlying the research and policy dialogue components of the project is based on three pillars: the extension of social protection as the main means of reversing informality; workers' agency and voice in order to prioritize the rights of informal workers through organizing the unorganized and taking collective action; and gender-responsive statistics adequately capturing informality so as to make

63 Advisory Support, Information Services and Training for Employment-Intensive Infrastructure Programmes.

64 ILO: Expansion of Employment Opportunities for Women (EEOW) in Cambodia, Information sheet (Phnom Penh, 2008).

65 The ITC-ILO continues to offer GPE courses on-line, for example distance learning course No. A970001 for 2009.

${ }^{66}$ Funded by the International Development Research Centre (IDRC), the Arab Gulf Programme for United Nations Development Organizations (AGFUND) and the ILO. The countries covered were Egypt, Lebanon, Jordan, Syrian Arab Republic, Tunisia and Yemen, as well as the occupied Palestinian territories. 
workers' concerns more visible and influence policy. As a result, the implications of the gendered nature of informality of employment - with differential earnings, choices and locations of activities, level of competition, and time allocated to work - were brought into focus. The project's publications include a regional overview, country case studies, a glossary on gender, employment and the informal economy, and several policy briefs.

307. Entrepreneurship is another successful strategy. For example, in Africa, ${ }^{67}$ WEDGE has been supporting women-owned operations through building capacity in business knowledge, including access to markets through trade fairs and exhibitions, providing training and strengthening women entrepreneurs' voice and representation through networks. Since 2000, several thousand women in sub-Saharan Africa have participated in WEDGE activities aimed at honing entrepreneurial skills.

308. A variety of active labour market policies and programmes have been developed with ILO assistance. Research on their impact shows, for example, that affirmative action is successful in redressing sex-based imbalances in access to recruitment and job retention. ${ }^{68}$ ILO policy advice on PTE is guided by the Part-Time Work Convention, 1994 (No. 175). It requires ratifying States to take measures to facilitate access to productive and freely chosen part-time work which meets the needs of both employers and workers, provided that the protection referred to in the Convention is ensured. ${ }^{69}$

\subsubsection{Social protection}

\section{Occupational safety and health}

309. The increasing proportion of women in the workforce raises a range of questions about the different effects of occupational risks on men and women. Integrating gender mainstreaming approaches in OSH is not new: a 1985 ILO resolution recommended that measures be taken to extend special protection to women and men concerning reproductive hazards and sexual harassment. ${ }^{70}$ Concerns have been expressed over the different effects on women and men of exposure to substances hazardous to reproductive health, notably the effects of biological agents. The physical demands of heavy work, ergonomic design of workplaces and length of the working day - especially when domestic duties are factored in - have gender dimensions.

\footnotetext{
67 The following countries in sub-Saharan Africa have been working with WEDGE for at least a oneyear project cycle: Ethiopia, Kenya, Lesotho, Malawi, Mozambique, South Africa, United Republic of Tanzania, Uganda and Zambia. New countries starting a project of at least one year in 2009 with WEDGE include Cameroon, Mali, Nigeria, Rwanda and Senegal.

68 As early as 1988, the UN Committee on the Elimination of Discrimination against Women, in its General Recommendation No. 5 on temporary special measures, recommended that States parties make more use of temporary special measures such as positive action, preferential treatment or quota systems to advance women's integration into education, the economy, politics and employment (UN document A/43/38). See also ILO: Equality at work: Tackling the challenges, Global Report under the follow-up to the ILO Declaration on Fundamental Principles and Rights at Work, Report I(B), ILC, 96th Session, Geneva, 2007, para. 233 (this report also addresses preferential public procurement policies as tools for achieving equality in employment), and J. Hodges Aeberhard: "Affirmative action in employment”, in International Labour Review, Vol. 138, No. 3 (Geneva, ILO, 1999).

69 Article 9(1) of the Convention.

${ }^{70}$ Resolution on equal opportunities and equal treatment for men and women in employment, ILC, 71 st Session, Geneva, 1985.
} 
310. ILO global estimates indicate that in some countries more than 30 per cent of all employees reportedly work more than 48 hours a week. ${ }^{71}$ In carrying out measures for the gradual reduction of hours of work, priority should be given to industries and occupations which involve a particularly heavy physical or mental strain or health risks for the workers concerned, especially where these consist mainly of women and young persons. ${ }^{72}$ Men tend to work longer average hours in paid employment than women worldwide, ${ }^{73}$ with women working shorter hours in almost every country studied. This is both a cause and an effect of sex stereotypes about men's breadwinner role and women's caregiving role, reinforcing existing divisions of labour. ${ }^{74}$ Long working hours undermine both men's and women's availability to provide care at home.

311. OSH research should capture any sex-based disparities; yet, at present, there is a dearth of information about the different risks for men and women of exposure to certain chemicals. Furthermore, it is slowly becoming clear that unexplained clusters of disease in the reproductive system are having an impact on particular working populations. Possible occupational causes are as yet unexplored, and research is needed to investigate the links between such illnesses and occupational exposures. ${ }^{75}$

312. On the one hand, more adult men than adult women work in jobs that expose them to accidents. They are more likely to be involved in fatal accidents and other workrelated deaths. Men also tend to be more exposed to substances that are carcinogenic or may cause circulatory and respiratory disease. Researchers have noted that women tend to adopt more preventive and protective ways of carrying out work. On the other hand, women work in large numbers in agriculture in developing countries, where they are vulnerable to communicable diseases such as malaria, hepatitis and other bacterial, viral and vector-borne diseases. ${ }^{76}$ Many occupational diseases and disorders develop over time through cumulative exposure. Women's lack of influence at OSH decision-making levels is a drawback. Because they are not often included in the decision-making bodies, or because they are intimidated by the processes or simply have too little time to do so, women have limited impact in setting OSH standards. ${ }^{77}$ Their lack of involvement has led to gender bias in the compensation of women workers for their injuries and illnesses. The ILO has observed that more attention needs to be paid to the claim that chronic injuries common to service-type work (traditionally women's work) are less likely to be

\footnotetext{
71 S. Lee, D. McCann and J.C. Messenger: Working time around the world: Trends in working hours, laws and policies in a global comparative perspective (Geneva, ILO, 2007).

72 Paragraph 9 of the Reduction of Hours of Work Recommendation, 1962 (No. 116).

73 An exception to this rule is the Philippines, where employed women are two to three times more likely than men to work exceptionally long hours in paid work, sometimes more than 64 hours a week. ILO: Role reversal: When it comes to who works the longest hours, many Philippine women are the global exception, Press release (Geneva, 8 June 2007).

74 S. Lee, D. McCann and J.C. Messenger: Working time around the world, op. cit.

75 S. Al-Tuwaijri, I. Fedotov et. al.: Beyond deaths and injuries: The ILO's role in promoting safe and healthy jobs, Introductory Report for XVIII World Congress on Safety and Health at Work, Seoul, June 2008, p. 20.

76 ILO: World Day for Safety and Health at Work 2005: A background paper, ILO InFocus Programme on SafeWork (Geneva), p. 7.

77 In ILC delegations generally, women barely account for 20 per cent, despite Office efforts for gender parity. See ILO: Gender balance in the International Labour Conference, GENDER (Geneva, 2002-08).
} 
compensated than those of workers with acute accident injuries, associated more with primary resource industries and manufacturing (traditionally men's work). ${ }^{78}$

313. Provisions for the protection of women (hours of work, wages, weekly rest and holidays, pregnancy and maternity) are covered by most systems of labour inspection. There is now evidence of an emerging role for labour inspectors in monitoring equality and diversity in the workplace. The economic consequences of a number of recently identified phenomena, including sexual harassment at work, have prompted countries such as Sweden and Switzerland to recruit and train specialist labour inspectors in the area of mental health at work. ${ }^{79}$ The ILO standards on inspection insist that both men and women must be eligible for appointment and recognize that special duties may be assigned to male and female inspectors, respectively.

\section{Social security}

314. Social security is part of the Decent Work Agenda. The current debate focuses on how to close existing coverage gaps and reach all those in need in the most effective and quickest manner. The evidence that women workers are more vulnerable to social exclusion and multiple risks is clear. ${ }^{80}$ Those who advocate universal social protection on economic grounds wish to avoid labour market distortions and economic inefficiencies by de-linking it from the employment relationship. Others support universal social protection based on principles of equality and inter-generational solidarity. ${ }^{81}$ The ILO Global Campaign on Social Security and Coverage for All addresses both aspects of the matter. In addition, the conclusions concerning social security adopted by the ILC in 2001 identified equality, with an emphasis on gender and disability, as one of the main areas for future social security research and meetings of experts. $^{82}$

315. From a gender perspective, it should be noted that some ILO social security Conventions contain references to the male breadwinner model. This has sometimes been an obstacle to ratification, showing a certain degree of misunderstanding of the Conventions. While the language used in the Conventions drafted in past decades may not correspond to today's realities, the wage levels of men in most countries and sectors are still higher than those of women; thus, the earnings of the male breadwinner still constitute a relevant reference for calculating benefits under the Conventions, while providing protected women with higher levels of benefits than if their own earnings were taken into account. ${ }^{83}$

\footnotetext{
${ }^{78}$ M. Cornish: Realizing the right of women to safe work - Building gender equality into occupational safety and health governance, ILO Concept Note for XVIII World Congress on Safety and Health at Work, Seoul, 29 June-2 July 2008.

79 ILO: Labour inspection, Report III(Part 1B), ILC, 95th Session, Geneva, 2006, paras 54-55.

${ }^{80}$ S. Chant and C. Pedwell: Women, gender and the informal economy: An assessment of ILO research and suggested ways forward (Geneva, ILO, 2008), p. 31.

${ }^{81}$ M. Chen: "Addressing informality, reducing poverty", in Jobs, jobs, jobs - The policy challenge, Poverty in Focus No. 16 (Brasilia, International Poverty Centre, Dec. 2008).

${ }^{82}$ ILO: Resolution and conclusions concerning social security, 2008, Provisional Record No. 16, ILC, 89th Session, Geneva, 2001, para. 18.

${ }^{83}$ ILO: Setting social security standards in a global society: An analysis of present state and practice and of future options for global social security standard setting in the International Labour Organization, Social Security Department (Geneva, 2008), p. 40.
} 


\section{Equal pay}

316. What measures have led to progress in diminishing the pay gap? First, research reveals that minimum wages have enjoyed a revival, with beneficial effects on lowerpaid women workers. ${ }^{84}$ Globally, over the period 2001-07 minimum wages were raised by an average of 5.7 per cent (in real terms), with developing countries driving this upward trend. ${ }^{85}$ Colombia stands out as a country where a rising minimum wage has been accompanied by a marked narrowing of the gender pay gap. To reduce gender biases in wage-fixing, it is important that minimum wages cover sectors and jobs where salaried women workers prevail and that the wage-fixing process itself does not undervalue female-dominated occupations. ${ }^{86}$

317. Second, more and more countries are including provisions guaranteeing equal pay for men and women in their employment law (for example, Czech Republic, Latvia, Poland, Turkey) or equality legislation (Austria, Bosnia and Herzegovina, Lithuania, Peru, Saint Lucia, Spain). Others have adopted special equal pay laws (Canada, Cyprus). Some countries (Finland, France, Spain) have adopted proactive laws requiring employers to take active measures to promote equal pay. ${ }^{87}$ Others are rectifying shortcomings in the way existing equal pay statutes have been interpreted. For example, US President Obama signed the Lilly Ledbetter Fair Pay Act into law in January 2009, making it easier to lodge claims of sex-based wage discrimination. It restores the longstanding interpretation of equal opportunities law that allows employees to challenge any discriminatory paycheck they receive. ${ }^{88}$ However, several countries still retain legal provisions that do not give expression to the concept of "work of equal value", and the ILO supervisory bodies have urged them to take the necessary steps to amend their legislation.

318. Third, there is the positive link between collective bargaining and pay equity. ${ }^{89}$ For example, in Latin America, the ILO is deepening research in this area in order to establish a baseline for monitoring impact. ${ }^{90}$ SACCAWU, an IUF affiliate organizing workers in the South African commercial food industry, has negotiated robust gender equality clauses since the mid-1980s in response to harsh conditions experienced by women at work. For example, a 2007 collective agreement specifically addresses the

${ }^{84}$ D. Grimshaw and M. Miozzo: Minimum wages and pay equity in Latin America, DECLARATION Working Paper No. 12 (Geneva, ILO, 2003); J. Rubery: Pay equity, minimum wage and equality at work: Theoretical framework and empirical evidence, DECLARATION Working Paper No. 19 (Geneva, ILO, 2003); See also Canada's combined sixth and seventh Periodic Report to the UN Committee on the Elimination of Discrimination against Women, CEDAW/C/CAN/7, 17 Aug. 2007.

85 ILO: Global Wage Report 2008/09: Minimum wages and collective bargaining: Towards policy coherence (Geneva, 2008).

${ }^{86}$ For example, in the Philippines, nursing, a stressful, high-risk and high-responsibility femaledominated profession, is undervalued in comparison to car-pool supervision, a low-risk job involving scheduling drivers, vehicles and deliveries traditionally held by men. G. Gust: Equality at work: Philippines (Manila, ILO Subregional Office for South-East Asia and the Pacific), p. 24.

87 ILO: Equality at work: Tackling the challenges, op. cit., para. 202.

${ }^{88}$ Lilly Ledbetter Fair Pay Act of 2009, Public Law 111-2, 111th Congress.

89 See A. Blackett and C. Sheppard: The links between collective bargaining and equality, DECLARATION Working Paper No. 10 (Geneva, ILO, 2002).

90 L. Abramo and M. Rangel (eds): América Latina: Negociación colectiva y equidad de género (Santiago, ILO, 2005). 
health and safety of pregnant women. ${ }^{91}$ In addition, the first international framework agreement, signed between the IUF and the French multinational Danone in 1988, states that the parties agree to promote coordinated initiatives in areas including the development of conditions to ensure real equality between men and women at work. This commitment was followed by the adoption of an Action Programme for the Promotion of Equality of Men and Women at the Workplace (1989).

319. Tools such as Work, income and gender equality in East Asia: Action guide 92 address the gender pay gap in a regional context. Practical measures to promote equal pay between women and men are under way in Asia. Examples include: pilot initiatives to make job evaluation methods free from gender bias in the Republic of Korea and the Philippines; development of web-based wage indicator tools in China and the Republic of Korea; tripartite action in the form of the adoption of guidelines and codes on fair employment practices, including equal pay in Singapore; the development of guidelines on reducing gender pay disparities and on realizing work-life balance in Japan; and trade union advocacy on pay equity in the Philippines and the Asian region as a whole.

\subsubsection{Social dialogue}

320. The participation of the tripartite partners, especially in times of crisis, is a crucial way of preserving gender equality achievements. For example, in the current financial and economic downturn, the ILO indicated that unemployment might increase worldwide by some 51 million, and that the number of working poor was also expected to rise. Since ILO pre-crisis figures estimated that 63 per cent of people living in poverty were women (see table A in the appendix), it is not difficult to extrapolate that women will also make up the majority of those affected by the crisis. Recognizing the need to collect information and statistical data and undertake research on changes in the patterns and structure of work at the national and sectoral levels, taking the distribution of men and women into account, the Employment Relationship Recommendation, 2006 (No. 198), calls on national labour administrations to engage in regular monitoring.

321. The Tripartite Consultation (International Labour Standards) Convention, 1976 (No. 144), also serves as guidance. It is imperative that the significance of gender equality in designing the responses to the labour and social consequences of the crisis remain at the forefront of the ILO's engagement. For this to happen, the tripartite partners need to be constantly aware of the gender implications of policies and programmes and to mainstream equal opportunity and treatment into all facets of work. ACT/EMP and ACTRAV are committed to strengthening the capacities of their respective constituents on gender equality. For example, in the area of better data collection and analysis, the 11th ILO Round Table for Caribbean Employers' Organizations (April 2008) called for capacity building for employers' organizations of the subregion to enable them to collect and analyse sex-disaggregated data on labour market trends. Office support for trade unions focuses on increasing representation of women within trade unions, capacity building on gender-sensitive collective bargaining and developing workers' education policies and programmes with a strong gender dimension.

\footnotetext{
91 South African Commercial, Catering and Allied Workers' Union (SACCAWU), Collective agreement regarding parental rights between Sun International Limited and SACCAWU, 25 July 2007.

${ }^{92}$ N. Haspels and E. Majurin: Work, income and gender equality in East Asia: Action guide (Bangkok, ILO, 2008).
} 
322. Countries have their own systems of industrial relations that serve as platforms for social dialogue on gender equality. Some have national tripartite commissions, while others have other bodies through which constructive dialogue can be conducted. In Bulgaria, following a series of family-friendly measures over the past few years, the social partners discussed the national strategy for gender equality in November 2008 so as to agree on more targeted action against inequality. These include maternity and paternity leave, childcare, flexible working hours, family allowances and the promotion of labour force participation of women. When helping governments and the social partners to establish new tripartite social dialogue bodies and train their new appointees, the ILO includes modules on gender equality in the workplace. The ILO has assisted judicial training colleges in developing and delivering courses on ILO standards, including the four key equality Conventions. The ITC-ILO likewise offers a dedicated training course for judges and legal practitioners that covers gender equality.

323. Existing equality legislation and its enforcement also determine the reliance of social partners on social dialogue, notably collective bargaining. More attention should be paid by national social dialogue commissions to promoting vocational education and training and implementing active labour market policies to rectify gender imbalances. ${ }^{93}$ This could be done in partnership with national gender machineries. For example, ILO support to national machineries in Latin America includes a 1990s programme to promote social dialogue on gender issues in the labour market, implemented for members of the Common Market of the Southern Cone (MERCOSUR). ${ }^{94}$ The tripartite commissions on gender equality subsequently established - and the strengthening of Chile's existing commission - have resulted in greater visibility of gender equality issues at the national level, better networking among key national actors and more coordinated social dialogue, increased technical capacity to mainstream gender perspectives in the world of work, and an enhanced regional dimension through the MERCOSUR commitment. ${ }^{95}$

324. It is equally important that employer and worker awareness-raising programmes on gender equality include or even specifically target men. For example, in order to combat workplace harassment and violence, men's involvement is crucial. The ITC-ILO has been offering training courses on gender equality and women's entrepreneurship for both workers' and employers' organizations. Recent employer initiatives include an online training package on work and family ${ }^{96}$ containing a wide range of information, activities, examples of good practices and other resources to guide action and to integrate these into competitive and productive enterprise management.

325. Workers' organizations in particular have been concerned about correcting gender inequalities. The new Trade Union Confederation of the Americas is a prime example of redressing the imbalance between men and women's membership (parity) and participation in governing structures (40 per cent female office-bearers). Studies have shown that trade union membership has a positive influence on the gender pay gap. ${ }^{97}$

\footnotetext{
93 See P. Auer, Ü. Efendioğlu and J. Leschke: Active labour market policies around the world: Coping with the consequences of globalization (Geneva, ILO, 2005).

94 Argentina, Brazil, Chile, Paraguay and Uruguay.

95 L. Wirth: Breaking through the glass ceiling: Women in management (Geneva, ILO, 2001), pp. 172-174.

96 ILO: Training package on work and family, ACT/EMP and TRAVAIL, available at www.ilo.org/public/english/dialogue/actemp/whatwedo/projects/diversity.htm.

97 ITUC: The global gender pay gap (Brussels), p. 10.
} 
For many years, the global union PSI has been carrying out a worldwide pay equity campaign in both developed and developing countries, providing resources and training materials and assisting women and trade unions to mobilize and enforce their pay equity rights. Both employers' and workers' organizations attended training on collective bargaining for women members from Burundi, Congo, Democratic Republic of the Congo and Rwanda in February 2008.

326. More attention is being paid by the social partners to workers in the informal economy. In India, the ILO has been working for a number of years on organizing and empowering rural informal-economy workers through an ILO-Norway workers' education project promoting social dialogue. ${ }^{98} \mathrm{~A}$ guide for unions to bridge the information gap on effective methods and processes for organizing informal economy workers, notably women, was completed in four West African countries. ${ }^{99}$ The IOE released a position paper on the employers' approach to the informal economy, offering guidance to national employer organizations. ${ }^{100}$ Studies have been carried out on how labour administrations could contribute to the debate on extending decent work to informal economy workers, who are excluded from labour and social security laws. ${ }^{101}$

327. Sectoral social dialogue at the international level benefits from direct consultation with governments and employers' and workers' organizations. Many of these efforts have gender dimensions. At the national level, the ILO works with the social partners to develop innovative responses to the challenges facing their sectors, enhance their capacity, and provide opportunities for them to share common concerns. Sectoral social dialogue has led to a wide range of sectoral labour standards which can cover traditionally female- or male-dominated occupations or both. Examples include the Nursing Personnel Convention, 1977 (No. 149), and the Safety and Health in Agriculture Convention, 2001 (No. 184).

\subsubsection{Principles and rights}

\section{Elimination of sex discrimination}

328. Convention No. 111 has influenced policy, legislation and practical measures in the area of equal opportunity and treatment over the past 50 years. It gives guidance on vocational training, access to employment and terms and conditions of employment so as to eliminate sex discrimination in the workplace. The ILO uses this Convention when providing technical assistance on the revision of equality laws as well as labour legislation that contains provisions on gender equality. An increasing number of countries have applied the Convention through a combination of legislative and administrative measures, public policies and practical programmes aimed at preventing discrimination and redressing de facto inequalities, and through the establishment of national specialized bodies mandated to promote gender equality and to deal with complaints. Enforcing equality legislation and repealing discriminatory laws, while clearly important, are not sufficient to eliminate gender inequality at work because it

\footnotetext{
98 See T. Haque and S. Varghese: The path of deliverance: Organizing and empowering rural informal economy workers (New Delhi, ILO, 2007).

99 ACTRAV-Ghana Trades Union Congress: Organising informal economy workers in West Africa: Focussing on women workers: Trade union strategies.

100 IOE: The informal economy: Employers' approach, revised.

101 See J.-L. Daza: Informal economy, undeclared work and labour administration, DIALOGUE Paper No. 9 (Geneva, ILO, 2005); and A. Sivananthiran and C.S. Venkata Ratnam (eds): Informal economy: The growing challenge for labour administration (ILO, 2005).
} 
often results from deeply entrenched societal and cultural attitudes and beliefs. Norway, for example, has adopted new legislation in the field of equality and non-discrimination concerning the obligations of employers, organizations and institutions in regard to prevention of sexual harassment and preferential treatment, the shared burden of proof and objective liability for damages when infringements of the law are identified.

\section{Freedom of association and collective bargaining}

329. Rights-based measures to address sex discrimination, in its multiple forms affecting adult workers, can include statutory provisions as well as legal provisions in collective agreements. It is therefore important that the freedom of association regime include a legislative framework that guarantees women and men the right to organize, negotiate and take industrial action. The regime could also create gender-inclusive institutions to facilitate collective bargaining and address possible conflicts. It should maintain an efficient labour administration and encourage strong and effective workers' and employers' organizations so that tripartism can play an enabling role in achieving gender equality. ${ }^{102}$

330. Women's participation in collective bargaining and as leaders of workers' organizations has been low. One reason was that countries excluded from the right to organize (and hence collective bargaining) so-called "essential services", in which large numbers of women work: the public service, education and health services. Another factor was that sectors employing mostly women workers happened to be more difficult to organize for practical reasons: agriculture, home work, domestic work and the informal economy. ${ }^{103}$ Nevertheless, much has been achieved in those sectors in many member States, proving that progress is possible if there is the will to achieve it. ${ }^{104}$

\section{Box 6.4 \\ Organizing rural workers: Integrating the gender dimension}

The Rural Workers' Organisations Recommendation, 1975 (No. 149), in providing guidance on how to organize rural workers, recognizes the gender-based challenges. It encourages the competent authorities to promote programmes focused on the role which women can and should play in the rural community, and to integrate them into general programmes of education and training, to which women and men should have equal access. The Recommendation promotes workers' education and adult education programmes specially adapted to the social, economic and cultural needs of the various categories of rural workers, including women.

331. Collective bargaining can cover a wide range of issues, including wages, working time, work organization, recruitment, restructuring, safety and health, and training, all of which have gender dimensions. More recent bargaining subjects include work/family

\footnotetext{
102 See ILO: Freedom of association in practice: Lessons learned, Global Report under the follow-up to the ILO Declaration on Fundamental Principles and Rights at Work, Report I(B), ILC, 97th Session, Geneva, 2008.

103 The Governing Body's Committee on Freedom of Association occasionally receives complaints alleging violations of trade union rights presented by workers' organizations from female-dominated sectors or concerning women's right to organize. See, for example, 350th Report, Governing Body, 302nd Session, Geneva, June 2008, GB.302/5, paras 31-34 (Cases Nos 2188 and 2402 (Bangladesh) on intimidation of members and leaders of the Bangladesh Diploma Nurses Association).

104 ILO: Freedom of association in practice: Lessons learned, op. cit., p. xi. See also D. Tajgman (ed.): Extending labour law to all workers: Promoting decent work in the informal economy in Cambodia, Thailand and Mongolia (Bangkok, ILO, 2006).
} 
balance and parental leave. ${ }^{105}$ The ILO has developed a practical guide to gender and collective bargaining and assists workers' organizations in focusing on gender mainstreaming in collective bargaining. ${ }^{106}$ In Kazakhstan, for example, the 2007-08 tripartite General Agreement covers the implementation of rights for women workers, recommending that regional, branch and enterprise collective agreements specifically address sex discrimination in the labour market.

332. The 2008-09 awareness-raising campaign on "Gender equality at the heart of decent work", funded by the Government of Norway, focuses on rights throughout its monthly themes, which are spread over the 12 months leading to the ILC discussion of this report. ${ }^{107}$

\section{Employment}

333. Employment policies are necessary instruments to ensure that employment is at the centre of overall national policy frameworks for growth. Gender equality contributes to the objectives of employment growth, efficiently functioning labour markets and social cohesion. The Employment Policy Convention, 1964 (No. 122), ${ }^{108}$ which, according to the 2008 Declaration, is one of the most significant Conventions from the viewpoint of governance, requires ratifying States to pursue an active policy designed to promote full, productive and freely chosen employment. It states that the policy shall ensure that there is freedom of choice of employment for each worker, irrespective of sex, among other grounds. Free choice of employment under the Convention has gender implications when properly implemented.

334. At the national level, policies for the promotion of entrepreneurship often take the gender dimension into account, and the importance of women entrepreneurs for progress and sustainable development is universally recognized. For example, in South Africa and Lithuania, training for the promotion of women's entrepreneurship and access to financial services and legal protection have been strengthened. ${ }^{110}$ The private sector can also play a useful role: the Business Development Bank of Canada, for example, has created "Bizlink" teams in its branches to offer regional networking opportunities to women entrepreneurs.

105 ILO: Freedom of association in practice: Lessons learned, op. cit., para. 88.

106 S. Olney et al.: Gender equality: A guide to collective bargaining (Geneva, ILO, 1998).

107 For detailed information on the monthly themes of the campaign, see: www.ilo.org/gender/Events/Campaign2008-2009/lang--en/index.htm.

108 Other relevant instruments to be used in tandem with the key equality Conventions are the Employment Policy Recommendation, 1964 (No. 122); the Employment Policy (Supplementary Provisions) Recommendation, 1984 (No. 169); the Human Resources Development Convention, 1975 (No. 142), and Recommendation, 2004 (No. 195); the Job Creation in Small and Medium-Sized Enterprises Recommendation, 1998 (No. 189); and the Termination of Employment Convention, 1982 (No. 158), and Recommendation, 1982 (No. 166).

109 See ILO: Promoting employment: Policies, skills, enterprises, Report III(Part 1B), ILC, 92nd Session, Geneva, 2004, paras 122-126.

${ }^{110}$ In some countries, the number of businesswomen is as high as or even higher than that of businessmen. However, they tend to be involved mostly in low-investment, less remunerative enterprises. In South Africa, women are slightly more likely than men to run any kind of business (11 per cent compared with 8 per cent). However, women are concentrated in the subsistence sector of SMEs (42 per cent of entrepreneurs in 1996). In Lithuania, the proportion of women out of the total number of enterprise managers increased significantly, from 29 per cent in 2000 to 40 per cent in 2001. ibid., paras 390-391. 


\section{Social security}

335. As most social security systems were initially set up on the basis of the male breadwinner model, different treatment was applied to men and women. However, with societal changes and more women joining the paid labour force, social security systems have gradually been reformed to take account of the new gender roles, either through the elimination of discriminatory practices in scheme design or through measures to equalize outcomes and compensate for inequalities generated outside the social security system, such as those arising in the labour market.

336. The weaknesses of social protection systems in most developing countries have prompted the World Commission on the Social Dimension of Globalization to highlight the need to extend unemployment insurance, income support, pensions and health systems so that a certain minimum level of social protection becomes an accepted, undisputed part of the socio-economic floor of the global economy. ${ }^{111}$ Yet ILO social security instruments - such as the Social Security (Minimum Standards) Convention, 1952 (No. 102) - have been ratified by a relatively low number of States, and the gender dimensions of social security coverage require attention. ${ }^{112}$

337. It is well accepted that the ILO's minimum set of non-contributory social security benefits would have a substantial impact on reducing gender inequalities throughout women's life cycle. This package would ensure that:

a all residents have access to essential basic health-care benefits, with the State being responsible for ensuring the adequacy of the delivery system and financing of the scheme;

- all children enjoy basic income security through family/child benefits aimed at facilitating access to nutrition, education and care;

a there is some targeted income for poor and unemployed persons in the economically active age group; and

口 all residents enjoy basic income security in old age and disability, through old-age and disability pensions.

\section{Remuneration}

338. Convention No. 100 is one of the most widely ratified ILO Conventions and, through its equal remuneration provisions, can have an impact on sex-segregated labour markets and equal access to employment for women workers. It is thus also relevant to the overall elimination of sex discrimination in employment. Pay equity action to rectify the discriminatory undervaluation of women's work should be treated as a right, and not merely as a privilege or a pay increase that can be eliminated when it suits an enterprise or government's cost-cutting agenda. ${ }^{113}$ Promoting equity: Gender-neutral job

\footnotetext{
${ }^{111}$ ILO: Setting social security standards in a global society, Social Security Department, Social Security Policy Briefings Paper No. 2 (Geneva, 2008), p. 19.

112 Gender-specific reasons given for non-ratification of Convention No. 102 include its definition of a wife; the reference to the male breadwinner model; the notion of "skilled manual male employee"; the payment of survivors' benefit to the widow (and not to the widower); ibid., p. 38 .

${ }^{113}$ M. Cornish: Securing pay equity for women's work - Everyone benefits: The international experience, Paper for ILO International Seminar on Equal Pay for Work of Equal Value, Santiago, Chile, 25 August 2008, p. 5.
} 
evaluation for equal pay: A step-by-step guide ${ }^{114}$ is designed specifically to address the economic characteristics of the pay gap (such as working hours, education, experience, unionization rate, economic sector, size of enterprise), as well its discriminatory causes. An innovative ILO pilot project was conducted with the European Social Fund and national tripartite partners in Portugal on job evaluation methods free from gender bias in the restaurant sector. Portugal is experiencing a massive influx of women in the labour market. Women's unemployment rates are systematically higher than men's, with women earning on average 79 per cent of their male peers' earnings. In Egypt, since 2007 ILO headquarters technical teams and the Subregional Office for North Africa in Cairo have been advising the Government and the social partners to address the comments made by the CEACR under Convention No. 100. The concept of "equal pay for work of equal value" has been clarified and a plan of action and recommendations have been adopted. ${ }^{115}$

339. Abusive pay practices, or the non-payment of wages by employers, seem to have a disproportionate impact on women workers. The sectors in which such practices occur frequently have predominantly female workforces. Where both men and women workers are employed, priority is given to men when employers decide to pay wages to some of the workforce. ${ }^{116}$

\section{Box 6.5 \\ Eliminating gender-specific pay differentials in Mauritius}

"The Committee [of Experts on the Application of Conventions and Recommendations] notes with interest the [Mauritian] Government's indications on the ongoing legislative action for the removal of all gender-specific pay differentials. It also notes the elimination of gender-specific job appellations in two recent Remuneration Order Regulations. The Committee further notes that under the revised Field Crop and Orchard Workers (Remuneration Order) Regulations, the terms 'male field labourer' and 'female field labourer' have been replaced by 'field labourer grade I' and 'field labourer grade II', respectively. It trusts that, as a result of the new gender-neutral job appellations, differentiated pay rates for men and women are no longer practised and measures are taken to avoid women being automatically classified as 'grade II field labourers', which would effectively preserve the gender-based pay differentials in a disguised manner."

Source: CEACR: Direct request addressed to Mauritius concerning its application of the Minimum Wage-Fixing Machinery Convention, 1928 (No. 26).

\section{Migration}

340. The Migration for Employment Convention (Revised), 1949 (No. 97), requires ratifying States to apply treatment to migrant workers no less favourable than that applying to national workers without discrimination based on sex, among other grounds. The Migrant Workers (Supplementary Provisions) Convention, 1975 (No. 143), is aimed at combating migration in abusive conditions and at ensuring equality of treatment for

\footnotetext{
114 M.-T. Chicha: Promoting equity: Gender-neutral job evaluation for equal pay: A step-by-step guide (Geneva, ILO, 2008).

115 See ILO: Information document on ratifications and standards-related activities (as to 31 December 2007), Report III(Part 2), ILC, 97th Session, Geneva, 2008, para. 52.

116 ILO: Protection of wages: Standards and safeguards relating to the payment of labour remuneration, General Survey of the Reports on the Protection of Wages Convention, 1949 (No. 95), and the Protection of Wages Recommendation, 1949 (No. 85), Report III(Part 1B), ILC, 91st Session, Geneva, 2003, para. 25.
} 
migrants. These Conventions are very useful in countering gender bias against domestic workers and care economy workers, for example. To date, however, many important North American and Asian countries of destination and many major Asian countries of origin have not ratified these two ILO Conventions. ${ }^{117}$ The ILO Multilateral Framework on Labour Migration advocates a rights-based approach to migration policies, and provides a comprehensive set of gender-sensitive guidelines and principles and good practices to achieve equality of treatment.

\section{Work and family}

341. The Workers with Family Responsibilities Convention, 1981 (No. 156), applies to men and women workers with responsibilities in relation to their dependent children and to other members of their immediate family who clearly need their care or support, and prohibits discrimination against persons with family responsibilities, especially their dismissal. A key feature is that it recognizes the role of men (as well as women) in sharing family responsibilities and requires state policies and support measures to cover both sexes. Indirectly, it challenges the male breadwinner model and the assumption that women's work is of less value and that family responsibilities are the sole remit of women. National reports on the application of the Convention often highlight the role of the State in providing adequate public childcare and elderly-care facilities.

342. Twenty years after its adoption, in 2001, the CEACR was able to note that there had been a progressive reinterpretation of gender-specific roles in marriage, family responsibilities and working life, recalling the Preamble of the UN Convention on the Elimination of All Forms of Discrimination against Women, 1979, to the effect that States parties are " "aware that a change in the traditional role of men as well as the role of women in society and in the family is needed to achieve full equality between men and women.' This reinterpretation has called for the transformation of the international rules regulating women's access to employment. While these rules may have aimed previously at protecting women against excessively arduous working conditions, they now need to be refocused to better reflect present-day principles of non-discrimination at work and gender equality." 118

343. Since this statement was made, a large number of legislative and practical measures have been adopted in order to achieve a work/family balance. ${ }^{119}$ Both work and family are changing. Women have moved into the public world of paid work in most countries, but in general this has not been accompanied by men assuming more responsibilities in the private world of household work (see table 6.5). In couples, research has shown that the less men participate in household tasks, the greater the difference between male and

117 See A. King Dejardin: Gender dimensions of globalization, Policy Integration and Statistics Department (Geneva, ILO, 2008), p. 17.

118 ILO: Night work of women in industry, Report III(Part 1B), ILC, 89th Session, Geneva, 2001, para. 30 .

119 See, for example, 2008 CEACR observations noting the following legislative improvements: Chile's Act No. 19670 of 15 April 2000 granting to fathers the same protection against dismissal as had existed for mothers who face both work and family demands; Croatia's National Policy for the Promotion of Gender Equality (2006-10) containing specific measures promoting the sharing of family responsibilities between men and women and increasing the availability of childcare services; and France's Act of 23 March 2006 on equal pay for men and women extending the scope of eligible expenditure for family tax credit to enterprises' expenditure on training for employees hired following their resignation from or termination of service during parental education leave. 
female pay in the marketplace. ${ }^{120}$ What is needed are measures to develop or promote community services, public or private, such as childcare and family services and facilities, as well as adjustments of working time and leave. ${ }^{121}$

Table 6.5. Gender and time allocation in a selection of countries *

\begin{tabular}{|c|c|c|c|c|c|c|c|}
\hline & & \multicolumn{3}{|c|}{$\begin{array}{l}\text { Cooking and cleaning } \\
\text { Hours and minutes per day }\end{array}$} & \multicolumn{3}{|c|}{$\begin{array}{l}\text { Care of children } \\
\text { Hours and minutes per day }\end{array}$} \\
\hline & & Women & Men & M/W \% & Women & Men & M/W \% \\
\hline Benin & (1998) & $2: 49$ & $0: 27$ & 11 & $0: 45$ & $0: 05$ & 11 \\
\hline France & (1989-99) & $3: 04$ & $0: 48$ & 16 & $0: 28$ & $0: 09$ & 32 \\
\hline Germany & $(2001-02)$ & $2: 32$ & $0: 52$ & 22 & $0: 26$ & $0: 10$ & 38 \\
\hline Madagascar & (2001) & $2: 51$ & $0: 17$ & 7 & $0: 31$ & $0: 08$ & 26 \\
\hline Mauritius & $(2003)$ & $3: 33$ & $0: 30$ & 9 & $0: 44$ & $0: 13$ & 30 \\
\hline Mexico & $(2002)$ & $4: 43$ & $0: 39$ & 6 & $1: 01$ & $0: 21$ & 21 \\
\hline Nicaragua & (1998) & $3: 31$ & $0: 31$ & 9 & $1: 01$ & $0: 17$ & 17 \\
\hline Norway & $(2000-01)$ & $2: 14$ & $0: 52$ & 24 & $0: 34$ & $0: 17$ & 50 \\
\hline Poland & $(2003-04)$ & $3: 13$ & 1:02 & 34 & $0: 39$ & $0: 16$ & 41 \\
\hline Republic of Korea & $(2004)$ & $2: 36$ & $0: 20$ & 9 & $0: 55$ & $0: 15$ & 27 \\
\hline South Africa & $(2000)$ & $3: 06$ & $1: 00$ & 33 & $0: 39$ & $0: 04$ & 10 \\
\hline United States & $(2005)$ & $1: 54$ & $0: 36$ & 23 & $0: 48$ & $0: 24$ & 50 \\
\hline
\end{tabular}

* The data refer to an average day of the year for the total population aged between 20 and 74 .

Source: M. Daly: The equal sharing of responsibilities between women and men, including caregiving in the context of HIVIAIDS, Background paper for the Expert Group Meeting, Geneva, 6-9 October 2008, EGM/ESOR/2008/BP.1.

\subsection{Working with the United Nations and international agencies}

344. Decent work has become a global goal and has been endorsed by a wide range of political bodies, including the EU, the African Union, the G8, the Organization of African Unity (OAU) and ECOSOC. The ITC-ILO is currently collaborating with UNIFEM and the European Commission (EC) in the EC-UN Partnership on Gender Equality for Development and Peace, which is aimed at ensuring that gender equality is high on the new aid effectiveness agenda and that gender equality priorities are appropriately reflected and budgeted for in national development frameworks and poverty reduction strategies. At country level, Decent Work Country Programmes constitute the ILO's main operational mechanism for achieving the strategic objectives and an entry point for "Delivering as One" within the UN system. Decent work is also a key element of the UN system-wide reform, and has been integrated in the MDGs.

345. The focus on decent work for women offers practical ways of accelerating the implementation of the Beijing Platform for Action and achieving all of the MDGs,

\footnotetext{
${ }^{120}$ G. Chichilnisky and E. Hermann Frederiksen: "An equilibrium analysis of the gender wage gap”, in International Labour Review, Vol. 147, No. 4 (Geneva, ILO, 2008), p. 298.

121 L. Addati and N. Cassirer: Equal sharing of responsibilities between women and men, including caregiving in the context of HIV/AIDS, Background paper for the Expert Group Meeting, Geneva, 6-9 Oct. 2008, EGM/ESOR/2008/BP.2.
} 
especially MDG 3 on gender equality. Other UN agencies increasingly link gender to development. UNDP, for example, promotes women's employment in recognition of its positive impact on health and education and thus on several MDGs. In preparation for the special session of the UN General Assembly, "Women 2000: Gender Equality, Development and Peace for the Twenty-first century", the ILO collaborated with UN DAW to produce the 1999 World Survey on the Role of Women in Development: Globalization, gender and work. In 2005, UNDP hosted a Global Conference on Unpaid Work and the Economy: Gender, Poverty, and the Millennium Development Goals, in which the ILO participated.

346. The ILO is a member of the UN Global Compact, launched in 2000, which advances ten universal principles in the areas of human rights, labour standards, the environment and anti-corruption with the aim of promoting responsible corporate citizenship. New initiatives include expanding the reach of equal opportunities for men and women through responsible enterprise-level practices. ${ }^{122}$

347. The Decent Work Country Programmes define the ILO contribution to such frameworks. They reflect and contribute to the inclusion of gender issues in the world of work in UN country programmes. UNIFEM and the ILO have collaborated to mainstream gender and Decent Work Country Programme issues in the Poverty Reduction Strategy Papers (PRSP) process of the United Republic of Tanzania.

\subsection{The way forward}

348. The wealth of issues covered in this chapter shows the importance of gender equality for adult workers, including the impact of inequalities that accumulate through the life cycle. The following indicative list highlights areas where ILO policies, programmes and activities can have an impact.

a Ratifying and implementing relevant standards that support a comprehensive approach to gender equality in the workplace.

- Establishing and implementing a national employment policy comprising active labour market policies and programmes - such as women's entrepreneurship and affirmative action for women or men (as required) - including the monitoring and evaluation of their gender-differentiated impact at national level.

- Strengthening human resources management and practices through research and capacity-building programmes on gender equality and encouraging responsible non-discriminatory practices at the enterprise level.

- Strengthening legal protection against sex discrimination by scaling up training programmes for enforcement authorities, especially labour inspectorates, industrial relations tribunals and labour courts.

a Providing social security protection which grants equal treatment to men and women or which equalizes outcomes and compensates for sex-based discrimination.

- Integrating gender concerns in pro-poor growth strategies and policies, ensuring that their employment content, in particular for women, is adequately addressed.

${ }^{122}$ See ILO: The labour principles of the United Nations Global Compact: A guide for business (Geneva, 2008). See also ILO and UN Global Compact: Your Rough Guide to the 2006 Global Compact Policy Dialogue: Combating discrimination and promoting equality (Geneva, 2006), pp. 59-65. 
- Reinforcing member States' provision of a system of quality childcare and elderly care so that adult workers can better balance work and family responsibilities.

- Adopting policies aimed at flexible working hours so as to allow work-family balance or enable women and men to continue their careers without interruption and without discrimination.

- Extending social dialogue, in particular access to collective bargaining, on issues affecting equality between men and women by removing barriers to representation of all workers.

a Prioritizing support to national gender machineries, in particular building their links to tripartite institutions or equality or human rights commissions, in order to promote an integrated approach to gender equality in the world of work, and building links with the national policy framework and budget.

- Providing technical assistance on legal protection against sex discrimination by supporting legislative reform, offering training on drafting equality legislation, and strengthening enforcement authorities, especially labour inspectorates, alternative dispute resolution bodies and courts.

- Replicating innovative measures to foster entrepreneurship and SME development as viable pathways to decent work - such as Work Improvements in Small Enterprises (WISE), Work Improvement in Neighbourhood Development (WIND), Women's Entrepreneurship Development and Gender Equality (WEDGE), Start and Improve Your Business (SIYB) - and supporting the creation of enabling business environments.

- Strengthening sex-disaggregated data collection and analysis, including capacity building for a wide range of national institutions responsible for data collection and analysis and for the social partners (for example, household surveys, time-use surveys, labour market situation analyses and mapping exercises).

- Studying the significance of the care economy for both formal and informal economies, including analyses of global care chains.

- Conducting dedicated research into the transition from unpaid (market) work and paid but precarious work to decent work, with the aim of developing a genderresponsive methodology.

- Promoting the recent research on gender-responsive social security systems so that a universal social floor is achieved.

- Reinforcing the role of States in integrating social care as part of social policy and promoting the creation of quality care systems for children, the elderly and people with disabilities.

- Intensifying capacity building on equal pay and, in particular, job evaluation methodologies free of gender bias, including sector-specific interventions, as a key means of achieving equal remuneration. Capacity building should cover in-depth explanation of the concept of "work of equal value", especially in countries which report that equal pay in their labour markets has been achieved.

- Disseminating current ILO tools (research findings, good-practice collections, guidelines, training manuals) on sexual harassment at work as the Office's contribution to the UN Secretary-General's campaign to eliminate violence against women and girls.

- Collating thorough information on gender and collective bargaining, including collective agreement provisions on measures to eliminate sex discrimination and promote equality. 



\section{Chapter 7}

\section{Older workers and the senior years: Rights, jobs and social security}

349. Longevity is one of the most positive and relevant demographic phenomena to emerge in recent decades. The ageing of populations and the new inter-generational relationships radically affect the human landscape and decent work. But as most of the world's older workers are not entitled to any form of old-age pension, ${ }^{1}$ living longer, for many people, also means living with scarcity for longer; poverty in old age is a key concern today. Increases in life expectancy involve changes in the entire life cycle. One fundamental change is a shift from "three-generation" societies to "four-generation" societies, ${ }^{2}$ as many of today's grandparents remain involved, mobile and active. ${ }^{3}$ Characteristics traditionally attributed to "seniors" are shifting to persons in an older age bracket (70s and 80s). ${ }^{4}$

350. The proportion of people aged over 60 in the population is projected to grow to 22 per cent by 2050 , amounting to 2 billion. This means that in roughly 40 years, one out of five people on the planet will be aged 60 years or older. Living longer means needing adequate income and good and affordable health care for longer. Families and societies have to regroup and develop ways of providing care and living arrangements for their older members and mobilize to provide the necessary health-care and other services. ${ }^{5}$ Discrimination against older people, particularly older women, and abuse of the elderly also need to be addressed. ${ }^{6}$

\footnotetext{
1 The Older Workers Recommendation, 1980 (No. 162), applies to "all workers who are liable to encounter difficulties in employment and occupation because of advancement in age", while allowing for more specific age categories to be adopted by the member States in a manner consistent with national laws, regulations and practice and appropriate under local conditions.

2 As quoted in G. and R. Ben-Israel: "Senior citizens: Social dignity, status and the right to representative freedom of organization", in International Labour Review, Vol. 141, No. 3 (Geneva, ILO, 2002), p. 253.

3 WHO coined the concept of "active ageing" in the 1990s. See A. Walker: "A strategy for active ageing”, in International Social Security Review, Vol. 55, No. 1, 2002.

${ }^{4}$ M.C. Bateson: Composing a further life: The age of active wisdom, forthcoming.

${ }^{5}$ Commission of the European Communities: Green Paper "Confronting demographic change: A new solidarity between the generations" (Brussels, 2005).
}

6 S. Perel-Levin: Discussing screening for elder abuse at primary health-care level (WHO, Geneva, 2008). 
351. In developing countries, older people who have no form of retirement benefit may have to work despite poor health, in order just to survive, even if few decent employment opportunities are available to them. At the same time, many older women and men in developed countries are in good physical and mental health and are perfectly capable and willing to offer their experience and skills to employers, even though they are entitled to retire.

352. Demographic shifts will have profound economic consequences on growth, savings, investment, consumption, labour markets, pensions, taxation and intergenerational transfers. ${ }^{7}$ The ILO has been working on the policy implications of a growing number of older workers, including fresh demands on the care economy. Increasingly, older people in many parts of the world - even those in poor health - may have no choice but to work continuously until a very old age. They may not be entitled to affordable retirement or have access to any retirement benefits to cover their living costs. There is active debate in OECD countries regarding mandatory retirement ages in situations in which many workers either need or wish to continue working, and whether this hampers efforts to promote youth employment. ${ }^{8}$ Longer lives require more and better jobs, targeted employment policies and effective social security systems, with pension entitlements that keep up with living costs over the years.

353. Table G1 in the appendix presents the projected life expectancy from birth of the female and male populations in 2008, 2018 and 2048. Table G2 in the appendix presents the projected life expectancy at 50,60,70 and 80 years for women and men in the same years. ${ }^{9}$ In the case of any country (but more so in countries with higher infant and child mortality), life expectancy for older people exceeds life expectancy at birth. Once women and men reach 50, their survival has already exceeded expectations at birth, and they can expect to survive to a more advanced age. There is an important sex-related difference in these data, which can be seen in virtually all countries and in all periods: more women survive at all ages, including those who have reached the age of 80 . The underside of this concerns their living conditions, especially those of older women, and the risk of female poverty.

354. Globally, there are large and increasing numbers of women who will need care and protection. If better-educated women enter the labour force in greater numbers and earn equal pay for work of equal value, they will be able to make suitable arrangements themselves. Until that time, however, the shortfall in women's economic participation and earnings means that they are inevitably at an economic disadvantage in old age. A fundamental policy objective is to build societies fit for people of all ages. ${ }^{10}$ This is high on the international community's agenda to allow the inclusion of all older women and men in such societies, as proclaimed by the Madrid World Assembly on Ageing in April 2002. ${ }^{11}$ A society for all ages requires rethinking the conventional course of working life.

\footnotetext{
7 United Nations: World population ageing 2007, DESA, Population Division, p. xxvi.

${ }^{8}$ In countries such as Belgium and France, where systems have encouraged earlier retirement ages, youth employment has not increased. See OECD: Live longer, work longer: A synthesis report (Paris, 2006).

9 The data are from the UN Population Division and are presented only by country, because weighted averages from the UN refer to regions that are substantially different from those of the ILO.

10 ILO: Promoting decent work for an ageing population: Actors, partners and corporate social responsibility, Background paper contributed by the ILO to the G8 high-level meeting on employment, Paris, 12-13 May 2003.

11 Gender dimensions of the Madrid International Plan of Action on Ageing and its implementation, http://daccessdds.un.org/doc/UNDOC/GEN/N03/433/34/PDF/N0343334.pdf.
} 
It entails introducing more flexible and tailored working patterns, but also ensuring that people have both the right to continue working if they so wish and the right to retire in decent, affordable conditions if they do not.

355. As figures 7.1 and 7.2 show, older working women and men in least and more developed countries will face different challenges in the decades to come. Older people should be able to choose to work, whether full or part time, and to benefit from social security, old-age, retirement or long-service benefits. ${ }^{12}$

356. Because women live longer than men, they form the majority of older people (55 per cent). Currently, women outnumber men by about 70 million among those aged 60 years or over. ${ }^{13}$ Over the last 50 years, the global life expectancy of women has increased from 48 to 67 years, compared with 45 to 63 years for men. The figures show that the proportion of women among the elderly is higher in more developed countries than in less developed ones.

357. Women accumulate disadvantages throughout their lives. They are especially vulnerable owing to their high numbers in unpaid, low-paid, part-time, frequently interrupted, or informal economy work. As a result, they are less often entitled to any contributory pension benefits in their own right, and even when they are, their pensions are often significantly lower than those of men owing to their lower earnings and shorter contribution periods. For example, in Germany, among those born between 1951 and 1955 , there was a gap of more than seven years in employment for women compared with men. ${ }^{14}$

358. Women's economic contribution consists in large part of the care they provide and the household chores and informal economy activity they undertake. Social security schemes providing minimum benefit guarantees and compensating for loss of entitlements because of family responsibilities are particularly relevant to women workers. There is evidence that basic, non-contributory social security pensions help to reduce gender inequalities in income and quality of life between older women and men. ${ }^{15}$

359. In some societies, a widow is often denied access to or control over her late husband's resources, which may be distributed among other family members. In these countries, widowhood means more than the loss of a husband: it is usually accompanied by a loss of status and of identity, destitution and even social ostracism. The expected increase in the numbers of widows over the current century will challenge society to provide not only the necessary immediate support through social security cash benefits, but also the opportunities to become more self-supporting.

\footnotetext{
12 The Older Workers Recommendation, 1980 (No. 162), defines old-age benefit as "a benefit provided in the case of survival beyond a prescribed age"; retirement benefit as "old-age benefit awarded upon the cessation of any gainful activity"; long-service benefit as a benefit granted "upon the completion of a long qualifying period, irrespective of age".
13 Among those aged 80 years or over, women are nearly twice as numerous as men, and among centenarians women are between four and five times as numerous as men. UN: World Population Ageing 2007, DESA, Population Division, p. xxviii.
${ }^{14}$ U. Klammer: Flexicurity in a life course perspective, Institute of Economic and Social Research, WSI/Hans Böckler Foundation (Düsseldorf), p. 286.

15 S. Tabor: Assisting the poor with cash: Design and implementation of social transfer programs, Social Protection Discussion Paper Series No. 223, Social Protection Unit, Human Development Network (Washington, DC, World Bank, 2002).
} 
Figure 7.1. Population pyramids by development group, 2005 (least developed countries)

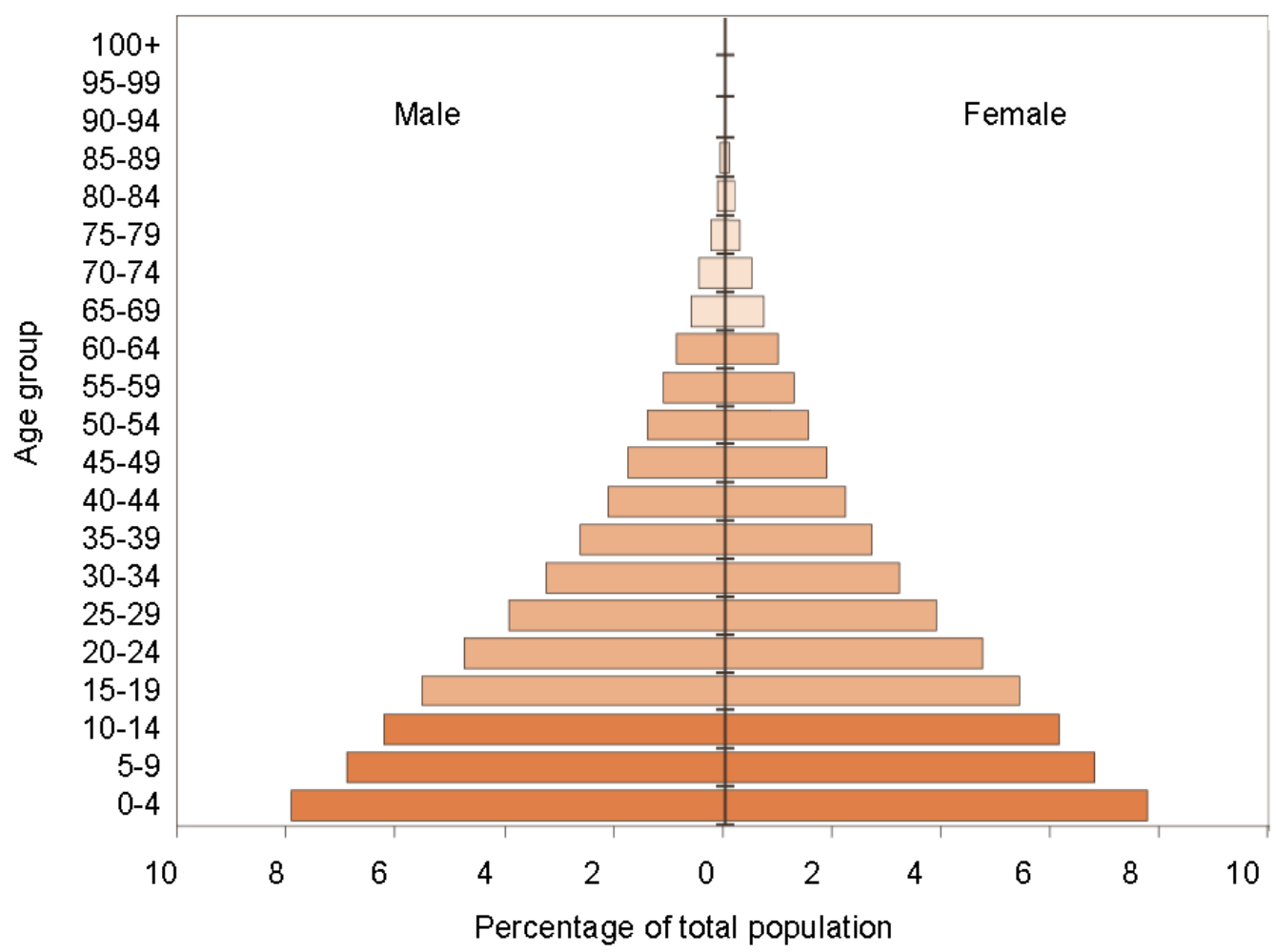

Source: United Nations Programme on Ageing, see http://un.org/ageing/popageing_demo.html.

Figure 7.2. Population pyramids by development group, 2005 (more developed countries)

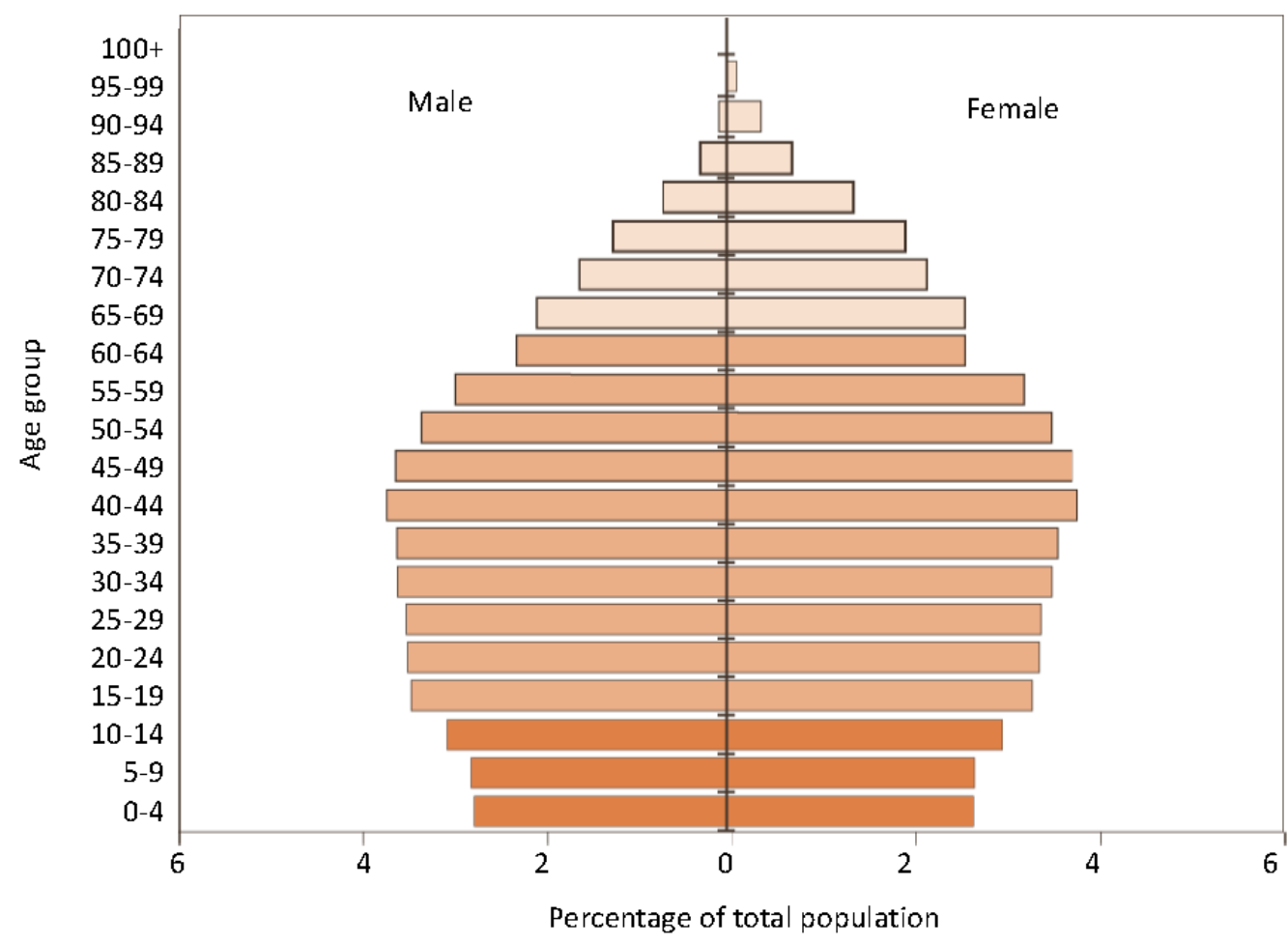

Source: United Nations Programme on Ageing, see http://un.org/ageing/popageing_demo.html. 
360. Labour force participation rates for older women are generally lower than for older men (see figure 7.3). While much attention was focused on retaining older male workers in the labour force over the past decades, this was not the case for older female workers. Their lower participation does not mean that older women are not working. Older women workers who work for only a few hours or undertake irregular or seasonal employment, women who are in unpaid employment, or those who work near or in their home, are often not captured in the labour market indicators. ILO analysis shows that older women who work shorter periods or do not work at all in formal employment may not be protected by existing social security provision. ${ }^{16}$

Figure 7.3. Labour force participation rates by age and sex, world, 2008, percentages

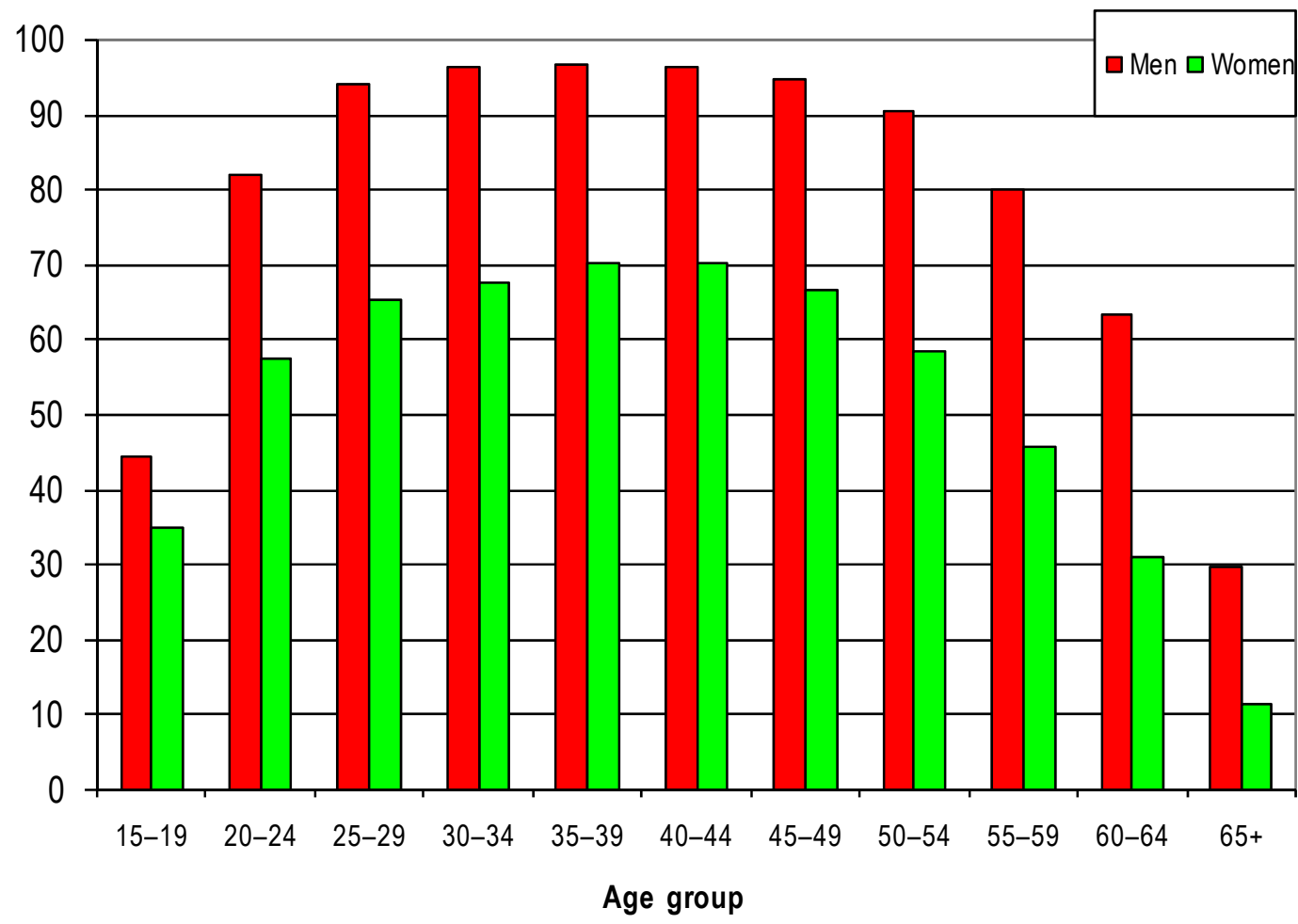

Source: ILO database of labour statistics. Economically active population estimates and projections 1980-2020 (EAPEP).

361. Age discrimination underlies many of the difficulties faced by older workers, notably older women workers. ${ }^{17}$ The CEACR has noted a gender-age discrimination correlation in relation to entitlement to social security benefits that are based on unjustified differences between the ages at which men and women can access pensions. In China and Viet Nam, for example, the different obligatory retirement ages for women and men pose a serious problem. The ability of older workers to learn new skills is sometimes questioned, although there is ample evidence that such prejudices are mostly unfounded. In countries where wage systems and benefits are strongly linked to age and length of service (Austria, Belgium, France, Japan and the United States), there is a

\footnotetext{
${ }^{16}$ ILO: Key Indicators of the Labour Market, fifth edition (Geneva, 2007).

17 ILO: Report III (Part 4B), Special Survey on equality in employment and occupation, ILC, 83rd Session, Geneva, 1996, para. 253. A lower pensionable age for women constitutes formal discrimination against men. See ILO: Social security: A new consensus (Geneva, 2001), p. 75; and N. Haspels and E. Majurin: Work, income and gender equality in East Asia: Action guide (Bangkok, ILO, 2008), pp. 57-58.
} 
reluctance to recruit and retain older workers. Social perceptions are slow to change and laws banning age discrimination are an important means of accelerating behavioural change. In countries such as Australia, Canada, New Zealand and the United States, the law has prohibited age discrimination for many years. ${ }^{18}$

362. The European Union aims to increase the employment rate of persons aged 55-64 years to 50 per cent by $2010 .{ }^{19}$ In 2003 , this rate was 41.7 per cent in the EU15 countries, led by Sweden with an employment rate of 68.6 per cent in this age bracket. However, there was a difference of almost 20 percentage points in the employment rates of men and women in the oldest age group, regarding lower education levels of women. ${ }^{20}$ Under the impetus of the EU Framework Directive on Equality, ${ }^{21}$ most Member States have transposed into national law the relevant provisions on agebased discrimination. For example, the United Kingdom's Employment Equality (Age) Regulations, which came into force in October 2006, prohibit direct and indirect discrimination, harassment or victimization on grounds of age.

363. In Eastern Europe, increasing overall employment levels, and thus an increasing ratio of pension contributors to beneficiaries, are seen as the solution to the problem of pension financing and population ageing. Several groups were targeted for special support to boost their participation rates, including women, persons with disabilities, young people and older people, and financial incentives were introduced for older workers to remain active longer and retire gradually. ${ }^{22}$

364. So where do older women work and what policies have given them decent work? When they work outside the home, they are mostly active in unprotected and precarious categories of work: in small-scale economic units or self-employed (usually in agriculture), where labour market statistics classify these activities as "unpaid" or as "helping family workers". These activities are not always taken into account when labour force participation is assessed. As to informal sector activities, home-based work, own-account work and domestic work are, proportionally, the most relevant categories. Home-based work may offer older women the opportunity to combine their domestic and family responsibilities with paid activities. ${ }^{23}$ Although women spend several hours a

\footnotetext{
18 The US Bureau of Labor Statistics reports that more Americans aged over 55 are now working than at any time over the past 30 years - many because they need to in order to maintain their standard of living.

19 There has been significant progress in the labour force participation and employment rates of older workers aged 55-64. In the EU15, the employment rate among this older age cohort rose by 9.4 points between 1995 and 2006. See ILO: Delivering decent work in Europe and Central Asia, Report of the Director-General, Vol. I, Part 1, Eighth European Regional Meeting, Lisbon, February 2009, p. 22.

${ }^{20}$ M. Ylikoski et al. (eds): Health in the world of work: Workplace health promotion as a tool for improving and extending work life, Ministry of Social Affairs and Health, Finnish Institute of Occupational Health (Helsinki, 2006), p. 51.

${ }^{21}$ Council Directive 2000/78/EC of 27 November 2000, establishing a general framework for equal treatment in employment and occupation.

22 ILO: Report of the Seventh European Regional Meeting, Budapest, 14-18 February 2005, ERM/VII/D.7, para. 30 .

${ }^{23}$ UN Economic Commission for Latin America and the Caribbean (ECLAC): The contribution of women to the economy and social protection especially in relation to unpaid work performed by women in the Caribbean, Tenth Session of the Regional Conference on Women in Latin America and the Caribbean, Quito, Ecuador, 6-9 August 2007, pp. 8-9.
} 
day on unpaid tasks, which limits their involvement in paid work, domestic work is still not counted as "work". ${ }^{24}$

\subsection{ILO action}

\subsubsection{Employment}

\section{Labour market policies}

365. Labour market policies that are adequately designed and targeted towards older workers, notably older women workers, can be highly effective in promoting their employment opportunities. Career guidance and counselling and job search assistance can play a key role in promoting older workers' employability. Training and continuing education are crucial in helping them to adapt to changing demands and opportunities. The demand for new skills and knowledge places older workers at a disadvantage, as their earlier training is likely to prove obsolete if it has not been continually updated. In some developing countries, older women are more likely than men to lack basic literacy and numeracy skills.

366. Lifelong learning rejects the notion of an age-structured society in which education is a one-off experience early in life. ${ }^{25}$ For adults with deficient initial education and training, many of whom are older women, lifelong learning is about delivering jobrelevant learning and building the foundation for further learning. "Employers will only offer training to low-qualified or older employees if they can expect a positive return on their investment. The foreseeable trend to delay the age at which older workers can withdraw from the labour force could raise incentives for employers to invest in lifelong learning since it will extend the time span of the pay-off period". ${ }^{26}$ At the 2008 session of the Conference, member States stressed that a lifelong learning agenda should target older workers by providing employment placement services, guidance and appropriate active labour market measures, and by adopting legislation to counter age discrimination and facilitate their workforce participation. ${ }^{27}$

367. Mid-career and older women often return to work after raising their families and may have specific skills and retraining needs. If these needs are not met, such women may be pushed into lower-level jobs. This underutilization of female workers' skills has implications for economic productivity. The GEA, which focuses on placing employment at the centre of economic and social policy-making in order to create more and better jobs, can provide a useful framework to meet the employment challenges of the older population. Employment policies, notably public and private employment

\footnotetext{
${ }^{24}$ S. Chant and C. Pedwell: Women, gender and the informal economy: An assessment of ILO research and suggested ways forward (Geneva, ILO, 2008).

25 ILO: A guide on employment of older women workers in Estonia, Series on Gender in Life Cycle, Gender Promotion Programme (Geneva, 2004), p. 54.

${ }^{26}$ U. Klammer: Flexicurity in a life course perspective, Institute of Economic and Social Research, WSI/Hans Böckler Foundation (Düsseldorf, 2004).

27 ILO: Conclusions, Report of the Committee on Skills, Provisional Record No. 16, ILC, 97th Session, Geneva, 2008, para. 37(d).
} 
services, need to be gender-sensitive and appropriately tailored to help older age groups. ${ }^{28}$

368. Addressing the training and retraining needs of women who re-enter the labour market after raising children, and the reintegration into the labour market of older women who have not had equal access to opportunities for lifelong learning, are integral components of a life-cycle approach. ${ }^{29}$ Training in the use of new technologies, including ICT, will have an important bearing for older persons. ICT holds great potential to enhance older workers' economic contribution and quality of life. Other opportunities to use innovative technological advances in health, energy, security, and ergonomics also contribute to policy responses on a daily basis. Older workers need to be viewed as active users of technology, and so investment in their training is needed, too.

369. The ILO, in its relevant international labour standards, as well through the promotion of the Decent Work Agenda, emphasizes that adequate employment policies, human resource development and lifelong learning are crucial to maximizing the potential of older women and men. For those seeking continuous productive employment, the impact of ageing and discrimination at work is greater on women workers. The gender dimension of older workers' labour force participation has been an important feature in employment policies targeting this age group, including the generation of opportunities for entrepreneurial activity.

\subsubsection{Social protection}

\section{Social security}

370. The ILO regards access to retirement through adequate pensions and health-care as part of its core mandate and as an integral component of the Decent Work Agenda. Office research establishes the knowledge base to counter the challenges of access to comprehensive social security protection, the lack of which is glaringly obvious as populations age. ${ }^{30}$ The Office is aware that informal mechanisms of social protection have declined because of the erosion of extended family systems, rapid urbanization and increasing mobility. ${ }^{31}$

371. The ILO also addresses the problem of low social protection coverage. This continues to be a problem in Latin America, for example, where governments have been paying increasing attention to providing income support to poor older persons who have not contributed to formal social protection systems (or have not contributed for long

\footnotetext{
${ }^{28}$ ILO: Promoting decent work for an ageing population: Actors, partners and corporate social responsibility, Background paper contributed by the ILO to the G8 high-level meeting on employment, Paris, 12-13 May 2003, p. 6.

${ }^{29}$ ILO: Skills for improved productivity, employment growth and development, Report V, ILC, 97th Session, Geneva, 2008.

${ }^{30}$ Eighty per cent of the world's population still lacks social security coverage. ILO: Can low-income countries afford basic social security?, Social Security Policy Briefings Paper No. 3, Geneva, 2008, p. 1.

${ }^{31}$ The Economic Commission for Africa reported low competing priorities for funds and lack of institutional capacity to respond to social protection needs. Social security coverage is mostly limited to the formal economy and to civil services. United Nations: Follow-up to the Second World Assembly on Ageing, Report of the Secretary-General, General Assembly, New York, 63rd Session, A/63/95, p. 4.
} 
enough). Since older women are on the lowest economic rung, they stand to benefit most from such schemes. ${ }^{32}$

372. The fiscal implications of the declining worker-to-retiree ratio are enormous, with fewer workers contributing to the support of each retiree. ${ }^{33}$ This decline in the number of workers per retiree will increasingly strain national budgets, as fewer and fewer workers fund the pension and health-care costs of an increasing number of retirees. The ILO is tracking countries that are considering raising retirement ages in order to be able to support their ageing populations. Many also promote the advantages of long-service benefits based on years of accumulated employment, in lieu of a mandatory cut-off retirement age. Some consider that there should not be a mandatory retirement age and that retirement decisions should be voluntary. Women in particular would benefit from this flexibility.

373. The role of social security as a productive factor in promoting employment, stimulating structural change and fostering economic growth needs to be emphasized. ${ }^{34}$ While high-income countries face the challenge of ensuring the sustainability of social protection systems, low-income countries face the challenge of extending social security coverage to uncovered majorities by gradually building up a basic social security system. In both cases, attention needs to be paid to older women's access to coverage. ${ }^{35}$

374. The Social Security (Minimum Standards) Convention, 1952 (No. 102), sets minimum requirements for a comprehensive social security system. ${ }^{36}$ The Office promotes application of this and other relevant Conventions through its Global Campaign to extend social security to all women and men, launched in 2001 to promote the need for a basic social security floor. The Campaign has a gender dimension in that women are more often among those not covered by any social security provisions. Similarly, it deals with the challenges to social security posed by ageing and with the global responses aimed at providing protection for growing numbers of elderly women and men while ensuring sustainable financing of expanded social security systems.

\section{Occupational safety and health (OSH)}

375. The health of an ageing individual is related to genetic make-up and lifestyle, combined with the impact of working conditions. That is why OSH policies, programmes and systems address arduous working conditions, such as manual handling of heavy loads, excessive noise exposure, atypical and asocial working hours. However,

\footnotetext{
32 In 2008, Chile undertook the biggest ever overhaul of its private pension system, adding significant public payouts for the low-income elderly. The new US\$2 billion a year programme will expand public pensions to groups left out by private pensions - the poor and self-employed, housewives, street vendors and farmers who have saved little for retirement - granting about a quarter of the nation's work force public pensions by 2012. This will supplement, not scrap, the current private pensions, while salaried employees continue paying in to private funds in a combination of state subsidy and free market.

33 A. Hayutin: How population ageing differs across countries: A briefing on global demographics, Stanford Center on Longevity, 2007, p. 33.

34 ILO: Social security for all: Investing in global social and economic development: A consultation, Issues in Social Protection Discussion Paper No. 16 (Geneva, 2006).

35 ILO: Employment and social protection in the new demographic context, Governing Body, 298th Session, Geneva, Mar. 2007, GB.298/2, p. 11.

36 ILO: Setting social security standards in a global society: An analysis of present state and practice and of future options for global social security standard setting in the International Labour Organization, Social Security Policy Briefings Paper No. 2 (Geneva, 2008).
} 
older workers often display skills, experience and maturity which counteract such health concerns. Office studies show that older workers are more dedicated to the workplace, taking less sick leave and staying longer in their jobs. These factors can improve the health and safety culture in a workplace. OSH management systems and training programmes for older workers together with ILO technical assistance take due account of this. ${ }^{37}$

376. As life expectancy and pressure to continue working rise, more research will be needed into the impact of exposure to hazardous substances on the health of older workers. Hazard assessment and subsequent regulatory work on hazardous substances should systematically integrate studies focused on the protection of vulnerable workers. ${ }^{38}$

377. Workers aged 55 years and above seem to be more likely to suffer fatal injuries at work compared to their younger colleagues. In the European Union, for example, the incidence rate of fatal accidents at work was 8.0 for the 55-64 year age group in 2000, but only 3.3 for the 18-24 year age group. As a result, many organizations are now giving attention to the occupational risks faced by older workers and how they can be addressed. ${ }^{39}$

\section{Older persons providing childcare}

378. Intergenerational households have long been lauded as promoting the psychological well-being of families through mutual aid and support. Being a vulnerable, dependent group, older persons are often the primary carers for children, the other vulnerable, dependent group. Older women in particular shoulder the responsibility of caregiving for younger children. A study of pensions in South Africa showed that when grandmothers received pensions, the nutritional status of grandchildren living with them improved. ${ }^{40}$

379. Within the traditional life cycle, grandparents freed the adults to maximize their earning potential and thus make the whole family secure. However, urbanization, and internal and international migration, have ruptured extended-family support networks. ${ }^{41}$ As mobility has eroded the bonds between the generations, reciprocal systems in which older persons assume responsibility as caregivers for children and, conversely, informal social protection is provided for the older persons, are no longer reliable. In Thailand, for example, where grandparents have always played a large role in taking care of

\footnotetext{
37 S. Al-Tuwaijri et al.: Beyond deaths and injuries: The ILO's role in promoting safe and healthy jobs, Introductory Report for the XVIII World Congress on Safety and Health at Work, Seoul, June 2008, p. 21.

38 ILO: Background information for developing an ILO policy framework for hazardous substances, Document for discussion at the Meeting of Experts to Examine Instruments, Knowledge, Advocacy, Technical Cooperation and International Collaboration as Tools with a view to Developing a Policy Framework for Hazardous Substances, MEPFHS/2007 (Geneva, 2007).

39 ILO: World Day for Safety and Health at Work 2005: A background paper, ILO InFocus Programme on SafeWork (Geneva, 2005), pp. 9-10.

40 World Bank: World Development Report 2006: Equity and development (New York, 2005), p. 104.

${ }^{41}$ N. Cassirer and L. Addati: Expanding women's employment opportunities: Informal economy workers and the need for childcare, Conditions of Work and Employment Programme (Geneva, ILO, 2007).
} 
grandchildren, some parents are now obliged to leave the responsibilities of childcare to grandparents for far too long without financial and psychological support. ${ }^{42}$

\subsubsection{Social dialogue}

380. Individual governments have key responsibilities in these times of major demographic change. On the one hand, they are entrusted with developing and implementing policies and programmes to avoid the premature exclusion of older workers from the labour market; on the other, they play the primary role in ensuring the development of a social floor and adequate levels of social protection for all citizens. They have a leading role in increasing the financial incentives to continue working, should older workers wish to do so, and in rewarding flexibility by combining income from work and pensions, so that older workers are better off.

\section{Box 7.1 \\ Effective social dialogue}

One example of this is the placing of the challenges facing older workers of both sexes on the agendas of tripartite bodies. In Singapore, the Tripartite Committee on the Employability of Older Workers recommended setting up a tripartite alliance for fair employment practices to positively shape the mindsets of employers, employees and the general public towards fair and responsible employment practices free of age and sex discrimination. The Tripartite Alliance, which was formed in 2006, aims to root out discrimination in hiring and employment and has been subsequently developing products and undertaking outreach activities.

Source: ILO: Re-engineering labour administration to promote decent work, p. 74. See also N. Haspels and E. Majurin: Work, income and gender equality in East Asia (Bangkok, ILO, 2008), pp. 65-66.

381. Employers' and workers' organizations also have a leading role in promoting job opportunities, employment policies and social security for older women and men through active social dialogue. The insecurity that older workers face and their fears of layoff or unemployment should not be underestimated. It will become urgently necessary to listen to the rising voices of older women and men addressing the issues of age discrimination, productive employment opportunities and access to social protection. Those who were unionized throughout their working lives may put this experience to good use to tackle the issues faced by older women and men. It is important to raise awareness of older workers' problems among employers' and workers' organizations and to seek joint solutions, in order to ensure that these workers' choices and rights are respected. This can best be achieved through social dialogue between willing and informed partners. ${ }^{43}$

382. ACT/EMP has made a CD-ROM on ageing as part of its series "Managing diversity and equality at the workplace". Employers recognize the impact of changing demographics on the labour market. This key challenge is to balance effective workplace policies for diverse workforces and to meet the needs of business. In noting the impact of labour and social legislation on hiring and firing, employers observed that in one country, collective agreements provided special benefits for older workers, such as salary

${ }^{42}$ K. Kusakabe: Reconciling work and family: Issues and policies in Thailand, Conditions of Work and Employment Series No. 14 (Geneva, ILO, 2006), p. xii.

43 The ILO's Older Workers Recommendation, 1980 (No. 162), calls for appropriate measures to be taken in order to inform the public and those responsible for guidance, training, placement and social services - as well as employers, workers and their respective organizations - of the problems which older workers may encounter. 
supplements, protection against lower wages in case of changes in their work tasks, and increased protection against dismissal. As these involve costs for employers which are not commensurate with the benefits, it is claimed that they discourage the creation of jobs for older workers. ${ }^{44}$

383. Workers' organizations have paid particular attention to the healthy ageing of workers by tackling the working conditions that lead to early ageing, in an effort to ensure that workers remain fit and healthy as they get older. Workers' organizations are also concerned about the increasing precariousness of employment. According to the Hans Böckler Foundation, the research and publications institute attached to the main German labour confederation, the costs of greater flexibility should be factored into the choices made by enterprises. Enterprises wishing for more flexibility should pay higher social insurance contributions than enterprises that offer better employment conditions. This "flexinsurance" proposal argues that the employer's social security contribution should be proportionate to the flexibility (precariousness) of the contract, so as to compensate for social risks. In order to motivate employers to equalize the working conditions of normal and atypical employees, a workplace tax for poor working conditions could be introduced, in much the same way that the "green tax" contributes to protecting the environment. ${ }^{45}$ Given that many women are employed in precarious, atypical jobs, such a regulation would have positive gender consequences on their income and benefits.

\section{Box 7.2 \\ Bargaining on gender equality for seniors}

The Collective Bargaining Convention, 1981 (No. 154), is an important vehicle for promoting gender equality for older workers. The negotiation of problems affecting older women workers leads to enforceable measures in collective bargaining agreements, notably concerning equal pay, hours of work, health and the working environment, and dignity at the workplace. Nevertheless this vehicle has not been fully utilized and dedicated research on the topic is needed.

Source: S. Olney and M. Rueda: Convention No. 154 - Promoting collective bargaining (Geneva, ILO).

\subsubsection{Principles and rights}

384. The only age-specific instrument, the Older Workers Recommendation, 1980 (No. 162), aims to protect the rights of older workers to equality of treatment and gives practical advice on measures that should be implemented. Paragraph 2 states: "Employment problems of older workers should be dealt with in the context of an overall and well-balanced strategy for full employment and, at the level of the undertaking, of an overall and well-balanced social policy, due attention being given to all population groups, thereby ensuring that employment problems are not shifted from one group to another".

385. The ILO has a range of social security Conventions dealing with key issues affecting workers throughout the life cycle and having clear implications for older persons, such as sickness, invalidity, old-age and survivor's benefits. The flagship Convention No. 102 has greatly contributed to the practical application of the right to

\footnotetext{
44 IOE: Trends in the workplace survey 2008: Enterprises in a globalizing world (Geneva, 2008), p. 20.

${ }^{45}$ H. Seifert and A. Tangian: Is work in Europe decent? A study based on the 4th European survey of working conditions 2005, Hans Böckler Foundation (Düsseldorf, 2008).
} 
social security through the provision of minimum standards and universally accepted basic social security principles. ${ }^{46}$ It has been crucially important in promoting universal coverage through the application of a basic social security floor, notably for older women who have fallen to the bottom of the social pile. ${ }^{47}$

386. Other equally relevant instruments include the Employment Policy Convention, 1964 (No. 122), which promotes full, productive and freely chosen employment for all who are available for and seeking work, with a view to stimulating economic growth and development, raising standards of living, and overcoming unemployment and underemployment. Although it does not specifically mention either women or older workers, the Human Resources Development Convention, 1975 (No. 142), can be used to support vocational training and lifelong learning for all adults. The recently adopted Human Resources Development Recommendation, 2004 (No. 195), and the Employment Relationship Recommendation, 2006 (No. 198), each contain specific references. Used together, they make a strong case for the inclusion of older women in formal work. ${ }^{48}$ The ILO Conventions on public and private employment services ${ }^{49}$ can be used for policy development that is gender sensitive as well as adequately designed to provide tailored help to older age groups. The OSH Conventions contain important considerations for older workers, and can be used to address the specific needs of women workers as well.

387. Is it fair to assume that older workers are aware of their rights to organize, as well as to bargain collectively on issues pertaining to their work situations? Once again, Conventions Nos 87 and 98 should be highlighted as underpinning social dialogue and policy implementation. ILO instruments relating to older workers can be used in tandem with instruments concerning equality of opportunity and treatment, such as Conventions Nos 111 and 100, that address discriminatory practices and principles of equal pay for work of equal value. While age is not specifically listed among the prohibited grounds of discrimination in Convention No. 111, a number of countries have used Article 1(1)(b) to include age among them. Article 5 of the Convention allows for the possibility of special measures to meet the particular needs of older workers, among others.

388. The continuous strengthening and implementation of legislation prohibiting gender and age discrimination are important in countering multiple forms of discrimination against older women, including sexist and ageist stereotypes. ${ }^{50}$ The Office's standards

\footnotetext{
46 ILO: Setting social security standards in a global society: An analysis of present state and practice and of future options for global social security standard setting in the International Labour Organization, Social Security Policy Briefings Paper No. 2 (Geneva, 2008), p. 42.

${ }^{47}$ Convention No. 102 does not exclude the payment of benefits to widowers. In many countries, however, survivors' benefits are granted only to widows, thereby discriminating against men. See ILO: Setting social security standards in a global society: An analysis of present state and practice and of future options for global social security standard setting in the International Labour Organization, Social Security Policy Briefings Paper No. 2 (Geneva, 2008), p. 68; and ILO: Social security: A new consensus (Geneva, 2001), p. 73.

48 See Paragraph 5(g) and (h) of Recommendation No. 195, and Paragraphs 5 and 6 of Recommendation No. 198.

49 Employment Services Convention, 1948 (No. 88), and the Private Employment Agencies Convention, 1997 (No. 181).

50 ILO: Promoting decent work for an ageing population: Actors, partners and corporate social responsibility, Background paper contributed by the ILO to the G8 high-level meeting on employment, Paris, 12-13 May 2003, p. 6.
} 
and technical assistance to revise law and policy can make all the difference between sound economic and social policies and a slide into poverty for older people.

\subsection{Links to the United Nations and international agencies}

389. Since the World Assemblies on Ageing, there has been greater international focus on gender issues and older persons. ${ }^{51}$ The Madrid International Plan of Action on Ageing emphasizes the role of older women in providing unpaid care. It stresses that these women bear the costs in the form of the financial penalties resulting from low pension contributions, promotions forgone, lower incomes, and the physical and emotional costs of balancing work and household obligations.

390. The International Day of Older Persons $2008^{52}$ on 1 October 2008 served as a platform to call for a Convention on the rights of older persons. ${ }^{53}$ The proposed Convention will incorporate the United Nations Principles for Older Persons and reflect the Madrid International Plan of Action on Ageing.

391. The CEDAW Committee ${ }^{54}$ has also expressed strong concern about the abuse of older women's rights. The Committee has recognized older women as a vulnerable group, and is studying a general recommendation on older women's rights.

\subsection{The way forward}

392. Recommendation No. 162 calls for appropriate measures to be taken in order to inform the public and those responsible for guidance, training, placement and social services - as well as employers, workers and their respective organizations - of the problems which older workers may encounter. The following indicative list highlights areas where the ILO's policies, programmes and activities can have an impact:

- Ratifying Convention No. 111. While age is not specifically listed among the prohibited grounds of discrimination, countries can add age by virtue of Article 1(1)(b) of the Convention. Article 5 of the Convention as already noted, provides for special measures to help older workers, among others.

- Strengthening and implementing legislation prohibiting age discrimination so as to ensure equality of opportunity and treatment for older women, since these workers experience multiple forms of discrimination, including sexist and ageist stereotypes.

- Dismantling barriers to hiring and retaining older workers, through action by governments and the social partners, is particularly important.

\footnotetext{
${ }^{51}$ ILO: An inclusive society for an ageing population: The employment and social protection challenge, paper contributed by the ILO to the Second World Assembly of Ageing, Madrid, 8-12 April 2002.

${ }^{52}$ Sponsored by the CONGO Committee on Ageing, in collaboration with the UN Department of Public Information, the UN Department of Economic and Social Affairs and the UN Population Fund.

${ }^{53}$ Through its global public awareness-raising campaign "Gender equality at the heart of decent work", the ILO celebrated this day with the monthly theme Rights, jobs and social security: New visions for older women and men.

${ }^{54}$ See the Committee's web site, at www.un.org/womenwatch/daw/cedaw/committee.htm.
} 
- Encouraging lifelong learning and skills development to upgrade competencies throughout working lives and providing opportunities for older workers, especially women. Acquiring entrepreneurial skills in later years is also an area for action.

- Promoting entrepreneurship for older men and women through fiscal incentives, business advisory services and access to finance is an additional policy option.

- Providing an adequate and flexible working environment for older workers by eliminating unsafe and unhealthy working conditions that may threaten their capacities and productivity This should be accomplished within the context of improving occupational health and safety for workers of all ages.

- Giving prominence to social security as a productive factor in promoting employment, stimulating structural change and fostering economic growth; in highincome countries, that means above all ensuring sustainable social protection systems and in low-income countries, extending social security coverage to uncovered population groups. All countries need to take older women's access to coverage into consideration.

- Conducting awareness-raising campaigns addressing the issues of age discrimination, productive employment opportunities and access to social protection.

- Promoting social dialogue among employers' and workers' organizations to raise awareness of older workers' problems so that joint solutions ensure that these workers' choices and rights are respected. 



\section{Chapter 8}

\section{Main policy orientations for international and national action}

\subsection{Leveraging social dialogue for gender equality}

393. Social dialogue is fundamentally about equitable participation. It is through participation that women and men can achieve decent and productive work in conditions of freedom, equity, security and human dignity. Conscious of its mandate, the ILO is investing in ways to build the capacity of its constituents to take part in, influence and benefit from international efforts to promote sustainable development. In this time of global financial and economic crisis, the goal of consensus building and democratic involvement is more important than ever.

394. The challenges of promoting gender equality through social dialogue are twofold. First, there is the matter of increasing the participation and status of women in the process. Second, there is the challenge of introducing a gender perspective into the content so as to reflect the changing nature of labour markets and patterns in the world of work. In a year that marks the 60th anniversary of Convention No. 98, it is important to recognize the centrality of collective bargaining to these challenges.

395. The equitable participation of women in the institutions of social dialogue is itself key to promoting gender equality through tripartism and social dialogue. Low participation rates of women in workers' and employers' organizations and in the relevant tripartite institutions have been well documented. In some regions, as women have increased their participation in the paid workforce, whether as employers or workers, they have also increased their participation in the relevant institutions of tripartism and social dialogue. Women have also been shown to place gender issues on the agenda more than men do. So an increased involvement of women in social dialogue has also resulted in greater attention to gender issues, ${ }^{1}$ for example with the emergence of national tripartite machineries for women in the 1990s in Latin America.

396. In general, however, the participation of women in social dialogue institutions has remained relatively low. This is attributable in part to the low participation of women in leadership positions among the workers' and employers' organizations. Governments have tended to nominate a higher proportion of women for their seats in the national tripartite institutions, just as they have succeeded in including a higher proportion of

\footnotetext{
1 See T. Breneman-Pennas and M. Rueda Catry: Women's participation in social dialogue institutions at the national level, Social Dialogue, Labour Law and Labour Administration Branch Paper No. 16 (Geneva, ILO, 2008).
} 
women in their delegations to the ILC, regional meetings ${ }^{2}$ and the Governing Body. The better performance of governments can be explained by progress in fighting sex discrimination in the civil service, including through proactive recruitment and promotion practices as well as acceptance of work and family balance.

397. For workers' organizations, the challenge has been to overcome the differences in union strength between sectors that have predominantly employed men (where union strength has been well established) and those that have predominantly employed women. In 2002, an awareness-raising campaign was launched by what is now ITUC to increase the participation of women in workers' organizations. In March 2008, ITUC launched a two-year campaign entitled the "Decent Work, Decent Life for Women Campaign". 3 Affiliate unions have been urged to aim for a target of one-third participation of women in leadership positions, with some unions actually opting for a target of parity. Women's committees have helped raise awareness, both at ITUC and among global union federations, and have encouraged greater participation of women in leadership positions and endorsed detailed platforms on gender-specific priorities. ${ }^{4}$

398. The IOE, national employers and their representative organizations espouse the "business case" for greater equality between men and women and many are endeavouring to increase diversity in the workplace. However, promoting women to corporate management positions remains a challenge in all regions. Enterprises engaged in bipartite social dialogue are starting to realize that there is a gender dimension to the issues that are usually under negotiation, ranging from wages, to conditions of work, terms of employment and, more recently, work/family balance. When the approaches of the social partners are compared, a convergence of views emerges on the importance of gender equality in the workplace.

\subsection{Men and women in leadership positions}

399. There is clear evidence of a gender gap in high-level positions around the world. Explanations vary as to why there are small numbers of women at the top in the public and private sectors. Research has identified three approaches to the issue: the first emphasizes observable differences between men and women, focusing on themes such as early socialization processes and the development of different behavioural traits in childhood which may result in gender-specific leadership styles; the second is based on the premise that women and men are fundamentally alike in terms of potential but that this potential is skewed by structural processes (such as positions in organizations, "glass ceilings" and biases in job evaluation); and the third considers the cultural context, in

\footnotetext{
${ }^{2}$ Sex-disaggregated statistics on participation at the ILO Eighth European Regional Meeting (Lisbon, Feb. 2009) show that the proportion of women delegates (members, deputy members and technical advisers combined) was as follows: among Governments, almost 40 per cent; among Workers, 32 per cent; and among Employers, 26 per cent.

${ }^{3}$ See www.ituc-csi.org/spip.php?rubrique198 (accessed 20 March 2009).

${ }^{4}$ See UNI Global Union: Conclusions and action points, from the second UNI World Women's Conference, Chicago, 20-21 August 2005; Gender equity and youth, BWI, Equality Policy, www.bwint.org/default.asp?Issue $=$ Gender $\% 20$ Equity $\% 20$ and $\% 20$ Youth $\&$ Language $=$ EN (accessed 20 March 2009); and IUF: All for one, one for all: A gender equality guide for trade unionists in the agriculture, food, hotel and catering sectors (Geneva, 2007). Furthermore, the PSI World Women's Committee has adopted a series of campaigns for the period 2007-12 on pay equity, maternity protection, international migration and women health workers, and women in the informal economy. See www.world-psi.org (accessed 20 March 2009).
} 
other words how roles, expectations and preferences are formed by cultural forces. ${ }^{5}$ Individuals can change the cultural forces shaping ideas about gender and leadership, but it takes time. For example, despite the fact that legislation to improve gender equality was introduced in Britain some 30 years ago, women still do not have equitable access to leadership positions. ${ }^{6}$ Affirmative action should never compromise the principle of merit and competency-based leadership.

\section{Box 8.1 \\ Leadership starts in education}

Leadership patterns within the teaching profession have implications both for the profession and for society in general. In primary schools, female teachers considerably outnumber male teachers; in some countries, more than 90 per cent of primary teachers are women. In secondary schools, women still make up more than half of all teachers in most countries. At the tertiary level, the sex ratio is reversed: teachers are more likely to be men than women. For example, in Italy in 2001, women accounted for 95 per cent of primary school teachers, 65 per cent of secondary school teachers and only 29 per cent of tertiary level teachers ${ }^{1} \mathrm{~A}$ lack of male teachers at the primary school level means a lack of male role models for children. ${ }^{2}$ Men also hold the majority of managerial positions in the academic world, such as school principals and university faculty heads and deans. Women are seriously under-represented at all levels in education ministries and teachers' organizations. This results in gender bias in social dialogue and can affect policies, curricula and guidance. ${ }^{3}$

${ }^{1}$ ILO: Breaking through the glass ceiling: Women in management, Update 2004 (Geneva, 2004), pp. 8-9.

${ }^{2}$ See Education and communication: Occupational segregation in education, United Nations Economic Commission for Europe (UNECE), 2009, at www.unece.org/stats/gender/genpols/keyinds/education/educonce.htm (accessed 20 March 2009).

${ }^{3}$ See ILO and UNESCO: Interim report on allegations received from teachers' organizations on nonobservance of the Recommendations of 1966 and 1997 concerning teachers, Joint ILO-UNESCO Committee of Experts on the Application of the Recommendations concerning Teaching Personnel (CEART), Geneva, 2008.

\subsection{Enhancing governance through gender equality}

400. Good governance is necessary for tripartism, employment policy and labour inspection and means giving voice to the women and men to whom leaders are accountable. ${ }^{7}$ Good governance upholds the rule of law, as well as respect for all internationally recognized human rights and fundamental freedoms and is characterized by predictability, transparency and reliability. Increased security and stability contribute directly to less disruption in the economic lives of the poor and to more resources becoming available for service provision, thus creating an environment conducive to better governance. ${ }^{8}$ In this context, poverty eradication, respect for human rights and

\footnotetext{
${ }^{5}$ See M. Lyly-Yrjänäinen and E.Fernández Macías: Women managers and hierarchical structures in working life (Dublin, European Foundation for the Improvement of Living and Working Conditions, 2009). See also L. Wirth: Breaking through the glass ceiling: Women in management (Geneva, ILO, 2001).

${ }^{6}$ See D. Higgs: Review of the role and effectiveness of non-executive directors, Consultation paper (London, DTI, 2002). This and other high profile corporate governance studies have emphasized the need to broaden the pool of candidates for directorships and have encouraged some companies to appoint women to their boards.

${ }^{7}$ ILO: Conclusions on promoting rural employment for poverty reduction, Report of the Committee on Rural Employment, Provisional Record No. 15, ILC, 97th Session, Geneva, 2008, p. 71.

${ }^{8}$ See Inter-Parliamentary Union (IPU), UNDP, World Bank, UNIFEM: Parliament, the budget and gender, Handbook for Parliamentarians No. 6, 2004.
} 
gender equality are interrelated, as is reinforced in the 2008 Declaration on Social Justice for a Fair Globalization.

401. Women's adequate representation at the highest levels where national policies are formulated is an indispensable condition for the elimination of sex discrimination in opportunities and treatment. Fiscal, trade and labour policies need to be designed so as not to cause adverse gender impacts. Policies also need to recognize the contribution of women in the informal economy. Furthermore, women should be actively involved in the development of macroeconomic policies. ${ }^{9}$ In some regions, the marginalization of women remains real despite the progress of recent years, and action is necessary in order to ensure the full and effective integration of women into political and socio-economic development. ${ }^{10}$ Under the MDGs, governments are accountable for policy commitments and budget allocations for poverty reduction. Administrations therefore need to have a clear understanding of how the national policies that encapsulate the goals may affect women and men differently. But women continue to be under-represented in leadership posts within public administrations, in elected government seats and in ministerial portfolios that oversee the implementation of poverty reduction. Data provided by the Inter-Parliamentary Union (IPU) show that the world average for women parliamentarians in both the lower and upper houses combined stands at a meagre 18.4 per cent, with some countries having no women parliamentarians at all. ${ }^{11}$ The country with the highest percentage of women in parliament is Rwanda, where 56.3 per cent of parliamentarians are women, giving them a strong role to play in the postgenocide reconciliation. This performance is followed by Sweden, where 47 per cent of parliamentarians are women, and Cuba, with 43.2 per cent.

402. Parliamentary committees covering women's issues and gender equality can ensure that progress towards the MDGs is on course and appropriately resourced. They can strengthen the national democratic oversight and accountability processes. About 60 national parliaments have established committees in order to work towards ensuring that gender equality issues remain on the table. ${ }^{12}$ One example is the Committee on Women of Costa Rica, which reviews and makes legislative proposals with respect to the situation of women in the country and works within the country's National Development Plan to develop a strategy for social dialogue. Key issues being raised by the Committee are the need for policies to combat violence against women, to promote female employment to close the income gap between men and women and to develop a childcare infrastructure. ${ }^{13}$

\footnotetext{
9 See Commonwealth Secretariat: The Commonwealth plan of action for gender equality 2005-15 (London, 2005), pp. 9, 41-42.

${ }^{10}$ New Partnership for Africa's Development (NEPAD): Declaration on democracy, political, economic and corporate governance, Assembly of Heads of State and Government, 38th Ordinary Session of the Organization of African Unity, Durban, South Africa, July 2002, para. 22.

11 IPU: Women in national parliaments, www.ipu.org/wmn-e/world.htm (accessed 20 March 2009).

${ }^{12}$ IPU: The role of parliamentary committees in mainstreaming gender and promoting the status of women, Seminar for members of parliamentary bodies dealing with gender equality, Geneva, 4-6 December 2006, p. 5.

${ }^{13}$ IPU, 2006, op. cit., pp. 16-18.
} 


\section{Box 8.2 \\ Gender-responsive budget initiatives}

Gender-responsive budgeting (GRB) is a tool to increase accountability on issues of gender equality. It is a powerful mechanism for change. Its success depends on whether political will can be generated within governments to support a process of transforming the traditional budget-making and policy processes by removing in-built biases that disadvantage women and girls. For example, it involves examining the linkages between care work and the paid economy, or the expenditure on infrastructure that relieves the burden of household work that would otherwise fall disproportionately on one sex or the other. GRB initiatives help bridge persistent inequalities between women and men by incorporating gender issues into macroeconomic policy, budgets and public expenditure. GRB advocates argue that it is also a human rights matter: budgets are not just about monetary figures but reflect a country's priorities and values. Budgets are the main instruments through which governments can fulfil people's social and economic rights. ${ }^{1}$

Pioneered in the 1980s, the process has inspired others to explore the potential of GRB, notably in the Commonwealth. ${ }^{2}$ Over 40 countries are using GRB initiatives at different levels of their economies. ${ }^{3}$ Recent efforts by UNIFEM have resulted in a number of good practices worldwide. For example, since 2006, Morocco has been evaluating the impact of its national budget on gender equality at the national and local levels through GRB analysis. As part of an integrated approach, ministries of finance, education, health, and agriculture and rural development are to report on expenditure and results achieved in accordance with defined gender equality objectives. ${ }^{4}$

GRB is particularly relevant for the ILO, as it covers employment as a key condition for women's economic empowerment, promotes gender-sensitive analysis in labour economics and implements results-based management through planning and budgeting exercises. Some of the ILO's Decent Work Country Programmes are using GRB as a means of analysing this impact and benefits on women. The ITC-ILO is conducting training courses to build GRB capacity among the ILO's social partners and civil society. ${ }^{5}$

${ }^{1}$ IPU, UNDP, World Bank, UNIFEM: Parliament, the budget and gender, Handbook for Parliamentarians No. 6 , 2004, pp. 22, 57-58, 71.

${ }^{2}$ See ILO: Overview of gender-responsive budget initiatives, GENDER discussion paper, Geneva, p. 6; and Commonwealth Secretariat, 2005, op. cit., p. 40.

${ }^{3} \mathrm{H}$. Hofbauer Balmori, Gender and budgets: Overview report (Brighton, University of Sussex, BRIDGE development-gender, 2003), p. 47.

${ }^{4}$ Economic Commission for Africa, African Union and African Development Bank: Assurer l'égalité des sexes et l'autonomisation des femmes en Afrique, 6th African Development Forum (ADF VI), Addis Ababa, 19-21 Nov. 2008, p. 10.

${ }^{5}$ See An introduction to gender budgeting, course description, ITC-Turin, 2009,

www.itcilo.org/calendar/4227?language_id=1 (accessed 20 March 2009).

403. Promoting gender equality is not only important in governments and public services, but it is also in the interest of businesses. Diversity benefits economic performance since businesses can tap into the creativity, innovation and skills of both men and women. ${ }^{14}$ According to a study of US Fortune 500 companies, having more women on company boards correlates strongly with above-average returns on shareholder equity, sales and inversed capital. ${ }^{15}$ Women also bring different perspectives to management. Yet they are under-represented in top managerial jobs compared to their share of overall employment; when climbing up an organization's hierarchy, the proportion of women managers diminishes sharply. A belief persists that

\footnotetext{
14 W. Sengenberger: Globalization and social progress: The role and impact of international labour standards, second edition (Bonn, Friedrich Ebert Stiftung, 2005), pp. 76-78.

${ }^{15}$ Where women were not present on boards, the Fortune 500 companies tended to have belowaverage returns. See The bottom line: Corporate performance and women's representation on boards, Catalyst, October 2007, www.catalyst.org/publication/200/ (accessed 20 March 2009).
} 
female and male managers have different work values or goals because of their sex. In reality, a recent study shows that men and women executives at major global companies share the same values in their workplaces and careers. ${ }^{16}$ In Europe, 9.7 per cent of board seats were held by women in 2008, compared to 8 per cent in $2004 .{ }^{17}$ Findings from 2009 reveal that the percentage of women in senior managerial positions globally has grown slightly from 19 per cent to 24 per cent since 2004. The Philippines came out top with 47 per cent of managerial positions being held by females, ahead of the Russian Federation (42 per cent) and Thailand (38 per cent). Denmark, Belgium and Japan recorded 13 per cent, 12 per cent and 7 per cent respectively. ${ }^{18}$

404. In Norway, there has been impressive growth in the number of women on boards, from 22 per cent in 2004 to 44.2 per cent in 2008. This followed from the adoption of legal provisions, which require that at least 40 per cent of board seats of state-owned and public limited companies in the private sector have to be filled by women and at least 40 per cent have to be filled by men. The Female Future programme of the Confederation of Norwegian Business and Industry played an important role in raising awareness and promoting the role of women on boards and in enterprise management. ${ }^{19}$ World businesses and the World Bank recently launched a Private Sector Leaders' Forum to promote women's economic empowerment and gender equality, including through investment in targeted lending programmes and training courses for businesswomen in developing countries who are suffering from the ongoing economic crisis. $^{20}$

\subsection{What has worked and what needs more attention}

405. True to the mandate that the constituents have entrusted to it in the policy decisions of the last two decades, there can be no doubt that the ILO has intensified its efforts around the world to make a difference regarding gender equality in the world of work. From the 1991 ILC resolution concerning ILO action for women workers and the 2004 ILC resolution concerning the promotion of gender equality, pay equity and maternity protection through to more recent Governing Body guidance on various practical measures (such as gender audits, monitoring through action plans and technical cooperation requirements with regard to gender equality), the clear message is that sustainable development cannot be achieved when glaring inequalities between women and men persist in the world of work. The Decent Work Agenda, which finds its policy anchor in the 2008 Declaration and operational delivery through instruments such as the Decent Work Country Programmes, has shown that the ILO can deliver from the point

\footnotetext{
${ }^{16}$ See New study shows gender, rank and regional differences in finding the right fit for top corporate talent, Catalyst, June 2008, www.catalyst.org/press-release/129/ (accessed 20 March 2009).

17 Third Bi-annual EuropeanPWN BoardWomen Monitor, European Professional Women's Network (PWN), 2008, www.europeanpwn.net/index.php?article_id=561 (accessed 23 March 2009).

${ }^{18}$ Grant Thornton International: International Business Report (IBR) (London, 2009). This group of independent accounting and consulting firms prepares a survey covering 7,200 privately held businesses in 36 countries, representing 81 per cent of global GDP.

${ }^{19}$ ILO: Employers' organizations taking the lead on gender equality: Case studies from 10 countries, Bureau for Employers' Activities, ACT/EMP No. 43, 2005, pp. 55-60.

${ }^{20}$ President Robert B. Zoellick Announces 6 New World Bank Group Commitments on Gender Equality, World Bank, press release, http://web.worldbank.org/WBSITE/EXTERNAL/TOPICS/ EXTGENDER/0,,contentMDK:21733293 menuPK:336874 pagePK:148956 piPK:216618 theSiteP K:336868,00.html (accessed 24 March 2009).
} 
of view of rights, employment, social protection and social dialogue. The usefulness of gender mainstreaming is clear from the ILO's current efforts to implement ILC resolutions and Governing Body decisions on that topic.

406. In terms of gender equality success, the research for each chapter of this report permits the conclusions to be positive. It is generally accepted that the status and treatment of girls and women in society have significantly advanced with regard to the adoption and enforcement of legislation (and particularly in the application of corrective measures addressing long-standing biases and direct discrimination against women), the provision of educational opportunities, access to participation in political processes and institutions, and the availability of work and employment opportunities. ${ }^{21}$ This report mentions a great number of successful policies and programmes that have helped advance workplace equality between women and men. The ILO's twofold approach to gender equality in the world of work (the rights-based and economic efficiency argument) is proving its worth.

407. One strong lesson learned from the analysis is that "one-off" interventions alone cannot achieve such an important goal; a holistic approach (changing societal attitudes and individual behaviour in tandem with addressing structural challenges and specific world of work measures) is essential. Economic growth and job creation do not always lead to greater progress in achieving gender equality. For example, some countries with highly developed economies continue to experience high levels of sex discrimination. Where outreach information campaigns and education prove that gender equality is not only a goal, but also makes good business sense because it taps into the productive power and creativity of not half of, but the whole population, then policy change can more easily be addressed. There is a better chance of achieving gender equality when legislation and labour inspectorates can address sex discrimination in parallel with efforts to facilitate women's access to and control over the means of production and benefits. Where the most vulnerable have equal access to a social floor and have a say in framing the policies and programmes aimed at improving their lives, gender equality will be squarely at the heart of decent work.

408. Another lesson learned is the vital role to be played by the tripartite constituents, both together and within each group. This report refers to the many advances that have been made towards eliminating workplace inequalities based on gender stereotypes as a result of the efforts of workers' and employers' organizations. Where employers have internalized the goal of gender equality and believe it to lie at the heart of decent work, there is some evidence that enterprises profit, competitiveness increases and growth is recorded. Many trade unions in all regions have taken up anti-discrimination work, ranging from updating internal procedures and structures, to launching media campaigns and to defending the principle in a wide range of economic and social forums.

409. Other successful interventions by governments and employers' and workers' organizations have been identified, leading to:

(a) pro-poor strategies that are in line with the ILO mandate of poverty reduction for the most vulnerable and which take into account the impact that they might have on both women and men;

(b) high rates of ratification of Conventions Nos 111 and 100;

${ }^{21}$ UN DESA: Social justice in an open world - The role of the United Nations, Document for the International Forum for Social Development, ST/ESA/305, New York, 2006, p. 39. 
(c) new gender equality provisions in a significant number of national laws, policies and programmes and, in some regions, major improvements in enforcement and workplace knowledge of the provisions by both employers and workers;

(d) gender-based policies addressing some aspects of maternity protection and infant health care;

(e) less gender-biased education for girls and boys;

(f) increased equal opportunities for skills upgrading and wider occupational choices for young women and men;

(g) the massive entry of women into the labour market and increased women's presence in small businesses and, in some regions, in management, and women's career advancement through affirmative action;

(h) gradual legislative attention to the contractual status of women and clarification of employment relationships for women;

(i) decreasing - albeit slowly - pay gaps and an acceptance by policy-makers in most regions that remuneration should be set without reference to the sex of the worker; and

(j) social financing as a vehicle for fostering entrepreneurship, especially among poor women.

410. Nevertheless, progress is continually challenged and many obstacles remain to the achievement of gender equality, such as the poor implementation and enforcement of national policies. Complacency, stagnation (sometimes referred to as "gender fatigue") and backlash can slow the pace of reforms. Crises, such as the current financial and economic downturn, can swiftly demolish years of achievement, giving rise to a reemergence of discriminatory attitudes and behaviours, as well as a change of workplace practices that had previously been free of sex discrimination. The importance of monitoring and evaluation should therefore be recognized, with their useful methodologies for tracking progress towards or backsliding away from goals.

411. One specific challenge relates to the systems that are used when analysing labour markets and preparing national data sets, which were not designed with the aim of tracking the differing impacts that policies and programmes may have on women and on men. In particular, in some systems, households are omitted from the theoretical framework, thus making it impossible to capture the gender dimension and plan accordingly. For example, in most systems, more analysis is needed of the care economy, where both paid and unpaid work occurs. It is increasingly accepted that obtaining and using sex-disaggregated data and context-specific information on inequalities between women/girls and men/boys is the only firm basis for an accurate situation analysis and for gender-responsive planning, monitoring and evaluation in any organization or workplace. Any analysis must be based on statistical data that can identify social and economic gaps between different groups of the population. In that way, priorities can be set in full knowledge of the problem that is to be addressed and policies and programmes can be monitored scientifically so that, if they have negative consequences on one sex or the other, they can be redesigned and remedial action can be taken before achievements are undermined permanently.

412. Examining gender-based differences in society - in order to understand their determinants, consider ways in which they can be altered, and take the measure of change that is achieved - requires a good and well-maintained evidence base. On this basis, it is possible to conclude that data collection and related research should always 
accommodate sex as a basic attribute and should include a dedicated analysis of the roles of men and women. Efforts to advance knowledge and improve information sharing in this area should be guided by the systematic collection of data showing what men and what women do in labour markets and more thorough analysis in reports of research findings, paying systematic attention to sex as a variable. The ILO is piloting the measurement of decent work in five countries using sex-disaggregated data and a set of gender-sensitive indicators to contribute towards monitoring the implementation of the 2008 Declaration. ${ }^{22}$

413. That sex discrimination has not disappeared from the world of work shows a lack of political commitment and - in some contexts - legal laxity, but the underlying cause remains embedded in societal attitudes. Development policies and programmes must challenge stereotyped assumptions about gender roles which have become systemic in social patterns, institutional structures and legal constructs in both formal and informal workplaces. Despite so much attention to this issue in recent decades and the massive entry of female workers into labour markets, this report shows that - in practice - more progress could have been achieved if prejudices about what women can do and what their male colleagues can do had disappeared. The striking example is the assumption, at all levels and across most regions, that care work is the domain of women and not men. Policies and programmes should be designed in ways which expand women's opportunities and choices, rather than restricting them only to traditional gender roles tied to motherhood and the household. They should also involve men in ways that break down gender stereotyping and open up possibilities for men and boys to take on a more active caring role.

414. In addition, de facto inequalities can be challenged by proactive measures that eliminate structural barriers to equality between women and men in the world of work, such as affirmative action, awareness raising, skills development, employment promotion, economic empowerment and reform of outdated systems and practices.

\subsection{Future work}

415. In view of the above, charting a strategic course for the ILO's future work to advance gender equality in the workplace depends on measures to:

\section{Knowledge development to support policy formulation}

a Strengthen the research agenda and knowledge base on new and emerging issues, especially in the context of the global financial crisis, by identifying new trends and patterns in the world of work, as well as links between economic efficiency and gender equality.

- Promote more sex-disaggregated data collection and analysis so that the evidencebased arguments can be presented for gender equality, especially regarding the gender pay gap. Conduct time use surveys as an effective means to capture women and men's involvement in paid and unpaid work.

口 Build the capacity of national statistical offices in designing gender-sensitive labour market information systems that are capable of informing policy choices.

${ }^{22}$ See ILO: Report of the Director-General: Third Supplementary Report, Tripartite Meeting of Experts on the Measurement of Decent Work, Governing Body, 303rd Session, Geneva, No. 2008, GB.303/19/3. The results of this initiative will be reported to the Governing Body in November 2009. 
- Develop and disseminate practical tools, manuals and checklists to support policymakers and practitioners in their efforts to mainstream gender equality into their work - particularly in the fields of education, economic participation, social protection and social dialogue.

- Collect information on the pressures placed on boys and men to conform to gender stereotypes in the world of work.

- Compile and disseminate good practices and innovative strategies to promote gender equality in the world of work, to support better policy formulation within Decent Work Country Programmes.

\section{Employment and job creation}

- Implement specific interventions for the creation of decent and productive employment and income, in particular for those who are unemployed or underemployed in the informal economy and the rural sector, in addition to further gender mainstreaming as part of the GEA. Such actions are especially important given the increasing job losses across the globe as a result of the current financial and economic crisis.

- Advocate gender-responsive employment creation as part of national policies and national development frameworks, such as PRSPs.

a Harmonize core and technical skills training and lifelong learning to improve employability, ensuring that skills development matches market needs.

a Focus on disadvantaged and vulnerable groups of women through povertyorientated labour market policies that take into account the need to remove the specific economic barriers faced by some women, such as those with disabilities, those from ethnic minorities, or migrants.

- Promote rural employment for women and men, including cooperative development, entrepreneurship and infrastructure improvement.

\section{Social protection}

- Pay greater attention to men's and women's specific occupational safety and health needs by promoting sex-differentiated policies and practices, where applicable.

- Upgrade national social security systems so that they are inclusive and nondiscriminatory, and so that they take account of the needs of workers with family responsibilities.

a Preserve investment - even in times of economic crisis - in public and community services, in particular in rural areas, to alleviate the unpaid work demands on households which particularly affect women and girls. This, alongside comprehensive national work-family policies, should help men and women balance work and family responsibilities.

a Base policy choices that aim to narrow the gender pay gap on the consistent monitoring of developments in the labour market, the organization of work structures, and variations in the size and causes of the gender pay gap. Where the identified problem is the high incidence of low pay, consideration should be given to ensuring an effective and gender-inclusive minimum wage policy. In countries with large formal economies and heavily sex-segregated labour markets, 
occupational classification systems and job evaluation methods that are free of gender bias may prove more effective.

\section{Social dialogue and tripartism}

- Engage in equitable and participatory social dialogue so as to influence policymaking at the international, regional, national, community and enterprise levels. In particular, make gender equality objectives visible in the strategies, indicators, activities and outputs of DWCPs.

- Create new or strengthen existing national gender machineries, such as equal employment opportunity commissions, comprising governments and employers' and workers' organizations.

- Require gender-balanced composition on tripartite bodies.

- Include gender equality concerns, especially the elimination of discrimination, in collective bargaining processes.

Principles and rights at work

- Strive for universal ratification of Convention No. 111 (168 out of 182 member States have done so), and Convention No. 100 (166 member States have already ratified it), and improved ratification rates for the other two key equality Conventions (Nos 156 and 183), and implementation of their provisions.

- Continue to provide technical assistance on improving national legislation and other regulatory frameworks to support the application of Conventions Nos 111, 100, 156 and 183.

- Take action to ensure adoption and effective application of the principles of maternity protection, in particular efforts to redress direct and indirect discrimination related to maternity and the inclusion of maternity benefits in the basic social security system.

- Enforce laws and collective agreements through labour administrations, including labour inspectorates, the judiciary and other government agencies, and through better partnerships with national gender machineries.

\section{International partnerships}

a Strengthen international partnerships with the UN family in areas where the mandate of each organization has strengths, for example in campaigns to eliminate violence against women and girls, in working towards the MDGs, and in ensuring the success of the "Delivering as One" initiative.

- Create opportunities for greater dialogue and collaboration between institutions and organizations working on the economic and social aspects of development so that holistic solutions can be developed, such as in the field of care work.

- Build partnerships (regional groups and institutions such as the EU, the African Union, the Organization of American States, the Gulf Cooperation Council, the Caribbean Community, UN agencies, trade unions and sectoral associations) to share existing databases on the world of work between and across regions and sectors. 
- Implement gender mainstreaming into all $\mathrm{UN}$ system training materials and programmes for UNCT members.

- Use the ILO Participatory Gender Audit as a tool for assessing progress towards achieving the goal of gender equality.

- Assist in achieving stated UN gender parity goals, especially at senior and policymaking levels and in the Resident Coordinator system.

- Systematically include the goal of gender equality in resource mobilization, knowledge sharing and technical cooperation, in partnership with donors.

\section{Information, advocacy and awareness raising}

- Organize research-based, awareness-raising activities, including major campaigns adapted across the regions and national levels and developed in consultation with the social partners and national gender machineries. These should target individual women and men, communities, decision-makers and societies.

- Support information and awareness-raising campaigns for particularly vulnerable segments of the labour force, such as girl child workers, domestic workers, rural workers, the self-employed, casual workers and different categories of informal economy workers.

416. This report illustrates that the ILO response to promoting gender equality has become stronger and progressively more practical, showing a marked evolution over time in line with advances in economic and social development, working conditions in general, and improvements in the status of women. The continuity of activities to promote gender equality proves that the Organization - with its tripartite partners: governments, employers and trade unions - has contributed greatly to the general recognition of the principle of equal opportunity and treatment for women and men. And that stands true for periods of crisis, such as the current global financial and economic downturn. That this report documents so many examples of research, policies and programmes that result in more equal opportunities for women and men is the hallmark of decent work. It remains the firm intention of the ILO to put policy into action, and put an end to workplace sex discrimination once and for all. By striving for social justice through a fair globalization, that aim might, as the Organization advances towards its centenary celebration, be within its reach. 


\section{Suggested points for discussion}

1. Globalization, with its positive and negative implications, is affecting women and men in different ways. Despite some gains over the last few decades, rapid changes in the labour market present gender-specific challenges. What are the key elements that should form part of the international, national and enterprise-level responses to address these challenges and achieve gender equality and decent work in a rapidly changing environment?

2. In view of the current global and economic crisis and its employment and social implications, what immediate, medium- and long-term measures need to be taken to preserve and advance gains achieved for gender equality and offset the negative gender effects of the crisis?

3. Direct and indirect discrimination, stereotyping, inadequate access to and control over productive resources, informal and atypical forms of employment, lack of voice and participation in decision-making are just a few of the challenges facing women in the labour market. How can the four strategic objectives of the Decent Work Agenda be implemented to achieve gender equality and women's empowerment in a tangible and sustainable manner?

4. In the light of the 2008 ILO Declaration on Social Justice for a Fair Globalization, how can the ILO strengthen the capacity of constituents - governments and employers' and workers' organizations - to achieve gender equality and respond effectively to constituents' needs? What can be done by governments and employers' and workers' organizations to achieve gender equality? 



\section{Appendix}

Table A. Estimated female and male earned income, proportion of total population below the poverty line and estimated female and male population below the poverty line of US\$1.25, ILO member States with data, regional and global summaries, 2005

\begin{tabular}{|c|c|c|c|c|c|c|c|c|c|c|}
\hline \multirow[t]{2}{*}{$\begin{array}{l}\text { Country (alphabetical order by } \\
\text { region) }\end{array}$} & \multicolumn{2}{|c|}{$\begin{array}{l}\text { Estimated earned } \\
\text { income (PPP US\$), } \\
20051\end{array}$} & \multirow{2}{*}{$\begin{array}{l}\text { Ratio of male } \\
\text { to female } \\
\text { earned } \\
\text { income }\end{array}$} & \multirow{2}{*}{$\begin{array}{l}\text { Proportion of } \\
\text { population } \\
\text { under poverty } \\
\text { line (US } \$ 1.25 \\
\text { per day) }(\%)\end{array}$} & \multirow{2}{*}{$\begin{array}{l}\text { Estimated } \\
\text { total } \\
\text { population in } \\
2005 \text { ('000s) }\end{array}$} & \multirow{2}{*}{$\begin{array}{l}\text { Estimated } \\
\text { population } \\
\text { below } 15 \text { and } \\
\text { over } 64 \\
\text { years, } 2005 \\
\text { ('000s) }\end{array}$} & \multicolumn{2}{|c|}{$\begin{array}{l}\text { Estimated population } \\
\text { aged 15-64 years, } \\
2005 \text { ('000s) }\end{array}$} & \multicolumn{2}{|c|}{$\begin{array}{l}\text { Estimated population } \\
\text { under the poverty line, } \\
2005 \text { (absolute numbers) }\end{array}$} \\
\hline & Female & Male & & & & & Female & Male & Female & Male \\
\hline Total for all countries with data & & & & & 6345756 & 2257378 & 2018568 & 2069811 & 829047000 & 522349000 \\
\hline Africa & & & & & 909055 & 407144 & 252964 & 248948 & 214365000 & 158343000 \\
\hline Algeria & 3546 & 10515 & 3.0 & 6.8 & 32854 & 11234 & 10691 & 10929 & 1479000 & 752000 \\
\hline Angola & 1787 & 2898 & 1.6 & 54.3 & 16095 & 7861 & 4198 & 4036 & 4901000 & 3840000 \\
\hline Benin & 732 & 1543 & 2.1 & 47.3 & 8490 & 3982 & 2239 & 2269 & 2390000 & 1629000 \\
\hline Botswana & 5913 & 19094 & 3.2 & 31.2 & 1836 & 715 & 563 & 558 & 379000 & 194000 \\
\hline Burkina Faso & 966 & 1458 & 1.5 & 56.5 & 13933 & 6862 & 3561 & 3510 & 4345000 & 3533000 \\
\hline Burundi & 611 & 791 & 1.3 & 81.3 & 7859 & 3752 & 2124 & 1983 & 3410000 & 2981000 \\
\hline Cameroon & 1519 & 3086 & 2.0 & 32.8 & 17795 & 8062 & 4876 & 4858 & 3463000 & 2376000 \\
\hline Cape Verde & 3087 & 8756 & 2.8 & 20.6 & 507 & 222 & 150 & 135 & 66000 & 38000 \\
\hline Central African Republic & 933 & 1530 & 1.6 & 62.4 & 4191 & 1950 & 1156 & 1086 & 1478000 & 1139000 \\
\hline Chad & 1126 & 1735 & 1.5 & 61.9 & 10146 & 4990 & 2606 & 2550 & 3482000 & 2802000 \\
\hline Comoros & 1337 & 2643 & 2.0 & 46.1 & 798 & 356 & 221 & 221 & 217000 & 151000 \\
\hline Congo & 841 & 1691 & 2.0 & 54.1 & 3610 & 1629 & 1001 & 981 & 1156000 & 797000 \\
\hline Côte d'Ivoire & 795 & 2472 & 3.1 & 23.3 & 18585 & 8343 & 4973 & 5268 & 2782000 & 1555000 \\
\hline Democratic Republic of the Congo & 488 & 944 & 1.9 & 59.2 & 58741 & 29244 & 14957 & 14539 & 20174000 & 14612000 \\
\hline
\end{tabular}




\begin{tabular}{|c|c|c|c|c|c|c|c|c|c|c|}
\hline \multirow[t]{2}{*}{$\begin{array}{l}\text { Country (alphabetical order by } \\
\text { region) }\end{array}$} & \multicolumn{2}{|c|}{$\begin{array}{l}\text { Estimated earned } \\
\text { income (PPP US\$), } \\
2005\end{array}$} & \multirow{2}{*}{$\begin{array}{l}\text { Ratio of male } \\
\text { to female } \\
\text { earned } \\
\text { income }\end{array}$} & \multirow{2}{*}{$\begin{array}{l}\text { Proportion of } \\
\text { population } \\
\text { under poverty } \\
\text { line (US } \$ 1.25 \\
\text { per day) }(\%)\end{array}$} & \multirow{2}{*}{$\begin{array}{l}\text { Estimated } \\
\text { total } \\
\text { population in } \\
2005 \text { ('000s) }\end{array}$} & \multirow{2}{*}{$\begin{array}{l}\text { Estimated } \\
\text { population } \\
\text { below } 15 \text { and } \\
\text { over } 64 \\
\text { years, } 2005 \\
\text { ('000s) }\end{array}$} & \multicolumn{2}{|c|}{$\begin{array}{l}\text { Estimated population } \\
\text { aged } 15-64 \text { years, } \\
2005 \text { ('000s) }\end{array}$} & \multicolumn{2}{|c|}{$\begin{array}{l}\text { Estimated population } \\
\text { under the poverty line, } \\
2005 \text { (absolute numbers) }\end{array}$} \\
\hline & Female & $\overline{\text { Male }}$ & & & & & Female & Male & Female & Male \\
\hline Djibouti & 1422 & 2935 & 2.1 & 18.8 & 804 & 333 & 236 & 235 & 91000 & 60000 \\
\hline Egypt & 1635 & 7024 & 4.3 & 2.0 & 72850 & 27804 & 22517 & 22529 & 1004000 & 446000 \\
\hline Equatorial Guinea & 4635 & 10814 & 2.3 & - & 484 & 225 & 132 & 128 & - & - \\
\hline Eritrea & 689 & 1544 & 2.2 & - & 4527 & 2053 & 1277 & 1197 & - & - \\
\hline Ethiopia & 796 & 1316 & 1.7 & 39.0 & 78986 & 37398 & 20993 & 20595 & 17417000 & 13419000 \\
\hline Gabon & 5049 & 8876 & 1.8 & 4.8 & 1291 & 524 & 383 & 384 & 36000 & 26000 \\
\hline Gambia & 1327 & 2525 & 1.9 & 34.3 & 1617 & 726 & 446 & 445 & 325000 & 230000 \\
\hline Ghana & 2056 & 2893 & 1.4 & 30.0 & 22535 & 9609 & 6394 & 6532 & 3707000 & 3051000 \\
\hline Guinea & 1876 & 2734 & 1.5 & 70.1 & 9003 & 4181 & 2388 & 2433 & 3471000 & 2842000 \\
\hline Guinea-Bissau & 558 & 1103 & 2.0 & 48.8 & 1597 & 806 & 403 & 388 & 453000 & 327000 \\
\hline Kenya & 1126 & 1354 & 1.2 & 19.7 & 35599 & 16135 & 9799 & 9665 & 3686000 & 3334000 \\
\hline Lesotho & 2340 & 4480 & 1.9 & 43.4 & 1981 & 894 & 598 & 488 & 504000 & 356000 \\
\hline Libyan Arab Jamahiriya & 4054 & 13460 & 3.3 & - & 5918 & 2020 & 1858 & 2040 & - & - \\
\hline Madagascar & 758 & 1090 & 1.4 & 67.8 & 18643 & 8753 & 4979 & 4911 & 6925000 & 5720000 \\
\hline Malawi & 565 & 771 & 1.4 & 73.9 & 13226 & 6623 & 3357 & 3247 & 5260000 & 4508000 \\
\hline Mali & 833 & 1234 & 1.5 & 51.4 & 11611 & 5961 & 2961 & 2689 & 3268000 & 2704000 \\
\hline Mauritania & 1489 & 2996 & 2.0 & 21.2 & 2963 & 1302 & 826 & 836 & 373000 & 254000 \\
\hline Mauritius & 7407 & 18098 & 2.4 & - & 1241 & 385 & 428 & 429 & - & - \\
\hline Morocco & 1846 & 7297 & 4.0 & 2.5 & 30495 & 10829 & 10083 & 9583 & 528000 & 235000 \\
\hline Mozambique & 1115 & 1378 & 1.2 & 74.7 & 20533 & 9737 & 5691 & 5105 & 8093000 & 7243000 \\
\hline Namibia & 5527 & 9679 & 1.8 & 49.1 & 2020 & 860 & 591 & 569 & 574000 & 418000 \\
\hline
\end{tabular}




\begin{tabular}{|c|c|c|c|c|c|c|c|c|c|c|}
\hline \multirow[t]{2}{*}{$\begin{array}{l}\text { Country (alphabetical order by } \\
\text { region) }\end{array}$} & \multicolumn{2}{|c|}{$\begin{array}{l}\text { Estimated earned } \\
\text { income (PPP US\$), } \\
20051\end{array}$} & \multirow{2}{*}{$\begin{array}{l}\text { Ratio of male } \\
\text { to female } \\
\text { earned } \\
\text { income }\end{array}$} & \multirow{2}{*}{$\begin{array}{l}\text { Proportion of } \\
\text { population } \\
\text { under poverty } \\
\text { line (US } \$ 1.25 \\
\text { per day) }(\%)\end{array}$} & \multirow{2}{*}{$\begin{array}{l}\text { Estimated } \\
\text { total } \\
\text { population in } \\
2005 \text { ('000s) }\end{array}$} & \multirow{2}{*}{$\begin{array}{l}\text { Estimated } \\
\text { population } \\
\text { below } 15 \text { and } \\
\text { over } 64 \\
\text { years, } 2005 \\
\text { ('000s) }\end{array}$} & \multicolumn{2}{|c|}{$\begin{array}{l}\text { Estimated population } \\
\text { aged 15-64 years, } \\
2005 \text { ('000s) }\end{array}$} & \multicolumn{2}{|c|}{$\begin{array}{l}\text { Estimated population } \\
\text { under the poverty line, } \\
2005 \text { (absolute numbers) }\end{array}$} \\
\hline & Female & Male & & & & & Female & Male & Female & Male \\
\hline Niger & 561 & 991 & 1.8 & 65.9 & 13264 & 6778 & 3245 & 3241 & 4961000 & 3777000 \\
\hline Rwanda & 1031 & 1392 & 1.4 & 76.6 & 9234 & 4243 & 2630 & 2361 & 3819000 & 3250000 \\
\hline Sao Tome and Principe & 1022 & 3357 & 3.3 & - & 153 & 70 & 42 & 40 & - & - \\
\hline Senegal & 1256 & 2346 & 1.9 & 33.5 & 11770 & 5466 & 3190 & 3114 & 2291000 & 1652000 \\
\hline Sierra Leone & 507 & 1114 & 2.2 & 53.4 & 5586 & 2575 & 1535 & 1476 & 1792000 & 1190000 \\
\hline South Africa & 6927 & 15446 & 2.2 & 26.2 & 47939 & 17430 & 15495 & 15013 & 7802000 & 4758000 \\
\hline Sudan & 832 & 3317 & 4.0 & - & 36900 & 16313 & 10250 & 10336 & - & - \\
\hline Tanzania, United Republic of & 627 & 863 & 1.4 & 87.6 & 38478 & 18226 & 10226 & 10026 & 18248000 & 15440000 \\
\hline Togo & 907 & 2119 & 2.3 & 38.7 & 6239 & 2891 & 1694 & 1653 & 1466000 & 947000 \\
\hline Tunisia & 3748 & 12924 & 3.4 & 2.6 & 10105 & 3264 & 3404 & 3436 & 177000 & 81000 \\
\hline Uganda & 1199 & 1708 & 1.4 & 51.5 & 28947 & 15008 & 6984 & 6955 & 8087000 & 6829000 \\
\hline Zambia & 725 & 1319 & 1.8 & 64.3 & 11478 & 5583 & 2964 & 2932 & 4240000 & 3139000 \\
\hline Zimbabwe & 1499 & 2585 & 1.7 & - & 13120 & 5644 & 3763 & 3713 & - & - \\
\hline Americas & & & & & 884303 & 308589 & 290924 & 284791 & 27169000 & 18628000 \\
\hline Argentina & 10063 & 18686 & 1.9 & 4.5 & 38747 & 14187 & 12403 & 12157 & 1038000 & 706000 \\
\hline Bahamas & 14656 & 20803 & 1.4 & - & 323 & 109 & 110 & 104 & - & - \\
\hline Barbados & 12868 & 20309 & 1.6 & - & 292 & 82 & 107 & 103 & - & - \\
\hline Belize & 4022 & 10117 & 2.5 & - & 276 & 115 & 79 & 81 & - & - \\
\hline
\end{tabular}




\begin{tabular}{|c|c|c|c|c|c|c|c|c|c|c|}
\hline \multirow[t]{2}{*}{$\begin{array}{l}\text { Country (alphabetical order by } \\
\text { region) }\end{array}$} & \multicolumn{2}{|c|}{$\begin{array}{l}\text { Estimated earned } \\
\text { income (PPP US\$), } \\
2005\end{array}$} & \multirow{2}{*}{$\begin{array}{l}\text { Ratio of male } \\
\text { to female } \\
\text { earned } \\
\text { income }\end{array}$} & \multirow{2}{*}{$\begin{array}{l}\text { Proportion of } \\
\text { population } \\
\text { under poverty } \\
\text { line (US\$1.25 } \\
\text { per day) (\%) }\end{array}$} & \multirow{2}{*}{$\begin{array}{l}\text { Estimated } \\
\text { total } \\
\text { population in } \\
2005 \text { ('000s) }\end{array}$} & \multirow{2}{*}{$\begin{array}{l}\text { Estimated } \\
\text { population } \\
\text { below } 15 \text { and } \\
\text { over } 64 \\
\text { years, } 2005 \\
\text { ('000s) }\end{array}$} & \multicolumn{2}{|c|}{$\begin{array}{l}\text { Estimated population } \\
\text { aged } 15-64 \text { years, } \\
2005 \text { ('000s) }\end{array}$} & \multicolumn{2}{|c|}{$\begin{array}{l}\text { Estimated population } \\
\text { under the poverty line, } \\
2005 \text { (absolute numbers) }\end{array}$} \\
\hline & Female & Male & & & & & Female & Male & Female & Male \\
\hline Brazil & 6204 & 10664 & 1.7 & 7.8 & 186831 & 63453 & 62705 & 60673 & 8515000 & 5983000 \\
\hline Canada & 25448 & 40000 & 1.6 & - & 32271 & 9927 & 11119 & 11224 & - & - \\
\hline Chile & 6871 & 17293 & 2.5 & 1.1 & 16295 & 5372 & 5479 & 5444 & 116000 & 64000 \\
\hline Colombia & 5680 & 8966 & 1.6 & 15.4 & 44946 & 15931 & 14835 & 14180 & 3952000 & 2952000 \\
\hline Costa Rica & 6983 & 13271 & 1.9 & 2.4 & 4327 & 1479 & 1397 & 1452 & 62000 & 41000 \\
\hline Cuba & 4268 & 9489 & 2.2 & - & 11260 & 3427 & 3904 & 3929 & - & - \\
\hline Dominican Republic & 4907 & 11465 & 2.3 & 5.0 & 9470 & 3698 & 2894 & 2878 & 293000 & 178000 \\
\hline Ecuador & 3102 & 5572 & 1.8 & 9.8 & 13061 & 5029 & 4013 & 4019 & 751000 & 527000 \\
\hline El Salvador & 3043 & 7543 & 2.5 & 14.3 & 6668 & 2640 & 2074 & 1954 & 597000 & 353000 \\
\hline Guatemala & 2267 & 6990 & 3.1 & 11.7 & 12710 & 6030 & 3510 & 3170 & 943000 & 544000 \\
\hline Guyana & 2665 & 6467 & 2.4 & 7.7 & 739 & 272 & 228 & 240 & 36000 & 21000 \\
\hline Haiti & 1146 & 2195 & 1.9 & 54.9 & 9296 & 3913 & 2753 & 2630 & 3016000 & 2088000 \\
\hline Honduras & 2160 & 4680 & 2.2 & 22.2 & 6834 & 3016 & 1945 & 1873 & 914000 & 602000 \\
\hline Jamaica & 3107 & 5503 & 1.8 & 0.2 & 2682 & 1050 & 836 & 796 & 4000 & 3000 \\
\hline Mexico & 6039 & 15680 & 2.6 & 0.7 & 104266 & 38149 & 34123 & 31994 & 434000 & 243000 \\
\hline Nicaragua & 1773 & 5577 & 3.1 & 15.8 & 5463 & 2286 & 1610 & 1567 & 562000 & 302000 \\
\hline Panama & 5537 & 9636 & 1.7 & 9.2 & 3232 & 1175 & 1021 & 1036 & 174000 & 123000 \\
\hline Paraguay & 2358 & 6892 & 2.9 & 9.3 & 5904 & 2397 & 1730 & 1777 & 354000 & 195000 \\
\hline Peru & 4269 & 7791 & 1.8 & 8.2 & 27274 & 10184 & 8539 & 8552 & 1320000 & 911000 \\
\hline Saint Lucia & 4501 & 8805 & 2.0 & 20.9 & 161 & 57 & 53 & 51 & 20000 & 13000 \\
\hline Saint Vincent and the Grenadines & 4449 & 8722 & 2.0 & - & 119 & 43 & 38 & 38 & - & - \\
\hline
\end{tabular}




\begin{tabular}{|c|c|c|c|c|c|c|c|c|c|c|}
\hline \multirow[t]{2}{*}{$\begin{array}{l}\text { Country (alphabetical order by } \\
\text { region) }\end{array}$} & \multicolumn{2}{|c|}{$\begin{array}{l}\text { Estimated earned } \\
\text { income (PPP US\$), } \\
2005\end{array}$} & \multirow{2}{*}{$\begin{array}{l}\text { Ratio of male } \\
\text { to female } \\
\text { earned } \\
\text { income }\end{array}$} & \multirow{2}{*}{$\begin{array}{l}\text { Proportion of } \\
\text { population } \\
\text { under poverty } \\
\text { line (US } \$ 1.25 \\
\text { per day) }(\%)\end{array}$} & \multirow{2}{*}{$\begin{array}{l}\text { Estimated } \\
\text { total } \\
\text { population in } \\
2005 \text { ('000s) }\end{array}$} & \multirow{2}{*}{$\begin{array}{l}\text { Estimated } \\
\text { population } \\
\text { below } 15 \text { and } \\
\text { over } 64 \\
\text { years, } 2005 \\
\text { ('000s) }\end{array}$} & \multicolumn{2}{|c|}{$\begin{array}{l}\text { Estimated population } \\
\text { aged 15-64 years, } \\
2005 \text { ('000s) }\end{array}$} & \multicolumn{2}{|c|}{$\begin{array}{l}\text { Estimated population } \\
\text { under the poverty line, } \\
2005 \text { (absolute numbers) }\end{array}$} \\
\hline & Female & Male & & & & & Female & $\overline{\text { Male }}$ & Female & $\overline{\text { Male }}$ \\
\hline Suriname & 4426 & 11029 & 2.5 & 15.5 & 452 & 163 & 145 & 144 & 45000 & 26000 \\
\hline United States & 25005 & 40000 & 1.6 & - & 299846 & 99168 & 100597 & 100082 & - & - \\
\hline Uruguay & 7203 & 12890 & 1.8 & 0.0 & 3326 & 1241 & 1060 & 1025 & 0 & 0 \\
\hline Venezuela, Bolivarian Republic of & 4560 & 8683 & 1.9 & 18.4 & 26726 & 9701 & 8478 & 8546 & 2948000 & 1972000 \\
\hline Asia and the Pacific & & & & & 3677526 & 1258748 & 1176029 & 1242750 & 575573000 & 337019000 \\
\hline Australia & 26311 & 37414 & 1.4 & - & 20310 & 6627 & 6812 & 6871 & - & - \\
\hline Bahrain & 10496 & 29796 & 2.8 & - & 725 & 213 & 205 & 307 & - & - \\
\hline Brunei Darussalam & 15658 & 37506 & 2.4 & - & 374 & 122 & 121 & 130 & - & - \\
\hline Cambodia & 2332 & 3149 & 1.4 & 40.2 & 13956 & 5680 & 4306 & 3969 & 3052000 & 2556000 \\
\hline China & 5220 & 8213 & 1.6 & 15.9 & 1312979 & 384236 & 449754 & 478989 & 120985000 & 88041000 \\
\hline Fiji & 3928 & 8103 & 2.1 & - & 828 & 307 & 256 & 265 & - & - \\
\hline India & 1620 & 5194 & 3.2 & 41.6 & 1134403 & 430598 & 338601 & 365204 & 313040000 & 159325000 \\
\hline Indonesia & 2410 & 5280 & 2.2 & 21.4 & 226063 & 76621 & 74710 & 74732 & 30213000 & 18255000 \\
\hline Iran, Islamic Republic of & 4475 & 11363 & 2.5 & 1.5 & 69421 & 23075 & 22942 & 23404 & 649000 & 357000 \\
\hline Japan & 17802 & 40000 & 2.2 & - & 127897 & 43013 & 42156 & 42728 & - & - \\
\hline Jordan & 2566 & 8270 & 3.2 & 0.4 & 5544 & 2239 & 1593 & 1712 & 14000 & 7000 \\
\hline Korea, Republic of & 12531 & 31476 & 2.5 & - & 47870 & 13442 & 16961 & 17466 & - & - \\
\hline Kuwait & 12623 & 36403 & 2.9 & - & 2700 & 689 & 736 & 1275 & - & - \\
\hline
\end{tabular}




\begin{tabular}{|c|c|c|c|c|c|c|c|c|c|c|}
\hline \multirow[t]{2}{*}{$\begin{array}{l}\text { Country (alphabetical order by } \\
\text { region) }\end{array}$} & \multicolumn{2}{|c|}{$\begin{array}{l}\text { Estimated earned } \\
\text { income (PPP US\$), } \\
2005\end{array}$} & \multirow{2}{*}{$\begin{array}{l}\text { Ratio of male } \\
\text { to female } \\
\text { earned } \\
\text { income }\end{array}$} & \multirow{2}{*}{$\begin{array}{l}\text { Proportion of } \\
\text { population } \\
\text { under poverty } \\
\text { line (US\$1.25 } \\
\text { per day) (\%) }\end{array}$} & \multirow{2}{*}{$\begin{array}{l}\text { Estimated } \\
\text { total } \\
\text { population in } \\
2005 \text { ('000s) }\end{array}$} & \multirow{2}{*}{$\begin{array}{l}\text { Estimated } \\
\text { population } \\
\text { below } 15 \text { and } \\
\text { over } 64 \\
\text { years, } 2005 \\
\text { ('000s) }\end{array}$} & \multicolumn{2}{|c|}{$\begin{array}{l}\text { Estimated population } \\
\text { aged 15-64 years, } \\
2005 \text { ('000s) }\end{array}$} & \multicolumn{2}{|c|}{$\begin{array}{l}\text { Estimated population } \\
\text { under the poverty line, } \\
2005 \text { (absolute numbers) }\end{array}$} \\
\hline & Female & Male & & & & & Female & Male & Female & Male \\
\hline Lebanon & 2701 & 8585 & 3.2 & - & 4011 & 1439 & 1332 & 1239 & 0 & 0 \\
\hline Malaysia & 5751 & 15861 & 2.8 & 0.5 & 25653 & 9170 & 8098 & 8385 & 90000 & 48000 \\
\hline Mongolia & 1413 & 2799 & 2.0 & 22.4 & 2581 & 847 & 870 & 864 & 353000 & 225000 \\
\hline Nepal & 1038 & 2072 & 2.0 & 55.1 & 27094 & 11547 & 7970 & 7577 & 8892000 & 6042000 \\
\hline New Zealand & 20666 & 29479 & 1.4 & - & 4097 & 1377 & 1377 & 1343 & - & - \\
\hline Oman & 4516 & 23880 & 5.3 & - & 2507 & 913 & 656 & 938 & - & - \\
\hline Pakistan & 1059 & 3607 & 3.4 & 22.6 & 158081 & 64894 & 45045 & 48141 & 23603000 & 12108000 \\
\hline Papua New Guinea & 2140 & 2960 & 1.4 & 35.8 & 6070 & 2608 & 1718 & 1744 & 1187000 & 987000 \\
\hline Philippines & 3883 & 6375 & 1.6 & 22.6 & 84566 & 33810 & 25238 & 25518 & 10959000 & 8170000 \\
\hline Qatar & 9211 & 37774 & 4.1 & - & 796 & 184 & 173 & 440 & - & - \\
\hline Samoa & 3338 & 8797 & 2.6 & - & 184 & 83 & 48 & 53 & - & - \\
\hline Saudi Arabia & 4031 & 25678 & 6.4 & - & 23612 & 8810 & 6196 & 8606 & - & - \\
\hline Singapore & 20044 & 39150 & 2.0 & - & 4327 & 1213 & 1542 & 1572 & - & - \\
\hline Solomon Islands & 1345 & 2672 & 2.0 & - & 472 & 205 & 130 & 138 & - & - \\
\hline Sri Lanka & 2647 & 6479 & 2.4 & 14.0 & 19121 & 5862 & 6730 & 6528 & 1722000 & 945000 \\
\hline Syrian Arab Republic & 1907 & 5684 & 3.0 & - & 18894 & 7511 & 5643 & 5739 & - & - \\
\hline Thailand & 6695 & 10732 & 1.6 & 0.4 & 63003 & 18569 & 22823 & 21612 & 147000 & 105000 \\
\hline United Arab Emirates & 8329 & 33555 & 4.0 & - & 4104 & 860 & 899 & 2345 & - & - \\
\hline Vanuatu & 2601 & 3830 & 1.5 & - & 215 & 93 & 61 & 62 & - & - \\
\hline Viet Nam & 2540 & 3604 & 1.4 & 21.5 & 85029 & 29927 & 27639 & 27462 & 10143000 & 8096000 \\
\hline Yemen & 424 & 1422 & 3.4 & 17.5 & 21096 & 10171 & 5411 & 5514 & 2367000 & 1331000 \\
\hline
\end{tabular}




\begin{tabular}{|c|c|c|c|c|c|c|c|c|c|c|}
\hline \multirow[t]{2}{*}{$\begin{array}{l}\text { Country (alphabetical order by } \\
\text { region) }\end{array}$} & \multicolumn{2}{|c|}{$\begin{array}{l}\text { Estimated earned } \\
\text { income (PPP US\$), } \\
2005\end{array}$} & \multirow{2}{*}{$\begin{array}{l}\text { Ratio of male } \\
\text { to female } \\
\text { earned } \\
\text { income }\end{array}$} & \multirow{2}{*}{$\begin{array}{l}\text { Proportion of } \\
\text { population } \\
\text { under poverty } \\
\text { line (US\$1.25 } \\
\text { per day) (\%) }\end{array}$} & \multirow{2}{*}{$\begin{array}{l}\text { Estimated } \\
\text { total } \\
\text { population in } \\
2005 \text { ('000s) }\end{array}$} & \multirow{2}{*}{$\begin{array}{l}\text { Estimated } \\
\text { population } \\
\text { below } 15 \text { and } \\
\text { over } 64 \\
\text { years, } 2005 \\
\text { ('000s) }\end{array}$} & \multicolumn{2}{|c|}{$\begin{array}{l}\text { Estimated population } \\
\text { aged } 15-64 \text { years, } \\
2005 \text { ('000s) }\end{array}$} & \multicolumn{2}{|c|}{$\begin{array}{l}\text { Estimated population } \\
\text { under the poverty line, } \\
2005 \text { (absolute numbers) }\end{array}$} \\
\hline & Female & Male & & & & & Female & Male & Female & Male \\
\hline Europe and Central Asia & & & & & 874872 & 282898 & 298651 & 293323 & 11940000 & 8359000 \\
\hline Armenia & 3893 & 6150 & 1.6 & 10.6 & 3018 & 993 & 1096 & 928 & 185000 & 136000 \\
\hline Austria & 18397 & 40000 & 2.2 & - & 8292 & 2650 & 2788 & 2854 & - & - \\
\hline Azerbaijan & 3960 & 6137 & 1.5 & 0.0 & 8352 & 2707 & 2930 & 2715 & 1000 & 1000 \\
\hline Belarus & 6236 & 9835 & 1.6 & 0.0 & 9795 & 2944 & 3532 & 3319 & 0 & 0 \\
\hline Belgium & 22182 & 40000 & 1.8 & - & 10398 & 3569 & 3391 & 3438 & - & - \\
\hline Bosnia and Herzegovina & 2864 & 4341 & 1.5 & 0.2 & 3915 & 1225 & 1365 & 1325 & 4000 & 3000 \\
\hline Bulgaria & 7176 & 11010 & 1.5 & 0.0 & 7745 & 2398 & 2688 & 2658 & 0 & 0 \\
\hline Croatia & 10587 & 15687 & 1.5 & 0.0 & 4551 & 1490 & 1537 & 1525 & 0 & 0 \\
\hline Cyprus & 16805 & 27808 & 1.7 & - & 836 & 268 & 292 & 277 & - & - \\
\hline Czech Republic & 13992 & 27440 & 2.0 & 0.0 & 10192 & 2947 & 3611 & 3635 & 0 & 0 \\
\hline Denmark & 28766 & 39288 & 1.4 & - & 5417 & 1836 & 1773 & 1808 & - & - \\
\hline Estonia & 12112 & 19430 & 1.6 & 0.0 & 1344 & 427 & 477 & 440 & 0 & 0 \\
\hline Finland & 26795 & 37739 & 1.4 & - & 5246 & 1746 & 1731 & 1769 & - & - \\
\hline France & 23945 & 37169 & 1.6 & - & 60991 & 21164 & 19932 & 19895 & - & - \\
\hline Georgia & 1731 & 5188 & 3.0 & 13.4 & 4473 & 1485 & 1565 & 1423 & 401000 & 200000 \\
\hline Germany & 21823 & 37461 & 1.7 & - & 82652 & 27395 & 27252 & 28005 & - & - \\
\hline Greece & 16738 & 30184 & 1.8 & - & 11100 & 3614 & 3708 & 3778 & - & - \\
\hline Hungary & 14058 & 22098 & 1.6 & 0.0 & 10086 & 3124 & 3531 & 3431 & 0 & 0 \\
\hline
\end{tabular}




\begin{tabular}{|c|c|c|c|c|c|c|c|c|c|c|}
\hline \multirow[t]{2}{*}{$\begin{array}{l}\text { Country (alphabetical order by } \\
\text { region) }\end{array}$} & \multicolumn{2}{|c|}{$\begin{array}{l}\text { Estimated earned } \\
\text { income (PPP US\$), } \\
20051\end{array}$} & \multirow{2}{*}{$\begin{array}{l}\text { Ratio of male } \\
\text { to female } \\
\text { earned } \\
\text { income }\end{array}$} & \multirow{2}{*}{$\begin{array}{l}\text { Proportion of } \\
\text { population } \\
\text { under poverty } \\
\text { line (US } \$ 1.25 \\
\text { per day) }(\%)\end{array}$} & \multirow{2}{*}{$\begin{array}{l}\text { Estimated } \\
\text { total } \\
\text { population in } \\
2005 \text { ('000s) }\end{array}$} & \multirow{2}{*}{$\begin{array}{l}\text { Estimated } \\
\text { population } \\
\text { below } 15 \text { and } \\
\text { over } 64 \\
\text { years, } 2005 \\
\text { ('000s) }\end{array}$} & \multicolumn{2}{|c|}{$\begin{array}{l}\text { Estimated population } \\
\text { aged 15-64 years, } \\
2005 \text { ('000s) }\end{array}$} & \multicolumn{2}{|c|}{$\begin{array}{l}\text { Estimated population } \\
\text { under the poverty line, } \\
2005 \text { (absolute numbers) }\end{array}$} \\
\hline & Female & Male & & & & & Female & Male & Female & Male \\
\hline Ireland & 21076 & 40000 & 1.9 & - & 4143 & 1320 & 1402 & 1422 & - & - \\
\hline Israel & 20497 & 31345 & 1.5 & - & 6692 & 2544 & 2082 & 2066 & - & - \\
\hline Italy & 18501 & 39163 & 2.1 & - & 58646 & 19779 & 19412 & 19455 & - & - \\
\hline Kazakhstan & 6141 & 9723 & 1.6 & 3.1 & 15211 & 4902 & 5347 & 4962 & 274000 & 201000 \\
\hline Kyrgyzstan & 1414 & 2455 & 1.7 & 21.8 & 5204 & 1920 & 1661 & 1622 & 664000 & 471000 \\
\hline Latvia & 10951 & 16842 & 1.5 & 0.0 & 2302 & 714 & 822 & 766 & 0 & 0 \\
\hline Lithuania & 12000 & 17349 & 1.4 & 0.4 & 3425 & 1099 & 1203 & 1123 & 8000 & 6000 \\
\hline Luxembourg & 20446 & 40000 & 2.0 & - & 457 & 149 & 152 & 155 & - & - \\
\hline Malta & 12834 & 25623 & 2.0 & - & 403 & 123 & 138 & 142 & - & - \\
\hline Moldova, Republic of & 1634 & 2608 & 1.6 & 8.1 & 3877 & 1204 & 1374 & 1299 & 183000 & 133000 \\
\hline Netherlands & 25625 & 39845 & 1.6 & - & 16328 & 5316 & 5450 & 5561 & - & - \\
\hline Norway & 30749 & 40000 & 1.3 & - & 4639 & 1589 & 1502 & 1548 & - & - \\
\hline Poland & 10414 & 17493 & 1.7 & 0.1 & 38196 & 11298 & 13556 & 13342 & 23000 & 16000 \\
\hline Portugal & 15294 & 25881 & 1.7 & - & 10528 & 3428 & 3595 & 3505 & - & - \\
\hline Romania & 7443 & 10761 & 1.4 & 0.8 & 21628 & 6583 & 7563 & 7481 & 91000 & 71000 \\
\hline Russian Federation & 8476 & 13581 & 1.6 & 0.2 & 143953 & 41586 & 53080 & 49287 & 134000 & 96000 \\
\hline Slovakia & 11777 & 20218 & 1.7 & 0.3 & 5387 & 1536 & 1936 & 1915 & 8000 & 6000 \\
\hline Slovenia & 17022 & 27779 & 1.6 & 0.0 & 1999 & 595 & 693 & 712 & 0 & 0 \\
\hline Spain & 18335 & 36324 & 2.0 & - & 43397 & 13561 & 14773 & 15063 & - & - \\
\hline Sweden & 29044 & 36059 & 1.2 & - & 9038 & 3130 & 2907 & 3000 & - & - \\
\hline Switzerland & 25056 & 40000 & 1.6 & - & 7424 & 2385 & 2530 & 2509 & - & - \\
\hline
\end{tabular}




\begin{tabular}{|c|c|c|c|c|c|c|c|c|c|c|}
\hline \multirow[t]{2}{*}{$\begin{array}{l}\text { Country (alphabetical order by } \\
\text { region) }\end{array}$} & \multicolumn{2}{|c|}{$\begin{array}{l}\text { Estimated earned } \\
\text { income (PPP US\$), } \\
20051\end{array}$} & \multirow{2}{*}{$\begin{array}{l}\text { Ratio of male } \\
\text { to female } \\
\text { earned } \\
\text { income }\end{array}$} & \multirow{2}{*}{$\begin{array}{l}\text { Proportion of } \\
\text { population } \\
\text { under poverty } \\
\text { line (US\$1.25 } \\
\text { per day) (\%) }\end{array}$} & \multirow{2}{*}{$\begin{array}{l}\text { Estimated } \\
\text { total } \\
\text { population in } \\
2005 \text { ('000s) }\end{array}$} & \multirow{2}{*}{$\begin{array}{l}\text { Estimated } \\
\text { population } \\
\text { below } 15 \text { and } \\
\text { over } 64 \\
\text { years, } 2005 \\
\text { ('000s) }\end{array}$} & \multicolumn{2}{|c|}{$\begin{array}{l}\text { Estimated population } \\
\text { aged 15-64 years, } \\
2005 \text { ('000s) }\end{array}$} & \multicolumn{2}{|c|}{$\begin{array}{l}\text { Estimated population } \\
\text { under the poverty line, } \\
2005 \text { (absolute numbers) }\end{array}$} \\
\hline & Female & Male & & & & & Female & Male & Female & Male \\
\hline Tajikistan & 992 & 1725 & 1.7 & 21.5 & 6550 & 2833 & 1890 & 1827 & 812000 & 596000 \\
\hline $\begin{array}{l}\text { The former Yugoslav Republic of } \\
\text { Macedonia }\end{array}$ & 4676 & 9734 & 2.1 & 0.5 & 2034 & 627 & 697 & 709 & 6000 & 4000 \\
\hline Turkey & 4385 & 12368 & 2.8 & 2.7 & 72970 & 24720 & 23820 & 24430 & 1305000 & 680000 \\
\hline Turkmenistan & 6108 & 9596 & 1.6 & 24.8 & 4833 & 1762 & 1558 & 1514 & 684000 & 515000 \\
\hline Ukraine & 4970 & 9067 & 1.8 & 0.1 & 46918 & 14424 & 16924 & 15569 & 28000 & 19000 \\
\hline United Kingdom & 26242 & 40000 & 1.5 & - & 60245 & 20511 & 19947 & 19787 & - & - \\
\hline Uzbekistan & 1547 & 2585 & 1.7 & 46.3 & 26593 & 10084 & 8300 & 8209 & 7113000 & 5194000 \\
\hline
\end{tabular}

$-=$ No information.

${ }_{1}^{1}$ Because of the lack of sex-disaggregated income data, female and male earned income is crudely estimated on the basis of data on the ratio of the female non-agricultural wage to the male non-agricultural wage, the female and

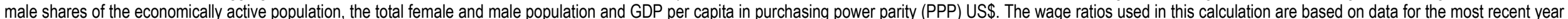
available between 1996 and 2005. For calculation methods see Technical note 1, in UNDP: Human Development Report 2007-08: Fighting climate change - Human solidarity in a divided world (New York, 2007).

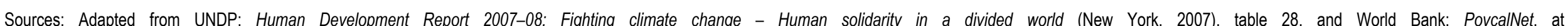

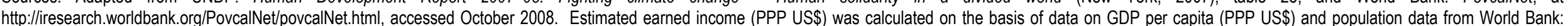
World Development Indicators 2007 (CD-ROM) (Washington, DC, 2007), unless otherwise specified in table 28 of UNDP, op. cit.; data on wages from ILO: LABORSTA database, at http://laborsta.ilo.org, accessed April 2007; data on

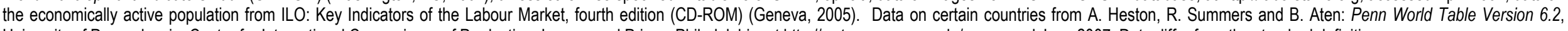
University of Pennsylvania, Center for International Comparisons of Production, Income and Prices, Philadelphia, at http://pwt.econ.upenn.edul, accessed June 2007. Data differ from the standard definition. 
Table B. Projected numbers of women aged 15-49 years, estimated numbers of pregnant women of working age, 2010, 2020 and 2050, and pregnant women in the labour force, 2010 and 2020, ILO member States with data and regional summaries

\begin{tabular}{|c|c|c|c|c|c|c|c|c|}
\hline \multirow{3}{*}{$\begin{array}{l}\text { Country (alphabetical order by } \\
\text { region) }\end{array}$} & \multicolumn{8}{|c|}{ Women aged $15-49$ years } \\
\hline & \multicolumn{3}{|c|}{ Projected numbers of women } & \multicolumn{3}{|c|}{$\begin{array}{l}\text { Estimated numbers of pregnant women of } \\
\text { working age }\end{array}$} & \multicolumn{2}{|c|}{$\begin{array}{l}\text { Estimated numbers of pregnant } \\
\text { women in the labour force }\end{array}$} \\
\hline & 2010 & 2020 & 2050 & 2010 & 2020 & 2050 & 2010 & 2020 \\
\hline Total for all countries with data & 1744861000 & 1858287000 & 2068812000 & 136217000 & 135339000 & 123425000 & 78239000 & 80447000 \\
\hline Africa & 236388000 & 295164000 & 524096000 & 36215000 & 38644000 & 39537000 & 21363000 & 23064000 \\
\hline Algeria & 10237000 & 10988000 & 11028000 & 726000 & 707000 & 613000 & 322000 & 347000 \\
\hline Angola & 4242000 & 5587000 & 11998000 & 861000 & 1007000 & 1133000 & 650000 & 758000 \\
\hline Benin & 2257000 & 3059000 & 5918000 & 383000 & 421000 & 445000 & 207000 & 228000 \\
\hline Botswana & 439000 & 418000 & 710000 & 48000 & 47000 & 42000 & 22000 & 22000 \\
\hline Burkina Faso & 3458000 & 4742000 & 9961000 & 688000 & 774000 & 826000 & 546000 & 619000 \\
\hline Burundi & 2159000 & 2726000 & 7211000 & 449000 & 550000 & 795000 & 418000 & 514000 \\
\hline Cameroon & 4395000 & 5370000 & 8822000 & 646000 & 639000 & 588000 & 349000 & 351000 \\
\hline Cape Verde & 152000 & 185000 & 249000 & 16000 & 16000 & 15000 & 6000 & 6000 \\
\hline Central African Republic & 1024000 & 1245000 & 2100000 & 162000 & 164000 & 150000 & 111000 & 113000 \\
\hline Chad & 2445000 & 3308000 & 7881000 & 520000 & 605000 & 694000 & 339000 & 399000 \\
\hline Comoros & 224000 & 295000 & 444000 & 28000 & 29000 & 28000 & 17000 & 17000 \\
\hline Congo & 1015000 & 1435000 & 2037000 & 134000 & 137000 & 138000 & 73000 & 75000 \\
\hline Côte d'Ivoire & 4759000 & 6054000 & 9195000 & 693000 & 693000 & 626000 & 439000 & 499000 \\
\hline Democratic Republic of the Congo & 14757000 & 20143000 & 50349000 & 3375000 & 4058000 & 4716000 & 1381000 & 1486000 \\
\hline Djibouti & 213000 & 265000 & 380000 & 24000 & 25000 & 24000 & 13000 & 14000 \\
\hline Egypt & 20860000 & 24688000 & 29160000 & 1858000 & 1817000 & 1614000 & 448000 & 442000 \\
\hline Equatorial Guinea & 123000 & 151000 & 315000 & 21000 & 24000 & 25000 & 11000 & 13000 \\
\hline Eritrea & 1230000 & 1673000 & 3066000 & 199000 & 201000 & 216000 & 121000 & 122000 \\
\hline
\end{tabular}




\begin{tabular}{|c|c|c|c|c|c|c|c|c|}
\hline \multirow{3}{*}{$\begin{array}{l}\text { Country (alphabetical order by } \\
\text { region) }\end{array}$} & \multicolumn{8}{|c|}{ Women aged $15-49$ years } \\
\hline & \multicolumn{3}{|c|}{ Projected numbers of women } & \multicolumn{3}{|c|}{$\begin{array}{l}\text { Estimated numbers of pregnant women of } \\
\text { working age }\end{array}$} & \multicolumn{2}{|c|}{$\begin{array}{l}\text { Estimated numbers of pregnant } \\
\text { women in the labour force }\end{array}$} \\
\hline & 2010 & 2020 & 2050 & 2010 & 2020 & 2050 & 2010 & 2020 \\
\hline Ethiopia & 20550000 & 26523000 & 49081000 & 3316000 & 3562000 & 3585000 & 2507000 & 2701000 \\
\hline Gabon & 376000 & 443000 & 521000 & 35000 & 34000 & 31000 & 22000 & 22000 \\
\hline Gambia & 417000 & 531000 & 950000 & 61000 & 65000 & 66000 & 37000 & 38000 \\
\hline Ghana & 134000 & 172000 & 10600000 & 707000 & 713000 & 666000 & 497000 & 509000 \\
\hline Guinea & 2343000 & 3090000 & 5951000 & 388000 & 422000 & 449000 & 322000 & 350000 \\
\hline Guinea-Bissau & 399000 & 550000 & 1408000 & 91000 & 112000 & 143000 & 58000 & 72000 \\
\hline Kenya & 9246000 & 12166000 & 22837000 & 1531000 & 1583000 & 1672000 & 1086000 & 1131000 \\
\hline Lesotho & 465000 & 449000 & 654000 & 58000 & 55000 & 44000 & 27000 & 26000 \\
\hline Liberia & 836000 & 1117000 & 3254000 & 207000 & 257000 & 339000 & 115000 & 144000 \\
\hline Libyan Arab Jamahiriya & 1759000 & 2018000 & 2190000 & 146000 & 128000 & 122000 & 68000 & 78000 \\
\hline Madagascar & 4997000 & 6636000 & 11887000 & 744000 & 799000 & 830000 & 588000 & 634000 \\
\hline Malawi & 3172000 & 4178000 & 8646000 & 596000 & 671000 & 714000 & 514000 & 586000 \\
\hline Mali & 3479000 & 4848000 & 9304000 & 633000 & 728000 & 800000 & 477000 & 555000 \\
\hline Mauritania & 833000 & 1101000 & 1611000 & 104000 & 106000 & 105000 & 59000 & 60000 \\
\hline Mauritius & 350000 & 347000 & 306000 & 19000 & 18000 & 16000 & 9000 & 9000 \\
\hline Morocco & 9297000 & 10243000 & 9723000 & 652000 & 628000 & 529000 & 202000 & 206000 \\
\hline Mozambique & 5207000 & 6331000 & 10853000 & 849000 & 859000 & 832000 & 704000 & 711000 \\
\hline Namibia & 540000 & 617000 & 799000 & 55000 & 57000 & 51000 & 26000 & 29000 \\
\hline Niger & 3469000 & 4935000 & 13293000 & 761000 & 990000 & 1504000 & 558000 & 732000 \\
\hline Nigeria & 33839000 & 43214000 & 77297000 & 6051000 & 6098000 & 5611000 & 2645000 & 2669000 \\
\hline Rwanda & 2572000 & 3203000 & 6164000 & 465000 & 487000 & 488000 & 381000 & 402000 \\
\hline
\end{tabular}




\begin{tabular}{ll}
\hline $\begin{array}{l}\text { Country (alphabetical order by } \\
\text { region) }\end{array}$ & Women aged 15-49 years \\
\cline { 2 - 2 } & Projected numbers of wome
\end{tabular}

Sao Tome and Principe
Senegal
Sierra Leone
Somalia
South Africa
Sudan
Swaziland
Tanzania, United Republic of
Togo
Tunisia
Uganda

Zambia

Zimbabwe

Americas

Argentina

Bahamas

Barbados

Belize

Bolivia

Brazil

Canada

\section{Projected numbers of women}

2010

45000

3280000

1417000

2238000

12409000

10026000

259000

10106000

1682000

3068000

7287000

2889000

3413000

242881000

10291000

95000

73000

79000

2529000

53955000

8188000
Estimated numbers of pregnant women of working age

$\begin{array}{rr}2020 & 2050 \\ 57000 & 76000\end{array}$

4205000

6693000

1820000

3641000

2995000

12064000

5652000

14294000

12337000

18823000

379000

12728000

2236000

3122000

10975000

3668000

3665000

258682000

11229000

101000

65000

95000

3054000

57288000

8095000
23484000

3820000

2702000

24998000

6310000

5071000

266768000

11349000

99000

49000

118000

3681000

56751000

8421000
2010

5000

446000

282000

392000

1063000

1241000

32000

1618000

250000

174000

1558000

480000

378000

15935000

698000

6000

3000

7000

261000

3634000

347000
249000
Estimated numbers of pregnant women in the labour force

\begin{tabular}{cc}
\hline 2010 & 2020 \\
2000 & 2000
\end{tabular}

455000

445000

321000

346000

438000

463000

1001000

818000

1276000

1214000

31000

26000

1662000

259000

171000

1868000

501000

371000

\section{0}

676000

6000

$$
3000
$$

$$
7000
$$

3402000

372000

1529000

231000

147000

2215000

492000

319000

14086000

604000

5000

3000

6000

197000

2956000

440000
261000

171000

247000

544000

298000

11000

1423000

129000

67000

1260000

341000

234000

10284000

484000

4000

3000

4000

169000

2413000

276000

269000

196000

277000

512000

308000

11000

1468000

134000

80000

1525000

355000

238000

10485000

521000

4000

2000

4000

169000

2366000

308000 


\begin{tabular}{|c|c|c|c|c|c|c|c|c|}
\hline \multirow{3}{*}{$\begin{array}{l}\text { Country (alphabetical order by } \\
\text { region) }\end{array}$} & \multicolumn{8}{|c|}{ Women aged $15-49$ years } \\
\hline & \multicolumn{3}{|c|}{ Projected numbers of women } & \multicolumn{3}{|c|}{$\begin{array}{l}\text { Estimated numbers of pregnant women of } \\
\text { working age }\end{array}$} & \multicolumn{2}{|c|}{$\begin{array}{l}\text { Estimated numbers of pregnant } \\
\text { women in the labour force }\end{array}$} \\
\hline & 2010 & 2020 & 2050 & 2010 & 2020 & 2050 & 2010 & 2020 \\
\hline$\overline{\text { Chile }}$ & 4554000 & 4567000 & 4251000 & 253000 & 250000 & 225000 & 112000 & 125000 \\
\hline Colombia & 13212000 & 14264000 & 13714000 & 863000 & 837000 & 722000 & 641000 & 671000 \\
\hline Costa Rica & 1262000 & 1366000 & 1366000 & 79000 & 76000 & 71000 & 46000 & 53000 \\
\hline Cuba & 3021000 & 2536000 & 1683000 & 115000 & 111000 & 82000 & 69000 & 69000 \\
\hline Dominican Republic & 2580000 & 2819000 & 3340000 & 231000 & 228000 & 184000 & 124000 & 137000 \\
\hline Ecuador & 3703000 & 4183000 & 4072000 & 278000 & 266000 & 217000 & 199000 & 209000 \\
\hline El Salvador & 2008000 & 2318000 & 2350000 & 156000 & 152000 & 126000 & 86000 & 93000 \\
\hline Grenada & 28000 & 29000 & 20000 & 2000 & 2000 & 1000 & - & - \\
\hline Guatemala & 3502000 & 4590000 & 7361000 & 459000 & 476000 & 402000 & 168000 & 183000 \\
\hline Guyana & 213000 & 198000 & 97000 & 12000 & 11000 & 5000 & 6000 & 6000 \\
\hline Haiti & 2393000 & 2769000 & 3823000 & 271000 & 268000 & 232000 & 170000 & 183000 \\
\hline Honduras & 2049000 & 2531000 & 2995000 & 201000 & 198000 & 162000 & 129000 & 136000 \\
\hline Jamaica & 722000 & 708000 & 617000 & 53000 & 50000 & 35000 & 31000 & 30000 \\
\hline Mexico & 32099000 & 34504000 & 28404000 & 2023000 & 1828000 & 1468000 & 928000 & 914000 \\
\hline Nicaragua & 1610000 & 1975000 & 1931000 & 140000 & 135000 & 104000 & 54000 & 55000 \\
\hline Panama & 916000 & 1022000 & 1164000 & 70000 & 69000 & 62000 & 43000 & 46000 \\
\hline Paraguay & 1742000 & 2147000 & 2392000 & 154000 & 152000 & 136000 & 117000 & 123000 \\
\hline Peru & 8003000 & 9027000 & 8900000 & 587000 & 572000 & 478000 & 399000 & 427000 \\
\hline Saint Lucia & 47000 & 47000 & 48000 & 3000 & 3000 & 3000 & 2000 & 2000 \\
\hline Saint Vincent and the Grenadines & 34000 & 33000 & 21000 & 2000 & 2000 & 1000 & 2000 & 1000 \\
\hline Suriname & 122000 & 119000 & 86000 & 9000 & 8000 & 5000 & 4000 & 3000 \\
\hline
\end{tabular}




\begin{tabular}{ll}
\hline $\begin{array}{l}\text { Country (alphabetical order by } \\
\text { region) }\end{array}$ & Women aged 15-49 years \\
\cline { 2 - 2 } & Projected numbers of women
\end{tabular}

Trinidad and Tobago
United States
Uruguay
Venezuela, Bolivarian
Asia and the Pacific
Afghanistan
Australia
Bahrain
Bangladesh
Brunei Darussalam
Cambodia

Fiji

India

Indonesia

Iran, Islamic Republic of

Iraq

Japan

Jordan

Korea, Republic of

Kuwait

\section{Projected numbers of women}

2010

74909000

860000

7708000

1044293000

7734000

5204000

199000

40605000

120000

4146000

367889000

229000

304778000

65099000

21959000

8172000

27335000

1641000

12872000

760000
Estimated numbers of pregnant women of working age

2010

20000

4352000

50000

599000

8662000

1097535000

10736000

5296000

219000

47971000

141000

4872000

337141000

238000

346496000

69228000

23553000

10560000

24964000

2032000

11400000

894000
86866000

766000

9765000

1106110000

20556000

5704000

243000

62679000

167000

6205000

266010000

209000

384443000

65365000

21536000

15755000

16461000

2440000

1103000
6686000
73556000

1441000

263000

13000

3989000

8000

399000

17718000

17000

26788000

4239000

1174000

941000

1011000

155000

433000

52000
Estimated numbers of pregnant women in the labour force

$\begin{array}{ll}2010 & 2020 \\ 11000\end{array}$

$18000 \quad 15000$

4374000

4583000

47000

40000

586000

516000

61026000

2019000

304000

13000

3470000

9000

371000

14510000

11000

20234000

3380000

1146000

1021000

736000

130000

288000

59000
3122000

36000

432000

39819000

620000

193000

4000

2265000

4000

318000

14794000

10000

9689000

2305000

588000

226000

647000

53000

241000

31000 


\begin{tabular}{|c|c|c|c|c|c|c|c|c|}
\hline \multirow{3}{*}{$\begin{array}{l}\text { Country (alphabetical order by } \\
\text { region) }\end{array}$} & \multicolumn{8}{|c|}{ Women aged $15-49$ years } \\
\hline & \multicolumn{3}{|c|}{ Projected numbers of women } & \multicolumn{3}{|c|}{$\begin{array}{l}\text { Estimated numbers of pregnant women of } \\
\text { working age }\end{array}$} & \multicolumn{2}{|c|}{$\begin{array}{l}\text { Estimated numbers of pregnant } \\
\text { women in the labour force }\end{array}$} \\
\hline & 2010 & 2020 & 2050 & 2010 & 2020 & 2050 & 2010 & 2020 \\
\hline Lao People's Democratic Republic & 1639000 & 2069000 & 2285000 & 160000 & 158000 & 126000 & 92000 & 92000 \\
\hline Lebanon & 1028000 & 1087000 & 1154000 & 74000 & 72000 & 62000 & 33000 & 37000 \\
\hline Malaysia & 7180000 & 8173000 & 8976000 & 552000 & 528000 & 476000 & 297000 & 330000 \\
\hline Mongolia & 827000 & 886000 & 736000 & 49000 & 47000 & 39000 & 29000 & 28000 \\
\hline Myanmar & 15132000 & 16111000 & 12787000 & 870000 & 807000 & 678000 & 613000 & 580000 \\
\hline Nepal & 7740000 & 9574000 & 13322000 & 814000 & 846000 & 794000 & 448000 & 484000 \\
\hline New Zealand & 1020000 & 992000 & 1048000 & 57000 & 56000 & 55000 & 42000 & 42000 \\
\hline Oman & 692000 & 875000 & 1044000 & 61000 & 66000 & 61000 & 19000 & 33000 \\
\hline Pakistan & 43722000 & 54323000 & 70105000 & 4681000 & 4869000 & 4322000 & 1806000 & 2514000 \\
\hline Papua New Guinea & 1652000 & 2028000 & 2908000 & 188000 & 195000 & 181000 & 136000 & 142000 \\
\hline Philippines & 23849000 & 27794000 & 34384000 & 2272000 & 2178000 & 1841000 & 1397000 & 1482000 \\
\hline Qatar & 179000 & 212000 & 254000 & 14000 & 14000 & 14000 & 6000 & 6000 \\
\hline Samoa & 43000 & 46000 & 49000 & 4000 & 4000 & 3000 & 2000 & 2000 \\
\hline Saudi Arabia & 6881000 & 8795000 & 10948000 & 631000 & 646000 & 594000 & 138000 & 177000 \\
\hline Singapore & 1165000 & 1058000 & 815000 & 37000 & 43000 & 37000 & 24000 & 32000 \\
\hline Solomon Islands & 134000 & 172000 & 241000 & 15000 & 16000 & 15000 & 9000 & 9000 \\
\hline Sri Lanka & 5758000 & 5714000 & 3866000 & 290000 & 273000 & 208000 & 117000 & 110000 \\
\hline Syrian Arab Republic & 5741000 & 7066000 & 8359000 & 542000 & 508000 & 451000 & 243000 & 265000 \\
\hline Thailand & 18275000 & 17830000 & 13781000 & 913000 & 838000 & 718000 & 674000 & 628000 \\
\hline Timor-Leste & 279000 & 364000 & 908000 & 52000 & 63000 & 76000 & 32000 & 39000 \\
\hline United Arab Emirates & 1050000 & 1300000 & 1540000 & 72000 & 70000 & 81000 & 32000 & 38000 \\
\hline
\end{tabular}




\begin{tabular}{l} 
Country (alphabetical ord \\
region) \\
\hline Vanuatu \\
Viet Nam \\
Yemen \\
Europe and Central Asia \\
Albania \\
Armenia \\
Austria \\
Azerbaijan \\
Belarus \\
Belgium \\
Bosnia and Herzegovina \\
Bulgaria \\
Croatia \\
Cyprus \\
Czech Republic \\
Denmark \\
Estonia \\
Finland \\
France \\
Georgia \\
Germany
\end{tabular}

\begin{tabular}{rrr}
\multicolumn{3}{l}{ Women aged 15-49 years } \\
\hline \multicolumn{3}{l}{ Projected numbers of women } \\
\hline 2010 & 2020 & $\mathbf{2 0 5 0}$ \\
\hline 59000 & 72000 & 113000 \\
25854000 & 27343000 & 25669000 \\
5652000 & 7910000 & 15256000 \\
221299000 & 206906000 & 171838000 \\
843000 & 845000 & 697000 \\
858000 & 764000 & 444000 \\
1952000 & 1696000 & 1579000 \\
2626000 & 2486000 & 1888000 \\
2517000 & 2187000 & 1287000 \\
2367000 & 2196000 & 2076000 \\
974000 & 874000 & 549000 \\
1786000 & 1558000 & 841000 \\
1057000 & 949000 & 666000 \\
231000 & 235000 & 239000 \\
2463000 & 2247000 & 1535000 \\
1243000 & 1211000 & 1105000 \\
325000 & 291000 & 218000 \\
1158000 & 1095000 & 1057000 \\
13785000 & 13179000 & 13613000 \\
1138000 & 979000 & 560000 \\
18989000 & 16599000 & 13528000
\end{tabular}

\begin{tabular}{|c|c|c|c|c|}
\hline \multicolumn{3}{|c|}{$\begin{array}{l}\text { Estimated numbers of pregnant women of } \\
\text { working age }\end{array}$} & \multicolumn{2}{|c|}{$\begin{array}{l}\text { Estimated numbers of pregnant } \\
\text { women in the labour force }\end{array}$} \\
\hline 2010 & 2020 & 2050 & 2010 & 2020 \\
\hline 7000 & 7000 & 7000 & 5000 & 6000 \\
\hline 1643000 & 1557000 & 1363000 & 1326000 & 1269000 \\
\hline 915000 & 1016000 & 1123000 & 311000 & 428000 \\
\hline 10511000 & 9726000 & 8776000 & 6773000 & 6462000 \\
\hline 52000 & 49000 & 38000 & 30000 & 28000 \\
\hline 38000 & 32000 & 23000 & 22000 & 20000 \\
\hline 77000 & 79000 & 81000 & 58000 & 61000 \\
\hline 143000 & 139000 & 107000 & 106000 & 115000 \\
\hline 89000 & 77000 & 57000 & 66000 & 58000 \\
\hline 109000 & 108000 & 104000 & 73000 & 74000 \\
\hline 34000 & 32000 & 25000 & 28000 & 27000 \\
\hline 65000 & 53000 & 39000 & 38000 & 32000 \\
\hline 41000 & 40000 & 36000 & 29000 & 28000 \\
\hline 11000 & 12000 & 13000 & 8000 & 9000 \\
\hline 92000 & 82000 & 73000 & 64000 & 59000 \\
\hline 60000 & 61000 & 57000 & 46000 & 46000 \\
\hline 14000 & 13000 & 12000 & 9000 & 9000 \\
\hline 59000 & 60000 & 57000 & 45000 & 46000 \\
\hline 742000 & 721000 & 711000 & 500000 & 488000 \\
\hline 46000 & 41000 & 29000 & 20000 & 18000 \\
\hline 674000 & 690000 & 674000 & 496000 & 513000 \\
\hline
\end{tabular}




\begin{tabular}{|c|c|c|c|c|c|c|c|c|}
\hline \multirow{3}{*}{$\begin{array}{l}\text { Country (alphabetical order by } \\
\text { region) }\end{array}$} & \multicolumn{8}{|c|}{ Women aged $15-49$ years } \\
\hline & \multicolumn{3}{|c|}{ Projected numbers of women } & \multicolumn{3}{|c|}{$\begin{array}{l}\text { Estimated numbers of pregnant women of } \\
\text { working age }\end{array}$} & \multicolumn{2}{|c|}{$\begin{array}{l}\text { Estimated numbers of pregnant } \\
\text { women in the labour force }\end{array}$} \\
\hline & 2010 & 2020 & 2050 & 2010 & 2020 & 2050 & 2010 & 2020 \\
\hline Greece & 2663000 & 2453000 & 1916000 & 102000 & 94000 & 95000 & 70000 & 69000 \\
\hline Hungary & 2380000 & 2225000 & 1568000 & 91000 & 86000 & 81000 & 55000 & 53000 \\
\hline Iceland & 75000 & 76000 & 69000 & 4000 & 4000 & 4000 & 4000 & 3000 \\
\hline Ireland & 1140000 & 1164000 & 1271000 & 68000 & 63000 & 67000 & 49000 & 48000 \\
\hline Israel & 1737000 & 1984000 & 2334000 & 136000 & 133000 & 124000 & 84000 & 84000 \\
\hline Italy & 13011000 & 11141000 & 9700000 & 516000 & 460000 & 472000 & 312000 & 290000 \\
\hline Kazakhstan & 4184000 & 3947000 & 3891000 & 302000 & 258000 & 211000 & 233000 & 205000 \\
\hline Kyrgyzstan & 1530000 & 1651000 & 1499000 & 117000 & 103000 & 80000 & 69000 & 63000 \\
\hline Latvia & 563000 & 481000 & 321000 & 21000 & 20000 & 16000 & 14000 & 14000 \\
\hline Lithuania & 872000 & 745000 & 475000 & 31000 & 30000 & 23000 & 21000 & 22000 \\
\hline Luxembourg & 122000 & 129000 & 160000 & 6000 & 7000 & 8000 & 4000 & 4000 \\
\hline Malta & 95000 & 94000 & 79000 & 4000 & 4000 & 4000 & 2000 & 3000 \\
\hline Moldova, Republic of & 1159000 & 1057000 & 539000 & 44000 & 40000 & 29000 & 33000 & 32000 \\
\hline Montenegro & 147000 & 142000 & 123000 & 8000 & 8000 & 7000 & 6000 & 6000 \\
\hline Netherlands & 3813000 & 3566000 & 3456000 & 176000 & 175000 & 177000 & 142000 & 143000 \\
\hline Norway & 1089000 & 1079000 & 1165000 & 56000 & 59000 & 61000 & 45000 & 47000 \\
\hline Poland & 9634000 & 8952000 & 5183000 & 360000 & 320000 & 242000 & 238000 & 223000 \\
\hline Portugal & 2538000 & 2374000 & 1805000 & 110000 & 99000 & 94000 & 81000 & 73000 \\
\hline Romania & 5396000 & 4916000 & 2767000 & 203000 & 170000 & 129000 & 120000 & 102000 \\
\hline Russian Federation & 36772000 & 32333000 & 21732000 & 1489000 & 1240000 & 1048000 & 1106000 & 944000 \\
\hline Serbia & 2516000 & 2392000 & 1953000 & 127000 & 117000 & 104000 & 87000 & 87000 \\
\hline
\end{tabular}




\begin{tabular}{|c|c|c|c|c|c|c|c|c|}
\hline \multirow{3}{*}{$\begin{array}{l}\text { Country (alphabetical order by } \\
\text { region) }\end{array}$} & \multicolumn{8}{|c|}{ Women aged $15-49$ years } \\
\hline & \multicolumn{3}{|c|}{ Projected numbers of women } & \multicolumn{3}{|c|}{$\begin{array}{l}\text { Estimated numbers of pregnant women of } \\
\text { working age }\end{array}$} & \multicolumn{2}{|c|}{$\begin{array}{l}\text { Estimated numbers of pregnant } \\
\text { women in the labour force }\end{array}$} \\
\hline & 2010 & 2020 & 2050 & 2010 & 2020 & 2050 & 2010 & 2020 \\
\hline Slovakia & 1407000 & 1300000 & 825000 & 53000 & 47000 & 39000 & 37000 & 35000 \\
\hline Slovenia & 466000 & 411000 & 286000 & 18000 & 16000 & 14000 & 14000 & 12000 \\
\hline Spain & 10833000 & 9661000 & 8218000 & 476000 & 408000 & 436000 & 326000 & 291000 \\
\hline Sweden & 2064000 & 1983000 & 2124000 & 105000 & 112000 & 115000 & 78000 & 84000 \\
\hline Switzerland & 1732000 & 1581000 & 1736000 & 70000 & 78000 & 89000 & 57000 & 66000 \\
\hline Tajikistan & 1901000 & 2259000 & 2716000 & 190000 & 192000 & 151000 & 98000 & 103000 \\
\hline $\begin{array}{l}\text { The former Yugoslav Republic of } \\
\text { Macedonia }\end{array}$ & 529000 & 495000 & 313000 & 22000 & 20000 & 15000 & 12000 & 11000 \\
\hline Turkey & 21099000 & 23012000 & 21661000 & 1377000 & 1308000 & 1143000 & 411000 & 383000 \\
\hline Turkmenistan & 1494000 & 1622000 & 1577000 & 110000 & 103000 & 85000 & 75000 & 74000 \\
\hline Ukraine & 11512000 & 9587000 & 5633000 & 414000 & 345000 & 255000 & 289000 & 252000 \\
\hline United Kingdom & 14456000 & 13761000 & 13937000 & 734000 & 752000 & 754000 & 550000 & 572000 \\
\hline Uzbekistan & 8058000 & 8942000 & 8924000 & 627000 & 569000 & 467000 & 413000 & 433000 \\
\hline
\end{tabular}


Table C. Children: Projected infant and child mortality, children at school and children at work,

selected ILO member States, 2003, 2004, 2005-10 and latest available year

\begin{tabular}{|c|c|c|c|c|c|c|c|c|c|c|c|c|c|c|c|c|c|c|c|}
\hline \multirow{3}{*}{$\begin{array}{l}\text { Country } \\
\text { (alphabetical } \\
\text { order by region) }\end{array}$} & \multicolumn{4}{|l|}{ Mortality } & \multicolumn{5}{|c|}{ Children at school } & \multicolumn{10}{|c|}{ Children at work (latest available year) } \\
\hline & \multirow[t]{2}{*}{$\begin{array}{l}\text { Projected } \\
\text { infant } \\
\text { mortality } \\
\text { (per 1,000 } \\
\text { live births) } \\
2005-10 \\
\\
\text { Girls and } \\
\text { boys }\end{array}$} & \multirow[t]{2}{*}{$\begin{array}{l}\text { Projected } \\
\text { child } \\
\text { mortality } \\
\text { (probability } \\
\text { of dying } \\
\text { before } \\
\text { age 5) (per } \\
1,000 \text { live } \\
\text { births) } \\
2005-10 \\
\\
\text { Girls and } \\
\text { boys }\end{array}$} & \multicolumn{2}{|c|}{$\begin{array}{l}\text { Primary education } \\
\text { net enrolment rate } \\
2003 \text { or } 2004 \text { (or } \\
\text { other year where } \\
\text { indicated) }\end{array}$} & \multicolumn{2}{|c|}{$\begin{array}{l}\text { Survival rate to } \\
\text { grade 5, } 2003 \text { or } \\
2004 \text { (or other year } \\
\text { where indicated; also } \\
\text { for girls and boys } \\
\text { combined where } \\
\text { indicated G\&B) }\end{array}$} & \multicolumn{2}{|c|}{$\begin{array}{l}\text { Lower secondary } \\
\text { education gross } \\
\text { enrolment ratio, } \\
\text { (all programmes } \\
\text { from } 10 \text { to } 13 \\
\text { years), } 2003 \text { or } \\
2004 \text { (or other year } \\
\text { where indicated; } \\
\text { also for girls and } \\
\text { boys combined } \\
\text { where indicated } \\
\text { G\&B) }\end{array}$} & \multirow{2}{*}{$\begin{array}{l}\text { Age at } \\
\text { end of } \\
\text { compul- } \\
\text {-sory } \\
\text { school- } \\
\text { ing } \\
\\
\text { Girls } \\
\text { and } \\
\text { boys }\end{array}$} & \multirow[t]{2}{*}{$\begin{array}{l}\text { Legal } \\
\text { minimum } \\
\text { age for } \\
\text { work } \\
\\
\text { Girls and } \\
\text { boys }\end{array}$} & \multicolumn{3}{|c|}{$\begin{array}{l}\text { Estimated proportion } \\
\text { of working children } \\
\text { aged 5-14 years (\%) }\end{array}$} & \multicolumn{3}{|c|}{$\begin{array}{l}\text { Estimated proportion } \\
\text { of all working children } \\
\text { who only work (\%) }\end{array}$} & \multicolumn{3}{|c|}{$\begin{array}{l}\text { Estimated proportion of } \\
\text { all working children who } \\
\text { both work and attend } \\
\text { school (\%) }\end{array}$} \\
\hline & & & Girls & Boys & Girls & Boys & Girls & Boys & & & Girls & Boys & $\begin{array}{l}\text { Total } \\
\text { girls } \\
\text { and } \\
\text { boys }\end{array}$ & Girls & Boys & $\begin{array}{l}\text { Total } \\
\text { girls } \\
\text { and } \\
\text { boys }\end{array}$ & Girls & Boys & $\begin{array}{r}\text { Total } \\
\text { girls } \\
\text { and } \\
\text { boys }\end{array}$ \\
\hline \multicolumn{20}{|l|}{ Africa } \\
\hline Burkina Faso & 116 & 186 & 35 & 46 & 78 & 74 & 14 & 19 & 16 & 15 & 44.3 & 31.0 & 37.9 & 69.8 & 71.6 & 70.4 & 30.2 & 28.4 & 29.6 \\
\hline Burundi & 99 & 173 & 54 & 60 & 62 & 64 & 14 & 18 & 12 & 16 & 52.6 & 41.1 & 63.5 & 65.4 & 44.6 & 36.5 & 34.6 & 55.4 & 63.5 \\
\hline Chad & 112 & 195 & 46 & 68 & 39 & 51 & 9 & 28 & 15 & 14 & 79.8 & 75.6 & 59.9 & 68.8 & 34.0 & 40.1 & 31.2 & 66.0 & 59.9 \\
\hline Ghana & 56 & 91 & $\begin{array}{r}65 \\
(2005)\end{array}$ & $\begin{array}{r}65 \\
(2005)\end{array}$ & $\begin{array}{r}65 \\
(2005)\end{array}$ & $\begin{array}{r}62 \\
(2005)\end{array}$ & $\begin{array}{r}59 \\
(2005)\end{array}$ & $\begin{array}{r}68 \\
(2005)\end{array}$ & 15 & 15 & 24.5 & 24.0 & 24.3 & 37.6 & 37.3 & 37.4 & 62.4 & 62.7 & 62.6 \\
\hline Guinea & 97 & 147 & 58 & 69 & 76 & 87 & 21 & 43 & 16 & 16 & 66.2 & 50.0 & 99.2 & 99.4 & 98.3 & 0.8 & 0.6 & 1.7 & 99.2 \\
\hline Lesotho & 59 & 113 & 88 & 83 & 69 & 58 & 51 & 40 & - & 15 & 43.2 & 36.8 & 28.3 & 16.5 & 23.6 & 71.7 & 83.5 & 76.4 & 28.3 \\
\hline Madagascar & 71 & 118 & 89 & 89 & 58 & 56 & 25 & 25 & 16 & 15 & 40.2 & 28.4 & 91.4 & 89.8 & 86.6 & 8.6 & 100.0 & 100.0 & 100.0 \\
\hline Malawi & 103 & 167 & 98 & 93 & $\begin{array}{r}38 \\
(2002)\end{array}$ & $\begin{array}{r}50 \\
(2002)\end{array}$ & 37 & 44 & $\mathrm{nc}$ & 14 & 24.9 & 21.0 & 23.0 & 20.1 & 19.5 & 20.0 & 79.9 & 80.5 & 80.0 \\
\hline Mali & 126 & 206 & 43 & 50 & 70 & 78 & 23 & 37 & 15 & 15 & 57.6 & 35.2 & 46.7 & 60.8 & 70.7 & 64.5 & 39.2 & 29.3 & 35.5 \\
\hline Namibia & 37 & 71 & 76 & 71 & 90 & 87 & 80 & 68 & 16 & 14 & 13.7 & 12.2 & 12.9 & 13.8 & 8.1 & 11.1 & 86.2 & 91.9 & 88.9 \\
\hline
\end{tabular}




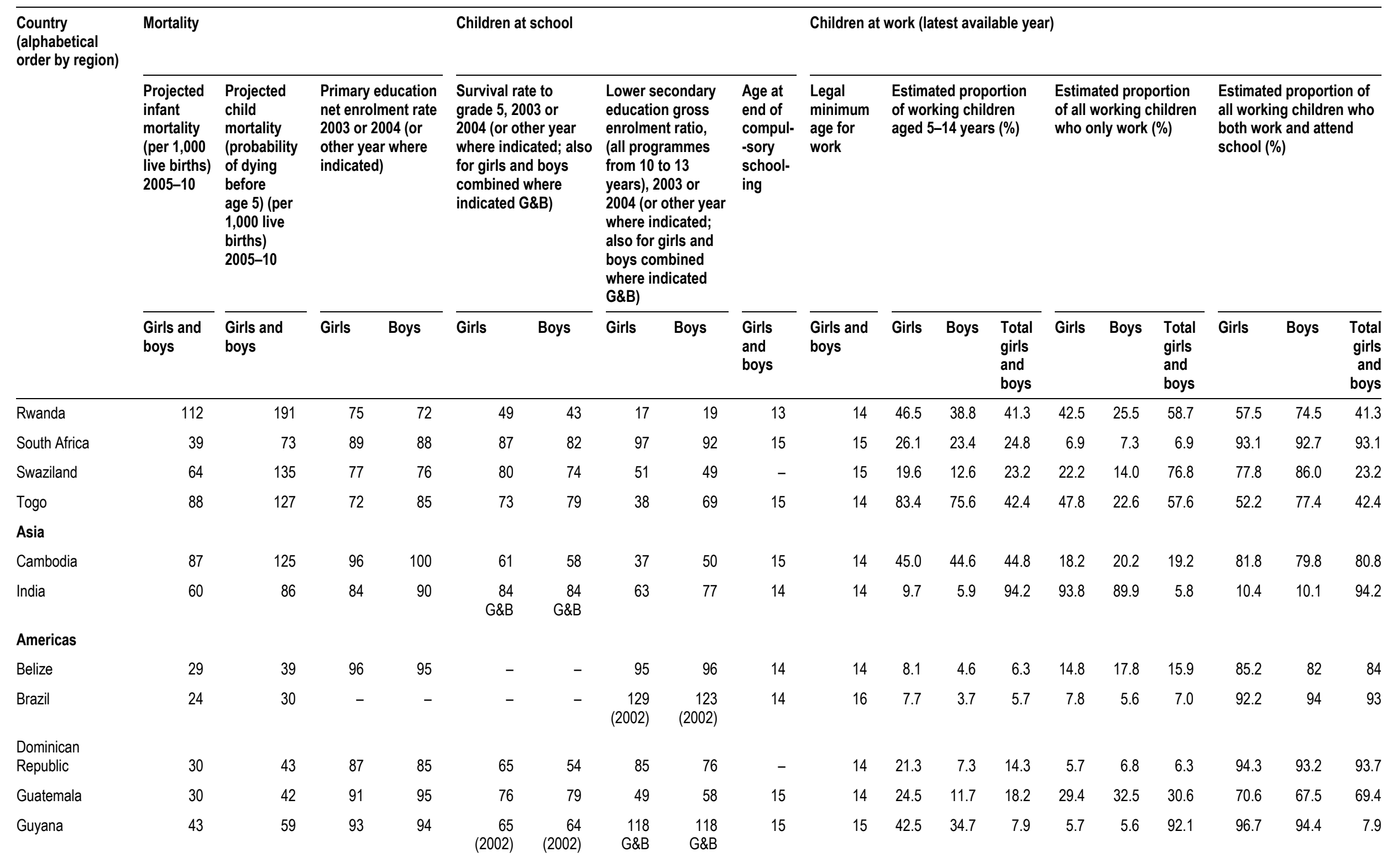




\begin{tabular}{|c|c|c|c|c|c|c|c|c|c|c|c|c|c|c|c|c|c|c|c|}
\hline \multirow{3}{*}{$\begin{array}{l}\text { Country } \\
\text { (alphabetical } \\
\text { order by region) }\end{array}$} & \multicolumn{4}{|l|}{ Mortality } & \multicolumn{5}{|c|}{ Children at school } & \multicolumn{10}{|c|}{ Children at work (latest available year) } \\
\hline & \multirow[t]{2}{*}{ 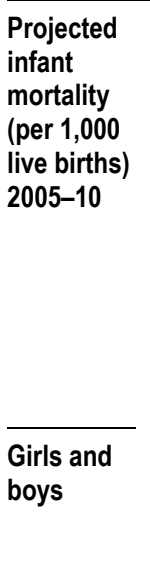 } & \multirow[t]{2}{*}{ 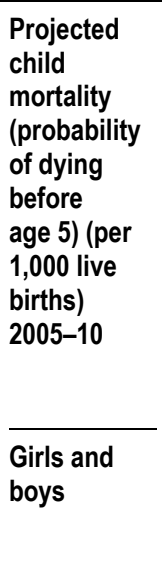 } & \multicolumn{2}{|c|}{$\begin{array}{l}\text { Primary education } \\
\text { net enrolment rate } \\
2003 \text { or } 2004 \text { (or } \\
\text { other year where } \\
\text { indicated) }\end{array}$} & \multicolumn{2}{|c|}{$\begin{array}{l}\text { Survival rate to } \\
\text { grade 5, } 2003 \text { or } \\
2004 \text { (or other year } \\
\text { where indicated; also } \\
\text { for girls and boys } \\
\text { combined where } \\
\text { indicated G\&B) }\end{array}$} & \multicolumn{2}{|c|}{$\begin{array}{l}\text { Lower secondary } \\
\text { education gross } \\
\text { enrolment ratio, } \\
\text { (all programmes } \\
\text { from } 10 \text { to } 13 \\
\text { years), } 2003 \text { or } \\
2004 \text { (or other year } \\
\text { where indicated; } \\
\text { also for girls and } \\
\text { boys combined } \\
\text { where indicated } \\
\text { G\&B) }\end{array}$} & \multirow{2}{*}{$\begin{array}{l}\text { Age at } \\
\text { end of } \\
\text { compul- } \\
\text {-sory } \\
\text { school- } \\
\text { ing } \\
\\
\text { Girls } \\
\text { and } \\
\text { boys }\end{array}$} & \multirow[t]{2}{*}{$\begin{array}{l}\text { Legal } \\
\text { minimum } \\
\text { age for } \\
\text { work } \\
\\
\text { Girls and } \\
\text { boys }\end{array}$} & \multicolumn{3}{|c|}{$\begin{array}{l}\text { Estimated proportion } \\
\text { of working children } \\
\text { aged 5-14 years (\%) }\end{array}$} & \multicolumn{3}{|c|}{$\begin{array}{l}\text { Estimated proportion } \\
\text { of all working children } \\
\text { who only work (\%) }\end{array}$} & \multicolumn{3}{|c|}{$\begin{array}{l}\text { Estimated proportion of } \\
\text { all working children who } \\
\text { both work and attend } \\
\text { school (\%) }\end{array}$} \\
\hline & & & Girls & Boys & Girls & Boys & Girls & Boys & & & Girls & Boys & $\begin{array}{l}\text { Total } \\
\text { girls } \\
\text { and } \\
\text { boys }\end{array}$ & Girls & Boys & $\begin{array}{l}\text { Total } \\
\text { girls } \\
\text { and } \\
\text { boys }\end{array}$ & Girls & Boys & $\begin{array}{r}\text { Total } \\
\text { girls } \\
\text { and } \\
\text { boys }\end{array}$ \\
\hline Honduras & 28 & 43 & 92 & 90 & - & - & 64 & 56 & 13 & 14 & 13.3 & 5.0 & 9.2 & 45.9 & 30.0 & 41.3 & 54.1 & 70.0 & $\overline{58.7}$ \\
\hline $\begin{array}{l}\text { Trinidad and } \\
\text { Tobago }\end{array}$ & - & 18 & 92 & 92 & $\begin{array}{r}100 \\
G \& B\end{array}$ & $\begin{array}{r}100 \\
\text { G\&B }\end{array}$ & 86 & 83 & 12 & 16 & 5.4 & 5.8 & 21.5 & 0.0 & 21.2 & 87.2 & 100.0 & 78.8 & 12.8 \\
\hline \multicolumn{20}{|l|}{ Europe } \\
\hline Ukraine & 15 & 17 & 82 & 82 & - & - & 93 & 94 & 15 & 16 & 3.1 & 1.8 & 2.4 & 2.8 & 1.5 & 2.3 & 97.2 & 98.5 & 97.7 \\
\hline \multicolumn{20}{|c|}{$-=$ No information. $n c=$ Schooling is not compulsory. G\&B $=$ Girls and boys. } \\
\hline \multicolumn{20}{|c|}{$\begin{array}{l}\text { The data on estimated proportions of children working are presented for all countries in which ILO-IPEC and its Statistical Information and Monitoring Programme on Child Labour (SIMPOC) have conducted surveys and } \\
\text { assessments. In addition, data are presented for the countries where other surveys have produced similar data - notably the World Bank's living standard measurement surveys and UNICEF's multiple indicator cluster surveys. } \\
\text { Because of the differences in the underlying survey instruments and in survey dates, estimates of working children are not fully comparable across countries. Caution should be exercised in drawing conclusions concerning } \\
\text { relative levels of child economic activity across countries or regions based on the published data. }\end{array}$} \\
\hline
\end{tabular}


Table D. Youth: Population, ages at marriage, end of compulsory schooling and admission to employment, activity rates,

literacy and enrolment, women and men, 15-24 years, selected ILO member States, latest available year circa 2005

\begin{tabular}{|c|c|c|c|c|c|c|c|c|c|c|c|c|c|}
\hline \multirow{3}{*}{$\begin{array}{l}\text { Country } \\
\text { (alphabetical } \\
\text { order by region) }\end{array}$} & \multirow{2}{*}{\multicolumn{2}{|c|}{$\begin{array}{l}\text { Estimated } \\
\text { population } \\
\text { aged 15-24 years } \\
\text { ('000s) } 2005\end{array}$}} & \multicolumn{5}{|c|}{ Landmark ages } & \multicolumn{4}{|c|}{ Youth activity rates } & \multirow{2}{*}{\multicolumn{2}{|c|}{ Youth literacy rate (\%) }} \\
\hline & & & \multirow{2}{*}{$\begin{array}{l}\text { Average age } \\
\text { at marriage } \\
\text { (singulate } \\
\text { mean age) } \\
\text { Female }\end{array}$} & \multirow{2}{*}{$\begin{array}{l}\text { Age at end } \\
\text { of compul- } \\
\text { sory } \\
\text { schooling }\end{array}$} & \multicolumn{2}{|c|}{$\begin{array}{l}\text { Minimum age at } \\
\text { marriage }\end{array}$} & \multirow{2}{*}{$\begin{array}{l}\text { Legal } \\
\text { minimum } \\
\text { age for } \\
\text { work } \\
\begin{array}{l}\text { Female } \\
\text { and male }\end{array}\end{array}$} & \multicolumn{2}{|c|}{$\begin{array}{l}\text { Estimated proportion of } \\
\text { youth aged } 15-19 \text { years } \\
\text { who are economically } \\
\text { active (activity rate \%) } \\
2006\end{array}$} & \multicolumn{2}{|c|}{$\begin{array}{l}\text { Estimated proportion of } \\
\text { youth aged } 20-24 \text { years } \\
\text { who are economically } \\
\text { active (activity rate \%) } \\
2006\end{array}$} & & \\
\hline & Female & Male & & & Female & Male & & Female & Male & Female & Male & Female & Male \\
\hline \multicolumn{14}{|l|}{ Africa } \\
\hline Angola & 1618 & 1598 & 19.4 & 14 & 18 & 18 & 14 & 69.9 & 82.9 & 75.2 & 89.8 & 63 & 84 \\
\hline Benin & 852 & 881 & 19.9 & 12 & 16 & 18 & 14 & 42.8 & 63.4 & 51.5 & 83.2 & 33 & 59 \\
\hline Botswana & 214 & 217 & 26.9 & - & 14 & 16 & 14 & 15.4 & 15.9 & 50.7 & 65.0 & 96 & 92 \\
\hline Burkina Faso & 1346 & 1376 & 18.9 & 16 & 19 & 20 & 15 & 71.0 & 76.8 & 75.6 & 85.9 & 25 & 38 \\
\hline Burundi & 855 & 848 & 22.5 & 12 & 18 & 18 & 16 & 83.9 & 79.9 & 94.1 & 94.8 & 70 & 77 \\
\hline Cameroon & 1745 & 1757 & 20.2 & na & 15 & 18 & 14 & 34.1 & 38.9 & 53.7 & 84.6 & - & - \\
\hline $\begin{array}{l}\text { Central African } \\
\text { Republic }\end{array}$ & 430 & 419 & 19.7 & 14 & 18 & 18 & 14 & 60.8 & 67.4 & 65.9 & 89.4 & 47 & 70 \\
\hline Chad & 957 & 948 & 18.1 & 15 & 15 & 18 & 14 & 53.5 & 45.7 & 62.5 & 64.5 & 23 & 56 \\
\hline Congo & 396 & 395 & 22.6 & 16 & - & - & 14 & 46.7 & 57.6 & 48.9 & 83.0 & - & - \\
\hline Côte d'Ivoire & 1990 & 1993 & 22.0 & - & 18 & 18 & 14 & 32.4 & 59.8 & 39.2 & 94.3 & 52 & 71 \\
\hline \multicolumn{14}{|l|}{$\begin{array}{l}\text { Democratic } \\
\text { Republic of the }\end{array}$} \\
\hline Congo & 5741 & 5741 & 20.0 & 15 & 15 & 14 & 14 & 55.7 & 72.5 & 69.0 & 93.1 & 63 & 78 \\
\hline Djibouti & 80 & 81 & - & - & - & - & 16 & 34.3 & 48.6 & 54.7 & 85.1 & - & - \\
\hline Equatorial Guinea & 49 & 49 & 21.7 & 12 & - & - & 14 & 48.1 & 82.9 & 50.1 & 95.5 & 95 & 95 \\
\hline
\end{tabular}




\begin{tabular}{|c|c|c|c|c|c|c|c|c|c|c|c|c|c|}
\hline \multirow{3}{*}{$\begin{array}{l}\text { Country } \\
\text { (alphabetical } \\
\text { order by region) }\end{array}$} & \multirow{2}{*}{\multicolumn{2}{|c|}{$\begin{array}{l}\text { Estimated } \\
\text { population } \\
\text { aged 15-24 years } \\
\text { ('000s) 2005 }\end{array}$}} & \multicolumn{5}{|c|}{ Landmark ages } & \multicolumn{4}{|c|}{ Youth activity rates } & \multicolumn{2}{|c|}{ Youth literacy rate (\%) } \\
\hline & & & \multirow{2}{*}{$\begin{array}{l}\text { Average age } \\
\text { at marriage } \\
\text { (singulate } \\
\text { mean age) }\end{array}$} & \multirow{2}{*}{$\begin{array}{l}\begin{array}{l}\text { Age at end } \\
\text { of compul- } \\
\text { sory } \\
\text { schooling }\end{array} \\
\begin{array}{l}\text { Female } \\
\text { and male }\end{array}\end{array}$} & \multicolumn{2}{|c|}{$\begin{array}{l}\text { Minimum age at } \\
\text { marriage }\end{array}$} & \multirow{2}{*}{$\begin{array}{l}\text { Legal } \\
\text { minimum } \\
\text { age for } \\
\text { work }\end{array}$} & \multicolumn{2}{|c|}{$\begin{array}{l}\text { Estimated proportion of } \\
\text { youth aged } 15-19 \text { years } \\
\text { who are economically } \\
\text { active (activity rate \%) } \\
2006\end{array}$} & \multicolumn{2}{|c|}{$\begin{array}{l}\text { Estimated proportion of } \\
\text { youth aged } 20-24 \text { years } \\
\text { who are economically } \\
\text { active (activity rate \%) } \\
2006\end{array}$} & \multirow[b]{2}{*}{ Female } & \multirow[b]{2}{*}{ Male } \\
\hline & Female & Male & & & Female & Male & & Female & Male & Female & Male & & \\
\hline Eritrea & 456 & 451 & 19.6 & $\mathrm{nc}$ & 18 & 18 & 14 & 50.2 & 68.0 & 65.9 & 93.4 & - & - \\
\hline Ethiopia & 7818 & 7825 & 20.5 & $\mathrm{nc}$ & 15 & 18 & 14 & 68.0 & 73.2 & 77.0 & 91.3 & - & - \\
\hline Gabon & 142 & 143 & 22.1 & 16 & 15 & 18 & 16 & 48.7 & 49.9 & 61.1 & 86.7 & - & - \\
\hline Gambia & 144 & 143 & 19.6 & $\mathrm{nc}$ & - & - & 14 & 48.5 & 59.2 & 57.5 & 86.8 & - & - \\
\hline Ghana & 2322 & 2405 & 21.2 & 15 & 18 & 18 & 15 & 34.9 & 34.0 & 67.1 & 68.7 & 55 & 76 \\
\hline Guinea & 869 & 924 & 18.7 & 16 & 17 & 18 & 16 & 69.2 & 70.0 & 78.9 & 85.9 & 34 & 59 \\
\hline Guinea-Bissau & 150 & 148 & - & - & 18 & 18 & 14 & 62.1 & 78.7 & 66.8 & 92.4 & - & - \\
\hline Kenya & 3916 & 3931 & 21.7 & 14 & 16 & 18 & 16 & 56.5 & 66.8 & 66.2 & 94.0 & 81 & 80 \\
\hline Lesotho & 235 & 226 & 21.3 & - & 21 & 21 & 15 & 24.4 & 33.0 & 47.2 & 81.2 & - & - \\
\hline Liberia & 329 & 334 & 20.2 & 16 & 18 & 21 & 16 & 47.3 & 48.8 & 56.0 & 83.0 & - & - \\
\hline Madagascar & 1813 & 1814 & 20.6 & 16 & 18 & 18 & 15 & 61.6 & 58.0 & 75.5 & 81.2 & 68 & 73 \\
\hline Malawi & 1279 & 1273 & 18.9 & $\mathrm{nc}$ & 18 & 18 & 14 & 76.6 & 71.1 & 85.1 & 90.4 & 71 & 82 \\
\hline Mali & 1353 & 1393 & 18.4 & 15 & 15 & 18 & 15 & 65.5 & 68.0 & 70.9 & 79.1 & 17 & 32 \\
\hline Mozambique & 2011 & 2004 & 18.0 & $\mathrm{nc}$ & 18 & 18 & 15 & 61.7 & 42.5 & 85.0 & 83.6 & - & - \\
\hline Namibia & 213 & 216 & 26.4 & 16 & - & - & 14 & 18.0 & 19.2 & 45.7 & 55.3 & 93 & 91 \\
\hline Niger & 1307 & 1394 & 17.6 & 16 & 14 & 16 & 14 & 66.3 & 89.0 & 71.0 & 94.8 & 23 & 52 \\
\hline Nigeria & 13400 & 13915 & 21.4 & 15 & - & - & 15 & 32.0 & 62.0 & 38.2 & 82.0 & - & - \\
\hline Rwanda & 1091 & 1060 & 22.7 & 13 & 21 & 2 & 14 & 60.7 & 59.6 & 79.6 & 87.6 & 77 & 79 \\
\hline
\end{tabular}




\begin{tabular}{|c|c|c|c|c|c|c|c|c|c|c|c|c|c|}
\hline \multirow{3}{*}{$\begin{array}{l}\text { Country } \\
\text { (alphabetical } \\
\text { order by region) }\end{array}$} & \multirow{2}{*}{\multicolumn{2}{|c|}{$\begin{array}{l}\text { Estimated } \\
\text { population } \\
\text { aged 15-24 years } \\
\text { ('000s) } 2005\end{array}$}} & \multicolumn{5}{|c|}{ Landmark ages } & \multicolumn{4}{|c|}{ Youth activity rates } & \multirow{2}{*}{\multicolumn{2}{|c|}{ Youth literacy rate (\%) }} \\
\hline & & & \multirow{2}{*}{$\begin{array}{l}\text { Average age } \\
\text { at marriage } \\
\text { (singulate } \\
\text { mean age) } \\
\text { Female }\end{array}$} & \multirow{2}{*}{$\begin{array}{l}\text { Age at end } \\
\text { of compul- } \\
\text { sory } \\
\text { schooling }\end{array}$} & \multicolumn{2}{|c|}{$\begin{array}{l}\text { Minimum age at } \\
\text { marriage }\end{array}$} & \multirow{2}{*}{$\begin{array}{l}\text { Legal } \\
\text { minimum } \\
\text { age for } \\
\text { work } \\
\begin{array}{l}\text { Female } \\
\text { and male }\end{array}\end{array}$} & \multicolumn{2}{|c|}{$\begin{array}{l}\text { Estimated proportion of } \\
\text { youth aged } 15-19 \text { years } \\
\text { who are economically } \\
\text { active (activity rate \%) } \\
2006\end{array}$} & \multicolumn{2}{|c|}{$\begin{array}{l}\text { Estimated proportion of } \\
\text { youth aged } 20-24 \text { years } \\
\text { who are economically } \\
\text { active (activity rate \%) } \\
2006\end{array}$} & & \\
\hline & Female & Male & & & Female & Male & & Female & Male & Female & Male & Female & Male \\
\hline Sierra Leone & 526 & 523 & 19.8 & 15 & 18 & 18 & 12 & 57.7 & 78.0 & 65.0 & 97.4 & 37 & 59 \\
\hline South Africa & 4780 & 4844 & 27.9 & 15 & 12 & 14 & 15 & 32.2 & 34.6 & 51.3 & 80.1 & 94 & 93 \\
\hline Sudan & 3581 & 3691 & 22.7 & na & 13 & 15 & 14 & 15.8 & 29.5 & 22.0 & 63.3 & 71 & 85 \\
\hline Swaziland & 136 & 135 & 26.0 & - & 16 & 18 & 15 & 19.4 & 28.9 & 37.4 & 87.4 & 90 & 87 \\
\hline $\begin{array}{l}\text { Tanzania, United } \\
\text { Republic of }\end{array}$ & 4110 & 4126 & 20.5 & 13 & 15 & 18 & 14 & 71.4 & 70.1 & 91.1 & 92.2 & 76 & 81 \\
\hline Togo & 638 & 634 & 21.3 & 15 & 17 & 20 & 14 & 44.3 & 68.0 & 50.4 & 94.4 & 64 & 84 \\
\hline Uganda & 2924 & 2941 & 19.6 & - & 18 & 16 & 14 & 70.2 & 72.8 & 75.4 & 84.8 & 71 & 83 \\
\hline Zambia & 1280 & 1285 & 20.6 & $\mathrm{nc}$ & 21 & 21 & 15 & 65.7 & 74.6 & 75.7 & 94.1 & 66 & 73 \\
\hline Zimbabwe & 1645 & 1641 & 21.1 & - & 16 & 18 & 14 & 35.1 & 55.8 & 61.9 & 89.8 & - & - \\
\hline \multicolumn{14}{|l|}{ Americas } \\
\hline Bahamas & 29 & 28 & 27.2 & 16 & - & - & 14 & 28.7 & 37.4 & 78.6 & 70.0 & - & - \\
\hline Barbados & 20 & 21 & 31.8 & 16 & 16 & 16 & 15 & 25.5 & 38.3 & 87.1 & 90.1 & - & - \\
\hline Belize & 28 & 29 & 26.2 & 14 & 18 & 18 & 14 & 21.2 & 45.0 & 52.2 & 88.0 & - & - \\
\hline Brazil & 17473 & 17869 & 23.4 & 14 & 16 & 16 & 16 & 39.5 & 51.2 & 65.8 & 85.9 & 98 & 96 \\
\hline Dominican Republic & 903 & 933 & 21.3 & - & - & - & 14 & 21.9 & 43.1 & 53.0 & 83.8 & 95 & 93 \\
\hline Guatemala & 1299 & 1253 & 20.5 & 15 & 14 & 16 & 14 & 31.3 & 57.3 & 35.4 & 87.9 & 78 & 86 \\
\hline Guyana & 72 & 73 & 27.8 & 15 & 16 & 16 & 15 & 22.8 & 51.8 & 46.8 & 88.6 & - & - \\
\hline Haiti & 996 & 1010 & 22.3 & - & 18 & 18 & 15 & 39.4 & 51.5 & 63.6 & 82.1 & - & - \\
\hline
\end{tabular}




\begin{tabular}{|c|c|c|c|c|c|c|c|c|c|c|c|c|c|}
\hline \multirow{3}{*}{$\begin{array}{l}\text { Country } \\
\text { (alphabetical } \\
\text { order by region) }\end{array}$} & \multirow{2}{*}{\multicolumn{2}{|c|}{$\begin{array}{l}\text { Estimated } \\
\text { population } \\
\text { aged 15-24 years } \\
\text { ('000s) } 2005\end{array}$}} & \multicolumn{5}{|c|}{ Landmark ages } & \multicolumn{4}{|c|}{ Youth activity rates } & \multirow{2}{*}{\multicolumn{2}{|c|}{ Youth literacy rate (\%) }} \\
\hline & & & \multirow{2}{*}{$\begin{array}{l}\text { Average age } \\
\text { at marriage } \\
\text { (singulate } \\
\text { mean age) } \\
\text { Female }\end{array}$} & \multirow{2}{*}{$\begin{array}{l}\text { Age at end } \\
\text { of compul- } \\
\text { sory } \\
\text { schooling } \\
\text { Female } \\
\text { and male }\end{array}$} & \multicolumn{2}{|c|}{$\begin{array}{l}\text { Minimum age at } \\
\text { marriage }\end{array}$} & \multirow{2}{*}{$\begin{array}{l}\text { Legal } \\
\text { minimum } \\
\text { age for } \\
\text { work } \\
\begin{array}{l}\text { Female } \\
\text { and male }\end{array}\end{array}$} & \multicolumn{2}{|c|}{$\begin{array}{l}\text { Estimated proportion of } \\
\text { youth aged } 15-19 \text { years } \\
\text { who are economically } \\
\text { active (activity rate \%) } \\
2006\end{array}$} & \multicolumn{2}{|c|}{$\begin{array}{l}\text { Estimated proportion of } \\
\text { youth aged } 20-24 \text { years } \\
\text { who are economically } \\
\text { active (activity rate \%) } \\
2006\end{array}$} & & \\
\hline & Female & Male & & & Female & Male & & Female & Male & Female & Male & Female & Male \\
\hline Honduras & 744 & 769 & 20.4 & 13 & 16 & 18 & 14 & 37.6 & 70.8 & 58.5 & 92.0 & 91 & 87 \\
\hline Jamaica & 251 & 252 & 33.2 & 14 & 18 & 18 & 15 & 11.9 & 18.4 & 59.1 & 79.6 & - & - \\
\hline Suriname & 44 & 45 & 18.6 & 12 & 15 & 18 & 14 & 4.7 & 19.8 & 23.4 & 61.0 & 94 & 96 \\
\hline \multicolumn{14}{|l|}{ Trinidad and } \\
\hline United States & 20737 & 21721 & 26.3 & $16^{1}$ & - & - & 16 & 46.3 & 45.5 & 73.0 & 79.7 & - & - \\
\hline \multicolumn{14}{|l|}{ Asia } \\
\hline Cambodia & 1689 & 1716 & 22.5 & 15 & 18 & 20 & 14 & 58.7 & 40.4 & 80.9 & 85.3 & 79 & 88 \\
\hline China & 103792 & 113557 & 23.3 & 15 & - & - & 16 & 55.8 & 48.8 & 85.8 & 89.7 & 99 & 99 \\
\hline India & 102078 & 109176 & 19.9 & 14 & 18 & 21 & 14 & 22.4 & 42.4 & 30.6 & 82.3 & 68 & 84 \\
\hline Myanmar & 4929 & 5005 & 24.5 & - & - & - & 15 & 52.4 & 53.9 & 59.7 & 87.5 & 93 & 96 \\
\hline Thailand & 5411 & 5483 & 23.5 & 16 & 17 & 17 & 15 & 18.5 & 33.0 & 64.1 & 77.2 & 98 & 98 \\
\hline \multicolumn{14}{|l|}{ Europe } \\
\hline Russian Federation & 11997 & 12306 & 21.8 & 15 & 16 & 16 & 16 & 11.1 & 16.2 & 57.0 & 67.4 & 100 & 100 \\
\hline Ukraine & 3628 & 3703 & 21.7 & 15 & 17 & 18 & 16 & 10.9 & 12.5 & 57.4 & 72.3 & 100 & 100 \\
\hline \multicolumn{14}{|c|}{$\begin{array}{l}\text { - = No information. na = Not applicable. } \mathrm{nc}=\text { Schooling is not compulsory. } \\
{ }^{1} \text { In most States. }\end{array}$} \\
\hline Source: ILO. & & & & & & & & & & & & & \\
\hline
\end{tabular}


Table E. Number of persons in the armed forces as a proportion of the estimated male population aged 17.5-29 years, ILO member States with data and regional summaries, 2005-07

\begin{tabular}{lll}
\hline $\begin{array}{l}\text { Country (alphabetical order } \\
\text { by region) }\end{array}$ & $\begin{array}{l}\text { Number of } \\
\text { persons in } \\
\text { the armed } \\
\text { forces }\end{array}$ & $\begin{array}{l}\text { Number of men } \\
\text { aged 17.5-29 years } \\
\text { ('000s), 2005 }\end{array}$ \\
& ('000s), 2007 & \\
\hline
\end{tabular}
Number of persons in the armed forces as a proportion of the estimated male population aged $17.5-29$ years (\%), 2005

\begin{tabular}{|c|c|c|c|}
\hline Africa & 2135 & 104257 & 2.0 \\
\hline Algeria & 138 & 4417 & 3.1 \\
\hline Angola & 107 & 1752 & 6.1 \\
\hline Benin & 5 & 962 & 0.5 \\
\hline Botswana & 9 & 249 & 3.6 \\
\hline Burkina Faso & 11 & 1610 & 0.7 \\
\hline Burundi & 35 & 897 & 3.9 \\
\hline Cameroon & 14 & 2084 & 0.7 \\
\hline Cape Verde & 1 & 62 & 1.6 \\
\hline Central African Republic & 3 & 467 & 0.6 \\
\hline Chad & 17 & 1084 & 1.6 \\
\hline Congo & 10 & 418 & 2.4 \\
\hline Côte d'Ivoire & 17 & 2203 & 0.8 \\
\hline $\begin{array}{l}\text { Democratic Republic of the } \\
\text { Congo }\end{array}$ & 51 & 6369 & 0.8 \\
\hline Djibouti & 11 & 96 & 11.5 \\
\hline Egypt & 469 & 8714 & 5.4 \\
\hline Equatorial Guinea & 1 & 51 & 2.0 \\
\hline Eritrea & 202 & 585 & 34.5 \\
\hline Ethiopia & 153 & 8642 & 1.8 \\
\hline Gabon & 5 & 151 & 3.3 \\
\hline Gambia & 1 & 171 & 0.6 \\
\hline Ghana & 14 & 2702 & 0.5 \\
\hline Guinea & 12 & 993 & 1.2 \\
\hline Guinea-Bissau & 9 & 163 & 5.5 \\
\hline Kenya & 24 & 4397 & 0.5 \\
\hline Lesotho & 2 & 243 & 0.8 \\
\hline Libyan Arab Jamahiriya & 76 & 810 & 9.4 \\
\hline Madagascar & 14 & 2019 & 0.7 \\
\hline Malawi & 5 & 1476 & 0.3 \\
\hline Mali & 7 & 1276 & 0.5 \\
\hline Mauritania & 16 & 347 & 4.6 \\
\hline Mauritius & 0 & 132 & 0.0 \\
\hline Morocco & 201 & 3607 & 5.6 \\
\hline Mozambique & 11 & 2222 & 0.5 \\
\hline Namibia & 9 & 243 & 3.7 \\
\hline
\end{tabular}


Country (alphabetical order by region)
Number of persons in the armed forces ('000s), 2007
Number of men aged 17.5-29 years ('000s), 2005
Number of persons in the armed forces as a proportion of the estimated male population aged $17.5-29$ years $(\%)$, 2005

\begin{tabular}{|c|c|c|c|}
\hline Niger & 5 & 1185 & 0.4 \\
\hline Nigeria & 85 & 15740 & 0.5 \\
\hline Rwanda & 33 & 1121 & 2.9 \\
\hline Senegal & 14 & 1333 & 1.1 \\
\hline Sierra Leone & 11 & 583 & 1.9 \\
\hline South Africa & 62 & 5712 & 1.1 \\
\hline Sudan & 105 & 4243 & 2.5 \\
\hline Tanzania, United Republic of & 27 & 4390 & 0.6 \\
\hline Togo & 9 & 706 & 1.3 \\
\hline Tunisia & 35 & 1286 & 2.7 \\
\hline Uganda & 45 & 3185 & 1.4 \\
\hline Zambia & 15 & 1356 & 1.1 \\
\hline Zimbabwe & 29 & 1809 & 1.6 \\
\hline Americas & 2896 & 89465 & 3.2 \\
\hline Argentina & 72 & 4131 & 1.7 \\
\hline Bahamas & 1 & 34 & 3.0 \\
\hline Barbados & 1 & 27 & 3.8 \\
\hline Belize & 1 & 33 & 3.0 \\
\hline Bolivia & 46 & 1014 & 4.5 \\
\hline Brazil & 288 & 21542 & 1.3 \\
\hline Canada & 63 & 2776 & 2.3 \\
\hline Chile & 76 & 1632 & 4.7 \\
\hline Colombia & 209 & 5021 & 4.2 \\
\hline Costa Rica & 0 & 510 & 0.0 \\
\hline Cuba & 49 & 970 & 5.1 \\
\hline Dominican Republic & 25 & 1029 & 2.4 \\
\hline Ecuador & 57 & 1472 & 3.9 \\
\hline El Salvador & 16 & 785 & 2.0 \\
\hline Guatemala & 16 & 1360 & 1.2 \\
\hline Guyana & 1 & 75 & 1.3 \\
\hline Honduras & 12 & 795 & 1.5 \\
\hline Jamaica & 3 & 276 & 1.1 \\
\hline Mexico & 238 & 10973 & 2.2 \\
\hline Nicaragua & 14 & 659 & 2.1 \\
\hline Panama & 0 & 352 & 0.0 \\
\hline Paraguay & 10 & 693 & 1.4 \\
\hline Peru & 80 & 3174 & 2.5 \\
\hline Suriname & 2 & 50 & 4.0 \\
\hline
\end{tabular}




\begin{tabular}{|c|c|c|c|}
\hline $\begin{array}{l}\text { Country (alphabetical order } \\
\text { by region) }\end{array}$ & $\begin{array}{l}\text { Number of } \\
\text { persons in } \\
\text { the armed } \\
\text { forces } \\
\text { ('000s), } 2007\end{array}$ & $\begin{array}{l}\text { Number of men } \\
\text { aged } 17.5-29 \text { years } \\
\text { ('000s), } 2005\end{array}$ & $\begin{array}{l}\text { Number of persons in the } \\
\text { armed forces as a } \\
\text { proportion of the estimated } \\
\text { male population } \\
\text { aged } 17.5-29 \text { years }(\%) \text {, } \\
2005\end{array}$ \\
\hline Trinidad and Tobago & 3 & 167 & 1.8 \\
\hline United States & 1506 & 26527 & 5.7 \\
\hline Uruguay & 25 & 313 & 8.0 \\
\hline Venezuela, Bolivarian Rep. of & 82 & 3073 & 2.7 \\
\hline Asia and the Pacific & 8879 & 411896 & 2.2 \\
\hline Australia & 52 & 1770 & 2.9 \\
\hline Bahrain & 11 & 91 & 12.0 \\
\hline Bangladesh & 127 & 18359 & 0.7 \\
\hline Brunei Darussalam & 7 & 45 & 15.5 \\
\hline Cambodia & 124 & 1666 & 7.4 \\
\hline China & 2255 & 132345 & 1.7 \\
\hline Fiji & 4 & 98 & 4.1 \\
\hline India & 1316 & 133319 & 1.0 \\
\hline Indonesia & 302 & 26403 & 1.1 \\
\hline Iran, Islamic Republic of & 545 & 10104 & 5.4 \\
\hline Japan & 240 & 9949 & 2.4 \\
\hline Jordan & 101 & 676 & 14.9 \\
\hline Korea, Republic of & 687 & 4706 & 14.6 \\
\hline Kuwait & 16 & 395 & 4.1 \\
\hline $\begin{array}{l}\text { Lao People's Democratic } \\
\text { Republic }\end{array}$ & 29 & 663 & 4.4 \\
\hline Lebanon & 72 & 433 & 16.6 \\
\hline Malaysia & 109 & 2904 & 3.8 \\
\hline Mongolia & 9 & 340 & 2.6 \\
\hline Myanmar & 375 & 5703 & 6.6 \\
\hline Nepal & 69 & 3096 & 2.2 \\
\hline New Zealand & 9 & 352 & 2.6 \\
\hline Oman & 42 & 357 & 11.8 \\
\hline Pakistan & 619 & 19356 & 3.2 \\
\hline Papua New Guinea & 3 & 682 & 0.4 \\
\hline Philippines & 106 & 9894 & 1.1 \\
\hline Qatar & 12 & 121 & 9.9 \\
\hline Saudi Arabia & 225 & 3032 & 7.4 \\
\hline Singapore & 73 & 346 & 21.1 \\
\hline Sri Lanka & 151 & 2094 & 7.2 \\
\hline Syrian Arab Republic & 308 & 2541 & 12.1 \\
\hline Thailand & 307 & 6371 & 4.8 \\
\hline Timor-Leste & 1 & 114 & 0.9 \\
\hline United Arab Emirates & 51 & 791 & 6.5 \\
\hline
\end{tabular}


Country (alphabetical order by region)
Number of persons in the armed

forces

('000s), 2007
Number of men aged 17.5-29 years ('000s), 2005
Number of persons in the armed forces as a proportion of the estimated male population aged $17.5-29$ years $(\%)$, 2005

\begin{tabular}{|c|c|c|c|}
\hline Viet Nam & 455 & 10289 & 4.4 \\
\hline Yemen & 67 & 2488 & 2.7 \\
\hline Europe and Central Asia & 4169 & 81954 & 5.1 \\
\hline Albania & 11 & 320 & 3.4 \\
\hline Armenia & 44 & 317 & 13.9 \\
\hline Austria & 40 & 645 & 6.2 \\
\hline Azerbaijan & 67 & 937 & 7.2 \\
\hline Belarus & 73 & 982 & 7.4 \\
\hline Belgium & 40 & 807 & 5.0 \\
\hline Bosnia and Herzegovina & 12 & 358 & 3.3 \\
\hline Bulgaria & 51 & 708 & 7.2 \\
\hline Croatia & 21 & 395 & 5.3 \\
\hline Cyprus & 10 & 80 & 12.5 \\
\hline Czech Republic & 25 & 967 & 2.6 \\
\hline Denmark & 22 & 395 & 5.6 \\
\hline Estonia & 4 & 128 & 3.1 \\
\hline Finland & 29 & 422 & 6.9 \\
\hline France & 255 & 4909 & 5.2 \\
\hline Georgia & 11 & 427 & 2.6 \\
\hline Germany & 246 & 6105 & 4.0 \\
\hline Greece & 147 & 993 & 14.8 \\
\hline Hungary & 32 & 930 & 3.4 \\
\hline Iceland & 0 & 27 & 0.0 \\
\hline Ireland & 10 & 427 & 2.3 \\
\hline Israel & 168 & 679 & 24.7 \\
\hline Italy & 191 & 4249 & 4.5 \\
\hline Kazakhstan & 66 & 1717 & 3.8 \\
\hline Kyrgyzstan & 13 & 620 & 2.1 \\
\hline Latvia & 5 & 217 & 2.3 \\
\hline Lithuania & 12 & 314 & 3.8 \\
\hline Luxembourg & 1 & 35 & 2.8 \\
\hline Malta & 2 & 39 & 5.1 \\
\hline Moldova, Republic of & 7 & 429 & 1.6 \\
\hline Netherlands & 53 & 1234 & 4.3 \\
\hline Norway & 23 & 359 & 6.4 \\
\hline Poland & 142 & 3997 & 3.6 \\
\hline Portugal & 44 & 940 & 4.7 \\
\hline Romania & 70 & 2189 & 3.2 \\
\hline
\end{tabular}




\begin{tabular}{|c|c|c|c|}
\hline $\begin{array}{l}\text { Country (alphabetical order } \\
\text { by region) }\end{array}$ & $\begin{array}{l}\text { Number of } \\
\text { persons in } \\
\text { the armed } \\
\text { forces } \\
\text { ('000s), } 2007\end{array}$ & $\begin{array}{l}\text { Number of men } \\
\text { aged } 17.5-29 \text { years } \\
\text { ('000s), } 2005\end{array}$ & $\begin{array}{l}\text { Number of persons in the } \\
\text { armed forces as a } \\
\text { proportion of the estimated } \\
\text { male population } \\
\text { aged } 17.5-29 \text { years (\%), } \\
2005\end{array}$ \\
\hline Russian Federation & 1027 & 14859 & 6.9 \\
\hline Slovakia & 15 & 571 & 2.6 \\
\hline Slovenia & 7 & 182 & 3.8 \\
\hline Spain & 147 & 3979 & 3.7 \\
\hline Sweden & 28 & 697 & 4.0 \\
\hline Switzerland & 4 & 568 & 0.7 \\
\hline Tajikistan & 8 & 753 & 1.1 \\
\hline $\begin{array}{l}\text { The former Yugoslav } \\
\text { Republic of Macedonia }\end{array}$ & 11 & 208 & 5.3 \\
\hline Turkey & 515 & 8581 & 6.0 \\
\hline Turkmenistan & 26 & 588 & 4.4 \\
\hline Ukraine & 188 & 4600 & 4.1 \\
\hline United Kingdom & 191 & 4841 & 3.9 \\
\hline Uzbekistan & 55 & 3229 & 1.7 \\
\hline
\end{tabular}


Table F1. Estimated numbers of females and males in the labour force (economically active population) and of working age, major age groups, ILO member States with data and regional summaries, 2000

\begin{tabular}{|c|c|c|c|c|c|c|c|c|c|c|c|c|}
\hline \multirow{3}{*}{$\begin{array}{l}\text { Country } \\
\text { (alphabetical order by region) }\end{array}$} & \multicolumn{6}{|c|}{ Labour force (economically active population) } & \multicolumn{6}{|c|}{ Working-age population } \\
\hline & \multicolumn{2}{|l|}{$15-24$ years } & \multicolumn{2}{|l|}{$25-39$ years } & \multicolumn{2}{|l|}{$40-64$ years } & \multicolumn{2}{|l|}{$15-24$ years } & \multicolumn{2}{|l|}{$25-39$ years } & \multicolumn{2}{|l|}{ 40-64 years } \\
\hline & Female & Male & Female & Male & Female & Male & Female & Male & Female & Male & Female & Male \\
\hline Africa & 41589000 & 58498000 & 47033000 & 72729000 & 35421000 & 55098000 & 82247000 & 83364000 & 76945000 & 75928000 & 62203000 & 58622000 \\
\hline Algeria & 886000 & 2274000 & 1415000 & 3371000 & 752000 & 2172000 & 3380000 & 3506000 & 3437000 & 3528000 & 2504000 & 2436000 \\
\hline Angola & 1011000 & 1177000 & 972000 & 1183000 & 737000 & 810000 & 1373000 & 1355000 & 1257000 & 1212000 & 939000 & 856000 \\
\hline Benin & 356000 & 542000 & 385000 & 627000 & 315000 & 460000 & 702000 & 718000 & 635000 & 652000 & 530000 & 485000 \\
\hline Botswana & 71000 & 85000 & 117000 & 153000 & 79000 & 102000 & 201000 & 202000 & 183000 & 173000 & 141000 & 120000 \\
\hline Burkina Faso & 837000 & 953000 & 812000 & 932000 & 568000 & 600000 & 1118000 & 1142000 & 971000 & 960000 & 679000 & 622000 \\
\hline Burundi & 586000 & 553000 & 512000 & 476000 & 461000 & 373000 & 663000 & 651000 & 530000 & 483000 & 483000 & 378000 \\
\hline Cameroon & 697000 & 1023000 & 876000 & 1295000 & 663000 & 974000 & 1523000 & 1530000 & 1376000 & 1352000 & 1125000 & 1047000 \\
\hline Cape Verde & 17000 & 33000 & 21000 & 40000 & 11000 & 17000 & 50000 & 49000 & 44000 & 42000 & 34000 & 20000 \\
\hline Central African Republic & 242000 & 286000 & 248000 & 316000 & 249000 & 254000 & 384000 & 372000 & 343000 & 324000 & 309000 & 262000 \\
\hline Chad & 463000 & 450000 & 492000 & 646000 & 426000 & 510000 & 792000 & 783000 & 720000 & 701000 & 576000 & 529000 \\
\hline Comoros & 38000 & 52000 & 44000 & 67000 & 31000 & 45000 & 74000 & 75000 & 68000 & 68000 & 48000 & 46000 \\
\hline Congo & 210000 & 286000 & 172000 & 300000 & 155000 & 208000 & 340000 & 338000 & 305000 & 302000 & 234000 & 213000 \\
\hline Côte d'Ivoire & 634000 & 1321000 & 613000 & 1513000 & 505000 & 1317000 & 1747000 & 1759000 & 1415000 & 1531000 & 1162000 & 1376000 \\
\hline Democratic Republic of the Congo & 3051000 & 4055000 & 2835000 & 4216000 & 2109000 & 3009000 & 4975000 & 4975000 & 4365000 & 4313000 & 3415000 & 3100000 \\
\hline Djibouti & 32000 & 47000 & 45000 & 67000 & 33000 & 49000 & 70000 & 71000 & 70000 & 71000 & 55000 & 52000 \\
\hline Egypt & 1314000 & 3110000 & 1853000 & 6210000 & 1129000 & 6002000 & 6873000 & 7105000 & 6641000 & 6551000 & 6479000 & 6474000 \\
\hline Equatorial Guinea & 20000 & 37000 & 20000 & 38000 & 21000 & 33000 & 42000 & 42000 & 40000 & 39000 & 37000 & 34000 \\
\hline
\end{tabular}




\begin{tabular}{|c|c|c|c|c|c|c|c|c|c|c|c|c|}
\hline \multirow{3}{*}{$\begin{array}{l}\text { Country } \\
\text { (alphabetical order by region) }\end{array}$} & \multicolumn{6}{|c|}{ Labour force (economically active population) } & \multicolumn{6}{|c|}{ Working-age population } \\
\hline & \multicolumn{2}{|l|}{$15-24$ years } & \multicolumn{2}{|l|}{$25-39$ years } & \multicolumn{2}{|l|}{$40-64$ years } & \multicolumn{2}{|l|}{ 15-24 years } & \multicolumn{2}{|l|}{$25-39$ years } & \multicolumn{2}{|l|}{ 40-64 years } \\
\hline & Female & Male & Female & Male & Female & Male & Female & Male & Female & Male & Female & Male \\
\hline Ethiopia & 4898000 & 5571000 & 5038000 & 6034000 & 3328000 & 4426000 & 6682000 & 6678000 & 6278000 & 6162000 & 4932000 & 4644000 \\
\hline Gabon & 72000 & 85000 & 86000 & 115000 & 63000 & 86000 & 128000 & 126000 & 121000 & 118000 & 94000 & 93000 \\
\hline Ghana & 1091000 & 1107000 & 1618000 & 1738000 & 1306000 & 1398000 & 2023000 & 2087000 & 1899000 & 1929000 & 1541000 & 1520000 \\
\hline Guinea & 571000 & 652000 & 676000 & 775000 & 550000 & 618000 & 768000 & 817000 & 757000 & 806000 & 643000 & 652000 \\
\hline Guinea-Bissau & 81000 & 106000 & 79000 & 116000 & 59000 & 88000 & 128000 & 127000 & 123000 & 118000 & 97000 & 90000 \\
\hline Kenya & 2136000 & 2742000 & 2211000 & 2778000 & 1542000 & 1749000 & 3408000 & 3423000 & 2845000 & 2828000 & 1963000 & 1830000 \\
\hline Lesotho & 87000 & 125000 & 104000 & 107000 & 92000 & 99000 & 216000 & 205000 & 168000 & 112000 & 163000 & 110000 \\
\hline Malawi & 924000 & 926000 & 936000 & 938000 & 699000 & 698000 & 1166000 & 1160000 & 1044000 & 964000 & 788000 & 728000 \\
\hline Mali & 827000 & 973000 & 781000 & 916000 & 573000 & 591000 & 1175000 & 1205000 & 986000 & 949000 & 744000 & 625000 \\
\hline Mauritania & 123000 & 178000 & 164000 & 238000 & 122000 & 171000 & 259000 & 259000 & 258000 & 247000 & 205000 & 183000 \\
\hline Mauritius & 38000 & 69000 & 77000 & 146000 & 64000 & 128000 & 106000 & 108000 & 146000 & 151000 & 151000 & 146000 \\
\hline Morocco & 782000 & 2108000 & 1130000 & 3110000 & 722000 & 2347000 & 3084000 & 3181000 & 3343000 & 3301000 & 2750000 & 2505000 \\
\hline Mozambique & 1377000 & 1150000 & 1693000 & 1435000 & 1269000 & 1161000 & 1811000 & 1731000 & 1849000 & 1473000 & 1373000 & 1185000 \\
\hline Namibia & 60000 & 69000 & 127000 & 160000 & 74000 & 100000 & 181000 & 183000 & 189000 & 185000 & 142000 & 126000 \\
\hline Niger & 758000 & 1083000 & 747000 & 1045000 & 560000 & 688000 & 1106000 & 1180000 & 999000 & 1060000 & 726000 & 705000 \\
\hline Nigeria & 4207000 & 8596000 & 5071000 & 9998000 & 5266000 & 7757000 & 11506000 & 11877000 & 10373000 & 10481000 & 8522000 & 8112000 \\
\hline
\end{tabular}




\begin{tabular}{|c|c|c|c|c|c|c|c|c|c|c|c|c|}
\hline \multirow{3}{*}{$\begin{array}{l}\text { Country } \\
\text { (alphabetical order by region) }\end{array}$} & \multicolumn{6}{|c|}{ Labour force (economically active population) } & \multicolumn{6}{|c|}{ Working-age population } \\
\hline & \multicolumn{2}{|l|}{$15-24$ years } & \multicolumn{2}{|l|}{$25-39$ years } & \multicolumn{2}{|l|}{$40-64$ years } & \multicolumn{2}{|l|}{$15-24$ years } & \multicolumn{2}{|l|}{$25-39$ years } & \multicolumn{2}{|l|}{$40-64$ years } \\
\hline & Female & Male & Female & Male & Female & Male & Female & Male & Female & Male & Female & Male \\
\hline Rwanda & 665000 & 643000 & 677000 & 607000 & 476000 & 432000 & 875000 & 836000 & 727000 & 627000 & 527000 & 457000 \\
\hline Sao Tome and Principe & 3000 & 10000 & 6000 & 12000 & 3000 & 7000 & 17000 & 17000 & 12000 & 12000 & 9000 & 8000 \\
\hline Senegal & 584000 & 784000 & 620000 & 885000 & 486000 & 579000 & 1057000 & 1062000 & 973000 & 915000 & 765000 & 625000 \\
\hline Sierra Leone & 260000 & 354000 & 257000 & 420000 & 208000 & 355000 & 414000 & 411000 & 434000 & 422000 & 391000 & 361000 \\
\hline Somalia & 468000 & 620000 & 413000 & 665000 & 282000 & 469000 & 703000 & 699000 & 687000 & 669000 & 510000 & 475000 \\
\hline South Africa & 2044000 & 2719000 & 3318000 & 4997000 & 2121000 & 3908000 & 4605000 & 4620000 & 5383000 & 5179000 & 4624000 & 4252000 \\
\hline Sudan & 612000 & 1604000 & 906000 & 2805000 & 698000 & 2164000 & 3304000 & 3403000 & 3284000 & 3313000 & 2633000 & 2546000 \\
\hline Swaziland & 35000 & 63000 & 44000 & 73000 & 24000 & 57000 & 116000 & 111000 & 97000 & 75000 & 78000 & 66000 \\
\hline Tanzania, United Republic of & 2953000 & 2959000 & 2976000 & 3076000 & 2382000 & 2295000 & 3575000 & 3583000 & 3151000 & 3141000 & 2588000 & 2365000 \\
\hline Togo & 272000 & 443000 & 274000 & 471000 & 213000 & 346000 & 547000 & 543000 & 493000 & 479000 & 388000 & 360000 \\
\hline Tunisia & 281000 & 511000 & 378000 & 1068000 & 176000 & 808000 & 971000 & 1017000 & 1132000 & 1122000 & 946000 & 929000 \\
\hline Uganda & 1802000 & 2009000 & 1656000 & 1852000 & 1241000 & 1207000 & 2454000 & 2467000 & 1917000 & 1938000 & 1395000 & 1274000 \\
\hline Zambia & 789000 & 934000 & 675000 & 923000 & 401000 & 619000 & 1112000 & 1116000 & 915000 & 935000 & 698000 & 646000 \\
\hline Zimbabwe & 709000 & 1013000 & 851000 & 1053000 & 709000 & 750000 & 1453000 & 1446000 & 1144000 & 1097000 & 882000 & 791000 \\
\hline Americas & 35019000 & 49495000 & 63766000 & 88609000 & 61334000 & 83481000 & 71281000 & 72860000 & 95116000 & 93489000 & $\begin{array}{r}102325 \\
000\end{array}$ & 96705000 \\
\hline Argentina & 1407000 & 2136000 & 2427000 & 3490000 & 2457000 & 3669000 & 3250000 & 3309000 & 3753000 & 3742000 & 4590000 & 4274000 \\
\hline Bahamas & 14000 & 15000 & 35000 & 32000 & 21000 & 24000 & 28000 & 27000 & 39000 & 37000 & 34000 & 31000 \\
\hline Barbados & 12000 & 14000 & 32000 & 34000 & 27000 & 29000 & 21000 & 21000 & 36000 & 36000 & 37000 & 33000 \\
\hline Belize & 9000 & 17000 & 12000 & 24000 & 7000 & 17000 & 25000 & 26000 & 25000 & 25000 & 17000 & 18000 \\
\hline Bolivia & 348000 & 485000 & 597000 & 786000 & 510000 & 640000 & 790000 & 802000 & 845000 & 825000 & 730000 & 674000 \\
\hline
\end{tabular}




\begin{tabular}{|c|c|c|c|c|c|c|c|c|c|c|c|c|}
\hline \multirow{3}{*}{$\begin{array}{l}\text { Country } \\
\text { (alphabetical order by region) }\end{array}$} & \multicolumn{6}{|c|}{ Labour force (economically active population) } & \multicolumn{6}{|c|}{ Working-age population } \\
\hline & \multicolumn{2}{|l|}{$15-24$ years } & \multicolumn{2}{|l|}{$25-39$ years } & \multicolumn{2}{|l|}{$40-64$ years } & \multicolumn{2}{|l|}{$15-24$ years } & \multicolumn{2}{|l|}{$25-39$ years } & \multicolumn{2}{|l|}{$40-64$ years } \\
\hline & Female & Male & Female & Male & Female & Male & Female & Male & Female & Male & Female & Male \\
\hline Canada & 1265000 & 1392000 & 2780000 & 3273000 & 3302000 & 3983000 & 2012000 & 2116000 & 3491000 & 3557000 & 4921000 & 4864000 \\
\hline Chile & 292000 & 515000 & 908000 & 1774000 & 790000 & 1649000 & 1231000 & 1265000 & 1874000 & 1881000 & 1927000 & 1837000 \\
\hline Costa Rica & 129000 & 259000 & 211000 & 452000 & 146000 & 359000 & 366000 & 385000 & 450000 & 471000 & 396000 & 402000 \\
\hline Cuba & 206000 & 393000 & 1051000 & 1567000 & 668000 & 1263000 & 733000 & 766000 & 1610000 & 1647000 & 1504000 & 1453000 \\
\hline Dominican Republic & 289000 & 553000 & 530000 & 938000 & 302000 & 670000 & 833000 & 860000 & 963000 & 977000 & 709000 & 723000 \\
\hline Ecuador & 568000 & 807000 & 927000 & 1313000 & 696000 & 1058000 & 1212000 & 1241000 & 1349000 & 1359000 & 1150000 & 1126000 \\
\hline El Salvador & 221000 & 441000 & 416000 & 601000 & 283000 & 445000 & 660000 & 673000 & 703000 & 641000 & 558000 & 493000 \\
\hline Honduras & 248000 & 536000 & 339000 & 626000 & 229000 & 425000 & 657000 & 676000 & 636000 & 645000 & 459000 & 447000 \\
\hline Jamaica & 94000 & 116000 & 242000 & 266000 & 168000 & 220000 & 235000 & 228000 & 309000 & 281000 & 241000 & 241000 \\
\hline Mexico & 3700000 & 6993000 & 5685000 & 10834000 & 3774000 & 7860000 & 10147000 & 10029000 & 12172000 & 11196000 & 9492000 & 8584000 \\
\hline Nicaragua & 141000 & 398000 & 216000 & 459000 & 142000 & 314000 & 537000 & 548000 & 488000 & 474000 & 348000 & 326000 \\
\hline Panama & 97000 & 178000 & 206000 & 348000 & 140000 & 266000 & 268000 & 277000 & 353000 & 357000 & 295000 & 296000 \\
\hline Paraguay & 311000 & 389000 & 395000 & 560000 & 264000 & 421000 & 531000 & 546000 & 556000 & 569000 & 450000 & 457000 \\
\hline Peru & 1122000 & 1556000 & 1960000 & 2808000 & 1333000 & 2253000 & 2540000 & 2607000 & 2862000 & 2915000 & 2428000 & 2410000 \\
\hline Saint Lucia & 7000 & 10000 & 13000 & 16000 & 8000 & 13000 & 15000 & 15000 & 18000 & 17000 & 15000 & 14000 \\
\hline Saint Vincent and the Grenadines & 6000 & 9000 & 9000 & 13000 & 5000 & 8000 & 13000 & 13000 & 13000 & 14000 & 9000 & 9000 \\
\hline
\end{tabular}




\begin{tabular}{|c|c|c|c|c|c|c|c|c|c|c|c|c|}
\hline \multirow{3}{*}{$\begin{array}{l}\text { Country } \\
\text { (alphabetical order by region) }\end{array}$} & \multicolumn{6}{|c|}{ Labour force (economically active population) } & \multicolumn{6}{|c|}{ Working-age population } \\
\hline & \multicolumn{2}{|l|}{$15-24$ years } & \multicolumn{2}{|l|}{$25-39$ years } & \multicolumn{2}{|l|}{$40-64$ years } & \multicolumn{2}{|l|}{$15-24$ years } & \multicolumn{2}{|l|}{$25-39$ years } & \multicolumn{2}{|l|}{$40-64$ years } \\
\hline & Female & Male & Female & Male & Female & Male & Female & Male & Female & Male & Female & Male \\
\hline Suriname & 6000 & 16000 & 29000 & 43000 & 17000 & 31000 & 42000 & 42000 & 51000 & 51000 & 43000 & 39000 \\
\hline Trinidad and Tobago & 55000 & 84000 & 96000 & 140000 & 76000 & 129000 & 132000 & 135000 & 152000 & 149000 & 158000 & 151000 \\
\hline United States & 11848000 & 13478000 & 23874000 & 29631000 & 30589000 & 34913000 & 19137000 & 20017000 & 31437000 & 31755000 & 43685000 & 41791000 \\
\hline Uruguay & 127000 & 194000 & 265000 & 331000 & 270000 & 350000 & 259000 & 268000 & 348000 & 345000 & 450000 & 409000 \\
\hline Venezuela, Bolivarian Republic of & 806000 & 1558000 & 1745000 & 2673000 & 1237000 & 2197000 & 2340000 & 2413000 & 2741000 & 2772000 & 2418000 & 2394000 \\
\hline Asia and the Pacific & 142742000 & 212672000 & 278174000 & 421237000 & 206463000 & 357968000 & 300668000 & 319598000 & 411506000 & 434024000 & $\begin{array}{r}376194 \\
000\end{array}$ & 391659000 \\
\hline Afghanistan & 793000 & 1738000 & 823000 & 2139000 & 591000 & 1641000 & 2146000 & 2312000 & 2018000 & 2180000 & 1614000 & 1710000 \\
\hline Australia & 873000 & 921000 & 1516000 & 1946000 & 1793000 & 2310000 & 1287000 & 1332000 & 2195000 & 2116000 & 2906000 & 2875000 \\
\hline Bahrain & 12000 & 36000 & 36000 & 134000 & 10000 & 81000 & 52000 & 61000 & 83000 & 135000 & 49000 & 85000 \\
\hline Bangladesh & 6576000 & 9729000 & 8481000 & 14235000 & 6064000 & 10543000 & 12695000 & 13457000 & 13713000 & 14580000 & 10668000 & 11057000 \\
\hline Brunei Darussalam & 11000 & 17000 & 29000 & 45000 & 11000 & 33000 & 31000 & 31000 & 47000 & 46000 & 27000 & 37000 \\
\hline Cambodia & 855000 & 723000 & 1135000 & 1175000 & 979000 & 856000 & 1244000 & 1246000 & 1329000 & 1215000 & 1208000 & 906000 \\
\hline China & 70837000 & 74316000 & 157757000 & 175901000 & 100788000 & 150421000 & 95870000 & 103085000 & 171895000 & 180106000 & $\begin{array}{r}154487 \\
000\end{array}$ & 165636000 \\
\hline Fiji & 37000 & 48000 & 52000 & 88000 & 45000 & 79000 & 81000 & 85000 & 88000 & 91000 & 85000 & 84000 \\
\hline India & 24600000 & 63800000 & 44111000 & 114981000 & 39536000 & 95654000 & 92047000 & 99063000 & 108935000 & 118584000 & 99802000 & 104200000 \\
\hline Indonesia & 8963000 & 14244000 & 14128000 & 24483000 & 12715000 & 20146000 & 20889000 & 21338000 & 25023000 & 25338000 & 22023000 & 21234000 \\
\hline Iran, Islamic Republic of & 2293000 & 4162000 & 2689000 & 6346000 & 1590000 & 4714000 & 7717000 & 8078000 & 6587000 & 6771000 & 5539000 & 5352000 \\
\hline Iraq & 428000 & 1529000 & 645000 & 2522000 & 257000 & 1423000 & 2463000 & 2562000 & 2545000 & 2628000 & 1732000 & 1733000 \\
\hline Japan & 3658000 & 3907000 & 8351000 & 13214000 & 13624000 & 20006000 & 7859000 & 8241000 & 13231000 & 13619000 & 21964000 & 21660000 \\
\hline Jordan & 110000 & 296000 & 178000 & 613000 & 66000 & 285000 & 504000 & 537000 & 532000 & 634000 & 323000 & 349000 \\
\hline
\end{tabular}




\begin{tabular}{|c|c|c|c|c|c|c|c|c|c|c|c|c|}
\hline \multirow{2}{*}{$\begin{array}{l}\text { Country } \\
\text { (alphabetical order by region) }\end{array}$} & \multicolumn{6}{|c|}{ Labour force (economically active population) } & \multicolumn{6}{|c|}{ Working-age population } \\
\hline & Female & Male & Female & Male & Female & Male & Female & Male & Female & Male & Female & Male \\
\hline Kuwait & 40000 & 77000 & 174000 & 542000 & 46000 & 283000 & 154000 & 177000 & 276000 & 546000 & 147000 & 318000 \\
\hline Lao People's Democratic Republic & 248000 & 320000 & 319000 & 482000 & 239000 & 349000 & 506000 & 518000 & 515000 & 501000 & 415000 & 383000 \\
\hline Malaysia & 858000 & 1266000 & 1423000 & 2589000 & 999000 & 2172000 & 2112000 & 2214000 & 2585000 & 2632000 & 2343000 & 2417000 \\
\hline Mongolia & 129000 & 166000 & 191000 & 293000 & 114000 & 179000 & 263000 & 267000 & 302000 & 302000 & 198000 & 193000 \\
\hline Myanmar & 2763000 & 3508000 & 4281000 & 5272000 & 3532000 & 4268000 & 4793000 & 4851000 & 5536000 & 5463000 & 4773000 & 4547000 \\
\hline epal & 1201000 & 1515000 & 1391000 & 2153000 & 1028000 & 1686000 & 2325000 & 2437000 & 2498000 & 2295000 & 2139000 & 1884000 \\
\hline New Zealand & 152000 & 169000 & 309000 & 376000 & 394000 & 474000 & 254000 & 258000 & 446000 & 411000 & 568000 & 554000 \\
\hline Philippines & 2861000 & 4622000 & 4412000 & 7936000 & 3799000 & 6045000 & 7583000 & 7842000 & 8051000 & 8169000 & 6578000 & 6443000 \\
\hline Qatar & 2000 & 19000 & 29000 & 138000 & 15000 & 114000 & 37000 & 42000 & 60000 & 142000 & 40000 & 118000 \\
\hline Samoa & 5000 & 10000 & 10000 & 19000 & 6000 & 13000 & 15000 & 18000 & 18000 & 19000 & 13000 & 14000 \\
\hline Saudi Arabia & 142000 & 969000 & 621000 & 3079000 & 145000 & 1664000 & 1888000 & 2012000 & 2184000 & 3165000 & 1293000 & 1884000 \\
\hline Singapore & 119000 & 121000 & 390000 & 524000 & 308000 & 567000 & 241000 & 259000 & 536000 & 537000 & 638000 & 644000 \\
\hline Solomon Islands & 23000 & 30000 & 25000 & 41000 & 16000 & 27000 & 43000 & 46000 & 42000 & 43000 & 29000 & 29000 \\
\hline Sri Lanka & 580000 & 1102000 & 1126000 & 2340000 & 890000 & 2108000 & 1874000 & 1927000 & 2327000 & 2455000 & 2269000 & 2487000 \\
\hline Syrian Arab Republic & 695000 & 1429000 & 672000 & 1710000 & 366000 & 1003000 & 1901000 & 1958000 & 1709000 & 1720000 & 1157000 & 1100000 \\
\hline Thailand & 2649000 & 3182000 & 6454000 & 7157000 & 5774000 & 7240000 & 5458000 & 5540000 & 7854000 & 7452000 & 8021000 & 7712000 \\
\hline
\end{tabular}




\begin{tabular}{|l|l}
\hline $\begin{array}{l}\text { Country } \\
\text { (alphabetical order by reg }\end{array}$ \\
\\
\hline Timor-Leste \\
United Arab Emirates \\
Vanuatu \\
Viet Nam \\
Yemen \\
Europe and Central Asia \\
Albania \\
Armenia \\
Austria \\
Azerbaijan \\
Belarus \\
Belgium \\
Bosnia and Herzegovina \\
Bulgaria \\
Croatia \\
Cyprus \\
Czech Republic \\
Denmark \\
Estonia \\
Finland \\
\\
\hline
\end{tabular}

\section{Labour force (economically active population)}

\begin{tabular}{|c|c|c|c|c|c|}
\hline $15-24$ years & & $25-39$ years & & 40-64 years & \\
\hline Female & Male & Female & Male & Female & Male \\
\hline
\end{tabular}

$23000 \quad 37000 \quad 29000 \quad 63000 \quad 33000 \quad 60000$

$\begin{array}{llllll}47000 & 201000 \quad 145000 \quad 936000 \quad 40000 \quad 499000\end{array}$

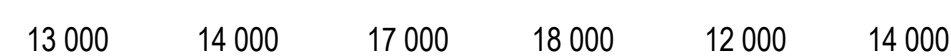

$5853000 \quad 5698000 \quad 8323000 \quad 8835000 \quad 4802000 \quad 5452000$

$\begin{array}{llllll}356000 \quad 1088000 & 591000 & 1303000 \quad 338000 & 1078000\end{array}$

$24967000 \quad 32693000 \quad 71465000 \quad 91025000 \quad 77544000 \quad 97021000$

$\begin{array}{rrrrrr}124000 & 149000 & 229000 & 285000 & 199000 & 323000 \\ 75000 & 71000 & 247000 & 261000 & 275000 & 307000 \\ 232000 & 297000 & 769000 & 948000 & 674000 & 963000 \\ 314000 & 377000 & 821000 & 885000 & 568000 & 674000 \\ 302000 & 373000 & 955000 & 973000 & 1057000 & 1072000 \\ 200000 & 246000 & 914000 & 1108000 & 780000 & 1172000 \\ 122000 & 149000 & 368000 & 423000 & 393000 & 469000 \\ 144000 & 172000 & 588000 & 678000 & 762000 & 849000 \\ 120000 & 143000 & 374000 & 431000 & 370000 & 517000 \\ 24000 & 35000 & 64000 & 79000 & 63000 & 97000 \\ 311000 & 410000 & 815000 & 1084000 & 1152000 & 1351000 \\ 207000 & 235000 & 497000 & 569000 & 622000 & 713000 \\ 34000 & 48000 & 114000 & 129000 & 164000 & 155000 \\ 163000 & 171000 & 412000 & 489000 & 658000 & 681000\end{array}$

Working-age population

\begin{tabular}{|c|c|c|c|c|c|}
\hline \multicolumn{2}{|l|}{ 15-24 years } & \multicolumn{2}{|l|}{$25-39$ years } & \multicolumn{2}{|l|}{$40-64$ years } \\
\hline Female & Male & Female & Male & Female & Male \\
\hline 55000 & 72000 & 51000 & 66000 & 62000 & 66000 \\
\hline 201000 & 309000 & 316000 & 945000 & 135000 & 507000 \\
\hline 18000 & 18000 & 20000 & 19000 & 14000 & 15000 \\
\hline 7890000 & 8029000 & 9367000 & 9204000 & 6929000 & 6678000 \\
\hline 1757000 & 1868000 & 1488000 & 1496000 & 1126000 & 1118000 \\
\hline 63799000 & 65866000 & 97223000 & 98069000 & $\begin{array}{r}134274 \\
000\end{array}$ & 125385000 \\
\hline
\end{tabular}

$268000 \quad 252000 \quad 334000 \quad 318000 \quad 365000 \quad 381000$

$277000 \quad 261000 \quad 343000 \quad 289000 \quad 444000 \quad 362000$

$\begin{array}{llllll}463000 \quad 484000 \quad 975000 & 1013000 & 1278000 & 1279000\end{array}$

$\begin{array}{llllll}736000 & 729000 & 1052000 \quad 941000 \quad 878000 \quad 806000\end{array}$

$\begin{array}{llllll}748000 & 782000 & 1100000 & 1088000 & 1648000 & 1418000\end{array}$

$611000 \quad 634000 \quad 1117000 \quad 1159000 \quad 1618000 \quad 1626000$

$276000 \quad 283000 \quad 447000 \quad 447000 \quad 651000 \quad 597000$

$559000 \quad 587000 \quad 810000 \quad 826000 \quad 1375000 \quad 1276000$

$304000 \quad 317000 \quad 463000 \quad 465000 \quad 763000 \quad 727000$

$\begin{array}{llllll}59000 \quad 62000 \quad 87000 & 82000 & 117000 & 112000\end{array}$

$765000 \quad 799000 \quad 1083000 \quad 1124000 \quad 1731000 \quad 1661000$

$\begin{array}{llllll}302000 \quad 312000 \quad 589000 \quad 612000 \quad 868000 & 879000\end{array}$

$\begin{array}{llllll}97000 \quad 101000 \quad 142000 \quad 137000 \quad 239000 & 198000\end{array}$

$\begin{array}{llllll}323000 & 337000 \quad 508000 & 529000 \quad 883000 & 884000\end{array}$ 


\begin{tabular}{|c|c|c|c|c|c|c|c|c|c|c|c|c|}
\hline \multirow{3}{*}{$\begin{array}{l}\text { Country } \\
\text { (alphabetical order by region) }\end{array}$} & \multicolumn{6}{|c|}{ Labour force (economically active population) } & \multicolumn{6}{|c|}{ Working-age population } \\
\hline & \multicolumn{2}{|l|}{$15-24$ years } & \multicolumn{2}{|l|}{$25-39$ years } & \multicolumn{2}{|l|}{$40-64$ years } & \multicolumn{2}{|l|}{$15-24$ years } & \multicolumn{2}{|l|}{$25-39$ years } & \multicolumn{2}{|l|}{$40-64$ years } \\
\hline & Female & Male & Female & Male & Female & Male & Female & Male & Female & Male & Female & Male \\
\hline France & 987000 & 1306000 & 5002000 & 5991000 & 5908000 & 7026000 & 3757000 & 3926000 & 6348000 & 6335000 & 9200000 & 8994000 \\
\hline Georgia & 102000 & 157000 & 326000 & 426000 & 505000 & 549000 & 364000 & 359000 & 530000 & 495000 & 732000 & 633000 \\
\hline Germany & 2165000 & 2593000 & 7131000 & 9235000 & 8246000 & 10743000 & 4473000 & 4690000 & 9333000 & 9887000 & 13769000 & 13856000 \\
\hline Greece & 275000 & 362000 & 862000 & 1211000 & 753000 & 1335000 & 756000 & 828000 & 1235000 & 1268000 & 1730000 & 1645000 \\
\hline Hungary & 242000 & 328000 & 696000 & 959000 & 931000 & 1041000 & 736000 & 769000 & 1038000 & 1071000 & 1783000 & 1596000 \\
\hline Iceland & 15000 & 15000 & 27000 & 30000 & 33000 & 38000 & 21000 & 22000 & 31000 & 32000 & 38000 & 39000 \\
\hline Ireland & 153000 & 189000 & 310000 & 396000 & 246000 & 430000 & 325000 & 336000 & 424000 & 421000 & 522000 & 524000 \\
\hline Israel & 182000 & 176000 & 430000 & 519000 & 455000 & 560000 & 506000 & 534000 & 631000 & 627000 & 759000 & 704000 \\
\hline Italy & 1117000 & 1519000 & 4281000 & 6247000 & 3630000 & 6693000 & 3276000 & 3410000 & 6797000 & 6921000 & 9434000 & 9106000 \\
\hline Kazakhstan & 644000 & 742000 & 1543000 & 1632000 & 1451000 & 1471000 & 1323000 & 1341000 & 1743000 & 1697000 & 2019000 & 1729000 \\
\hline Kyrgyzstan & 203000 & 266000 & 404000 & 503000 & 311000 & 363000 & 482000 & 487000 & 543000 & 538000 & 468000 & 430000 \\
\hline Latvia & 51000 & 73000 & 205000 & 223000 & 264000 & 248000 & 166000 & 172000 & 251000 & 246000 & 413000 & 339000 \\
\hline Lithuania & 75000 & 103000 & 343000 & 362000 & 390000 & 382000 & 243000 & 249000 & 392000 & 387000 & 567000 & 477000 \\
\hline Luxembourg & 8000 & 10000 & 38000 & 51000 & 29000 & 52000 & 25000 & 26000 & 53000 & 54000 & 66000 & 68000 \\
\hline Malta & 16000 & 19000 & 15000 & 38000 & 13000 & 50000 & 29000 & 30000 & 37000 & 39000 & 65000 & 64000 \\
\hline Moldova, Republic of & 155000 & 167000 & 400000 & 409000 & 422000 & 471000 & 375000 & 383000 & 459000 & 441000 & 666000 & 569000 \\
\hline Netherlands & 636000 & 682000 & 1449000 & 1848000 & 1381000 & 2064000 & 906000 & 945000 & 1856000 & 1941000 & 2544000 & 2605000 \\
\hline Norway & 161000 & 182000 & 411000 & 472000 & 517000 & 593000 & 264000 & 276000 & 497000 & 515000 & 671000 & 689000 \\
\hline Poland & 1067000 & 1340000 & 3043000 & 3747000 & 3771000 & 4226000 & 3216000 & 3347000 & 3875000 & 3986000 & 6260000 & 5855000 \\
\hline Portugal & 300000 & 384000 & 955000 & 1063000 & 993000 & 1233000 & 732000 & 757000 & 1159000 & 1144000 & 1629000 & 1495000 \\
\hline Romania & 660000 & 916000 & 1849000 & 2225000 & 2201000 & 2535000 & 1732000 & 1808000 & 2366000 & 2426000 & 3495000 & 3259000 \\
\hline
\end{tabular}




\begin{tabular}{|c|c|c|c|c|c|c|c|c|c|c|c|c|}
\hline \multirow{3}{*}{$\begin{array}{l}\text { Country } \\
\text { (alphabetical order by region) }\end{array}$} & \multicolumn{6}{|c|}{ Labour force (economically active population) } & \multicolumn{6}{|c|}{ Working-age population } \\
\hline & \multicolumn{2}{|l|}{ 15-24 years } & \multicolumn{2}{|l|}{$25-39$ years } & \multicolumn{2}{|l|}{$40-64$ years } & \multicolumn{2}{|l|}{$15-24$ years } & \multicolumn{2}{|l|}{$25-39$ years } & \multicolumn{2}{|l|}{$40-64$ years } \\
\hline & Female & Male & Female & Male & Female & Male & Female & Male & Female & Male & Female & Male \\
\hline Russian Federation & 4202000 & 5359000 & 13339000 & 14534000 & 16584000 & 16372000 & 11584000 & 11854000 & 15854000 & 15715000 & 25352000 & 21416000 \\
\hline Serbia & 268000 & 430000 & 750000 & 1061000 & 729000 & 1178000 & 779000 & 834000 & 1074000 & 1127000 & 1642000 & 1601000 \\
\hline Slovakia & 192000 & 233000 & 474000 & 572000 & 521000 & 612000 & 451000 & 469000 & 586000 & 600000 & 842000 & 781000 \\
\hline Slovenia & 50000 & 62000 & 198000 & 212000 & 186000 & 232000 & 140000 & 147000 & 217000 & 225000 & 326000 & 325000 \\
\hline Spain & 1216000 & 1593000 & 3547000 & 4822000 & 2573000 & 4798000 & 2908000 & 3055000 & 5003000 & 5159000 & 6016000 & 5841000 \\
\hline Sweden & 249000 & 268000 & 758000 & 850000 & 1121000 & 1212000 & 499000 & 524000 & 908000 & 946000 & 1402000 & 1430000 \\
\hline Switzerland & 280000 & 290000 & 653000 & 801000 & 827000 & 1050000 & 415000 & 411000 & 832000 & 831000 & 1192000 & 1156000 \\
\hline Tajikistan & 195000 & 233000 & 414000 & 565000 & 224000 & 330000 & 610000 & 617000 & 642000 & 630000 & 422000 & 422000 \\
\hline $\begin{array}{l}\text { The former Yugoslav Republic of } \\
\text { Macedonia }\end{array}$ & 50000 & 77000 & 143000 & 209000 & 127000 & 215000 & 162000 & 169000 & 223000 & 230000 & 293000 & 287000 \\
\hline Turkey & 1862000 & 4057000 & 2443000 & 7836000 & 1745000 & 5197000 & 6681000 & 6926000 & 8048000 & 8394000 & 6923000 & 6856000 \\
\hline Turkmenistan & 194000 & 237000 & 409000 & 476000 & 268000 & 306000 & 446000 & 452000 & 512000 & 503000 & 399000 & 364000 \\
\hline Ukraine & 1361000 & 1591000 & 4384000 & 4644000 & 5222000 & 5260000 & 3618000 & 3677000 & 5241000 & 5086000 & 8660000 & 7185000 \\
\hline United Kingdom & 2313000 & 2610000 & 5035000 & 6015000 & 5919000 & 7175000 & 3546000 & 3590000 & 6680000 & 6417000 & 9067000 & 8877000 \\
\hline Uzbekistan & 949000 & 1248000 & 2031000 & 2499000 & 1311000 & 1638000 & 2465000 & 2506000 & 2755000 & 2705000 & 2050000 & 1962000 \\
\hline
\end{tabular}


Table F2. Estimated numbers of females and males in the labour force (economically active population) and of working age, major age groups, ILO member States with data and regional summaries, 2020

\begin{tabular}{|c|c|c|c|c|c|c|c|c|c|c|c|c|}
\hline \multirow{3}{*}{$\begin{array}{l}\text { Country } \\
\text { (alphabetical order by region) }\end{array}$} & \multicolumn{6}{|c|}{ Labour force (economically active population) } & \multicolumn{6}{|c|}{ Working-age population } \\
\hline & \multicolumn{2}{|l|}{$15-24$ years } & \multicolumn{2}{|l|}{$25-39$ years } & \multicolumn{2}{|l|}{$40-64$ years } & \multicolumn{2}{|l|}{$15-24$ years } & \multicolumn{2}{|l|}{ 25-39 years } & \multicolumn{2}{|l|}{ 40-64 years } \\
\hline & Female & Male & Female & Male & Female & Male & Female & Male & Female & Male & Female & Male \\
\hline Africa & 62511000 & 84705000 & 83092000 & 128398000 & 56396000 & 90911000 & 121424000 & 123730000 & 130415000 & 133951000 & 99095000 & 98555000 \\
\hline Algeria & 913000 & 2005000 & 2999000 & 5187000 & 2390000 & 4606000 & 2946000 & 3063000 & 5263000 & 5415000 & 5426000 & 5500000 \\
\hline Angola & 1706000 & 2004000 & 1810000 & 2252000 & 1253000 & 1422000 & 2394000 & 2362000 & 2346000 & 2308000 & 1610000 & 1516000 \\
\hline Benin & 570000 & 921000 & 788000 & 1291000 & 560000 & 926000 & 1253000 & 1296000 & 1307000 & 1358000 & 960000 & 990000 \\
\hline Botswana & 61000 & 77000 & 118000 & 211000 & 37000 & 83000 & 196000 & 198000 & 195000 & 234000 & 83000 & 96000 \\
\hline Burkina Faso & 1504000 & 1606000 & 1652000 & 1930000 & 1098000 & 1213000 & 2064000 & 2127000 & 1954000 & 2038000 & 1289000 & 1284000 \\
\hline Burundi & 978000 & 970000 & 1178000 & 1205000 & 725000 & 700000 & 1102000 & 1094000 & 1223000 & 1216000 & 763000 & 709000 \\
\hline Cameroon & 922000 & 1241000 & 1499000 & 2329000 & 934000 & 1502000 & 2124000 & 2137000 & 2395000 & 2440000 & 1640000 & 1638000 \\
\hline Cape Verde & 20000 & 34000 & 39000 & 79000 & 22000 & 49000 & 65000 & 65000 & 84000 & 83000 & 72000 & 64000 \\
\hline Central African Republic & 348000 & 422000 & 385000 & 533000 & 255000 & 303000 & 553000 & 540000 & 538000 & 544000 & 318000 & 312000 \\
\hline Chad & 848000 & 769000 & 962000 & 1132000 & 691000 & 821000 & 1481000 & 1473000 & 1350000 & 1342000 & 900000 & 871000 \\
\hline Comoros & 56000 & 80000 & 81000 & 125000 & 62000 & 98000 & 114000 & 117000 & 125000 & 127000 & 103000 & 101000 \\
\hline Congo & 312000 & 451000 & 333000 & 571000 & 254000 & 370000 & 653000 & 652000 & 574000 & 581000 & 382000 & 375000 \\
\hline Côte d'Ivoire & 877000 & 1880000 & 1213000 & 2749000 & 636000 & 1758000 & 8971000 & 8934000 & 8185000 & 8188000 & 5489000 & 5371000 \\
\hline $\begin{array}{l}\text { Democratic Republic of the } \\
\text { Congo }\end{array}$ & 5597000 & 7366000 & 5318000 & 8029000 & 3473000 & 5216000 & 2466000 & 2458000 & 2703000 & 2776000 & 1689000 & 1833000 \\
\hline Djibouti & 45000 & 70000 & 72000 & 112000 & 52000 & 83000 & 104000 & 106000 & 114000 & 116000 & 91000 & 90000 \\
\hline Egypt & 1416000 & 3059000 & 3347000 & 10849000 & 1885000 & 10027000 & 8230000 & 8428000 & 11028000 & 10900000 & 11112000 & 10921000 \\
\hline
\end{tabular}




\begin{tabular}{|c|c|c|c|c|c|c|c|c|c|c|c|c|}
\hline \multirow{3}{*}{$\begin{array}{l}\text { Country } \\
\text { (alphabetical order by region) }\end{array}$} & \multicolumn{6}{|c|}{ Labour force (economically active population) } & \multicolumn{6}{|c|}{ Working-age population } \\
\hline & \multicolumn{2}{|l|}{$15-24$ years } & \multicolumn{2}{|l|}{$25-39$ years } & \multicolumn{2}{|l|}{$40-64$ years } & \multicolumn{2}{|l|}{$15-24$ years } & \multicolumn{2}{|l|}{$25-39$ years } & \multicolumn{2}{|l|}{$40-64$ years } \\
\hline & Female & Male & Female & Male & Female & Male & Female & Male & Female & Male & Female & Male \\
\hline Equatorial Guinea & 39000 & 64000 & 31000 & 61000 & 25000 & 39000 & 73000 & 73000 & 60000 & 63000 & 40000 & 41000 \\
\hline Eritrea & 387000 & 548000 & 438000 & 680000 & 299000 & 454000 & 686000 & 695000 & 694000 & 692000 & 504000 & 468000 \\
\hline Ethiopia & 8077000 & 8927000 & 9000000 & 10941000 & 5315000 & 7122000 & 11200000 & 11253000 & 11225000 & 11339000 & 7958000 & 7784000 \\
\hline Gabon & 97000 & 123000 & 137000 & 196000 & 98000 & 132000 & 178000 & 181000 & 194000 & 203000 & 145000 & 145000 \\
\hline Gambia & 108000 & 150000 & 140000 & 210000 & 130000 & 181000 & 207000 & 208000 & 224000 & 222000 & 203000 & 194000 \\
\hline Ghana & 1334000 & 1409000 & 2818000 & 3212000 & 2212000 & 2413000 & 2767000 & 2884000 & 3357000 & 3493000 & 2653000 & 2703000 \\
\hline Guinea & 973000 & 1045000 & 1138000 & 1314000 & 858000 & 949000 & 1323000 & 1410000 & 1274000 & 1386000 & 984000 & 1048000 \\
\hline Guinea-Bissau & 160000 & 210000 & 139000 & 214000 & 95000 & 144000 & 248000 & 247000 & 220000 & 217000 & 155000 & 147000 \\
\hline Kenya & 2925000 & 3841000 & 4281000 & 5446000 & 2612000 & 3489000 & 4877000 & 4898000 & 5453000 & 5560000 & 3352000 & 3647000 \\
\hline Lesotho & 66000 & 96000 & 128000 & 192000 & 53000 & 65000 & 200000 & 193000 & 210000 & 204000 & 103000 & 77000 \\
\hline Liberia & 263000 & 286000 & 262000 & 444000 & 181000 & 268000 & 514000 & 520000 & 448000 & 466000 & 298000 & 296000 \\
\hline Libyan Arab Jamahiriya & 127000 & 342000 & 744000 & 940000 & 477000 & 857000 & 591000 & 620000 & 915000 & 954000 & 942000 & 976000 \\
\hline Madagascar & 1903000 & 1939000 & 2406000 & 2654000 & 1848000 & 2053000 & 2775000 & 2776000 & 2744000 & 2738000 & 2169000 & 2114000 \\
\hline Malawi & 1657000 & 1629000 & 1527000 & 1687000 & 916000 & 941000 & 2020000 & 2048000 & 1670000 & 1766000 & 982000 & 991000 \\
\hline Mali & 1452000 & 1508000 & 1609000 & 1738000 & 1104000 & 1044000 & 2139000 & 2219000 & 1965000 & 2005000 & 1341000 & 1224000 \\
\hline Mauritania & 205000 & 301000 & 286000 & 425000 & 229000 & 340000 & 447000 & 448000 & 449000 & 444000 & 386000 & 365000 \\
\hline Mauritius & 34000 & 44000 & 86000 & 149000 & 116000 & 186000 & 97000 & 100000 & 150000 & 153000 & 234000 & 228000 \\
\hline Morocco & 662000 & 1998000 & 1698000 & 4282000 & 1674000 & 4505000 & 3154000 & 3234000 & 4549000 & 4588000 & 5188000 & 4932000 \\
\hline Mozambique & 1986000 & 1673000 & 2413000 & 2590000 & 1687000 & 1517000 & 2793000 & 2795000 & 2636000 & 2706000 & 1829000 & 1575000 \\
\hline Namibia & 82000 & 96000 & 188000 & 269000 & 80000 & 131000 & 260000 & 263000 & 285000 & 309000 & 168000 & 175000 \\
\hline Niger & 1559000 & 2190000 & 1473000 & 2061000 & 1083000 & 1415000 & 2243000 & 2387000 & 1948000 & 2093000 & 1390000 & 1450000 \\
\hline
\end{tabular}




\begin{tabular}{|c|c|c|c|c|c|c|c|c|c|c|c|c|}
\hline \multirow{2}{*}{$\begin{array}{l}\text { Country } \\
\text { (alphabetical order by region) }\end{array}$} & \multicolumn{6}{|c|}{ Labour force (economically active population) } & \multicolumn{6}{|c|}{ Working-age population } \\
\hline & Female & Male & Female & Male & Female & Male & Female & Male & Female & Male & Female & Male \\
\hline Rwanda & 850000 & 879000 & 1336000 & 1375000 & 818000 & 730000 & 1252000 & 1221000 & 1454000 & 1413000 & 926000 & 795000 \\
\hline Sao Tome and Principe & 4000 & 10000 & 11000 & 25000 & 6000 & 17000 & 20000 & 21000 & 26000 & 26000 & 20000 & 18000 \\
\hline Sierra Leone & 469000 & 664000 & 452000 & 742000 & 334000 & 572000 & 760000 & 755000 & 753000 & 745000 & 621000 & 581000 \\
\hline Somalia & 820000 & 1102000 & 726000 & 1159000 & 596000 & 968000 & 1246000 & 1257000 & 1186000 & 1165000 & 1036000 & 982000 \\
\hline South Africa & 1932000 & 2743000 & 3286000 & 5880000 & 1857000 & 4137000 & 4863000 & 4978000 & 5384000 & 6079000 & 4684000 & 4656000 \\
\hline Sudan & 882000 & 1850000 & 1442000 & 4708000 & 1192000 & 3941000 & 4709000 & 4856000 & 5260000 & 5429000 & 4606000 & 4588000 \\
\hline Swaziland & 34000 & 66000 & 53000 & 133000 & 10000 & 31000 & 120000 & 119000 & 117000 & 137000 & 37000 & 35000 \\
\hline Uganda & 3562000 & 3642000 & 3926000 & 4089000 & 2363000 & 2410000 & 4941000 & 4988000 & 4463000 & 4470000 & 2595000 & 2623000 \\
\hline ambia & 1177000 & 1416000 & 1153000 & 1636000 & 447000 & 837000 & 1684000 & 1690000 & 1568000 & 1657000 & 770000 & 872000 \\
\hline Zimbabwe & 750000 & 1146000 & 1301000 & 1856000 & 625000 & 836000 & 1574000 & 1569000 & 1722000 & 1905000 & 780000 & 882000 \\
\hline Americas & 39725000 & 46360000 & 86231000 & 107003000 & 101010000 & 119388000 & 77447000 & 80083000 & 114429000 & 115146000 & 152326000 & 143608000 \\
\hline Argentina & 1740000 & 2236000 & 4296000 & 4706000 & 4671000 & 5011000 & 3327000 & 3430000 & 4948000 & 5028000 & 6245000 & 5939000 \\
\hline Bahamas & 16000 & 16000 & 40000 & 35000 & 35000 & 40000 & 30000 & 30000 & 45000 & 41000 & 59000 & 53000 \\
\hline Barbados & 9000 & 11000 & 25000 & 28000 & 36000 & 43000 & 16000 & 16000 & 28000 & 29000 & 53000 & 52000 \\
\hline Belize & 13000 & 21000 & 30000 & 42000 & 20000 & 34000 & 32000 & 33000 & 42000 & 43000 & 39000 & 38000 \\
\hline Bolivia & 535000 & 750000 & 974000 & 1277000 & 1056000 & 1142000 & 1105000 & 1144000 & 1317000 & 1337000 & 1252000 & 1186000 \\
\hline
\end{tabular}




\begin{tabular}{|c|c|c|c|c|c|c|c|c|c|c|c|c|}
\hline \multirow{3}{*}{$\begin{array}{l}\text { Country } \\
\text { (alphabetical order by region) }\end{array}$} & \multicolumn{6}{|c|}{ Labour force (economically active population) } & \multicolumn{6}{|c|}{ Working-age population } \\
\hline & \multicolumn{2}{|l|}{$15-24$ years } & \multicolumn{2}{|l|}{$25-39$ years } & \multicolumn{2}{|l|}{$40-64$ years } & \multicolumn{2}{|l|}{$15-24$ years } & \multicolumn{2}{|l|}{$25-39$ years } & \multicolumn{2}{|l|}{$40-64$ years } \\
\hline & Female & Male & Female & Male & Female & Male & Female & Male & Female & Male & Female & Male \\
\hline Brazil & 9450000 & 10597000 & 19628000 & 22849000 & 19632000 & 23034000 & 17184000 & 17728000 & 25162000 & 25129000 & 32442000 & 29494000 \\
\hline Canada & 1383000 & 1455000 & 3210000 & 3593000 & 4787000 & 5037000 & 2003000 & 2107000 & 3690000 & 3803000 & 6288000 & 6305000 \\
\hline Chile & 297000 & 311000 & 1300000 & 1836000 & 1415000 & 2494000 & 1263000 & 1305000 & 2110000 & 2152000 & 2939000 & 2850000 \\
\hline Colombia & 2640000 & 2916000 & 5625000 & 6121000 & 5674000 & 6456000 & 4528000 & 4719000 & 6205000 & 6270000 & 7872000 & 7248000 \\
\hline Costa Rica & 176000 & 225000 & 510000 & 650000 & 515000 & 681000 & 400000 & 422000 & 636000 & 668000 & 744000 & 761000 \\
\hline Cuba & 182000 & 328000 & 762000 & 1070000 & 1130000 & 1770000 & 644000 & 680000 & 1078000 & 1137000 & 2108000 & 2112000 \\
\hline Dominican Republic & 382000 & 518000 & 874000 & 1208000 & 862000 & 1141000 & 924000 & 958000 & 1263000 & 1292000 & 1335000 & 1284000 \\
\hline Ecuador & 846000 & 947000 & 1566000 & 1779000 & 1603000 & 1803000 & 1375000 & 1426000 & 1831000 & 1847000 & 2036000 & 1966000 \\
\hline El Salvador & 271000 & 324000 & 702000 & 868000 & 697000 & 863000 & 757000 & 781000 & 975000 & 981000 & 1109000 & 988000 \\
\hline Guatemala & 649000 & 1251000 & 796000 & 1663000 & 557000 & 1113000 & 1809000 & 1806000 & 1948000 & 1766000 & 1558000 & 1220000 \\
\hline Guyana & 23000 & 43000 & 49000 & 77000 & 59000 & 91000 & 60000 & 62000 & 82000 & 83000 & 119000 & 103000 \\
\hline Haiti & 589000 & 684000 & 1002000 & 1244000 & 542000 & 842000 & 1003000 & 1028000 & 1270000 & 1281000 & 945000 & 880000 \\
\hline Honduras & 556000 & 775000 & 815000 & 1135000 & 660000 & 873000 & 916000 & 952000 & 1124000 & 1161000 & 947000 & 943000 \\
\hline Jamaica & 81000 & 113000 & 224000 & 294000 & 232000 & 295000 & 240000 & 253000 & 313000 & 320000 & 373000 & 329000 \\
\hline Mexico & 3321000 & 4056000 & 8342000 & 13388000 & 9690000 & 15176000 & 10238000 & 10234000 & 14869000 & 14154000 & 18852000 & 16727000 \\
\hline Nicaragua & 183000 & 517000 & 425000 & 864000 & 323000 & 675000 & 686000 & 706000 & 890000 & 892000 & 746000 & 701000 \\
\hline Panama & 131000 & 161000 & 342000 & 425000 & 411000 & 482000 & 329000 & 343000 & 435000 & 448000 & 552000 & 546000 \\
\hline Paraguay & 537000 & 570000 & 831000 & 960000 & 621000 & 768000 & 770000 & 796000 & 956000 & 974000 & 870000 & 859000 \\
\hline Peru & 1555000 & 1718000 & 3444000 & 3937000 & 3138000 & 4049000 & 2879000 & 2976000 & 3991000 & 4070000 & 4398000 & 4339000 \\
\hline Saint Lucia & 7000 & 10000 & 19000 & 21000 & 15000 & 20000 & 13000 & 14000 & 23000 & 23000 & 25000 & 23000 \\
\hline Saint Vincent and the Grenadines & 5000 & 6000 & 13000 & 14000 & 12000 & 15000 & 9000 & 9000 & 15000 & 15000 & 17000 & 18000 \\
\hline
\end{tabular}




\begin{tabular}{|c|c|c|c|c|c|c|c|c|c|c|c|c|}
\hline \multirow{3}{*}{$\begin{array}{l}\text { Country } \\
\text { (alphabetical order by region) }\end{array}$} & \multicolumn{6}{|c|}{ Labour force (economically active population) } & \multicolumn{6}{|c|}{ Working-age population } \\
\hline & \multicolumn{2}{|l|}{$15-24$ years } & \multicolumn{2}{|l|}{$25-39$ years } & \multicolumn{2}{|l|}{$40-64$ years } & \multicolumn{2}{|l|}{$15-24$ years } & \multicolumn{2}{|l|}{$25-39$ years } & \multicolumn{2}{|l|}{ 40-64 years } \\
\hline & Female & Male & Female & Male & Female & Male & Female & Male & Female & Male & Female & Male \\
\hline Suriname & 5000 & 16000 & 28000 & 49000 & 27000 & 46000 & 39000 & 40000 & 52000 & 54000 & 68000 & 66000 \\
\hline Trinidad and Tobago & 34000 & 48000 & 99000 & 161000 & 102000 & 169000 & 83000 & 85000 & 165000 & 166000 & 218000 & 202000 \\
\hline United States & 12645000 & 13508000 & 26377000 & 32575000 & 38770000 & 40982000 & 21777000 & 22880000 & 34711000 & 35679000 & 53164000 & 51572000 \\
\hline Uruguay & 138000 & 210000 & 333000 & 378000 & 423000 & 453000 & 271000 & 283000 & 381000 & 393000 & 561000 & 537000 \\
\hline Venezuela, Bolivarian Republic of & f 1326000 & 2019000 & 3550000 & 3756000 & 3295000 & 3790000 & 2737000 & 2837000 & 3874000 & 3910000 & 4392000 & 4267000 \\
\hline Asia and the Pacific & 142401029 & 215183060 & 321199046 & 492864094 & 330000035 & 558588083 & 325599000 & 346806000 & 486957000 & 515781000 & 617545000 & 630160000 \\
\hline Afghanistan & 1924000 & 3734000 & 2269000 & 4638000 & 1548000 & 3316000 & 4604000 & 4938000 & 4397000 & 4728000 & 3274000 & 3450000 \\
\hline Australia & 937000 & 972000 & 1784000 & 2135000 & 2769000 & 2850000 & 1346000 & 1402000 & 2397000 & 2464000 & 3855000 & 3724000 \\
\hline Bahrain & 16000 & 42000 & 52000 & 131000 & 21000 & 159000 & 66000 & 72000 & 101000 & 132000 & 121000 & 180000 \\
\hline Bangladesh & 8025000 & 11845000 & 13152000 & 21572000 & 10175000 & 20169000 & 16257000 & 16943000 & 21332000 & 22128000 & 20675000 & 21369000 \\
\hline Brunei Darussalam & 13000 & 21000 & 39000 & 63000 & 22000 & 53000 & 39000 & 41000 & 67000 & 65000 & 65000 & 67000 \\
\hline Cambodia & 1119000 & 1024000 & 2101000 & 2312000 & 1446000 & 1391000 & 1661000 & 1713000 & 2428000 & 2421000 & 1838000 & 1486000 \\
\hline China & 58733000 & 64035000 & 137735000 & 157796000 & 148475000 & 226376000 & 84195000 & 93540000 & 149541000 & 162709000 & 248198000 & 254274000 \\
\hline Fiji & 37000 & 46000 & 69000 & 109000 & 79000 & 117000 & 77000 & 82000 & 104000 & 112000 & 123000 & 126000 \\
\hline India & 29549000 & 67238000 & 62541000 & 157902000 & 65194000 & 154535000 & 113041000 & 119312000 & 154457000 & 163263000 & 166700000 & 172223000 \\
\hline Indonesia & 7939000 & 13543000 & 18952000 & 29468000 & 23641000 & 35103000 & 20405000 & 21013000 & 30274000 & 30360000 & 38337000 & 37627000 \\
\hline Iran, Islamic Republic of & 2169000 & 2859000 & 7963000 & 11739000 & 5171000 & 8463000 & 5677000 & 5947000 & 12315000 & 12819000 & 10797000 & 10895000 \\
\hline Iraq & 907000 & 2471000 & 1546000 & 4457000 & 762000 & 3208000 & 3991000 & 4127000 & 4492000 & 4626000 & 3940000 & 3958000 \\
\hline Japan & 2513000 & 2628000 & 7249000 & 9783000 & 13623000 & 18788000 & 5866000 & 6171000 & 9990000 & 10404000 & 21122000 & 21286000 \\
\hline Jordan & 217000 & 422000 & 452000 & 871000 & 262000 & 796000 & 717000 & 750000 & 860000 & 900000 & 842000 & 957000 \\
\hline Korea, Republic of & 602000 & 676000 & 1597000 & 2605000 & 1956000 & 3573000 & 1753000 & 1814000 & 2692000 & 2777000 & 3977000 & 3908000 \\
\hline
\end{tabular}




\begin{tabular}{|c|c|c|c|c|c|c|c|c|c|c|c|c|}
\hline \multirow{3}{*}{$\begin{array}{l}\text { Country } \\
\text { (alphabetical order by region) }\end{array}$} & \multicolumn{6}{|c|}{ Labour force (economically active population) } & \multicolumn{6}{|c|}{ Working-age population } \\
\hline & \multicolumn{2}{|l|}{$15-24$ years } & \multicolumn{2}{|l|}{$25-39$ years } & \multicolumn{2}{|l|}{$40-64$ years } & \multicolumn{2}{|l|}{$15-24$ years } & \multicolumn{2}{|l|}{$25-39$ years } & \multicolumn{2}{|l|}{$40-64$ years } \\
\hline & Female & Male & Female & Male & Female & Male & Female & Male & Female & Male & Female & Male \\
\hline Kuwait & 82000 & 106000 & 335000 & 554000 & 222000 & 699000 & 245000 & 261000 & 401000 & 563000 & 444000 & 824000 \\
\hline $\begin{array}{l}\text { Lao People's Democratic } \\
\text { Republic }\end{array}$ & 395000 & 505000 & 558000 & 885000 & 435000 & 667000 & 782000 & 809000 & 900000 & 917000 & 759000 & 729000 \\
\hline Lebanon & 63000 & 199000 & 327000 & 481000 & 244000 & 511000 & 326000 & 337000 & 483000 & 492000 & 621000 & 563000 \\
\hline Malaysia & 1221000 & 1536000 & 2832000 & 3736000 & 1745000 & 3685000 & 2661000 & 2801000 & 3586000 & 3763000 & 4196000 & 4211000 \\
\hline Mongolia & 124000 & 150000 & 261000 & 412000 & 244000 & 402000 & 250000 & 261000 & 415000 & 424000 & 444000 & 432000 \\
\hline Myanmar & 2512000 & 3242000 & 5813000 & 6984000 & 6155000 & 7291000 & 4574000 & 4670000 & 7366000 & 7346000 & 8391000 & 7786000 \\
\hline Nepal & 1724000 & 2227000 & 2577000 & 3922000 & 2108000 & 2916000 & 3435000 & 3581000 & 4206000 & 4195000 & 3845000 & 3310000 \\
\hline New Zealand & 174000 & 186000 & 336000 & 404000 & 594000 & 596000 & 280000 & 296000 & 441000 & 464000 & 725000 & 669000 \\
\hline Oman & 73000 & 164000 & 265000 & 454000 & 118000 & 459000 & 291000 & 309000 & 401000 & 459000 & 323000 & 531000 \\
\hline Pakistan & 6699000 & 14773000 & 15468000 & 23678000 & 10757000 & 18441000 & 19232000 & 20412000 & 24898000 & 26489000 & 20301000 & 21620000 \\
\hline Papua New Guinea & 475000 & 508000 & 669000 & 799000 & 611000 & 634000 & 761000 & 814000 & 858000 & 955000 & 785000 & 775000 \\
\hline Philippines & 4483000 & 6129000 & 9419000 & 12040000 & 9056000 & 11187000 & 9375000 & 9766000 & 12280000 & 12563000 & 12369000 & 12108000 \\
\hline Qatar & 4000 & 25000 & 50000 & 190000 & 50000 & 238000 & 64000 & 72000 & 85000 & 203000 & 113000 & 255000 \\
\hline Samoa & 6000 & 11000 & 10000 & 17000 & 9000 & 22000 & 20000 & 23000 & 17000 & 17000 & 21000 & 24000 \\
\hline Saudi Arabia & 306000 & 1544000 & 1647000 & 4375000 & 542000 & 3699000 & 3038000 & 3182000 & 3975000 & 4508000 & 3312000 & 4271000 \\
\hline Singapore & 136000 & 134000 & 418000 & 508000 & 499000 & 764000 & 270000 & 290000 & 477000 & 510000 & 969000 & 965000 \\
\hline Solomon Islands & 33000 & 43000 & 44000 & 75000 & 35000 & 60000 & 65000 & 70000 & 73000 & 78000 & 63000 & 65000 \\
\hline Sri Lanka & 29 & 60 & 46 & 94 & 35 & 83 & 1567000 & 1618000 & 2547000 & 2647000 & 3604000 & 3774000 \\
\hline Syrian Arab Republic & 983000 & 1920000 & 1910000 & 3282000 & 1253000 & 2567000 & 2365000 & 2461000 & 3186000 & 3287000 & 2818000 & 2793000 \\
\hline Thailand & 1826000 & 2687000 & 6947000 & 7419000 & 9397000 & 9961000 & 4908000 & 5018000 & 7848000 & 7878000 & 12104000 & 11037000 \\
\hline
\end{tabular}




\begin{tabular}{|c|c|c|c|c|c|c|c|c|c|c|c|c|}
\hline \multirow{3}{*}{$\begin{array}{l}\text { Country } \\
\text { (alphabetical order by region) }\end{array}$} & \multicolumn{6}{|c|}{ Labour force (economically active population) } & \multicolumn{6}{|c|}{ Working-age population } \\
\hline & \multicolumn{2}{|l|}{$15-24$ years } & \multicolumn{2}{|l|}{$25-39$ years } & \multicolumn{2}{|l|}{$40-64$ years } & \multicolumn{2}{|l|}{$15-24$ years } & \multicolumn{2}{|l|}{$25-39$ years } & \multicolumn{2}{|l|}{$40-64$ years } \\
\hline & Female & Male & Female & Male & Female & Male & Female & Male & Female & Male & Female & Male \\
\hline United Arab Emirates & 108000 & 305000 & 400000 & 1332000 & 242000 & 1477000 & 359000 & 500000 & 587000 & 1344000 & 565000 & 1510000 \\
\hline Vanuatu & 20000 & 21000 & 26000 & 31000 & 23000 & 25000 & 26000 & 26000 & 32000 & 32000 & 27000 & 27000 \\
\hline Yemen & 901000 & 1950000 & 1815000 & 3164000 & 890000 & 2144000 & 3280000 & 3395000 & 3427000 & 3539000 & 2298000 & 2258000 \\
\hline Europe and Central Asia & 19148000 & 25384000 & 71334000 & 86610000 & 94712000 & 109414000 & 50914000 & 53155000 & 92951000 & 94577000 & 155754000 & 146332000 \\
\hline Albania & 110000 & 145000 & 248000 & 335000 & 260000 & 331000 & 244000 & 259000 & 401000 & 403000 & 502000 & 457000 \\
\hline Armenia & 39000 & 41000 & 285000 & 330000 & 280000 & 310000 & 158000 & 180000 & 406000 & 381000 & 539000 & 387000 \\
\hline Austria & 189000 & 245000 & 647000 & 743000 & 998000 & 1126000 & 399000 & 428000 & 755000 & 824000 & 1516000 & 1569000 \\
\hline Bosnia and Herzegovina & 107000 & 113000 & 359000 & 387000 & 469000 & 472000 & 202000 & 213000 & 387000 & 396000 & 713000 & 682000 \\
\hline Bulgaria & 60000 & 90000 & 453000 & 588000 & 669000 & 738000 & 312000 & 329000 & 696000 & 726000 & 1297000 & 1248000 \\
\hline Croatia & 85000 & 90000 & 343000 & 387000 & 394000 & 456000 & 219000 & 230000 & 423000 & 438000 & 788000 & 759000 \\
\hline Cyprus & 24000 & 26000 & 102000 & 109000 & 112000 & 117000 & 55000 & 57000 & 111000 & 114000 & 166000 & 150000 \\
\hline Czech Republic & 149000 & 157000 & 725000 & 934000 & 1373000 & 1469000 & 447000 & 469000 & 955000 & 996000 & 1836000 & 1836000 \\
\hline Denmark & 208000 & 255000 & 404000 & 463000 & 699000 & 758000 & 344000 & 362000 & 497000 & 508000 & 937000 & 947000 \\
\hline Estonia & 16000 & 24000 & 101000 & 129000 & 167000 & 156000 & 60000 & 64000 & 139000 & 144000 & 227000 & 199000 \\
\hline Finland & 159000 & 158000 & 404000 & 483000 & 627000 & 663000 & 291000 & 306000 & 490000 & 521000 & 855000 & 868000 \\
\hline France & 931000 & 1272000 & 4550000 & 5321000 & 6745000 & 7158000 & 3648000 & 3828000 & 5584000 & 5803000 & 10295000 & 9986000 \\
\hline
\end{tabular}




\begin{tabular}{|c|c|c|c|c|c|c|c|c|c|c|c|c|}
\hline \multirow{3}{*}{$\begin{array}{l}\text { Country } \\
\text { (alphabetical order by region) }\end{array}$} & \multicolumn{6}{|c|}{ Labour force (economically active population) } & \multicolumn{6}{|c|}{ Working-age population } \\
\hline & \multicolumn{2}{|l|}{$15-24$ years } & \multicolumn{2}{|l|}{$25-39$ years } & \multicolumn{2}{|l|}{$40-64$ years } & \multicolumn{2}{|l|}{$15-24$ years } & \multicolumn{2}{|l|}{$25-39$ years } & \multicolumn{2}{|l|}{$40-64$ years } \\
\hline & Female & $\overline{\text { Male }}$ & Female & Male & Female & Male & Female & Male & Female & Male & Female & Male \\
\hline Georgia & 50000 & 107000 & 203000 & 401000 & 477000 & 563000 & 222000 & 244000 & 468000 & 467000 & 763000 & 624000 \\
\hline Germany & 1775000 & 2055000 & 6013000 & 7122000 & 11233000 & 11578000 & 4036000 & 4232000 & 7570000 & 7795000 & 14871000 & 14826000 \\
\hline Greece & 168000 & 211000 & 865000 & 1062000 & 1398000 & 1701000 & 538000 & 568000 & 1032000 & 1114000 & 2103000 & 2129000 \\
\hline Hungary & 110000 & 128000 & 673000 & 850000 & 1040000 & 1144000 & 486000 & 510000 & 935000 & 973000 & 1778000 & 1717000 \\
\hline Iceland & 15000 & 16000 & 28000 & 33000 & 45000 & 50000 & 21000 & 22000 & 34000 & 34000 & 52000 & 52000 \\
\hline Ireland & 121000 & 158000 & 407000 & 449000 & 695000 & 721000 & 278000 & 289000 & 479000 & 484000 & 875000 & 878000 \\
\hline Israel & 221000 & 178000 & 633000 & 697000 & 766000 & 789000 & 645000 & 681000 & 828000 & 861000 & 1119000 & 1092000 \\
\hline Italy & 731000 & 893000 & 3294000 & 4019000 & 5701000 & 7797000 & 2665000 & 2826000 & 4382000 & 4565000 & 10809000 & 10756000 \\
\hline Kazakhstan & 476000 & 537000 & 1691000 & 1760000 & 1960000 & 1767000 & 962000 & 986000 & 1911000 & 1889000 & 2481000 & 2085000 \\
\hline Kyrgyzstan & 206000 & 300000 & 514000 & 700000 & 537000 & 608000 & 506000 & 525000 & 769000 & 777000 & 813000 & 738000 \\
\hline Latvia & 27000 & 40000 & 183000 & 219000 & 268000 & 253000 & 93000 & 98000 & 236000 & 244000 & 392000 & 349000 \\
\hline Lithuania & 36000 & 52000 & 322000 & 343000 & 412000 & 417000 & 153000 & 162000 & 368000 & 378000 & 598000 & 529000 \\
\hline Luxembourg & 7000 & 9000 & 45000 & 53000 & 61000 & 73000 & 31000 & 32000 & 56000 & 56000 & 100000 & 100000 \\
\hline Malta & 12000 & 12000 & 37000 & 45000 & 32000 & 51000 & 22000 & 23000 & 43000 & 45000 & 68000 & 71000 \\
\hline Moldova, Republic of & 93000 & 104000 & 462000 & 500000 & 418000 & 529000 & 212000 & 223000 & 531000 & 540000 & 737000 & 656000 \\
\hline Netherlands & 744000 & 842000 & 1276000 & 1502000 & 1831000 & 2353000 & 990000 & 1036000 & 1506000 & 1578000 & 2939000 & 3014000 \\
\hline Norway & 196000 & 217000 & 390000 & 431000 & 650000 & 675000 & 302000 & 315000 & 461000 & 474000 & 802000 & 814000 \\
\hline Poland & 490000 & 532000 & 3439000 & 4026000 & 3532000 & 4044000 & 1844000 & 1943000 & 4225000 & 4383000 & 6720000 & 6517000 \\
\hline Portugal & 227000 & 281000 & 830000 & 889000 & 1531000 & 1603000 & 579000 & 607000 & 946000 & 964000 & 2034000 & 1990000 \\
\hline Romania & 237000 & 250000 & 1535000 & 1853000 & 2044000 & 2455000 & 1035000 & 1086000 & 2171000 & 2245000 & 3838000 & 3683000 \\
\hline Russian Federation & 1993000 & 2707000 & 13955000 & 14616000 & 16120000 & 15305000 & 6742000 & 7023000 & 15547000 & 15252000 & 25485000 & 20798000 \\
\hline
\end{tabular}




\begin{tabular}{|c|c|c|c|c|c|c|c|c|c|c|c|c|}
\hline \multirow{3}{*}{$\begin{array}{l}\text { Country } \\
\text { (alphabetical order by region) }\end{array}$} & \multicolumn{6}{|c|}{ Labour force (economically active population) } & \multicolumn{6}{|c|}{ Working-age population } \\
\hline & \multicolumn{2}{|l|}{ 15-24 years } & \multicolumn{2}{|l|}{$25-39$ years } & \multicolumn{2}{|l|}{$40-64$ years } & \multicolumn{2}{|l|}{ 15-24 years } & \multicolumn{2}{|l|}{$25-39$ years } & \multicolumn{2}{|l|}{$40-64$ years } \\
\hline & Female & Male & Female & Male & Female & Male & Female & Male & Female & Male & Female & Male \\
\hline Serbia & 310000 & 334000 & 927000 & 1117000 & 926000 & 1245000 & 586000 & 630000 & 1078000 & 1149000 & 1713000 & 1735000 \\
\hline Slovakia & 103000 & 102000 & 468000 & 580000 & 591000 & 734000 & 267000 & 279000 & 593000 & 615000 & 996000 & 968000 \\
\hline Slovenia & 21000 & 42000 & 169000 & 186000 & 226000 & 264000 & 87000 & 92000 & 179000 & 191000 & 360000 & 367000 \\
\hline Spain & 724000 & 1023000 & 3055000 & 3587000 & 5437000 & 7154000 & 2107000 & 2229000 & 3724000 & 3871000 & 8732000 & 8752000 \\
\hline Sweden & 250000 & 274000 & 736000 & 855000 & 1182000 & 1265000 & 496000 & 533000 & 900000 & 957000 & 1483000 & 1503000 \\
\hline Switzerland & 278000 & 287000 & 630000 & 643000 & 1056000 & 1033000 & 398000 & 405000 & 707000 & 679000 & 1328000 & 1236000 \\
\hline Tajikistan & 258000 & 332000 & 673000 & 895000 & 413000 & 509000 & 790000 & 811000 & 1064000 & 1044000 & 859000 & 746000 \\
\hline $\begin{array}{l}\text { The former Yugoslav Republic of } \\
\text { Macedonia }\end{array}$ & 30000 & 53000 & 148000 & 215000 & 171000 & 259000 & 117000 & 125000 & 228000 & 240000 & 354000 & 355000 \\
\hline Turkey & 1971000 & 4873000 & 3079000 & 8949000 & 3105000 & 9662000 & 7024000 & 7258000 & 9910000 & 10094000 & 12586000 & 12690000 \\
\hline Turkmenistan & 200000 & 243000 & 644000 & 744000 & 503000 & 580000 & 467000 & 475000 & 781000 & 781000 & 790000 & 710000 \\
\hline Ukraine & 603000 & 816000 & 3858000 & 4119000 & 4408000 & 4430000 & 1865000 & 1940000 & 4654000 & 4473000 & 7852000 & 6254000 \\
\hline United Kingdom & 2367000 & 2496000 & 4993000 & 5744000 & 7243000 & 7861000 & 3671000 & 3760000 & 6222000 & 6431000 & 10376000 & 9998000 \\
\hline Uzbekistan & 1366000 & 1457000 & 3713000 & 4135000 & 2789000 & 3144000 & 2697000 & 2783000 & 4281000 & 4357000 & 4149000 & 3873000 \\
\hline
\end{tabular}


Table F3. Estimated and projected economic activity rates of females and males, major age groups,

ILO member States with data and regional summaries, 2000 and 2020

\begin{tabular}{|c|c|c|c|c|c|c|c|c|c|c|c|c|}
\hline \multirow{3}{*}{$\begin{array}{l}\text { Country } \\
\text { (alphabetical order by region) }\end{array}$} & \multicolumn{6}{|l|}{2000} & \multicolumn{6}{|l|}{2020} \\
\hline & \multicolumn{2}{|c|}{$15-24$ years } & \multicolumn{2}{|c|}{$25-39$ years } & \multicolumn{2}{|c|}{$40-64$ years } & \multicolumn{2}{|c|}{$15-24$ years } & \multicolumn{2}{|c|}{$25-39$ years } & \multicolumn{2}{|c|}{$40-64$ years } \\
\hline & Female & Male & Female & Male & Female & Male & Female & Male & Female & Male & Female & Male \\
\hline Africa & 50.6 & 70.2 & 61.1 & 95.8 & 56.9 & 94.0 & 51.5 & 68.5 & 63.7 & 95.9 & 56.9 & 92.2 \\
\hline Algeria & 26.2 & 64.9 & 41.2 & 95.5 & 30.0 & 89.2 & 31.0 & 65.5 & 57.0 & 95.8 & 44.0 & 83.7 \\
\hline Angola & 73.6 & 86.9 & 77.3 & 97.6 & 78.5 & 94.6 & 71.3 & 84.8 & 77.2 & 97.6 & 77.8 & 93.8 \\
\hline Benin & 50.7 & 75.5 & 60.6 & 96.2 & 59.4 & 94.8 & 45.5 & 71.1 & 60.3 & 95.1 & 58.3 & 93.5 \\
\hline Botswana & 35.3 & 42.1 & 63.9 & 88.4 & 56.0 & 85.0 & 31.1 & 38.9 & 60.5 & 90.2 & 44.6 & 86.5 \\
\hline Burkina Faso & 74.9 & 83.5 & 83.6 & 97.1 & 83.7 & 96.5 & 72.9 & 75.5 & 84.5 & 94.7 & 85.2 & 94.5 \\
\hline Burundi & 88.4 & 84.9 & 96.6 & 98.6 & 95.4 & 98.7 & 88.7 & 88.7 & 96.3 & 99.1 & 95.0 & 98.7 \\
\hline Cameroon & 45.8 & 66.9 & 63.7 & 95.8 & 58.9 & 93.0 & 43.4 & 58.1 & 62.6 & 95.5 & 57.0 & 91.7 \\
\hline Cape Verde & 34.0 & 67.3 & 47.7 & 95.2 & 32.4 & 85.0 & 30.8 & 52.3 & 46.4 & 95.2 & 30.6 & 76.6 \\
\hline Central African Republic & 63.0 & 76.9 & 72.3 & 97.5 & 80.6 & 96.9 & 62.9 & 78.1 & 71.6 & 98.0 & 80.2 & 97.1 \\
\hline Chad & 58.5 & 57.5 & 68.3 & 92.2 & 74.0 & 96.4 & 57.3 & 52.2 & 71.3 & 84.4 & 76.8 & 94.3 \\
\hline Comoros & 51.4 & 69.3 & 64.7 & 98.5 & 64.6 & 97.8 & 49.1 & 68.4 & 64.8 & 98.4 & 60.2 & 97.0 \\
\hline Congo & 61.8 & 84.6 & 56.4 & 99.3 & 66.2 & 97.7 & 47.8 & 69.2 & 58.0 & 98.3 & 66.5 & 98.7 \\
\hline Côte d'Ivoire & 36.3 & 75.1 & 43.3 & 98.8 & 43.5 & 95.7 & 9.8 & 21.0 & 14.8 & 33.6 & 11.6 & 32.7 \\
\hline Democratic Republic of the Congo & 61.3 & 81.5 & 64.9 & 97.8 & 61.8 & 97.1 & 227.0 & 299.7 & 196.7 & 289.2 & 205.6 & 284.6 \\
\hline Djibouti & 45.7 & 66.2 & 64.3 & 94.4 & 60.0 & 94.2 & 43.3 & 66.0 & 63.2 & 96.6 & 57.1 & 92.2 \\
\hline Egypt & 19.1 & 43.8 & 27.9 & 94.8 & 17.4 & 92.7 & 17.2 & 36.3 & 30.4 & 99.5 & 17.0 & 91.8 \\
\hline Equatorial Guinea & 47.6 & 88.1 & 50.0 & 97.4 & 56.8 & 97.1 & 53.4 & 87.7 & 51.7 & 96.8 & 62.5 & 95.1 \\
\hline
\end{tabular}




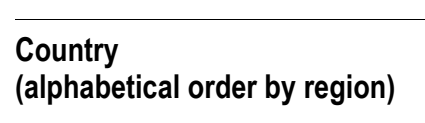

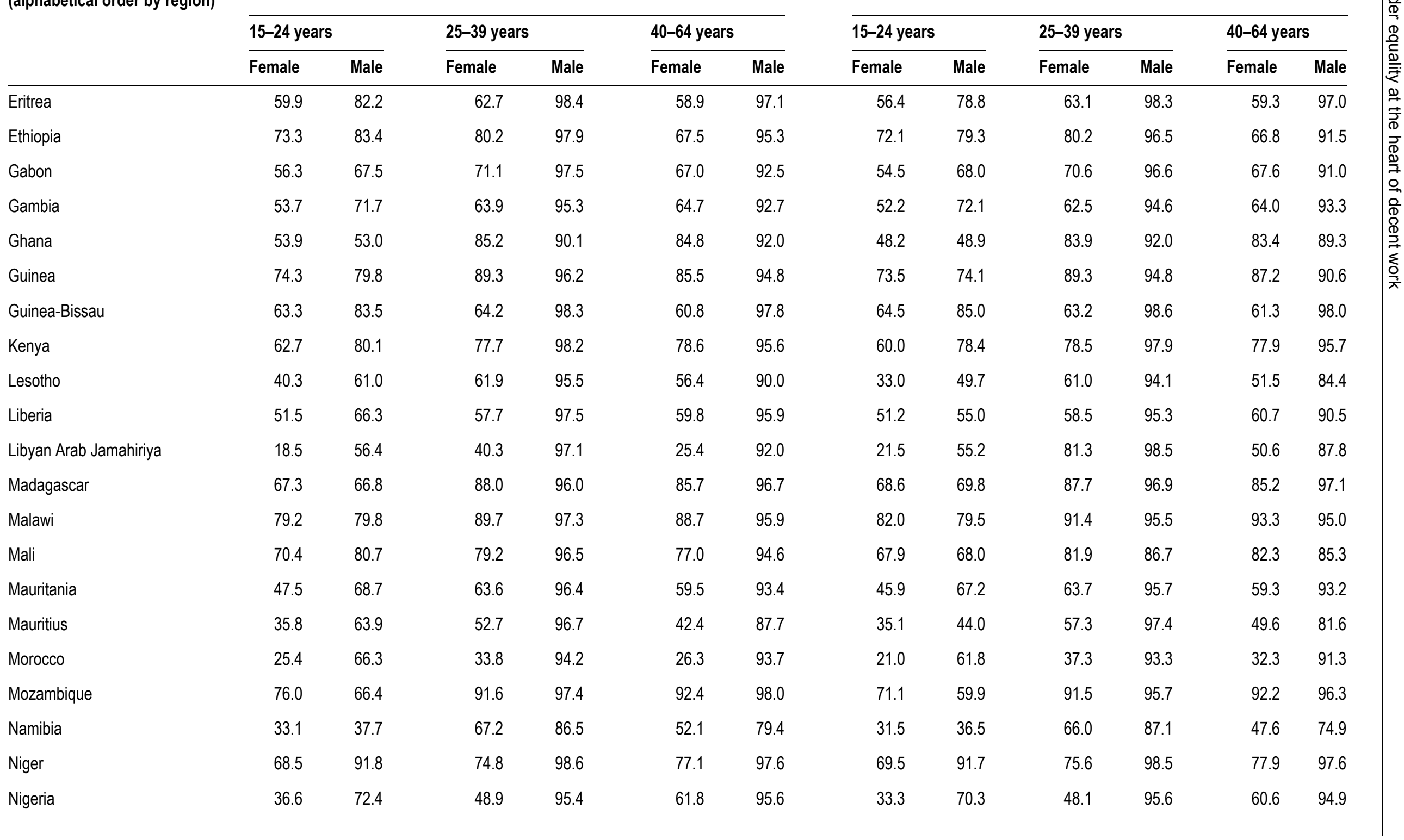




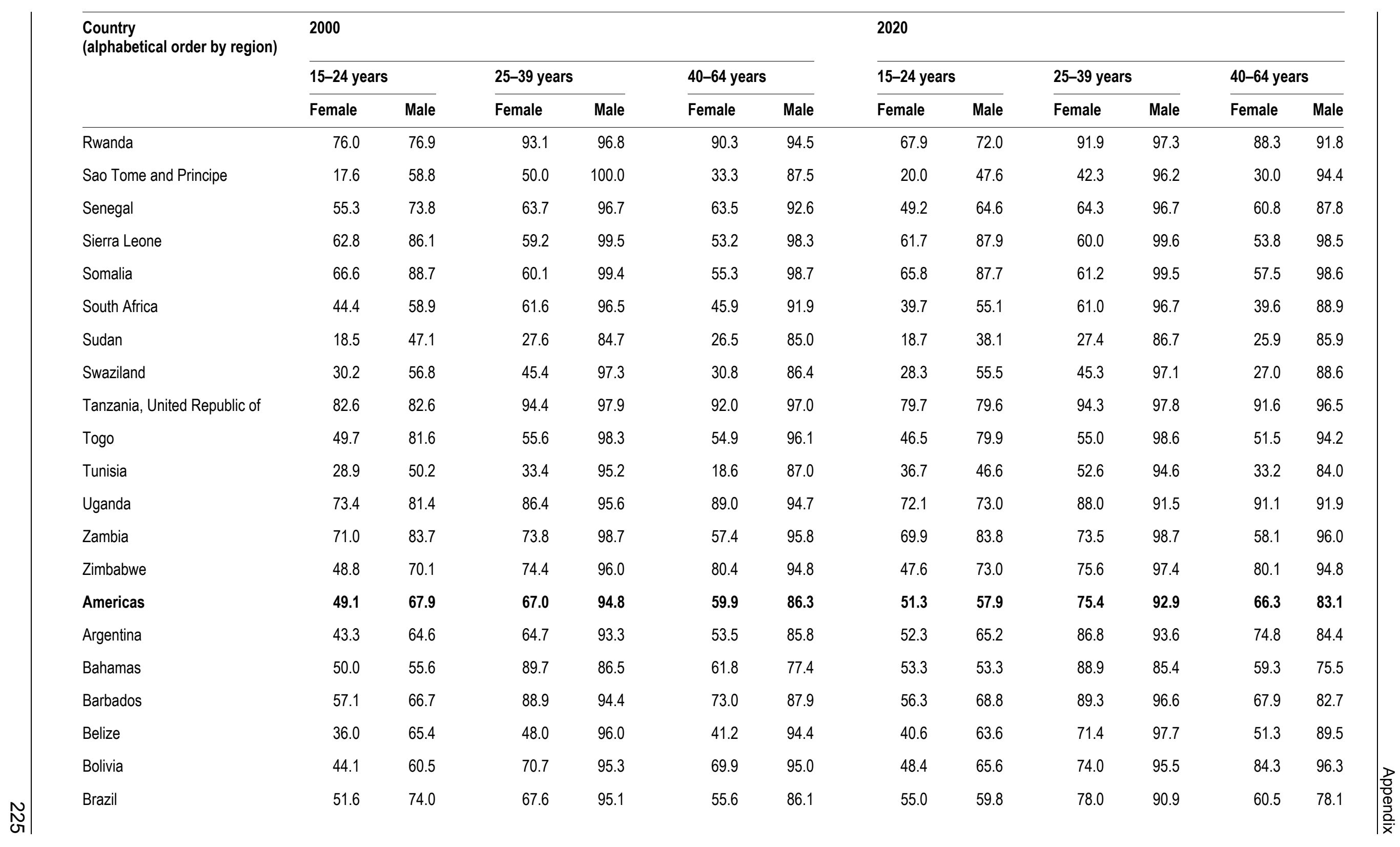




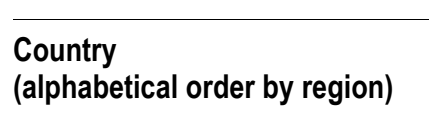

\begin{tabular}{llllll}
\hline $15-24$ years & 25-39 years & & & 40-64 years \\
\cline { 2 - 2 }$\quad$ Male & Female $\quad$ Male & Female Male
\end{tabular}

\begin{tabular}{lllll}
\hline 15-24 years & & & & \multicolumn{2}{l}{ 25-39 years } & & & years \\
\cline { 5 - 6 } & Female & Male & Female $\quad$ Male & Female Male
\end{tabular}

Canada

$62.9 \quad 65.8$

$79.6 \quad 92.0$

\section{Chile}

Colombia

$23.7 \quad 40.7$

$48.5 \quad 94.3$

$67.1 \quad 81.9$

$50.1 \quad 65.1$

$73.5 \quad 97.7$

$41.0 \quad 89.8$

Costa Rica

Cuba

Dominican Republic

Ecuador

El Salvador

Guatemala

Guyana

Haiti

Honduras

Jamaica

Mexico

Nicaragua

Panama

Paraguay

Peru

Saint Lucia

Saint Vincent and the Grenadines

Suriname

$35.2 \quad 67.3$

$46.9 \quad 96.0$

$55.4 \quad 90.9$

$28.1 \quad 51.3$

$34.7 \quad 64.3$

$46.9 \quad 65.0$

$33.5 \quad 65.5$

$32.4 \quad 71.6$

$34.6 \quad 70.4$

$48.6 \quad 64.3$

$37.7 \quad 79.3$

$40.0 \quad 50.9$

$36.5 \quad 69.7$

$26.3 \quad 72.6$

$36.2 \quad 64.3$

$58.6 \quad 71.2$

$65.3 \quad 95.1$

$55.0 \quad 96.0$

$68.7 \quad 96.6$

$59.2 \quad 93.8$

$37.5 \quad 95.3$

$50.5 \quad 94.3$

$64.9 \quad 96.1$

$53.3 \quad 97.1$

$78.3 \quad 94.7$

$46.7 \quad 96.8$

$44.3 \quad 96.8$

$\begin{array}{llll}58.4 & 97.5 & 47.5 & 89.9 \\ 71.0 & 98.4 & 58.7 & 92.1\end{array}$

$\begin{array}{ll}55.4 & 90.9 \\ 36.9 & 89.3\end{array}$

$44.4 \quad 86.9$

$\begin{array}{ll}42.6 & 92.7\end{array}$

$60.5 \quad 94.0$

$50.7 \quad 90.3$

$34.2 \quad 92.4$

$69.0 \quad 69.1$

$\begin{array}{ll}34.2 & 92.4 \\ 47.9 & 88.5\end{array}$

$23.5 \quad 23.8$

$\begin{array}{ll}47.9 & 88.5 \\ 57.9 & 95.3\end{array}$

$58.3 \quad 61.8$

$\begin{array}{ll}58.3 & 61.8 \\ 44.0 & 53.3\end{array}$

$\begin{array}{ll}57.9 & 95.3\end{array}$

28.3

$\begin{array}{ll}49.9 & 95.1\end{array}$

$\begin{array}{ll}28.3 & 48.2 \\ 41.3 & 54.1\end{array}$

$\begin{array}{ll}61.5 & 66.4 \\ 35.8 & 41.5\end{array}$

69.791 .3

$\begin{array}{ll}35.8 & 41.5 \\ 35.9 & 69.3\end{array}$

$39.8 \quad 91.6$

35.9

$\begin{array}{ll}38.3 & 69.3\end{array}$

$\begin{array}{ll}38.3 & 69.4 \\ 58.7 & 66.5 \\ 60.7 & 81.4\end{array}$

$\begin{array}{ll}60.7 & 81.4 \\ 33.8 & 44.7 \\ 32.4 & 39.6\end{array}$

$87.0 \quad 94.5$

$\begin{array}{ll}39.8 & 91.6 \\ 40.8 & 96.3\end{array}$

$\begin{array}{ll}32.7 & 73.2 \\ 39.8 & 46.9\end{array}$

$61.6 \quad 85.3$

$90.7 \quad 97.6$

$\begin{array}{ll}76.1 & 79.9 \\ 48.1 & 87.5\end{array}$

80.297 .3

$72.1 \quad 89.1$

$70.7 \quad 94.1$

$69.2 \quad 93.5$

$85.5 \quad 96.3$

$69.2 \quad 89.5$

$53.6 \quad 83.8$

$\begin{array}{ll}53.6 & 83.8 \\ 64.6 & 88.9\end{array}$

$\begin{array}{ll}85.5 & 96.3 \\ 72.0 & 88.5\end{array}$

$\begin{array}{ll}62.8 & 87.3 \\ 35.8 & 91.2\end{array}$

$\begin{array}{llllll}32.4 & 39.6 & 56.1 & 94.6 & 51.4 & 90.7 \\ 26.7 & 73.2 & 47.8 & 96.9 & 43.3 & 96.3 \\ 39.8 & 46.9 & 78.6 & 94.9 & 74.5 & 88.3 \\ 69.7 & 71.6 & 86.9 & 98.6 & 71.4 & 89.4 \\ 54.0 & 57.7 & 86.3 & 96.7 & 71.4 & 93.3 \\ 53.8 & 71.4 & 82.6 & 91.3 & 60.0 & 87.0 \\ 55.6 & 66.7 & 86.7 & 93.3 & 70.6 & 83.3 \\ 12.8 & 40.0 & 53.8 & 90.7 & 39.7 & 69.7\end{array}$

$\begin{array}{ll}40.9 & 94.2 \\ 59.8 & 92.8\end{array}$

$\begin{array}{ll}35.8 & 91.2 \\ 49.6 & 88.3\end{array}$

$\begin{array}{llll}78.9 & 97.1 & 57.4 & 95.7 \\ 72.5 & 97.8 & 69.7 & 92.6 \\ 71.6 & 91.9 & 62.2 & 89.7\end{array}$

$\begin{array}{llll}72.5 & 97.8 & 69.7 & 92.6 \\ 71.6 & 91.9 & 62.2 & 89.7 \\ 56.1 & 94.6 & 51.4 & 90.7 \\ 47.8 & 96.9 & 43.3 & 96.3\end{array}$

$\begin{array}{llllll}44.2 & 59.7 & 68.5 & 96.3 & 54.9 & 93.5 \\ 46.7 & 66.7 & 72.2 & 94.1 & 53.3 & 92.9\end{array}$

$\begin{array}{llllll}46.2 & 69.2 & 69.2 & 92.9 & 53.3 & 92.9 \\ 14.3 & 38.1 & 55.6 & 88.9\end{array}$

$\begin{array}{llllll}14.3 & 38.1 & 56.9 & 84.3 & 39.5 & 79.5\end{array}$




\begin{tabular}{|c|c|c|c|c|c|c|c|c|c|c|c|c|}
\hline \multirow{3}{*}{$\begin{array}{l}\text { Country } \\
\text { (alphabetical order by region) }\end{array}$} & \multicolumn{6}{|l|}{2000} & \multicolumn{6}{|l|}{2020} \\
\hline & \multicolumn{2}{|c|}{$15-24$ years } & \multicolumn{2}{|c|}{$25-39$ years } & \multicolumn{2}{|c|}{$40-64$ years } & \multicolumn{2}{|c|}{$15-24$ years } & \multicolumn{2}{|c|}{$25-39$ years } & \multicolumn{2}{|c|}{$40-64$ years } \\
\hline & Female & Male & Female & Male & Female & Male & Female & Male & Female & Male & Female & Male \\
\hline Trinidad and Tobago & 41.7 & 62.2 & 63.2 & 94.0 & 48.1 & 85.4 & 41.0 & 56.5 & 60.0 & 97.0 & 46.8 & 83.7 \\
\hline United States & 61.9 & 67.3 & 75.9 & 93.3 & 70.0 & 83.5 & 58.1 & 59.0 & 76.0 & 91.3 & 72.9 & 79.5 \\
\hline Uruguay & 49.0 & 72.4 & 76.1 & 95.9 & 60.0 & 85.6 & 50.9 & 74.2 & 87.4 & 96.2 & 75.4 & 84.4 \\
\hline Venezuela, Bolivarian Republic of & 34.4 & 64.6 & 63.7 & 96.4 & 51.2 & 91.8 & 48.4 & 71.2 & 91.6 & 96.1 & 75.0 & 88.8 \\
\hline Asia and the Pacific & 47.5 & 66.5 & 67.6 & 97.1 & 54.9 & 91.4 & 43.7 & 62.0 & 66.0 & 95.6 & 53.4 & 88.6 \\
\hline Afghanistan & 37.0 & 75.2 & 40.8 & 98.1 & 36.6 & 96.0 & 41.8 & 75.6 & 51.6 & 98.1 & 47.3 & 96.1 \\
\hline Australia & 67.8 & 69.1 & 69.1 & 92.0 & 61.7 & 80.3 & 69.6 & 69.3 & 74.4 & 86.6 & 71.8 & 76.5 \\
\hline Bahrain & 23.1 & 59.0 & 43.4 & 99.3 & 20.4 & 95.3 & 24.2 & 58.3 & 51.5 & 99.2 & 17.4 & 88.3 \\
\hline Bangladesh & 51.8 & 72.3 & 61.8 & 97.6 & 56.8 & 95.4 & 49.4 & 69.9 & 61.7 & 97.5 & 49.2 & 94.4 \\
\hline Brunei Darussalam & 35.5 & 54.8 & 61.7 & 97.8 & 40.7 & 89.2 & 33.3 & 51.2 & 58.2 & 96.9 & 33.8 & 79.1 \\
\hline Cambodia & 68.7 & 58.0 & 85.4 & 96.7 & 81.0 & 94.5 & 67.4 & 59.8 & 86.5 & 95.5 & 78.7 & 93.6 \\
\hline China & 73.9 & 72.1 & 91.8 & 97.7 & 65.2 & 90.8 & 69.8 & 68.5 & 92.1 & 97.0 & 59.8 & 89.0 \\
\hline Fiji & 45.7 & 56.5 & 59.1 & 96.7 & 52.9 & 94.0 & 48.1 & 56.1 & 66.3 & 97.3 & 64.2 & 92.9 \\
\hline India & 26.7 & 64.4 & 40.5 & 97.0 & 39.6 & 91.8 & 26.1 & 56.4 & 40.5 & 96.7 & 39.1 & 89.7 \\
\hline Indonesia & 42.9 & 66.8 & 56.5 & 96.6 & 57.7 & 94.9 & 38.9 & 64.5 & 62.6 & 97.1 & 61.7 & 93.3 \\
\hline Iran, Islamic Republic of & 29.7 & 51.5 & 40.8 & 93.7 & 28.7 & 88.1 & 38.2 & 48.1 & 64.7 & 91.6 & 47.9 & 77.7 \\
\hline Iraq & 17.4 & 59.7 & 25.3 & 96.0 & 14.8 & 82.1 & 22.7 & 59.9 & 34.4 & 96.3 & 19.3 & 81.1 \\
\hline Japan & 46.5 & 47.4 & 63.1 & 97.0 & 62.0 & 92.4 & 42.8 & 42.6 & 72.6 & 94.0 & 64.5 & 88.3 \\
\hline Jordan & 21.8 & 55.1 & 33.5 & 96.7 & 20.4 & 81.7 & 30.3 & 56.3 & 52.6 & 96.8 & 31.1 & 83.2 \\
\hline Korea, Republic of & 33.3 & 41.7 & 59.8 & 92.7 & 51.2 & 91.6 & 34.3 & 37.3 & 59.3 & 93.8 & 49.2 & 91.4 \\
\hline Kuwait & 26.0 & 43.5 & 63.0 & 99.3 & 31.3 & 89.0 & 33.5 & 40.6 & 83.5 & 98.4 & 50.0 & 84.8 \\
\hline
\end{tabular}




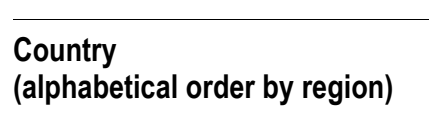

\begin{tabular}{|c|c|c|c|c|}
\hline & \multirow{2}{*}{ 15-24 years } & \multirow{2}{*}{\multicolumn{2}{|c|}{ 25-39 years }} & \multirow{2}{*}{ 40-64 years } \\
\hline & & & & \\
\hline & Female & Female & Male & Female \\
\hline
\end{tabular}

Lao People's Democratic Republic $\quad 49.0 \quad 61.8$

$61.9 \quad 96.2$

$57.6 \quad 91.1$

Lebanon

Malaysia

Mongolia

Myanmar

Nepal

New Zealand

Oman

Pakistan

Papua New Guinea

Philippines

Qatar

Samoa

Saudi Arabia

Singapore

Solomon Islands

Sri Lanka

Syrian Arab Republic

Thailand

Timor-Leste

United Arab Emirates

$18.7 \quad 58.1$

$40.6 \quad 57.2$

$49.0 \quad 62.2$

$57.6 \quad 72.3$

$51.7 \quad 62.2$

$59.8 \quad 65.5$

$14.7 \quad 54.3$

$21.8 \quad 70.3$

$60.7 \quad 57.7$

$37.7 \quad 58.9$

$5.4 \quad 45.2$

$33.3 \quad 55.6$

$7.5 \quad 48.2$

$49.4 \quad 46.7$

$53.5 \quad 65.2$

$30.9 \quad 57.2$

$36.6 \quad 73.0$

$48.5 \quad 57.4$

$41.8 \quad 51.4$

$23.4 \quad 65.0$

$\begin{array}{llll}48.3 & 96.5 & 29.6 & 92.0\end{array}$

$\begin{array}{llll}55.0 & 98.4 & 42.6 & 89.9\end{array}$

$\begin{array}{ll}42.6 & 89.9 \\ 57.6 & 92.7\end{array}$

$$
63.2
$$

$77.3 \quad 96.5$

$74.0 \quad 93.9$

$55.7 \quad 93.8$

$69.3 \quad 91.5$

$30.2 \quad 98.2$

$37.4 \quad 96.8$

$48.1 \quad 89.5$

$69.4 \quad 85.6$

$16.0 \quad 90.1$

$\begin{array}{llll}78.1 & 83.1 & 77.9 & 82.7\end{array}$

$\begin{array}{llll}54.8 & 97.1 & 57.8 & 93.8\end{array}$

$\begin{array}{llll}48.3 & 97.2 & 37.5 & 96.6\end{array}$

$55.6-100.0$

$46.2 \quad 92.9$

$28.4 \quad 97.3$

$72.8 \quad 97.6$

$11.2 \quad 88.3$

$59.5 \quad 95.3$

$48.3 \quad 88.0$

$\begin{array}{lll}95.3 & 55.2 & 93.1\end{array}$

$\begin{array}{llll}48.4 & 95.3 & 39.2 & 84.8\end{array}$

$\begin{array}{llll}39.3 & 99.4 & 31.6 & 91.2\end{array}$

$\begin{array}{llll}82.2 & 96.0 & 72.0 & 93.9\end{array}$

$\begin{array}{llll}56.9 & 95.5 & 53.2 & 90.9\end{array}$

$45.9 \quad 99.0$

$29.6 \quad 98.4$

2020

\begin{tabular}{lll}
\hline 15-24 years & & $25-39$ years \\
$\quad$ Memale & Female
\end{tabular}

50.5

$\begin{array}{ll}50.5 & 62.4 \\ 19.3 & 59.1\end{array}$

62.0

$\begin{array}{ll}19.3 & 59.1 \\ 45.9 & 54.8\end{array}$

$67.7 \quad 97.8$

$\begin{array}{ll}45.9 & 54.8 \\ 49.6 & 57.5\end{array}$

$79.0 \quad 99.3$

$\begin{array}{llll}49.6 & 57.5 & 62.9 & 97.2\end{array}$

$54.9 \quad 69.4$

$50.2 \quad 62.2$

$62.1 \quad 62.8$

$25.1 \quad 53.1$

$34.8 \quad 72.4$

$62.4 \quad 62.4$

$47.8 \quad 62.8$

$6.3 \quad 34.7$

$30.0 \quad 47.8$

$10.1 \quad 48.5$

$50.4 \quad 46.2$

$50.8 \quad 61.4$

$0.0 \quad 0.0$

$41.6 \quad 78.0$

$37.2 \quad 53.5$

$58.5 \quad 71.4$

$30.1 \quad 61.0$

$78.9 \quad 95.1$

$61.3 \quad 93.5$

$76.2 \quad 87.1$

$66.1 \quad 98.9$

$\begin{array}{ll}62.1 & 89.4 \\ 78.0 & 83.7\end{array}$

$\begin{array}{ll}78.0 & 83.7\end{array}$

$76.7 \quad 95.8$

\begin{tabular}{cc} 
& \\
\hline 40-64 years & \\
\hline Female & Male \\
\hline 57.3 & 91.5 \\
39.3 & 90.8 \\
41.6 & 87.5 \\
55.0 & 93.1 \\
73.4 & 93.6 \\
54.8 & 88.1 \\
81.9 & 89.1 \\
36.5 & 86.4 \\
53.0 & 85.3 \\
77.8 & 81.8 \\
73.2 & 92.4 \\
44.2 & 93.3 \\
42.9 & 91.7 \\
16.4 & 86.6 \\
51.5 & 79.2 \\
55.6 & 92.3 \\
0.0 & 0.0 \\
44.5 & 91.9 \\
77.6 & 90.3 \\
56.5 & 85.9 \\
42.8 & 97.8 \\
& \\
\hline
\end{tabular}




\begin{tabular}{|c|c|c|c|c|c|c|c|c|c|c|c|c|}
\hline \multirow{3}{*}{$\begin{array}{l}\text { Country } \\
\text { (alphabetical order by region) }\end{array}$} & \multicolumn{6}{|l|}{2000} & \multicolumn{6}{|l|}{2020} \\
\hline & \multicolumn{2}{|c|}{$15-24$ years } & \multicolumn{2}{|c|}{ 25-39 years } & \multicolumn{2}{|c|}{$40-64$ years } & \multicolumn{2}{|c|}{$15-24$ years } & \multicolumn{2}{|c|}{$25-39$ years } & \multicolumn{2}{|c|}{$40-64$ years } \\
\hline & Female & Male & Female & Male & Female & Male & Female & Male & Female & Male & Female & Male \\
\hline Vanuatu & 72.2 & 77.8 & 85.0 & 94.7 & 85.7 & 93.3 & 76.9 & 80.8 & 81.3 & 96.9 & 85.2 & 92.6 \\
\hline Viet Nam & 74.2 & 71.0 & 88.9 & 96.0 & 69.3 & 81.6 & 69.4 & 65.9 & 89.2 & 94.9 & 66.1 & 79.7 \\
\hline Yemen & 20.3 & 58.2 & 39.7 & 87.1 & 30.0 & 96.4 & 27.5 & 57.4 & 53.0 & 89.4 & 38.7 & 95.0 \\
\hline Europe and Central Asia & 39.1 & 49.6 & 73.5 & 92.8 & 57.8 & 77.4 & 37.6 & 47.8 & 76.7 & 91.6 & 60.8 & 74.8 \\
\hline Albania & 46.3 & 59.1 & 68.6 & 89.6 & 54.5 & 84.8 & 45.1 & 56.0 & 61.8 & 83.1 & 51.8 & 72.4 \\
\hline Armenia & 27.1 & 27.2 & 72.0 & 90.3 & 61.9 & 84.8 & 24.7 & 22.8 & 70.2 & 86.6 & 51.9 & 80.1 \\
\hline Austria & 50.1 & 61.4 & 78.9 & 93.6 & 52.7 & 75.3 & 47.4 & 57.2 & 85.7 & 90.2 & 65.8 & 71.8 \\
\hline Azerbaijan & 42.7 & 51.7 & 78.0 & 94.0 & 64.7 & 83.6 & 55.1 & 56.0 & 91.0 & 96.7 & 66.5 & 71.0 \\
\hline Belarus & 40.4 & 47.7 & 86.8 & 89.4 & 64.1 & 75.6 & 36.9 & 47.2 & 83.2 & 85.9 & 57.1 & 60.6 \\
\hline Belgium & 32.7 & 38.8 & 81.8 & 95.6 & 48.2 & 72.1 & 29.0 & 40.0 & 82.3 & 93.2 & 59.3 & 65.9 \\
\hline Bosnia and Herzegovina & 44.2 & 52.7 & 82.3 & 94.6 & 60.4 & 78.6 & 53.0 & 53.1 & 92.8 & 97.7 & 65.8 & 69.2 \\
\hline Bulgaria & 25.8 & 29.3 & 72.6 & 82.1 & 55.4 & 66.5 & 19.2 & 27.4 & 65.1 & 81.0 & 51.6 & 59.1 \\
\hline Croatia & 39.5 & 45.1 & 80.8 & 92.7 & 48.5 & 71.1 & 38.8 & 39.1 & 81.1 & 88.4 & 50.0 & 60.1 \\
\hline Cyprus & 40.7 & 56.5 & 73.6 & 96.3 & 53.8 & 86.6 & 43.6 & 45.6 & 91.9 & 95.6 & 67.5 & 78.0 \\
\hline Czech Republic & 40.7 & 51.3 & 75.3 & 96.4 & 66.6 & 81.3 & 33.3 & 33.5 & 75.9 & 93.8 & 74.8 & 80.0 \\
\hline Denmark & 68.5 & 75.3 & 84.4 & 93.0 & 71.7 & 81.1 & 60.5 & 70.4 & 81.3 & 91.1 & 74.6 & 80.0 \\
\hline Estonia & 35.1 & 47.5 & 80.3 & 94.2 & 68.6 & 78.3 & 26.7 & 37.5 & 72.7 & 89.6 & 73.6 & 78.4 \\
\hline Finland & 50.5 & 50.7 & 81.1 & 92.4 & 74.5 & 77.0 & 54.6 & 51.6 & 82.4 & 92.7 & 73.3 & 76.4 \\
\hline France & 26.3 & 33.3 & 78.8 & 94.6 & 64.2 & 78.1 & 25.5 & 33.2 & 81.5 & 91.7 & 65.5 & 71.7 \\
\hline Georgia & 28.0 & 43.7 & 61.5 & 86.1 & 69.0 & 86.7 & 22.5 & 43.9 & 43.4 & 85.9 & 62.5 & 90.2 \\
\hline Germany & 48.4 & 55.3 & 76.4 & 93.4 & 59.9 & 77.5 & 44.0 & 48.6 & 79.4 & 91.4 & 75.5 & 78.1 \\
\hline
\end{tabular}




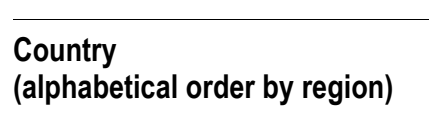

\begin{tabular}{|c|c|c|c|c|c|c|c|c|c|c|c|c|}
\hline \multirow[t]{3}{*}{ alpn } & & & & & & & \\
\hline & \multicolumn{2}{|c|}{$15-24$ years } & \multicolumn{2}{|c|}{$25-39$ years } & \multicolumn{2}{|c|}{$40-64$ years } & \multicolumn{2}{|c|}{ 15-24 years } & \multicolumn{2}{|c|}{$25-39$ years } & \multicolumn{2}{|c|}{$40-64$ years } \\
\hline & Female & Male & Female & Male & Female & Male & Female & Male & Female & Male & Female & Male \\
\hline Greece & 36.4 & 43.7 & 69.8 & 95.5 & 43.5 & 81.2 & 31.2 & 37.1 & 83.8 & 95.3 & 66.5 & 79.9 \\
\hline Hungary & 32.9 & 42.7 & 67.1 & 89.5 & 52.2 & 65.2 & 22.6 & 25.1 & 72.0 & 87.4 & 58.5 & 66.6 \\
\hline Iceland & 71.4 & 68.2 & 87.1 & 93.8 & 86.8 & 97.4 & 71.4 & 72.7 & 82.4 & 97.1 & 86.5 & 96.2 \\
\hline Ireland & 47.1 & 56.3 & 73.1 & 94.1 & 47.1 & 82.1 & 43.5 & 54.7 & 85.0 & 92.8 & 79.4 & 82.1 \\
\hline Israel & 36.0 & 33.0 & 68.1 & 82.8 & 59.9 & 79.5 & 34.3 & 26.1 & 76.4 & 81.0 & 68.5 & 72.3 \\
\hline Italy & 34.1 & 44.5 & 63.0 & 90.3 & 38.5 & 73.5 & 27.4 & 31.6 & 75.2 & 88.0 & 52.7 & 72.5 \\
\hline Kazakhstan & 48.7 & 55.3 & 88.5 & 96.2 & 71.9 & 85.1 & 49.5 & 54.5 & 88.5 & 93.2 & 79.0 & 84.7 \\
\hline Kyrgyzstan & 42.1 & 54.6 & 74.4 & 93.5 & 66.5 & 84.4 & 40.7 & 57.1 & 66.8 & 90.1 & 66.1 & 82.4 \\
\hline Latvia & 30.7 & 42.4 & 81.7 & 90.7 & 63.9 & 73.2 & 29.0 & 40.8 & 77.5 & 89.8 & 68.4 & 72.5 \\
\hline Lithuania & 30.9 & 41.4 & 87.5 & 93.5 & 68.8 & 80.1 & 23.5 & 32.1 & 87.5 & 90.7 & 68.9 & 78.8 \\
\hline Luxembourg & 32.0 & 38.5 & 71.7 & 94.4 & 43.9 & 76.5 & 22.6 & 28.1 & 80.4 & 94.6 & 61.0 & 73.0 \\
\hline Malta & 55.2 & 63.3 & 40.5 & 97.4 & 20.0 & 78.1 & 54.5 & 52.2 & 86.0 & 100.0 & 47.1 & 71.8 \\
\hline Moldova, Republic of & 41.3 & 43.6 & 87.1 & 92.7 & 63.4 & 82.8 & 43.9 & 46.6 & 87.0 & 92.6 & 56.7 & 80.6 \\
\hline Netherlands & 70.2 & 72.2 & 78.1 & 95.2 & 54.3 & 79.2 & 75.2 & 81.3 & 84.7 & 95.2 & 62.3 & 78.1 \\
\hline Norway & 61.0 & 65.9 & 82.7 & 91.7 & 77.0 & 86.1 & 64.9 & 68.9 & 84.6 & 90.9 & 81.0 & 82.9 \\
\hline Poland & 33.2 & 40.0 & 78.5 & 94.0 & 60.2 & 72.2 & 26.6 & 27.4 & 81.4 & 91.9 & 52.6 & 62.1 \\
\hline Portugal & 41.0 & 50.7 & 82.4 & 92.9 & 61.0 & 82.5 & 39.2 & 46.3 & 87.7 & 92.2 & 75.3 & 80.6 \\
\hline Romania & 38.1 & 50.7 & 78.1 & 91.7 & 63.0 & 77.8 & 22.9 & 23.0 & 70.7 & 82.5 & 53.3 & 66.7 \\
\hline Russian Federation & 36.3 & 45.2 & 84.1 & 92.5 & 65.4 & 76.4 & 29.6 & 38.5 & 89.8 & 95.8 & 63.3 & 73.6 \\
\hline Serbia & 34.4 & 51.6 & 69.8 & 94.1 & 44.4 & 73.6 & 52.9 & 53.0 & 86.0 & 97.2 & 54.1 & 71.8 \\
\hline Slovakia & 42.6 & 49.7 & 80.9 & 95.3 & 61.9 & 78.4 & 38.6 & 36.6 & 78.9 & 94.3 & 59.3 & 75.8 \\
\hline
\end{tabular}




\begin{tabular}{|c|c|c|c|c|c|c|c|c|c|c|c|c|}
\hline \multirow{3}{*}{$\begin{array}{l}\text { Country } \\
\text { (alphabetical order by region) }\end{array}$} & \multicolumn{6}{|l|}{2000} & \multicolumn{6}{|l|}{2020} \\
\hline & \multicolumn{2}{|c|}{$15-24$ years } & \multicolumn{2}{|c|}{$25-39$ years } & \multicolumn{2}{|c|}{ 40-64 years } & \multicolumn{2}{|c|}{$15-24$ years } & \multicolumn{2}{|c|}{ 25-39 years } & \multicolumn{2}{|c|}{$40-64$ years } \\
\hline & Female & Male & Female & Male & Female & Male & Female & Male & Female & Male & Female & Male \\
\hline Slovenia & 35.7 & 42.2 & 91.2 & 94.2 & 57.1 & 71.4 & 24.1 & 45.7 & 94.4 & 97.4 & 62.8 & 71.9 \\
\hline Spain & 41.8 & 52.1 & 70.9 & 93.5 & 42.8 & 82.1 & 34.4 & 45.9 & 82.0 & 92.7 & 62.3 & 81.7 \\
\hline Sweden & 49.9 & 51.1 & 83.5 & 89.9 & 80.0 & 84.8 & 50.4 & 51.4 & 81.8 & 89.3 & 79.7 & 84.2 \\
\hline Switzerland & 67.5 & 70.6 & 78.5 & 96.4 & 69.4 & 90.8 & 69.8 & 70.9 & 89.1 & 94.7 & 79.5 & 83.6 \\
\hline Tajikistan & 32.0 & 37.8 & 64.5 & 89.7 & 53.1 & 78.2 & 32.7 & 40.9 & 63.3 & 85.7 & 48.1 & 68.2 \\
\hline $\begin{array}{l}\text { The former Yugoslav Republic of } \\
\text { Macedonia }\end{array}$ & 30.9 & 45.6 & 64.1 & 90.9 & 43.3 & 74.9 & 25.6 & 42.4 & 64.9 & 89.6 & 48.3 & 73.0 \\
\hline Turkey & 27.9 & 58.6 & 30.4 & 93.4 & 25.2 & 75.8 & 28.1 & 67.1 & 31.1 & 88.7 & 24.7 & 76.1 \\
\hline Turkmenistan & 43.5 & 52.4 & 79.9 & 94.6 & 67.2 & 84.1 & 42.8 & 51.2 & 82.5 & 95.3 & 63.7 & 81.7 \\
\hline Ukraine & 37.6 & 43.3 & 83.6 & 91.3 & 60.3 & 73.2 & 32.3 & 42.1 & 82.9 & 92.1 & 56.1 & 70.8 \\
\hline United Kingdom & 65.2 & 72.7 & 75.4 & 93.7 & 65.3 & 80.8 & 64.5 & 66.4 & 80.2 & 89.3 & 69.8 & 78.6 \\
\hline Uzbekistan & 38.5 & 49.8 & 73.7 & 92.4 & 64.0 & 83.5 & 50.6 & 52.4 & 86.7 & 94.9 & 67.2 & 81.2 \\
\hline Source: ILO. & & & & & & & & & & & & \\
\hline
\end{tabular}


Table G1. Projected life expectancy at birth, female and male population, ILO member States with data, 2008, 2018 and 2048

\begin{tabular}{|c|c|c|c|c|c|c|}
\hline \multirow[t]{3}{*}{ Country (alphabetical order by region) } & \multicolumn{6}{|c|}{ Projected life expectancy at birth (years) } \\
\hline & \multicolumn{2}{|l|}{2008} & \multicolumn{2}{|l|}{2018} & \multicolumn{2}{|l|}{2048} \\
\hline & Female population & Male population & Female population & Male population & Female population & Male population \\
\hline \multicolumn{7}{|l|}{ Africa } \\
\hline Algeria & 73.7 & 70.9 & 76.1 & 72.8 & 80.9 & 77.1 \\
\hline Angola & 44.3 & 41.2 & 48.2 & 45.0 & 60.2 & 56.2 \\
\hline Benin & 57.8 & 55.6 & 62.5 & 60.2 & 71.8 & 69.6 \\
\hline Botswana & 50.7 & 50.5 & 54.0 & 54.7 & 67.9 & 65.8 \\
\hline Burkina Faso & 56.6 & 52.6 & 60.1 & 55.7 & 70.6 & 65.7 \\
\hline Burundi & 51.0 & 48.1 & 54.6 & 51.3 & 65.9 & 61.7 \\
\hline Cameroon & 50.8 & 50.0 & 54.9 & 53.3 & 65.7 & 63.2 \\
\hline Cape Verde & 74.5 & 68.3 & 76.7 & 70.7 & 81.2 & 75.7 \\
\hline Central African Republic & 46.1 & 43.3 & 49.4 & 46.4 & 61.1 & 56.2 \\
\hline Chad & 52.0 & 49.3 & 55.5 & 52.8 & 67.0 & 63.5 \\
\hline Comoros & 67.4 & 63.0 & 71.4 & 66.6 & 78.4 & 73.4 \\
\hline Congo & 56.6 & 54.0 & 59.7 & 56.9 & 69.5 & 66.1 \\
\hline Côte d'Ivoire & 49.3 & 47.5 & 52.8 & 51.3 & 63.5 & 61.8 \\
\hline Democratic Republic of the Congo & 47.7 & 45.2 & 51.0 & 48.2 & 62.5 & 59.3 \\
\hline Djibouti & 56.0 & 53.6 & 61.1 & 58.3 & 70.5 & 67.1 \\
\hline Egypt & 73.6 & 69.1 & 76.1 & 71.4 & 80.9 & 76.2 \\
\hline Equatorial Guinea & 52.8 & 50.4 & 57.4 & 54.8 & 67.6 & 64.4 \\
\hline Eritrea & 60.3 & 55.6 & 63.7 & 59.7 & 71.7 & 67.7 \\
\hline Ethiopia & 54.3 & 51.7 & 58.3 & 55.6 & 69.1 & 65.5 \\
\hline Gabon & 57.1 & 56.4 & 62.6 & 62.0 & 69.9 & 69.0 \\
\hline
\end{tabular}




\begin{tabular}{|c|c|c|c|c|c|c|}
\hline \multirow[t]{3}{*}{ Country (alphabetical order by region) } & \multicolumn{6}{|c|}{ Projected life expectancy at birth (years) } \\
\hline & \multicolumn{2}{|l|}{2008} & \multicolumn{2}{|l|}{2018} & \multicolumn{2}{|l|}{2048} \\
\hline & Female population & Male population & Female population & Male population & Female population & Male population \\
\hline Gambia & 60.3 & 58.6 & 64.2 & 63.2 & 72.5 & 70.4 \\
\hline Ghana & 60.5 & 59.6 & 64.2 & 62.8 & 72.2 & 69.7 \\
\hline Guinea & 57.6 & 54.4 & 62.9 & 59.3 & 74.1 & 69.8 \\
\hline Guinea-Bissau & 47.9 & 44.9 & 51.8 & 49.1 & 63.4 & 60.2 \\
\hline Kenya & 55.2 & 53.0 & 60.2 & 57.1 & 69.0 & 65.4 \\
\hline Lesotho & 42.3 & 42.9 & 45.3 & 47.1 & 56.4 & 55.3 \\
\hline Liberia & 46.6 & 44.8 & 50.3 & 48.5 & 61.6 & 59.4 \\
\hline Libyan Arab Jamahiriya & 76.9 & 71.7 & 78.7 & 73.6 & 82.6 & 77.7 \\
\hline Madagascar & 61.3 & 57.7 & 64.9 & 60.3 & 73.6 & 69.0 \\
\hline Malawi & 48.4 & 48.1 & 51.5 & 51.5 & 61.7 & 58.8 \\
\hline Mali & 56.6 & 52.1 & 60.4 & 56.0 & 70.4 & 65.8 \\
\hline Mauritania & 66.0 & 62.4 & 69.2 & 65.3 & 75.8 & 71.5 \\
\hline Mauritius & 76.2 & 69.5 & 77.6 & 71.3 & 81.6 & 75.9 \\
\hline Morocco & 73.4 & 69.0 & 75.9 & 71.3 & 80.8 & 76.1 \\
\hline Mozambique & 42.4 & 41.7 & 45.6 & 45.6 & 58.8 & 55.6 \\
\hline Namibia & 53.1 & 52.5 & 54.0 & 54.7 & 63.3 & 61.7 \\
\hline Niger & 56.0 & 57.8 & 60.2 & 61.5 & 70.4 & 69.1 \\
\hline Nigeria & 47.3 & 46.4 & 50.8 & 49.9 & 62.9 & 61.4 \\
\hline Rwanda & 47.8 & 44.6 & 52.6 & 48.7 & 64.0 & 59.8 \\
\hline Sao Tome and Principe & 67.4 & 63.6 & 69.9 & 65.7 & 76.1 & 71.7 \\
\hline Senegal & 65.1 & 61.1 & 67.8 & 63.3 & 73.6 & 68.5 \\
\hline Sierra Leone & 44.2 & 41.0 & 47.0 & 43.7 & 58.8 & 54.8 \\
\hline Somalia & 49.4 & 46.9 & 53.5 & 50.8 & 65.5 & 62.0 \\
\hline South Africa & 49.7 & 48.8 & 51.8 & 52.1 & 64.1 & 61.2 \\
\hline
\end{tabular}




\begin{tabular}{|c|c|c|c|c|c|c|}
\hline \multirow[t]{3}{*}{ Country (alphabetical order by region) } & \multicolumn{6}{|c|}{ Projected life expectancy at birth (years) } \\
\hline & \multicolumn{2}{|l|}{2008} & \multicolumn{2}{|l|}{2018} & \multicolumn{2}{|l|}{2048} \\
\hline & Female population & Male population & Female population & Male population & Female population & Male population \\
\hline Sudan & 60.1 & 57.1 & 63.9 & 60.6 & 72.3 & 68.5 \\
\hline Swaziland & 39.4 & 39.8 & 40.9 & 43.7 & 54.0 & 53.9 \\
\hline Tanzania, United Republic of & 53.6 & 51.4 & 57.4 & 55.0 & 67.6 & 64.6 \\
\hline Togo & 60.1 & 56.7 & 63.9 & 60.2 & 72.0 & 68.1 \\
\hline Tunisia & 76.0 & 71.9 & 77.9 & 73.4 & 82.1 & 77.5 \\
\hline Uganda & 52.2 & 50.8 & 57.6 & 55.5 & 66.5 & 64.0 \\
\hline Zambia & 42.5 & 42.1 & 46.8 & 46.6 & 59.0 & 55.9 \\
\hline Zimbabwe & 42.7 & 44.1 & 49.8 & 50.6 & 65.7 & 62.8 \\
\hline \multicolumn{7}{|l|}{ Americas } \\
\hline Argentina & 79.1 & 71.6 & 80.8 & 73.3 & 84.5 & 77.0 \\
\hline Bahamas & 76.3 & 70.6 & 78.6 & 72.9 & 83.5 & 78.0 \\
\hline Barbados & 79.8 & 74.4 & 81.2 & 76.2 & 84.1 & 79.1 \\
\hline Belize & 79.2 & 73.3 & 79.3 & 72.5 & 82.9 & 78.4 \\
\hline Bolivia & 67.7 & 63.4 & 71.0 & 66.6 & 79.0 & 74.0 \\
\hline Brazil & 76.1 & 68.8 & 78.3 & 71.2 & 83.0 & 76.0 \\
\hline Canada & 82.9 & 78.3 & 84.1 & 79.9 & 87.5 & 83.2 \\
\hline Chile & 81.5 & 75.5 & 82.8 & 76.7 & 85.4 & 79.0 \\
\hline Colombia & 76.6 & 69.2 & 78.4 & 71.4 & 82.0 & 76.0 \\
\hline Costa Rica & 81.2 & 76.5 & 82.4 & 77.5 & 84.7 & 79.5 \\
\hline Cuba & 80.4 & 76.2 & 82.0 & 77.8 & 85.0 & 80.8 \\
\hline Dominican Republic & 75.5 & 69.3 & 77.4 & 71.1 & 81.1 & 74.6 \\
\hline Ecuador & 78.0 & 72.1 & 79.5 & 73.6 & 83.0 & 77.1 \\
\hline El Salvador & 74.9 & 68.8 & 77.1 & 70.8 & 82.0 & 75.5 \\
\hline Grenada & 70.4 & 67.0 & 72.2 & 68.5 & 78.3 & 74.0 \\
\hline
\end{tabular}




\begin{tabular}{|c|c|c|c|c|c|c|}
\hline \multirow[t]{3}{*}{ Country (alphabetical order by region) } & \multicolumn{6}{|c|}{ Projected life expectancy at birth (years) } \\
\hline & \multicolumn{2}{|l|}{2008} & \multicolumn{2}{|l|}{2018} & \multicolumn{2}{|l|}{2048} \\
\hline & Female population & Male population & Female population & Male population & Female population & Male population \\
\hline Guatemala & 73.8 & 66.7 & 76.1 & 69.1 & 81.5 & 74.5 \\
\hline Guyana & 69.9 & 64.2 & 73.1 & 67.7 & 78.7 & 73.5 \\
\hline Haiti & 62.8 & 59.1 & 66.4 & 62.4 & 76.6 & 71.8 \\
\hline Honduras & 73.7 & 66.9 & 75.7 & 69.4 & 80.4 & 74.4 \\
\hline Jamaica & 75.2 & 70.0 & 76.5 & 71.6 & 79.8 & 75.2 \\
\hline Mexico & 78.6 & 73.7 & 80.6 & 75.8 & 83.5 & 78.9 \\
\hline Nicaragua & 76.0 & 69.9 & 78.9 & 72.6 & 81.6 & 75.2 \\
\hline Panama & 78.2 & 73.0 & 79.9 & 74.4 & 83.5 & 77.5 \\
\hline Paraguay & 73.9 & 69.7 & 75.9 & 71.5 & 79.5 & 75.1 \\
\hline Saint Lucia & 75.6 & 71.9 & 77.6 & 73.6 & 81.8 & 77.7 \\
\hline Saint Vincent and the Grenadines & 73.8 & 69.5 & 75.6 & 71.2 & 79.5 & 75.2 \\
\hline Suriname & 73.6 & 67.0 & 75.5 & 69.2 & 80.1 & 74.8 \\
\hline Trinidad and Tobago & 71.8 & 67.8 & 75.0 & 70.9 & 80.9 & 76.4 \\
\hline United States & 80.8 & 75.6 & 82.1 & 76.8 & 85.7 & 80.4 \\
\hline Uruguay & 79.9 & 72.8 & 81.4 & 74.6 & 84.7 & 78.5 \\
\hline Venezuela, Bolivarian Republic of & 76.8 & 70.9 & 78.6 & 72.6 & 82.7 & 76.5 \\
\hline \multicolumn{7}{|l|}{ Asia and the Pacific } \\
\hline Afghanistan & 43.8 & 43.9 & 47.2 & 47.2 & 58.9 & 58.5 \\
\hline Australia & 83.6 & 78.9 & 84.8 & 80.6 & 88.0 & 84.1 \\
\hline Bahrain & 77.5 & 74.3 & 79.1 & 75.7 & 82.9 & 79.2 \\
\hline Bangladesh & 65.0 & 63.2 & 69.5 & 66.8 & 77.6 & 73.6 \\
\hline Brunei Darussalam & 79.7 & 75.0 & 81.0 & 76.0 & 83.7 & 78.7 \\
\hline Cambodia & 61.9 & 57.3 & 67.0 & 63.4 & 76.2 & 71.8 \\
\hline China & 74.8 & 71.3 & 76.9 & 73.2 & 81.3 & 77.4 \\
\hline
\end{tabular}




\begin{tabular}{|c|c|c|c|c|c|c|}
\hline \multirow[t]{3}{*}{ Country (alphabetical order by region) } & \multicolumn{6}{|c|}{ Projected life expectancy at birth (years) } \\
\hline & \multicolumn{2}{|l|}{2008} & \multicolumn{2}{|l|}{2018} & \multicolumn{2}{|l|}{2048} \\
\hline & Female population & Male population & Female population & Male population & Female population & Male population \\
\hline Fiji & 71.1 & 66.6 & 72.9 & 68.2 & 78.6 & 73.8 \\
\hline India & 66.4 & 63.2 & 70.4 & 66.6 & 77.9 & 73.4 \\
\hline Indonesia & 72.7 & 68.7 & 75.7 & 71.4 & 80.8 & 76.4 \\
\hline Iran, Islamic Republic of & 72.6 & 69.4 & 75.3 & 71.6 & 80.4 & 76.3 \\
\hline Iraq & 61.5 & 57.8 & 70.6 & 66.9 & 78.3 & 73.8 \\
\hline Japan & 86.1 & 79.0 & 87.9 & 80.5 & 90.9 & 83.3 \\
\hline Jordan & 74.5 & 70.8 & 76.7 & 72.8 & 81.3 & 77.1 \\
\hline Korea, Republic of & 82.2 & 75.0 & 83.8 & 76.6 & 87.1 & 79.9 \\
\hline Kuwait & 79.9 & 76.0 & 81.2 & 77.3 & 84.4 & 80.5 \\
\hline Lao People's Democratic Republic & 65.8 & 63.0 & 70.1 & 66.7 & 77.8 & 73.5 \\
\hline Lebanon & 74.2 & 69.9 & 76.0 & 71.7 & 80.8 & 76.4 \\
\hline Malaysia & 76.7 & 72.0 & 78.5 & 73.8 & 82.4 & 77.8 \\
\hline Mongolia & 69.9 & 63.9 & 72.4 & 67.3 & 78.6 & 73.9 \\
\hline Myanmar & 65.3 & 59.1 & 69.5 & 63.9 & 77.3 & 71.9 \\
\hline Nepal & 64.2 & 63.2 & 68.8 & 66.8 & 77.3 & 73.6 \\
\hline New Zealand & 82.2 & 78.2 & 83.4 & 79.9 & 86.8 & 83.5 \\
\hline Oman & 77.5 & 74.2 & 79.4 & 75.9 & 83.1 & 79.4 \\
\hline Pakistan & 65.8 & 65.2 & 69.1 & 68.4 & 77.0 & 74.4 \\
\hline Papua New Guinea & 60.4 & 54.6 & 62.7 & 57.3 & 69.7 & 65.8 \\
\hline Philippines & 73.9 & 69.5 & 76.3 & 71.7 & 81.0 & 76.4 \\
\hline Qatar & 76.4 & 75.2 & 78.2 & 76.6 & 82.2 & 79.9 \\
\hline Samoa & 74.9 & 68.5 & 77.0 & 71.0 & 81.4 & 75.8 \\
\hline Saudi Arabia & 75.3 & 70.9 & 77.3 & 72.8 & 81.6 & 77.1 \\
\hline Singapore & 81.9 & 78.0 & 83.2 & 79.2 & 86.7 & 82.6 \\
\hline
\end{tabular}




\begin{tabular}{|c|c|c|c|c|c|c|}
\hline \multirow[t]{3}{*}{ Country (alphabetical order by region) } & \multicolumn{6}{|c|}{ Projected life expectancy at birth (years) } \\
\hline & \multicolumn{2}{|l|}{2008} & \multicolumn{2}{|l|}{2018} & \multicolumn{2}{|l|}{2048} \\
\hline & Female population & Male population & Female population & Male population & Female population & Male population \\
\hline Sri Lanka & 76.2 & 68.8 & 77.6 & 70.2 & 80.9 & 74.3 \\
\hline Syrian Arab Republic & 76.1 & 72.3 & 78.0 & 74.0 & 82.1 & 77.9 \\
\hline Thailand & 75.0 & 66.5 & 76.6 & 69.1 & 81.1 & 74.9 \\
\hline Timor-Leste & 61.7 & 60.0 & 66.6 & 64.2 & 76.3 & 72.3 \\
\hline United Arab Emirates & 81.5 & 77.2 & 82.8 & 78.4 & 86.3 & 81.9 \\
\hline Vanuatu & 72.1 & 68.3 & 74.9 & 70.7 & 80.2 & 75.8 \\
\hline Viet Nam & 76.2 & 72.3 & 78.4 & 74.2 & 82.5 & 78.2 \\
\hline Yemen & 64.4 & 61.1 & 68.9 & 65.1 & 77.3 & 72.7 \\
\hline \multicolumn{7}{|l|}{ Europe and Central Asia } \\
\hline Albania & 79.7 & 73.4 & 81.0 & 75.0 & 84.3 & 78.7 \\
\hline Armenia & 75.1 & 68.4 & 76.5 & 69.9 & 80.0 & 74.3 \\
\hline Austria & 82.6 & 76.9 & 83.8 & 78.2 & 87.2 & 81.7 \\
\hline Azerbaijan & 71.2 & 63.8 & 73.5 & 65.6 & 77.6 & 71.2 \\
\hline Belarus & 75.2 & 63.1 & 76.4 & 65.0 & 80.0 & 71.2 \\
\hline Belgium & 82.3 & 76.5 & 83.6 & 77.8 & 87.0 & 81.3 \\
\hline Bosnia and Herzegovina & 77.4 & 72.2 & 78.6 & 73.5 & 82.3 & 77.5 \\
\hline Bulgaria & 76.7 & 69.5 & 78.0 & 71.2 & 81.8 & 75.9 \\
\hline Croatia & 79.2 & 72.3 & 80.5 & 74.0 & 83.3 & 77.8 \\
\hline Cyprus & 81.6 & 76.5 & 82.9 & 77.8 & 86.0 & 81.0 \\
\hline Czech Republic & 79.5 & 73.4 & 81.1 & 75.1 & 84.9 & 79.1 \\
\hline Denmark & 80.6 & 76.0 & 82.0 & 77.4 & 85.2 & 80.7 \\
\hline Estonia & 76.8 & 65.9 & 78.4 & 68.8 & 82.4 & 75.4 \\
\hline Finland & 82.4 & 76.1 & 83.7 & 78.0 & 87.0 & 81.5 \\
\hline France & 84.1 & 77.1 & 85.3 & 78.4 & 88.5 & 81.8 \\
\hline
\end{tabular}




\begin{tabular}{|c|c|c|c|c|c|c|}
\hline \multirow[t]{3}{*}{ Country (alphabetical order by region) } & \multicolumn{6}{|c|}{ Projected life expectancy at birth (years) } \\
\hline & \multicolumn{2}{|l|}{2008} & \multicolumn{2}{|l|}{2018} & \multicolumn{2}{|l|}{2048} \\
\hline & Female population & Male population & Female population & Male population & Female population & Male population \\
\hline Georgia & 74.8 & 67.1 & 76.1 & 68.6 & 79.6 & 73.1 \\
\hline Germany & 82.1 & 76.5 & 83.4 & 77.9 & 86.8 & 81.4 \\
\hline Greece & 81.9 & 77.1 & 83.2 & 78.4 & 86.6 & 81.8 \\
\hline Hungary & 77.4 & 69.2 & 79.1 & 71.5 & 82.8 & 76.3 \\
\hline Iceland & 83.3 & 80.2 & 84.5 & 81.3 & 87.7 & 84.5 \\
\hline Ireland & 81.4 & 76.5 & 82.7 & 77.8 & 86.2 & 81.3 \\
\hline Israel & 82.8 & 78.6 & 84.0 & 80.1 & 87.3 & 83.4 \\
\hline Italy & 83.5 & 77.5 & 84.6 & 78.8 & 87.9 & 82.1 \\
\hline Kazakhstan & 72.4 & 61.6 & 75.3 & 65.7 & 80.4 & 73.0 \\
\hline Kyrgyzstan & 69.9 & 62.0 & 72.0 & 64.3 & 77.3 & 70.9 \\
\hline Latvia & 77.7 & 67.3 & 79.3 & 70.0 & 83.4 & 75.7 \\
\hline Lithuania & 78.3 & 67.5 & 79.8 & 70.1 & 83.4 & 75.8 \\
\hline Luxembourg & 81.6 & 75.7 & 83.0 & 77.1 & 86.4 & 80.7 \\
\hline Malta & 81.4 & 77.3 & 82.7 & 78.6 & 86.2 & 82.0 \\
\hline Moldova, Republic of & 72.5 & 65.1 & 74.2 & 67.0 & 78.5 & 72.8 \\
\hline Montenegro & 76.8 & 72.4 & 78.1 & 73.7 & 81.9 & 77.1 \\
\hline Netherlands & 81.9 & 77.5 & 83.0 & 78.8 & 85.9 & 82.1 \\
\hline Norway & 82.5 & 77.8 & 83.8 & 79.3 & 87.2 & 82.7 \\
\hline Poland & 79.8 & 71.3 & 81.1 & 73.2 & 84.3 & 77.4 \\
\hline Portugal & 81.2 & 75.0 & 82.5 & 76.5 & 85.7 & 79.9 \\
\hline Romania & 76.1 & 69.0 & 78.0 & 71.3 & 82.1 & 76.1 \\
\hline Russian Federation & 72.6 & 59.0 & 73.7 & 60.8 & 77.9 & 68.5 \\
\hline Serbia & 76.3 & 71.7 & 77.7 & 73.1 & 81.7 & 77.2 \\
\hline Slovakia & 78.5 & 70.7 & 80.0 & 72.7 & 83.5 & 77.1 \\
\hline
\end{tabular}




\begin{tabular}{|c|c|c|c|c|c|c|}
\hline \multirow[t]{3}{*}{ Country (alphabetical order by region) } & \multicolumn{6}{|c|}{ Projected life expectancy at birth (years) } \\
\hline & \multicolumn{2}{|l|}{2008} & \multicolumn{2}{|l|}{2018} & \multicolumn{2}{|l|}{2048} \\
\hline & Female population & Male population & Female population & Male population & Female population & Male population \\
\hline Slovenia & 81.5 & 74.1 & 82.9 & 75.7 & 86.3 & 79.6 \\
\hline Spain & 84.2 & 77.7 & 85.4 & 78.9 & 88.6 & 82.3 \\
\hline Sweden & 83.0 & 78.7 & 84.2 & 80.3 & 87.0 & 83.5 \\
\hline Switzerland & 84.2 & 79.0 & 85.3 & 80.2 & 88.6 & 83.3 \\
\hline Tajikistan & 69.4 & 64.1 & 71.4 & 66.0 & 76.6 & 71.5 \\
\hline The former Yugoslav Republic of Macedonia & 76.6 & 71.8 & 77.9 & 73.2 & 81.8 & 77.2 \\
\hline Turkey & 74.3 & 69.4 & 76.1 & 71.3 & 80.9 & 76.1 \\
\hline Turkmenistan & 67.5 & 59.0 & 70.4 & 62.1 & 76.4 & 69.6 \\
\hline Ukraine & 73.8 & 62.1 & 75.1 & 64.5 & 79.1 & 71.0 \\
\hline United Kingdom & 81.6 & 77.2 & 82.9 & 78.5 & 86.4 & 81.9 \\
\hline Source: United Nations Population Division. & & & & & & \\
\hline
\end{tabular}




\begin{tabular}{|c|c|c|c|c|c|c|c|c|c|c|c|c|c|c|c|c|c|c|c|c|c|c|c|c|}
\hline \multirow{4}{*}{$\begin{array}{l}\text { Country } \\
\text { (alphabetical order } \\
\text { by region) }\end{array}$} & \multicolumn{24}{|c|}{ Projected life expectation (years) } \\
\hline & \multicolumn{8}{|l|}{$\ln 2008$} & \multicolumn{8}{|l|}{$\ln 2018$} & \multicolumn{8}{|l|}{ In 2048} \\
\hline & \multicolumn{2}{|c|}{ At 50 years } & \multicolumn{2}{|c|}{ At 60 years } & \multicolumn{2}{|c|}{ At 70 years } & \multicolumn{2}{|c|}{ At 80 years } & \multicolumn{2}{|c|}{ At 50 years } & \multicolumn{2}{|c|}{ At 60 years } & \multicolumn{2}{|c|}{ At 70 years } & \multicolumn{2}{|c|}{ At 80 years } & \multicolumn{2}{|c|}{ At 50 years } & \multicolumn{2}{|c|}{ At 60 years } & \multicolumn{2}{|c|}{ At 70 years } & \multicolumn{2}{|c|}{ At 80 years } \\
\hline & Female & Male & Female & Male & Female & Male & Female & Male & Female & Male & Female & Male & Female & Male & Female & Male & Female & Male & Female & Male & Female & Male & Female & Male \\
\hline \multicolumn{25}{|l|}{ Africa } \\
\hline Algeria & 28.3 & 25.9 & 19.7 & 17.4 & 12.3 & 10.4 & 6.8 & 5.5 & 29.3 & 26.6 & 20.5 & 18.0 & 12.8 & 10.8 & 7.1 & 5.7 & 32.8 & 29.1 & 23.7 & 20.2 & 15.5 & 12.5 & 9.0 & 6.8 \\
\hline Angola & 21.8 & 19.4 & 15.0 & 13.3 & 9.3 & 8.1 & 5.3 & 4.6 & 22.6 & 20.4 & 15.6 & 13.9 & 9.6 & 8.5 & 5.5 & 4.8 & 25.1 & 22.8 & 17.5 & 15.8 & 10.9 & 9.7 & 6.1 & 5.5 \\
\hline Benin & 24.9 & 22.3 & 16.8 & 14.9 & 9.9 & 8.7 & 5.1 & 4.6 & 25.9 & 23.4 & 17.6 & 15.7 & 10.4 & 9.2 & 5.3 & 4.8 & 28.9 & 26.4 & 19.9 & 17.9 & 12.0 & 10.6 & 6.1 & 5.5 \\
\hline Botswana & 22.8 & 18.7 & 16.2 & 13.4 & 9.8 & 8.3 & 5.4 & 4.9 & 21.7 & 19.0 & 15.7 & 13.5 & 9.5 & 8.5 & 5.2 & 5.0 & 25.7 & 22.9 & 18.3 & 15.9 & 11.6 & 9.9 & 6.7 & 5.7 \\
\hline Burkina Faso & 23.3 & 20.1 & 15.4 & 13.2 & 9.2 & 8.0 & 5.0 & 4.6 & 24.3 & 21.2 & 16.1 & 13.9 & 9.4 & 8.3 & 4.9 & 4.6 & 28.1 & 24.7 & 19.0 & 16.3 & 11.0 & 9.5 & 5.3 & 4.9 \\
\hline Burundi & 23.3 & 21.1 & 16.2 & 14.5 & 10.0 & 8.9 & 5.7 & 5.1 & 23.9 & 21.8 & 16.6 & 14.9 & 10.3 & 9.2 & 5.8 & 5.2 & 26.5 & 24.3 & 18.6 & 16.9 & 11.6 & 10.5 & 6.5 & 5.9 \\
\hline Cameroon & 23.3 & 21.3 & 16.3 & 14.7 & 10.1 & 9.1 & 5.7 & 5.2 & 24.0 & 22.0 & 16.8 & 15.3 & 10.4 & 9.4 & 5.9 & 5.4 & 26.5 & 24.6 & 18.7 & 17.2 & 11.7 & 10.7 & 6.5 & 6.1 \\
\hline Cape Verde & 27.8 & 24.3 & 19.1 & 16.4 & 11.7 & 10.0 & 6.3 & 5.6 & 29.3 & 25.2 & 20.4 & 17.1 & 12.7 & 10.4 & 7.0 & 5.8 & 32.9 & 27.8 & 23.8 & 19.1 & 15.6 & 11.8 & 9.0 & 6.5 \\
\hline \multicolumn{25}{|l|}{ Central African } \\
\hline Republic & 22.4 & 19.1 & 15.9 & 13.5 & 9.8 & 8.4 & 5.6 & 4.9 & 23.1 & 19.8 & 16.4 & 14.0 & 10.2 & 8.7 & 5.8 & 5.1 & 25.8 & 22.3 & 18.2 & 15.8 & 11.3 & 9.9 & 6.3 & 5.8 \\
\hline Chad & 23.7 & 21.0 & 16.0 & 14.0 & 9.3 & 8.2 & 4.9 & 4.4 & 24.4 & 21.6 & 16.5 & 14.5 & 9.7 & 8.4 & 5.0 & 4.5 & 27.4 & 24.3 & 18.8 & 16.4 & 11.2 & 9.7 & 5.7 & 5.1 \\
\hline Comoros & 25.4 & 22.8 & 17.4 & 15.4 & 10.6 & 9.4 & 5.8 & 5.3 & 26.5 & 23.7 & 18.2 & 16.0 & 11.1 & 9.8 & 6.0 & 5.4 & 30.6 & 26.4 & 21.7 & 18.0 & 13.8 & 11.0 & 7.7 & 6.0 \\
\hline Congo & 23.6 & 20.7 & 16.3 & 14.2 & 9.9 & 8.7 & 5.5 & 5.0 & 24.2 & 21.4 & 16.8 & 14.6 & 10.2 & 9.0 & 5.6 & 5.1 & 26.9 & 23.8 & 18.7 & 16.3 & 11.4 & 10.0 & 6.1 & 5.6 \\
\hline Côte d'Ivoire & 23.2 & 20.2 & 15.8 & 13.6 & 9.2 & 8.0 & 4.8 & 4.3 & 23.9 & 21.0 & 16.3 & 14.1 & 9.5 & 8.3 & 4.9 & 4.4 & 26.8 & 23.7 & 18.5 & 16.1 & 11.0 & 9.5 & 5.6 & 5.0 \\
\hline $\begin{array}{l}\text { Democratic Republic } \\
\text { of the Congo }\end{array}$ & 22.6 & 20.4 & 15.6 & 14.0 & 9.6 & 8.5 & 5.5 & 4.9 & 23.2 & 21.0 & 16.0 & 14.4 & 9.9 & 8.8 & 5.7 & 5.0 & 25.8 & 23.7 & 18.1 & 16.4 & 11.2 & 10.2 & 6.3 & 5.8 \\
\hline Djibouti & 23.3 & 21.0 & 15.9 & 14.2 & 9.7 & 8.7 & 5.5 & 5.0 & 24.4 & 22.1 & 16.7 & 15.0 & 10.2 & 9.1 & 5.7 & 5.2 & 26.5 & 23.9 & 18.3 & 16.2 & 11.2 & 9.9 & 6.1 & 5.5 \\
\hline
\end{tabular}




\begin{tabular}{|c|c|c|c|c|c|c|c|c|c|c|c|c|c|c|c|c|c|c|c|c|c|c|c|c|}
\hline \multirow{4}{*}{$\begin{array}{l}\text { Country } \\
\text { (alphabetical order } \\
\text { by region) }\end{array}$} & \multicolumn{24}{|c|}{ Projected life expectation (years) } \\
\hline & \multicolumn{8}{|l|}{$\ln 2008$} & \multicolumn{8}{|l|}{ In 2018} & \multicolumn{8}{|l|}{ In 2048} \\
\hline & \multicolumn{2}{|c|}{ At 50 years } & \multicolumn{2}{|c|}{ At 60 years } & \multicolumn{2}{|c|}{ At 70 years } & \multicolumn{2}{|c|}{ At 80 years } & \multicolumn{2}{|c|}{ At 50 years } & \multicolumn{2}{|c|}{ At 60 years } & \multicolumn{2}{|c|}{ At 70 years } & \multicolumn{2}{|c|}{ At 80 years } & \multicolumn{2}{|c|}{ At 50 years } & \multicolumn{2}{|c|}{ At 60 years } & \multicolumn{2}{|c|}{ At 70 years } & \multicolumn{2}{|c|}{ At 80 years } \\
\hline & Female & Male & Female & Male & Female & Male & Female & Male & Female & Male & Female & Male & Female & Male & Female & Male & Female & Male & Female & Male & Female & Male & Female & Male \\
\hline Egypt & 27.6 & 24.4 & 18.9 & 16.5 & 11.3 & 9.9 & 5.8 & 5.4 & 29.0 & 25.3 & 20.0 & 17.1 & 12.2 & 10.4 & 6.4 & 5.6 & 32.6 & 28.1 & 23.4 & 19.4 & 15.2 & 12.0 & 8.6 & 6.6 \\
\hline Equatorial Guinea & 23.9 & 22.0 & 16.5 & 15.2 & 10.2 & 9.3 & 5.8 & 5.3 & 24.7 & 23.0 & 17.1 & 15.8 & 10.6 & 9.7 & 6.0 & 5.5 & 26.8 & 25.1 & 18.7 & 17.4 & 11.7 & 10.8 & 6.6 & 6.2 \\
\hline Eritrea & 22.9 & 18.8 & 15.9 & 12.9 & 10.2 & 8.4 & 6.2 & 5.3 & 24.3 & 20.2 & 17.0 & 13.9 & 11.0 & 8.9 & 6.6 & 5.5 & 28.1 & 23.6 & 20.0 & 16.2 & 13.0 & 10.4 & 7.8 & 6.3 \\
\hline Ethiopia & 23.9 & 21.9 & 16.5 & 15.0 & 10.2 & 9.2 & 5.8 & 5.3 & 24.8 & 22.8 & 17.2 & 15.7 & 10.7 & 9.7 & 6.0 & 5.5 & 27.5 & 25.5 & 19.3 & 17.7 & 12.0 & 11.0 & 6.7 & 6.2 \\
\hline Gabon & 25.3 & 22.9 & 17.9 & 16.1 & 11.1 & 10.0 & 6.2 & 5.7 & 26.2 & 24.4 & 18.6 & 17.1 & 11.5 & 10.7 & 6.4 & 6.1 & 27.8 & 26.4 & 19.8 & 18.6 & 12.4 & 11.7 & 6.9 & 6.7 \\
\hline Gambia & 24.0 & 22.2 & 15.9 & 14.7 & 9.3 & 8.7 & 4.9 & 4.7 & 25.2 & 23.6 & 16.8 & 15.5 & 9.7 & 8.9 & 4.9 & 4.6 & 29.6 & 26.7 & 20.8 & 18.0 & 12.9 & 10.6 & 7.0 & 5.4 \\
\hline Ghana & 25.5 & 23.9 & 17.8 & 16.5 & 11.0 & 10.2 & 6.2 & 5.8 & 26.4 & 24.8 & 18.5 & 17.2 & 11.5 & 10.7 & 6.4 & 6.1 & 28.7 & 26.8 & 20.2 & 18.7 & 12.7 & 11.8 & 7.0 & 6.7 \\
\hline Guinea & 24.9 & 22.3 & 16.8 & 14.8 & 9.9 & 8.7 & 5.1 & 4.6 & 26.1 & 23.3 & 17.8 & 15.6 & 10.5 & 9.1 & 5.4 & 4.8 & 30.0 & 26.5 & 20.9 & 18.0 & 12.7 & 10.7 & 6.5 & 5.5 \\
\hline Guinea-Bissau & 22.7 & 20.3 & 15.7 & 13.9 & 9.7 & 8.5 & 5.5 & 4.8 & 23.5 & 21.4 & 16.3 & 14.7 & 10.0 & 9.0 & 5.7 & 5.1 & 26.1 & 23.9 & 18.2 & 16.6 & 11.3 & 10.3 & 6.4 & 5.9 \\
\hline Kenya & 24.4 & 21.7 & 17.2 & 15.3 & 10.7 & 9.5 & 6.0 & 5.5 & 25.4 & 22.9 & 17.8 & 16.0 & 11.1 & 9.9 & 6.2 & 5.7 & 27.6 & 25.1 & 19.5 & 17.6 & 12.2 & 11.0 & 6.8 & 6.3 \\
\hline Lesotho & 21.1 & 16.3 & 15.3 & 12.0 & 9.3 & 7.6 & 5.1 & 4.6 & 21.3 & 17.6 & 15.5 & 12.8 & 9.3 & 8.1 & 5.1 & 4.8 & 24.5 & 20.3 & 17.5 & 14.5 & 10.7 & 9.0 & 5.8 & 5.3 \\
\hline Liberia & 21.4 & 19.2 & 14.7 & 13.1 & 9.0 & 8.1 & 5.1 & 4.7 & 22.1 & 19.9 & 15.1 & 13.5 & 9.3 & 8.3 & 5.3 & 4.8 & 24.4 & 22.0 & 16.8 & 15.0 & 10.3 & 9.2 & 5.7 & 5.2 \\
\hline $\begin{array}{l}\text { Libyan Arab } \\
\text { Jamahiriya }\end{array}$ & 30.0 & 25.3 & 21.4 & 17.4 & 14.1 & 11.2 & 8.4 & 6.7 & 31.3 & 26.4 & 22.5 & 18.3 & 14.9 & 11.8 & 9.0 & 7.0 & 34.2 & 29.5 & 25.1 & 20.8 & 17.0 & 13.5 & 10.3 & 8.0 \\
\hline Madagascar & 25.4 & 23.5 & 17.6 & 16.2 & 10.9 & 10.0 & 6.2 & 5.6 & 26.3 & 24.0 & 18.3 & 16.6 & 11.4 & 10.3 & 6.4 & 5.8 & 28.7 & 26.4 & 20.1 & 18.4 & 12.6 & 11.5 & 7.0 & 6.5 \\
\hline Malawi & 23.5 & 19.4 & 16.4 & 13.5 & 9.6 & 8.0 & 4.9 & 4.4 & 24.1 & 20.3 & 16.9 & 14.1 & 9.9 & 8.3 & 5.0 & 4.5 & 27.0 & 22.5 & 19.0 & 15.7 & 11.3 & 9.3 & 5.8 & 4.9 \\
\hline Mali & 25.8 & 22.5 & 17.7 & 15.3 & 11.0 & 9.5 & 6.2 & 5.5 & 26.1 & 23.0 & 17.8 & 15.5 & 10.7 & 9.4 & 5.8 & 5.3 & 28.8 & 25.5 & 19.7 & 17.1 & 11.6 & 10.1 & 5.8 & 5.3 \\
\hline Mauritania & 24.7 & 22.5 & 16.0 & 14.6 & 9.0 & 8.3 & 4.4 & 4.4 & 26.4 & 23.9 & 17.4 & 15.6 & 9.8 & 8.9 & 4.6 & 4.5 & 30.1 & 27.2 & 20.8 & 18.5 & 12.4 & 11.0 & 6.1 & 5.8 \\
\hline Mauritius & 29.1 & 24.1 & 20.8 & 16.8 & 13.7 & 11.0 & 8.3 & 6.7 & 30.1 & 25.0 & 21.7 & 17.5 & 14.4 & 11.4 & 8.7 & 6.9 & 33.3 & 28.0 & 24.4 & 19.7 & 16.5 & 12.9 & 10.1 & 7.7 \\
\hline Morocco & 27.6 & 24.9 & 18.9 & 16.8 & 11.4 & 10.1 & 6.0 & 5.4 & 28.8 & 25.7 & 19.9 & 17.4 & 12.1 & 10.5 & 6.4 & 5.6 & 32.5 & 28.1 & 23.4 & 19.3 & 15.2 & 11.9 & 8.7 & 6.4 \\
\hline
\end{tabular}




\begin{tabular}{|c|c|c|c|c|c|c|c|c|c|c|c|c|c|c|c|c|c|c|c|c|c|c|c|c|}
\hline \multirow{4}{*}{$\begin{array}{l}\text { Country } \\
\text { (alphabetical order } \\
\text { by region) }\end{array}$} & \multicolumn{24}{|c|}{ Projected life expectation (years) } \\
\hline & \multicolumn{8}{|l|}{ In 2008} & \multicolumn{8}{|l|}{ In 2018} & \multicolumn{8}{|l|}{ In 2048} \\
\hline & \multicolumn{2}{|c|}{ At 50 years } & \multicolumn{2}{|c|}{ At 60 years } & \multicolumn{2}{|c|}{ At 70 years } & \multicolumn{2}{|c|}{ At 80 years } & \multicolumn{2}{|c|}{ At 50 years } & \multicolumn{2}{|c|}{ At 60 years } & \multicolumn{2}{|c|}{ At 70 years } & \multicolumn{2}{|c|}{ At 80 years } & \multicolumn{2}{|c|}{ At 50 years } & \multicolumn{2}{|c|}{ At 60 years } & \multicolumn{2}{|c|}{ At 70 years } & \multicolumn{2}{|c|}{ At 80 years } \\
\hline & Female & Male & Female & Male & Female & Male & Female & Male & Female & Male & Female & Male & Female & Male & Female & Male & Female & Male & Female & Male & Female & Male & Female & Male \\
\hline Mozambique & 22.0 & 18.4 & 15.7 & 13.2 & 9.7 & 8.2 & 5.5 & 4.9 & 22.2 & 19.1 & 16.0 & 13.7 & 9.9 & 8.6 & 5.7 & 5.1 & 25.4 & 21.8 & 18.1 & 15.6 & 11.3 & 9.9 & 6.3 & 5.8 \\
\hline Namibia & 24.1 & 19.9 & 17.1 & 14.1 & 10.3 & 8.7 & 5.6 & 5.1 & 23.0 & 19.6 & 16.6 & 14.0 & 10.0 & 8.7 & 5.4 & 5.1 & 26.0 & 21.9 & 18.9 & 15.5 & 12.0 & 9.7 & 6.9 & 5.6 \\
\hline Niger & 25.0 & 26.2 & 17.1 & 18.2 & 10.5 & 11.4 & 5.8 & 6.5 & 25.9 & 26.5 & 17.5 & 18.2 & 10.5 & 11.1 & 5.6 & 6.1 & 28.6 & 27.8 & 19.5 & 19.0 & 11.5 & 11.4 & 5.7 & 6.0 \\
\hline Nigeria & 22.6 & 20.6 & 15.6 & 14.2 & 9.6 & 8.7 & 5.5 & 4.9 & 23.1 & 21.3 & 16.0 & 14.7 & 9.9 & 9.0 & 5.6 & 5.1 & 25.9 & 24.3 & 18.1 & 16.9 & 11.3 & 10.5 & 6.3 & 5.9 \\
\hline Rwanda & 22.6 & 20.3 & 15.7 & 14.0 & 9.8 & 8.6 & 5.6 & 5.0 & 23.4 & 21.2 & 16.3 & 14.6 & 10.1 & 9.0 & 5.8 & 5.2 & 26.2 & 23.9 & 18.3 & 16.7 & 11.5 & 10.4 & 6.5 & 6.0 \\
\hline $\begin{array}{l}\text { Sao Tome and } \\
\text { Principe }\end{array}$ & 27.1 & 24.3 & 18.5 & 16.3 & 11.0 & 9.6 & 5.6 & 5.0 & 27.9 & 25.0 & 19.1 & 16.8 & 11.4 & 9.9 & 5.8 & 5.1 & 30.5 & 27.2 & 21.3 & 18.5 & 13.0 & 11.0 & 6.7 & 5.7 \\
\hline Senegal & 25.9 & 23.3 & 17.2 & 15.4 & 10.0 & 9.0 & 5.0 & 4.8 & 26.9 & 24.2 & 18.0 & 16.0 & 10.4 & 9.3 & 5.1 & 4.9 & 29.4 & 26.2 & 20.1 & 17.6 & 11.8 & 10.3 & 5.7 & 5.3 \\
\hline Sierra Leone & 21.9 & 19.7 & 14.4 & 13.0 & 8.4 & 7.5 & 4.4 & 4.1 & 22.4 & 20.2 & 14.9 & 13.3 & 8.7 & 7.7 & 4.6 & 4.2 & 25.0 & 22.3 & 16.8 & 14.8 & 9.9 & 8.7 & 5.1 & 4.6 \\
\hline Somalia & 22.6 & 20.8 & 15.4 & 14.1 & 9.5 & 8.5 & 5.4 & 4.8 & 23.4 & 21.6 & 16.1 & 14.7 & 9.9 & 8.9 & 5.6 & 5.0 & 26.3 & 24.4 & 18.2 & 16.8 & 11.3 & 10.4 & 6.4 & 5.9 \\
\hline South Africa & 23.7 & 17.6 & 17.3 & 12.7 & 11.3 & 8.5 & 6.8 & 5.4 & 23.9 & 18.5 & 17.7 & 13.4 & 11.6 & 8.9 & 7.0 & 5.7 & 28.1 & 22.3 & 20.7 & 15.9 & 13.7 & 10.4 & 8.3 & 6.4 \\
\hline Sudan & 25.2 & 23.2 & 17.5 & 16.0 & 10.9 & 9.9 & 6.1 & 5.6 & 26.2 & 24.1 & 18.2 & 16.7 & 11.4 & 10.4 & 6.4 & 5.9 & 28.5 & 26.3 & 20.0 & 18.4 & 12.5 & 11.5 & 7.0 & 6.5 \\
\hline Swaziland & 20.9 & 15.8 & 15.2 & 11.9 & 9.2 & 7.7 & 5.0 & 4.7 & 19.4 & 15.8 & 14.5 & 11.8 & 8.8 & 7.6 & 4.8 & 4.6 & 21.7 & 18.8 & 15.5 & 13.6 & 9.4 & 8.7 & 5.1 & 5.2 \\
\hline $\begin{array}{l}\text { Tanzania, United } \\
\text { Republic of }\end{array}$ & 24.0 & 21.4 & 16.9 & 15.0 & 10.5 & 9.3 & 5.9 & 5.4 & 25.0 & 22.3 & 17.6 & 15.6 & 10.9 & 9.7 & 6.2 & 5.6 & 27.5 & 25.0 & 19.4 & 17.6 & 12.1 & 11.0 & 6.8 & 6.3 \\
\hline Togo & 25.6 & 22.5 & 17.4 & 15.1 & 10.3 & 8.8 & 5.3 & 4.7 & 26.5 & 23.3 & 18.1 & 15.7 & 10.7 & 9.2 & 5.5 & 4.8 & 29.2 & 25.8 & 20.3 & 17.5 & 12.2 & 10.4 & 6.2 & 5.4 \\
\hline Tunisia & 29.0 & 25.5 & 20.0 & 17.3 & 12.2 & 10.5 & 6.4 & 5.7 & 30.3 & 26.2 & 21.3 & 17.8 & 13.3 & 10.8 & 7.2 & 5.9 & 33.6 & 29.2 & 24.4 & 20.4 & 16.0 & 12.8 & 9.2 & 7.2 \\
\hline Uganda & 23.6 & 21.3 & 16.6 & 14.8 & 10.3 & 9.2 & 5.8 & 5.3 & 24.5 & 22.4 & 17.3 & 15.6 & 10.7 & 9.7 & 6.1 & 5.6 & 26.7 & 24.6 & 18.9 & 17.3 & 11.8 & 10.8 & 6.6 & 6.2 \\
\hline Zambia & 21.7 & 18.3 & 15.6 & 13.2 & 9.6 & 8.3 & 5.5 & 4.9 & 22.2 & 19.2 & 16.0 & 13.8 & 9.9 & 8.7 & 5.7 & 5.1 & 24.6 & 21.4 & 17.6 & 15.4 & 11.0 & 9.8 & 6.2 & 5.8 \\
\hline Zimbabwe & 21.7 & 17.7 & 16.1 & 13.3 & 10.0 & 8.6 & 5.7 & 5.3 & 23.5 & 20.2 & 17.1 & 14.7 & 10.6 & 9.4 & 6.0 & 5.6 & 27.8 & 24.3 & 20.0 & 17.4 & 12.7 & 11.0 & 7.2 & 6.4 \\
\hline
\end{tabular}




\begin{tabular}{|c|c|c|c|c|c|c|c|c|c|c|c|c|c|c|c|c|c|c|c|c|c|c|c|}
\hline \multirow{4}{*}{$\begin{array}{l}\text { Country } \\
\text { (alphabetical order } \\
\text { by region) }\end{array}$} & \multicolumn{23}{|c|}{ Projected life expectation (years) } \\
\hline & \multicolumn{7}{|l|}{ In 2008} & \multicolumn{8}{|l|}{ In 2018} & \multicolumn{8}{|l|}{ In 2048} \\
\hline & \multicolumn{2}{|c|}{ At 50 years } & \multicolumn{2}{|c|}{ At 60 years } & At 70 years & \multicolumn{2}{|c|}{ At 80 years } & \multicolumn{2}{|c|}{ At 50 years } & \multicolumn{2}{|c|}{ At 60 years } & \multicolumn{2}{|c|}{ At 70 years } & \multicolumn{2}{|c|}{ At 80 years } & \multicolumn{2}{|c|}{ At 50 years } & \multicolumn{2}{|c|}{ At 60 years } & \multicolumn{2}{|c|}{ At 70 years } & \multicolumn{2}{|c|}{ At 80 years } \\
\hline & Female & Male & Female & Male & Female Male & Female & Male $\mathrm{F}$ & Female & Male & Female & Male & Female & Male & Female & Male & Female & Male & Female & Male & Female & Male & Female & Male \\
\hline \multicolumn{24}{|l|}{ Americas } \\
\hline Argentina & 31.8 & 25.9 & 23.0 & 18.1 & 15.211 .6 & 9.0 & 6.9 & 33.1 & 27.1 & 24.2 & 19.1 & 16.1 & 12.4 & 9.7 & 7.4 & 35.9 & 29.6 & 26.7 & 21.3 & 18.2 & 14.0 & 11.1 & 8.5 \\
\hline Bahamas & 31.8 & 27.0 & 23.2 & 19.5 & 15.413 .1 & 9.2 & 8.1 & 33.0 & 27.6 & 24.2 & 19.8 & 16.1 & 13.1 & 9.7 & 8.0 & 35.6 & 30.5 & 26.5 & 22.0 & 18.2 & 14.6 & 11.3 & 8.8 \\
\hline Barbados & 31.8 & 27.0 & 22.7 & 18.5 & 14.711 .3 & 8.4 & 6.2 & 32.9 & 28.2 & 23.8 & 19.5 & 15.6 & 12.1 & 9.0 & 6.7 & 35.5 & 30.9 & 26.2 & 21.9 & 17.7 & 14.2 & 10.8 & 8.2 \\
\hline Belize & 32.5 & 28.7 & 23.5 & 20.4 & 15.613 .2 & 9.3 & 7.7 & 33.2 & 28.4 & 24.2 & 20.3 & 16.1 & 13.1 & 9.7 & 7.7 & 34.6 & 30.7 & 25.5 & 22.0 & 17.4 & 14.5 & 10.7 & 8.6 \\
\hline Bolivia & 26.8 & 24.3 & 18.8 & 16.7 & 11.610 .2 & 6.4 & 5.6 & 28.4 & 25.5 & 20.2 & 17.8 & 12.8 & 11.1 & 7.2 & 6.3 & 33.0 & 28.9 & 24.1 & 20.7 & 16.0 & 13.4 & 9.5 & 7.9 \\
\hline Brazil & 30.6 & 26.7 & 22.5 & 19.5 & 15.313 .3 & 9.7 & 8.6 & 31.9 & 27.8 & 23.5 & 20.2 & 16.1 & 13.8 & 10.2 & 8.8 & 35.0 & 29.9 & 26.1 & 21.8 & 18.0 & 14.7 & 11.3 & 9.2 \\
\hline Canada & 34.3 & 30.4 & 25.2 & 21.7 & 16.914 .1 & 10.2 & 8.3 & 35.4 & 31.7 & 26.2 & 22.8 & 17.8 & 15.0 & 10.8 & 8.9 & 38.3 & 34.5 & 28.9 & 25.3 & 20.1 & 17.1 & 12.6 & 10.3 \\
\hline Chile & 33.4 & 28.9 & 24.5 & 20.7 & 16.513 .7 & 10.0 & 8.4 & 34.4 & 29.7 & 25.4 & 21.3 & 17.2 & 14.2 & 10.5 & 8.7 & 36.5 & 31.2 & 27.2 & 22.6 & 18.7 & 15.1 & 11.5 & 9.2 \\
\hline Colombia & 30.5 & 27.3 & 21.9 & 19.3 & 14.412 .5 & 8.6 & 7.4 & 31.7 & 28.2 & 23.0 & 20.1 & 15.3 & 13.1 & 9.2 & 7.8 & 34.2 & 30.3 & 25.2 & 21.8 & 17.1 & 14.4 & 10.4 & 8.7 \\
\hline Costa Rica & 33.4 & 30.0 & 24.4 & 21.6 & 16.314 .3 & 9.8 & 8.7 & 34.3 & 30.6 & 25.2 & 22.1 & 17.0 & 14.7 & 10.3 & 8.9 & 36.0 & 31.7 & 26.8 & 23.0 & 18.3 & 15.4 & 11.1 & 9.3 \\
\hline Cuba & 32.3 & 29.1 & 23.5 & 20.8 & 15.613 .6 & 9.3 & 8.1 & 33.6 & 30.2 & 24.6 & 21.7 & 16.5 & 14.3 & 9.9 & 8.6 & 36.1 & 32.3 & 26.8 & 23.5 & 18.3 & 15.8 & 11.2 & 9.6 \\
\hline Dominican Republic & 30.9 & 27.7 & 22.7 & 20.3 & 15.714 .0 & 10.0 & 9.1 & 31.9 & 28.3 & 23.6 & 20.7 & 16.3 & 14.2 & 10.4 & 9.2 & 34.0 & 29.6 & 25.3 & 21.6 & 17.5 & 14.7 & 11.1 & 9.3 \\
\hline Ecuador & 32.2 & 29.3 & 23.5 & 21.2 & 15.614 .0 & 9.3 & 8.4 & 33.0 & 29.8 & 24.2 & 21.5 & 16.2 & 14.3 & 9.7 & 8.6 & 35.2 & 31.0 & 26.1 & 22.5 & 17.8 & 15.0 & 10.8 & 9.1 \\
\hline El Salvador & 30.3 & 26.4 & 21.9 & 18.6 & 14.511 .9 & 8.7 & 6.9 & 31.5 & 27.2 & 22.9 & 19.3 & 15.3 & 12.5 & 9.3 & 7.4 & 34.6 & 29.6 & 25.6 & 21.3 & 17.4 & 14.0 & 10.7 & 8.4 \\
\hline Grenada & 26.2 & 23.9 & 17.9 & 16.1 & $10.9 \quad 9.8$ & 5.9 & 5.5 & 26.8 & 24.4 & 18.4 & 16.5 & 11.2 & 10.0 & 6.1 & 5.6 & 30.5 & 26.7 & 21.5 & 18.2 & 13.7 & 11.1 & 7.6 & 6.1 \\
\hline Guatemala & 29.9 & 27.0 & 21.5 & 19.2 & 14.012 .2 & 8.3 & 7.1 & 31.0 & 27.7 & 22.5 & 19.8 & 14.9 & 12.8 & 8.9 & 7.5 & 34.4 & 29.8 & 25.4 & 21.5 & 17.2 & 14.2 & 10.5 & 8.5 \\
\hline Guyana & 28.2 & 24.1 & 20.0 & 16.7 & 12.810 .7 & 7.4 & 6.4 & 29.5 & 25.3 & 21.1 & 17.7 & 13.6 & 11.3 & 7.9 & 6.7 & 32.0 & 27.6 & 23.1 & 19.4 & 15.3 & 12.5 & 9.1 & 7.4 \\
\hline Haiti & 24.7 & 23.6 & 17.0 & 16.6 & $10.4 \quad 10.2$ & 5.8 & 5.8 & 26.5 & 24.3 & 18.4 & 16.8 & 11.6 & 10.5 & 6.6 & 6.0 & 32.2 & 28.4 & 23.4 & 20.3 & 15.6 & 13.2 & 9.4 & 7.9 \\
\hline
\end{tabular}




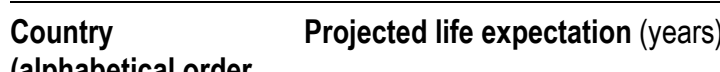

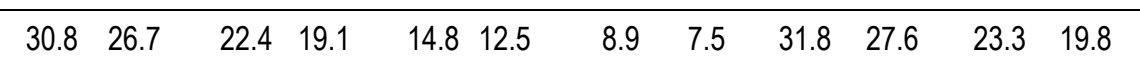

Honduras

Jamaica

Mexico

Nicaragua

Panama

Paraguay

Peru

Saint Lucia

Saint Vincent and the Grenadines

Suriname

Trinidad and Tobago United States

Uruguay

Venezuela, Bolivarian Republic of

Asia and the Pacific Afghanistan Australia

Bahrain

$\begin{array}{llll}29.7 & 27.0 & 21.6 & 19.3\end{array}$

14.512 .7

$31.6 \quad 28.9$

22.920 .7

15.213 .5

$\begin{array}{llll}8.9 & 7.7 & 30.5 & 27.6\end{array}$

$22.2 \quad 19.8$

15.613 .0

$9.4 \quad 7.9$

\begin{tabular}{ll}
34.329 .7 \\
\hline
\end{tabular}

$30.6 \quad 27.5$

22.419 .9

15.213 .3

$\begin{array}{llll}9.2 & 8.1 & 32.9 & 29.8\end{array}$

$24.1 \quad 21.5$

14.913 .0

9.27 .8

$32.6 \quad 29.3$

25.521 .6

17.314.

$31.7 \quad 28.7$

$22.8 \quad 20.3$

14.713 .0

$\begin{array}{llllll}9.6 & 8.2 & 32.5 & 28.7 & 23.9 & 20.8\end{array}$

16.214 .2

$9.8 \quad 8.5$

$35.0 \quad 31.4$

23.921 .0

16.113 .8

$16.4 \quad 13.9$

$10.3 \quad 8.6$

34.329 .8

26.022 .8

$17.7 \quad 15.2$

$\begin{array}{llllll}8.4 & 7.4 & 32.7 & 29.3 & 23.7 & 20.9\end{array}$

15.613 .4

$\begin{array}{llll}9.1 & 7.8 & 35.3 & 30.7\end{array}$

$25.4 \quad 21.6$

17.514 .5

$\begin{array}{llll}29.6 & 27.4 & 21.3 & 19.4\end{array}$

14.012 .7

$8.3 \quad 7.6$

$\begin{array}{llll}30.8 & 28.2 & 22.3 & 20.1\end{array}$

$14.8 \quad 13.2$

$\begin{array}{llll}8.9 & 7.9 & 32.9 & 29.7\end{array}$

$26.0 \quad 22.1$

$17.6 \quad 14.6$

$\begin{array}{llll}29.2 & 26.1 & 20.8 & 18.3\end{array}$

13.511 .8

$22.1 \quad 19.3$

$14.6 \quad 12.6$

$\begin{array}{llll}8.7 & 7.6 & 33.8 & 29.4\end{array}$

$24.2 \quad 21.4$

16.314 .2

$\begin{array}{llll}29.3 & 25.7 & 21.0 & 17.7\end{array}$

14.011 .4

$8.6 \quad 6.9$

$27.5 \quad 24.7$

$28.9 \quad 25.2$

$18.9 \quad 16.7$

11.510 .2

$\begin{array}{llllll}6.2 & 5.6 & 28.4 & 25.4 & 19.7 & 17.2\end{array}$

14.711 .8

$9.0 \quad 7.0$

$33.7 \quad 29.5$

24.921 .1

$16.8 \quad 14.0$

12.110 .5

$\begin{array}{llll}6.5 & 5.8 & 31.4 & 27.4\end{array}$

$24.7 \quad 20.8$

$16.7 \quad 13.5$

$\begin{array}{llll}27.7 & 24.2 & 19.7 & 16.9\end{array}$

13.511 .9

$\begin{array}{llll}8.2 & 7.5 & 29.9 & 26.3\end{array}$

$21.4 \quad 18.7$

14.212 .5

$8.6 \quad 7.8$

$32.6 \quad 28.7$

$22.4 \quad 18.7$

$14.4 \quad 11.5$

$23.8 \quad 20.5$

16.013 .6

$14.0 \quad 11.2$

$\begin{array}{llll}8.4 & 6.5 & 32.9 & 28.4\end{array}$

24.120 .0

16.212 .8

17.113 .9

$\begin{array}{llll}10.6 & 8.3 & 37.0 & 32.4\end{array}$

27.723 .5

32.426 .5

4.220 .3

16.413 .3

$\begin{array}{llllll}10.1 & 7.9 & 34.1 & 29.6 & 25.1 & 21.1\end{array}$

16.312 .8

$\begin{array}{llll}9.6 & 7.7 & 36.0 & 30.5\end{array}$

26.822.

19.115 .6

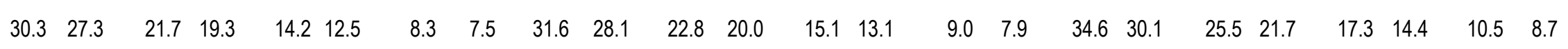

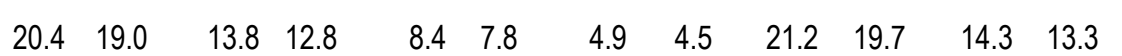

34.930 .9

$25.7 \quad 22.0$

17.214 .3

$\begin{array}{llll}10.2 & 8.3 & 35.9 & 32.1\end{array}$

$26.6 \quad 23.0$

$8.8 \quad 8.1$

$5.0 \quad 4.7$

18.015 .1

10.88

$29.8 \quad 26.8$

20.918 .4

13.111 .3

$\begin{array}{llll}7.2 & 6.3 & 31.1 & 27.8\end{array}$

$22.1 \quad 19.2$

14.111 .9

7.96.

$38.7 \quad 34.9$

16.014 .7

$9.8 \quad 9.0$

$5.5 \quad 5.1$

34.230 .8

$25.0 \quad 21.9$

16.6

$12.7 \quad 10.3$

8.8 


\begin{tabular}{|c|c|c|c|c|c|c|c|c|c|c|c|c|c|c|c|c|c|c|c|c|c|c|c|}
\hline \multirow{4}{*}{$\begin{array}{l}\text { Country } \\
\text { (alphabetical order } \\
\text { by region) }\end{array}$} & \multicolumn{23}{|c|}{ Projected life expectation (years) } \\
\hline & \multicolumn{7}{|l|}{$\ln 2008$} & \multicolumn{8}{|l|}{$\ln 2018$} & \multicolumn{8}{|l|}{$\ln 2048$} \\
\hline & \multicolumn{2}{|c|}{ At 50 years } & \multicolumn{2}{|c|}{ At 60 years } & At 70 years & \multicolumn{2}{|c|}{ At 80 years } & \multicolumn{2}{|c|}{ At 50 years } & \multicolumn{2}{|c|}{ At 60 years } & \multicolumn{2}{|c|}{ At 70 years } & \multicolumn{2}{|c|}{ At 80 years } & \multicolumn{2}{|c|}{ At 50 years } & \multicolumn{2}{|c|}{ At 60 years } & \multicolumn{2}{|c|}{ At 70 years } & \multicolumn{2}{|c|}{ At 80 years } \\
\hline & Female & Male & Female & Male & $\overline{\text { Female Male }}$ & Female & Male $\mathrm{F}$ & Female & Male & Female & Male & Female & Male & Female & Male & Female & Male & Female & Male & Female & Male & Female & Male \\
\hline Bangladesh & 24.8 & 22.9 & 16.9 & 15.4 & $10.3 \quad 9.4$ & 5.7 & 5.3 & 25.9 & 23.8 & 17.7 & 16.1 & 10.8 & 9.8 & 5.9 & 5.5 & 29.9 & 26.4 & 21.0 & 18.0 & 13.2 & 11.0 & 7.3 & 6.0 \\
\hline Brunei Darussalam & 31.4 & 27.2 & 22.4 & 18.4 & 14.710 .6 & 8.6 & 5.1 & 32.5 & 28.1 & 23.4 & 19.2 & 15.5 & 11.3 & 9.2 & 5.6 & 34.9 & 30.3 & 25.6 & 21.3 & 17.3 & 13.2 & 10.5 & 7.0 \\
\hline Cambodia & 24.4 & 21.3 & 16.7 & 14.5 & $\begin{array}{ll}10.2 & 8.9\end{array}$ & 5.7 & 5.1 & 25.4 & 22.9 & 17.4 & 15.5 & 10.6 & 9.5 & 5.8 & 5.3 & 29.3 & 25.7 & 20.5 & 17.5 & 12.8 & 10.7 & 7.0 & 5.9 \\
\hline China & 29.4 & 26.3 & 20.7 & 18.2 & 13.211 .5 & 7.6 & 6.6 & 30.6 & 27.2 & 21.7 & 18.9 & 14.1 & 12.0 & 8.1 & 6.9 & 33.5 & 29.8 & 24.4 & 21.0 & 16.2 & 13.5 & 9.7 & 7.8 \\
\hline Fiji & 25.3 & 21.8 & 17.3 & 14.6 & $\begin{array}{ll}10.8 & 9.1\end{array}$ & 6.1 & 5.3 & 26.4 & 22.6 & 18.3 & 15.2 & 11.5 & 9.5 & 6.6 & 5.5 & 30.7 & 26.1 & 21.9 & 17.9 & 14.3 & 11.3 & 8.4 & 6.6 \\
\hline India & 26.9 & 24.0 & 18.8 & 16.9 & 12.111 .2 & 7.2 & 7.1 & 28.3 & 25.2 & 20.0 & 17.8 & 12.9 & 11.8 & 7.6 & 7.3 & 31.7 & 28.2 & 22.8 & 20.0 & 15.0 & 13.2 & 8.9 & 8.1 \\
\hline Indonesia & 27.0 & 24.4 & 18.5 & 16.5 & 11.310 .1 & 6.1 & 5.6 & 28.5 & 25.5 & 19.8 & 17.3 & 12.2 & 10.6 & 6.6 & 5.8 & 32.5 & 28.3 & 23.4 & 19.6 & 15.3 & 12.2 & 8.8 & 6.8 \\
\hline Iran, Islamic Rep. of & 27.2 & 24.5 & 18.5 & 16.5 & 11.010 .0 & 5.7 & 5.4 & 28.4 & 25.4 & 19.5 & 17.2 & 11.7 & 10.4 & 6.1 & 5.7 & 32.3 & 28.2 & 23.1 & 19.5 & 14.9 & 12.1 & 8.4 & 6.7 \\
\hline Iraq & 24.3 & 22.0 & 16.4 & 14.7 & $9.7 \quad 8.8$ & 5.2 & 4.9 & 26.4 & 23.7 & 17.9 & 15.9 & 10.7 & 9.6 & 5.6 & 5.2 & 30.6 & 26.4 & 21.6 & 18.0 & 13.5 & 10.9 & 7.4 & 5.9 \\
\hline Japan & 37.1 & 30.9 & 27.8 & 22.1 & 19.014 .4 & 11.6 & 8.5 & 38.7 & 32.1 & 29.3 & 23.2 & 20.4 & 15.3 & 12.7 & 9.1 & 41.5 & 34.6 & 31.9 & 25.4 & 22.8 & 17.1 & 14.7 & 10.3 \\
\hline Jordan & 28.1 & 25.5 & 19.7 & 17.7 & 12.611 .4 & 7.2 & 6.8 & 29.5 & 26.3 & 20.8 & 18.2 & 13.4 & 11.6 & 7.7 & 6.8 & 33.0 & 29.0 & 23.9 & 20.4 & 15.9 & 13.1 & 9.4 & 7.6 \\
\hline Korea, Republic of & 33.5 & 27.0 & 24.3 & 18.6 & 15.911 .6 & 9.1 & 6.5 & 35.0 & 28.4 & 25.6 & 19.8 & 17.1 & 12.5 & 10.1 & 7.1 & 38.0 & 31.4 & 28.5 & 22.5 & 19.7 & 14.6 & 12.2 & 8.5 \\
\hline Kuwait & 31.4 & 28.5 & 22.3 & 19.8 & 14.512 .3 & 8.5 & 6.9 & 32.5 & 29.4 & 23.4 & 20.6 & 15.4 & 13.0 & 9.1 & 7.3 & 35.5 & 32.1 & 26.2 & 23.0 & 17.8 & 15.0 & 10.8 & 8.7 \\
\hline $\begin{array}{l}\text { Lao People's } \\
\text { Democratic Republic }\end{array}$ & 25.0 & 22.9 & 17.1 & 15.4 & $10.4 \quad 944$ & 58 & 5.3 & 26.1 & 238 & 178 & 16.0 & 10.9 & 98 & 59 & 5.5 & 30.1 & 26.4 & 21.2 & 180 & 134 & 110 & 75 & 60 \\
\hline Lebanon & 27.6 & 24.8 & 19.0 & 16.8 & 11.610 .3 & 6.2 & 5.7 & 28.8 & 25.6 & 20.0 & 17.4 & 12.4 & 10.6 & 6.7 & 5.8 & 32.5 & 28.3 & 23.4 & 19.6 & 15.3 & 12.2 & 8.8 & 6.8 \\
\hline Malaysia & 29.0 & 25.5 & 20.3 & 17.6 & 12.911 .2 & 7.4 & 6.6 & 30.5 & 26.4 & 21.6 & 18.2 & 14.0 & 11.5 & 8.1 & 6.7 & 33.8 & 29.5 & 24.7 & 20.8 & 16.5 & 13.4 & 9.8 & 7.8 \\
\hline Mongolia & 26.5 & 22.4 & 19.0 & 15.5 & $\begin{array}{ll}12.8 & 10.1\end{array}$ & 8.1 & 6.3 & 27.8 & 23.8 & 20.0 & 16.5 & 13.4 & 10.7 & 8.3 & 6.5 & 31.5 & 27.3 & 22.9 & 19.2 & 15.4 & 12.4 & 9.4 & 7.4 \\
\hline Myanmar & 26.8 & 23.6 & 18.9 & 16.6 & 12.210 .7 & 7.3 & 6.5 & 28.3 & 25.1 & 20.1 & 17.6 & 13.0 & 11.3 & 7.7 & 6.8 & 31.7 & 28.0 & 22.9 & 19.8 & 15.2 & 12.8 & 9.1 & 7.6 \\
\hline Nepal & 24.7 & 22.9 & 16.8 & 15.4 & $\begin{array}{ll}10.3 & 9.4\end{array}$ & 5.7 & 5.3 & 25.7 & 23.8 & 17.6 & 16.1 & 10.7 & 9.8 & 5.9 & 5.5 & 29.7 & 26.5 & 20.8 & 18.0 & 13.1 & 11.0 & 7.2 & 6.0 \\
\hline
\end{tabular}




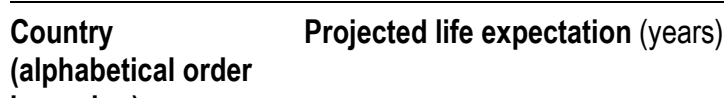

Oman

Pakistan

Papua New Guinea

Philippines

Qatar

Samoa

Saudi Arabia

$29.8 \quad 26.8$

$26.3 \quad 25.1$

$\begin{array}{llll}24.6 & 21.3 \quad 16.5 & 13.8\end{array}$

$\begin{array}{ll}9.8 & 8.0\end{array}$

Female Male

13.211 .2

$\begin{array}{llll}7.3 & 6.1 & 31.3 & 27.9\end{array}$

$25.6 \quad 22.5$

$\begin{array}{llll}22.7 & 18.6 & 15.7 & 12.7\end{array}$

11.611 .4

$22.3 \quad 19.3$

17.314 .7

10.48.

$27.5 \quad 24.7$

19.016 .7

10.18 .2

$\begin{array}{llll}6.8 & 7.0 & 27.4 & 26.1\end{array}$

19.118 .2

14.311 .9

$8.1 \quad 6.6$

$\begin{array}{ll}37.7 & 34.3\end{array}$

$28.3 \quad 25.1$

19.616 .8

$29.2 \quad 27.6$

20.919 .2

11.610 .2

$\begin{array}{llll}6.1 & 5.2 & 23.7 & 19.3\end{array}$

$16.5 \quad 13.2$

12.211 .9

7.17 .3

$25.2 \quad 22.0$

16.814 .1

$10.6 \quad 8.6$

$6.4 \quad 5.3$

22.120 .2

$14.4 \quad 13.3$

$28.7 \quad 23.5$

$20.3 \quad 16.1$

13.912 .2

6.25 .6

$\begin{array}{llll}29.0 & 25.6 & 20.2 & 17.4\end{array}$

12.510 .6

$6.8 \quad 5.8$

$18.9 \quad 15.4$

12.29 .9

14.712 .9

$23.6 \quad 19.6$

15.412 .2

$16.8 \quad 14.8$

$\begin{array}{llll}28.2 & 25.2 & 19.5 & 17.1\end{array}$

11.910 .4

$\begin{array}{ll}7.9 & 6.2\end{array}$

$30.1 \quad 24.7$

$\begin{array}{llll}21.6 & 17.0 & 14.2 & 10.9\end{array}$

$8.5 \quad 6.5$

$33.8 \quad 31.5$

$24.8 \quad 22.6$

$16.4 \quad 12.5$

33.129 .7

23.921 .0

15.713 .6

$\begin{array}{llll}6.4 & 5.8 & 29.7 & 26.1\end{array}$

20.917 .7

13.110 .8

$7.2 \quad 5.9$

33.229 .0

$24.4 \quad 19.5$

$15.8 \quad 12.7$

Singapore

Sri Lanka

Syrian Arab Republic

Thailand

Timor-Leste

United Arab Emirates

Vanuatu

$29.1 \quad 24.7$

$20.5 \quad 17.4$

13.311 .6

$16.7 \quad 14.4$

$9.8 \quad 8.5$

$37.5 \quad 33.8$

28.124 .6

$19.4 \quad 16.5$

$28.8 \quad 25.8$

$20.0 \quad 17.5$

12.410 .7

$21.4 \quad 17.7$

13.911 .7

8.27

$32.7 \quad 27.1$

$23.7 \quad 18.9$

15.712 .2

$30.3 \quad 24.6$

$22.3 \quad 17.3$

15.311 .1

$\begin{array}{llll}6.7 & 5.9 & 30.2 & 26.6\end{array}$

$21.3 \quad 18.2$

13.511 .1

$\begin{array}{ll}7.5 & 6.1\end{array}$

$33.6 \quad 29.6$

$24.4 \quad 20.8$

16.113 .2

$\begin{array}{llll}9.8 & 6.7 & 33.8 & 27.7\end{array}$

25.019 .4

17.112 .3

$10.5 \quad 9.5$

$5.8 \quad 5.3$

$28.9 \quad 25.8$

20.217 .5

12.510 .7

33.129 .0

$33.9 \quad 20.2$

$15.7 \quad 12.7$

$\begin{array}{llll}5.6 & 5.2 & 25.2 & 23.1\end{array}$

17.215 .6

$\begin{array}{ll}16.6 & 13.5\end{array}$

$\begin{array}{llll}9.8 & 7.6 & 37.2 & 33.1\end{array}$

$27.8 \quad 24.0$

19.215 .8

$\begin{array}{llllll}26.8 & 24.3 & 18.4 & 16.4 & 11.2 & 10.0\end{array}$

$\begin{array}{llll}6.1 & 5.6 & 28.0 & 25.2\end{array}$

19.317 .1

$11.8 \quad 10.4$

$\begin{array}{llll}6.3 & 5.8 & 32.0 & 27.8\end{array}$

$\begin{array}{llll}23.0 & 19.1 \quad 14.9 & 11.8\end{array}$

$\begin{array}{llll}25.0 & 21.9 & 16.7 & 14.1\end{array}$

29.827.

13.312 .1

$\begin{array}{llll}7.5 & 6.8 & 31.2 & 28.5\end{array}$

$22.3 \quad 20.0$

$14.4 \quad 12.6$

$\begin{array}{llll}8.2 & 7.1 & 34.2 & 30.7\end{array}$

$20.9 \quad 17.7$

13.110 .8

Yemen

$\begin{array}{llllllllllll}24.7 & 22.4 & 16.8 & 15.1 & 10.3 & 9.2 & 5.7 & 5.2 & 25.8 & 23.3 & 17.6 & 15.7\end{array}$

$10.7 \quad 9.6$

$5.9 \quad 5.4$

29.726 .0

20.9 


\begin{tabular}{|c|c|c|c|c|c|c|c|c|c|c|c|c|c|c|c|c|c|c|c|c|c|c|c|}
\hline \multirow{4}{*}{$\begin{array}{l}\text { Country } \\
\text { (alphabetical order } \\
\text { by region) }\end{array}$} & \multicolumn{23}{|c|}{ Projected life expectation (years) } \\
\hline & \multicolumn{7}{|l|}{ In 2008} & \multicolumn{8}{|l|}{ In 2018} & \multicolumn{8}{|l|}{ In 2048} \\
\hline & \multicolumn{2}{|c|}{ At 50 years } & \multicolumn{2}{|c|}{ At 60 years } & At 70 years & \multicolumn{2}{|c|}{ At 80 years } & \multicolumn{2}{|c|}{ At 50 years } & \multicolumn{2}{|c|}{ At 60 years } & \multicolumn{2}{|c|}{ At 70 years } & \multicolumn{2}{|c|}{ At 80 years } & \multicolumn{2}{|c|}{ At 50 years } & \multicolumn{2}{|c|}{ At 60 years } & \multicolumn{2}{|c|}{ At 70 years } & \multicolumn{2}{|c|}{ At 80 years } \\
\hline & Female & Male & Female & Male & Female Male & Female & Male & Female & Male & Female & Male & Female & Male & Female & Male & Female & Male & Female & Male & Female & Male & Female & Male \\
\hline \multicolumn{24}{|c|}{ Europe and Central Asia } \\
\hline Albania & 32.7 & 27.5 & 23.4 & 18.9 & 14.911 .6 & 8.2 & 6.4 & 33.5 & 28.0 & 24.2 & 19.3 & 15.6 & 11.9 & 8.8 & 6.5 & 35.8 & 30.7 & 26.4 & 21.7 & 17.8 & 13.8 & 10.5 & 7.8 \\
\hline Armenia & 29.0 & 24.1 & 20.3 & 16.6 & $13.1 \quad 10.8$ & 7.7 & 6.7 & 29.9 & 24.9 & 21.1 & 17.3 & 13.7 & 11.3 & 8.1 & 6.9 & 32.3 & 27.5 & 23.3 & 19.3 & 15.5 & 12.6 & 9.3 & 7.6 \\
\hline Austria & 33.8 & 29.1 & 24.6 & 20.7 & 16.113 .3 & 9.3 & 7.7 & 35.0 & 30.2 & 25.7 & 21.6 & 17.1 & 14.0 & 10.0 & 8.2 & 38.0 & 33.1 & 28.6 & 24.1 & 19.8 & 16.0 & 12.2 & 9.6 \\
\hline Azerbaijan & 29.5 & 23.8 & 21.1 & 16.6 & 13.910 .9 & 8.3 & 6.7 & 30.3 & 24.5 & 21.7 & 17.1 & 14.4 & 11.2 & 8.6 & 6.9 & 32.0 & 26.8 & 23.2 & 18.8 & 15.5 & 12.3 & 9.3 & 7.4 \\
\hline Belarus & 27.8 & 19.6 & 19.4 & 13.3 & 12.18 .6 & 6.8 & 5.3 & 28.7 & 20.6 & 20.2 & 14.0 & 12.8 & 9.0 & 7.3 & 5.5 & 31.7 & 24.3 & 22.8 & 16.7 & 15.0 & 10.7 & 8.8 & 6.4 \\
\hline Belgium & 33.7 & 28.8 & 24.5 & 20.3 & 16.112 .8 & 9.3 & 7.3 & 34.8 & 29.9 & 25.5 & 21.2 & 17.0 & 13.6 & 10.0 & 7.8 & 37.8 & 32.8 & 28.4 & 23.8 & 19.6 & 15.7 & 12.1 & 9.3 \\
\hline $\begin{array}{l}\text { Bosnia and } \\
\text { Herzegovina }\end{array}$ & 29.7 & 25.4 & 20.9 & 17.5 & 13.311 .0 & 7.6 & 6.4 & 30.7 & 26.2 & 21.8 & 18.0 & 14.1 & 11.3 & 8.1 & 6.5 & 33.7 & 29.2 & 24.6 & 20.5 & 16.4 & 13.2 & 9.7 & 7.6 \\
\hline Bulgaria & 29.1 & 23.4 & 20.3 & 16.0 & 12.510 .0 & 6.7 & 5.8 & 30.1 & 24.4 & 21.2 & 16.7 & 13.3 & 10.4 & 7.3 & 5.9 & 33.3 & 27.6 & 24.2 & 19.2 & 15.9 & 12.0 & 9.2 & 6.8 \\
\hline Croatia & 30.8 & 25.3 & 21.8 & 17.5 & 13.811 .0 & 7.6 & 6.4 & 32.0 & 26.6 & 22.9 & 18.5 & 14.7 & 11.7 & 8.3 & 6.7 & 34.4 & 29.5 & 25.2 & 20.9 & 16.7 & 13.5 & 9.9 & 7.9 \\
\hline Cyprus & 32.9 & 28.9 & 23.6 & 20.1 & 15.112 .4 & 8.4 & 6.6 & 34.1 & 29.8 & 24.7 & 20.9 & 16.2 & 13.0 & 9.2 & 7.1 & 36.9 & 32.2 & 27.4 & 23.1 & 18.6 & 14.9 & 11.2 & 8.5 \\
\hline Czech Republic & 30.8 & 25.6 & 21.8 & 17.6 & 13.810 .9 & 7.6 & 6.1 & 32.3 & 26.8 & 23.2 & 18.5 & 14.9 & 11.5 & 8.5 & 6.4 & 35.8 & 30.5 & 26.5 & 21.7 & 17.9 & 14.0 & 10.8 & 8.1 \\
\hline Denmark & 32.2 & 28.2 & 23.4 & 19.7 & 15.612 .6 & 9.4 & 7.3 & 33.4 & 29.3 & 24.4 & 20.6 & 16.5 & 13.3 & 10.0 & 7.7 & 36.2 & 31.9 & 27.0 & 22.9 & 18.5 & 15.1 & 11.5 & 8.9 \\
\hline Estonia & 29.4 & 22.2 & 20.8 & 15.6 & 13.110 .1 & 7.3 & 6.2 & 30.7 & 23.5 & 22.0 & 16.4 & 14.1 & 10.5 & 8.0 & 6.3 & 33.8 & 27.5 & 24.7 & 19.2 & 16.5 & 12.3 & 9.9 & 7.1 \\
\hline Finland & 33.7 & 28.5 & 24.5 & 20.0 & 16.012 .7 & 9.1 & 7.2 & 34.8 & 29.9 & 25.5 & 21.2 & 16.9 & 13.6 & 9.9 & 7.9 & 37.8 & 32.6 & 28.4 & 23.6 & 19.6 & 15.5 & 12.0 & 9.2 \\
\hline France & 35.4 & 29.6 & 26.2 & 21.1 & 17.613 .7 & 10.5 & 8.0 & 36.4 & 30.6 & 27.1 & 21.9 & 18.4 & 14.3 & 11.1 & 8.4 & 39.3 & 33.4 & 29.8 & 24.4 & 20.9 & 16.3 & 13.1 & 9.8 \\
\hline Georgia & 29.2 & 24.3 & 20.4 & 16.8 & 12.810 .5 & 7.1 & 6.0 & 30.0 & 25.0 & 21.1 & 17.3 & 13.4 & 10.8 & 7.5 & 6.2 & 32.2 & 27.3 & 23.1 & 19.1 & 15.1 & 12.1 & 8.8 & 7.0 \\
\hline Germany & 33.5 & 28.5 & 24.3 & 20.0 & 16.012 .7 & 9.3 & 7.3 & 34.6 & 29.6 & 25.4 & 20.9 & 16.9 & 13.5 & 10.0 & 7.8 & 37.7 & 32.7 & 28.3 & 23.7 & 19.5 & 15.7 & 12.1 & 9.3 \\
\hline Greece & 33.3 & 29.4 & 24.0 & 20.8 & 15.513 .4 & 8.7 & 7.7 & 34.4 & 30.3 & 25.1 & 21.6 & 16.5 & 14.0 & 9.5 & 8.1 & 37.5 & 32.9 & 28.0 & 23.8 & 19.2 & 15.8 & 11.7 & 9.4 \\
\hline
\end{tabular}




\begin{tabular}{|c|c|c|c|c|c|c|c|c|c|c|c|c|c|c|c|c|c|c|c|c|c|c|c|}
\hline \multirow{4}{*}{$\begin{array}{l}\text { Country } \\
\text { (alphabetical order } \\
\text { by region) }\end{array}$} & \multicolumn{23}{|c|}{ Projected life expectation (years) } \\
\hline & \multicolumn{7}{|l|}{ In 2008} & \multicolumn{8}{|l|}{ In 2018} & \multicolumn{8}{|l|}{ In 2048} \\
\hline & \multicolumn{2}{|c|}{ At 50 years } & \multicolumn{2}{|c|}{ At 60 years } & At 70 years & \multicolumn{2}{|c|}{ At 80 years } & \multicolumn{2}{|c|}{ At 50 years } & \multicolumn{2}{|c|}{ At 60 years } & \multicolumn{2}{|c|}{ At 70 years } & \multicolumn{2}{|c|}{ At 80 years } & \multicolumn{2}{|c|}{ At 50 years } & \multicolumn{2}{|c|}{ At 60 years } & \multicolumn{2}{|c|}{ At 70 years } & \multicolumn{2}{|c|}{ At 80 years } \\
\hline & Female & Male & Female & Male & Female Male & Female & Male $\mathrm{F}$ & Female & Male & Female & Male & Female & Male & Female & Male & Female & Male & Female & Male & Female & Male & Female & Male \\
\hline Hungary & 29.6 & 23.0 & 21.0 & 16.0 & 13.210 .2 & 7.4 & 6.0 & 30.9 & 24.4 & 22.1 & 16.9 & 14.2 & 10.7 & 8.1 & 6.2 & 34.1 & 28.0 & 25.0 & 19.6 & 16.7 & 12.5 & 9.9 & 7.2 \\
\hline Iceland & 34.3 & 31.5 & 25.1 & 22.5 & 16.714 .6 & 9.8 & 8.4 & 35.4 & 32.4 & 26.1 & 23.3 & 17.6 & 15.3 & 10.5 & 8.9 & 38.4 & 35.2 & 28.9 & 25.8 & 20.1 & 17.4 & 12.5 & 10.4 \\
\hline Ireland & 32.8 & 28.4 & 23.7 & 19.7 & 15.512 .4 & 9.0 & 7.0 & 33.9 & 29.5 & 24.7 & 20.6 & 16.4 & 13.1 & 9.7 & 7.5 & 37.1 & 32.3 & 27.7 & 23.2 & 19.0 & 15.2 & 11.7 & 8.9 \\
\hline Israel & 34.0 & 30.8 & 24.7 & 21.9 & 16.214 .1 & 9.3 & 8.1 & 35.1 & 32.0 & 25.7 & 23.0 & 17.1 & 15.0 & 10.0 & 8.7 & 38.2 & 34.7 & 28.7 & 25.5 & 19.8 & 17.1 & 12.2 & 10.2 \\
\hline Italy & 34.8 & 29.8 & 25.5 & 21.1 & 17.013 .5 & 9.9 & 7.8 & 35.8 & 30.8 & 26.5 & 21.9 & 17.8 & 14.2 & 10.6 & 8.3 & 38.7 & 33.6 & 29.2 & 24.5 & 20.4 & 16.3 & 12.7 & 9.7 \\
\hline Kazakhstan & 26.8 & 20.0 & 18.8 & 13.9 & $12.0 \quad 9.3$ & 7.0 & 6.0 & 28.6 & 21.9 & 20.2 & 15.2 & 13.0 & 10.0 & 7.6 & 6.3 & 32.4 & 25.9 & 23.5 & 18.0 & 15.7 & 11.7 & 9.4 & 7.1 \\
\hline Kyrgyzstan & 26.7 & 21.7 & 18.5 & 14.8 & 11.59 .1 & 6.4 & 5.2 & 27.8 & 22.7 & 19.4 & 15.6 & 12.2 & 9.7 & 6.9 & 5.6 & 30.8 & 25.9 & 22.1 & 18.0 & 14.3 & 11.4 & 8.4 & 6.6 \\
\hline Latvia & 30.1 & 22.4 & 21.4 & 15.4 & $13.7 \quad 9.8$ & 7.8 & 5.8 & 31.4 & 23.8 & 22.5 & 16.4 & 14.6 & 10.3 & 8.4 & 6.0 & 34.8 & 27.6 & 25.6 & 19.2 & 17.2 & 12.2 & 10.3 & 7.0 \\
\hline Lithuania & 30.7 & 23.4 & 22.0 & 16.6 & 14.211 .1 & 8.2 & 7.0 & 31.9 & 24.6 & 23.0 & 17.3 & 15.0 & 11.4 & 8.8 & 7.0 & 34.8 & 27.9 & 25.6 & 19.6 & 17.3 & 12.6 & 10.4 & 7.4 \\
\hline Luxembourg & 33.2 & 28.1 & 24.0 & 19.6 & 15.712 .2 & 9.0 & 6.8 & 34.3 & 29.1 & 25.1 & 20.4 & 16.6 & 12.9 & 9.7 & 7.2 & 37.3 & 31.9 & 27.9 & 22.9 & 19.1 & 14.9 & 11.7 & 8.6 \\
\hline Malta & 32.8 & 29.3 & 23.7 & 20.4 & 15.612 .6 & 9.1 & 6.9 & 34.0 & 30.3 & 24.8 & 21.3 & 16.5 & 13.5 & 9.8 & 7.5 & 37.1 & 33.3 & 27.7 & 24.1 & 19.1 & 15.8 & 11.8 & 9.2 \\
\hline Moldova, Republic of & 25.9 & 21.4 & 17.8 & 14.7 & 11.19 .3 & 6.3 & 5.6 & 27.5 & 22.6 & 19.2 & 15.7 & 12.1 & 10.0 & 6.9 & 6.0 & 30.9 & 26.2 & 22.1 & 18.3 & 14.5 & 11.8 & 8.5 & 7.0 \\
\hline Montenegro & 30.4 & 27.2 & 21.6 & 19.7 & 14.013 .7 & 8.1 & 9.0 & 31.5 & 28.0 & 22.6 & 20.3 & 14.9 & 14.1 & 8.8 & 9.3 & 34.2 & 29.7 & 25.1 & 21.5 & 16.9 & 14.6 & 10.3 & 9.2 \\
\hline Netherlands & 33.3 & 29.4 & 24.2 & 20.7 & 15.913 .1 & 9.3 & 7.5 & 34.3 & 30.5 & 25.1 & 21.6 & 16.7 & 13.9 & 9.9 & 8.0 & 36.9 & 33.4 & 27.5 & 24.3 & 18.9 & 16.1 & 11.6 & 9.6 \\
\hline Norway & 33.7 & 29.9 & 24.5 & 21.0 & 16.113 .3 & 9.3 & 7.5 & 34.9 & 30.9 & 25.6 & 22.0 & 17.1 & 14.1 & 10.1 & 8.0 & 38.0 & 33.6 & 28.5 & 24.4 & 19.7 & 16.2 & 12.2 & 9.5 \\
\hline Poland & 31.4 & 24.8 & 22.5 & 17.4 & 14.511 .3 & 8.3 & 6.8 & 32.6 & 25.9 & 23.6 & 18.1 & 15.4 & 11.6 & 8.9 & 6.9 & 35.5 & 29.1 & 26.2 & 20.6 & 17.7 & 13.4 & 10.7 & 7.9 \\
\hline Portugal & 32.8 & 27.4 & 23.6 & 18.7 & 15.211 .4 & 8.4 & 6.2 & 33.9 & 28.5 & 24.7 & 19.8 & 16.1 & 12.3 & 9.2 & 6.7 & 36.7 & 31.5 & 27.3 & 22.5 & 18.6 & 14.5 & 11.2 & 8.3 \\
\hline Romania & 28.8 & 23.6 & 20.0 & 16.1 & 12.410 .0 & 6.7 & 5.7 & 30.2 & 24.7 & 21.3 & 16.9 & 13.5 & 10.5 & 7.5 & 6.0 & 33.6 & 28.0 & 24.4 & 19.5 & 16.1 & 12.2 & 9.4 & 6.9 \\
\hline Russian Federation & 26.8 & 18.6 & 18.7 & 13.0 & 11.78 .5 & 6.6 & 5.3 & 27.8 & 19.5 & 19.5 & 13.6 & 12.3 & 8.9 & 7.0 & 5.5 & 30.9 & 23.5 & 22.3 & 16.3 & 14.5 & 10.5 & 8.5 & 6.4 \\
\hline
\end{tabular}




\begin{tabular}{|c|c|c|c|c|c|c|c|c|c|c|c|c|c|c|c|c|c|c|c|c|c|c|c|}
\hline \multirow{4}{*}{$\begin{array}{l}\text { Country } \\
\text { (alphabetical order } \\
\text { by region) }\end{array}$} & \multicolumn{23}{|c|}{ Projected life expectation (years) } \\
\hline & \multicolumn{7}{|l|}{ In 2008} & \multicolumn{8}{|l|}{ In 2018} & \multicolumn{8}{|l|}{ In 2048} \\
\hline & \multicolumn{2}{|c|}{ At 50 years } & \multicolumn{2}{|c|}{ At 60 years } & At 70 years & \multicolumn{2}{|c|}{ At 80 years } & \multicolumn{2}{|c|}{ At 50 years } & \multicolumn{2}{|c|}{ At 60 years } & \multicolumn{2}{|c|}{ At 70 years } & \multicolumn{2}{|c|}{ At 80 years } & \multicolumn{2}{|c|}{ At 50 years } & \multicolumn{2}{|c|}{ At 60 years } & \multicolumn{2}{|c|}{ At 70 years } & \multicolumn{2}{|c|}{ At 80 years } \\
\hline & Female & Male & Female & Male & Female Male & Female & Male & Female & Male & Female & Male & Female & Male & Female & Male & Female & Male & Female & Male & Female & Male & Female & Male \\
\hline Serbia & 28.7 & 25.0 & 20.0 & 17.2 & 12.411 .0 & 6.8 & 6.5 & 29.8 & 25.8 & 20.9 & 17.8 & 13.2 & 11.3 & 7.3 & 6.6 & 33.1 & 28.9 & 24.0 & 20.3 & 15.8 & 13.1 & 9.2 & 7.6 \\
\hline Slovakia & 30.2 & 24.0 & 21.3 & 16.5 & 13.510 .5 & 7.5 & 6.2 & 31.5 & 25.2 & 22.5 & 17.3 & 14.5 & 10.9 & 8.2 & 6.4 & 34.7 & 28.6 & 25.4 & 20.1 & 17.0 & 12.9 & 10.1 & 7.5 \\
\hline Slovenia & 33.0 & 26.3 & 23.9 & 18.1 & 15.711 .2 & 9.1 & 6.3 & 34.2 & 27.6 & 24.9 & 19.1 & 16.6 & 12.0 & 9.8 & 6.8 & 37.3 & 31.0 & 27.9 & 22.2 & 19.2 & 14.4 & 11.8 & 8.4 \\
\hline Spain & 35.4 & 29.9 & 26.0 & 21.3 & 17.213 .7 & 10.0 & 7.9 & 36.4 & 30.9 & 27.0 & 22.1 & 18.2 & 14.4 & 10.8 & 8.4 & 39.3 & 33.7 & 29.8 & 24.6 & 20.8 & 16.4 & 13.0 & 9.8 \\
\hline Sweden & 34.1 & 30.3 & 24.8 & 21.4 & 16.413 .6 & 9.5 & 7.6 & 35.2 & 31.5 & 25.8 & 22.5 & 17.3 & 14.5 & 10.2 & 8.3 & 37.7 & 34.3 & 28.3 & 25.0 & 19.5 & 16.6 & 12.0 & 9.8 \\
\hline Switzerland & 35.4 & 31.1 & 26.1 & 22.2 & 17.514 .4 & 10.4 & 8.4 & 36.4 & 32.0 & 27.1 & 23.1 & 18.4 & 15.1 & 11.1 & 8.8 & 39.4 & 34.7 & 29.8 & 25.5 & 20.9 & 17.1 & 13.2 & 10.3 \\
\hline Tajikistan & 28.2 & 24.1 & 20.1 & 16.8 & 13.210 .9 & 8.0 & 6.6 & 29.0 & 24.8 & 20.7 & 17.3 & 13.7 & 11.2 & 8.2 & 6.8 & 31.4 & 27.0 & 22.7 & 19.0 & 15.1 & 12.3 & 9.1 & 7.4 \\
\hline $\begin{array}{l}\text { The former Yugoslav } \\
\text { Republic of Macedonia }\end{array}$ & 29.1 & 25.0 & 20.4 & 16.9 & 12.910 .3 & 7.3 & 5.7 & 30.1 & 25.8 & 21.3 & 17.5 & 13.6 & 10.7 & 7.8 & 5.9 & 33.3 & 28.9 & 24.1 & 20.1 & 16.0 & 12.7 & 9.5 & 7.1 \\
\hline Turkey & 27.9 & 24.5 & 19.1 & 16.5 & 11.410 .0 & 5.9 & 5.4 & 29.0 & 25.3 & 20.1 & 17.1 & 12.2 & 10.3 & 6.4 & 5.6 & 32.6 & 28.0 & 23.5 & 19.3 & 15.2 & 12.0 & 8.6 & 6.6 \\
\hline Turkmenistan & 26.9 & 21.9 & 18.7 & 15.1 & $11.7 \quad 9.6$ & 6.6 & 5.7 & 28.1 & 22.9 & 19.7 & 15.8 & 12.4 & 10.1 & 7.1 & 6.0 & 30.9 & 25.9 & 22.1 & 18.1 & 14.4 & 11.6 & 8.4 & 6.9 \\
\hline Ukraine & 27.5 & 20.1 & 19.2 & 14.0 & $11.9 \quad 9.0$ & 6.6 & 5.5 & 28.6 & 21.3 & 20.2 & 14.8 & 12.7 & 9.5 & 7.1 & 5.8 & 31.6 & 24.8 & 22.8 & 17.3 & 14.9 & 11.1 & 8.7 & 6.6 \\
\hline United Kingdom & 33.0 & 29.1 & 24.0 & 20.4 & 15.913 .1 & 9.4 & 7.5 & 34.2 & 30.1 & 25.0 & 21.3 & 16.8 & 13.8 & 10.1 & 8.0 & 37.3 & 32.9 & 27.9 & 23.7 & 19.2 & 15.7 & 11.9 & 9.3 \\
\hline Uzbekistan & 27.9 & 23.6 & 19.7 & 16.5 & 12.910 .8 & 7.8 & 6.7 & 28.7 & 24.3 & 20.4 & 17.0 & 13.4 & 11.2 & 8.1 & 6.9 & 31.3 & 26.8 & 22.6 & 18.9 & 15.0 & 12.4 & 9.1 & 7.5 \\
\hline
\end{tabular}

